\title{
Éxito laboral: el rol de los profesionales universitarios en las organizaciones. Una comparación entre graduados europeos y latinoamericanos
}

ANGELA MARÍA GRISALES DEL RÍO 


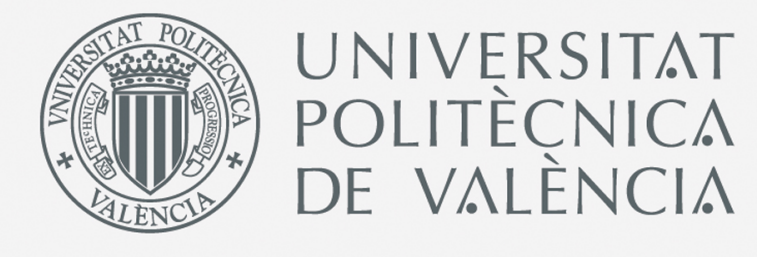

Departamento de Estadística e Investigación Operativa Aplicadas y Calidad

\section{TESIS DOCTORAL}

\section{ÉXITO LABORAL}

EL ROL DE LOS PROFESIONALES UNIVERSITARIOS

EN LAS ORGANIZACIONES.

UNA COMPARACIÓN ENTRE GRADUADOS EUROPEOS Y LATINOAMERICANOS.

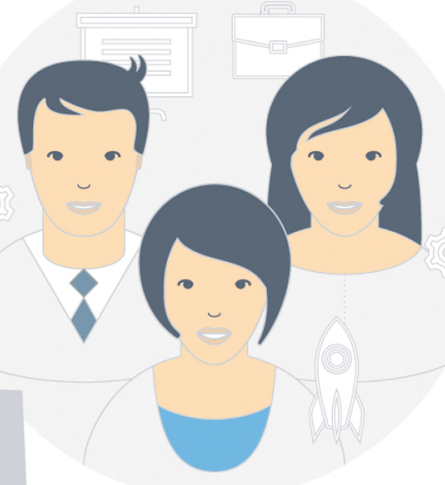

Presentada por:

D. ${ }^{a}$ Angela María Grisales del Río

Dirigida por:

Dr. D. Andrés Carrión García

Dr. D. José-Ginés Mora Ruiz 


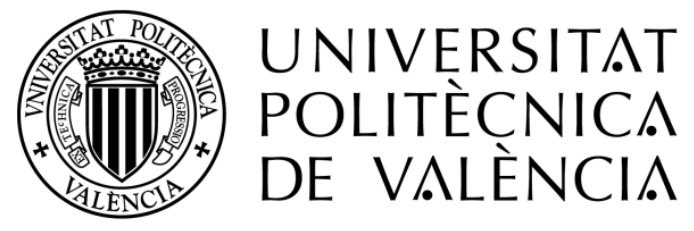

Éxito Laboral. El Rol de los Profesionales Universitarios en las Organizaciones.

Una Comparación entre Graduados Europeos y Latinoamericanos

\author{
TESIS DOCTORAL \\ Presentada por: \\ Angela María Grisales del Rio
}

Dirigida por:

Andrés Carrión García

José-Ginés Mora Ruiz 


\section{Colección Tesis Doctorales}

๑) Angela Maria Grisales del Rio

() 2015, de la presente edición: Editorial Universitat Politècnica de València Telf.: 963877012 / www.lalibreria.upv.es

ISBN: 978-84-9048-335-0 (versión impresa)

Queda prohibida la reproducción, distribución, comercialización, transformación, y en general, cualquier otra forma de explotación, por cualquier procedimiento, de todo o parte de los contenidos de esta obra sin autorización expresa y por escrito de sus autores. 


\section{Agradecimientos}

La elaboración de esta tesis ha sido posible gracias a la ayuda y participación de muchas personas a las que quisiera agradecer su apoyo durante la realización de este trabajo.

En primer lugar a mis directores de tesis, Andrés Carrión y José-Ginés Mora, quienes con su experiencia y buen hacer me dieron las orientaciones necesarias para desarrollar la investigación. Gracias a su dedicación, confianza y valiosos aportes he podido llevar a buen término este proyecto que me ha permitido seguir creciendo como profesional.

De igual manera quiero agradecer al profesor José Miguel Carot y a las compañeras/os del Centro de Gestión de la Calidad y del Cambio, quienes me dieron todas las facilidades para poder realizar mi trabajo. Por su amistad, colaboración y apoyo permanente durante estos años en que hemos compartido el día a día.

A mis amigos de Colombia y otros países de Latinoamérica con los que coincidí temporalmente en la UPV. Ellos fueron un apoyo en muchos momentos de mi etapa de estudios, juntos resolvimos dudas e inquietudes propias de quienes inician una carrera investigadora y aunque cada uno ejerce su profesión en sus países de origen, seguimos manteniendo los lazos de amistad y de colaboración profesional. Gracias Jaqueline y María José, porque a pesar de la diáspora seguimos adelante concretando un proyecto desde España.

Quisiera agradecer a mi familia que a pesar de la distancia siempre me ha dado el cariño y respaldo que he necesitado para salir adelante con mis proyectos personales y profesionales. A la familia Carrión porque siempre han estado dispuestos para acompañar y finalmente quiero dar las gracias a Andrés por su apoyo incondicional y comprensión infinita. 

Dedicado a mi madre y a la memoria de mi padre.

A mis hermanos y sobrinos. 



\section{Resumen}

Los últimos años han mostrado una transformación en el entorno de las organizaciones, impulsándolas a realizar cambios en las formas de gestionar los recursos de los que disponen, para poder garantizar su permanencia y así poder prestar un servicio a la sociedad. Los puestos de trabajo y las nuevas formas de establecer las relaciones trabajador- organización han estado demandando cambios en el perfil profesional, mayor flexibilidad y capacidad de adaptación. Tradicionalmente el éxito laboral ha estado asociado a un puesto de trabajo de larga duración, que permite tener un adecuado nivel de ingresos y un estatus acorde con la profesión. Siendo lo anterior un concepto muy válido e importante, también es cierto que existen otras razones que hacen sentir a una persona exitosa laboralmente.

Esta investigación tiene como objetivo el estudio del papel de los titulados universitarios dentro de las organizaciones y su éxito profesional. El análisis se realizó considerando variables relacionadas con los conceptos teóricos de éxito objetivo y subjetivo, el rol en el puesto de trabajo, las competencias y los valores laborales, realizando además una comparación entre profesionales universitarios europeos y latinoamericanos.

Para ello, en la primera parte se presentan los objetivos de la investigación, la justificación y se estructura el marco teórico de referencia para el planteamiento de la investigación.

En la segunda parte se propone el modelo teórico que posteriormente es analizado empíricamente. Para este análisis empírico se han utilizado datos de dos proyectos de seguimiento de graduados universitarios, los proyectos Reflex y Proflex, que han permitido ampliar el conocimiento sobre los estudios superiores, el empleo y las competencias de los graduados universitarios de Europa y de América Latina.

En la tercera parte se presenta el análisis descriptivo y una comparación por área geográfica, además del proceso de validación del modelo de investigación y un breve resumen de los resultados obtenidos, entre los que cabe destacar:

a) Existen evidencias para afirmar que el éxito laboral objetivo y el éxito laboral subjetivo están relacionados. Su análisis conjunto con el rol en el puesto de trabajo, las competencias personales y requeridas, así como otras características del trabajo, llamados también valores laborales amplían la visión del éxito laboral. 
b) Los titulados universitarios de Europa y Latinoamérica, desempeñan su rol profesional y están bien posicionados en el mercado laboral de cada uno de sus países.

c) La sobrecualificación en competencias afecta la percepción positiva o negativa que se tiene del éxito laboral desde sus dos componentes el éxito objetivo y subjetivo.

Palabras clave: Éxito laboral, éxito profesional, éxito objetivo, éxito subjetivo, rol profesional, competencias, valores laborales. 


\section{Resum}

Els últims anys han mostrat una transformació a l'entorn de les organitzacions, cosa que les ha impulsades a fer canvis en les formes de gestionar els recursos de què disposen per poder garantir la seua permanència i així poder prestar un servei a la societat. Els llocs de treball i les noves formes d'establir les relacions treballador-organització han menat a una demanda de canvis en el perfil professional, major flexibilitat i capacitat d'adaptació. Tradicionalment l'èxit laboral ha estat associat a un lloc de treball de llarga durada, que permet tenir un nivell d'ingressos adequat i un estatus d'acord amb la professió. Tot i que aquest és un concepte molt vàlid i important, també és cert que hi ha altres raons que fan que una persona se senta reeixida laboralment.

Aquesta recerca té com a objectiu l'estudi del paper dels titulats universitaris dins de les organitzacions i el seu èxit professional. L'anàlisi es va fer considerant variables relacionades amb els conceptes teòrics d'èxit objectiu i subjectiu, el rol al lloc de treball i les competències i els valors laborals, i a més es va fer una comparació entre professionals universitaris europeus i llatinoamericans.

Amb aquest objectiu, en la primera part es presenten els objectius de la recerca i la justificació, i s'estructura el marc teòric de referència per al plantejament de la recerca.

En la segona part es proposa el model teòric que després s'analitza empíricament. Per a aquesta anàlisi empírica s'han utilitzat dades de dos projectes de seguiment de graduats universitaris, els projectes Reflex i Proflex, que han permès ampliar el coneixement sobre els estudis superiors, l'ocupació i les competències dels graduats universitaris d'Europa i de l'Amèrica Llatina.

En la tercera part es presenta l'anàlisi descriptiva i una comparació per àrea geogràfica, a més del procés de validació del model de recerca i un breu resum dels resultats obtinguts, entre els quals cal destacar els següents:

a) Hi ha proves que permeten afirmar que l'èxit laboral objectiu i l'èxit laboral subjectiu estan relacionats. L'anàlisi conjunta amb el rol al lloc de treball, les competències personals i requerides, així com altres característiques del treball, elements que s'anomenen també valors laborals, amplien la visió de l'èxit laboral.

b) Els titulats universitaris d'Europa i l'Amèrica Llatina exerceixen el seu rol professional i estan ben posicionats en el mercat laboral de cadascun dels seus països. 
c) La sobrequalificació en competències afecta la percepció positiva o negativa que es té de l'èxit laboral des dels dos components que comprèn, l'èxit objectiu i subjectiu.

Paraules clau: Èxit laboral, èxit professional, èxit objectiu, èxit subjectiu, rol professional, competències, valors laborals. 


\begin{abstract}
Recent years have seen a transformation in the environment of organizations, urging them to make changes in the way they manage the resources at their disposal, to ensure being able to provide goods and services to the community. The jobs and the new ways to establish workerorganization relations have been demanding changes in the professional profile, greater flexibility and adaptability. Traditionally job success has been associated with a stable job, which allows employee having an adequate level of incomes and a status concordant with the professional level. This approach is valid and important, but it is also true that there are other reasons that make a person feeling occupationally successful.
\end{abstract}

This research aims to study the role of university graduates within organizations and their professional success. The analysis was performed considering variables related to the theoretical concepts of objective and subjective success, role in the workplace, skills and work values. A comparison between European and Latin American professionals was also developed.

With this aim, in the first part of the research the objectives, the rationale and the theoretical framework are presented, showing the structure of the research.

In the second part the theoretical model is proposed, to be later empirically analyzed. For this empirical analysis we have used data from two research projects on university graduates, Proflex and Reflex projects, that have expanded the knowledge about higher education, employment and skills of university graduates in Europe and Latin America.

The third part includes the descriptive analysis and the comparison by geographic area, in addition to the process of validating the research model and a brief summary of the results. Among these we can highlight:

a) There is evidence to assert that the objective career success and subjective career success are related. It's analysis, together with the role analysis, personal and required skills and other job characteristics (known as job values) expanded the vision and concept of professional success.

b) Both graduates of Europe and Latin America, perform their professional role and are well positioned in the labor market in each of their countries.

c) Over-qualification in skills affect the positive or negative perception of job success, in the two components of objective and subjective success. 
Keywords: Job Success, career success, objective success, subjective success, professional role, skills, work values. 


\section{Índice General}

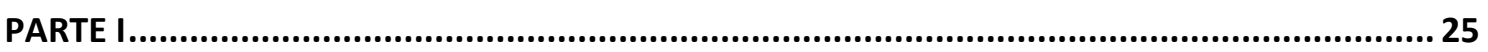

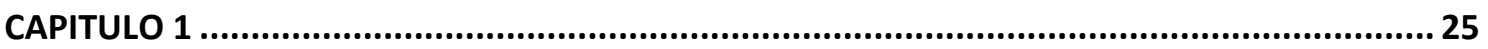

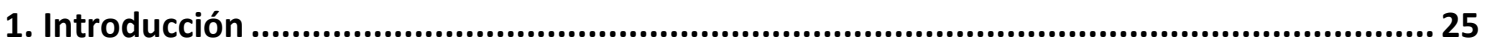

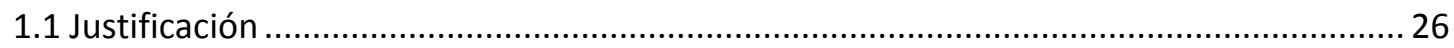

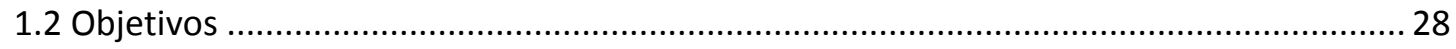

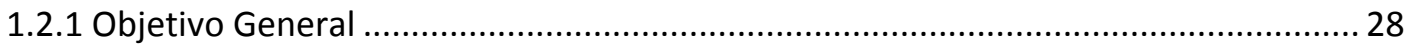

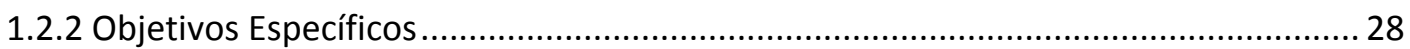

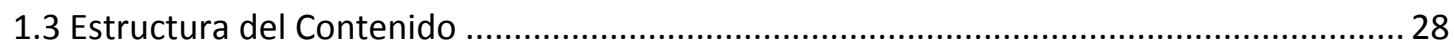

CAPITULO 2

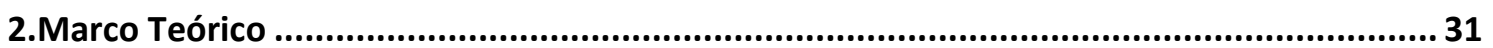

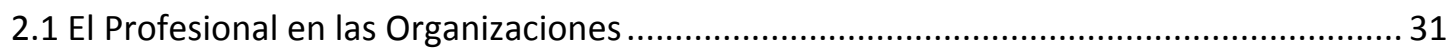

2.1.1 Evolución Histórica de las Teorías de Gestión............................................................. 31

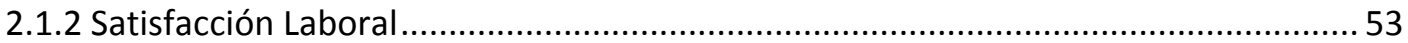

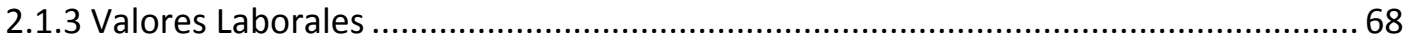

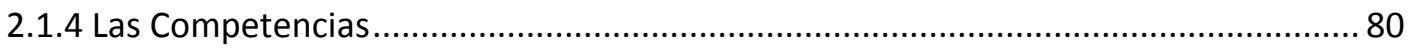

2.1.5 El Rol Profesional de los Graduados en la Educación Superior .................................. 90

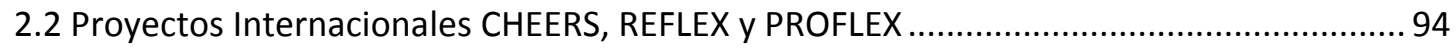

2.2.1 El Proyecto CHEERS "Careers after Higher Education_An European Research Study"

2.2.2 El Proyecto REFLEX “El Profesional Flexible en la Sociedad del Conocimiento: Nuevas exigencias de la educación superior en Europa" ................................................................. 96

2.2.3 El Proyecto PROFLEX “El Profesional Flexible en la Sociedad del Conocimiento" ..... 98

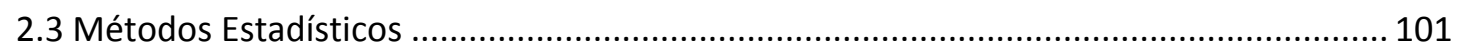

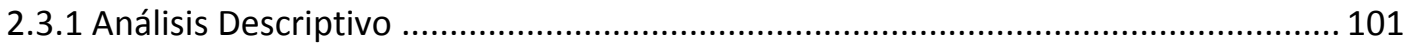

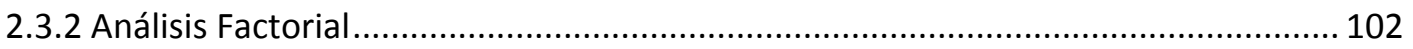

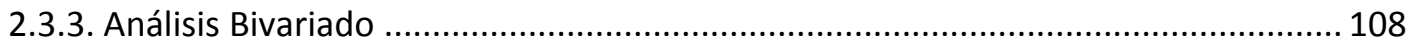

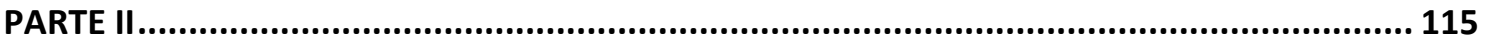

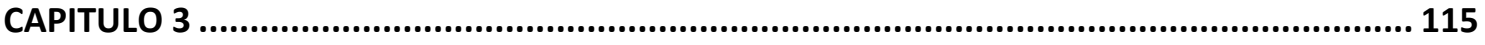

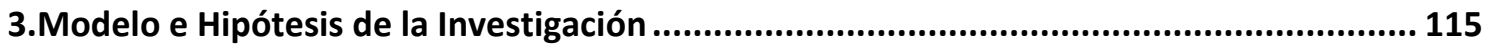

3.1 Descripción del Modelo de Investigación ........................................................................... 115

3.1.1 Proceso de obtención de la hipótesis .................................................................... 115

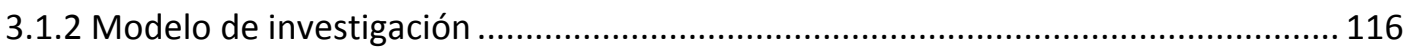

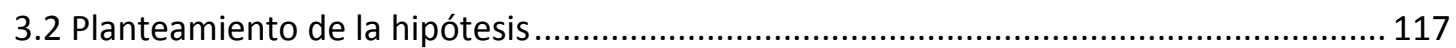




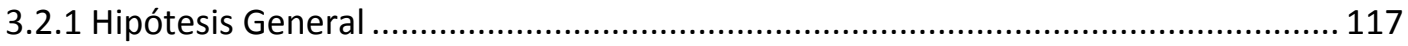

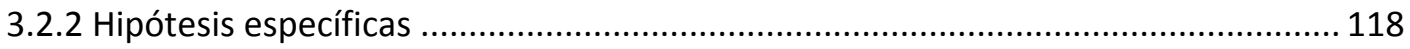

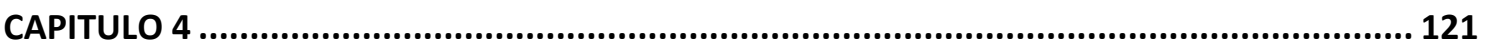

4.Metodología y Diseño de la Investigación ............................................................. 121

4.1 Metodología de la investigación .................................................................... 121

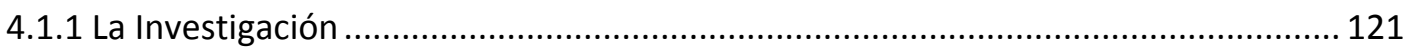

4.1.2 Estrategias de Investigación .............................................................. 123

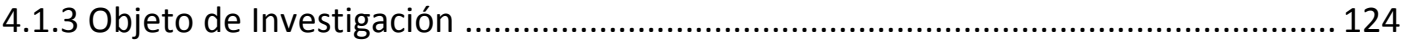

4.1.4 Proceso de Investigación .................................................................................. 125

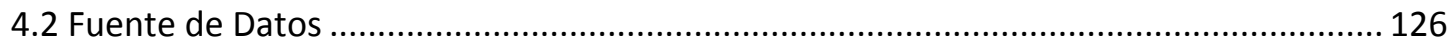

4.3 Población y muestra .................................................................................... 127

4.3.1 Descripción General de la población y muestra............................................. 127

4.3.2 Método de Muestreo ................................................................................ 127

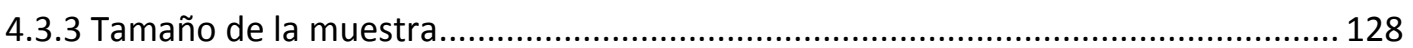

4.4 Método de recolección de datos ....................................................................... 129

4.5 Cuestionario - Preguntas seleccionadas ............................................................. 129

4.6 Variables dependientes e independientes .................................................... 130

4.6.1 Variables dependientes....................................................................... 130

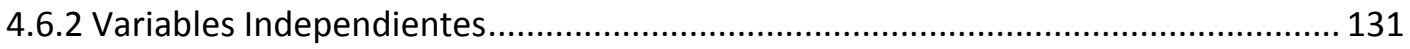

4.6.3 Variables de Control .............................................................................. 134

4.7 Definición de las variables ........................................................................... 138

4.8 Herramientas Informáticas y Técnicas Estadísticas .............................................. 139

4.8.1 Herramientas Informáticas ....................................................................... 139

4.8.2 Técnicas Estadísticas ............................................................................. 139

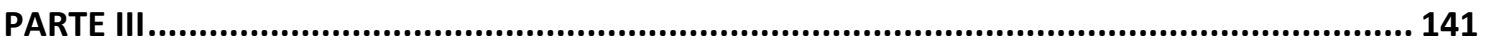

CAPITULO 5 ....................................................................................................... 141

5.Análisis de Datos y Resultados...................................................................... 141

5.1 Análisis Descriptivo .......................................................................... 141

5.1.1 Datos demográficos y económicos .............................................................. 141

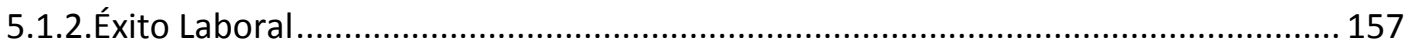

5.1.3. Rol - Funciones .................................................................................. 161

5.1.4 Las Competencias de los Profesionales Universitarios ...................................... 170

5.1.5 Los Valores Laborales de los Profesionales Universitarios .................................... 175

5.2 Análisis de correlación y análisis de Fiabilidad .................................................... 179 
5.2.1 Análisis de Correlación 179

5.2.2 Análisis de fiabilidad 180

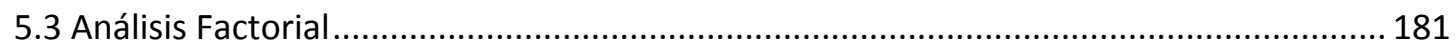

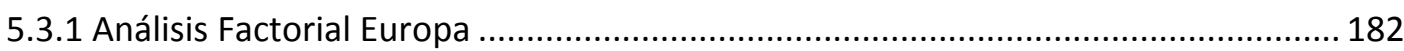

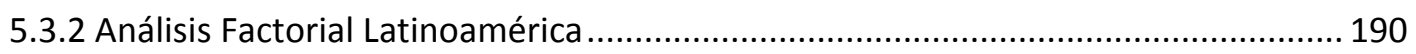

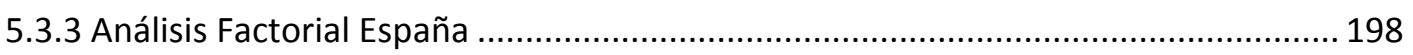

5.4 Modelo Final de la investigación una vez se ha reducido el número de variables a través

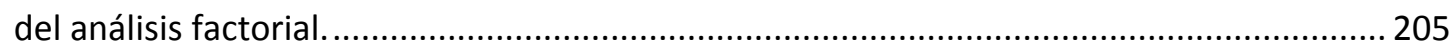

5.4.1 Modelo Final de Investigación para Europa ............................................................. 206

5.4.2 Modelo Final de Investigación para Latinoamérica ................................................. 207

5.4.3 Modelo Final de Investigación para España ......................................................... 208

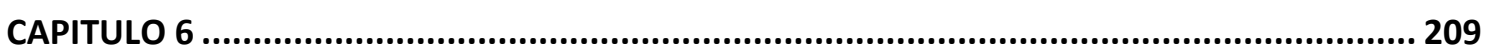

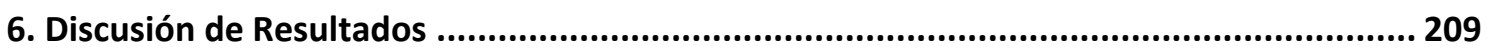

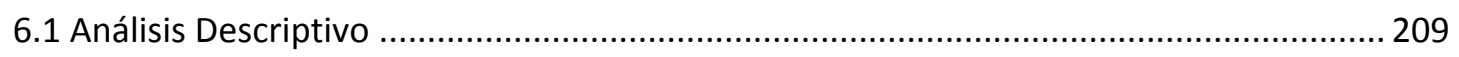

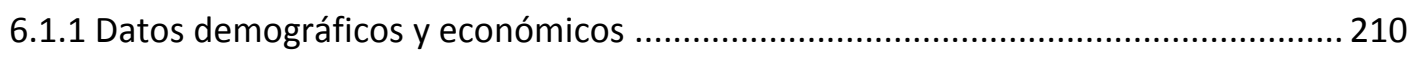

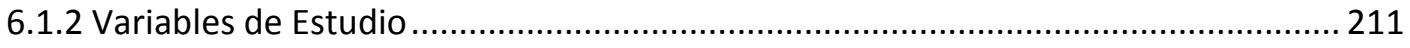

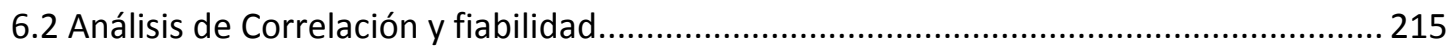

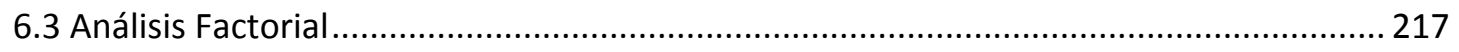

6.3.1 Diferencias en el Comportamiento de Europa y Latinoamérica en cada una de los Variables independientes. Análisis Gráfico de las Medias.............................................. 217

6.3.2 Análisis Factorial. Comparativa de la Variable Éxito Laboral ................................... 222

6.3.3 Análisis Factorial. Comparativa de la Variable Rol en el Trabajo .............................. 224

6.3.4 Análisis Factorial. Comparativa de la Variable Competencias Personales ................ 225

6.3.5 Análisis Factorial. Comparativa de la Variable Competencias Requeridas ............... 228

6.3.6 Análisis Factorial. Comparativa de la Variable Ajuste de Competencias .................. 229

6.3.7 Análisis Factorial. Comparativa de la Variable Valores Laborales Personales ......... 231

6.3.8 Análisis Factorial. Comparativa de la Variable Valores Laborales en el Trabajo...... 233

6.3.9 Análisis Factorial. Comparativa de la Variable Ajuste de Valores Laborales Personales

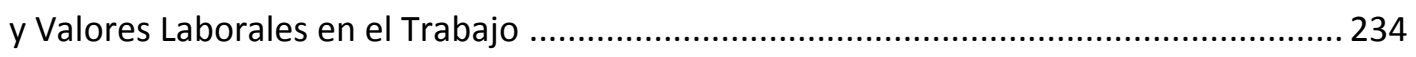

6.4 Correlaciones Bivariadas y Comprobación de hipótesis ................................................ 236

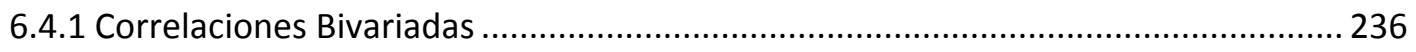

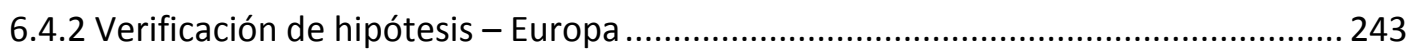

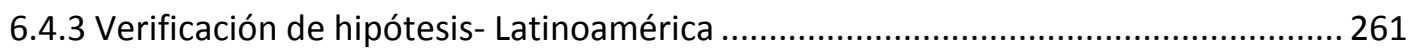

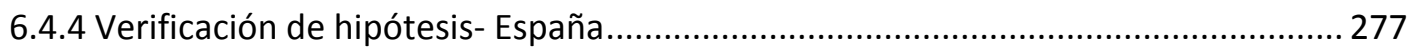

6.4.5 Comparativa de la evaluación de las hipótesis por área geográfica ......................... 294 


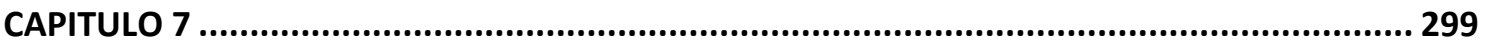

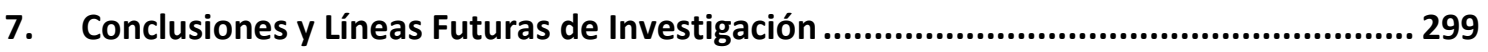

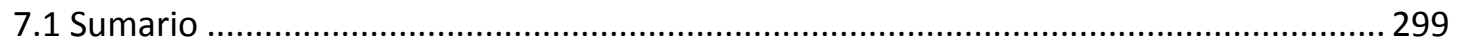

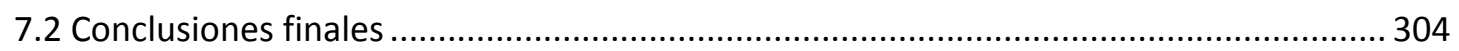

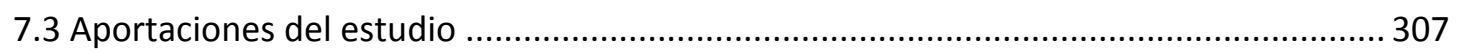

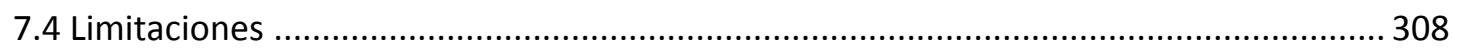

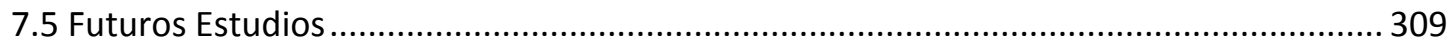

CAPITULO 8

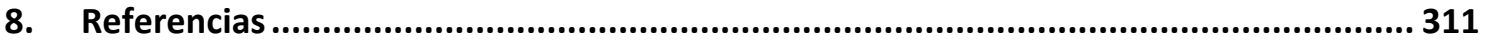

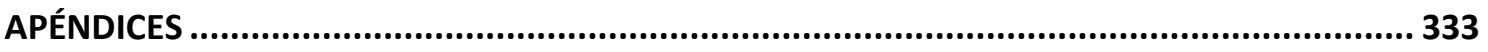

Anexo A. Preguntas seleccionadas del cuestionario PROFLEX (2007) .................................. 335

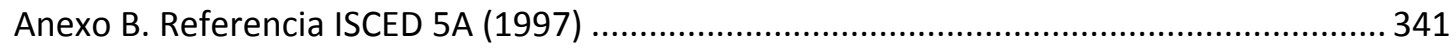

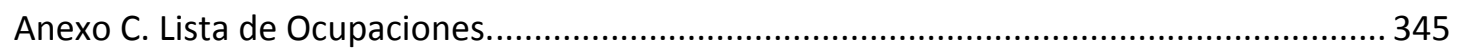

Anexo D. Lista de Sector Económico Encuesta Proflex ......................................................... 353

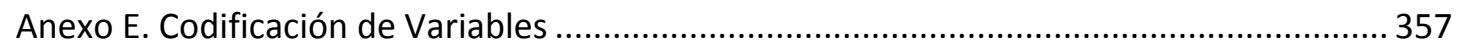

Anexo F. Resumen del Análisis Exploratorio: Éxito Laboral Objetivo y Subjetivo, Rol,

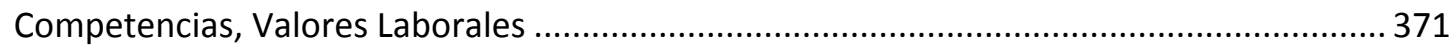

Anexo G. Ajuste de los Valores Monetarios ...................................................................... 379

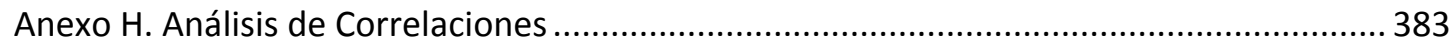

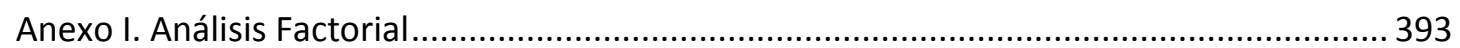

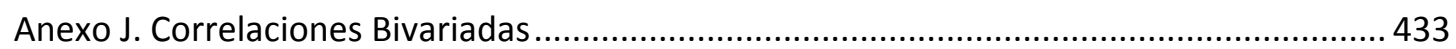




\section{Índice de Tablas}

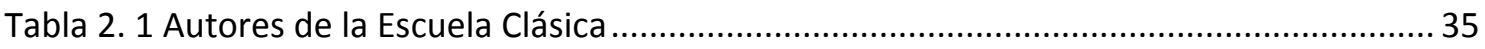

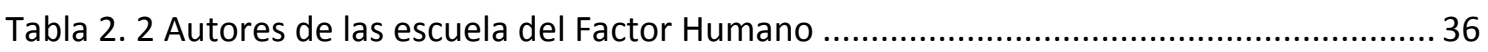

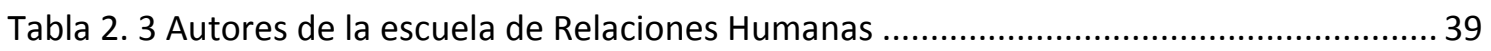

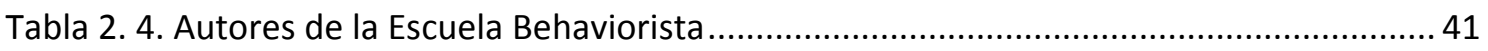

Tabla 2. 5 Autores de la Escuela del Desarrollo de la Organización (D.O.) ................................. 43

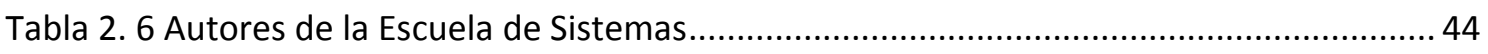

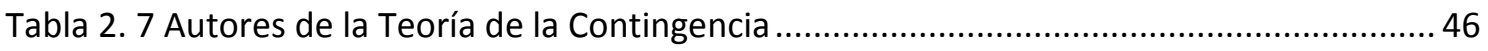

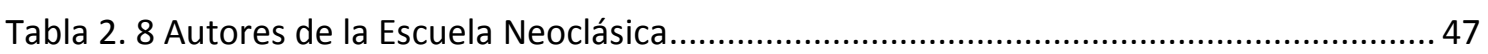

Tabla 2. 9 Autores de la Administración de la Calidad Total....................................................... 48

Tabla 2. 10 Autores de la Gestión Estratégica.......................................................................... 49

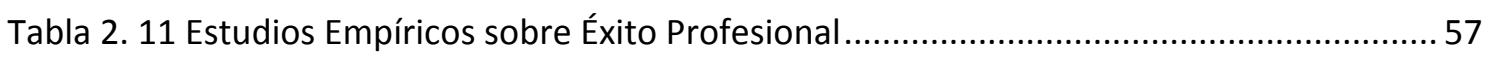

Tabla 2. 12 Criterios de éxito objetivo y subjetivo hallados en algunos estudios.........................64

Tabla 2. 13 Tipos de Valor motivacional según Schwartz (2001) .............................................. 72

Tabla 2. 14 Compatibilidades y Conflictos entre Valores según Schwartz (2001) ........................ 73

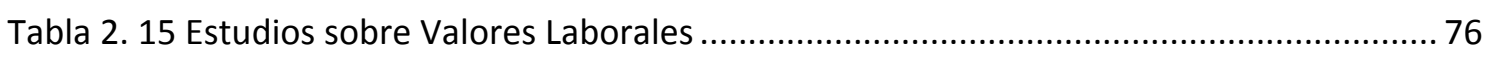

Tabla 2. 16 Valores con más frecuencia de aparición en Escalas de Valores /autor(es) ............. 79

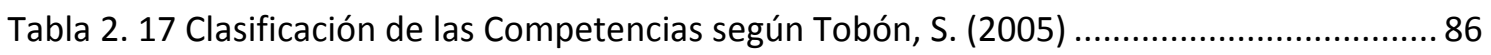

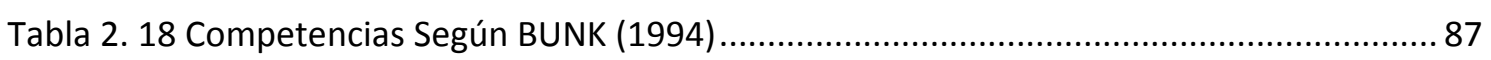

Tabla 2. 19 Clasificación e Importancia de los Tipos de Competencias Profesionales ................ 89

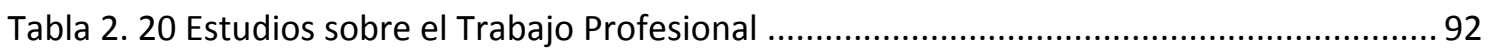

Tabla 2. 21 Técnicas estadísticas empleadas para el análisis de datos...................................... 101

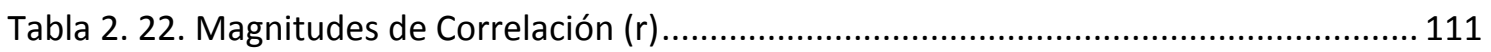

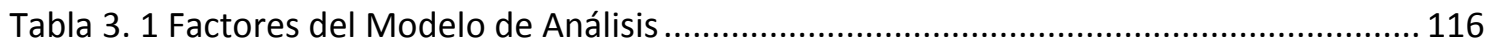

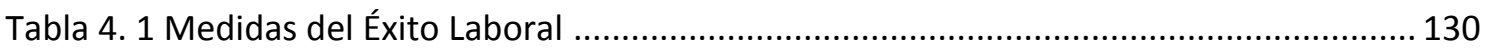

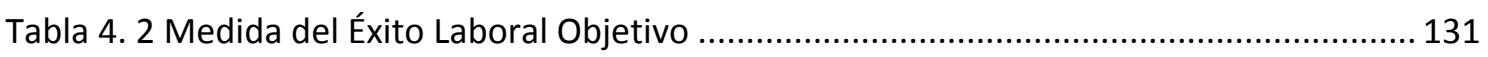

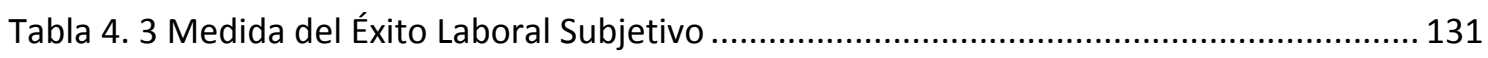

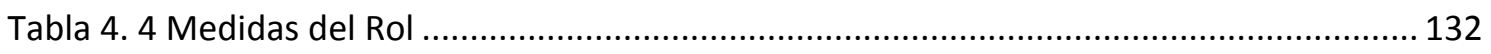

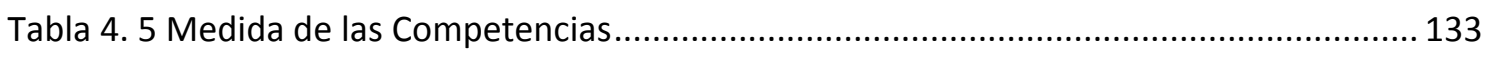

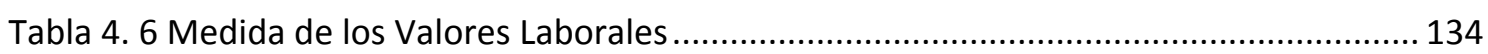

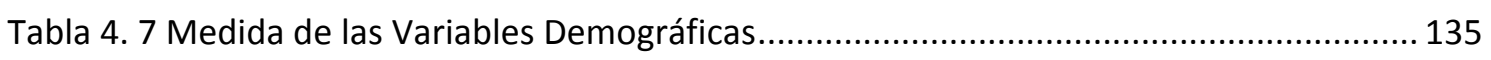

Tabla 4. 8 Medida de las Variables del entorno del puesto de Trabajo.................................... 136

Tabla 4. 9 Medida de las Variables que Caracterizan la Organización ....................................... 137

Tabla 4. 10 Tipo y Cantidad de Variables del Cuestionario ........................................................ 138

Tabla 4. 11 Tipos de Datos o Escalas de Medida según SPSS v.17 ......................................... 138

Tabla 5. 1 Graduados universitarios de la base de datos conjunta de REFLEX y PROFLEX ........ 143

Tabla 5. 2 Situación de Convivencia de los Graduados Universitarios - País / (\%) ..................... 146

Tabla 5. 3 Graduados Universitarios con hijos - País / (\%) ..................................................... 147

Tabla 5. 4 \% de Graduados según el área de estudio, país y continente .................................. 149 


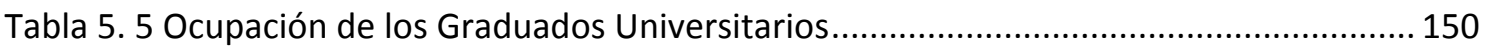

Tabla 5. 6 Ocupación de los Profesionales Universitarios (\% País) .......................................... 151

Tabla 5. 7 Tipo de Contrato de los Profesionales Universitarios (\% País - \% Continente) ........ 153

Tabla 5. 8 Sector Económico en el que trabajan los Profesionales Universitarios (\% y № /País)

Tabla 5. 9 Horas de dedicación semana al trabajo por País (Media aritmética). 158

Tabla 5. 10 Salario Mensual Bruto según contrato y total en Dólares USD y Dólares USD (IPC)

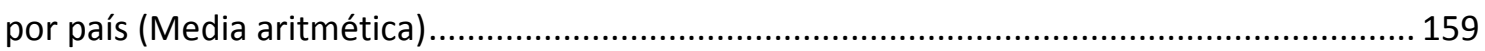

Tabla 5. 11 Uso de Conocimientos y habilidades en el Trabajo actual (\%) ............................... 160

Tabla 5. 12 Requerimiento de conocimientos y habilidades (\%) .......................................... 161

Tabla 5. 13 Grado de Satisfacción en el Trabajo actual (\%) ..................................................... 161

Tabla 5. 14 Ajuste entre el área de estudio en la universidad y la requerida en el trabajo por

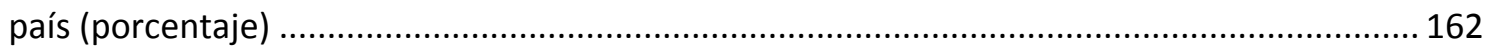

Tabla 5. 15 Responsabilidad para establecer objetivos en la organización ................................ 163

Tabla 5. 16 Responsabilidad para establecer objetivos del propio trabajo ............................... 164

Tabla 5. 17 Responsabilidad de decidir estrategias de trabajo para la organización. ............... 164

Tabla 5. 18 Responsabilidad de decidir cómo hacer el trabajo propio ...................................... 165

Tabla 5. 19 Perjuicio a la organización por cometer errores graves en el trabajo...................... 165

Tabla 5. 20 Los compañeros, clientes, etc. acuden a mí para pedirme consejo ......................... 167

Tabla 5. 21 Mantengo informados a mis compañeros de profesión sobre nuevos desarrollos en

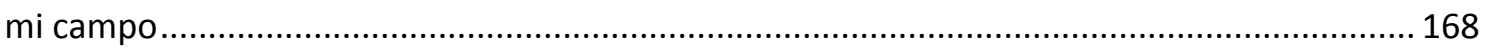

Tabla 5. 22 Suelo iniciar relaciones profesionales con expertos ajenos a la organización ........ 169

Tabla 5. 23 Importancia de la ética profesional como parte importante de las funciones ....... 169

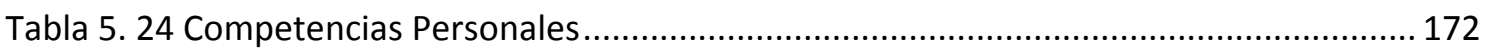

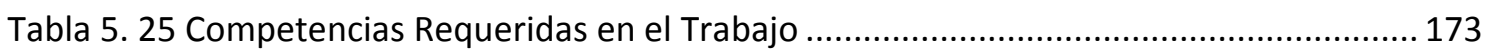

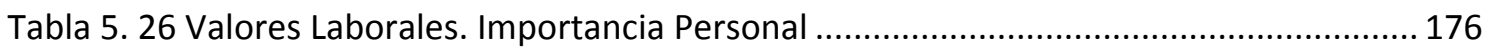

Tabla 5. 27 Valores Laborales. Grado de aplicación a la situación laboral .............................. 177

Tabla 5. 28 Resultados de los análisis de Fiabilidad para las escalas de medición ..................... 180

Tabla 5. 29 Interpretación de los Componentes Principales. Rol en el Trabajo (Europa).......... 183

Tabla 5. 30 Interpretación de los Componentes Principales. Competencias Propias (Europa) 184

Tabla 5. 31 Interpretación de los Componentes Principales. Competencias Requeridas en el

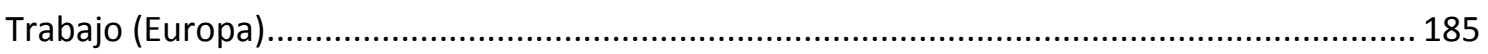

Tabla 5. 32 Interpretación de los Componentes Principales. Valores Laborales Personales

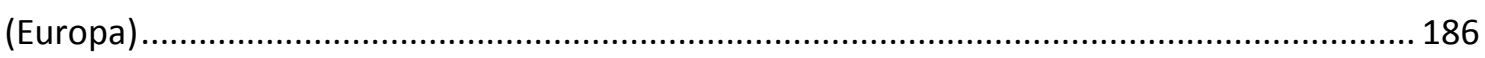

Tabla 5. 33 Interpretación de los Componentes Principales. Valores Laborales en el Trabajo

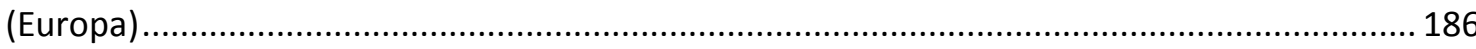

Tabla 5. 34 Interpretación de los Componentes Principales. Ajuste de Competencias (Europa)

Tabla 5. 35 Interpretación de los Componentes Principales. Ajuste de Valores Laborales (Europa)

Tabla 5. 36 Variables Modelo Final EUROPA. Porcentaje de la varianza explicada y fiabilidad de las escalas resultantes. 188

Tabla 5. 37 Interpretación de los Componentes Principales. Rol en el Trabajo (Latinoamérica) 
Tabla 5. 38 Interpretación de los Componentes Principales. Competencias Personales (Latinoamérica)

Tabla 5. 39 Interpretación de los Componentes Principales. Competencias Requeridas en el Trabajo (Latinoamérica)

Tabla 5. 40 Interpretación de los Componentes Principales. Valores Laborales Personales

(Latinoamérica)

Tabla 5. 41 Interpretación de los Componentes Principales. Valores Laborales en el Trabajo

(Latinoamérica)

Tabla 5. 42 Interpretación de los Componentes Principales. Ajuste de Competencias

(Latinoamérica)

Tabla 5. 43 Interpretación de los Componentes Principales. Ajuste de Valores Laborales

(Latinoamérica)

Tabla 5. 44 Variables Modelo Final LATINOAMÉRICA. Porcentaje de la varianza explicada y fiabilidad de las escalas resultantes

Tabla 5. 45 Interpretación de los Componentes Principales. Rol en el Trabajo (España).......... 199

Tabla 5. 46 Interpretación de los Componentes Principales. Competencias Personales (España)

Tabla 5. 47 Interpretación de los Componentes Principales. Competencias Requeridas en el Trabajo (España). 201

Tabla 5. 48 Interpretación de los Componentes Principales. Valores Laborales Personales (España).

Tabla 5. 49 Interpretación de los Componentes Principales. Valores Laborales en el Trabajo

(España)

Tabla 5. 50 Interpretación de los Componentes Principales. Ajuste de Competencias (España)

Tabla 5. 51 Interpretación de los Componentes Principales. Ajuste de Valores Laborales (España)

Tabla 5. 52 Variables Modelo Final ESPAÑA. Porcentaje de la varianza explicada y fiabilidad de

las escalas resultantes 204

Tabla 6. 1 Comparativa de la Prueba Factorial. Variable Éxito Laboral

Tabla 6. 2 Comparativa de la Prueba Factorial. Variable Rol en el Trabajo ............................... 224

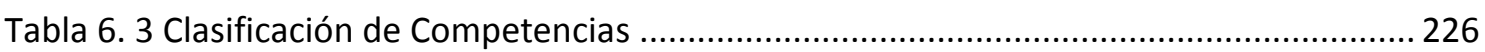

Tabla 6. 4 Comparativa de la Prueba Factorial. Variable Competencias Personales ................. 227

Tabla 6. 5 Comparativa de la Prueba Factorial. Variable Competencias Requeridas ................ 228

Tabla 6. 6 Comparativa de la Prueba Factorial. Variable Ajuste de Competencias ................... 229

Tabla 6. 7 Comparativa de la Prueba Factorial. Variable Valores Laborales Personales .......... 231

Tabla 6. 8 Comparativa de la Prueba Factorial. Variable Valores Laborales en el Trabajo........ 233

Tabla 6. 9 Comparativa de la Prueba Factorial. Variable Ajuste de Valores Laborales.............. 234

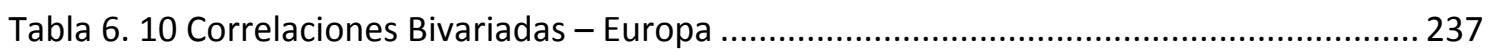

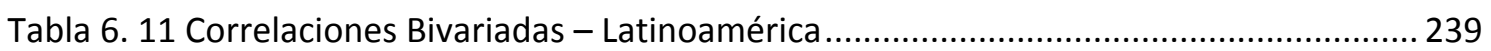

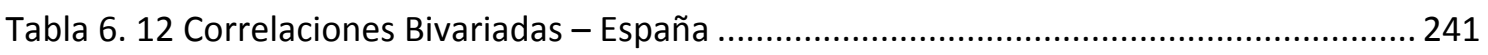

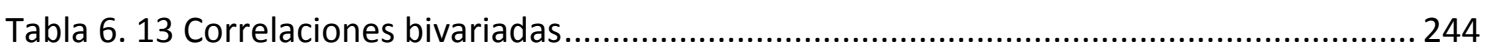

Tabla 6. 14 Correlaciones bivariadas Éxito Laboral_Valores Laborales en el Trabajo_E - H1b 245 
Tabla 6. 15 Correlaciones bivariadas Éxito laboral_Ajuste Valores Laborales (AJVTE) - H1c ... 246

Tabla 6. 16 Correlaciones bivariadas Éxito laboral_Competencias Personales (CPE) H2a ....... 248

Tabla 6. 17 Correlaciones bivariadas Éxito laboral__Competencias requeridas en el trabajo

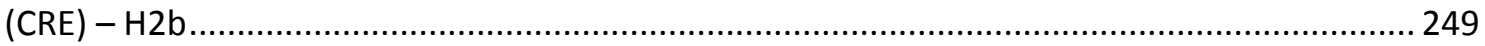

Tabla 6. 18 Correlaciones bivariadas Éxito laboral_Ajuste de Competencias (AJCE) - H2c ...... 250

Tabla 6. 19 Correlaciones bivariadas Éxito laboral_Rol - H3 ............................................... 252

Tabla 6. 20 Correlaciones bivariadas Rol_Valores Personales_E H4a..................................... 253

Tabla 6. 21 Correlaciones bivariadas Rol_Valores Laborales en el Trabajo_E - H4b................. 254

Tabla 6. 22 Correlaciones bivariadas Rol_Competencias Personales_E - H5a .......................... 256

Tabla 6. 23 Correlaciones bivariadas Rol_Competencias Requeridas_E - H5b ........................ 257

Tabla 6. 24 Correlaciones bivariadas Competencias Requeridas_E_Valores Laborales en el

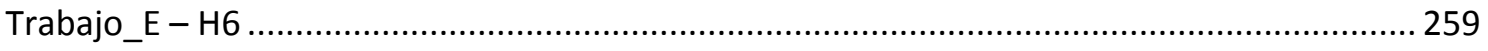

Tabla 6. 25 Correlaciones bivariadas Éxito laboral_Valores laborales personales (VPLA) - H1a

Tabla 6. 26 Correlaciones bivariadas Éxito laboral _ Valores laborales en el trabajo (VLTLA) -

$\mathrm{H} 1 \mathrm{~b}$

Tabla 6. 27 Correlaciones bivariadas Éxito laboral_Ajuste Valores Laborales (AJVTLA) - H1c.. 263

Tabla 6. 28 Correlaciones bivariadas Éxito laboral_Competencias Personales (CPLA) - H2a .. 265

Tabla 6. 29 Correlaciones bivariadas Éxito laboral_Competencias requeridas en el trabajo (CRLA) - H2b

Tabla 6. 30 Correlaciones bivariadas Éxito laboral_Ajuste de Competencias (AJCLA) - H2c .... 267

Tabla 6. 31 Correlaciones bivariadas Éxito laboral_Rol - H3 ................................................... 269

Tabla 6. 32 Correlaciones bivariadas Rol_Valores Personales_LA - H4a.................................... 270

Tabla 6. 33 Correlaciones bivariadas Rol_Valores Laborales en el Trabajo_LA - H4b.............. 271

Tabla 6. 34 Correlaciones bivariadas Rol_Competencias Personales_LA - H5a ....................... 273

Tabla 6. 35 Correlaciones bivariadas Rol_Competencias Requeridas_LA - H5b ....................... 274

Tabla 6. 36 Correlaciones bivariadas Competencias Requeridas_LA_Valores Laborales en el

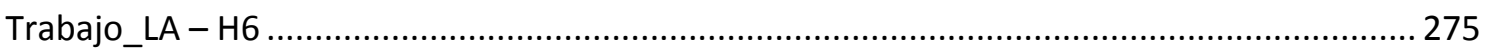

Tabla 6. 37 Correlaciones bivariadas Éxito laboral_ Valores laborales personales (VPSPN) _ H1a

Tabla 6. 38 Correlaciones bivariadas Éxito laboral _ Valores laborales en el trabajo (VLTSPN) H1b.

Tabla 6. 39 Correlaciones bivariadas Éxito laboral_Ajuste Valores Laborales (AJVTSpn) - H1c

Tabla 6. 40 Correlaciones bivariadas Éxito laboral_Competencias Personales (CPSPN) - H2a282 Tabla 6. 41 Correlaciones bivariadas Éxito laboral_C Competencias requeridas en el trabajo (CRSPN) - $\mathrm{H} 2 \mathrm{~b}$

Tabla 6. 42 Correlaciones bivariadas Éxito laboral_Ajuste de Competencias (AJCSpn) - H2c . 284

Tabla 6. 43 Correlaciones bivariadas Éxito laboral_Rol - H3 ................................................ 286

Tabla 6. 44 Correlaciones bivariadas Rol_Valores Laborales Personales (VPSPN) - H4a .......... 287

Tabla 6. 45 Correlaciones bivariadas Rol_Valores Laborales en el Trabajo (VLTSPN) - H4b .... 288

Tabla 6. 46 Correlaciones bivariadas Rol_Competencias Personales (CPSPN) - H5a ................ 290

Tabla 6. 47 Correlaciones bivariadas Rol_Competencias Requeridas (CRSPN) - H5b ............... 291

Tabla 6. 48 Correlaciones bivariadas Competencias Requeridas (CRSPN)_Valores Laborales en

el Trabajo (VLTSPN) - H6 
Tabla 6. 49 Comparativa de la Evaluación de las Hipótesis por Área Geográfica 


\section{Índice de Figuras}

Figura 2. 1 Evolución histórica de las teorías de gestión

Figura 3. 1 Modelo de Investigación 116

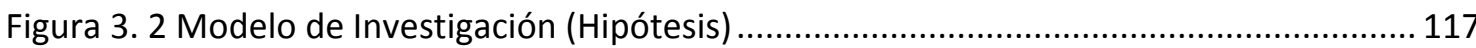

Figura 3. 3 Modelo Propuesto

Figura 4. 1 126

Figura 5. 1 \% Graduados Universitarios que respondieron encuesta REFLEX - PROFLEX ......... 142

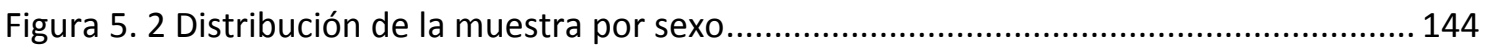

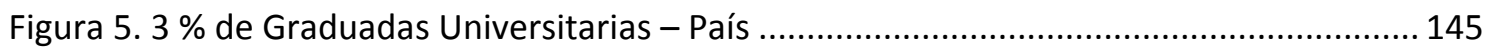

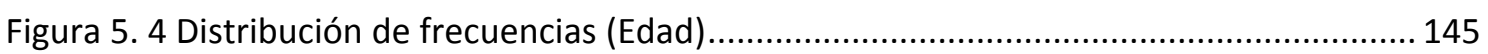

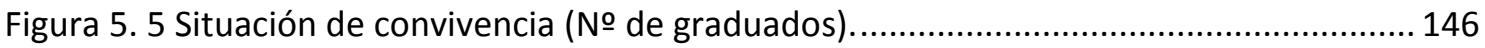

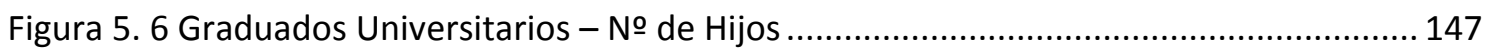

Figura 5. 7 Graduados Universitarios - Área de Estudio........................................................ 148

Figura 5. 8 Profesionales Universitarios - Tipo de Contrato .................................................... 152

Figura 5. 9 Sector Económico en el que trabajan los Profesionales Universitarios .................... 154

Figura 5. 10 Sector Económico donde trabajan los Graduados Universitarios .......................... 156

Figura 5. 11 Tamaño de las Organizaciones donde Trabajan los Graduados Universitarios .... 157

Figura 5. 12 Horas de dedicación semanal al trabajo por continente (Media aritmética) ........ 158

Figura 5. 13 Ajuste entre el área de estudio en la universidad y la requerida en el trabajo .... 162

Figura 5. 14 Relaciones de Responsabilidad en el Trabajo ...................................................... 166

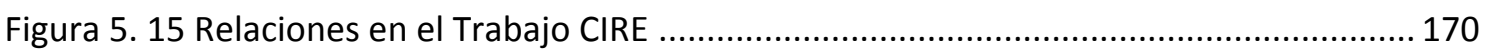

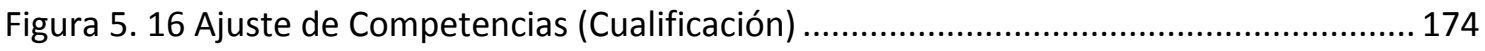

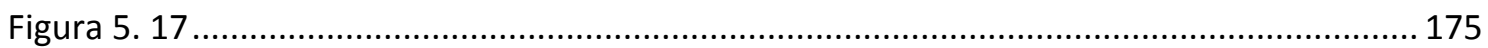

Figura 5. 18 Ajuste de Valores Laborales (Conformidad) ......................................................... 178

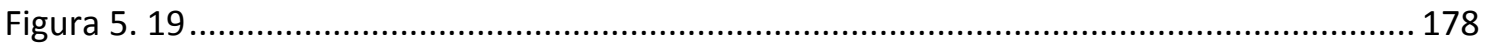

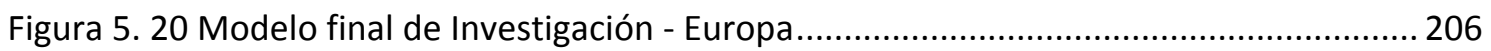

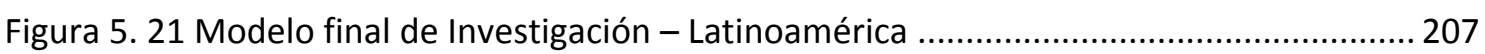

Figura 5. 22 Modelo final de Investigación - España ................................................................... 208

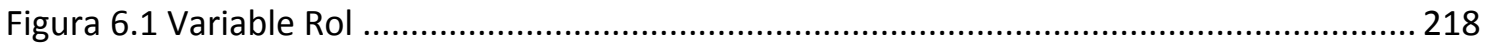

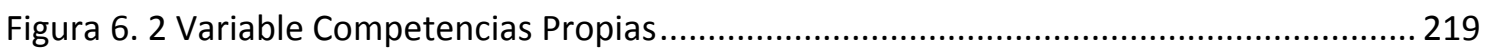

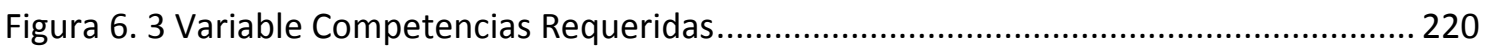

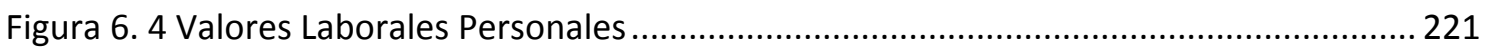

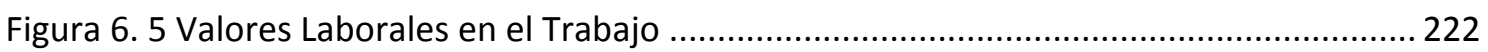




\section{Lista de Abreviaturas}

ALFA: Programa de cooperación entre instituciones de educación superior de la Unión Europea y América Latina.

CHEERS: Careers after Higher Education - An European research study.

CIU0-88: Clasificación internacional uniforme de ocupaciones, OIT.

EHEA: European Higher Education Area

HEGESCO: Higher education as a generator of strategic competences.

ISCED 5A: Clasificación de las áreas de estudio a partir de las titulaciones.

MoW: Meaning of Working Study.

OIT: Organización internacional del trabajo.

PROFLEX: El profesional flexible en la sociedad del conocimiento.

REFLEX: The flexible professional in the knowledge society project.

UNESCO: Organización de las Naciones Unidas para la educación, la ciencia y la cultura.

UPV: Universitat Politècnica de València. 



\section{PARTE I}

\section{CAPITULO 1}

\section{Introducción}

A lo largo del siglo XX las teorías organizacionales marcaron los principios que ayudaron a entender la estructura de las organizaciones y las empresas tal como las conocemos hoy en día. Estos principios siguen actualizándose y adaptándose a las necesidades y transformaciones de la sociedad del conocimiento, una sociedad en la que el capital humano con formación es el principal factor de producción y generación de valor agregado (Bermeo, 2007). En un entorno de globalización, que ha llevado a las empresas a trabajar de lo local a lo internacional, en donde las tecnologías de información y las comunicaciones, ayudan a las organizaciones a transformar la forma de gestionar sus negocios y recursos, cobra especial relevancia el papel que desempeñan los profesionales universitarios como motores de desarrollo económico.

Es ampliamente reconocido que los trabajadores y las organizaciones de hoy en día están experimentando diferentes modelos de carreras profesionales en comparación con décadas anteriores y que ambos tienen que compartir responsabilidad de gestionar y controlar los procesos y los desafíos del éxito profesional.

En este contexto, el estudio del éxito profesional es un tema que a lo largo de los años ha sido motivo de interés y preocupación. La diversidad de estudios e investigaciones realizadas, así como la publicación de numerosos libros y artículos, sobre todo en lengua inglesa, así lo demuestra. Todo esto se ha visto reforzado por conceptos de la profesión provenientes de diversos campos como la sociología, psicología, la administración y la economía entre otros. El concepto de éxito laboral tradicionalmente ha sido evaluado desde lo objetivo es decir, en términos medibles como los ingresos, la ocupación y el estatus social que se desprende del mismo, etc. A pesar que en la actualidad se reconoce la dualidad del éxito laboral, definido como éxito laboral objetivo y éxito laboral subjetivo, la mayor parte de las investigaciones recientes han centrado sus análisis y medidas en el éxito laboral objetivo.

En la presente investigación se ha explorado el papel de los titulados universitarios dentro de las organizaciones y su éxito profesional. El análisis se realizó considerando variables relacionadas con el concepto teórico del éxito objetivo y subjetivo, el rol en el puesto de 
trabajo, las competencias y los valores laborales. Con estos factores y sus relaciones se propone el modelo teórico que posteriormente es analizado empíricamente. Para este análisis empírico se han utilizado datos de dos proyectos de seguimiento de graduados universitarios, los proyectos Reflex y Proflex, que han permitido ampliar el conocimiento sobre los estudios superiores, el empleo y las competencias de los graduados universitarios de Europa y de América Latina.

Partiendo de los datos de los proyectos mencionados y del interés por la dinámica de las empresas que actualmente actúan en un mundo competitivo y globalizado, nace la oportunidad de profundizar en el estudio del éxito laboral de los profesionales universitarios.

Este trabajo, centrado en el estudio del rol de los profesionales universitarios en las organizaciones, busca hacer un aporte al estudio del éxito profesional de los jóvenes graduados universitarios, realizando además una comparación entre profesionales universitarios europeos y latinoamericanos.

\subsection{Justificación}

En los últimos tiempos, el mercado laboral que más ha crecido y de una forma acelerada, ha sido el de los trabajadores del conocimiento, aquellos cuyas tareas necesitan una formación avanzada. Los trabajadores del conocimiento son los verdaderos propietarios de los nuevos medios de producción. Su trabajo puede ser desarrollado indistintamente tanto por hombres como por mujeres, tienden a identificarse con su campo de saber en lugar de la organización donde trabajan y al igual que el resto de las personas, para los trabajadores del conocimiento, el dinero es importante pero no sustituye el desarrollo y aquellos otros valores que les lleva a tener éxito profesional. Estos temas, han logrado captar el interés de los investigadores de diferentes áreas. Los profesionales del conocimiento seguirán aumentando en las próximas generaciones y se convertirán en el eje central del desarrollo económico de la sociedad futura (Drucker, 2001).

En años recientes, tres tendencias principales están afectando las demandas que se hacen a los graduados de educación superior: Una tendencia evidente es el creciente énfasis que se ha puesto en la educación y la formación que es visto por muchos como el factor más importante que influye en el crecimiento económico (World Bank, 2002). El término "sociedad del conocimiento", ha sido acuñado para indicar no sólo la ampliación de la participación en la 
educación superior o de sectores intensivos en conocimiento y alta tecnología de la economía, sino más bien una situación en la que las características de las organización del trabajo han cambiado bajo la influencia de la creciente importancia del conocimiento (Teichler, 1999). La segunda tendencia se refiere a los cambios en los procesos del mercado de trabajo. La tercera tendencia se refiere a la internacionalización y la globalización de los mercados de productos y los mercados laborales y su impacto sobre la educación superior (Van Damme, 2001; Marginson \& van der Wende, 2007).

Las demandas del mundo del trabajo a los profesionales universitarios, tales como el conocimiento profesional, la flexibilidad funcional, la capacidad de innovación y gestión del conocimiento, etc., justifican la formulación de las siguientes preguntas de investigación:

- ¿Cuáles son los factores del éxito laboral de los graduados universitarios en una organización?

- ¿La percepción de la satisfacción laboral de los graduados universitarios está relacionada con las características del puesto de trabajo?

- ¿Los valores y expectativas personales sobre el puesto de trabajo están relacionados con el éxito laboral?

- ¿La percepción del éxito laboral de los graduados universitarios está relacionada con otros aspectos del trabajo actual?

- ¿ ¿La percepción del éxito laboral está relacionada con el nivel de remuneración?

- ¿ ¿La percepción del éxito laboral está relacionada con el ajuste de competencias propias y requeridas en el trabajo?

- ¿Existen diferencias entre los graduados de Europa y Latinoamérica en los temas arriba citados?

Para intentar dar respuesta a las preguntas formuladas, la presente investigación se desarrolla con los objetivos concretos que se definen a continuación. 


\subsection{Objetivos}

\subsubsection{Objetivo General}

El objetivo general de la investigación consiste en realizar un análisis que permita aportar conocimiento en el estudio del rol y del éxito de los profesionales universitarios en las organizaciones donde desempeñan su labor profesional.

\subsubsection{Objetivos Específicos}

Los objetivos específicos del trabajo de investigación son:

1. Hacer una revisión bibliográfica de la literatura para describir el estado del arte y plantear definiciones de trabajo en cuanto a los valores, las competencias, el rol, la satisfacción y el éxito laboral.

2. Plantear un modelo teórico para analizar la relación entre los valores, las competencias, el rol y la influencia de estos sobre la satisfacción y éxito laboral de los profesionales universitarios.

3. Identificar características de los puestos de trabajo que ocupan los profesionales universitarios en las organizaciones y las funciones que desempeñan.

4. Validar el modelo teórico a partir de una encuesta dirigida a graduados universitarios europeos y latinoamericanos, cuatro o cinco años después de su graduación.

5. Realizar una comparación de resultados entre los profesionales de diferentes países y áreas de conocimiento a partir de una encuesta dirigida a graduados universitarios europeos y latinoamericanos, cuatro o cinco años después de su graduación.

\subsection{Estructura del Contenido}

Esta tesis se articula en tres partes:

En la primera parte se aborda la introducción y el marco de referencia conceptual y teórico de este tema de estudio.

El Capítulo 1 corresponde a la introducción, justificación y objetivos, que resumen la composición de la investigación. 
En el Capítulo 2 se documenta la revisión bibliográfica realizada y se plantea un marco teórico para el concepto de organización, el éxito profesional, la satisfacción laboral, el rol en el trabajo, las competencias y los valores laborales.

La segunda parte se inicia con el capítulo 3, en el que se plantea el modelo de análisis y se define la hipótesis general y otras hipótesis derivadas, de interés para la investigación.

En el capítulo 4 se detalla la metodología y el diseño de la investigación utilizada en la validación del modelo propuesto. Se presenta la fuente de datos, la población y muestra seleccionada y los métodos utilizados para la obtención de la información. Se definen los tipos de variables a utilizar en el análisis y se hace una breve descripción de las técnicas estadísticas utilizadas.

La tercera parte está compuesta por cinco capítulos. En los capítulos 5 y 6 se valida el modelo de investigación propuesto. El capítulo 5 corresponde al análisis de datos y resultados. Está compuesto por cuatro secciones en las que se realizan análisis y pruebas estadísticas para la posterior comprobación de las hipótesis. En el capítulo 6 se hace una comparativa entre los resultados obtenidos a partir de la validación del modelo.

En el capítulo 7 se plantean las conclusiones obtenidas como resultado del trabajo de investigación desarrollado en la presente tesis doctoral, así como las aportaciones y limitaciones de la investigación. Se dejan planteadas líneas de continuación del tema de estudio para el futuro.

El capítulo 8 contiene las referencias bibliográficas utilizadas para la consulta y redacción del documento.

Finalmente se adjuntan los apéndices con la información de las variables usadas, las pruebas y análisis incluidos en algunos de los capítulos de la memoria. 



\section{CAPITULO 2}

\section{Marco Teórico}

En el presente capítulo se hace una exposición de las diversas ideas relacionadas con el éxito laboral. Se ha llevado a cabo una revisión de la literatura asociada con la evolución de la gestión en las organizaciones, la definición de las competencias en las organizaciones actuales y los valores que determinan el éxito en los profesionales universitarios dentro de las mismas.

El modelo de la investigación supone que el éxito laboral de un profesional dentro de una organización cualquiera, depende del rol que cumple (funciones, responsabilidad) y a la vez está relacionado con las competencias propias y las requeridas por la organización, siendo un elemento importante y complementario para alcanzar el éxito, el ajuste que exista entre los valores laborales del profesional y los de la organización.

La revisión de la literatura que se desarrolla en este capítulo tiene como primer objetivo delimitar conceptualmente la presente investigación, puesto que se exponen ideas y conceptos de investigaciones anteriores que sirven de referencia para la elaboración del modelo teórico propuesto. El segundo objetivo es presentar nuevos enfoques que lleguen a ser un aporte en la construcción de nuevo conocimiento.

\subsection{El Profesional en las Organizaciones}

\subsubsection{Evolución Histórica de las Teorías de Gestión}

Desde la antigüedad, el ser humano ha tenido necesidad de organizarse cuando tuvo que hacerlo para cazar, construir, protegerse de sus enemigos, etc. Todo esto se ha visto reflejado en el testimonio que dan las obras monumentales que han permanecido a lo largo de los siglos, las pirámides de Egipto, la muralla china, las grandes catedrales, etc., cuyos esfuerzos, tanto físicos como económicos, requirieron de una organización y de unos organizadores.

Todas esas experiencias organizativas desarrolladas lentamente a través de los siglos anteriores, fueron utilizadas en el excepcional desarrollo que se dio a partir de la revolución industrial en la segunda mitad del siglo XVIII, con las compañías mercantiles. Los métodos y 
normas de trabajo emergentes de la organización de pequeños talleres y tiendas comerciales a finales del siglo XVIII, fueron propagándose hasta llegar a considerarse la organización como una ciencia.

La recopilación de principios y conocimientos se vendría a denominar "organización científica del trabajo", cuyos máximos representantes, modificando, aplicando y perfeccionando esos conocimientos y principios, fueron Taylor, Gantt, Gilbreth, Ford, etc. ya en el siglo XX.

Aunque desarrollar las teorías de gestión, no es objetivo de este trabajo, una síntesis de su evolución en el tiempo, puede ayudar a entender su relación con el papel del recurso humano dentro de las organizaciones.

Según De Lucas ${ }^{1}$, la evolución científica de la organización como ciencia se ha perfilado en tres etapas. La primera, fue una época que se ha venido a denominar, "mecanicista" y se impulsó por el racionalismo de sus grandes maestros (Weber, Taylor, Fayol, etc.) y en que el ser humano en el ámbito del trabajo casi se encuentra a un nivel inferior a la máquina en cuanto a importancia; es un recurso más.

La segunda etapa se inició con las experiencias de Elton Mayo en la fábrica de Western Electric, al introducir en los esquemas mecanicistas anteriores el término del factor humano, descubriéndose la importancia del mismo. La tercera, se originó en paralelo con la sociología de las organizaciones y se desarrolló desde varios aspectos, tales como la motivación, la comunicación, el comportamiento grupal, el liderazgo, etc., con lo que toma una posición relevante el ser humano en el ámbito laboral. Posteriormente, esa última etapa evolucionaría hasta recibir el impacto de las nuevas tecnologías, esencialmente la informática, con lo que aparecen nuevos sistemas de organización ${ }^{2}$.

A lo largo del siglo XX y en los inicios del siglo XXI, han ido estableciéndose distintas filosofías administrativas de igual manera que lo han hecho las formas organizacionales que han ido cambiando para satisfacer nuevas necesidades. El ámbito laboral actual es distinto del que se tenía hace cincuenta años y sigue cambiando.

Los aportes que a la gestión actual han hecho las escuelas, se reflejan de alguna manera en muchas empresas y organizaciones que utilizan métodos y esquemas derivados de

\footnotetext{
${ }^{1}$ De Lucas Ortueta, Ramón: “La dirección y la estructura de la empresa”, Index, Madrid, 1979, p.140.

2 Porret Gelabert, Miquel: "Recursos Humanos" ESIC, Madrid, 2008
} 
las teorías clásicas y de otras más modernas. Aunque no hay unanimidad entre los diversos autores cuando citan los nombres de estas escuelas.

A continuación se realizará una breve revisión de estas teorías en orden de aparición cronológico para entender la evolución conceptual que se ha producido en el campo de la gestión. Se utiliza como punto de referencia central el capítulo "Evolución histórica del pensamiento sobre gestión del libro Introducción a la Gestión", de Enrique de Miguel Fernández. ${ }^{3}$

\footnotetext{
${ }^{3}$ De Miguel Fernández, E. (1993). Introducción a la Gestión - Management I, Valencia:UPV. Pag. 143-194.
} 

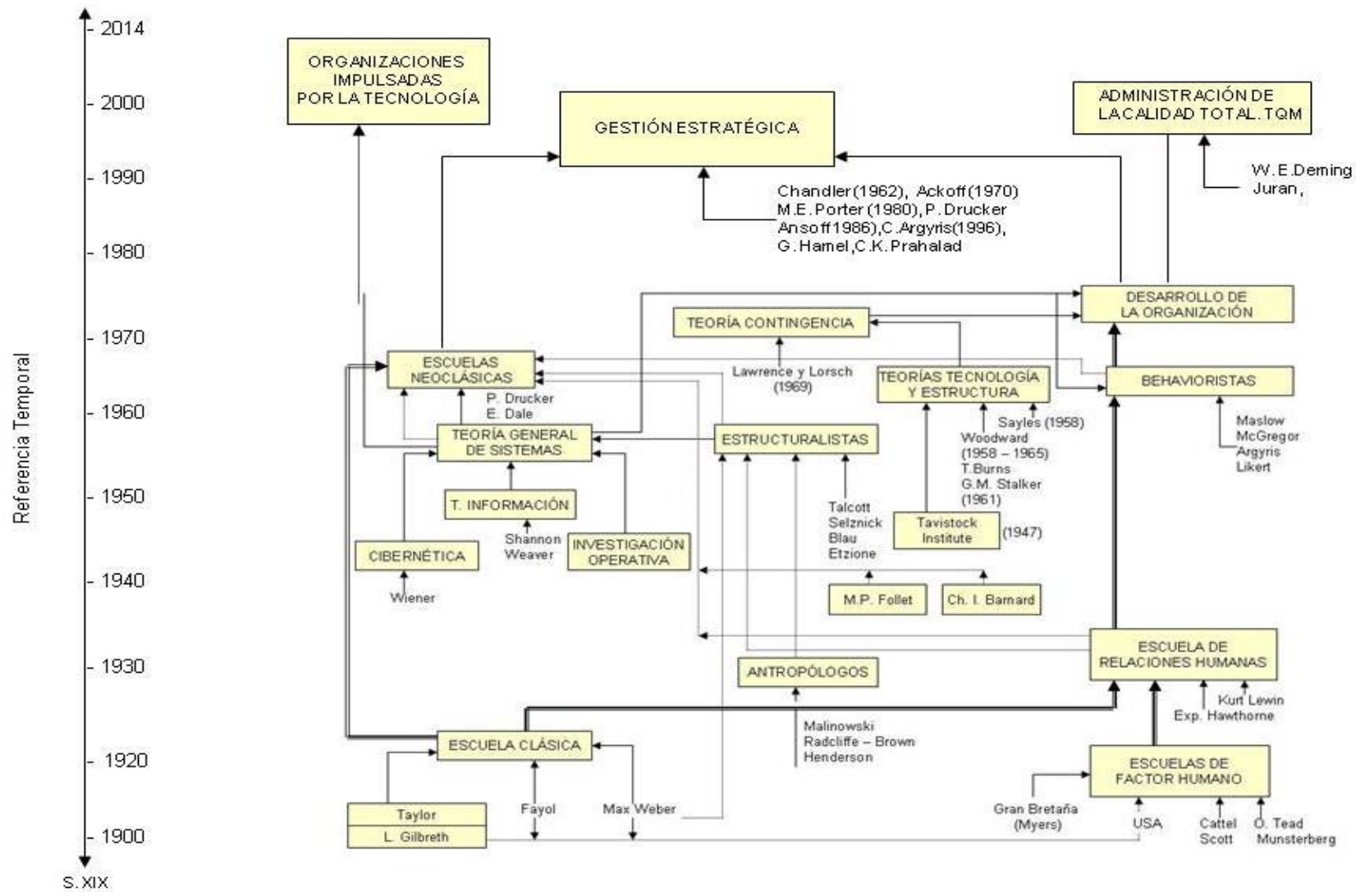

Figura 2. 1 Evolución histórica de las teorías de gestión

Fuente: Adaptación a partir de, De Miguel. E. Introducción a la Gestión - Management I, fig 3.1 pag. 144. 


\subsubsection{La Escuela o Teoría Clásica}

La escuela o teoría clásica, está constituida por tres ramas bien diferenciadas:

La visión económica y racional de la escuela clásica no piensa que el hombre sea un elemento sin importancia dentro de la empresa; lo que piensa es que se siente motivado por objetivos económicos y que elige aquello que le proporciona mayores beneficios de este tipo. El punto de vista racional queda de manifiesto: ${ }^{4}$

Tabla 2. 1 Autores de la Escuela Clásica

\begin{tabular}{|c|c|c|}
\hline \multicolumn{3}{|c|}{$\begin{array}{c}\text { AUTORES DE LA ESCUELA CLÁSICA } \\
\text { Management Científico }\end{array}$} \\
\hline Autor & Obra & Año \\
\hline F.W. Taylor & $\begin{array}{c}\text { The Principles of Scientific Management. Harper \& } \\
\text { Row. New York }\end{array}$ & 1911 \\
\hline F.B. Gilbreth & Motion Study. Van Nostrand, New York & 1911 \\
\hline H. Emerson & $\begin{array}{l}\text { The Twelve Principles of Efficiency. Engineering } \\
\text { Magazine. New York }\end{array}$ & 1913 \\
\hline L.M. Gilbreth & $\begin{array}{l}\text { The Psychology of Management. Sturgis \& Walton, } \\
\text { N.Y. }\end{array}$ & 1914 \\
\hline H.L. Gantt & $\begin{array}{l}\text { Industry Leadership. Yale University Press. New } \\
\text { Haven, Conn. }\end{array}$ & 1916 \\
\hline \multicolumn{3}{|c|}{ Principios Administrativos } \\
\hline Autor & Obra & Año \\
\hline H. Fayol & $\begin{array}{l}\text { Administration industrielle et générale; } \\
\text { prévoyance, organisation, commandement, } \\
\text { coordination, controle. Paris, H. Dunod et E. Pinat }\end{array}$ & 1916 \\
\hline L.F. Urwick & The Elements of administration. Harper \& Row, N.Y. & 1944 \\
\hline \multicolumn{3}{|c|}{ Burocracia } \\
\hline Autor & Obra & Año \\
\hline Max Weber & $\begin{array}{l}\text { "Wirtschaft und Gesellschaft" } \\
\text { Economía y Sociedad. }\end{array}$ & 1922 \\
\hline
\end{tabular}

Fuente: Adaptación a partir de De Miguel Fernández. E. Introducción a la Gestión - Management I, pag. 181

Las personas son motivadas por las recompensas económicas

Puesto que las empresas controlan los incentivos económicos, un individuo es fundamentalmente un recurso pasivo que puede ser manipulado, controlado $y$ motivado por la empresa.

\footnotetext{
${ }^{4}$ De Miguel Fernández, E: Introducción a la Gestión (Management I), Fig.3.3 Pag 147.
} 
- $\quad$ Debe impedirse que las emociones irracionales interfieran con la racionalidad económica.

- $\quad$ Las empresas pueden organizarse de tal manera que se controlen emociones irracionales, y por tanto, los comportamientos imprevistos y disfuncionales de los empleados.

La visión de los clásicos supone que el hombre tiene emociones y que pueden ser controladas mediante la estructuración lógica y racional del trabajo.

\subsubsection{El Factor Humano - Perspectiva Humanista}

La perspectiva humanista enfatiza la importancia de entender los comportamientos, las necesidades y las actitudes humanas en el ámbito laboral así como las interacciones sociales y los procesos de grupo ${ }^{5}$. Se puede interpretar esta perspectiva a través de tres escuelas: El factor humano, escuela de las relaciones humanas y los autores de la escuela behaviorista.

Tabla 2. 2 Autores de las escuela del Factor Humano

\begin{tabular}{|c|c|c|}
\hline \multicolumn{3}{|c|}{ AUTORES DE LA ESCUELA DEL FACTOR HUMANO } \\
\hline Autor & Obra & Año \\
\hline W. McDougall & An Introduction to Social Psychology, Methuen & 1908 \\
\hline D. Scott & $\begin{array}{l}\text { The Psychology of Advertising. Small. Maynard, } \\
\text { Boston }\end{array}$ & 1908 \\
\hline H. Münsterberg's & Psychology and Industrial Efficiency & 1913 \\
\hline O. Tead & Instincts In Industry. Small. Maynard, Boston & 1918 \\
\hline C.S. Myers & Industrial Psychology in Great Bretain, Cape & 1924 \\
\hline E.P. Cathcart & $\begin{array}{l}\text { The Human Factor in Industry. Oxford University } \\
\text { Press. }\end{array}$ & 1926 \\
\hline $\begin{array}{c}\text { Roethlisberger, F.J. y } \\
\text { W.J. Dickson }\end{array}$ & $\begin{array}{c}\text { Management and The Worker, Harvard } \\
\text { University Press, Cambridge }\end{array}$ & 1939 \\
\hline
\end{tabular}

Fuente: Adaptación a partir de De Miguel Fernández. E.

Introducción a la Gestión - Management I, pag. 182

A principios del siglo $\mathrm{XX}$, aparecen tendencias que dan una mayor importancia al factor humano, apoyándose en ciencias como la psicología y la sociología. Nuevas teorías como "la teoría del instinto" de Mc.Dougall (1908) que rechaza al hombre "racional" de los economistas

\footnotetext{
${ }^{5}$ Gregory M. Bounds, Gregory H. Dobbins, y Oscar S. Fowler, Management: A Total Quality Perspective. Cincinnati: South Western Publishing, 1995., 52-53.
} 
y por tanto, las ideas planteadas en el taylorismo. O.Tead fue uno de los seguidores de Mc.Dougall, quedando constancia de ello en los libros publicados entre 1918 y 1935.

La psicología aplicada en los Estados Unidos destaca el aporte de H. Münsterberg quien establece una aplicación de la psicología a la industria y la administración. En 1909 sugirió que la psicología podía ser usada en una variedad de aplicaciones industriales, incluidas la gestión, las decisiones vocacionales, mejora del trabajo y motivación del empleado.

La realización de diferentes estudios, relacionados con la fatiga, las condiciones ambientales y el absentismo mejoraron el conocimiento sobre el factor humano.

\subsubsection{Las Relaciones Humanas}

Durante el periodo comprendido entre 1924 y 1940 surgieron importantes teorías en el campo de la administración de empresas. En el año 1924 comienzan unos experimentos en la factoría Hawthorne, de la empresa Western Electric, en las cercanías de Chicago. Su intención era comprobar la influencia de los distintos niveles de alumbrado sobre los rendimientos de los trabajadores. Estos experimentos tenían un enfoque de factor humano, similar al de la psicología industrial británica. Se pretendía con ellos encontrar una relación entre la producción y distintas variables físicas y fisiológicas, así como valorar el efecto de los incentivos. Elton Mayo (1880 - 1940) y otros colaboradores de la Universidad de Harvard, investigadores de Hawthorne llegaron a la conclusión de que además de los factores básicos de motivación conocidos, salarios y seguridad en el trabajo existía un nuevo factor psíquico, y otros factores relacionados con el grupo.

Estudios sucesivos, estuvieron relacionados con la existencia de grupos informales de trabajo, la organización formal y la informal. Las teorías derivadas de los experimentos Hawthorne se llaman también de relaciones humanas.

Los teóricos de las relaciones humanas no rechazan todas las aportaciones de la escuela clásica; lo que señalan es que no pueden funcionar bien, porque las personas no actúan siempre de manera "racional". El punto de vista de esta teoría es la siguiente:

- $\quad$ Las personas son motivadas por las necesidades sociales

- $\quad$ Las personas obtienen su sentido de identidad gracias a sus relaciones con los demás. 
- $\quad$ Debido al progreso industrial y a las tareas cada vez más rutinarias, el trabajo produce insatisfacción.

- Los empleados responden positivamente ante los esfuerzos e interés demostrados por los mandos para satisfacer las necesidades sociales.

Los planteamientos de las Relaciones Humanas fueron utilizados por las empresas americanas desde el año 40 hasta finales de los años 50.

La teoría de las relaciones humanas no solo deriva de los experimentos Hawthorne, sino también de los conocimientos desarrollados hasta entonces por la psicología y la sociología.

En el año 1935, Kurt Lewin analiza la importancia de la motivación y la frustración sobre la conducta. En su teoría de campo expone que la conducta humana no depende del pasado ni del futuro, sino del campo dinámico actual. En 1939, Lewin, Lippit y White publicaron un trabajo sobre el liderazgo. Comprobaron que el grupo de estudio utilizaba tres estilos de liderazgo: autoritario, liberal y democrático que fueron ampliamente descritos por los autores. Los resultados del estudio se intentaron aplicar a las empresas con el fin de mejorar la dirección. La teoría de Las relaciones humanas defiende la conveniencia de la dirección democrática.

Se supone que Kurt Lewin fue el fundador de la dinámica de grupo, por los trabajos que hizo en el centro de investigaciones de la dinámica de grupo en la Universidad de Michigan. Sus trabajos son la base de las teorías sobre el desarrollo de la organización (D.O.).

En esta misma línea, Mary Parker Follet (1863 - 1933) destaca la orientación psicológica de la gestión. Señala la relevancia del grupo como bloque fundamental de la organización y precisa que solo mediante las relaciones con otros grupos la persona adquiere su verdadera identidad y llega a ser completamente creativa. Para esta autora, la responsabilidad de un mando no es dar órdenes, sino más bien definir y articular las metas comunes del grupo. Cuando las personas trabajan en cooperación para llegar a tales objetivos demuestran su integridad y responsabilidad. Las ideas de M.P. Follet han sido continuadas por teóricos behavioristas como Cyert, March, McGregor, Likert y Argyris.

Chester I. Barnard (1886-1961), ha sido uno de los autores que más ha propiciado el auge de las teorías sobre gestión. Según Barnard la dificultad fundamental con la que se 
encuentra un jefe, es como obtener la cooperación de las personas para que la organización alcance sus objetivos. Para lograrlo ha de dar incentivos positivos, o bien reducir las presiones negativas que soportan los miembros de la organización.

Entre los incentivos potenciales señala los siguientes:

- $\quad$ Dinero y bienes materiales

- $\quad$ Oportunidades de distinción, prestigio, poder personal o logro de un puesto con poder.

- $\quad$ Condiciones agradables del trabajo.

- $\quad$ Alcanzar los ideales personales.

- $\quad$ Ambiente social atractivo.

- $\quad$ Condiciones del trabajo, actitudes y prácticas del trabajo familiares.

- $\quad$ Oportunidad para la comunicación, camaradería y apoyo mutuo.

Tabla 2. 3 Autores de la escuela de Relaciones Humanas

\begin{tabular}{|c|c|c|}
\hline \multicolumn{3}{|c|}{ AUTORES DE LA ESCUELA DE RELACIONES HUMANAS } \\
\hline Autor & Obra & Año \\
\hline E. Mayo & $\begin{array}{c}\text { The human problems of an industrial } \\
\text { civilization, Cap 3-5. The MacMillan Co., } \\
\text { New York. }\end{array}$ & 1933 \\
\hline \multirow{2}{*}{ K. Lewin, R. Lippitt } & $\begin{array}{c}\text { An experimental approach to the study of } \\
\text { autocracy and democracy. A preliminary } \\
\text { note', Sociometry 1:292-300. }\end{array}$ & 1938 \\
\hline Ch.I. Barnard & $\begin{array}{r}\text { The Functions of the Executive, Harvard Univ. } \\
\text { Press, Cambridge, Mass. }\end{array}$ & 1938 \\
\hline M.P. Follet & $\begin{array}{c}\text { Dynamic Admistration: The Collected Papers of } \\
\text { Mary Parker Follet, edt.: H.C. Metcalf y L. Urwick. } \\
\text { Harper \& Row, N.Y. }\end{array}$ & 1940 \\
\hline K. Lewin & $\begin{array}{r}\text { Field Theory in Social Science; Selected } \\
\text { theoretical papers. D. Cartwright (ed.). New York: } \\
\text { Harper \& Row. }\end{array}$ & 1951 \\
\hline
\end{tabular}

Fuente: Adaptación a partir de De Miguel Fernández. E. Introducción a la Gestión - Management I, pag 182

Se reconoce de Barnard el concepto de organización informal y el aporte que hace sobre el concepto de la organización como "un sistema de actividades o esfuerzos de dos o más personas coordinadas conscientemente". El sistema de la organización incluía, según Barnard, otros elementos además de los empleados; los proveedores, clientes o inversores. Fue el primer teórico de la organización que juzgó la organización como un sistema, aplicando 
conceptos del campo de la biología. Sin embargo, este planteamiento de sistema no fue aprovechado por otros teóricos de la organización hasta los años 60.

\subsubsection{Teoría Behaviorista}

Conocida también como "Nueva Escuela de Relaciones Humanas". "Psicólogos de la organización" y "Humanistas de la Organización". Continúa la línea abierta por la escuela de Relaciones Humanas, alcanzando una gran importancia en los Estados Unidos al final de los años 50 y principios de los 60. La evolución posterior ha conducido a lo que viene llamándose "Desarrollo de la Organización".

Algunos de los autores más característicos de la teoría behaviorista son: H. Maslow, Douglas McGregor, Rensis Likert y Chris Argyris. Se destacan cinco aspectos primordiales:

- El tratamiento dado a la motivación.
- $\quad$ Los diferentes estudios sobre los estilos de mando.
- $\quad$ El proceso de toma de decisiones.
- El comportamiento en la empresa u organización (el significado de comportamiento está relacionado con la productividad o cooperación con los mandos del grupo de trabajo).

- La planificación para el desarrollo de la organización o "Desarrollo de la Organización" (D.O.)

Los behavioristas opinaban que era más conveniente para la naturaleza humana un trabajo con mayor libertad y satisfacción del que se venía practicando hasta entonces, y que los trabajadores que se sienten motivados en la empresa producen mayores beneficios a ésta que si se siguen criterios burocráticos. El parecer de los behavioristas es que el diseño "racional" del trabajo conduce a la monotonía y que los empleados no pueden aplicar todo su poder creativo. A diferencia de las escuelas clásica y de relaciones humanas que resaltaban las motivaciones externas al trabajador (gratificaciones económicas y aceptación social), la escuela behaviorista estudia con bastante profundidad las motivaciones internas. 
Tabla 2. 4. Autores de la Escuela Behaviorista

\begin{tabular}{|c|c|c|}
\hline \multicolumn{3}{|c|}{ ESCUELA BEHAVIORISTA } \\
\hline Autor & Obra & Año \\
\hline \multirow{2}{*}{ A.H. Maslow } & A Theory of Human Motivation. Psychological Review. Vol.50(4). & 1943 \\
\hline & Motivation and Personality. Harper \& Row, N.Y. & 1954 \\
\hline C.Argyris & Personality and Organization. Harper \& Row, N.Y. & 1957 \\
\hline J.G. March y H.A. Simon & Organizations. Jhon Wiley \& Sons, N.Y. & 1958 \\
\hline $\begin{array}{l}\text { F. Herzberg, B.Mausner } \\
\text { y B.B. Snyderman }\end{array}$ & The Motivation to Work. Jhon Wiley \& Sons, N.Y. & 1959 \\
\hline H.A. Simon & $\begin{array}{l}\text { The New Science of Management Decision. Prentice Hall. } \\
\text { Englewood Cliffs, N.J. }\end{array}$ & 1960 \\
\hline D. McGregor & The Human Side of Enterprise. McGraw Hill, N.Y. & 1960 \\
\hline C. Argyris & $\begin{array}{l}\text { Understanding Organizational Behavior. Dorsey Press. } \\
\text { Homewood, III. }\end{array}$ & 1960 \\
\hline R. Likert & New Patterns of Management. McGraw Hill, N.Y. & 1961 \\
\hline D.C. McClelland & The Achieving Society. D. Van Nostrand, N.Y. & 1961 \\
\hline $\begin{array}{c}\text { R. Tannenbaum, I.R. } \\
\text { Weschler y F. Massarik }\end{array}$ & Leadership and Organization. Jhon Wiley \& Sons. N.Y. & 1961 \\
\hline C. Argyris & $\begin{array}{l}\text { Interpersonal Competence and Organizational Effectiveness. } \\
\text { Irwin-Dorsey, Homewood-III. }\end{array}$ & 1962 \\
\hline R.M. Cyert y J.G. March & A Behavioral Theory of the Firm. Prentice Hall, Englewood Cliffs, N.J. & 1963 \\
\hline C. Argyris & $\begin{array}{l}\text { T-Groups for Organizational Effectiveness. Harvard Business Review, } \\
\text { Marzo-Abril. }\end{array}$ & 1964 \\
\hline F. Herzberg & Work and the Nature of Man. World Publishing, Cleveland & 1966 \\
\hline D. McGregor & Leadership and Motivation. M.I.T. Press. Cambridge, Mass & 1966 \\
\hline R. Likert & $\begin{array}{l}\text { The Human Organization: Its Management and Value. McGraw Hill. } \\
\text { N.Y. }\end{array}$ & 1967 \\
\hline D. McGregor & The Professional Manager. McGraw Hill. N.Y. & 1967 \\
\hline
\end{tabular}

Fuente: Adaptación a partir de De Miguel Fernández. E.

Introducción a la Gestión Management I, pag. 183

\subsubsection{Escuela del Desarrollo de la Organización (D.0.)}

E.F. Huse y Th. G. Cummings en $1985^{6}$, definen el desarrollo de la organización como el proceso mediante el cual los conocimientos y prácticas de la ciencia del comportamiento son utilizados para ayudar a las organizaciones a conseguir una mayor eficacia, incluyendo además una mejor calidad de vida en el trabajo y aumento de la productividad.

\footnotetext{
${ }^{6}$ E.F. Huse y Th. G. Cummings, “Organization Development and Change”. 3a Edic. West Publ. St. Paul. Minn 1985
} 
W.G. Bennis (1969) señala el D.O. como una estrategia educativa adaptada para lograr un cambio planeado de la organización, donde las personas son el punto de partida y no las metas, estructuras y técnicas de la organización. Su estrategia realza la importancia del comportamiento a través de la experiencia. Se utiliza el feedback, entrenamientos, reuniones de confrontación y otros métodos apoyados en las experiencias, para generar datos de público conocimiento que constituyan el punto de partida para la planificación y la acción. Se utilizan agentes externos, se supone una relación de cooperación, se comparte una filosofía social y un conjunto de valores referentes al mundo en general y a las relaciones humanas en particular. D.A. Nadler (1977) señala que el D.O. es un intento planeado y sistemático de cambio de los patrones de comportamiento en la organización.

Según Cummings y Worley (2008), el D.O. emerge de cinco antecedentes muy importantes

- El crecimiento de los National Training Laboratories (NTL) y el desarrollo de los training groups.

- los primeros trabajos de investigación sobre encuestas y feedback donde son fundamentales las investigaciones de Kurt Lewin.

- El punto de vista normativo del D.O. un marco de gestión participativa y el mejor camino para diseñar y operar las organizaciones.

- la orientación hacia la productividad y la calidad de vida en el trabajo.

- La influencia más reciente sobre la práctica actual, supone un cambio estratégico y de transformación de la organización. 
Tabla 2. 5 Autores de la Escuela del Desarrollo de la Organización (D.O.)

\begin{tabular}{|c|c|c|}
\hline \multicolumn{3}{|c|}{ ESCUELA DEL DESARROLLO DE LA ORGANIZACIÓN (D.O.) } \\
\hline Autor & Obra & Año \\
\hline P.R. Lawrence & $\begin{array}{l}\text { The Changing of Organizational Behavior Patterns. Harvard Univ. } \\
\text { Press, Cambridge, Mass. }\end{array}$ & 1958 \\
\hline \multirow{2}{*}{ W.G. Bennis } & $\begin{array}{l}\text { A New Role for the Behavioral Sciences: Effecting organizational } \\
\text { change. Administrative Science Quarterly, vol } 8 .\end{array}$ & 1963 \\
\hline & $\begin{array}{l}\text { Organization Development: Its Nature, Origins, and Prospects. } \\
\text { Addison-Wesley. Reading Mass. }\end{array}$ & 1969 \\
\hline E.E. Lawler & Motivation in work Organizations. Brooks/Cole, Monterey, Calif & 1973 \\
\hline D.A. Nadler & $\begin{array}{l}\text { Feedback and Organization Development: Using Data - Based } \\
\text { Methods. Addison-Wesley. Reading Mass. }\end{array}$ & 1977 \\
\hline J. Walker & Human Resource Planning. McGraw Hill, N.Y. & 1980 \\
\hline $\begin{array}{l}\text { R. Pascale, A. } \\
\text { Athos }\end{array}$ & The Art of Japanese Management. Simon \& Shuster, N.Y. & 1981 \\
\hline W.G. Ouchi & Theory Z. Addison-Weslwy. Reading, Mass. & 1981 \\
\hline $\begin{array}{l}\text { T.J. Peters, R.H. } \\
\text { Waterman }\end{array}$ & In Search of Excellence. Harper \& Row. N.Y. & 1983 \\
\hline $\begin{array}{l}\text { E.F. Huse y } \\
\text { T.G. Cummings }\end{array}$ & Organization Development and Change. West Publish, St.Paul, Minn. & 1985 \\
\hline R.L. Daft & Management. The Dryden Press. N.Y. & 1983 \\
\hline $\begin{array}{l}\text { Th. G. } \\
\text { Cummings y } \\
\text { C.G Worley }\end{array}$ & $\begin{array}{c}\text { Organization Development and Change. 9a Edic. South } \\
\text { Western-Cengage Learning, Mason } \mathrm{OH}, \mathrm{USA} \text {. }\end{array}$ & 2008 \\
\hline
\end{tabular}

Fuente: Adaptación a partir de De Miguel Fernández. E.

Introducción a la Gestión Management I, pags 184-186.

\subsubsection{Teoría de Sistemas}

Las teorías estructuralistas fueron base de la teoría de sistemas. Surgió en los Estados Unidos a finales de los años 50, dentro de la administración de empresas como una síntesis de la teoría clásica y de la teoría de las relaciones humanas (Chiavenato, 2006). El estructuralismo estudia las organizaciones, su estructura y sus interacciones.

Para Etzione (1961) y T. Parsons (1960), las organizaciones son definidas como unidades sociales intencionalmente construidas y reconstruidas para conseguir objetivos específicos. Los estructuralistas pretendieron encontrar la relación entre la organización formal y la informal siendo los objetivos de la organización de gran interés en las teorías estructuralistas. 
La inclusión del entorno es fundamental para comprender el estructuralismo; los objetivos de la organización no son estáticos, sino que se van modificando en función de la interacción con el entorno.

La importancia de estudiar el entorno se manifestó en la década de 1960, sin embargo el antecedente de la teoría de sistemas se origina en los estudios de Von Bertalanffy (1924), quien trabajaba en una teoría integradora que pudiera proporcionar principios y modelos generales para otras ciencias, de tal manera que los descubrimientos realizados en una de ellas pudieran aplicarse a las demás. La teoría general de sistemas se debe a Bertalanffy y gran parte de su desarrollo a Ashby, Boulding y Beer que junto con sus primeros seguidores entendieron que la teoría de sistemas comprendía en su seno la investigación operativa, la teoría de la información, la cibernética, la teoría de la decisión entre otras.

Tabla 2. 6 Autores de la Escuela de Sistemas

\begin{tabular}{|c|c|c|}
\hline \multicolumn{3}{|c|}{ TEORÍAS ESTRUCTURALISTAS } \\
\hline Autor & Obra & Año \\
\hline T. Parsons & Structure and Process in Modern Societies. Free Press, N.Y. & 1960 \\
\hline A. Etzione & Complex Organizations. Holt, Rinehart \& Winston, N.Y. & 1961 \\
\hline A. Etzione & $\begin{array}{c}\text { A Comparative Analysis of Complex Organizations. Free } \\
\text { Press, Glencoe, III }\end{array}$ & 1961 \\
\hline $\begin{array}{l}\text { P.M. Blau y R.A. } \\
\text { Schoenherr }\end{array}$ & The Structure of Organizations. Basic Books, N.Y. & 1971 \\
\hline A. Etzione & Modern Organizations. Prentice Hall. Englewood Cliffs N.J. & 1984 \\
\hline I. Chiavenato & $\begin{array}{l}\text { Introducción a la Teoría General de la Administración. } \\
\text { McGraw Hill. }\end{array}$ & 2006 \\
\hline \multicolumn{3}{|c|}{ ESCUELA DE SISTEMAS } \\
\hline Autor & Obra & Año \\
\hline L. von. Bertalanffy & $\begin{array}{l}\text { General System Theory: A new approach to unity of } \\
\text { science. Human Biology. }\end{array}$ & 1951 \\
\hline W.R. Ashby & An Introduction to cybernetics. John Wiley \& Sons, N.Y. & 1956 \\
\hline K.E. Boulding & $\begin{array}{c}\text { General Systems Theory: The skeleton of science. } \\
\text { Management Science }\end{array}$ & 1956 \\
\hline Daniel Katz, Robert Kahn & The Social Psychology of Organization. & 1966 \\
\hline $\begin{array}{c}\text { Richard A. Jhonson, } \\
\text { Fremont Kast y James E. } \\
\text { Rosenzweig }\end{array}$ & Designing Management Systems. John Wiley \& Sons, N.Y. & 1968 \\
\hline
\end{tabular}

Fuente: Adaptación a partir de De Miguel Fernández. E. Introducción a la Gestión - Management I, pag 172 y 187 
Daniel Katz, Robert Khan y James Thompson (1960), postularon que una organización es un sistema abierto que toma recursos del exterior y los convierte en bienes y servicios que devuelve al entorno para ser adquiridos por los clientes.

La empresa, entendida como una organización, es decir, como estructura social completa y agente de producción, tiene las características de un sistema abierto ligado por múltiples relaciones con su entorno; es también dinámico puesto que persigue simultáneamente una pluralidad de objetivos y está compuesto de una serie de subsistemas, también dinámicos, en relación de interdependencia e igualmente orientados hacia los objetivos. Otras aportaciones relacionadas con la visión de sistemas dentro del campo de las ciencias económicas, son la teoría de juegos de Morgenstern y Von Neumann (1944), la teoría de la decisión, expuesta por Luce y Raiffa (1957) y el análisis "input-output" de Leontieff (1951).

\subsubsection{Teoría de las Contingencias}

Formulada en la década de 1960, por Tom Burns y G.M. Stalker en Inglaterra y Jay Lorsch en Estados Unidos. El concepto fundamental es que no hay una manera óptima de organizar: las estructuras y los sistemas de control que eligen los administradores dependen de las características del medio en que se desenvuelve la organización.

Dependiendo de las características del entorno se determina el diseño de la estructura y los sistemas de control de la organización. Burns y Stalker, inspirados en la teoría clásica propusieron dos formas de administrar las organizaciones (Jones y George,2003).

$>\quad$ En entornos estables las organizaciones prefieren una estructura mecanicista: autoridad centralizada, comunicación vertical, control mediante reglas y procedimientos estrictos.

$>\quad$ En entornos cambiantes las organizaciones escogen una estructura orgánica: autoridad descentralizada, comunicación horizontal, cooperación entre departamentos.

Los teóricos de la contingencia piensan que las personas son motivadas por fuerzas o influencias que les rodean y no creen que respondan únicamente a sus instintos o necesidades básicas. Un aspecto importante de la teoría está relacionado con la estructura de las organizaciones. No hay una estructura ideal que se adapte a cualquier tipo de empresa. En 
principio la estructura depende de varios factores tanto internos como externos: entorno, estrategia, tecnología y tamaño.

Tabla 2. 7 Autores de la Teoría de la Contingencia

\begin{tabular}{|c|c|c|}
\hline \multicolumn{3}{|c|}{ TEORÍA DE LA CONTINGENCIA } \\
\hline Autor & Obra & Año \\
\hline T. Burns y G.M.Stalker & $\begin{array}{c}\text { The Management of Innovation. } \\
\text { Tavitock Publ, Londres }\end{array}$ & 1961 \\
\hline $\begin{array}{c}\text { P.R. Lawrence y J.R. } \\
\text { Lorsh }\end{array}$ & $\begin{array}{c}\text { Organization and Environmental, } \\
\text { Boston Harvard University }\end{array}$ & 1967 \\
\hline
\end{tabular}

Fuente: Adaptación a partir de G.Jones y J.George (2008)

\subsubsection{Teorías Neoclásicas}

Los avances en la teoría de la gestión de empresas no han sido obstáculo para que sigan vigentes muchos conceptos de los teóricos clásicos. La orientación neoclásica investiga la actualización de los criterios clásicos.

Las principales características de estas teorías son las siguientes:

-Se da un gran valor a los aspectos prácticos de la gestión.

-Como reacción a las teorías behavioristas, se hace actualización de las ideas clásicas.

-Consideración de los conceptos de estructura, autoridad y responsabilidad, departamentalización y otros.

-Impulso y actualización de los principios clásicos de Fayol.

-Importancia de los objetivos y resultados

-Empleo de las ideas de otras teorías que se juzguen de interés.

Llamada también escuela operacional o del proceso administrativo, para los exponentes de esta teoría la administración consiste en orientar, dirigir y controlar los esfuerzos de un grupo de individuos para lograr un fin común con un mínimo de recursos y de esfuerzo y con la menor interferencia, con otras actividades útiles. Los autores más relevantes de esta escuela son Peter F. Drucker, Harold Koontz, Ernest Dale, Cyril O’Donell. 
Tabla 2. 8 Autores de la Escuela Neoclásica

\begin{tabular}{|c|c|c|}
\hline \multicolumn{3}{|c|}{ AUTORES DE LA TEORÍA NEOCLASICA } \\
\hline Autor & Obra & Año \\
\hline \multirow{2}{*}{ P.F. Drucker } & The Future of Industrial Man. John Day, N.Y. & 1942 \\
\hline & The Concept of the Corporation. John Day, N.Y. & 1946 \\
\hline E. Dale & $\begin{array}{c}\text { Planning and Developing the Company Organization } \\
\text { Structure. AMA, N.Y. }\end{array}$ & 1952 \\
\hline $\begin{array}{l}\text { H.Koontz y C. } \\
\text { O'Donnell }\end{array}$ & Principles of Management. Harper \& Row. N.Y. & 1954 \\
\hline E. Dale & $\begin{array}{l}\text { Management. Theory and Practice. } \\
\text { McGraw Hill, N.Y. }\end{array}$ & 1965 \\
\hline H. Koontz & $\begin{array}{l}\text { Appraising Managers as Managers. } \\
\text { McGraw Hill, N.Y. }\end{array}$ & 1971 \\
\hline P.F. Drucker & $\begin{array}{c}\text { People and Performance: The Best of Peter Drucker on } \\
\text { Management. Harper's College Press, N.Y. }\end{array}$ & 1977 \\
\hline G. Odiorne & $\begin{array}{l}\text { The effective executive's guide to successful goal setting. } \\
\text { MBO Inc. Westfield, Mass. }\end{array}$ & 1980 \\
\hline P.F. Drucker & $\begin{array}{c}\text { Innovation and Entrepreneurship. } \\
\text { Harper \& Row, N.Y. }\end{array}$ & 1985 \\
\hline
\end{tabular}

Fuente: Adaptación a partir de De Miguel Fernández. E.

Introducción a la Gestión - Management I, pag. 190

\subsubsection{Administración de la Calidad Total (TQM)}

El movimiento de la calidad surgió en Japón como resultado de la influencia americana tras la segunda guerra mundial. Las teorías del norteamericano W. Edwars Deming fueron adoptadas y modificadas por los japoneses para ayudar a la reconstrucción de sus industrias, obteniendo una ventaja sobre el modelo industrial americano.

Durante la década de 1980 y en la primera parte de la década de 1990 se extiende y consolida, la administración de la calidad total (TQM), un concepto que centra la atención en la administración de la organización en forma total para proporcionar calidad a los clientes. Cuatro elementos significativos de la administración de la calidad son: la participación de los empleados, el centrar la atención en el cliente, la fijación de puntos de referencia y de comparación (Benchmarking) y el mejoramiento continuo, un compromiso extensivo a toda la organización para infundir calidad dentro de todas las actividades. J. Juran junto con W. Edwards Deming, destacan como los autores más representativos. 
Tabla 2. 9 Autores de la Administración de la Calidad Total

\begin{tabular}{|c|c|c|}
\hline \multicolumn{3}{|c|}{ ADMINISTRACIÓN DE LA CALIDAD TOTAL (TQM) } \\
\hline Autor & Obra & Año \\
\hline W. Shewhart & Statistical Method From the Viewpoint of Quality Control. & 1939 \\
\hline $\begin{array}{l}\text { A.V. } \\
\text { Feigenbaum }\end{array}$ & $\begin{array}{l}\text { Quality Control: Principles, Practice and Administration. } \\
\text { McGraw-Hill, New York. }\end{array}$ & 1945 \\
\hline $\begin{array}{c}\text { A.V. } \\
\text { Feigenbaum }\end{array}$ & Total Quality Control. McGraw Hill, New York. & 1961 \\
\hline J. Juran & Managerial Breakthrough. New York, McGraw Hill. & 1964 \\
\hline $\begin{array}{l}\text { W. Edwards } \\
\text { Deming }\end{array}$ & Some Theory of Sampling. Dover Publications & 1966 \\
\hline J. Juran & Management of Quality Control. N.Y. & 1967 \\
\hline P. B. Crosby & $\begin{array}{c}\text { The Strategy of Situation Management: A new and unique } \\
\text { approach to managing personal and business problems } \\
\text { more effectively. Boston Mass. }\end{array}$ & 1969 \\
\hline K. Ishikawa & $\begin{array}{c}\text { [original Japanese ed. 1970]. QC Circle Koryo : General } \\
\text { Principles of the QC Circle. Tokyo: QC Circle Headquarters, } \\
\text { Union of Japanese Scientists and Engineers. }\end{array}$ & 1980 \\
\hline $\begin{array}{l}\text { W. Edwards } \\
\text { Deming }\end{array}$ & Out of the Crisis. MIT Press, New York & 1986 \\
\hline J. Juran & Juran on Planning for Quality. The Free Press & 1988 \\
\hline $\begin{array}{l}\text { W. Edwards } \\
\text { Deming }\end{array}$ & $\begin{array}{l}\text { The New Economics for Industry, Government, Education } \\
\text { (1nd ed.). MIT Press. }\end{array}$ & 1993 \\
\hline P. B. Crosby & Quality and Me: Lessons from an Evolving Life. Jossey-Bass. & 1999 \\
\hline
\end{tabular}

Fuente: Elaboración Propia

\subsubsection{La Gestión Estratégica}

Las ideas más beneficiosas de la escuela neoclásica y de la escuela del desarrollo de la organización (D.O.) han sido punto de referencia en la definición de los conceptos actuales sobre la gestión estratégica.

Daft, define la gestión estratégica como el conjunto de decisiones y acciones empleadas para formular y seguir estrategias que presenten un ajuste competitivamente superior entre la empresa y su entorno para lograr los objetivos empresariales (Daft, 1988).

Para algunos autores, la gestión estratégica como disciplina académica es un planteamiento metodológico acerca de cómo coordinar las acciones de las diferentes partes 
de una organización con el fin de asegurar su desarrollo y mantenimiento en el espacio y en el tiempo y todo ello en un entorno de competencia (Garrido, 2006).

Tabla 2. 10 Autores de la Gestión Estratégica

\begin{tabular}{|c|c|c|}
\hline \multicolumn{3}{|c|}{ GESTIÓN ESTRATÉGICA } \\
\hline Autor & Obra & Año \\
\hline A. Chandler & Strategy and Structure. Mitt Press, Cambridge Mass. & 1962 \\
\hline R.L. Ackoff & A Concept of corporate planning. Wiley, New York & 1970 \\
\hline P.F. Drucker & $\begin{array}{c}\text { Management: Tasks, Responsabilities Practices. Harper \& } \\
\text { Row, N.Y. }\end{array}$ & 1974 \\
\hline H.I. Ansoff & $\begin{array}{l}\text { From Strategic Planning to Strategic Management. Wiley, } \\
\text { New York. }\end{array}$ & 1976 \\
\hline $\begin{array}{l}\text { Ch.W. Hofery } \\
\text { D. Schendel }\end{array}$ & $\begin{array}{l}\text { Stra tegy Formulation: Ana lytical Concepts. West, St. Paul, } \\
\text { Minn. }\end{array}$ & 1978 \\
\hline G.A. Steiner & Strategic Planning. The Free Press, New York. & 1979 \\
\hline $\begin{array}{l}\text { A.C. Haxy } \\
\text { N.S. Majluf }\end{array}$ & $\begin{array}{c}\text { Organizational Design. Massachusetts Institute of } \\
\text { Technology }\end{array}$ & 1979 \\
\hline M.E. Porter & Competitive Strategy. Free Press, N.Y. & 1980 \\
\hline $\begin{array}{l}\text { R. Amara y } \\
\text { A.J. Lipinsky }\end{array}$ & $\begin{array}{c}\text { Business planning for an uncertain future: Scenarios and } \\
\text { strategies. Pergamon Press, N.Y. }\end{array}$ & 1983 \\
\hline M.E. Porter & Competitive Advantage. Free Press, N.Y. & 1985 \\
\hline M. Godet & Prospective et planification stra tégique. Economica, París & 1985 \\
\hline $\begin{array}{l}\text { J.A. Pearce y } \\
\text { R.B. Robinson }\end{array}$ & Stra tegic Management. Irwin, Homewood. III & 1988 \\
\hline $\begin{array}{l}\text { Ch.W.L. Hill y } \\
\text { G.R. Jones }\end{array}$ & $\begin{array}{l}\text { Strategic Management: An integrated approach. Houghton } \\
\text { Mifflin, Boston }\end{array}$ & 1989 \\
\hline $\begin{array}{l}\text { A.A. Thompson y } \\
\text { A.J. Strickland }\end{array}$ & $\begin{array}{l}\text { Strategic Management: Concepts and cases, 5a edic. } \\
\text { BPI/Irwin, Homewood, III }\end{array}$ & 1990 \\
\hline $\begin{array}{l}\text { C.A. Montgomery } \\
\text { y M.E. Porter }\end{array}$ & $\begin{array}{c}\text { Strategy: Seeking and securing competitive advantage. } \\
\text { Harvard Business School Press. }\end{array}$ & 1991 \\
\hline $\begin{array}{l}\text { C.K. Prahalad y } \\
\text { G. Hamel }\end{array}$ & Competing for the future. Congress Library, U.S. & 1994 \\
\hline P.F. Drucker & Management challenges for the 21 st century. Elsevier. & 2007 \\
\hline
\end{tabular}

Fuente: Elaboración Propia

La estrategia en el campo de la organización de empresas ha sufrido diferentes enfoques hasta llegar a lo que hoy se conoce como gestión o dirección estratégica. Aparece en los años cincuenta como consecuencia del traslado al campo de las grandes empresas, algunos principios de planificación del desarrollo previamente utilizados por los planificadores gubernamentales en los niveles macroeconómicos. 
El nacimiento de las grandes corporaciones y la necesidad de herramientas para la coordinación que abarcaran periodos superiores a un año tuvo como consecuencia la búsqueda de herramientas de planificación encaminadas a lograr la coordinación y coherencia de los objetivos de las organizaciones a largo plazo (Garrido, 2006). Esta etapa dio lugar a la denominación de planificación empresarial. Los autores más importantes de esta etapa son Alfred Chandler (1962) y G.A. Steiner (1979).

Los trabajos de Chandler uno de los autores clásicos en materia de dirección estratégica utiliza como elemento común en sus trabajos las relaciones que existen entre estrategia y estructura. Fue el primer historiador en sostener la importancia de la estrategia en el desarrollo, gestión y éxito de la corporación.

A partir de 1965 la planificación es de reacción y adaptación a las condiciones del entorno. Hasta 1973 está fundamentada en criterios de racionalidad y abundan en la terminología las denominaciones de estrategia y planificación estratégica. Los autores más relevantes son R.A. Ackoff (1969) y H.I. Ansoff (1976). Su obra hay que entenderla en el contexto de la década de los años 60 y 70, que defiende la estrategia como resultado de un proceso formalizado de planificación estratégica (Garrido, 2006).

Las circunstancias de 1973, crisis del petróleo, turbulencias mundiales y una competencia internacional en aumento, hicieron cuestionar un enfoque que consideraba el entorno como un solo presupuesto sobre el cual planificar, dando un paso más al pasar de la planificación estratégica a lo que se conoce como gestión estratégica.

Este nuevo enfoque considera el entorno como algo dinámico en lo que las organizaciones se encuentran inmersas y en el que la acción no puede ser planificada sin considerar todos sus elementos. Destacan autores como: H.E. Porter (1980) A.C. Hax (1981), H.I. Ansoff (1984).

M. Porter es el autor más conocido en el uso del análisis estratégico como en las metodologías desarrolladas y utilizadas por él. Su aporte puede nombrarse en tres conceptos:

\footnotetext{
$>\quad$ La cadena de valor de una empresa y/o sector.

$>\quad$ El análisis de las fuerzas de un sector.

$>\quad$ Las posibles estrategias.
}

La gestión estratégica ha seguido evolucionando en dos campos (De Miguel, 2005): Primero, el análisis estratégico del portafolio de actividades apoyado en los trabajos de Boston Consulting Group y en la visión del entorno competitivo de Porter. 
En segundo lugar, el sistema social donde según los esquemas del desarrollo de la organización es primordial la existencia de una cultura participativa que fomente el dialogo y aporte las condiciones para toda la organización se movilice hacia la consecución de unos objetivos previamente marcados. Llamado "cultura estratégica", es la actualización de los planteamientos behavioristas (Godet M., 1985).

\subsubsection{Situación Actual}

Las filosofías administrativas y las formas organizacionales han cambiado a lo largo del tiempo para satisfacer nuevas necesidades. El ámbito laboral de la actualidad es muy distinto del que se tenía hace cincuenta años; en realidad, aún es muy distinto del que se tenía incluso hace diez años. Sin embargo, existen ideas y prácticas que provienen del pasado y que todavía son altamente relevantes y aplicables a la organización de hoy en día.

Las organizaciones actuales están enfrentadas a diferentes presiones que llegan desde la economía, la tecnología, y las estructuras sociales en general. La adaptación a las nuevas demandas, ha exigido cambios en la planificación y la gestión de las carreras de los empleados.

Los horizontes que guían la gestión actual son por una parte, la teoría de sistemas abiertos y por otra la teoría de la contingencia. Los métodos de gestión estratégica pretenden aplicar los conceptos más provechosos de la escuela neoclásica y el desarrollo de la organización (D.O.) y la administración de la calidad total, ampliamente implementada en las organizaciones actuales. Estas teorías, siguen recibiendo el aporte de autores que ofrecen nuevos enfoques que aportan al enriquecimiento de las mismas y al entendimiento de los cambios del entorno. Una gestión en donde la tecnología desempeña un papel fundamental.

El acelerado desarrollo de las tecnologías de información ha llegado a influenciar profundamente la gestión y el funcionamiento de las organizaciones y empresas así como sus relaciones con el entorno. Las ideas, la información y las relaciones logran mayor relevancia. En un mundo cada vez más digitalizado, un gran número de organizaciones y trabajadores tratan con aspectos intangibles tales como las ideas y la información. Las nuevas tecnologías dan forma a las organizaciones en sí mismas y en cuanto a la forma de ser administradas. La tecnología proporciona la arquitectura que da apoyo y que refuerza el nuevo ámbito laboral.

Hace unos 40 años Peter Drucker utilizó por primera vez la expresión "trabajo del conocimiento ", pero ha sido hasta años recientes que los administradores han reconocido genuinamente al conocimiento como un importante recurso organizacional que debe ser administrado del mismo modo que los demás recursos con los que cuenta la organización. 
Un sistema de gestión del conocimiento que incluye no solamente la tecnología para capturar y almacenar conocimientos que puedan ser fácilmente recuperados, sino aquellos valores administrativos que dan apoyo a la toma de riesgos, al aprendizaje y a la colaboración. En lugar de ver a los empleados como factores de producción y en lugar de buscar formas de usar los recursos humanos y materiales con miras a una mayor eficiencia, los administradores más exitosos de la actualidad valoran a las personas por su capacidad para pensar, crear, compartir conocimientos y formar relaciones ${ }^{7}$.

\footnotetext{
${ }^{7}$ Introducción a la administración, R.L. Daft y D. Marcic 4ạ Ed., International Thomson Editores 2006.
} 


\subsubsection{Satisfacción Laboral}

\section{Definiciones}

Existe abundante información relacionada con el estudio de la satisfacción laboral, y a pesar de ello se puede indicar que no existe una definición unánime. Una cuidadosa revisión de los estudios realizados por los distintos investigadores y autores permite detectar la variedad de enfoques y definiciones. Todo ello tiene su justificación teniendo en cuenta que los estudios teóricos y empíricos acerca de la satisfacción laboral han sido llevados a cabo desde distintas áreas como la psicología, sociología o la administración.

Algunos autores se refieren a ella como un estado emocional, de respuestas afectivas o sentimentales. Para Koontz y Weihrich (1998), la motivación implica un impulso hacia un resultado mientras la satisfacción es el resultado ya experimentado.

Locke (1976) la define como "estado emocional positivo o placentero resultante de la percepción subjetiva de las experiencias laborales de la persona" y para Muchinsky (2000) es "el grado de placer que el empleado obtiene de su trabajo". Afirman que un trabajador se siente satisfecho con su trabajo, cuando a raíz del mismo experimenta sentimientos de bienestar, placer o felicidad (Leal, 2004).

Para otros autores el concepto va más allá de las emociones y es descrito como una actitud generalizada ante el trabajo.

Según García A. (2005), la satisfacción laboral es "actitud del trabajador frente a su propio trabajo". Las actitudes son determinadas conjuntamente por las características reales del puesto, así como por las percepciones que tiene el trabajador de lo que debería ser (lo que se desea y espera de su puesto), como sus necesidades, sus valores y sus rasgos personales.

El concepto de satisfacción laboral también se puede abordar desde dos perspectivas: La unidimensional y la multidimensional. La primera se centra en la satisfacción laboral como actitud con relación al trabajo en general, lo cual no equivale a la suma de las facetas que componen el contexto de trabajo pero depende de ellas (Bravo et al.,2002; Cavalcante, 2004 ). La segunda, la perspectiva multidimensional, considera que la satisfacción deriva de un conjunto de factores asociados al trabajo, y que es posible medir la satisfacción de los sujetos en relación con cada uno de ellos. Los factores o dimensiones de la satisfacción laboral más mencionados son los siguientes: La satisfacción con la supervisión, con la organización, con los 
compañeros de trabajo, con las condiciones de trabajo, con el progreso en la carrera, con las perspectivas de promoción, con el salario, con los subordinados, con la estabilidad en el empleo, la satisfacción extrínseca en general, la satisfacción con el tipo de trabajo, con la cantidad de trabajo, con el desarrollo personal y la satisfacción intrínseca general (Bravo et al., 2002). Este concepto de satisfacción laboral (general y por facetas) implica un modelo compensatorio, de forma que un nivel elevado de satisfacción en una determinada faceta del trabajo puede compensar deficiencias existentes en otras áreas.

La división más simple de la satisfacción laboral es la que distingue entre satisfacción laboral intrínseca y extrínseca. La intrínseca está originada por factores relacionados con la tarea en sí (variedad, dificultad, interés autonomía, posibilidad de aprender, etc.). Por su parte la extrínseca tiene su origen en fuentes externas al empleado, ligadas al contexto o ambiente en que la tarea se desarrolla (relaciones con los supervisores y con los compañeros, salario, horas de trabajo, seguridad, reconocimiento, etc.).

La satisfacción laboral se ha intentado explicar desde diferentes teorías, como se ha enunciado en el apartado anterior, referido a las teorías de gestión.

En la mayoría de los casos se han utilizado las teorías motivacionales como tales debido al papel central que la satisfacción juega en muchas de ellas. Sin embargo, hay que tener en cuenta que la motivación y la satisfacción aunque están relacionados no son conceptos sinónimos ni describen el mismo fenómeno (Bravo et al., 2002).

Muchas de las teorías se asientan en el concepto de discrepancias o desajuste que parte de la idea de que la satisfacción depende del grado de coincidencia entre lo que un individuo busca de su trabajo y lo que realmente consigue de él. Cuanto mayor sea la distancia entre lo que quiere conseguir y lo que se obtiene del trabajo, menor será la satisfacción laboral. Existe menos consenso entre los teóricos sobre cuáles son los estándares relevantes para la confrontación de las experiencias laborales. Algunas de las alternativas barajadas son las siguientes (Gamero, 2005):

-comparación entre necesidades y resultados (teoría de las necesidades de Maslow y McClelland). Los sujetos cotejan continuamente su estado actual de necesidades con el nivel de satisfacción que desean obtener de sus puestos de trabajo. Si no se satisfacen las necesidades aparece un estado de tensión que hace que los trabajadores estén insatisfechos; en caso contrario se sentirán satisfechos. 
-Comparación con otros (teoría de la privación relativa). Los individuos basan su concepto de justicia en la confrontación de los resultados propios con los obtenidos por otros sujetos en su medio de trabajo o marco de referencia.

-Comparación aportaciones / resultados (teoría de la equidad de Adams). El trabajador observa los esfuerzos realizados por otros en su trabajo y las recompensas que obtienen y lo coteja con su situación. La única condición deseable es aquella en la que tal comparación indica igualdad.

-Comparación con lo esperado (teoría de las expectativas de Vroom). La satisfacción laboral es función de las discrepancias percibidas por el individuo entre lo que él debe darle a su actual trabajo y lo que realmente obtiene como producto o gratificación.

-Comparación con valores (teoría del valor de Locke 1976). Los sujetos hacen comparaciones con sus objetivos o metas generales (lo que quieren, desean o valoran) en relación con la experiencia laboral.

-Discrepancias múltiples (teoría de las discrepancias múltiples). Supone una integración de las anteriores, por cuanto propone que la gente utiliza una combinación de estándares al evaluar su actual experiencia laboral.

Para Wright (2006), cabe la posibilidad de que la satisfacción con el trabajo sea el indicador más importante de la satisfacción con la vida y además, siga presentando relaciones igualmente significativas con el rendimiento y la productividad, aspectos a los que se ha prestado atención más frecuentemente (Laffaldano y Muchinsky, 1985; Judge et al., 2001).

\subsubsection{1 Éxito Profesional}

La revisión teórica de los estudios sobre éxito profesional realizados por diversos investigadores durante años, es la base para la construcción del marco teórico del presente trabajo. Uno de los aspectos que a primera vista se puede detectar, es la variedad de términos que se utilizan para definirlo (éxito profesional, éxito laboral, éxito objetivo, éxito subjetivo, éxito extrínseco, éxito intrínseco,...).

Para comenzar, la investigación del éxito profesional se basa en la teoría sobre la carrera o profesión por lo tanto se fundamenta en las ideas, conceptos, definiciones y supuestos que incluye la teoría de la profesión (Arthur et al., 2005). Eliot Freidson (2001) en la teoría de las profesiones y en su análisis sobre el estado del arte; señala que los 
planteamientos teóricos sobre la definición de Profesión formulados desde 1915 hasta nuestros días, comparten algunos rasgos, aunque todavía no existe consenso sobre cuáles deben ser enfatizados en la elaboración de un concepto teórico de esta. Según Freidson no hay definición única. Partiendo de esta idea, a continuación se utiliza la definición de profesión según Arthur, Hall y Lawrence (1989) que la definen como el desarrollo de la secuencia de las experiencias de trabajo de una persona durante un periodo de tiempo.

Para Hughes (1937) principalmente una carrera es la historia de la forma en que una persona interpreta el significado de lo que ha hecho y las cosas que le han sucedido, la llamada carrera subjetiva. $\mathrm{O}$ es principalmente un mapa del territorio social que ha atravesado, por ejemplo los trabajos que ha llevado a cabo, los honores que le han conferido (carrera objetiva).

Las investigaciones sobre éxito profesional se sirven de los planteamientos teóricos de profesión (Gunz y Heslin, 2005) y estos conforman un universo amplio de información generado por conceptos de profesión provenientes la psicología social, la psicología, las ciencias políticas y la administración entre otras.

Arthur, M. Khapova, S. Wilderom, C. (2005), analizaron ochenta artículos relacionados con investigaciones empíricas sobre el éxito profesional. Basándose en el grado de aplicación de la teoría de la profesión, los hallazgos de este análisis determinaron que la mayoría de los trabajos consideran como sujeto de análisis principal los factores objetivos de la carrera (Ingresos, ascensos, nivel jerárquico), un segundo grupo considera la relevancia de la carrera subjetiva sobre la objetiva (satisfacción laboral, satisfacción con la vida, desarrollo, compromiso ocupacional) y un tercer grupo insiste que ambas consideraciones del éxito profesional son interdependientes.

La tabla 2.11 resume algunos de los artículos que fueron analizados utilizando como criterio de referencia el éxito profesional y los factores que más destacan desde los factores considerados objetivos y subjetivos.

La mayoría corresponde a estudios realizados a trabajadores de empresas, algunos dirigidos a directivos, otros a trabajadores de diversos niveles y categorías, graduados universitarios insertados en el mercado laboral. 
Tabla 2. 11 Estudios Empíricos sobre Éxito Profesional

\begin{tabular}{|c|c|c|c|c|c|}
\hline \multicolumn{6}{|c|}{$\begin{array}{l}\text { RESUMEN DE ESTUDIOS EMPÍRICOS SOBRE ÉXITO PROFESIONAL (1992-2012) } \\
\text { PUBLICACIONES EN REVISTAS DE GESTIÓN Y OTRAS CIENCIAS SOCIALES }\end{array}$} \\
\hline № & Autores & Muestra & Criterio & Factores Carrera objetiva & $\begin{array}{l}\text { Factores Carrera } \\
\text { Subjetiva }\end{array}$ \\
\hline 1 & $\begin{array}{l}\text { Martins et al. } \\
\qquad(2002)\end{array}$ & $\begin{array}{l}975 \\
\text { Administradores }\end{array}$ & $\begin{array}{c}\text { Resultados Carrera, } \\
\text { Satisfacción } \\
\text { Profesional }\end{array}$ & $\begin{array}{c}\text { Resultados Financieros, } \\
\text { ascenso Carrera, } \\
\text { autonomía, poder }\end{array}$ & $\begin{array}{c}\text { Satisfacción } \\
\text { Profesional, ascenso o } \\
\text { desarrollo de la } \\
\text { satisfacción }\end{array}$ \\
\hline 2 & Tharenou (2001) & - & $\begin{array}{l}\text { Ascenso o } \\
\text { desarrollo } \\
\text { gerencial }\end{array}$ & $\begin{array}{c}\text { Salario, tipo de } \\
\text { posición, lapso de } \\
\text { control, promociones } \\
\text { gerenciales, años de } \\
\text { supervisión a otros, } \\
\text { tiempos sin promoción }\end{array}$ & - \\
\hline 3 & $\begin{array}{l}\text { Seibert, Kraimer } \\
\text { and Liden (2001) }\end{array}$ & $\begin{array}{l}448 \text { empleados } \\
\text { diversas } \\
\text { ocupaciones y } \\
\text { organizaciones }\end{array}$ & $\begin{array}{l}\text { Éxito Profesional } \\
\text { (carrera) }\end{array}$ & Promociones, salario & Satisfacción Profesional \\
\hline 4 & $\begin{array}{l}\text { Judiesch and } \\
\text { Lyness (1999) }\end{array}$ & \begin{tabular}{|c|}
11.815 \\
administra dores \\
en organización de \\
servicios \\
financieros, \\
durante 1 año
\end{tabular} & $\begin{array}{l}\text { Éxito Profesional } \\
\text { (carrera) }\end{array}$ & $\begin{array}{c}\text { Nivel jerárquico, } \\
\text { salario, promoción, \% } \\
\text { de incremento salarial, } \\
\text { sistemas de evaluación }\end{array}$ & - \\
\hline 5 & $\begin{array}{c}\text { Konard and } \\
\text { Cannings (1997) }\end{array}$ & & $\begin{array}{l}\text { Ascenso o } \\
\text { desarrollo } \\
\text { gerencial }\end{array}$ & $\begin{array}{c}\text { Nivel jerárquico,número } \\
\text { de promociones }\end{array}$ & - \\
\hline 6 & $\begin{array}{l}\text { Cable and DeRue } \\
\qquad(2002)\end{array}$ & & Resultados Carrera & Aumento de sueldo & $\begin{array}{c}\text { Satisfacción } \\
\text { profesional, } \\
\text { satisfacción en el } \\
\text { trabajo, compromiso } \\
\text { ocupacional } \\
\end{array}$ \\
\hline 7 & $\begin{array}{l}\text { Jansen and Stoop } \\
\qquad(2001)\end{array}$ & & $\begin{array}{l}\text { Éxito Profesional } \\
\text { (carrera) }\end{array}$ & $\begin{array}{l}\text { Crecimiento promedio } \\
\text { del salario }\end{array}$ & - \\
\hline 8 & $\begin{array}{c}\text { Van Scotter et al. } \\
\text { (2000) }\end{array}$ & $\begin{array}{c}\text { Grupos de } \\
\text { mecanicos de la } \\
\text { Fuerza Aérea de } \\
\text { EEUU }\end{array}$ & Resultados Carrera & $\begin{array}{c}\text { Rango, } \\
\text { medallas,calificaciones } \\
\text { de ascenso, premios }\end{array}$ & - \\
\hline 9 & $\begin{array}{c}\text { Lyness and } \\
\text { Thompson (2000) }\end{array}$ & & $\begin{array}{l}\text { Éxito Profesional } \\
\text { (carrera) }\end{array}$ & $\begin{array}{c}\text { Nivel, salario base, } \\
\text { bonos, opciones sobre } \\
\text { acciones }\end{array}$ & - \\
\hline 10 & $\begin{array}{c}\text { Ragins and Cotton } \\
\text { (1999) } \\
\end{array}$ & & Resultados Carrera & $\begin{array}{c}\text { Tasa de promoción, } \\
\text { compensación }\end{array}$ & - \\
\hline 11 & $\begin{array}{l}\text { Seibert et al. } \\
\text { (1999) }\end{array}$ & $\begin{array}{c}496(320 \mathrm{~h}-176 \mathrm{~m}) \\
\text { empleados de } \\
\text { diferentes } \\
\text { ocupaciones y } \\
\text { organizaciones }\end{array}$ & $\begin{array}{l}\text { Éxito Profesional } \\
\text { (carrera) }\end{array}$ & Promociones, salario & Satisfacción Profesional \\
\hline 12 & $\begin{array}{l}\text { Judge, Thoresen, } \\
\text { Pucik, and } \\
\text { Welbourne (1999) }\end{array}$ & $\begin{array}{c}514 \text { empleados de } \\
6 \text { organizaciones }\end{array}$ & Resultado Carrera & $\begin{array}{c}\text { Salario, nivel de puesto, } \\
\text { rendimiento en el } \\
\text { trabajo }\end{array}$ & $\begin{array}{c}\text { compromiso con la } \\
\text { organización, } \\
\text { satisfacción en el } \\
\text { trabajo }\end{array}$ \\
\hline 13 & $\begin{array}{c}\text { Lyness and } \\
\text { Thompson (1997) }\end{array}$ & \begin{tabular}{|c|}
107 ejecutivos de \\
servicios \\
financieros (51m y \\
$56 \mathrm{~h})$
\end{tabular} & $\begin{array}{c}\text { Los resultados del } \\
\text { trabajo }\end{array}$ & $\begin{array}{c}\text { Rango organizacional, } \\
\text { compensación, } \\
\text { oportunidades de } \\
\text { desarrollo } \\
\end{array}$ & $\begin{array}{l}\text { Satisfaccón con las } \\
\text { oportunidades de la } \\
\text { carrera, satisfacción } \\
\text { con compensación }\end{array}$ \\
\hline 14 & $\begin{array}{c}\text { Dreher and Cox } \\
(1996) \\
\end{array}$ & $\begin{array}{c}\text { Graduados MBA } \\
\text { EEUU } \\
\end{array}$ & Resultados Carrera & $\begin{array}{c}\text { Compensación total } \\
\text { anual }\end{array}$ & - \\
\hline 15 & $\begin{array}{l}\text { Murphy and } \\
\text { Ensher (2001) }\end{array}$ & 158 empleados & $\begin{array}{c}\text { Éxito Profesional } \\
\text { (carrera) percibido }\end{array}$ & - & $\begin{array}{c}\text { Éxito Profesional } \\
\text { percibido, satisfacción } \\
\text { laboral }\end{array}$ \\
\hline
\end{tabular}




\begin{tabular}{|c|c|c|c|c|c|}
\hline \multicolumn{6}{|c|}{$\begin{array}{l}\text { RESUMEN DE ESTUDIOS EMPÍRICOS SOBRE ÉXITO PROFESIONAL (1992-2012) } \\
\text { PUBLICACIONES EN REVISTAS DE GESTIÓN Y OTRAS CIENCIAS SOCIALES }\end{array}$} \\
\hline № & Autores & Muestra & Criterio & Factores Carrera objetiva & $\begin{array}{l}\text { Factores Carrera } \\
\text { Subjetiva }\end{array}$ \\
\hline 16 & $\begin{array}{l}\text { Blake-Beard } \\
\text { (1999) }\end{array}$ & & Éxito profesional & $\begin{array}{l}\text { Compensación, tasa de } \\
\text { promoción }\end{array}$ & \begin{tabular}{|c|} 
Satisfacción con la \\
compensación, \\
satisfacción con el \\
desarrollo de la carrera \\
\end{tabular} \\
\hline 17 & $\begin{array}{l}\text { Lee and Nolan } \\
\text { (1998) }\end{array}$ & & $\begin{array}{l}\text { La promoción } \\
\text { profesional }\end{array}$ & Categoría, recursos & Emoción, auto-concepto \\
\hline 18 & $\begin{array}{c}\text { Kirchmeyer, C } \\
(1998)\end{array}$ & 292 administradores & Éxito Profesional & Ingresos, nivel & $\begin{array}{l}\text { Percepción del éxito } \\
\text { profesional }\end{array}$ \\
\hline 19 & $\begin{array}{l}\text { Judge and Bretz } \\
\qquad(1994)\end{array}$ & $\begin{array}{c}\text { Graduados } \\
\text { universitarios }\end{array}$ & Éxito profesional & $\begin{array}{l}\text { Salario, nivel del puesto, } \\
\text { número de promociones }\end{array}$ & $\begin{array}{c}\text { Satisfacción laboral, } \\
\text { satisfacción con la vida }\end{array}$ \\
\hline 20 & Aryee et al. (1996) & $\begin{array}{l}432 \text { Empleados } \\
\text { profesionales que } \\
\text { trabajan a tiempo } \\
\text { completo en Hong } \\
\text { Kong }\end{array}$ & Éxito profesional & $\begin{array}{l}\text { Salario, número de } \\
\text { promociones }\end{array}$ & Satisfacción profesional \\
\hline 21 & Tharenou (1999) & $\begin{array}{c}\text { Directivos y } \\
\text { profesionales Año } \\
\text { 1:3555, Año 2: } 2339\end{array}$ & $\begin{array}{l}\text { Desarrollo en la } \\
\text { carrera } \\
\text { administrativa }\end{array}$ & $\begin{array}{l}\text { Nivel administrativo } \\
\text { salario, total de } \\
\text { promociones } \\
\text { administrativas }\end{array}$ & - \\
\hline 22 & $\begin{array}{l}\text { Wayne et al. } \\
\text { (1999) }\end{array}$ & $\begin{array}{l}245 \text { parejas } \\
\text { supervisor- } \\
\text { subordinado }\end{array}$ & Éxito profesional & Progresión salarial & $\begin{array}{c}\text { Satisfacción carrera, } \\
\text { evaluación subjetiva del } \\
\text { supervisor, ascenso de } \\
\text { los empleados según } \\
\text { evaluación subjetiva del } \\
\text { supervisor }\end{array}$ \\
\hline 23 & Orpen, C. (1998) & & Éxito profesional & \begin{tabular}{|c|}
$\begin{array}{c}\text { Crecimiento del salario, } \\
\text { promociones }\end{array}$ \\
\end{tabular} & - \\
\hline 24 & Orpen, C. (1995) & & Éxito profesional & \begin{tabular}{|c|}
$\begin{array}{c}\text { Crecimiento del salario, } \\
\text { promociones }\end{array}$ \\
\end{tabular} & - \\
\hline 25 & Chi-Ching (1992) & & Éxito profesional & \begin{tabular}{|c|}
$\begin{array}{c}\text { Movilidad con relación a } \\
\text { la edad, salario }\end{array}$ \\
\end{tabular} & \begin{tabular}{|c|} 
Satisfacción con el \\
desarrollo de la carrera
\end{tabular} \\
\hline 26 & $\begin{array}{l}\text { Johnson and } \\
\text { Stokes (2002) }\end{array}$ & - & Resultados carrera & $\begin{array}{c}\text { Estabilidad de la } \\
\text { clasificación ocupacional }\end{array}$ & $\begin{array}{c}\text { Desarrollo del trabajo, } \\
\text { compromiso con la } \\
\text { carrera } \\
\end{array}$ \\
\hline 27 & Wiese et al. (2002) & $\begin{array}{l}82 \text { Jovenes } \\
\text { profesionales }(44 \% \mathrm{~h})\end{array}$ & $\begin{array}{l}\text { Éxito profesional } \\
\text { subjetivo }\end{array}$ & - & $\begin{array}{l}\text { Éxito subjetivo en el } \\
\text { ámbito del trabajo, } \\
\text { satisfacción laboral }\end{array}$ \\
\hline 28 & De Fruyt (2002) & $\begin{array}{l}401 \text { estudiantes de } \\
\text { último año que } \\
\text { participan en el } \\
\text { mercado laboral }\end{array}$ & $\begin{array}{l}\text { Profesión intrinseca } \\
\text { resultados }\end{array}$ & - & $\begin{array}{c}\text { Satisfacción laboral, } \\
\text { desarrollo de } \\
\text { habilidades, } \\
\text { participación en el } \\
\text { desarrollo del trabajo, } \\
\text { estrés percibido } \\
\end{array}$ \\
\hline 29 & Wallace (2001) & & $\begin{array}{l}\text { Profesión y } \\
\text { resultados } \\
\text { emocionales }\end{array}$ & Ingresos & \begin{tabular}{|} 
Oportunidades \\
promocionales \\
percibidas, justicia en \\
procedimiento, sentido \\
de integración social \\
con los compañeros de \\
trabajo, satisfacción \\
profesional, intento de \\
mantenerse en la \\
profesión, expectativas \\
satisfechas, conflictos \\
del trabajo.
\end{tabular} \\
\hline
\end{tabular}




\begin{tabular}{|c|c|c|c|c|c|}
\hline \multicolumn{6}{|c|}{$\begin{array}{l}\text { RESUMEN DE ESTUDIOS EMPÍRICOS SOBRE ÉXITO PROFESIONAL (1992-2012) } \\
\text { PUBLICACIONES EN REVISTAS DE GESTIÓN Y OTRAS CIENCIAS SOCIALES }\end{array}$} \\
\hline № & Autores & Muestra & Criterio & Factores Carrera objetiva & $\begin{array}{l}\text { Factores Carrera } \\
\text { Subjetiva }\end{array}$ \\
\hline 30 & $\begin{array}{l}\text { Seibert and } \\
\text { Kraimer (2001) }\end{array}$ & $\begin{array}{c}496 \text { empleados (318 } \\
\text { H. y } 178 \text { M.) de } \\
\text { diferentes } \\
\text { organizaciones y } \\
\text { ocupaciones }\end{array}$ & Éxito profesional & Promociones, salario & Satisfacción profesional \\
\hline 31 & $\begin{array}{l}\text { Boudreau, } \\
\text { Boswell, and } \\
\text { Judge (2001) }\end{array}$ & $\begin{array}{l}\text { Ejecutivos de Estados } \\
\text { Unidos y de Europa }\end{array}$ & Éxito profesional & $\begin{array}{c}\text { Remuneración, } \\
\text { ascendencia, proximidad } \\
\text { CEO, empleabilidad }\end{array}$ & $\begin{array}{l}\text { Satisfacción laboral, } \\
\text { satisfacción con la vida, } \\
\text { satisfacción profesional }\end{array}$ \\
\hline 32 & Brown et al. (2000) & & $\begin{array}{l}\text { Decisión de carrera - } \\
\text { Eficacia personal }\end{array}$ & $\begin{array}{c}\text { Medida objetiva del } \\
\text { estatus de ego-identidad, } \\
\text { medida de la identidad. }\end{array}$ & - \\
\hline 33 & $\begin{array}{l}\text { Dreher and } \\
\text { Chargois (1998) }\end{array}$ & & Resultado carrera & $\begin{array}{l}\text { Compensación total } \\
\text { anual }\end{array}$ & - \\
\hline 34 & $\begin{array}{c}\text { Hurley and } \\
\text { Sonnenfeld (1998) }\end{array}$ & $\begin{array}{l}683 \text { Altos directivos } \\
\text { vs } 683 \text { directivos } \\
\text { cargos de nivel medio }\end{array}$ & $\begin{array}{l}\text { Éxito carrera } \\
\text { administrativa }\end{array}$ & $\begin{array}{l}\text { Nivel profesional de los } \\
\text { administradores }\end{array}$ & - \\
\hline 35 & $\begin{array}{c}\text { Schneer and } \\
\text { Reitman (1997) }\end{array}$ & - & Éxito Profesional & $\begin{array}{l}\text { Ingreso, Nivel } \\
\text { administración }\end{array}$ & Satisfacción profesional \\
\hline 36 & Chao, G.T. (1997) & $\begin{array}{l}244 \text { (tres grupos) } \\
\text { profesionales con y } \\
\text { sin mentor }\end{array}$ & Resultados carrera & Ingreso & $\begin{array}{l}\text { Plan de carrera y } \\
\text { participación de } \\
\text { carrera, socialización } \\
\text { organizacional } \\
\end{array}$ \\
\hline 37 & $\begin{array}{l}\text { Murrell et al. } \\
\text { (1996) }\end{array}$ & $\begin{array}{c}671 \text { directivos } \\
\text { hombre y mujeres } \\
\text { durante siete años }\end{array}$ & Resultados carrera & Salario, promociones & $\begin{array}{c}\text { Satisfacción laboral, } \\
\text { compromiso } \\
\text { organizacional } \\
\end{array}$ \\
\hline 38 & $\begin{array}{l}\text { Schneer and } \\
\text { Reitman (1995) }\end{array}$ & $\begin{array}{l}676 \text { MBA graduados } \\
\text { entre } 1975-1980\end{array}$ & Trayectoria carrera & $\begin{array}{c}\text { Ingreso, horas de trabajo, } \\
\text { nivel de gestión o nivel } \\
\text { administrativo }\end{array}$ & Satisfacción profesional \\
\hline 39 & Peluchette (1993) & $\begin{array}{l}424 \text { miembros de una } \\
\text { facultad, en dos } \\
\text { institutos de } \\
\text { investigación }\end{array}$ & $\begin{array}{l}\text { Éxito Profesional } \\
\text { subjetivo }\end{array}$ & - & $\begin{array}{c}\text { Papel del trabajo, } \\
\text { interpersonal, } \\
\text { económico, jerarquico y } \\
\text { éxito en la vida }\end{array}$ \\
\hline 40 & Taylor et al. (1996) & $\begin{array}{c}109 \text { directores } \\
\text { generales de } \\
\text { Empresas Fortune } \\
500 \\
\end{array}$ & $\begin{array}{l}\text { Éxito profesional en } \\
\text { el pasado }\end{array}$ & $\begin{array}{c}\text { Número de niveles } \\
\text { organizacionales entre } \\
\text { administrador (gerente)y } \\
\text { CEO }\end{array}$ & - \\
\hline 41 & $\begin{array}{c}\text { Boudreau, } \\
\text { Boswell, Judge, } \\
\text { and Bretz (2001) }\end{array}$ & & Carrera resultados & Compensación & Satisfacción la boral \\
\hline 42 & $\begin{array}{l}\text { Seibert, Kraimer } \\
\text { and Crant (2001) }\end{array}$ & $\begin{array}{l}180 \text { Empleados a } \\
\text { tiempo completo y } \\
\text { supervisores }\end{array}$ & Éxito profesional & Progresion profesional & Satisfacción profesional \\
\hline 43 & $\begin{array}{l}\text { Judge, Higgins, } \\
\text { Thoresen, and } \\
\text { Barrick (1999) }\end{array}$ & $\begin{array}{l}\text { Estudios } \\
\text { intergeneracionales }\end{array}$ & Éxito profesional & $\begin{array}{l}\text { Ingreso anual antes de } \\
\text { impuestos, estado } \\
\text { ocupacional }\end{array}$ & Satisfacción laboral \\
\hline
\end{tabular}




\begin{tabular}{|c|c|c|c|c|c|}
\hline \multicolumn{6}{|c|}{$\begin{array}{l}\text { RESUMEN DE ESTUDIOS EMPÍRICOS SOBRE ÉXITO PROFESIONAL (1992-2012) } \\
\text { PUBLICACIONES EN REVISTAS DE GESTIÓN Y OTRAS CIENCIAS SOCIALES }\end{array}$} \\
\hline № & Autores & Muestra & Criterio & Factores Carrera objetiva & $\begin{array}{l}\text { Factores Carrera } \\
\text { Subjetiva }\end{array}$ \\
\hline 44 & Qu H., Zhao, X.R. & $\begin{array}{c}126 \text { vendedores en } 26 \\
\text { hoteles de China }\end{array}$ & $\begin{array}{c}\text { Impacto de la } \\
\text { satisfacción con la } \\
\text { vida sobre la } \\
\text { satisfacción laboral } \\
\text { en diferentes } \\
\text { situaciones de } \\
\text { conflicto trabajo- } \\
\text { familia. }\end{array}$ & - & $\begin{array}{c}\text { satisfacción laboral, } \\
\text { satisfacción con la vida }\end{array}$ \\
\hline 45 & $\begin{array}{l}\text { Rasdi, R.M., } \\
\text { Ismail, M., } \\
\text { Garavan, T.N. } \\
\text { (2011) }\end{array}$ & $\begin{array}{l}288 \text { Administradores } \\
\text { de diferentes niveles }\end{array}$ & Éxito profesional & $\begin{array}{l}\text { Capital humano, } \\
\text { variables demográficas }\end{array}$ & $\begin{array}{l}\text { Variables estructurales, } \\
\text { variables individuales y } \\
\text { variables demográficas }\end{array}$ \\
\hline 46 & $\begin{array}{c}\text { Kapoutsis, I., } \\
\text { Papalexandris, A., } \\
\text { Thanos, I.C. } \\
\text { Nikolopoulos, A.G. } \\
(2012)\end{array}$ & $\begin{array}{l}117 \text { mandos } \\
\text { intermedios }\end{array}$ & $\begin{array}{l}\text { Éxito profesional } \\
\text { (carrera) }\end{array}$ & - & $\begin{array}{l}\text { Percepción éxito } \\
\text { profesional }\end{array}$ \\
\hline 47 & $\begin{array}{l}\text { Khong, H., Cheung, } \\
\text { C., Song, H. (2012) }\end{array}$ & - & $\begin{array}{l}\text { Satisfacción } \\
\text { profesional (carrera) }\end{array}$ & - & $\begin{array}{c}\text { Evaluación carrera, } \\
\text { desarrollo profesional, } \\
\text { formación }\end{array}$ \\
\hline 48 & \begin{tabular}{|c|} 
Rezaean, A., \\
Hatami, S., Dastar, \\
H. (2012)
\end{tabular} & $\begin{array}{c}92 \text { empleados unidad } \\
\text { militar }\end{array}$ & $\begin{array}{c}\text { Satisfacción } \\
\text { profesional (carrera) }\end{array}$ & - & $\begin{array}{c}\text { Evaluación, desarrollo y } \\
\text { formación }\end{array}$ \\
\hline 49 & Yuchen (2012) & $\begin{array}{c}219 \text { personal apoyo } \\
\text { de servicios }\end{array}$ & $\begin{array}{c}\text { Satisfacción } \\
\text { profesional (carrera) }\end{array}$ & - & $\begin{array}{c}\text { Apoyo organizaciónal, } \\
\text { éxito profesional, } \\
\text { compromiso con la } \\
\text { carrera } \\
\end{array}$ \\
\hline 50 & Ballout (2007) & - & $\begin{array}{l}\text { Éxito profesional } \\
\text { (carrera) }\end{array}$ & - & Desarrollo de la carrera \\
\hline
\end{tabular}

Fuente: Elaboración Propia

La teoría del capital humano proporciona una base teórica para la comprensión del enfoque personal para el éxito profesional. La teoría del capital humano (Becker, 1975) sugiere que las personas que más invierten en los atributos del capital humano como la educación, la formación y la experiencia se espera que muestren un mayor nivel de rendimiento en el trabajo y posteriormente obtengan mayores recompensas de la organización.

Para explicar el éxito profesional, los investigadores lo han estudiado desde tres enfoques: el personal, estructural y desde las perspectivas de comportamiento (Rosenbaum, 1989; Aryee et al., 1994).

El enfoque personal se basa en gran medida de las variables personales que se encuentran en la literatura sobre capital humano y las teorías motivacionales. Este enfoque se 
centra en la persona, que desarrolla su propio capital humano y por lo tanto maximiza su inversión en educación y en sus habilidades para lograr el éxito en la profesión.

Según esta teoría, la progresión de una persona de carrera y el éxito depende de la cantidad y calidad de los activos humanos que uno tenga en el mercado de trabajo (Becker, 1964) y que las habilidades y experiencias que los individuos aportan a su trabajo se relacionan con su indemnización (Agarwal, 1981). En la medida en que los factores de capital humano influyen en el rendimiento de los empleados, mayores atributos personales que les permitan realizar mejor su trabajo y su salario debe aumentar de acuerdo para compensar la cantidad adicional de capital humano requerido por su trabajo. La evidencia empírica reciente apoya la vinculación positiva entre las variables de capital humano y el éxito profesional (Ng et al, 2005; Tharenou, 2001).

El enfoque estructural para el éxito profesional sostiene que la ayuda de ciertas características estructurales ayuda a unos y dificultan a otros individuos en su desarrollo profesional. Bajo este enfoque, ciertos factores organizacionales, como el tamaño de la organización y las prácticas internas de promoción influyen en los aspirantes a tener éxito profesional.

La tesis central gerencialista (managerialism) es que la compensación (medida objetiva del éxito de la carrera) es principalmente una función del tamaño de la organización (Tosi et al., 2000).

Las organizaciones grandes tienen más posibilidades de facilitar la movilidad de carrera y el éxito así, el pago de esas personas aumenta a medida que ascienden en la jerarquía corporativa. Como afirman Gattiker y Larwood (1988), la frecuencia de la promoción es una medida valiosa de la movilidad en la carrera y el éxito, ya que es importante para el individuo ascender en la escala corporativa. Oliver (1977) afirma que las grandes organizaciones todavía recompensan con planes de ascenso en la carrera. Hall y Moss (1998) consideran que tales planes de carrera prometidos son las partes internas de la estructura de las grandes organizaciones. La reciente evidencia empírica apoya el enfoque estructural de las trayectorias profesionales (McDonald et al., 2005).

El enfoque del comportamiento asume que las personas tienen cierto control sobre la escogencia de su carrera y desarrollo y por lo tanto pueden evaluar sus perspectivas profesionales y poner en práctica planes adecuados de carrera y las tácticas que contribuyan al éxito de la carrera (Gould y Penley, 1984; Greenhaus et al., 2000). 
El supuesto básico de este enfoque es que los aspirantes a desarrollar su profesión dentro de una organización deben asumir un papel proactivo en la gestión de sus propias carreras y llevar a cabo estrategias que sean congruentes en el contexto de las estrategias de la organización (Gunz y Jalland, 1996; Gunz et al., 1998), en lugar de confiar pasivamente en los sistemas de carrera de la organización.

Gould y Penley (1984) sugieren que los empleados utilizan las estrategias de carrera, tanto interpersonales e intrapersonales, ya que tales estrategias de conducta (autonombramientos y redes de trabajo) puede ayudarles a recibir evaluaciones favorables de desempeño. Se encontró relación entre el uso de estas estrategias y la progresión de los salarios de los gerentes. Nabi (2003) encontró que los autonombramientos y las redes de trabajo median la relación entre perspectivas de carrera y éxito profesional intrínseco (éxito subjetivo).

Enfoques anteriores sobre el éxito profesional se han visto impulsados por la creencia de que el éxito profesional es racional y predecible, determinado por un conjunto de recursos humanos, variables estructurales y variables de comportamiento. Los enfoques recientes de las carreras han sido impulsados por las nuevas realidades de la reestructuración organizativa contemporánea del éxito profesional y los cambios psicológicos en el contrato de trabajo (Arthur et al.; Sullivan, 1999). De esto resulta interesante para el análisis de las perspectivas contemporáneas de las carreras desde la naturaleza de la relación del trabajo que ha cambiado radicalmente en los últimos años de manera que la relación contractual del empleador / trabajador pasa de ser un contrato fijo a temporal y la progresión de la carrera sea lateral en vez de lineal.

Seibert, et al. (1999), realizaron una estudio en el que concluyen que la personalidad proactiva esta positivamente asociada con los indicadores objetivos (salarios y promociones) y subjetivos del éxito profesional (satisfacción profesional). A partir de sus resultados determinaron que a la vez estaban controlados por importantes variables relevantes (demografía, capital humano, motivacional, organizacional) que previamente han demostrado ser predictivos en los resultados de la carrera profesional.

Siguiendo la línea contemporánea, Arthur et al. (2005) propone dos conceptos de éxito: objetivo y subjetivo a partir de dos acepciones de éxito del diccionario Oxford: a) "el logro de un objeto de acuerdo a nuestro deseo" que sugiere un enfoque personal (éxito subjetivo) y b) "el logro próspero de algo que se ha intentado", que implica una forma de éxito que depende las comparaciones sociales (éxito objetivo). 
se

Éxito Profesional objetivo (Arthur et al., 2006):

“Es una perspectiva externa que delinea indicadores más o menos tangibles de la situación de la carrera profesional de un individuo. Estos pueden involucrar ocupación, familia, movilidad, atributos de la tarea, ingreso y nivel del cargo (Van Maanen, 1977). El éxito profesional es de acceso público y se ocupa del papel social y de la posición oficial."

Los escritores que ven el éxito profesional desde esta perspectiva la enfocan en términos estructurales (Wilensky, 1961) y hacen énfasis en la inclinación de las personas por organizarse en relación a diferencias de estatus (Nichelson, 1998).

Éxito Profesional subjetivo (Arthur et al., 2006):

"Se puede definir como la aprehensión y evaluación interna de un individuo de su carrera profesional, a través de cualquier dimensión que sea importante para ese individuo (Van Maanen, 1977). Las personas tienen diferentes aspiraciones y le asignan diferentes valores a factores como ingreso, seguridad laboral, ubicación del trabajo, estatus, progresión en diferentes cargos, acceso al aprendizaje, la importancia del trabajo versus tiempo para la familia y así sucesivamente".

Teóricos como Heslin, Hall y Chandler, entre otros, proponen la integración de los conceptos objetivo y subjetivo de éxito en las investigaciones de ésta área. Heslin (2005) señala que los criterios objetivos de éxito profesional pueden estar contaminados y presentar deficiencias potenciales. Contaminados porque están afectados por factores que van más allá del control del individuo y deficientes en cuanto a que no capturan factores relevantes del modelo teórico. En la tabla 2.12 se muestran criterios hallados en algunos estudios.

En cuanto a las fuentes de contaminación del éxito objetivo, éstas se relacionan con factores tales como: las diferencias en las estructuras de poder entre las sociedades, estratificación económica y social e indicadores de estatus entre otros. Inclusive en las mismas sociedades el éxito objetivo puede variar de una profesión u ocupación a otra.

Los criterios tradicionales de éxito objetivo, (salario, estatus) no son los únicos resultados que los individuos buscan en sus carreras (Heslin, 2005). 
Tabla 2. 12 Criterios de éxito objetivo y subjetivo hallados en algunos estudios

\begin{tabular}{|c|c|c|}
\hline Autor & Criterios Objetivos & Criterios Subjetivos \\
\hline Cochran (1990) & & Sentido de propósito \\
\hline Friedman y Greenhaus (2000) & Estatus & $\begin{array}{c}\text { Tiempo personal, social, reto } \\
\text { y seguridad }\end{array}$ \\
\hline Finegold y Mohrman (2001) & & $\begin{array}{c}\text { Balance entre el trabajo y la } \\
\text { vida privada }\end{array}$ \\
\hline Wrzesniewski (2002) & & Sentido de significado \\
\hline Dobrow (2003) & & Sentido de trascendencia \\
\hline Hall y Chandler (2005) & & Sentido de contribución \\
\hline
\end{tabular}

Fuente: Elaboración propia a partir de Hall y Chandler (2005)

Un método comúnmente usado para manejar las deficiencias de los criterios objetivos de éxito señala Heslin (2005), es medir el éxito profesional subjetivo en conjunción con los logros objetivos.

Hall y Chandler (2005) reconocen la interdependencia de las perspectivas objetiva y subjetiva de éxito, amplían la investigación sobre este concepto y describen una condición en la cual la profesión subjetiva conduce a resultados objetivos.

Según Arthur et al. (2005) la dualidad del éxito profesional objetivo y subjetivo también es señalada, así como su interdependencia. Concluyen que las profesiones se desarrollan sobre el tiempo. El éxito profesional tiene ambos componentes objetivo y subjetivo de la profesión, donde la dualidad e interdependencia del éxito profesional los hace mutuamente relevantes y que, en el transcurso del tiempo, el uno puede ejercer influencia sobre el otro.

Este enfoque se ve reflejado en los conceptos teóricos empleados en estudios recientes sobre el tema en los que se define éxito profesional como la acumulación de resultados laborales y psicológicamente positivos fruto de la experiencia laboral (Seibert y Kraimer, 2001) o como lo ha definido Baudreau et al. (1999), los resultados extrínsecos e intrínsecos o logros que los individuos han acumulado como resultado de su experiencia laboral. 


\subsubsection{2 Éxito Profesional de los Graduados en Educación Superior}

El éxito laboral se ha estudiado frecuentemente en la literatura económica y social. Las perspectivas dominantes han explicado el éxito laboral a partir de factores netamente estructurales, con independencia de las diferentes expectativas. Por ejemplo, dando por supuesto que para todos los individuos el éxito laboral vendría dado por tener salarios elevados, se estudiaban las diferencias salariales entre grupos y se atribuía mayor éxito laboral a aquellos grupos con salarios más elevados que el resto. Hasta el momento siempre se han considerado como exitosas las carreras profesionales que incluían el desempeño de algún cargo bien remunerado y en una posición en la jerarquía de la organización. Sin embargo, numerosos estudios han detectado que los individuos con este perfil no siempre se encuentran satisfechos con su situación laboral. Algunos de ellos experimentan cierta sensación de pérdida de sentido del trabajo que realizan, e incluso frustración y estrés (Korman, Wittig-Berman y Lang, 1981).

Para Seibert, Kraimer y Crant (2001) el incremento en la movilidad de los individuos o la adquisición de nuevas competencias profesionales requeridas por el trabajo son claros indicadores de la necesidad de redefinir los conceptos de trayectoria y éxito profesional.

Muchos resultados en investigación ofrecen evidencia a la hipótesis de una creciente complejidad en las relaciones entre educación superior y trabajo (Teichler, 1999).

Las nuevas demandas en cuanto a la flexibilidad individual en el mercado laboral pueden influenciar esas orientaciones. De ahí que los investigadores cada vez utilizan el concepto de éxito profesional, con un amplio rango de medidas, tales como:

Las variables dependientes para medir el éxito laboral que a la vez se agrupan en medidas objetivas y medidas subjetivas.

Medidas objetivas: tiempo de búsqueda de empleo desde la graduación hasta conseguir el primer empleo, ingresos y posición.

Medidas subjetivas: carrera y estatus, uso de los conocimientos, nivel del puesto de trabajo apropiado al nivel educativo obtenido y satisfacción en el trabajo.

Existen otras condicionantes aparte del país, las condiciones estructurales y culturales, la institución y programa de estudio las que determinan el éxito profesional individual. La historia socio biográfica, tales como el género y la historia socio biográfica de los padres, las 
competencias adquiridas hasta la graduación, las condiciones del empleo (ej.: sector económico, tamaño de la organización) y las experiencias después de la graduación (educación posterior y entrenamiento) son todas relevantes para el éxito profesional. No hay un factor individual el cual prevalezca sobre otros (Schomburg, 2007).

Las experiencias pueden ser descritas según Arthur, Khapova y Wilderon (2005) de dos maneras fundamentales:

Desde el sentido propio del individuo, de su profesión y lo que ésta ha llegado a ser (profesión subjetiva).

Reflejando los cargos, las situaciones y el estatus más o menos públicos y observables "que sirven de indicadores para medir el avance de una persona a través del entorno social" (profesión objetiva).

Se constata que cada vez es más difícil alcanzar el éxito profesional tal y como se ha entendido este concepto tradicionalmente, es decir mediante un alto nivel de ingresos y una buena promoción. Este cambio de concepto toma relevancia, en cuanto que algunos estudios corroboran la relación entre éxito personal de los empleados y el éxito de la empresa (Sturges, 1999). Por esta razón muchas empresas están realizando numerosos esfuerzos en la identificación de los factores personales y laborales que influyen en la obtención del éxito profesional (Boudreau, Boswell y Judge, 2001).

Existen estudios que propugnan la prevalencia de la dimensión objetiva sobre la subjetiva y viceversa. Por el contrario otros estudios descartan el predominio de una dimensión sobre otra y defienden que existe una relación de interdependencia entre ambas (Seibert, Kraimer y Liden, 2001).

Frente a las tres alternativas nombradas anteriormente, se puede afirmar que no es unánime la definición de éxito laboral y que este dependerá de los factores que se analicen en el contexto que corresponda. Mientras exista un elemento de valoración subjetivo es muy difícil hallar unanimidad de criterios, pero se pueden relacionar elementos que nos permitan entender que el concepto cambia según cambian las condiciones del individuo y las condiciones externas a él. 


\subsubsection{Dimensiones del Éxito Profesional (laboral)}

La dimensión del éxito profesional se debe medir teniendo en cuanta la dimensión objetiva y la dimensión subjetiva, por lo tanto sus indicadores deben reflejarlas de tal manera que en conjunto puedan ayudar a medir el éxito profesional.

La dimensión objetiva es el conjunto de indicadores cuantificables que definen la situación laboral de un individuo. Se utiliza habitualmente el salario y la posición en la escala jerárquica de la organización.

Otros autores proponen además los siguientes indicadores: La duración del periodo de búsqueda del primer empleo (Shomburg, 2007), la movilidad del empleo, el tipo de contrato, el ajuste entre la educación recibida y el empleo (Allen y de Weert, 2007; Teichler y Schomburg, 2007) o los beneficios no monetarios (O'Shea, Betsinger y King, 1999), entendidos como bienes y servicios que recibe el individuo por su condición de empleado y que son financiados por el empleador, como las condiciones laborales relativas al entorno de trabajo (Mora, et. al., 2005).

La dimensión subjetiva se define como la concepción y la evaluación individual de la carrera profesional. En este sentido, numerosos estudios sobre el éxito profesional utilizan como indicador más adecuado de esta dimensión la "satisfacción laboral" (Judge, et al., 1995; Mora, et al., 2007). La dimensión subjetiva del éxito incluye el conjunto de valores y expectativas del individuo relativas a un trabajo vinculado a su proyecto de vida. Según Schomburg (2007), es posible delimitar perfiles típicos de éxito aceptados intersubjetivamente en grupos diferenciados por variables que han demostrado ser relevantes, como son el contexto del país de residencia del titulado, la rama de conocimiento en que se graduó y otras.

El estudio del éxito laboral de los graduados superiores en la actualidad, sigue siendo objeto de interés para muchos investigadores de Europa y Norteamérica, regiones de donde proceden la mayoría de investigaciones relacionadas con el tema. Tiene sentido el interés de los investigadores de otras regiones por realizar estudios sobre éxito laboral.

El mercado laboral actual viene presentando una serie de acontecimientos que están cambiando el concepto tradicional del empleo estable y para toda la vida, por el de un empleo en donde al profesional se le pide ser competitivo, autónomo, que tenga capacidad de asumir riesgos y que sea flexible. Por lo tanto, el éxito profesional no puede entenderse solamente como un aspecto de la posición en la escala jerárquica de una organización o como las ganancias percibidas por el trabajo realizado. 
Las investigaciones sobre el éxito profesional han pasado de definirlo como un aspecto relacionado con lo económico y el estatus, como así lo demuestran los distintos resultados de investigaciones empíricas sobre satisfacción laboral nombrados en este trabajo. El enfoque contemporáneo sobre éxito profesional ha llevado a los investigadores a proponer una definición en un sentido más amplio, considerando la dimensión objetiva y subjetiva del éxito que en su conjunto puedan dar una medida del éxito profesional.

\subsubsection{Valores Laborales}

Los valores son conceptos o convicciones que definen la forma en que vivimos. En la vida profesional o laboral estos valores influyen sobremanera en cómo los individuos abordan el trabajo. Los valores guían en la toma decisiones ayudan a la persona a encontrar la fortaleza necesaria para mantenerse firme en lo que son sus creencias y en lo que defiende. Consecuentemente los valores individuales podrían ser el factor principal que determina el comportamiento y la opinión sobre las personas, las situaciones o los acontecimientos.

Para abordar el tema, se parte del primer modelo teórico referido al tema de las creencias, expectativas y valores que posee el trabajador respecto del trabajo en general. El modelo de investigación llamado $\mathrm{MOW}^{8}$ (Meaning of Working Study) ó significado del trabajo, propuesto por International Research Team (1987).

Investigaciones posteriores utilizan su estructura teórica inicial, de manera más o menos explícita al utilizar su mismo dispositivo de recolección de datos (Harpaz, 1990; Díaz Vilela, 1994, 1997 y estudios relacionados: Pérez Quintana, Díaz Vilela y Lorenzo Leal, 1993; Núñez Rodríguez, Díaz Vilela, Lorenzo Leal, Rodríguez Hernández y Chams-El Dim Delgado, 1995). A partir de aquí la referencia se hace extensiva a otras investigaciones que participan de su misma concepción teórica de partida y luego agregan las aportaciones específicas que se obtienen de esos estudios. (Pérezgonzález y Vilela, 2005). De igual manera, hay investigaciones que utilizan algunos elementos centrales del MOW y sus respectivos instrumentos de medida

\footnotetext{
${ }^{8}$ El equipo de investigadores del MOW, está integrado por científicos sociales que diseñaron, desarrollaron e implementaron una investigación sobre determinados colectivos de trabajadores. El objetivo principal del estudio, llevado a cabo en ocho países diferentes por catorce investigadores de distintas disciplinas, era obtener resultados que fueran comparables a nivel a nivel europeo y que permitieran advertir las diferencias del significado del trabajo entre los distintos países entre $1987 \mathrm{y}$ 2002.
} 
cuando tienen que definir los elementos que forman parte de la investigación (Ruiz Quintanilla y Wilpert, 1991; Claes, Depolo y Ruiz Quintanilla, 1992).

El modelo define tres categorías de variable:

Variables condicionales o antecedentes (situación familiar y personal; trabajo actual e historial de carrera, ambiente macro-socio-económico); variables centrales (centralidad, normas sociales, resultados laborales valorados, metas laborales e identificación con roles laborales) y consecuencias. Para el MOW International Research Team, el significado del trabajo está determinado tanto por el individuo (sus elecciones y experiencias) como por el contexto ambiental y organizacional en el que vive y trabaja. En el marco de estas investigaciones, los autores consideran que el referente del estudio es el trabajo en general (work involvement de Kanungo, 1979, 1982) y no el trabajo que el individuo desempeña actualmente (job involvement). Por otra parte el trabajo es entendido como aquella actividad por la que se recibe una contraprestación económica a cambio.

Originalmente el MOW planteó cinco dimensiones que al final de la investigación se redujeron a cuatro:

1. Centralidad en el trabajo, que la distinguen de dos formas la centralidad absoluta y la centralidad relativa. La primera trata determinar el valor o creencia general de la importancia de trabajar en términos absolutos. La segunda determina la importancia que una persona concede al trabajo con relación a la que concede a otras áreas relevantes de la vida como la familia, el tiempo libre, la religión o la participación en la vida social de la comunidad.

2. Normas sociales sobre el trabajo, que agrupaba el factor de normas relativas a derechos laborales y el factor de normas relativas a deberes laborales.

3. Resultados valorados/metas preferidas, que agrupaba los factores función de producción de ingresos, función de autoexpresividad, función de contacto interpersonal, función de confort, función de aprendizaje y desarrollo y función religiosa y de servicio social.

4. Identificación del Rol del trabajo, que podría definirse como el grado en el que uno se identifica personalmente con el trabajo que realiza, con la organización/compañía en la que trabaja, el producto/servicio o la ocupación/profesión que desempeña (Harpaz,1990). Esta dimensión agrupaba los factores identificación con el producto, identificación con las tareas e identificación 
con la organización. Esta última categoría desapareció, a criterio de los investigadores, debido a problemas metodológicos que presentaba.

Como resultado el MOW International Research Team (1987) concluye con un modelo del significado del trabajo, derivado empíricamente, representado en tres círculos concéntricos:

El núcleo del modelo parece ser la Centralidad del Trabajo (que puede ser alta o baja), entendida como el grado de importancia y valor que el trabajo tiene para la vida de un individuo dado, sea por las razones que fueran. Este elemento es de fundamental importancia para entender el significado del trabajo para el individuo.

El segundo círculo del modelo son las normas sociales acerca del trabajo: creencias y expectativas normativas acerca del rol del trabajo en la propia vida. Estas pueden oscilar entre los polos de orientación a los derechos laborales, a los deberes para con el trabajo, o bien para implicar una orientación balanceada entre ambos. Las normas sociales acerca del trabajo ocupan el círculo concéntrico alrededor de la centralidad porque son la segunda fuente de importancia para entender el significado del trabajo.

- El tercer círculo, los Resultados valorados del trabajo/Metas laborales preferidas. Seis categorías de resultados/metas fueron las encontradas por el equipo internacional y, según ellos, tienen un nivel medio de abstracción, dependiente de los intereses propios del individuo y son multidimensionales, complejas e idiosincrásicas por naturaleza. Aun así representan la tercera fuente en importancia para entender el significado del trabajo. Estos seis resultados/metas laborales valoradas son:

Los ingresos

$>$ El contacto interpersonal

$>$ El confort

$>$ La autoexpresión

$>$ Las oportunidades de mejora y aprendizaje

$>$ La función de mejora y de servicio social del trabajo

La distinción que el Grupo MOW hace entre los resultados valorados del trabajo y la importancia para las personas de los distintos aspectos laborales, les ha servido para abordar el análisis de los valores laborales (García-Montalvo et al., 2003). 
Modelo del Valor de Schwartz (1992)

Los valores han sido analizados básicamente atendiendo a su dimensión motivacional, en tanto que creencias relativas a metas deseadas, a partir de las que pueden definirse formas de comportarse y en general, estilos de vida. Este es el planteamiento que sostiene el modelo de Valor de Schwartz (1992) en la búsqueda de una clasificación amplia del contenido de los valores afirmando que estos constituyen el nivel más abstracto de un sistema que incluye creencias y actitudes y que anteceden y modulan la relación con la conducta. Así los valores fijan los criterios para evaluar y justificar las acciones que se llevan a cabo y también sobre aquellas que no se realizan (Suarez y Hernández, 2008).

Los trabajos de investigación orientados a evaluar los valores en el área laboral o aquellos relacionados con el trabajo, han utilizado el marco conceptual del modelo de Valor desarrollado por Shalom Schwartz (2001), quien define a los valores como metas deseables y trans-situacionales, que varían en importancia, que sirven como principios en la vida de una persona o de otra entidad social.

De la definición anterior se deduce que los valores: Sirven a los intereses de alguna entidad social, pueden motivar a la acción, dándole dirección e intensidad emocional, funcionan como criterios para juzgar y justificar la acción, se adquieren a través de la socialización en los valores del grupo dominante como a través de la experiencia personal del aprendizaje (Filippi, 2008).

De los datos obtenidos a partir de muestras de diferentes países de diversas culturas, Schwartz (1992) identifica diez tipos de valor motivacional (tabla 2.13) distintas que es probable que sean reconocidas dentro y entre las culturas y utilizado para formar las prioridades de valor. Logra demostrar que el conjunto de tipos de valor es relativamente amplio y abarca prácticamente todos los tipos de valores a los que los individuos atribuyen al menos moderada importancia como criterio de evaluación. Reúne evidencias que muestran que el significado de los tipos de valor y de la mayor parte de los valores individuales que las constituyen es razonablemente equivalente en la mayoría de los grupos. Descubre dos dimensiones básicas que organizan los sistemas de valores en un integrada estructura motivacional con los conflictos de valores consistentes y compatibilidades. 
Tabla 2. 13 Tipos de Valor motivacional según Schwartz (2001)

\begin{tabular}{|c|c|}
\hline Tipo de Valor Motivacional & Valores \\
\hline Poder & $\begin{array}{l}\text { El logro de estatus social y prestigio, control o } \\
\text { dominio sobre las personas y los recursos }\end{array}$ \\
\hline Logro & Emoción, novedad y reto en la vida \\
\hline Hedonismo & Placer, o gratificación sensual para uno mismo \\
\hline Estimulación & Emoción, novedad y reto en la vida \\
\hline Autodirección & Libertad, creatividad, pensamiento independiente \\
\hline Benevolencia & $\begin{array}{l}\text { Preservación y mejora del bienestar de la gente } \\
\text { con la que se tiene frecuente contacto personal }\end{array}$ \\
\hline Tradición & $\begin{array}{c}\text { El respeto, el compromiso y la aceptación de las } \\
\text { costumbres e ideas que la cultura o la religión } \\
\text { imponen al individuo }\end{array}$ \\
\hline Conformidad & $\begin{array}{l}\text { Hacen hincapié en la moderación en la interacción } \\
\text { cotidiana, normalmente con otras personas } \\
\text { cercanas (obediencia, cortesía, autodisciplina...) }\end{array}$ \\
\hline Universalismo & $\begin{array}{c}\text { La comprensión, el aprecio, tolerancia y protección } \\
\text { del bienestar de todas las personas y para la } \\
\text { naturaleza. }\end{array}$ \\
\hline Seguridad & $\begin{array}{l}\text { La seguridad, la armonía y la estabilidad de la } \\
\text { sociedad, de las relaciones y de sí mismo. }\end{array}$ \\
\hline
\end{tabular}

El análisis de los conflictos y compatibilidades que pueden ocurrir cuando las personas intentan realizar estos valores de forma simultánea, puede ser la base de la formulación de hipótesis sobre las relaciones entre prioridades de valores (Schwartz, 1992).

Como señala Schwartz (2001), desarrollar los valores de logro puede entrar en conflicto con la persecución de los valores de benevolencia: la búsqueda del éxito personal es posible que sea un obstáculo para aquellas acciones orientadas a mejorar el bienestar de los 
demás que necesitan de nuestra ayuda. De igual manera, el intentar mantener valores tradicionales puede entrar en conflicto con la búsqueda de la estimulación: aceptar las costumbres culturales y religiosas y las ideas transmitidas del pasado puede inhibir la novedad, el desafío y el entusiasmo. Por otro lado, sostener valores de benevolencia y conformidad resulta compatible, pues ambos tipos de valores implican un comportamiento que es aceptado por el grupo íntimo.

Tabla 2. 14 Compatibilidades y Conflictos entre Valores según Schwartz (2001)

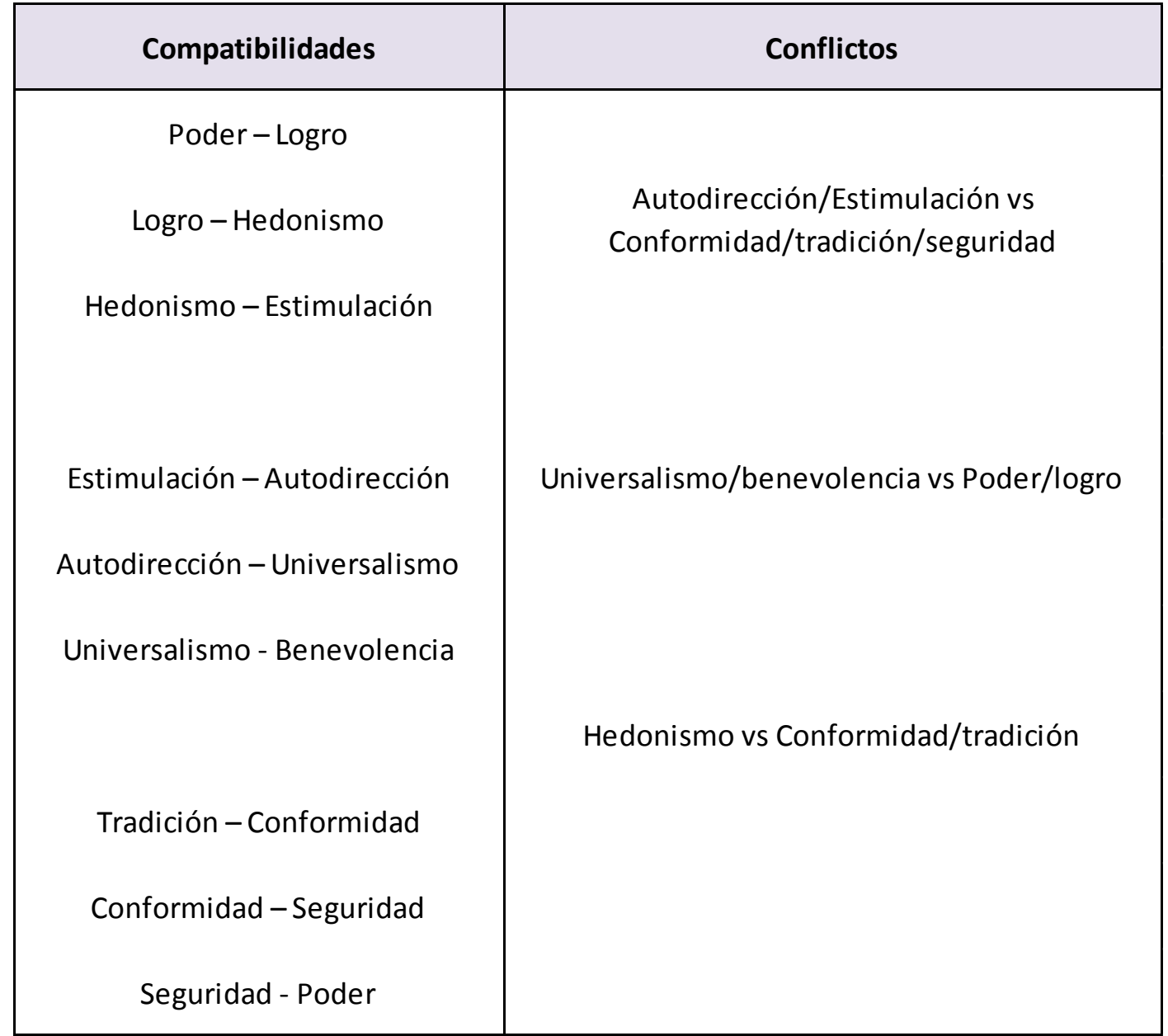

Los valores que las personas adquieren y desarrollan sobre el trabajo representan un componente importante del significado del trabajo, junto con los aspectos normativos y creencias sobre el mismo y la centralidad que este ocupa en sus vidas (Valls, Martínez, 2004).

Los valores laborales hacen referencia a lo que una persona desea alcanzar a cambio de su dedicación en el puesto de trabajo. 
Hoppok y Super (1950) proporcionaron una primera aproximación al concepto de valores de trabajo cuando observaron que las expresiones generalizadas sobre satisfacción del trabajo tendían a relacionarse con expresiones de satisfacción hacía aspectos específicos del trabajo como ingresos, horarios, ascensos, variedad.

Posteriormente, Super (1968) considera los valores del trabajo como las metas que motivan a los individuos a trabajar: esas metas podían ser intrínsecas o extrínsecas al trabajo. Pryor (1981) considera que los valores de trabajo representan cualidades o recompensas específicas que uno desea del trabajo (por ejemplo: dinero, seguridad, altruismo, etc.).

Los valores laborales tienen un contenido, que se refiere a lo que la persona quiere obtener. Asimismo tienen un equilibrio y un punto óptimo: la importancia de un valor puede variar en función de la cantidad ya poseída del mismo.

\section{Valores laborales Extrínsecos e Intrínsecos}

La valoración intrínseca está relacionada con aquellas recompensas que recibe el individuo por su propia acción, sin mediación de otras personas, siendo así percibidas por el sujeto como consecuencias dependientes de sí mismo.

La valoración extrínseca está provocada por recompensas de la propia actividad del sujeto y cuyo control depende de eventos externos (Filippi, 2008).

Salanova et al. (1996) afirman que la valoración intrínseca se centra en la propia actividad laboral del sujeto (aspectos relacionados con el contenido del trabajo) y de los cuales la persona experimenta un control interno. Esa actividad es un fin en sí misma y es una actividad expresiva, valiosa y satisfactoria para la persona. Por el contrario, la valoración extrínseca, no se centra en la actividad laboral que realiza la persona sino en los aspectos relacionados con el contexto del trabajo, de los cuales experimenta un control externo, ya que cae bajo la atención de objetos, eventos o situaciones externas a la propia persona. Esa actividad laboral, realizada para obtener unos beneficios, no es un fin en sí misma sino que se convierte en un medio para obtener un fin.

Los aspectos extrínsecos hacen referencia a las características de la propia actividad laboral: si el trabajo plantea tareas variadas, con responsabilidades y además ofrece oportunidades de emplear las habilidades que uno tiene, o proporciona oportunidades para aprender. Al mismo tiempo existen aspectos importantes del trabajo que son extrínsecos a la propia actividad laboral: las condiciones del trabajo como el horario, la estabilidad laboral y las 
retribuciones. Los aspectos sociales del trabajo son aspectos valorados por los trabajadores; las relaciones con los compañeros y el estatus social adquirido (Valls y Martínez, 2004).

Los estudios asociados a los valores laborales han centrado su atención en las siguientes áreas de interés. La primera está relacionada con el estudio de los valores laborales intrínsecos y los valores laborales extrínsecos, la segunda a las relaciones existentes entre los valores laborales y las competencias, la tercera corresponde a la relación entre valores laborales con la satisfacción en el trabajo y la cuarta, a las congruencias y conflictos entre valores, en este caso las diversas investigaciones comparan valores laborales específicos, basados en variedad de investigaciones donde el objeto de estudio son estudiantes universitarios de últimos años, empleadores y trabajadores a diferentes escalas jerárquicas.

El estudio de la jerarquía de los valores de los individuos, ha llevado a diferentes autores a elaborar inventarios, clasificaciones y escalas de valores, que a la vez han sido utilizadas como marco de referencia para otras investigaciones, como lo refleja la tabla 2.15 
Tabla 2. 15 Estudios sobre Valores Laborales

\begin{tabular}{|c|c|c|}
\hline Autor & Año & Tema de Estudio \\
\hline \multirow{2}{*}{ Super } & 1957 & Valores de trabajo. \\
\hline & 1970 & The Work Values Inventory "WVI". \\
\hline Claes & 1987 & $\begin{array}{l}\text { Los jóvenes se inclinan por valores Instrumentales. } \\
\text { Los mayores se inclinan por valores expresivos o } \\
\text { intrínsecos. }\end{array}$ \\
\hline Schwartz & $\begin{array}{c}1992 ; \\
1999 ; 2001\end{array}$ & Valores sociales: Congruencias y conflictos \\
\hline Huang y Healy & 1997 & $\begin{array}{l}\text { Estudio longitudinal } 18.137 \text { estudiantes en EEUU. } \\
\text { Valores relevantes: Prestigio, ayuda a los demás, } \\
\text { estar bien con uno mismo. }\end{array}$ \\
\hline Roe, Schwartz y Surkiss & 1999 & Valores sociales: Congruencias y conflictos \\
\hline Ghorpade, Lackritz y Singh & 2001 & $\begin{array}{l}\text { Estudio con } 749 \text { estudiantes universitarios. Valores } \\
\text { laborales: altruismo, iniciativa y saber trabajar en } \\
\text { grupo correlación positiva con: capacidad de } \\
\text { dirección en el mundo laboral. Valor: Individualismo } \\
\text { correlaciona negativamente. }\end{array}$ \\
\hline Johnson & 2001 & $\begin{array}{l}\text { La transición a la vida adulta profesional es un } \\
\text { proceso fundamental en los universitarios por su } \\
\text { influencia en los valores laborales. }\end{array}$ \\
\hline Daehlen & $2005 ; 2007$ & \\
\hline Jensen y Aamodt & 2002 & $\begin{array}{l}\text { Estudio con } 908 \text { estudiantes noruegos. Diferentes } \\
\text { áreas de conocimiento: Oportunidad de ser útil y } \\
\text { hacer algo para la sociedad. Seguridad económica. }\end{array}$ \\
\hline Kopelman, Rovenpor,Guan & 2003 & $\begin{array}{c}\text { Valores laborales Intrínsecos, Valores laborales } \\
\text { extrínsecos }\end{array}$ \\
\hline Feather y Rauter & 2004 & $\begin{array}{l}\text { Valores intrínsecos suelen ir asociados con } \\
\text { estabilidad laboral. Valores extrínsecos suelen ir } \\
\text { asociados con precariedad e inestabilidad. }\end{array}$ \\
\hline Berings, Fruyt, Bouwen & 2004 & Intereses Profesionales \\
\hline Xenikou & 2005 & Personalidad \\
\hline Pérezgonzáles y Vilela & 2005 & Investigación Empírica: La Centralidad en el trabajo. \\
\hline
\end{tabular}




\begin{tabular}{|c|c|c|}
\hline Autor & Año & Tema de Estudio \\
\hline Leong, Hérding y Gaylor & 2005 & $\begin{array}{l}\text { Valores laborales estudiantes de Medicina (EEUU). } \\
\text { Mediante "Values Scales" (Super y Nevill, 1986): } \\
\text { +Apreciados: altruismo, éxito, promoción, la estética, } \\
\text { la autoridad y autonomía. - apreciados: Resistencia a } \\
\text { la frustración y el riesgo. }\end{array}$ \\
\hline Lyons, Duxbury, Higgins & 2006 & $\begin{array}{l}549 \text { Trabajadores Canadienses del sector público, } \\
\text { semipúblico: Universalismo, benevolencia y del } \\
\text { sector privado: Autodirección, benevolencia. }\end{array}$ \\
\hline Duffy y Sedlacek & 2007 & $\begin{array}{c}\text { Mediante "Values Scales" (Super y Nevill, 1986). } \\
\text { Muestra de } 3570 \text { estudiantes universitarios en EEUU. } \\
\text { Inclinación por los valores intrínsecos (especialmente } \\
\text { mujeres), seguido por salarios altos, contribución a la } \\
\text { sociedad y prestigio. }\end{array}$ \\
\hline Hattrup, Ghorpade y Lackritz & 2007 & $\begin{array}{l}\text { Trabajo transcultural. } 1882 \text { estudiantes universitarios } \\
\text { de Ecuador, Alemania, India, México, EEUU. } \\
\text { Correlación positiva entre valor del colectivismo y la } \\
\text { centralidad en el trabajo. No hay diferencias } \\
\text { significativas de los resultados entre países. }\end{array}$ \\
\hline Mora, García-Aracil y Vila & 2007 & $\begin{array}{l}\text { Los más satisfechos en el trabajo valoran la vida } \\
\text { familiar, prestigio social y el desarrollo personal. }\end{array}$ \\
\hline Daehlen & 2007 & $\begin{array}{c}\text { Trabajo longitudinal con } 1.700 \text { estudiantes noruegos } \\
\text { de último año y cuatro años después de su } \\
\text { graduación. Encuentra diferentes comportamientos } \\
\text { según la ocupación, resultados que se matizan según } \\
\text { la estabilidad en el trabajo, el género y el tipo de } \\
\text { familia. }\end{array}$ \\
\hline Song y Gale & 2008 & $\begin{array}{c}\text { La formación holística en valores laborales vinculado } \\
\text { con las competencias es básica para líderes o } \\
\text { directores de proyectos. }\end{array}$ \\
\hline Fuming y Jiliang & 2008 & $\begin{array}{l}\text { Estudio en China: Los profesores asocian satisfacción } \\
\text { laboral con buena relación con compañeros y la } \\
\text { insatisfacción con el descenso en el salario. }\end{array}$ \\
\hline
\end{tabular}




\begin{tabular}{|c|c|c|}
\hline Autor & Año & Tema de Estudio \\
\hline Alonso Fernández y Nyssen & 2009 & $\begin{array}{c}\text { Empleadores y graduados universitarios de } \\
\text { diferentes ramas señalan que el aprendizaje en } \\
\text { valores laborales y la ética en el trabajo son } \\
\text { imprescindibles en el mundo laboral, aunque ambos } \\
\text { grupos critican que se adolece de dicho aprendizaje } \\
\text { en la universidad. }\end{array}$ \\
\hline Cortés & 2009 & $\begin{array}{r}\text { Vinculación entre valores laborales con las } \\
\text { competencias participativas y personales }\end{array}$ \\
\hline Cortés & 2009 & $\begin{array}{c}374 \text { alumnos área de educación: benevolencia, } \\
\text { universalismo. Valores intrínsecos y sociales. }\end{array}$ \\
\hline $\begin{array}{c}\text { Conchado, Cortés, Mora y } \\
\text { Carot }\end{array}$ & 2012 & $\begin{array}{c}\text { Los valores laborales se asocian con otras variables } \\
\text { profesionales }\end{array}$ \\
\hline
\end{tabular}

Fuente: Elaboración propia.

Martínez y Rocabert (2000), en un estudio comparativo de las diferentes escalas de valores, encontraron similitud en una amplia gama de valores con respecto a la escala de valores de Super (1970), escala utilizada como referencia de comparación.

En este proceso de revisión, tienen en consideración que hay diferencias transculturales en los valores de trabajo (tabla 2.16). 
Tabla 2. 16 Valores con más frecuencia de aparición en Escalas de Valores /autor(es)

\begin{tabular}{|c|c|c|}
\hline Autor(es) Escala / Año & Categoría de Valores & Valores \\
\hline $\begin{array}{l}\text { Super (1970) Vs. } \\
\text { Manhardt (1972) }\end{array}$ & & $\begin{array}{c}\text { Habilidad, estimulación } \\
\text { intelectual, logro, estética. }\end{array}$ \\
\hline $\begin{array}{l}\text { Cochran (1983) } \\
\text { Prior (1983) } \\
\text { Krau (1987) }\end{array}$ & Orientados a uno mismo & $\begin{array}{l}\text { Creatividad, desarrollo } \\
\text { personal, altruismo, } \\
\text { independencia, modo o } \\
\text { estilo de vida. }\end{array}$ \\
\hline $\begin{array}{l}\text { Yates (1990) } \\
\text { Erez, Borochov y Mannheim } \\
\text { (1988) } \\
\text { Ravlin y Meglino (1987) }\end{array}$ & Orientados al grupo & $\begin{array}{c}\text { Interacciones sociales, } \\
\text { asociación, identidad } \\
\text { cultural, relaciones sociales, } \\
\text { condiciones o ambiente } \\
\text { laboral, variedad. }\end{array}$ \\
\hline $\begin{array}{c}\text { Roberson et al. (1989) } \\
\text { Bridges ( 1989) }\end{array}$ & Valores materiales & $\begin{array}{c}\text { Promoción, retribuciones } \\
\text { económicas, seguridad, } \\
\text { prestigio. }\end{array}$ \\
\hline Elizur, Borg, Hurt y Beck (1991) & & \\
\hline $\begin{array}{c}\text { Holt y Keats (1992) } \\
\text { Harrington y O’Shea (1993) } \\
\text { Bozhinova, Jiliova y Georgieva } \\
\text { (1994) } \\
\text { MOW (1987) }\end{array}$ & Requieren habilidad física & $\begin{array}{c}\text { Habilidad física, riesgo, } \\
\text { actividad física. }\end{array}$ \\
\hline
\end{tabular}

Fuente: Elaboración propia a partir de Martínez y Rocabert (2000).

De cada una de las escalas mencionan aspectos diferentes. Los valores de trabajo con mayor frecuencia hallados en esta revisión son: independencia y retribuciones económicas, seguidas por estimulación intelectual y modo de vida; a continuación aparecen logro, altruismo, dirección, administración y asociación. En el otro lado, los valores de menor repetición en las escalas de valores son: estética, creatividad y relaciones con los superiores. 


\subsubsection{Las Competencias}

Para las actividades que se realizan en las organizaciones, siempre ha sido necesario contar con el recurso humano. El modelo de gestión de las organizaciones, ha evolucionado con el paso de los años y paralelamente el enfoque sobre el papel que desempeñan las personas dentro de ellas. Como se ha descrito en el apartado de evolución de las teorías de gestión, las personas han pasado de ser un instrumento más dentro de los que dispone la organización, a ser considerado el capital más importante, el llamado Capital Humano. Muchos autores, investigaciones y teorías diversas hay sobre el tema. Puede decirse que no hay una definición única, unánime que explique el papel del capital humano en las organizaciones de la actualidad, pero sí que ha permitido mostrar los distintos vínculos que conceptos como el de las competencias entre otros, justifican el papel del capital humano en las organizaciones.

\subsubsection{El Capital Humano}

La teoría del capital humano tal como se conoce hoy en día es una derivada del trabajo del economista británico Adam Smith (1776), pionero del concepto de que la existencia del capital de una nación incluye las habilidades y conocimientos adquiridos por sus habitantes. Basado en sus observaciones, afirma que las habilidades humanas aumentan la riqueza de la sociedad en general, así como la individual.

La conceptualización moderna del capital humano se ha dado gracias a los escritos de notables economistas; Becker $(1962,1964)$; Mincer $(1958,1962,1974)$ y Schultz $(1961,1962)$. Becker (1964), refinó la suposición de Smith al clasificar la educación como una buena inversión. Hasta ese momento los niveles avanzados de educación estaban considerados como un bien de consumo y referencia de status social. Esta categorización se atribuyó al hecho de que la capacidad de consumir más educación no obligatoria era una gran privilegio más a menudo ejercido por las clases medias y altas, y como tal fue utilizado para señalar la clase social más alta (Machin y Vignoles, 2005).

Becker, en su análisis teórico y empírico, destaca la importancia económica del capital humano, especialmente en la educación. Las personas con mayores habilidades y más altamente educadas casi siempre tienden a ganar más que otras. Esto ha sido verdad durante muchos años como lo demuestran los países desarrollados. Pocos países han alcanzado un periodo sostenido de desarrollo económico sin haber invertido cantidades importantes en su fuerza de trabajo. En la mayoría de los estudios que han intentado evaluaciones cuantitativas de las contribuciones al crecimiento, se ha asignado un papel importante a la inversión en 
capital humano y en los efectos económicos y no económicos que supone. De este modo, el concepto de capital humano ha dominado la economía de la educación y ha tenido gran influencia en el análisis de los mercados laborales, la determinación de salarios, y en otras ramas de la economía como el análisis del crecimiento económico. Un ejemplo de ello, son los resultados de las investigaciones de Psacharopoulos que concluyen que la educación es un factor explicativo del crecimiento económico, pero que su grado de explicación varía con el nivel de desarrollo de las economías (García, 2003).

La definición de Capital humano no es única, sin embargo el concepto refleja la idea general de que los individuos pueden decidir utilizar sus recursos bien para su consumo presente, bien para obtener rendimientos futuros los cuales, a su vez, podrán ser monetarios o no monetarios (Mora, Garcia y Vila, 2006). Los beneficios monetarios están relacionados con los ingresos recibidos por las personas con estudios, respecto a las que no los tienen y los beneficios no monetarios están relacionados con los beneficios recibidos en el entorno socioeconómico del individuo. En la última década se ha producido una tendencia hacia una definición más amplia de educación para incluir el aprendizaje continuo a lo largo de la vida laboral, la mayoría de los cuales se adquiere a través del tiempo de permanencia o la experiencia adquirida en el puesto de trabajo (Reich, 1991; Senge, 1990). Becker (2001), reconoció el concepto de aprendizaje a lo largo de la vida y convino en que como la mayoría de los activos, el capital humano de los empleados de una empresa es un activo que se deprecia y necesita inversión continua (Manville, 2001). Reiteró su opinión de que la educación formal es todavía un componente crítico de la teoría del capital humano, que sin duda otros factores pueden estar en el trabajo, pero las habilidades otorgadas por adquirir una educación universitaria son más importantes en la nueva economía de hoy en día de lo que estuvo en años anteriores (Manville, 2001).

\section{Definición General y Definición Específica de Capital Humano}

El capital humano representa los conocimientos y habilidades individuales adquiridas a través de una combinación de educación y experiencia personal única y que luego es llevada a la organización.

El capital humano general, está caracterizado por la educación total y la experiencia práctica, que se puede usar en una variedad de actividades y es fácilmente transferible de una actividad o situación a otra; sin pérdida significativa de valor (Gervais, Livshits y Meh, 2006). 
El capital humano específico está caracterizado por la educación y experiencia que está dirigido a una actividad o situación en particular y puede ser usado en un limitado número de actividades (Becker,1964; Gervais et al., Gimeno et al. 1997).

La visión del mundo de la gestión empresarial, en relación al capital humano lo define como el rendimiento que una organización obtiene de la fidelidad, creatividad, esfuerzo, logros y productividad de sus empleados (Tracey, 2004). Aunque no existe una definición acordada entre los gestores de recursos humanos en las organizaciones, hay un punto constante es que el capital humano representa la relación existente entre lo que la organización invierte en sus empleados y el éxito consiguiente a la inversión (Phillips, 2005).

\subsubsection{El Concepto de Competencias}

Desde un enfoque más económico que educativo, el concepto de la formación por competencias se inicia a finales de 1960 cuando la economía de los EE.UU. y el Reino Unido experimentan presiones causadas por la globalización, la mayor competencia internacional y el cambio tecnológico. Ambos países responden a estas fuerzas externas en forma similar. En primer lugar, hubo un movimiento para mejorar el nivel y el desempeño del sistema educativo, viendo que estaban fallando ambos, las empresas y los individuos al no coincidir con las necesidades del mercado de trabajo o lograr dotar a los jóvenes con conocimientos y habilidades apropiados para obtener un empleo y hacer un buen trabajo.

Las reformas del sistema educativo ocurrieron primero en los EE.UU. y luego en el Reino Unido. Ambos procedieron a transformar su sistema de formación docente $y$ posteriormente, todos los sectores de la educación incluida la educación superior en los años 90. De otro lado, hubo un movimiento para elevar el nivel de formación en el lugar de trabajo. El empeoramiento de los resultados económicos de Gran Bretaña durante la década de 1980 llevó al gobierno a iniciar una serie de investigaciones e informes, que hacían hincapié en la necesidad de una mano de obra flexible y adaptable, que pudiera responder a los cambios económicos y un amplio programa de capacitación basado en las nuevas normas de competencias laborales.

De esta forma, en estos países lo que establecen es un marco de competencias nacional que establece una definición precisa de las competencias necesarias para cada puesto de trabajo, la asignación de puestos de trabajo a los niveles apropiados y además evolucionan rigurosas pruebas para determinar si las personas cumplen con los estándares. No solo se limita a las ocupaciones manuales y técnicos, pero es completamente exhaustivo, cubriendo 
todas las posiciones manuales, técnicos, administrativos, profesionales y posiciones de gestión (Pilbeam y Corbridge, 2006).

Referido a las organizaciones, la gestión de competencias refleja un cambio desde un enfoque de trabajo basado en los recursos. Creció en la década de 1980, de un contexto económico de mayor globalización y aumento de la competitividad en los mercados mundiales, el surgimiento de una economía de servicios basada en el conocimiento, estructuras organizativas más planas y con mayor descentralización, más énfasis en el trabajo en equipo y la necesidad de flexibilidad funcional y personal en las organizaciones. Las organizaciones de los sectores público y privado han adoptado marcos de competencia que están diseñados para reflejar la misión y metas de la organización y la integración de las estrategias de recursos humanos de la organización, tanto horizontal como verticalmente.

Hay significados diferentes para la definición de competencias. Un enfoque que puede ser la base para el desarrollo de marcos de competencia, los cuales incluye trabajos, tareas, roles, personas y organizaciones. Por otra parte, las competencias se refieren a diferentes niveles dentro de una organización - estratégico, de supervisión y operativo. Los términos competencia, las competencias, se utilizan casi indistintamente llevando a una cierta confusión no menos importante con respecto a si el término se refiere a una actividad, un rasgo de la personalidad, una habilidad o una tarea (CIPD, 2001). ${ }^{9}$

Según Boyatzis (1982), competencia se refiere a la característica de comportamiento de un individuo que está causalmente relacionada con el rendimiento efectivo o superior en un trabajo. Para Fletcher (1991), competencia es la capacidad de realizar actividades dentro de una profesión a nivel prescrito. Estas dos definiciones reflejan una diferencia de enfoque: el primero se refiere a las entradas que ayudan a lograr un desempeño exitoso en el trabajo y el segundo a los resultados de la competencia. Estos son a menudo descritos como competencias conductuales y competencias basadas en los resultados.

Según el Diccionario de Inglés Oxford, competencia es la "habilidad para hacer algo exitosamente o eficientemente" (Competence or competency, Oxford 2012). Esta definición simple, relaciona términos de uso común y que están asociados al significado de competencias como desarrollo de habilidades físicas y manuales. De igual modo se pueden encontrar en el mismo nivel los términos actitud, aptitud, destreza, capacidad.

\footnotetext{
${ }^{9}$ CIPD: The Chartered Institute of Personnel and Development, London.
} 
Actitud: Disposición de ánimo manifestada de algún modo (Diccionario de la Real Academia Española 22a edición). Las actitudes definidas como la disposición afectiva a la acción, de manera que las actitudes impulsan al comportamiento de los seres humanos.

Aptitud: Capacidad para operar competentemente en una determinada actividad. Suficiencia o idoneidad para obtener y ejercer un empleo o cargo. Capacidad y disposición para el buen desempeño o ejercicio de un negocio, de una industria, de un arte, etc. (Diccionario de la real Academia Española 22a edición). La aptitud se refiere a las potencialidades innatas que los seres humanos poseen y que necesitan ser desarrolladas mediante la educación. Sin duda una persona no podría poseer una competencia si no tuviese una aptitud previa hacia ella. Pero, obviamente, la competencia requiere un desarrollo efectivo de tal aptitud innata mediante la formación en ella (Tejada et al., 2006).

Destrezas: Desarrollo de las aptitudes innatas desde un punto de vista motor e intelectual sin que medie la educación, lo que faculta a ciertos seres humanos para realizar ciertas actividades físicas con mayor precisión que otros. Lógicamente, una persona competente es bastante más que simplemente diestro en ciertas tareas o actividades.

Habilidad: Capacidad y disposición para algo, Cada una de las cosas que una persona ejecuta con gracia y destreza (Diccionario de la Real Academia Española 22a edición).

Las habilidades Implican la formación en ciertas tareas o actividades para llevarlas a cabo con perfección, de manera que la persona habilidosa es capaz de realizar aquellos procesos para los que se ha entrenado con eficacia y eficiencia.

Una persona competente es algo más que habilidosa, pues aporta la comprensión del contexto en el que desarrolla la tarea, conciencia crítica, consciencia de las posibles repercusiones de sus acciones, además de responsabilidad sobre las consecuencias que acarree su actuación (Tejada et al., 2006).

Capacidad: Aptitud, talento, cualidad que dispone a alguien para el buen ejercicio de algo.

La Capacidad denota la posibilidad de actuar de manera competente, pero exclusivamente como potencialidad. La competencia, implica necesariamente la actuación efectiva de manera idónea, reconocible por otros y demostrada en la práctica como tal.

En la cultura organizacional actual, el termino competencias es un término confuso (Robotham y Jubb, 1996; Soto, 2002), en la medida en que no está claro si las competencias se 
refieren a lo que las personas son capaces de hacer, deben de ser capaces de hacer, tienen que hacer para alcanzar el éxito en un puesto de trabajo o en una organización (Gil, 2002). Esto indica que es un concepto polisémico que facilita el acomodamiento del discurso a los propósitos de quien habla (Levy - Loboyer, 2000) y a las diversas situaciones.

Nordhaug y Gronhaug (1994), definen las competencias como los recursos productivos de las empresas. La misión de la empresa solo puede cubrirse fijando objetivos estratégicos para todos los departamentos. Cada objetivo exige una competencia clave (realmente propia y diferencial) que la empresa ha de poseer para alcanzarlo. Sin competencia clave no hay diferenciación en el mercado y sin diferenciación la empresa no sobrevive a largo plazo. Las competencias clave se desglosan en competencias operativas para facilitar su conversión en perfiles que los empleados han de aportar para poder desempeñar con éxito sus puestos. Este camino virtuoso alinea, en consecuencia, la estrategia empresarial con la gestión de las personas mediante competencias. Las competencias empresariales constituyen la razón de ser, el hecho diferenciador de las organizaciones. Constituyen un repositorio de conocimientos, comportamientos y habilidades que permiten a los empleados de una empresa alinear su desempeño con la estrategia corporativa (Fernández, J., 2005).

El estudio de las competencias por lo tanto, es un aspecto más amplio que el tradicional que incide en la importancia de tener los conocimientos y habilidades apropiadas al desempeño de las tareas que se realizan en el puesto de trabajo.

\subsubsection{Las Competencias de los Graduados en Educación Superior}

Existe una diversa clasificación de las competencias. Para al objetivo de este trabajo se presentan aquellas más extendidas y habituales sobre el tema. Una de las clasificaciones más extendidas a partir de la teoría de capital humano de Becker (1964) y de las investigaciones posteriores que confirman que el capital humano de los graduados universitarios, es una combinación de competencias genéricas y específicas (Becker, 1964; Heijke, Meng y Ris, 2003; Kellerman, 2001; Semejin, Van der Velden, Heijke, Van der Vleuten y Bozhuizen, 2005).

Hartog (1992), define las competencias como las aptitudes, destrezas y capacidades de los graduados en educación superior que contribuyen a aumentar su productividad son percibidas como el elemento clave para un crecimiento económico sostenible y el desarrollo en la economía globalizada. Cada vez más los responsables de las políticas se centran en la importancia de las competencias del capital humano (García-Aracil et al., 2004). En este sentido intentan dar respuesta a la sociedad actual que está cambiando aceleradamente debido a una serie de factores generales tales como la globalización, el impacto de las 
tecnologías de la información y comunicación, la administración del conocimiento y la necesidad de patrocinar y gestionar la diversidad.

Tobón (2005), clasifica las competencias en tres tipos: Las competencias básicas son las consideradas esenciales para vivir en sociedad y desenvolverse ellas, un ejemplo son las competencias cognitivas de procesamiento de la información. Las competencias genéricas se definen como aquellas comunes a varias profesiones. En el ámbito universitario las competencias genéricas están teniendo mayor relevancia en los estudios, pues al tratarse de competencias esenciales en un conjunto de profesiones afines entre sí, permite a los alumnos cuya formación ha incidido especialmente en ellas adaptarse con mayor facilidad a los continuos cambios del mercado laboral y profesional. Las competencias específicas son aquellas propias de una determinada profesión. Sin embargo para Tejada et al. (2006) en un sentido más integrador, las competencias las clasifica en cuatro dimensiones: cognoscitiva, social, comunicativa y ética.

Tabla 2.17 Clasificación de las Competencias según Tobón, S. (2005)

\begin{tabular}{|l|l|l|}
\hline \multicolumn{1}{|c|}{ Básicas } & \multicolumn{1}{|c|}{ Genéricas } & \multicolumn{1}{c|}{ Específicas } \\
\hline $\begin{array}{c}\text { Esenciales para vivir en } \\
\text { sociedad }\end{array}$ & $\begin{array}{c}\text { Comunes en varias } \\
\text { profesiones }\end{array}$ & $\begin{array}{c}\text { Propias de una } \\
\text { determinada profesión }\end{array}$ \\
\hline - Interpretativa & - Gestión de recursos & $\begin{array}{l}\text { - Poseen un alto grado } \\
\text { de especialización } \\
\text { - Pueden ser } \\
\text { obligatorias, optativas y } \\
\text { adicionales. }\end{array}$ \\
- Propositiva & $\begin{array}{l}\text { - Trabajo en equipo } \\
\text { - Gestión de la } \\
\text { información } \\
\text { - Comprensión } \\
\text { sistemática } \\
\text { - Resolución de } \\
\text { problemas } \\
\text { - Planificación del } \\
\text { trabajo }\end{array}$ & \\
\hline
\end{tabular}

Fuente: Tejada et al. (2006)

Bunk (1994) desarrolla un concepto de competencia en un modelo amplio del cambio estructural que se produce en la sociedad actual. Tiene competencia profesional quien dispone de los conocimientos, destrezas y aptitudes necesarios para ejercer una profesión, puede resolver los problemas profesionales de forma autónoma y flexible, y está capacitado para 
colaborar en su entorno profesional y en la organización del trabajo. Como se muestra en la tabla 2.18, Bunk diferencia entre cuatro tipos de competencias distintas: técnica, metodológica, social y de cooperación. Buena parte de los contenidos de la clasificación coinciden con las demandas hechas desde la teoría de organización empresarial.

Tabla 2. 18 Competencias Según BUNK (1994)

\begin{tabular}{|c|c|c|c|}
\hline Técnica & Metodológica & Social & Participativa \\
\hline $\begin{array}{c}\text { Conocimientos, } \\
\text { Destrezas, Aptitudes }\end{array}$ & Procedimientos & $\begin{array}{c}\text { Formas de } \\
\text { Comportamiento }\end{array}$ & $\begin{array}{c}\text { Formas de } \\
\text { organización }\end{array}$ \\
\hline $\begin{array}{l}\text {-Trasciende los límites } \\
\text { de la profesión. } \\
\text {-Relacionada con la } \\
\text { profesión. } \\
\text {-Profundiza la profesión } \\
\text {-Amplía la profesión. } \\
\text {-Relacionada con la } \\
\text { empresa. }\end{array}$ & $\begin{array}{l}\text {-Procedimientos de } \\
\text { trabajo variable. } \\
\text {-Solución adaptada a la } \\
\text { situación. } \\
\text {-Resolución de } \\
\text { problemas. } \\
\text {-Pensamiento, trabajo, } \\
\text { planificación, realización } \\
\text { y control autónomos. } \\
\\
\text {-Capacidad de } \\
\text { adaptación. }\end{array}$ & $\begin{array}{l}\text { Individuales: } \\
\text {-Disposición al trabajo. } \\
\text {-Capacidad de } \\
\text { adaptación. } \\
\text {-Capacidad de } \\
\text { intervención. } \\
\text { Interpersonales: } \\
\text {-Disposición a la } \\
\text { cooperación. } \\
\text {-Honradez. } \\
\text {-Rectitud. } \\
\text {-Altruismo. } \\
\text {-Espíritu de equipo. }\end{array}$ & $\begin{array}{l}\text { Capacidad de: } \\
\text {-Coordinación. } \\
\text {-Organización. } \\
\text {-Relación. } \\
\text {-Convicción. } \\
\text {-Decisión. } \\
\text {-Responsabilidad. } \\
\text {-Dirección. }\end{array}$ \\
\hline
\end{tabular}

Fuente: Carrera, F. Universidad de Lleida.

Para Kellermann (2003), los seres humanos adquieren competencias a través del aprendizaje y las competencias específicas a través de la educación específica como el caso de la educación superior. De otro lado, para realizar una acción determinada, resolver una situación concreta se requieren competencias. Según crece la división social del trabajo, se requiere competencias especiales y profesionales para poder realizar los trabajos de una forma profesional y especializada, para ello define cuatro categorías de competencias: 
- $\quad$ Las habilidades intelectuales - académicas: Se refieren al dominio cognoscitivo de los seres humanos. Estas son capacidades básicas requeridas para el estudio apropiado y el trabajo profesional. Estas se desarrollan a través del aprendizaje y del trabajo ya sea estudiante o profesional titulado. No se refiere a los planes de estudio en concreto sino más bien corresponde a la parte oculta o subyacente de los planes de estudios académicos.

El conocimiento científico - experto: Pertenece al dominio cognoscitivo. Son los asuntos esenciales y centrales de cada plan formal de estudios universitarios. Vienen constituidos por la temática oficial de conferencias, seminarios y libros de texto, son aquellos asuntos de los que el alumno se examina y se titula.

Las habilidades profesionales - operativas se refieren a las habilidades psicomotrices o a los dominios y posibilidades físicas de una personalidad educada. Son competencias exigidas para cubrir las demandas físicas y operativas específicas de una profesión. Se adquieren en los ejercicios y prácticas que contienen los planes de estudios.

Se suelen relacionar las capacidades interactivas - sociales con competencias sociales y emocionales. Normalmente no es un asunto contenido en un plan de estudios formal, sin embargo pueden ser adquiridos mediante actos concretos en otras situaciones sociales y emocionales.

García-Aracil et al. (2004), proponen una clasificación más amplia, establecen ocho categorías diferentes de competencias: participativas, metodológicas, especializadas, aplicación de normas, físicas, genéricas, socioemocionales, organizativas.

En la línea del estudio de las competencias en el ámbito de la educación superior. El proyecto TUNING "Tuning Educational Structures in Europe", con el objetivo de ofrecer un planteamiento concreto que posibilitara la aplicación del proceso de Bolonia en el ámbito de las disciplinas o áreas de estudio y en el de las instituciones de educación superior de Europa, el proyecto realizó una clasificación de las competencias, para que sirvieran de referencia en el diseño y la evaluación de los planes de estudio. Las competencias genéricas clasificadas en instrumentales, interpersonales y sistémicas. Las competencias específicas son las que corresponden a cada área temática que incluyen las destrezas y el conocimiento. (González y Wagenaar, 2003).

En relación a las competencias que deben tener los profesionales y en particular los graduados universitarios, los autores a lo largo de los últimos años y como resultado de 
diversos proyectos e investigaciones, han discutido que tipo de competencias serían las necesarias para ocupar los puestos de trabajo en las áreas que se realizaron los estudios. La tabla 2.19 muestra una recopilación de algunas de estas clasificaciones.

Tabla 2. 19 Clasificación e Importancia de los Tipos de Competencias Profesionales

\begin{tabular}{|c|c|c|}
\hline Autor & Año & Clasificación Competencias \\
\hline Bowen & 1977 & $\begin{array}{l}\text { Importancia de las competencias genéricas frente a las } \\
\text { específicas. }\end{array}$ \\
\hline Bishop & 1995 & $\begin{array}{l}\text { Desarrollo de las competencias específicas frente a las } \\
\text { genéricas. }\end{array}$ \\
\hline $\begin{array}{c}\text { Heijke, Meng y } \\
\text { Ramaekers }\end{array}$ & 2003 & $\begin{array}{l}\text { Competencias específicas de la disciplina, } \\
\text { competencias genéricas que se consiguen mediante } \\
\text { educación inicial, competencias de gestión } \\
\text { desarrolladas en el contexto de trabajo del graduado. }\end{array}$ \\
\hline Boshuizen & 2004 & $\begin{array}{l}\text { Competencias específicas importantes para aumentar } \\
\text { la probabilidad de encontrar trabajo en el área de } \\
\text { estudio en la universidad. }\end{array}$ \\
\hline Vila & 2005 & $\begin{array}{l}\text { Competencias agrupadas en ocho categorías: } \\
\text { Organizativa, ejecutiva, instrumental, conocimiento } \\
\text { especializado, disciplina, físico-manual, conocimiento } \\
\text { genérico y cooperación. }\end{array}$ \\
\hline Kellerman & 2007 & $\begin{array}{l}\text { Competencias genéricas y académicas, competencias } \\
\text { científicas y operativas, competencias personales y } \\
\text { profesionales, competencias sociales y reflexivas, } \\
\text { competencias físicas y manuales. }\end{array}$ \\
\hline $\begin{array}{c}\text { García-Aracil y } \\
\text { Van der Velden }\end{array}$ & 2008 & $\begin{array}{l}\text { Competencias agrupadas en seis categorías: } \\
\text { Organizativa, metodológica, participativa, } \\
\text { conocimiento especializado, conocimiento genérico y } \\
\text { socio-emocionales. }\end{array}$ \\
\hline
\end{tabular}

Fuente: Elaboración propia a partir de Conchado, A. (2011).

De las clasificaciones de competencias, se puede concluir que no existe una única definición y que según el objetivo pueden existir diversas clasificaciones. Destaca de una forma general, la clasificación de las competencias genéricas y las competencias específicas; a partir de ellas la discusión está abierta, según el objetivo, el contexto y el tipo de análisis. En este sentido, algunos investigadores están de acuerdo cuando afirman que otras clasificaciones ad- 
hoc están hechas de acuerdo a la disponibilidad de datos y propósitos particulares (Allen y Van der Velden, 2001) y de la no existencia de acuerdo general en el ámbito teórico y empírico sobre la clasificación de competencias (Mora, García y Vila, 2005).

\subsubsection{El Rol Profesional de los Graduados en la Educación Superior}

Se hace difícil imaginar nuestro mundo sin considerar el papel que desempeñan los profesionales en las diversas capas y sectores de la sociedad actual. Para Perkin (1996), las profesiones han desempeñado un papel clave en los cambios de la historia moderna, una "revolución de los profesionales" o el "surgimiento de la sociedad profesional", en donde los servicios basados en el conocimiento son competencia de personal experto sin los cuales no existirían. El conocimiento profesional está basado en el capital humano, creado mediante una educación avanzada y una experiencia en el trabajo, y el mismo recurso escaso que permite a los profesionales altas rentas y reconocimientos en especie (Perkin, 1996).

De otro lado, las ciencias del comportamiento de manera reiterada han puesto de manifiesto que la vida laboral constituye uno de los roles más característicos de la etapa adulta en los seres humanos (Atchley, 1975; Bromley, 1966; Havighurst, 1982; Levinson, 1977 y Neugarten y Hagestad, 1976, entre otros). El rol laboral ha de iniciarse cuando las personas llegan a una determinada edad (Cain, 1976) y constituye tanto una exigencia como un síntoma de ajuste al sistema social y al sistema productivo todo lo cual tiene importantes repercusiones sobre los mecanismos de ajuste psicológico (Jahoda, 1987).

Diversos estudios afirman que las medidas de satisfacción con el trabajo tienden a mostrar relaciones con las medidas de satisfacción con la vida (Spector, 1997; Spector y Jex, 1991). Según Spector (1997) los empleados con mayor satisfacción con la vida suelen ser más cooperativos, ayudan más a sus compañeros, son más puntuales, gestionan mejor el tiempo, están menos tiempo de baja laboral y permanecen más tiempo en la organización. Además y de manera recíproca, los empleados que informan de más síntomas positivos de bienestar son evaluados como más competentes y eficientes por sus supervisores (Wright y Bonnet, 1997; Wright y Staw, 1999). Las organizaciones en las que la gente trabaja afectan a sus pensamientos, sentimientos y acciones fuera de él. Al mismo tiempo, los pensamientos, sentimientos y acciones de las personas influyen en las organizaciones en las que trabajan (Brief y Weiss, 2002). Para los autores mencionados, existe una influencia directa de un 
aspecto de la realidad organizacional sobre las dimensiones del bienestar subjetivo el afecto positivo, el afecto negativo y la satisfacción con la vida.

Al abordar la revisión de la literatura sobre el estudio del trabajo, puede afirmarse que el rol del profesional está relacionado con la autonomía (Friedson, 1994), experticia (Schön, 1983), cuerpo de conocimiento (Etzioni, 1969). La autonomía aquí no es la autonomía en el trabajo de los individuos sino la autonomía del grupo de profesionales para establecer reglas y regulaciones para su trabajo. Estas características están relacionadas con conceptos del estatus y el capital cultural (Bordieu y Passeron, 1977). La etiqueta constituye en el punto de vista de Foucault (1977) un recurso de retórica, y fuente de poder.

Recientes estudios sobre el trabajo profesional abordan temas sobre el cierre social, la exclusión, la movilidad, el discurso y la identidad, capital cultural, el poder y la clase. La tabla 2.20 resume algunos estudios relacionados. 
Tabla 2. 20 Estudios sobre el Trabajo Profesional

\begin{tabular}{|c|c|c|}
\hline Autor & Año & Tema de Estudio \\
\hline Brunetto, Y. & 2001 & $\begin{array}{l}\text { Impacto en la cultura organizacional a la respuesta de } \\
\text { grupos profesionales a los procesos de cambio. Poder y } \\
\text { autoridad. }\end{array}$ \\
\hline Squires, G. & 2001 & $\begin{array}{l}\text { El Management, disciplina profesional caracterizada por } \\
\text { complejas interacciones de las funciones, contingencias y } \\
\text { procesos. }\end{array}$ \\
\hline Kitchener, M. & 2000 & $\begin{array}{l}\text { La supervisión del trabajo profesional en las } \\
\text { organizaciones del sector público. }\end{array}$ \\
\hline Evetts. J. & 2002 & $\begin{array}{l}\text { Autonomía profesional y auto regulación a nivel de estado } \\
\text { y a nivel internacional. Poder de los grupos } \\
\text { ocupacionales. }\end{array}$ \\
\hline Dent, $\mathrm{M}$. & 2002 & \multirow[t]{3}{*}{$\begin{array}{l}\text { Estudios sobre los Profesionales de la salud (enfermeras, } \\
\text { médicos). Profesionalización, organización del trabajo, } \\
\text { autonomía, identidad profesional y vocación. }\end{array}$} \\
\hline Hallam, J. & 2002 & \\
\hline McLaughlin, J. & 2001 & \\
\hline Burrell, G. & 2002 & $\begin{array}{l}\text { Evolución de las profesiones durante el siglo XX: } \\
\text { Experiencia Angloamericana. Formación de grupos } \\
\text { profesionales asociados con el aumento de las } \\
\text { profesiones. }\end{array}$ \\
\hline Cohen, L. et al. & 2002 & $\begin{array}{l}\text { Las consecuencias en el trabajo profesional y la } \\
\text { reestructuración de las organizaciones en la sociedad } \\
\text { capitalista. }\end{array}$ \\
\hline Greenwood, R. & 2002 & $\begin{array}{l}\text { El papel de las asociaciones profesionales en la } \\
\text { transformación de los campos institucionalizados. }\end{array}$ \\
\hline Kärreman, D. et al. & 2002 & $\begin{array}{l}\text { Autonomía, auto regulación, honradez y la contribución } \\
\text { positiva/negativa al respeto dado a la profesión médica. }\end{array}$ \\
\hline Neal, M. and Morgan, J. & 2000 & $\begin{array}{l}\text { Comparativa del desarrollo histórico de las profesiones en } \\
\text { Reino Unido y Alemania. }\end{array}$ \\
\hline Sullivan, W. M. & 2000 & $\begin{array}{l}\text { La profesionalidad y la identidad profesional: Confianza } \\
\text { de la sociedad, responsabilidad moral, discreción y } \\
\text { prestigio de la profesión. }\end{array}$ \\
\hline
\end{tabular}

Fuente: Elaboración Propia 
Para Morrell (2004), en los análisis contemporáneos de las profesiones, no se integran conocimientos del estudio de tres esferas diferentes de interacción:

1. La manera en que el conocimiento profesional se construye como un elemento de una práctica discursiva (Abott, 1988; Foucault, 1977; Friedson, 1988; Katz, 1984 Joseph, 1994; McLaughlin, 2001; Mashaw, 1983).

2. La forma en que las funciones profesionales se negocian y construyen dentro y través de los límites organizativos (Exworthy y Halford, 1999, Forbes y Prime, 1999; Hudson, 1987; Lipsky, 1980; Minzberg, 1990; Thompson, 1967).

3. El papel que las profesiones desempeñan en la creación y el mantenimiento de los sistemas de valor y de poder (Althusser, 1969; Illich, 1970; Johnson, 1972; Macdonald, 1995; Nettleton, 1995).

El autor propone la construcción de los argumentos a partir del análisis de las ideas de cada esfera de interacción. El argumento del conocimiento que señala el carácter arbitrario de la experiencia profesional. El argumento de la organización que socava las reivindicaciones profesionales de la autoridad y el argumento del poder identificar como los grupos profesionales reflejan y refuerzan las desigualdades sociales.

El rol profesional desde el punto de vista de este trabajo, considerando el marco de las organizaciones sociales formales, no pretende abarcar todo el ámbito del estudio del trabajo sino que intenta desarrollar los aspectos más relevantes que tienen que ver directamente con el papel desempeñado por los graduados universitarios en el puesto de trabajo que ocupan dentro de las organizaciones y sus efectos en la satisfacción laboral. 


\subsection{Proyectos Internacionales CHEERS, REFLEX y PROFLEX}

Los proyectos internacionales de investigación que se describen a continuación, están basados en estudios de seguimiento de egresados universitarios, realizados por equipos de investigación en el marco de proyectos internacionales, interesados en conocer la situación de jóvenes egresados de las universidades, la opinión acerca de su experiencia universitaria y durante los primeros años como profesionales. El proyecto Careers After Higher Education An European Research Study (CHEERS), El Profesional Flexible en la Sociedad del Conocimiento: Nuevas exigencias de la educación superior en Europa (REFLEX) y la versión adaptada para Latinoamérica (PROFLEX).

\subsubsection{El Proyecto CHEERS “Careers after Higher Education_An European Research Study” \\ El proyecto CHEERS "Careers after Higher Education - An European Research Study", se} llevó a cabo entre 1998 y 2000. Alrededor de 37,000 graduados universitarios respondieron a una encuesta realizada en 9 países Europeos; Austria, Finlandia, Francia, Alemania, Italia, Países Bajos, España, Suecia, Reino Unido, Noruega, Republica Checa y Japón. Los graduados universitarios obtuvieron la titulación durante el año académico 1994/95, por lo tanto en el momento de la entrevista habían transcurrido cuatro años desde su graduación.

Los encuestados respondieron a diversas cuestiones, relacionadas con su entorno socioeconómico, trayectoria profesional, transición de la universidad al mercado laboral, primeros años de trabajo y relación entre los estudios y el empleo. De igual manera, se les preguntó por el nivel de satisfacción con su trabajo y la evaluación de sus estudios de educación superior.

El objetivo del proyecto CHEERS, es el análisis de la experiencia en el mercado laboral de los graduados de instituciones de educación superior durante los primeros años después de la graduación. En particular el objetivo se divide en las siguientes cuestiones:

El conocimiento profundo sobre cuestiones actuales de la educación superior y el mercado Laboral

Entorno socio-biográfico y carreras profesionales

Movilidad internacional

Carrera profesional de los graduados durante los primeros años

Identificación del impacto de la educación superior

Mejoras teóricas y metodológicas 
Estudio preliminar para la creación de una base de datos sobre inserción laboral y empleo en Europa.

La herramienta utilizada fue un cuestionario estándar enviado a cada uno de los graduados seleccionados entre la población de estudio. Con dicho método, fue posible incluir un gran número de graduados en cada país de una manera eficaz, y de esta forma obtener información comparable y representativa del empleo de los graduados universitarios. El desarrollo de los cuestionarios se basó en parte en los enfoques y las experiencias de anteriores trabajos de investigación realizados en distintos países de Europa. Los equipos de investigación en cada país contribuyeron a la conceptualización del estudio que finalmente reflejaron en el cuestionario definitivo.

Los temas principales de la encuesta fueron:

- Historial académico previo al ingreso a la universidad

- $\quad$ Carreras universitarias

- $\quad$ Búsqueda de trabajo e historial de actividades profesionales

- Trabajo actual

- $\quad$ Competencias profesionales y su aplicación

- $\quad$ Relaciones entre la educación superior y el trabajo actual

- Valoración y Satisfacción del trabajo

- $\quad$ Ampliación de estudios y formación

- Datos Socio-biográficos

Los resultados de este proyecto revelaron una marcada diversidad entre los diferentes países en lo referente a la educación superior y a los vínculos entre la educación superior y el empleo y el trabajo de graduados universitarios. Más allá de la sustantiva relevancia académica y política de sus resultados, el proyecto tuvo como objetivo proporcionar la base conceptual, metodológica e instrumental para realizar encuestas regulares a gran escala a graduados universitarios europeos y de otras latitudes, como así lo demuestran los proyectos de investigación REFLEX y PROFLEX, que se describen más adelante. 
El estudio CHEERS proporcionó por primera vez datos comparativos fiables. Haciendo uso de las potencialidades de estudio comparativo los resultados revelaron una marcada diversidad entre los diferentes países en lo referente a la educación superior y el empleo y el trabajo de graduados universitarios (Schomburg, 2002).

\subsubsection{El Proyecto REFLEX “El Profesional Flexible en la Sociedad del Conocimiento: Nuevas} exigencias de la educación superior en Europa"

Siguiendo en línea con el proyecto CHEERS, pero en este caso con objetivos más amplios que permitieron adaptar ideas, instrumento e instrumentos desarrollados en el CHEERS, se llevó a cabo el proyecto de investigación REFLEX ${ }^{10}$.

El estudio, llamado "El Profesional Flexible en la Sociedad del Conocimiento: Nuevas exigencias de la educación superior en Europa", más conocido como REFLEX, es una iniciativa que formó parte del 6o programa marco de la Unión Europea. Participaron universidades de catorce países que colaboraron en dicho proyecto: Italia, Francia, Austria, Alemania, Países Bajos, Reino Unido, Finlandia, Noruega, República Checa, Suiza, Bélgica, Estonia, España y Japón.

Una encuesta realizada durante los años 2005 y 2006 dirigida a los graduados del año académico 1999-2000. Como resultado se obtuvo una base de datos internacional con 40.787 registros (Allen y Van der Velden, 2011).

El proyecto REFLEX se centró en el análisis de las siguientes cuestiones:

- Las competencias que requieren los egresados para funcionar adecuadamente en la sociedad del conocimiento.

- $\quad$ El papel de los centros de educación superior para ayudar a los graduados universitarios a desarrollar las competencias.

- Las tensiones que surgen a medida que graduados universitarios, centros de educación superior, empresarios y otras figuras importantes se esfuerzan en alcanzar sus propios objetivos y formas de resolverlas.

\footnotetext{
${ }^{10}$ The Flexible Professional in the Knolowdge Society: REFLEX Project: Contract №: CIT2-CT-2004-506352.
} 
El proyecto, constituye una revisión de los mejores logros en el área de la educación superior y del empleo de graduados universitarios en Europa. Proporciona un marco conceptual en el que integrar ideas recientes tanto de teorías económicas como sociológicas y educativas. Este marco sirve de base para el análisis del rol de los graduados universitarios en la Sociedad del Conocimiento. Presta atención al tema de las desigualdades de género y proporciona información sobre la estructura de la educación superior y su posición relativa en el sistema educativo de cada uno de los países involucrados. Describe factores estructurales e institucionales relevantes como las condiciones generales del mercado laboral, los índices de participación en la educación superior y proporciona un análisis sobre la tendencia general en la integración de los recién graduados universitarios en el mercado laboral. Contiene los resultados de un estudio cualitativo sobre las competencias de los graduados universitarios en la Sociedad del Conocimiento.

La población de estudio fue definida como: Graduados universitarios que obtuvieron la titulación durante el curso académico 1999-2000 correspondiente al nivel ISCED 5A. Solo se incluyeron los graduados con titulaciones como Diplomados, Ingenieros Técnicos, Ingenieros Superiores, Licenciados, Arquitectos y Arquitectos Técnicos. La encuesta no incluye posgrados ni doctorados.

El instrumento clave utilizado en el estudio es una encuesta a graduados universitarios unos 4 años después de graduarse. Para llevar a cabo la recolección de la información, el cuestionario podía completarse mediante tres formas: on-line, por correo postal o entrevista telefónica.

El cuestionario constaba de varios apartados referidos a la experiencia educativa del graduado durante la universidad así como la experiencia de transición al mercado laboral, características de la organización y su trabajo actual.

A. Carrera en la que te graduaste en $1999 / 2000$

B. Otras experiencias en el ámbito educativo

C. Transición de los estudios al trabajo

D. Primer trabajo después de la graduación

E. Historial laboral y situación actual

F. Trabajo actual 
- $\quad$ G. Organización en la que trabajas

- H. Competencias

- $\quad$ I. Evaluación de la carrera

- J. Valores y orientaciones

- $\quad$ K. Información personal

El conjunto de datos obtenidos de esta encuesta es la fuente de información del presente trabajo.

\subsubsection{El Proyecto PROFLEX “El Profesional Flexible en la Sociedad del Conocimiento"}

El proyecto PROFLEX ${ }^{11}$ “El Profesional Flexible en la Sociedad del Conocimiento", nació a partir de la experiencia del proyecto REFLEX. Cofinanciado por la Unión Europea en el marco del programa ALFA II, y las universidades europeas y latinoamericanas pertenecientes a la red de socios del proyecto, que está compuesta por instituciones de trece países de ambos continentes.

La herramienta fundamental del proyecto es una encuesta que trata los aspectos cualitativos de la formación de los egresados en relación con su inserción laboral. Esta encuesta se aplicó en algunas universidades de Argentina, Brasil, Bolivia, Chile, Colombia, Honduras, México, Panamá, Puerto Rico y Uruguay (Mora, Carot y Conchado, 2010).

Gracias al trabajo realizado por las dieciséis universidades socias del proyecto y las treinta y cuatro que posteriormente se incorporaron voluntariamente, se obtuvo una base de datos de aproximadamente 10.000 egresados latinoamericanos graduados en el año 2002/2003, que aporta información sobre sus trayectorias educativas y profesionales, cinco años después de su graduación.

El primer objetivo del proyecto fue obtener resultados sobre la educación superior y el empleo de los graduados universitarios de Latinoamérica y poder establecer una comparación entre los países latinoamericanos participantes en el proyecto PROFLEX y los países europeos que participaron en el proyecto REFLEX.

Para ello, se hizo la réplica de la misma encuesta del proyecto REFLEX en las universidades latinoamericanas participantes. El equipo europeo coordinado por la

\footnotetext{
${ }^{11}$ El Profesional Flexible en la Sociedad del Conocimiento: proyecto PROFLEX-ALFA II-0546-A. http://www.seguimientoegresados.com/
} 
Universidad Politécnica de Valencia, proporcionó la encuesta, la metodología, la codificación, tratamiento de datos etc. (ya desarrolladas dentro del proyecto REFLEX) mientras que las universidades latinoamericanas se encargaron de gestionar la encuesta entre sus respectivos graduados.

Otros objetivos planteados por el proyecto son:

- $\quad$ Analizar el rol que desempeñan diversas aptitudes específicas y genéricas en las diferentes fases del trabajo y de la carrera profesional de los graduados universitarios.

- Proporcionar indicadores que sirvan como referencias internacionales y facilitar la comparabilidad del mercado laboral de graduados en Latinoamérica con resultados semejantes en países europeos y otros países desarrollados.

- $\quad$ Fortalecer la cooperación en el área de la educación superior y del empleo de graduados universitarios entre Europa y Latinoamérica.

- Desarrollar criterios para los instrumentos de investigación que puedan ser utilizados en el futuro por las universidades latinoamericanas.

La población de estudio fue definida como: Graduados universitarios que obtuvieron la titulación durante el curso académico 2002-2003 correspondiente al nivel ISCED 5A. Solo se incluyeron los graduados con titulaciones universitarias equivalentes en todos los países participantes. La encuesta no incluye posgrados ni doctorados.

Se diseñó una plataforma como un apoyo para gestionar la encuesta, de tal forma que los egresados latinoamericanos pudieran acceder a responderla por Internet mediante un formulario on-line. Se proporcionó una herramienta de codificación en línea a los equipos nacionales para codificar las profesiones, la industria, los campos de estudio e información geográfica según el estándar nacional de codificaciones, así como para proporcionar cualquier tipo de información.

El cuestionario constaba de varios apartados referidos a la experiencia educativa del graduado durante la universidad así como la experiencia de transición al mercado laboral, características de la organización y su trabajo actual. Los cambios se ajustaron a las diferencias de interpretación del idioma en cada país. 


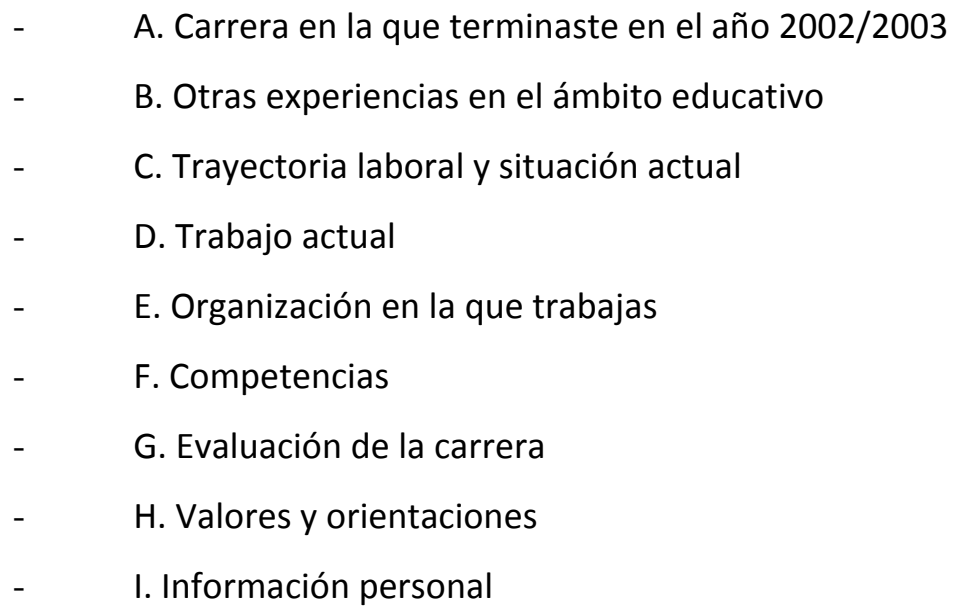

Se realizó un muestreo aleatorio estratificado, proporcional a la población por área de estudio y país (Conchado, 2011).

El conjunto de datos obtenidos de esta encuesta son la fuente de información del presente trabajo.

Otro proyecto que contiene idénticos objetivos y utiliza similar metodología de implantación, llamado Proyecto HEGESCO "Higher Education as a Generator of Strategic Competences", se aplica en los países del este de Europa: Eslovenia, Hungría, Polonia, Lituania y Turquía (Allen y Van der Velden, 2009; Pavlin, 2009). 


\subsection{Métodos Estadísticos}

Para abordar el objetivo planteado para este trabajo se han empleado diversas técnicas estadísticas de análisis univariado, bivariado y multivariado aplicados en las diferentes etapas en las que se ha requerido de su utilización como se muestra en la tabla 2.21 .

Tabla 2. 21 Técnicas estadísticas empleadas para el análisis de datos

\begin{tabular}{|c|c|}
\hline Análisis & Técnica \\
\hline $\begin{array}{c}\text { Caracterización de la muestra } \\
\text { de Graduados Universitarios }\end{array}$ & $\begin{array}{c}\text { Estadística descriptiva } \\
\text { unidimensional y } \\
\text { bidimensional. }\end{array}$ \\
\hline $\begin{array}{c}\text { Análisis de la estructura de los } \\
\text { datos. }\end{array}$ & Análisis Factorial. \\
$\begin{array}{c}\text { Identificación de factores } \\
\text { influyentes en el éxito } \\
\text { profesional }\end{array}$ & Análisis Bivariado. \\
Relaciones entre variables y \\
Comprobación de hipótesis \\
Correlación /Contraste de \\
hipótesis.
\end{tabular}

Fuente: Elaboración propia

\subsubsection{Análisis Descriptivo}

Con el objeto de identificar las características más relevantes de la muestra, el tratamiento analítico de los datos se desarrolla inicialmente utilizando las herramientas del análisis descriptivo y exploratorio: tablas de frecuencias, cálculo de parámetros que sinteticen la variabilidad observada (posición, dispersión, asimetría, etc.), estimadores de normalidad y representaciones gráficas como gráficos de barras, histogramas o diagramas de dispersión.

Para el estudio descriptivo de las variables bidimensionales de naturaleza cualitativa y cuantitativa, se puede lograr una buena caracterización mediante la construcción de tablas de frecuencias cruzadas y diagramas de dispersión respectivamente. Para cuantificar el grado de relación lineal existente entre dos variables se utilizan los parámetros de la covarianza y el coeficiente de correlación (Romero y Zúnica, 2005). 


\subsubsection{Análisis Factorial}

El análisis factorial, es una técnica multivariante que se aplica desde dos enfoques: el exploratorio (AFE) y el confirmatorio (AFC). El AFE es una técnica de construcción de conceptos a partir de datos o variables empíricas. Desde el punto de vista operativo se trata de seleccionar una serie de variables, bajo unos supuestos previos de relaciones (correlaciones) entre las mismas e intentar reducir ese número $p$ de variables observables a un número $k$ de factores o variables complejas que aglutinen toda la información compartida por las $p$ variables empíricas (Castro et al, 2000). Es una técnica de modelado cuyo objetivo es explicar la variabilidad de una matriz de datos por medio de estructuras simples (Lejeune, 1993).

El Análisis Factorial Confirmatorio, es una técnica en la que el investigador parte del supuesto de que la relación que vincula causalmente a las variables dependientes (observables o empíricas) con las variables independientes (factores) es única y por tanto no interviene otro tipo de factores (aparte los términos de error) en la determinación de las variables dependientes.

Teniendo en consideración el objetivo de este trabajo, se busca analizar las relaciones existentes entre las variables y los factores de forma individual, así como identificar la posible existencia de interacciones que afecten a las variables consideradas. Se ha seleccionado el análisis factorial exploratorio mediante componentes principales. Para su realización se ha tenido en cuenta algunos criterios que evalúan la adecuación de los datos para el AFE:

a. La medida de fiabilidad a través del Alfa de Cronbach, que indica fiabilidad de la escala de medición. Los valores de este coeficiente oscilan entre 0 y 1 y se considera mayor la consistencia de la escala en la medida que se acerca al valor de 1. Valores superiores a 0,6 pueden ser considerados aceptables para esta medición.

b. La medida de adecuación muestral de Kaiser-Meyer-Olkin (KMO), Contrasta si las correlaciones parciales entre las variables son pequeñas e indica si es aceptable para la realización del análisis factorial. Valores pequeños de KMO indican que las correlaciones entre los pares de variables no pueden ser explicadas por otras variables. Valores por debajo de 0,5 indican que no es aconsejable realizar el análisis factorial, los valores por encima de 0,7 son considerados aceptables.

c. La prueba de esfericidad de Barlett, busca evaluar si la matriz pueda ser factorizada o no. Contrasta si la matriz de correlaciones es una matriz identidad, que 
indicaría que el modelo factorial es inadecuado. Si $\chi^{2}$ resultara no significativo, entonces se debería aceptar la hipótesis nula $\left(\mathrm{H}_{\mathrm{o}}\right)$, renunciando a factorizar la matriz, porque las variables pueden considerarse como un conjunto de elementos no correlacionados.

\section{El modelo matemático del Análisis Factorial}

El AFE es un modelo de regresión lineal múltiple aplicado a múltiples variables dependientes. Se pretende predecir el valor de un conjunto $p$ de variables a partir de un conjunto $k$ de factores o variables latentes cuya influencia queda matizada por unos pesos $o$ cargas, incluyendo un término de error.

El término de error estará compuesto por la especificidad de las variables y la parte de su varianza correspondiente al error (Castro, 2000).

La ecuación fundamental del análisis factorial tiene la siguiente representación general:

$$
\begin{aligned}
& Y_{1}=a_{11} F_{1}+a_{12} F_{2}+a_{13} F_{3}+\cdots+a_{1 k} F_{k}+U_{1} d_{1} \\
& Y_{2}=a_{21} F_{1}+a_{22} F_{2}+a_{23} F_{3}+\cdots+a_{2 k} F_{k}+U_{2} d_{2} \\
& Y_{3}=a_{31} F_{1}+a_{32} F_{2}+a_{33} F_{3}+\cdots+a_{3 k} F_{k}+U_{3} d_{3} \\
& Y_{p}=a_{p 1} F_{1}+a_{p 2} F_{2}+a_{p 3} F_{3}+\cdots+a_{p k} F_{k}+U_{p} d_{p}
\end{aligned}
$$

O bien:

$$
Y_{i}=\sum_{j=1}^{k} a_{i j} F_{j}+U_{i} d_{i}
$$


Esta ecuación, al igual que el sistema de ecuaciones puede expresarse también en forma matricial como sigue:

$$
Y=A F+U D
$$

Dónde:

$Y=\left\{Y_{1}, Y_{2}, Y_{3}, \ldots ., Y_{p}\right\}$ es el vector de puntuaciones en las variables observadas, que se consideran tipificadas o estandarizadas.

$\mathrm{F}=\left\{\mathrm{F}_{1}, \mathrm{~F}_{2}, \mathrm{~F}_{3}, \ldots, \mathrm{F}_{\mathrm{K}\}}\right.$ es el vector de las variables latentes o factores comunes.

A es la matriz $p \times k$ de pesos o saturaciones de las variables en los factores.

$\left\{a_{i j}\right\}$ es el peso de la variable i en el factor $\mathrm{j}$.

$\mathrm{U}=\left\{\mathrm{u}_{1}, \mathrm{U}_{2}, \mathrm{U}_{3}, \ldots ., \mathrm{u}_{\mathrm{p}}\right\}$ es el vector de pesos o contribuciones de los factores específicos.

$D=$ Es la matriz diagonal con las saturaciones de los factores únicos.

Desde el punto de vista del investigador, los factores comunes son los únicos que tienen interés y son susceptibles de interpretación experimental. La imposibilidad de expresar $\mathrm{n}$ variables en función de un número reducido $\mathrm{m}$ de factores comunes, es la razón por la que se incluyen los factores únicos en el modelo (Conchado, 2011).

En los modelos ortogonales de análisis factorial se imponen las siguientes condiciones a los factores:

Tipificación: Los factores comunes $\left(F_{j}\right)$ y los únicos $\left(U_{i}\right)$ son variables de media 0 y desviación típica 1.

Ortogonalidad: Los factores están incorrelacionados entre sí. La ausencia de correlación se mide mediante la covarianza, cuyo valor es 0 en caso de independencia.

Al asumir las condiciones de tipificación y ortogonalidad a los modelos, es posible descomponer la varianza de cada variable de la siguiente forma (Álvarez, 2000). Partiendo de la expresión para cada variable observada $Y_{i}$ :

$$
Y_{i}=a_{i 1} F_{1}+a_{i 2} F_{2}+a_{i 3} F_{3}+\cdots+a_{i k} F_{k}+U_{i} d_{i}
$$


Se obtiene al calcular momentos:

$$
\operatorname{Var}\left(Y_{i}\right)=a_{i 1}^{2} \operatorname{Var}\left(F_{1}\right)+a_{i 2}^{2} \operatorname{Var}\left(F_{2}\right)+a_{i 3}^{2} \operatorname{Var}\left(F_{3}\right)+\cdots+a_{i k}^{2} \operatorname{Var}\left(F_{k}\right)+d_{i}^{2} \operatorname{Var}\left(U_{i}\right)
$$

Al estar tipificados tanto las variables como los factores, sus varianzas son todas igual a 1 . Con ello:

$$
\operatorname{Var}\left(Y_{i}\right)=a_{i 1}^{2}+a_{i 2}^{2}+a_{i 3}^{2}+\cdots+a_{i k}^{2}+d_{i}^{2}
$$

Dónde:

$$
\begin{gathered}
1=\sum_{j=1}^{k} a_{i j}^{2}+d_{i}^{2} \\
1=h_{i}^{2}+d_{i}^{2}
\end{gathered}
$$

Siendo, para cada variable $Y_{i}$

$h_{i}^{2} \quad$ la comunalidad de la variable. Parte de la varianza de una variable que es explicada por los factores comunes.

$d_{i}^{2} \quad$ la unicidad de la variable. Parte de la varianza de una variable que no es explicada por los factores comunes sino por el factor único.

La comunalidad varía de 0 a 1, indicando el cero que los factores comunes explican nada de la varianza de la variable, y 1 que toda la varianza de la variable está explicada por los factores comunes.

El modelo queda solucionado cuando se obtienen los coeficientes $a_{i j}$, denominados saturaciones, los cuales tienen naturaleza de coeficiente de correlación entre la variable $Y_{i}$ y el factor $F_{j}$.

Aunque teóricamente válido, el análisis factorial común tiene varios problemas. En primer lugar, adolece de indeterminación de factores. Significa que para cualquier encuestado individual, se puede calcular varias puntuaciones de factores diferentes a partir de los resultados del modelo factorial. La segunda cuestión se refiere al cálculo de las varianzas 
compartidas estimadas que se usan para representar la varianza compartida. Cuando se utilizan muestras de gran tamaño se requieren recursos sustanciales de ordenador. Las complicaciones del análisis factorial común han contribuido al uso generalizado del análisis de componentes principales (Hair et al., 2008).

Rotación de factores: En ocasiones, la solución que se ofrece tras un AFE inicial propone la constitución de unos factores cuyas cargas o saturaciones en determinadas variables son muy parecidas, por lo que arrojan resultados ambiguos, difíciles de interpretar. Para corregirlo, Thurstone $(1931,1945)$ propuso tres criterios que cumpliría un AFE que se ajustase a los requisitos de la "estructura simple":

- $\quad$ Cualquier columna de la matriz factorial debe tener muchos de sus elementos próximos a 0 , y el resto lo más alto posible.

- $\quad$ Una fila determinada de la matriz factorial, es decir, el vector de cargas de una variable a lo largo de los factores, debe contener pocos elementos de alto valor.

Dos columnas cualesquiera de la matriz, o sea, dos factores cualesquiera deben mostrar una distribución diferente de las cargas altas y bajas.

La rotación de factores facilita conseguir un resultado que se ajusta mejor a los criterios de una estructura simple, con lo que se obtiene una nueva matriz de coeficientes o saturaciones (Castro, 2000).

La rotación de los factores significa que giran en el origen los ejes de referencia de los factores hasta alcanzar una determinada posición. Las soluciones factoriales no rotadas extraen factores según su orden de importancia. El primer factor tiende a ser un factor general por el que casi toda variable se ve afectada significativamente dando cuenta del mayor porcentaje de varianza. La rotación ortogonal, es aquella en la que los ejes se mantienen formando un ángulo de 90 grados entre los ejes de referencia. Cuando no se limita a ser ortogonal, la rotación se denomina oblicua (Hair, 2008). 


\section{Análisis de Componentes Principales}

El método de componentes principales se basa en los trabajos de Pearson (1901) junto con las adaptaciones específicas al análisis factorial sugeridas por Hotelling (1933). Este método transforma un conjunto de variables correlacionadas (variables observables) en otro conjunto de variables incorrelacionadas (componentes principales). Se trata de obtener unas nuevas variables, denominadas componentes, como combinación lineal de las variables observadas:

$$
C_{i}=\sum_{j=1}^{n} u_{i j} X_{j}
$$

Para ello se tiene en cuenta:

- la tipificación de las variables observadas: $X_{i}(0 ; 1) \quad i=1,2,3, \ldots, n$

- la ortogonalidad de las componentes: $\operatorname{CoV}\left(C_{i}, C_{j}\right)=0 \quad i \neq j$

- La primera componente, $\mathrm{C}_{1}$ explica la mayor parte posible de la varianza total de las variables observadas; la segunda componente la mayor parte posible de la varianza remanente; $y$ así sucesivamente hasta explicar la varianza total.

El procedimiento equivale al cálculo de los valores y vectores propios de la matriz de correlaciones (Cuadras, 1991).

Es posible calcular tantas componentes como variables observadas, aunque si se utilizan las $n$ posibles no se obtiene beneficio alguno del método. La interpretación de los componentes resultantes, se logra estudiando la correlación que presentan con las variables observadas (Álvarez, 2000). Por ello, se seleccionan solo los factores que más información recogen, usando para ello el autovalor como criterio de decisión.

En el análisis de componentes principales el producto final es una matriz transformada, cuyas columnas son los vectores propios de la matriz de correlaciones y que define los componentes principales como una combinación lineal de las variables observadas (Vidal Díaz de Rada, 2002).

En esta investigación el análisis factorial con componentes principales ha sido empleado para identificar variables latentes que reduzcan la considerable cantidad de 
variables observadas, facilitando el análisis y permitiendo una mejor interpretación de los resultados.

\subsubsection{Análisis Bivariado}

Para estudiar las relaciones entre pares de variables se utilizan los estadísticos de correlación (Cuesta, 2003; Moreu, 1999).

El análisis de correlación tiene por objetivo estudiar y cuantificar el grado de ajuste de cierto modelo al conjunto de puntos correspondientes a la población o muestra observada. En el caso de considerar una variable independiente, $y=f(x)$, se utiliza el análisis de correlación simple y en el caso de más de una variable independiente, $y=f(x, z, v, .$.$) el análisis de$ correlación múltiple (Álvarez, 2000). Para el objetivo del presente trabajo, los coeficientes de mayor frecuencia de utilización, son el Coeficiente de correlación lineal de Pearson y el coeficiente de correlación de Spearman.

\subsubsection{Cálculo del Coeficiente de Correlación de Pearson $\left(\rho_{x y}\right)$.}

Para el cálculo de las correlaciones observadas, el coeficiente de Pearson puede estimarse para grandes muestras mediante la fórmula:

$$
r=\frac{\sum(x-\bar{x})(y-\bar{y})}{(n-1) S_{x} S_{y}}
$$

El coeficiente varía de -1 a +1 , siendo la interpretación de los extremos y su signo la siguiente:

$r=+1 \quad$ Ajuste lineal perfecto entre las variables. Aumentos positivos de la variable independiente se corresponden con aumento positivos de la variable dependiente.

$r=-1 \quad$ Ajuste lineal perfecto entre las variables. El signo negativo indica que al ocurrir incrementos positivos de la variable independiente, se producen decrementos de la variable dependiente.

$r=0 \quad$ Ausencia de relación lineal entre las variables. 
Habitualmente se interpreta este coeficiente en términos de porcentaje de la siguiente forma:

$(r)^{2} * 100 \%=\%$ de la variación de la variable dependiente que viene explicado por la variación de la variable independiente, a través de la recta de regresión.

Para verificar el grado de significación del coeficiente de correlación lineal de Pearson, se somete a $r$ a la prueba de verificación de la hipótesis nula (Ho: $\rho=0$ ). En este caso se afirma que la correlación entre las variables de la población no difiere significativamente de cero.

Para pruebas con un tamaño muestral superior o igual a $30(n \geq 30)$, el estadístico de prueba sigue la distribución $\mathrm{N}(0 ; 1)$ y se define como:

$$
Z=\frac{r}{S_{r}}
$$

Donde,

$r$, es el valor del coeficiente de correlación lineal de Pearson obtenido por los n pares observados.

$\mathrm{S}_{\mathrm{r}}$, es el error típico o desviación típica de $\mathrm{r}$, definido como: $S_{r}=\frac{1}{\sqrt{n-1}}$

Una vez fijado el nivel de confianza, $1-\alpha$, con el que se desea verificar Ho, se determina la región de aceptación en la curva de la distribución que sigue el estadístico de prueba.

Este coeficiente de correlación de Pearson es adecuado cuando las variables implicadas son cuantitativas.

\subsubsection{Cálculo del Coeficiente de correlación de Spearman.}

Si las variables observadas $x$ e $y$, son rangos o valores de orden (secuencia de números naturales consecutivos, de 1 a $n$ observaciones) el coeficiente de Pearson no es adecuado y la correlación entre ambas series de rangos se mide a través del Coeficiente de Correlación de Spearman, el cual se calcula a partir de la fórmula siguiente (Álvarez, 2000): 


$$
r_{s}=1-\frac{6 \sum d_{i}^{2}}{n\left(n^{2}-1\right)}
$$

Donde,

$d_{i}$, es a diferencia para la observación $\mathrm{i}$, entre el rango de $x$ y el rango de $y$.

$n \quad$ es el número de observaciones

Interesa más la situación respecto al grupo, los rangos, que las puntuaciones observadas en sí.

Este coeficiente es considerado una versión no paramétrica del coeficiente de correlación lineal de Pearson, por lo que también varía de -1 a +1 , teniendo una interpretación similar:

$$
\begin{aligned}
& r_{s}=+1 \text { Correlación entre rangos perfecta y del mismo sentido } \\
& r_{s}=-1 \text { Correlación entre rangos perfecta y de signo opuesto }
\end{aligned}
$$

Se puede también realizar una prueba de significación para los coeficientes de correlación de Spearman, a fin de asegurar que el valor obtenido difiere significativamente de cero. Para ello hay varios métodos alternativos.

Un método aproximado frecuentemente usado parte de que el estadístico:

$$
t=\frac{\rho}{\sqrt{\left(1-\rho^{2}\right) /(n-2)}}
$$

Sigue una distribución $t$ de Student con $n-2$ grados de libertad, donde $\mathrm{n}$ es el tamaño de la muestra.

\subsubsection{Valoración de la magnitud de la correlación.}

Además de la significación del coeficiente de correlación, es decir de la valoración de si difiere significativamente de cero, resulta muy importante la discusión sobre el valor del coeficiente y su relevancia de cara a la utilización del mismo. 
No hay una respuesta única y definitiva cuando se valora si un coeficiente de correlación es suficientemente alto. Sin embargo es posible ofrecer orientaciones para valorar la magnitud de los coeficientes. Como criterio orientador pueden encontrarse diversas valoraciones en obras como Morales (1988), quien plantea que como criterio orientador (sin convertirlo en norma) se suelen sugerir las valoraciones indicadas en la tabla 2.22.

Tabla 2. 22. Magnitudes de Correlación ( $r$ )

\begin{tabular}{|c|c|}
\hline Un valor de r entre: & Indica una relación: \\
\hline 0 y $.20 \ldots \ldots \ldots \ldots \ldots \ldots \ldots \ldots \ldots$ & muy baja \\
\hline .20 y $.40 \ldots \ldots \ldots \ldots \ldots \ldots \ldots$ & baja \\
\hline 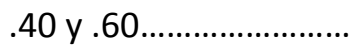 & moderada \\
\hline .60 y $.80 \ldots \ldots \ldots \ldots \ldots \ldots \ldots$ & apreciable, más bien alta \\
\hline 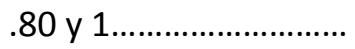 & alta o muy alta \\
\hline
\end{tabular}

Fuente: Morales (2008).

Las valoraciones suelen darse considerando únicamente la magnitud, pero una correlación baja puede tener también interés interpretativo (Morales, 2008).

Cohen (1988), establece (y justifica) como criterio orientador estas valoraciones: correlación pequeña $r=.10$, media $r=.30$ y grande $r=.50$. Basa sus valoraciones en que en las ciencias de la conducta las correlaciones suelen ser bajas.

Se pueden hacer varias consideraciones de interés respecto al uso e interpretación de los coeficientes de correlación.

a) Una correlación no significativa o simplemente muy baja, puede ser tan informativa e interesante como una correlación alta. El descubrir una no relación puede tener tanto interés como verificar que si existe relación.

b) Las correlaciones muy bajas a veces se deben no a que la relación es efectivamente baja, sino a que se miden mal las variables, con instrumentos poco precisos que no detectan bien las diferencias entre sujetos, etc. En un cuadro general de coeficientes más bien bajos, obtenidos con instrumentos semejantes y en un mismo planteamiento de investigación, pueden destacar los coeficientes altos en términos relativos. 
Los coeficientes bajos aunque sean estadísticamente significativos, cuesta interpretarlos adecuadamente, dado que los coeficientes altos o moderadamente altos no suelen ser problema para el investigador.

La primera observación sobre los coeficientes muy bajos (.30 y menores), es que simplemente expresan que la relación entre dos variables (tal como se han medido) es muy pequeña. Con muestras grandes es normal encontrar correlaciones estadísticamente significativas pero tan pequeñas que pueden ser prácticamente irrelevantes. Aun así estos coeficientes pequeños pueden dar información útil o dan pistas sobre la razón de no encontrar una relación apreciable donde cabría esperarla.

Algunos autores como Cohen (1981); Cohen (1988) entre otros hacen la misma observación: Una correlación de .30 (aparentemente baja) viene a indicar el tipo de relación que un observador puede detectar casualmente; es una relación detectable a simple vista y ciertamente relevante. Cohen, J. (1988) cita coeficientes de correlación importantes que son de esta magnitud (.30).

Hay que tener en cuenta la situación y el uso del coeficiente. Un valor pequeño (por ejemplo $r=.20$ ) puede ser poco útil (o nada útil) con fines predictivos, y ser sin embargo de interés en una investigación teórica, donde a veces lo que interesa es constatar si se da alguna relación. Estas consideraciones sobre los coeficientes pequeños de correlación hay que complementarlas con otras sobre las posibles causas de estos valores bajos, sobre todo si cabría esperar que fueran mayores.

Una correlación baja puede significar simplemente eso, que la relación entre dos variables es pequeña. Sin embargo una correlación baja donde hubiéramos esperado un valor mayor invita a preguntarnos el porqué de esa correlación baja o nula. A continuación se enumeran algunas posibles explicaciones:

a) Poca fiabilidad o poca precisión en los instrumentos de medición: Entre dos variables puede haber una verdadera relación, pero no detectable si medimos con poca precisión, sin diferenciar adecuadamente unos sujetos de otros. Hay que tener en cuenta que en ocasiones se intenta medir sentimientos profundos, recuerdos del pasado, valoraciones difíciles de hacer con preguntas sencillas. Quizás no hay otra manera mejor de hacerlo en un momento dado pero en cuanto instrumentos de medición resultan pobres (aunque puedan ser muy útiles).

b) Homogeneidad de la muestra: La relación verificada (que es lo que indica el coeficiente de correlación) supone diferencias entre los sujetos en las variables cuya relación 
nos interesa comprobar. Con muestras muy homogéneas los coeficientes son bajos; con muestras heterogéneas es más fácil detectar relaciones.

c) Instrumentos poco discriminantes: Puede suceder que el poco matiz de algunas medidas no recoge las diferencias que de hecho se dan, e impide encontrar coeficientes de correlación altos. Se trata de limitaciones en el instrumento de medida. Con frecuencia se da el caso cuando se pretende medir una de las variables cuyos valores apenas se diferencian. Otro ejemplo se da cuando se mide una variable con unas preguntas que admiten pocas respuestas y por tanto no recogen la diversidad que de hecho puede estar presente en la muestra. 



\section{PARTE II}

\section{CAPITULO 3}

\section{Modelo e Hipótesis de la Investigación}

A partir del análisis teórico que se realizó en el capítulo dos, se estructuró el presente modelo de investigación. Este capítulo recoge los principales aspectos relacionados con los objetivos de la investigación, modelo e hipótesis.

El objetivo principal de esta investigación es analizar la influencia que tienen sobre el éxito laboral, los valores laborales, las competencias y el rol desempeñado por los profesionales universitarios en las organizaciones donde ejercen su actividad. Para ello se dispuso de los resultados de dos encuestas realizadas a graduados universitarios de Europa y Latinoamérica, cinco años después de su graduación.

\subsection{Descripción del Modelo de Investigación}

\subsubsection{Proceso de obtención de la hipótesis}

Según Black y Champion (1976), una hipótesis es diferente de la afirmación de un hecho. En el ámbito de la investigación científica las hipótesis son proposiciones tentativas acerca de las relaciones entre dos o más variables, y se apoyan en conocimientos organizados y sistematizados. Las variables adquieren valor para la investigación científica cuando llegan a relacionarse con otras variables, es decir, si forman parte de una hipótesis o teoría (Hernández, 2006). La tabla 3.1 presenta el punto de partida del modelo de la investigación. 
Tabla 3. 1 Factores del Modelo de Análisis

\begin{tabular}{|c|l|}
\hline Factor Dependiente & \multicolumn{1}{|l|}{ Factores Independientes } \\
\hline & - Valores laborales \\
Éxito Laboral & - Competencias \\
& - Rol (Funciones) \\
\hline
\end{tabular}

\subsubsection{Modelo de investigación}

A la luz de los trabajos referenciados en la revisión del marco teórico (sección 2.1) se elabora la presente propuesta.

El modelo de esta investigación pretende analizar, como actúan las posibles causas o factores independientes (valores laborales, competencias propias del individuo, competencias requeridas por las organizaciones y el rol entendido como el papel que se desempeña desde el puesto de trabajo); sobre determinado fenómeno o factor dependiente (Éxito Laboral).

La figura 3.1 muestra el modelo básico sobre el que se trabajó.

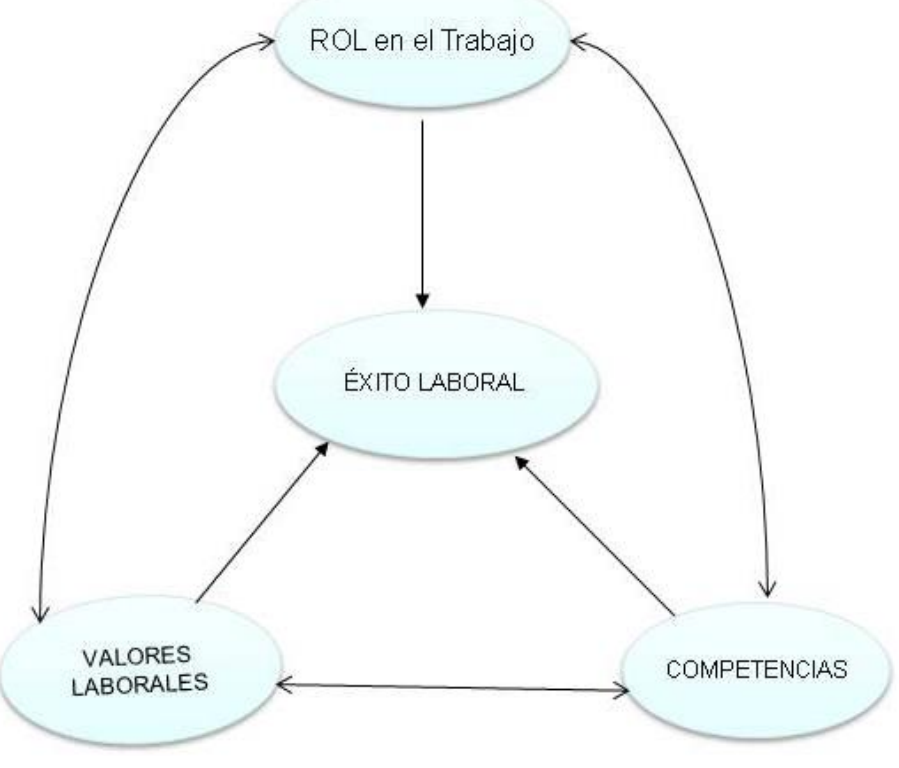

Figura 3. 1 Modelo de Investigación 


\subsection{Planteamiento de la hipótesis}

En este apartado se realizará el planteamiento de las hipótesis de trabajo. La naturaleza del modelo de investigación es relacional y por ende las hipótesis del trabajo. En este tipo de hipótesis solo se enuncia una posible relación entre las variables y su intensidad, pero sin especificar una dirección de la relación. El orden de las variables no influye en la significación de la hipótesis. Es lo mismo indicar "a mayor $x$, menor $y$ " que "a menor $y$, mayor x" (Sarabia, 2013).

\subsubsection{Hipótesis General}

Las hipótesis surgen del planteamiento del problema, después de una concienzuda revisión de la teoría. Son la guía de la investigación, indican lo que se intenta probar y se definen como explicaciones tentativas del fenómeno investigado. De hecho son respuestas provisionales a las preguntas de investigación. Existe pues, una relación entre el planteamiento del problema, la revisión de la literatura y las hipótesis (Hernández et al., 2010).

La figura 3.2 representa el modelo de análisis, en él se recogen las seis relaciones que se han identificado y representan las hipótesis específicas de la investigación. El objetivo por lo tanto, es identificar si la existencia de relación entre los valores laborales, las competencias y el rol desempeñado, en conjunto favorecen el éxito de los profesionales universitarios en las organizaciones donde ejercen su actividad.

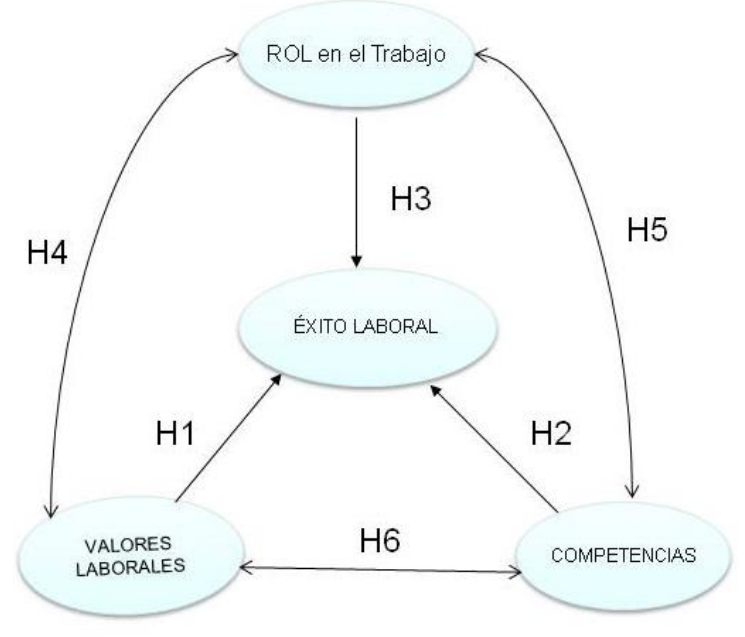

Figura 3. 2 Modelo de Investigación (Hipótesis) 


\subsubsection{Hipótesis específicas}

H1: El éxito laboral de los profesionales universitarios está relacionado con la importancia que dan a sus valores (Arthur et al. 2006, Bravo et al. 2002; Cavalcante, 2004, Van Maanen, 1977).

H1a: El éxito laboral de los profesionales universitarios está condicionado por la importancia personal que dan a los valores laborales.

H1b: El éxito laboral de los profesionales universitarios está condicionado por el grado de aplicación de los valores laborales en el trabajo.

H1c: El éxito laboral de los profesionales universitario está relacionado con el ajuste entre los valores laborales personales y los valores laborales en el trabajo.

H2: El éxito laboral de los profesionales universitarios tiene relación con las competencias personales y las competencias requeridas en el trabajo (Busato, Prins, Elshout y Hamaker, 2000; Heijke, Meng y Ramaekers, 2002).

H2a: El éxito laboral de los profesionales universitarios se ve favorecido por sus competencias personales.

H2b: El éxito laboral de los profesionales universitarios tiene relación con el nivel de competencias requeridas en el trabajo.

H2c: El éxito laboral de los profesionales universitarios se ve favorecido por el ajuste entre las competencias propias y las requeridas por las organizaciones

H3: La satisfacción laboral de los graduados universitarios está relacionada con el rol que desempeñan dentro de las organizaciones (Gamero 2005; García, 2005; Seibert et al. 1999).

H4: El rol de los profesionales universitarios está relacionado con la importancia que dan a sus valores laborales (Schwartz, 2001; Valls y Martínez, 2004).

H4a: El rol de los profesionales universitarios está relacionado con la importancia personal que dan a sus valores laborales.

H4b: El rol de los profesionales universitarios está relacionado con la importancia personal que dan a sus valores laborales en el trabajo. 
H5. El rol de los profesionales universitarios en las organizaciones está relacionado con las competencias personales y las competencias requeridas por la organización (Allen y de Weert, 2007; Teichler y Schomburg, 2007).

H5a: El rol de los profesionales universitarios en las organizaciones está relacionado con las competencias personales.

H5b: El rol de los profesionales universitarios en las organizaciones está relacionado con el nivel de competencias requerido en el trabajo.

H6. Los valores laborales de los profesionales universitarios en el trabajo están relacionados con las competencias requeridas por la organización (Cortes, 2009; Song y Gale, 2008).

El modelo propuesto queda representado en la figura 3.3.

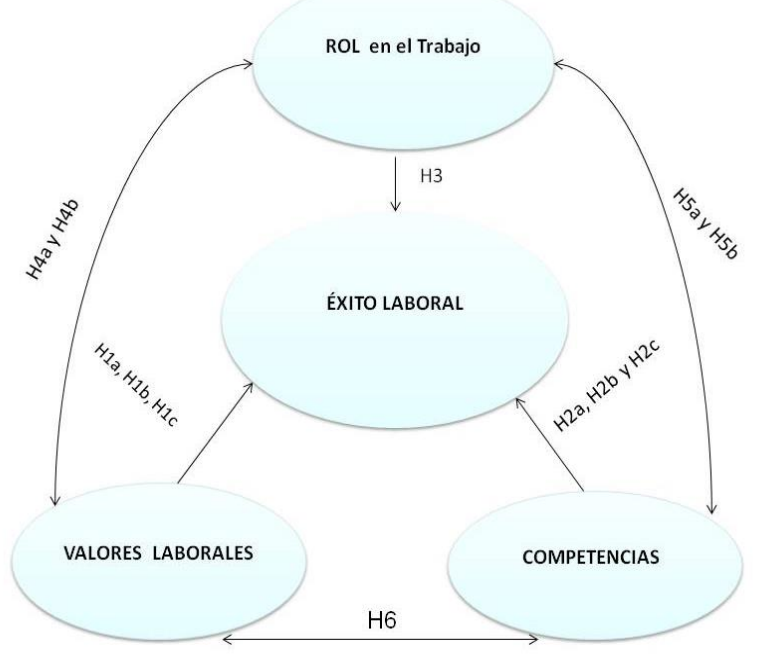

Figura 3. 3 Modelo Propuesto 



\section{CAPITULO 4}

\section{Metodología y Diseño de la Investigación}

\subsection{Metodología de la investigación}

En este capítulo se detallan las cuestiones sobre metodología y el diseño de la investigación de forma que esté en concordancia con el modelo propuesto en el capítulo 3. Basados en el método científico ${ }^{12}$, se utilizan diversas estrategias de investigación, técnicas de consulta y análisis de datos que permiten la validación del modelo de investigación y la comprobación de las hipótesis. Se hace una descripción de la muestra de profesionales universitarios de Europa y Latinoamérica encuestados cinco años después de su graduación, las fuentes de datos y el marco en el que fue realizada la encuesta, así como la definición de las variables y escalas de medida para el análisis de datos y las técnicas estadísticas utilizadas.

\subsubsection{La Investigación}

De acuerdo a las diversas alternativas bajo los cuales es posible abordar y estudiar un campo de las ciencias sociales con la ayuda del método científico, en esta tesis se sigue una filosofía positivista, en cuanto se asume que la realidad y los hechos existen separados de nuestra observación y que podemos conocer la realidad de forma empírica a través de la observación (Montoro, 2004).

La naturaleza de esta investigación es principalmente cuantitativa en cuanto que los planteamientos a investigar son específicos y delimitados desde el inicio del estudio. Las hipótesis se establecen previamente, esto es, antes de recolectar y analizar los datos. La recolección de los datos se fundamenta en la medición y el análisis mediante procedimientos estadísticos. Se aplica la lógica deductiva, que va de la teoría generada por las investigaciones antecedentes "marco teórico" a la recolección de los datos en los casos particulares de una muestra. Brinda además, la posibilidad de réplica y un enfoque sobre los puntos específicos de los fenómenos, además que facilita la comparación entre estudios similares (Hernández, 2006).

\footnotetext{
${ }^{12}$ El Método Científico es un conjunto de procedimientos por los cuales se plantean los problemas científicos y se ponen a prueba las hipótesis y los instrumentos de trabajo investigativo (Tamayo, 2001).
} 
Desde el punto de vista epistemológico, la generación de conocimiento se construye siguiendo dos tipos de método: El constructivista en donde el conocimiento se construye como resultado de la interacción entre quien investiga (sujeto) y lo que se investiga (objeto). El determinista es un método en el que el conocimiento se construye sobre teorías y leyes ya existentes, siguiendo un método lógico para dar respuesta a lo que se investiga (Castellanos, 2006). Conforme al método determinista, en esta tesis se formulan las hipótesis sobre la base de la literatura y haciendo uso de un método deductivo y lineal, se evalúan y comprueban, dando lugar a un nuevo conocimiento sobre el objeto de estudio.

La contribución al conocimiento y desarrollo científico, tiene lugar según el tipo investigación: descriptiva, exploratoria, correlacional y explicativa. En la práctica, cualquier investigación puede incluir elementos de más de uno de estos alcances de investigación. Los estudios exploratorios sirven para preparar el terreno y por lo común anteceden a investigaciones con alcances descriptivos, correlaciónales o explicativos. La investigación descriptiva solo se ocupa de caracterizar las variables que representan a un sujeto, objeto o fenómeno real. Por lo general es la base de las investigaciones correlaciónales, las cuales a su vez proporcionan información para llevar a cabo estudios explicativos, que generan un sentido de entendimiento altamente estructurados (Hernández, 2010).

Esta tesis es una investigación exploratoria porque ayuda a entender la naturaleza general del problema haciendo una revisión general de éste (Miquel, 1997). Es una investigación descriptiva porque se especifican las características y los perfiles del objeto de estudio que se somete a análisis. Su valor está en que permite mostrar las dimensiones de un fenómeno, contexto o situación. Se emplean métodos cuantitativos apoyados en la estadística para resolver algunas de las preguntas planteadas.

En esencia, es de carácter correlacional, su finalidad es conocer la relación y grado de asociación que existe entre dos o más conceptos, categorías o variables en un contexto particular. Con ella se analiza la medida del éxito laboral con el rol, las competencias y los valores laborales de los graduados universitarios de Europa y Latinoamérica en los puestos de trabajo que ocupan, cinco años después de la finalización de sus estudios. Se verifica si existe una relación significativa entre estos constructos; se determina si la relación entre las variables está influida por terceras variables intercorrelacionadas. 


\subsubsection{Estrategias de Investigación}

Para la realización de esta tesis, se han utilizado las siguientes estrategias de investigación para el estudio del rol de los graduados universitarios de Europa y Latinoamérica en las organizaciones, cinco años después de su graduación.

\section{- Las Fuentes de Información}

Utilizadas para recoger y analizar la información teórica y empírica publicada con anterioridad por otros investigadores y entidades, con relación al objeto de estudio. Para ello se ha contado con la red de expertos que aportan conocimiento en aspectos puntuales y el soporte de personas con experiencia en investigación. Profesores de la Universidad Politécnica de Valencia que contribuyen a la solución de dudas a través de su asesoría personal o mediante cursos específicos realizados a lo largo del proceso docente e investigador.

Se ha hecho uso de fuentes documentales primarias: libros técnicos, artículos de revistas científicas y de divulgación, tesis doctorales, informes de proyectos internacionales relacionados con el objetivo de la presente tesis.

Fuentes documentales secundarias: Páginas Web, bases de datos bibliográficas, diccionarios.

\section{- Cuestionamiento}

Se busca responder las preguntas de investigación. Según los objetivos de la investigación, el cuestionamiento se puede realizar con propósito exploratorio, descriptivo o explicativo (Saunders et al., 2003). Mientras los estudios exploratorios buscan reconocer lo que está pasando con el fenómeno, los descriptivos reflejan la realidad y elaboran un perfil de la situación a través de las variables, y los explicativos buscan establecer las relaciones y causas entre las variables, para encontrar argumentos que expliquen el fenómeno (Bermeo, 2007).

En esta tesis, la búsqueda de respuestas a las preguntas de investigación formuladas en el capítulo 1 , se orientó inicialmente a la descripción de la realidad y el entorno del objeto de investigación, para luego encaminarse hacia la explicación de una parte de la realidad que es propia del objeto de estudio.

\section{- El estudio en el tiempo}

Estrategia que permite hacer un análisis del fenómeno de estudio con dos perspectivas diferentes en el tiempo: en un momento dado del tiempo o estudio trans-seccional, o durante 
un periodo de tiempo o estudio longitudinal (Saunders et al., 2003). En esta tesis se ha utilizado el enfoque trans-seccional dado que la información fue recopilada en un momento único, a partir de una muestra de elementos de una población.

\section{- La Encuesta}

Se utiliza para obtener cierto tipo de información cuantitativa con respecto del problema u objeto de la investigación (Montoro, 2004). Entre las encuestas se puede distinguir: la encuesta personal, la encuesta postal, la encuesta telefónica y la encuesta vía internet.

\footnotetext{
- Encuesta personal: Se produce un contacto directo entre entrevistador, información y el entrevistado o persona que proporciona la información.
}

- $\quad$ Encuesta postal: El cuestionario se hace llegar por correo a cada uno de los entrevistados, devolviéndolo éste por correo al investigador una vez cumplimentado.

- Encuesta telefónica: El contacto entre el entrevistador y el entrevistado se establece vía teléfono, así como la recogida de la información facilitada por el entrevistado.

- $\quad$ Encuesta vía Internet: Se crea una plataforma on-line. El cuestionario se envía al correo electrónico del entrevistado mediante enlace para que este responda la encuesta desde un ordenador y la plataforma registra las respuestas, que después serán gestionadas por los responsables de realizar la encuesta.

En el marco de los proyectos internacionales en las que se desarrollaron las encuestas, por la variedad y particularidad de los países en donde se realizaron, se utilizaron las cuatro modalidades de encuestas expuestas en el párrafo anterior.

\subsubsection{Objeto de Investigación}

El objeto de investigación corresponde a los graduados universitarios de Europa y Latinoamérica, que participaron de una encuesta realizada en el marco de dos proyectos Internacionales, cofinanciados por la Unión Europea y Universidades de Europa y Latinoamérica. 
El Proyecto REFLEX (2005) "The Flexible Professional in The Knowledge Society New Demands on Higher Education in Europe", fue llevado a cabo en catorce países de Europa y Japón.

El proyecto ALFA PROFLEX (2007-2010) “El profesional Flexible en la Sociedad del Conocimiento", contó con la participación de graduados de universidades de once países de Latinoamérica. A los graduados se les preguntaba sobre su visión de la universidad y el mundo laboral cinco años después de haber terminado sus estudios superiores.

La razón para centrar el estudio en estas promociones es que, según numerosas investigaciones realizadas por expertos en educación, en este preciso momento los graduados tienden a la reflexión sobre su experiencia académica y sus expectativas futuras en el mercado laboral. De esta forma se garantiza que han adquirido suficiente perspectiva de sus estudios y posibilidades en el mercado laboral sin olvidar sus experiencias tras su paso por la universidad.

\subsubsection{Proceso de Investigación}

Hernández et al. (2010) define la investigación como un conjunto de procesos sistemáticos y empíricos que se aplican al estudio de un fenómeno. Estos procesos facilitan al lector conocer el proceso que se ha llevado a cabo. Para esta tesis, el proceso general de investigación de referencia, se resume en la figura 4.1.

La metodología se estructura en seis etapas generales:

a) Definición del tema objeto de investigación, es decir, se definen los objetivos generales y específicos y se hace la revisión documental, basándose principalmente en los resultados de estudios anteriores.

b) Formulación de las hipótesis centrales, basándose en una clara definición de las variables y una formulación específica de las relaciones entre las mismas.

c) Diseño de la investigación, que sirve de guía en el proceso de recoger, analizar e interpretar las observaciones que se lleven a cabo, dependiendo de los objetivos planteados en la investigación y de las preguntas formuladas en la hipótesis de investigación.

d) Recolección de la Información, que se puede obtener de diferentes formas: A partir de encuestas, entrevistas personales, grupos de discusión, datos de archivo.

e) Análisis e interpretación de datos, que deben adecuarse al objetivo y el diseño de la misma. Se realiza una exploración de los datos con el análisis y visualización por variables 
de estudio, se evalúa la confiabilidad de los instrumentos escogidos. Se realiza un análisis estadístico descriptivo de cada variable de estudio, se realizan los análisis estadísticos inferenciales respecto a las hipótesis planteadas, para su posterior comprobación.

f) Presentación de Resultados, incluye el apartado de la interpretación de los resultados obtenidos en donde se explican los aspectos más importantes de la investigación, la existencia de las limitaciones de la misma para evitar interpretaciones inadecuadas de los resultados, también se intenta relacionarlos con otros estudios previos, y así mismo resaltar en qué medida el estudio de la investigación expande nuestra comprensión del fenómeno de estudio.

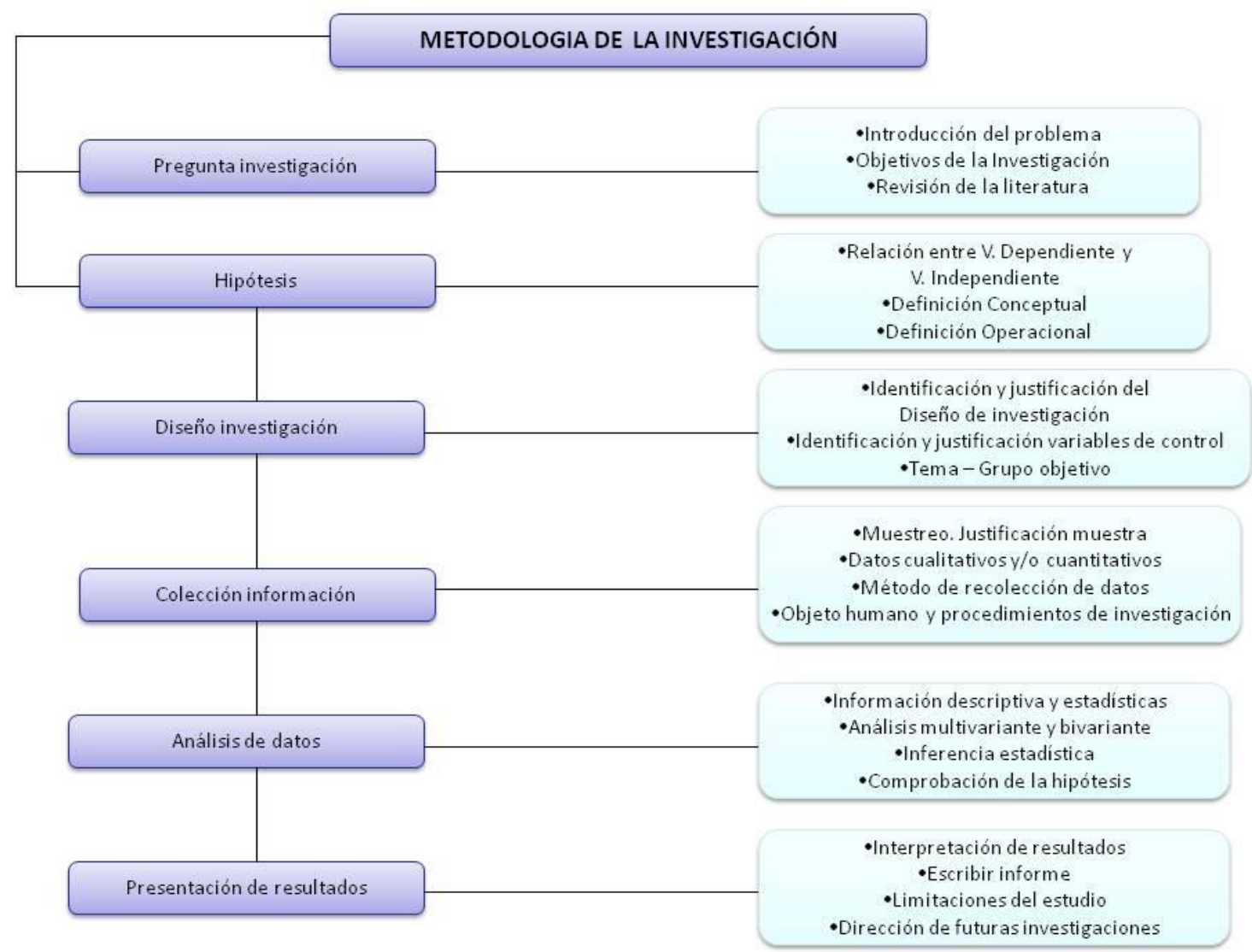

Figura 4. 1

Fuente: Elaboración propia a partir de Montoro (2004)

\subsection{Fuente de Datos}

Las bases de datos obtenidas del proyecto REFLEX para Europa y del proyecto ALFAPROFLEX para Latinoamérica, son la fuente de información de esta tesis. 
Como resultado se tiene una base internacional conjunta de 38.286 graduados europeos y 9.808 graduados latinoamericanos. La existencia de ambos proyectos así como sus características, han permitido acercar el objetivo de la presente tesis para realizar una selección de apartados del contenido de la encuesta para su estudio, análisis y comparación.

\subsection{Población y muestra}

\subsubsection{Descripción General de la población y muestra}

La población corresponde a graduados de veinticuatro países que obtuvieron un título de educación superior correspondiente al nivel ISCED 5A (no incluye los doctorados ni otro tipo de posgrados) y que fueron encuestados cinco años después de la finalización de sus estudios. Por lo tanto la muestra está compuesta por graduados universitarios de 14 países de Europa que obtuvieron la titulación en el curso 1999/2000 y fueron encuestados durante el año 2005 y graduados universitarios de 10 países de Latinoamérica que finalizaron los estudios durante los años 2002/2003 y que fueron encuestados entre los años 2007/2008.

\section{Ámbito:}

- $\quad$ Latinoamérica: Argentina, Bolivia, Brasil, Chile, Colombia, Honduras, México, Puerto Rico, Uruguay y Panamá.

- $\quad$ Europa: Austria, España, Francia, Austria, Alemania, Países Bajos, Reino Unido, Finlandia, Noruega, República Checa, Suiza, Portugal, Bélgica y Estonia.

\subsubsection{Método de Muestreo}

Tipo de muestreo: Muestreo aleatorio estratificado proporcional a la población por área de estudio y país.

- Marco muestral: Datos procedentes del Institute for Statistics del portal Web de la Organización de Naciones Unidas para la Educación, la Ciencia y la Cultura (UNESCO):

http://www.uis.unesco.org 
Muestra Procedente del Proyecto REFLEX: La muestra nacional se fijó en 2000 registros aunque se redefinió posteriormente en función de las tasas de respuesta de cada país. Para incrementar la eficiencia de la muestra se realizó un muestreo estratificado bietápico. Cada país seleccionó los estratos más adecuados a su contexto de trabajo pero básicamente se incluyeron categorías como tipo de grado, área de estudio, región, etc. No obstante, a pesar de haber diseñado con detalle la muestra para cada país se aplicó una ponderación a los datos obtenidos para compensar las diferencias debidas a bajas tasas de respuesta (Conchado, 2011).

Muestra Procedente del Proyecto PROFLEX ${ }^{13}$ : La muestra diseñada para cada universidad se calculó mediante muestreo aleatorio estratificado atendiendo a las áreas de estudio de las titulaciones ofrecidas. Sin embargo frecuentemente no existía una correspondencia estricta entre la muestra obtenida por cada universidad y la especificada en el proyecto, tanto por exceso como por defecto. Aunque estas diferencias no resultaron suficientes para producir un incremento significativo en el error muestral global, se aplicó una ponderación sobre los datos con el fin de que cada Institución de Educación Superior (IES) pudiera utilizar posteriormente el esfuerzo invertido en la elaboración de la base de datos para realizar análisis internos más detallados. Esta ponderación de los datos incluyó todas las modificaciones correspondientes a cada región y área de estudio.

\subsubsection{Tamaño de la muestra ${ }^{14}$}

- $\quad$ Tamaño de la muestra original: 50.595 egresados.

- $\quad$ Margen de error: $0,311 \%$ para los datos globales considerando $p=q$ y un margen de confianza de $95,5 \%$.

Para el objetivo del presente trabajo se excluye de la muestra original (50.595) la información de los graduados de Japón (2.501). El tamaño de muestra que se utiliza para los análisis es de 48.094 egresados.

\footnotetext{
${ }^{13}$ Informe PROFLEX (2010), páginas 22-23.

${ }^{14}$ Informe PROFLEX (2010), página 26.
} 


\subsection{Método de recolección de datos}

- Recogida de información: Con el fin de posibilitar la distribución del cuestionario en los distintos entornos de trabajo de los países participantes se plantearon diversas opciones: Cuestionario autocumplimentado por correo postal, vía online, entrevistas telefónicas y visitas domiciliarias.

Cada Universidad participante asumió la tarea de definir y establecer los procedimientos necesarios para la gestión del pase de la encuesta. Concretamente la implicación de las universidades resulto vital en las cuestiones relacionadas con los recursos humanos y técnicos internos de la institución. El contacto entre universidades y egresados, se realizó mediante una estrategia formal de comunicación, utilizando el soporte acorde a su conveniencia (carta, folleto explicativo, etc.).

\subsection{Cuestionario - Preguntas seleccionadas}

El cuestionario ha sido validado a partir de las investigaciones previas, fruto del trabajo de investigación de expertos de universidades y organismos internacionales. Fue dirigido a los graduados universitarios y fue adaptado al contexto educacional y laboral de cada país a partir de un cuestionario estándar. Los resultados obtenidos de los proyectos REFLEX y PROFLEX, similares desde el punto de vista de su conceptualización y objetivos, permitieron comparar la situación laboral de los graduados en Latinoamérica con la que encuentran los graduados Europeos.

El cuestionario cuenta con más de 150 preguntas, estructurado en nueve secciones, de las cuáles para el objetivo de esta tesis fueron seleccionadas 89 preguntas que pertenecen a los siguientes segmentos:

- $\quad$ Carrera que terminó cinco años antes

- Trabajo actual

- $\quad$ Organización en la que trabaja

- $\quad$ Competencias (Conocimientos, habilidades y destrezas)

- Valores y orientaciones (Características del trabajo)

- Información Personal

Las variables implicadas en los análisis de este trabajo se han clasificado en seis grupos tal como se describe en el Anexo A. 


\subsection{Variables dependientes e independientes}

\subsubsection{Variables dependientes}

\subsubsection{1 Éxito Laboral}

La literatura actual propone el éxito laboral desde dos aspectos integrados, el éxito objetivo y el éxito subjetivo, las personas valoran su éxito basados en criterios diversos que integran la vida personal y laboral. Según esas valoraciones construyen su concepto personal de éxito laboral. Para esta investigación, el éxito laboral (Exlab) está compuesto por el éxito laboral objetivo (Exlabob) junto con el éxito laboral subjetivo (Exlabsu).

Tabla 4. 1 Medidas del Éxito Laboral

\begin{tabular}{|c|c|c|}
\hline Abreviación & Factor & Medición \\
\hline Exlab & Éxito Laboral & \\
\hline Exlabob & Éxito Laboral Objetivo & Nivel de Ingresos (sueldo) \\
\hline Exlabsu & Éxito Laboral Subjetivo & $\begin{array}{c}\text {-Uso de conocimientos y } \\
\text { habilidades }\end{array}$ \\
& & $\begin{array}{c}\text {-Conocimiento y habilidades } \\
\text { requeridos en el puesto de } \\
\text { trabajo }\end{array}$ \\
& & -Satisfacción en el Trabajo \\
\hline
\end{tabular}

\section{Éxito Laboral Objetivo}

El éxito laboral objetivo medido según indicadores tangibles, en función del nivel de ingresos y el número de horas promedio trabajadas durante la semana. Estas variables utilizan tipos de datos de escala. 
Tabla 4. 2 Medida del Éxito Laboral Objetivo

\begin{tabular}{|c|c|c|}
\hline Indicadores & Variables & Tipo de dato \\
\hline $\begin{array}{c}\text { Éxito Laboral } \\
\text { Objetivo } \\
\text { Exlabob }\end{array}$ & Nivel de Ingresos (sueldo) & Escala \\
\hline
\end{tabular}

\section{Éxito Laboral Subjetivo}

El éxito laboral subjetivo medido según indicadores intangibles, en función de la Satisfacción laboral, el grado en que al profesional le es requerido un determinado nivel de conocimientos y habilidades y si realmente utiliza sus conocimientos y habilidades en el puesto de trabajo. La medida utilizada es la escala Likert que va desde $1=$ Nada a 5 = Mucho.

Tabla 4. 3 Medida del Éxito Laboral Subjetivo

\begin{tabular}{|c|c|c|}
\hline Indicadores & Variables & Tipo de dato \\
\hline & -Uso de conocimientos y habilidades & \\
Éxito Laboral & -Conocimiento y habilidades requeridos en \\
Exlabsu & el puesto de trabajo & Escala Ordinal 1 a 5 \\
& -Satisfacción en el Trabajo & \\
\hline
\end{tabular}

\subsubsection{Variables Independientes}

\subsubsection{Rol - Funciones}

El Rol, definido como el papel que desempeña el profesional dentro de la organización, a través de su puesto de trabajo y las funciones asociadas al mismo. Para establecer una relación entre el rol y el éxito laboral se proponen las variables área de estudio adecuada al puesto de trabajo, la valoración de la responsabilidad, las relaciones en el trabajo. Las variables de responsabilidad, relaciones y perjuicio utilizan la escala Likert que va desde $1=$ Nada a 5 = Mucho. 
Tabla 4. 4 Medidas del Rol

\begin{tabular}{|c|c|}
\hline Variables & Tipo de dato \\
\hline $\begin{array}{l}\text { Responsabilidad } \\
\text {-Establecer objetivos para la organización } \\
\text {-Establecer Objetivos para el propio trabajo } \\
\text {-Decidir estrategias de trabajo para la } \\
\text { organización } \\
\text {-Decidir cómo hacer el propio trabajo }\end{array}$ & Escala Ordinal 1 a 5 \\
\hline $\begin{array}{l}\text { Relaciones Personales } \\
\text {-Compañeros y clientes piden consejo } \\
\text {-Dar información a compañeros de profesión } \\
\text { sobre nuevos desarrollos } \\
\text {-Inicia relaciones profesionales con expertos } \\
\text { ajenos a la organización } \\
\text {-Las cuestiones de ética son parte importante } \\
\text { de las funciones en el trabajo }\end{array}$ & Escala Ordinal 1 a 5 \\
\hline $\begin{array}{l}\text { Perjuicio } \\
\text {-Grado de perjuicio a la organización si } \\
\text { cometiera un error grave en el trabajo. }\end{array}$ & Escala Ordinal 1 a 5 \\
\hline
\end{tabular}

\subsubsection{Competencias}

Las competencias propuestas para este trabajo corresponden a la valoración que hacen los profesionales universitarios del nivel de competencias propias y el nivel de las competencias requeridas en el puesto de trabajo. La medida utilizada para la valoración, es la escala Likert de 1 a 7 , donde $1=$ Muy bajo y 7 = Muy alto. 
Tabla 4. 5 Medida de las Competencias

\begin{tabular}{|c|c|}
\hline Variables & Tipo de dato - Escala Ordinal \\
\hline Dominio de tu área o disciplina & Muy bajo 1 a 7 Muy alto \\
\hline $\begin{array}{l}\text { Conocimientos de otras áreas o } \\
\text { disciplinas }\end{array}$ & Muy bajo 1 a 7 Muy alto \\
\hline Pensamiento analítico & Muy bajo 1 a 7 Muy alto \\
\hline $\begin{array}{l}\text { Capacidad para adquirir con rapidez } \\
\text { nuevos conocimientos }\end{array}$ & Muy bajo 1 a 7 Muy alto \\
\hline Capacidad para negociar de forma eficaz & Muy bajo 1 a 7 Muy alto \\
\hline Capacidad para trabajar bajo presión & Muy bajo 1 a 7 Muy alto \\
\hline $\begin{array}{l}\text { Capacidad para detectar nuevas } \\
\text { oportunidades }\end{array}$ & Muy bajo 1 a 7 Muy alto \\
\hline Capacidad para coordinar actividades & Muy bajo 1 a 7 Muy alto \\
\hline $\begin{array}{l}\text { Capacidad para usar el tiempo de forma } \\
\text { efectiva }\end{array}$ & Muy bajo 1 a 7 Muy al to \\
\hline Capacidad para trabajar en equipo & Muy bajo 1 a 7 Muy alto \\
\hline $\begin{array}{l}\text { Capacidad para movilizar las capacidades } \\
\text { de otros }\end{array}$ & Muy bajo 1 a 7 Muy alto \\
\hline Capacidad para hacerse entender & Muy bajo 1 a 7 Muy alto \\
\hline Capacidad para hacer valer la autoridad & Muy bajo 1 a 7 Muy alto \\
\hline $\begin{array}{l}\text { Capacidad para utilizar herramientas } \\
\text { informáticas }\end{array}$ & Muy bajo 1 a 7 Muy alto \\
\hline $\begin{array}{l}\text { Capacidad para encontrar nuevas ideas y } \\
\text { soluciones }\end{array}$ & Muy bajo 1 a 7 Muy alto \\
\hline $\begin{array}{l}\text { Predisposición para cuestionar ideas } \\
\text { propias o ajenas }\end{array}$ & Muy bajo 1 a 7 Muy alto \\
\hline $\begin{array}{l}\text { Capacidad para presentar en público } \\
\text { productos, ideas o informes }\end{array}$ & Muy bajo 1 a 7 Muy alto \\
\hline $\begin{array}{l}\text { Capacidad para redactar informes o } \\
\text { documentos }\end{array}$ & Muy bajo 1 a 7 Muy al to \\
\hline $\begin{array}{l}\text { Capacidad para escribir y hablar idiomas } \\
\text { extranjeros }\end{array}$ & Muy bajo 1 a 7 a Muy alto \\
\hline
\end{tabular}




\subsubsection{Valores Laborales}

Las variables de valores laborales de este trabajo, evalúan la importancia que los profesionales universitarios dan a los valores laborales personales y el grado en que esos valores laborales se aplican a su situación laboral. La medida utilizada es la escala Likert de 1 a 5.

Tabla 4. 6 Medida de los Valores Laborales

\begin{tabular}{|l|c|}
\hline \multicolumn{1}{|c|}{ Variables } & Tipo de dato - Escala Ordinal \\
\hline Autonomía en el trabajo & Ninguna 1 a 5 Mucha \\
\hline Estabilidad laboral & Ninguna 1 a 5 Mucha \\
\hline Oportunidad de aprender cosas nuevas & Ninguna 1 a 5 Mucha \\
\hline Ingresos Elevados & Ninguna 1 a 5 Mucha \\
\hline Afrontar nuevos retos & Ninguna 1 a 5 Mucha \\
\hline Buenas perspectivas profesionales & Ninguna 1 a 5 Mucha \\
\hline Tener tiempo para actividades recreativas & Ninguna 1 a 5 Mucha \\
\hline Reconocimiento / Prestigio social & Ninguna 1 a 5 Mucha \\
\hline $\begin{array}{l}\text { Oportunidad de hacer algo útil para la } \\
\text { sociedad }\end{array}$ & Ninguna 1 a 5 Mucha 1 a 5 Mucha \\
\hline Facilidad para combinar trabajo y familia & Ninguna \\
\hline
\end{tabular}

\subsubsection{Variables de Control}

Las variables de control son un tipo de variable independiente que no se manipula sino que se mantiene constante para neutralizar sus efectos sobre la variable dependiente. Algunas 
de las variables que se presentan son utilizadas como variables de control en los análisis realizados.

\subsubsection{Datos demográficos}

Las variables seleccionadas y que se muestran en la tabla 4.7 en su mayoría de tipo nominal, corresponden al país, continente, género y edad de los encuestados. Se utilizan como variables de control.

Tabla 4. 7 Medida de las Variables Demográficas

\begin{tabular}{|c|c|c|}
\hline Variables & Descripción & Tipo de dato \\
\hline País & $\begin{array}{c}\text { País donde se originó la encuesta del } \\
\text { Graduado Universitario }\end{array}$ & Nominal \\
\hline Continente & Países de Europa y Latinoamérica & Nominal \\
\hline Género & Hombre - Mujer & Nominal \\
\hline Edad & No de Años & Escala \\
\hline
\end{tabular}

\subsubsection{Entorno del puesto de trabajo y tipo de organización}

La descripción y tipo de medida de las variables del entorno del puesto de trabajo se muestran en la tabla 4.8. 
Tabla 4. 8 Medida de las Variables del entorno del puesto de Trabajo

\begin{tabular}{|c|c|c|}
\hline Variables & Descripción & Tipo de dato \\
\hline Ocupación & Cargo ocupado en el momento de la entrevista & Nominal \\
\hline Horas Trabajadas & Promedio de horas de trabajo semanal & Escala \\
\hline $\begin{array}{c}\text { Área de } \\
\text { Conocimiento }\end{array}$ & $\begin{array}{c}\text { Agrupación que se hace de los programas académicos, } \\
\text { teniendo en cuenta cierta afinidad en los contenidos, en } \\
\text { le acción de la educación superior cuyos propósitos de } \\
\text { formación conduzcan a la investigación o al desempeño } \\
\text { de ocupaciones, profesiones y disciplinas. }\end{array}$ & Nominal \\
\hline Ajuste Horizontal & $\begin{array}{c}\text { Percepción que el graduado tiene acerca del área de } \\
\text { estudios más apropiado para el puesto de trabajo que } \\
\text { ocupa. }\end{array}$ & Nominal \\
\hline
\end{tabular}

La descripción y tipo de medida de las variables que caracterizan la organización se muestran en la tabla 4.9. Principalmente nos dan una información acerca del sector económica en el que realizan su actividad, el tipo de sector, su tamaño, permitiendo obtener una imagen general del tipo de organizaciones en las que realizan su actividad los graduados universitarios que participaron en la encuesta. 
Tabla 4. 9 Medida de las Variables que Caracterizan la Organización

\begin{tabular}{|c|c|c|}
\hline Variables & Descripción & Tipo de dato \\
\hline $\begin{array}{c}\text { Sector económico al } \\
\text { que pertenece }\end{array}$ & $\begin{array}{c}\text { Parte de la actividad económica cuyos elementos tienen } \\
\text { características comunes, guardan una unidad y se } \\
\text { diferencian de otras agrupaciones. }\end{array}$ & Nominal \\
\hline $\begin{array}{c}\text { Tipo de sector } \\
\text { (público-privado-sin } \\
\text { ánimo de lucro- } \\
\text { otros) }\end{array}$ & $\begin{array}{r}\text { Define el carácter de la organización según corresponda } \\
\text { el capital y el control de la misma. }\end{array}$ & Nominal \\
\hline $\begin{array}{c}\text { Tamaño de la } \\
\text { organización / } \\
\text { Establecimientos }\end{array}$ & $\begin{array}{r}\text { La organización puede ser pequeña, mediana o grande y y } \\
\text { tener uno o varios establecimientos. }\end{array}$ & Nominal \\
\hline
\end{tabular}




\subsection{Definición de las variables}

En la tabla 4.10 se presentan las clases de variables y sus escalas de medida inicial, para determinar los diferentes análisis estadísticos posibles. El listado de las variables y la codificación correspondiente, se puede cotejar en el anexo E.

Tabla 4. 10 Tipo y Cantidad de Variables del Cuestionario

\begin{tabular}{|c|c|}
\hline Tipo & Cantidad \\
\hline Nominales & 14 \\
\hline Ordinal & 69 \\
\hline Escala & 6 \\
\hline Total Variables & 89 \\
\hline
\end{tabular}

En estadística se han clasificado cuatro escalas de medida diferentes: nominal, ordinal, intervalo y de razón, pero para el software estadístico SPSS v.17 estas escalas se resumen en tres y el significado se resume en la tabla 4.11.

Tabla 4. 11 Tipos de Datos o Escalas de Medida según SPSS v.17

\begin{tabular}{|c|l|}
\hline $\begin{array}{c}\text { Escala de } \\
\text { Medida }\end{array}$ & \multicolumn{1}{|c|}{ Características } \\
\hline Nominal & $\begin{array}{l}\text { Sus valores representan categorías que no obedecen a una ordenación } \\
\text { intrínseca. Ej: región, área de conocimiento. }\end{array}$ \\
\hline Ordinal & $\begin{array}{l}\text { Una variable puede tratarse como ordinal cuando sus valores representan } \\
\text { categorías con alguna ordenación intrínseca (Ej: Niveles de satisfacción de menor } \\
\text { a mayor). }\end{array}$ \\
\hline Escala & $\begin{array}{l}\text { Una variable puede ser tratada como escala cuando sus valores representan } \\
\text { categorías ordenadas con una métrica con significado, por lo que son adecuadas } \\
\text { las comparaciones de distancia entre valores. Ej: Edad, ingresos en Euros. }\end{array}$ \\
\hline
\end{tabular}

Fuente: SPSS v.17 Statistical Package for Social Sciences Para Windows. 


\subsection{Herramientas Informáticas y Técnicas Estadísticas}

\subsubsection{Herramientas Informáticas}

Para el análisis de datos, se utilizaron las siguientes herramientas informáticas:

- $\quad$ El Software SPSS v.17 (Statistical Package for Social Science Para Windows).

- Microsoft Excel para la elaboración y exportación de datos desde SPSS, el uso de técnicas gráficas y manejo de tablas.

\subsubsection{Técnicas Estadísticas}

Para el análisis de los datos, se llevó a cabo el siguiente proceso:

- $\quad$ Caracterización de las variables.

- Depuración de datos.

- Análisis descriptivo y exploratorio: Análisis de frecuencias y análisis exploratorio, pruebas de normalidad, linealidad y homocedasticidad.

- $\quad$ Análisis de fiabilidad de las escalas.

- $\quad$ Estadística bivariante.

- Estadística Multivariante: Análisis factorial.

Los datos cualitativos y cuantitativos se agruparon en una sola base de datos para facilitar el análisis estadístico univariado, bivariado y multivariado. 



\section{PARTE III}

\section{CAPITULO 5}

\section{Análisis de Datos y Resultados}

\subsection{Análisis Descriptivo}

La información de la base de datos que ha sido utilizada para análisis, corresponde a las encuestas de los proyectos REFLEX y PROFLEX que incluye a 14 países de Europa, 10 países de Latinoamérica, habiéndose excluido la información de los graduados universitarios de Japón.

Los resultados del análisis descriptivo, se han obtenido mediante la utilización el software estadístico SPSS v.17.

En el análisis descriptivo la información se presenta de una forma simple para obtener una idea general de los datos recogidos, normalmente mediante un proceso de descripción de la misma, pudiéndose recoger en esta categoría el análisis univariado (Miquel et al., 1997). Este como muchos análisis, depende de las características de las variables y de los datos disponibles. En este caso en particular la mayoría de las variables son de tipo ordinal (escalas likert), además de un reducido número de variables nominales y de intervalo. El análisis proporciona información acerca del comportamiento de cada una de las variables a partir de diversos indicadores estadísticos.

Para el análisis univariado se utilizaron los siguientes estadísticos de tendencia central y dispersión: Media, mediana, moda, valor mínimo, valor máximo y desviación típica, coeficientes de asimetría y curtosis y se usó también estimadores robustos: M-Huber (Normalidad). En el anexo F. se resumen los resultados para cada una de las variables del análisis.

\subsubsection{Datos demográficos y económicos}

Con el objeto de describir y explorar cómo está compuesta la muestra y comprobar en su caso la normalidad de las distribuciones, se realizó una descripción general de las características personales, el contexto familiar y laboral de los encuestados. En este apartado se muestran determinados estadísticos descriptivos relacionados con algunos países 
seleccionados de la muestra y para los subconjuntos muestrales de Europa y Latinoamérica. Se excluye de la muestra total (50.595) la información de los graduados de Japón (2.501).

\subsubsection{Número de graduados / Países:}

La base de datos conjunta contiene 48,094 registros que corresponden a las respuestas obtenidas de los graduados universitarios de catorce países europeos entrevistados durante los años 2005-2006 y de los graduados universitarios de diez países latinoamericanos entrevistados durante los años 2007-2010. La Figura 5.1 refleja la distribución de la muestra por continentes.

\section{Graduados Universitarios \% Respuestas / Continente}

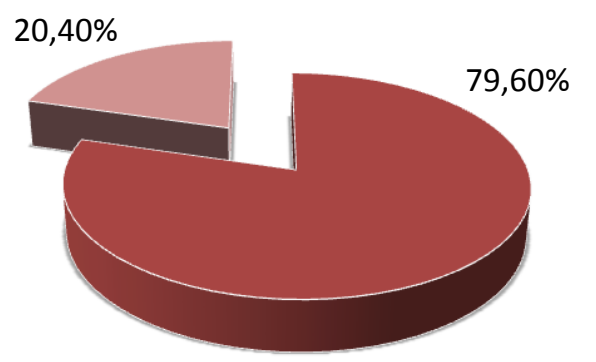

- Europa - Reflex

- Latinoamérica - Proflex

Figura 5. 1 \% Graduados Universitarios que respondieron encuesta REFLEX - PROFLEX

Se considera que la base de datos es homogénea en información y que las características similares facilitan la realización de comparaciones entre los graduados que participaron de la encuesta en los diferentes países. Se ha considerado escoger algunos países, para realizar los análisis comparativos, que se desarrollan a lo largo de este trabajo. El criterio de selección de los ocho países a partir de la muestra total, ha sido el ranking de países según su producto interior bruto (PIB) para el año $2012^{15}$.

Por lo tanto, para el análisis se tiene en cuenta la información obtenida de los siguientes países: España, Francia, Alemania, R. Unido, Suiza, Chile, México, Uruguay y la información agrupada por continente: Europa (14 países) y Latinoamérica (10 países).

\footnotetext{
${ }^{15}$ http://www.worldbank.org/
} 
La tabla 5.1 muestra la composición de graduados universitarios de la base de datos conjunta: 38,286 graduados universitarios europeos $(79,6 \%)$ y 9,808 graduados universitarios latinoamericanos $(20,4 \%)$ conforman la distribución de la muestra utilizada, que sirve de punto de partida para los análisis posteriores.

Tabla 5. 1 Graduados universitarios de la base de datos conjunta de REFLEX y PROFLEX

\begin{tabular}{|c|c|c|c|c|c|}
\hline № de $\operatorname{Res}$ & puestas de lc & s Graduados & Universitarios / & E. PROFLEX y & E. REFLEX \\
\hline País & Respuestas & Porcentaje & País & Respuestas & Porcentaje \\
\hline Italia (IT) & 3139 & 6,5 & Argentina (AR) & 219 & 0,5 \\
\hline España (ES) & 5474 & 11,4 & Bolivia (BO) & 308 & 0,6 \\
\hline Francia (FR) & 1700 & 3,5 & Brasil (BR) & 127 & 0,3 \\
\hline Austria (AT) & 1821 & 3,8 & Chile (CL) & 2987 & 6,2 \\
\hline $\begin{array}{c}\text { Alemania } \\
\text { (DE) }\end{array}$ & 1700 & 3,5 & Colombia (CO) & 420 & 0,9 \\
\hline $\begin{array}{c}\text { Países Bajos } \\
(\mathrm{NL})\end{array}$ & 3425 & 7,1 & Honduras (HN) & 98 & 0,2 \\
\hline $\begin{array}{c}\text { Reino } \\
\text { Unido (UK) }\end{array}$ & 1578 & 3,3 & México (MX) & 4672 & 9,7 \\
\hline $\begin{array}{c}\text { Finlandia } \\
(\mathrm{FI})\end{array}$ & 2676 & 5,6 & $\begin{array}{c}\text { Puerto Rico } \\
\text { (PR) }\end{array}$ & 106 & 0,2 \\
\hline $\begin{array}{c}\text { Noruega } \\
\text { (NO) }\end{array}$ & 2201 & 4,6 & Uruguay (UR) & 671 & 1,4 \\
\hline $\begin{array}{l}\text { República } \\
\text { Checa (Cz) }\end{array}$ & 6794 & 14,1 & Panamá (PA) & 200 & 0,4 \\
\hline Suiza $(\mathrm{CH})$ & 4882 & 10,2 & Latinoamérica & 9808 & 20,4 \\
\hline $\begin{array}{l}\text { Portugal } \\
\text { (PT) }\end{array}$ & 645 & 1,3 & \multirow{4}{*}{\multicolumn{3}{|c|}{ Total Respuestas $=48,094(100 \%)$}} \\
\hline Bélgica (BE) & 1291 & 2,7 & & & \\
\hline $\begin{array}{c}\text { Estonia } \\
\text { (EST) }\end{array}$ & 960 & 2 & & & \\
\hline Europa & 38286 & 79,6 & & & \\
\hline
\end{tabular}

Fuente: Datos REFLEX y PROFLEX 


\subsubsection{Género}

En el apartado género, el conjunto de la muestra refleja en la figura 5.2, que 25,693 graduadas universitarias $(57,8 \%)$ respondieron a este aspecto frente a los 18,748 graduados universitarios (42.2\%).

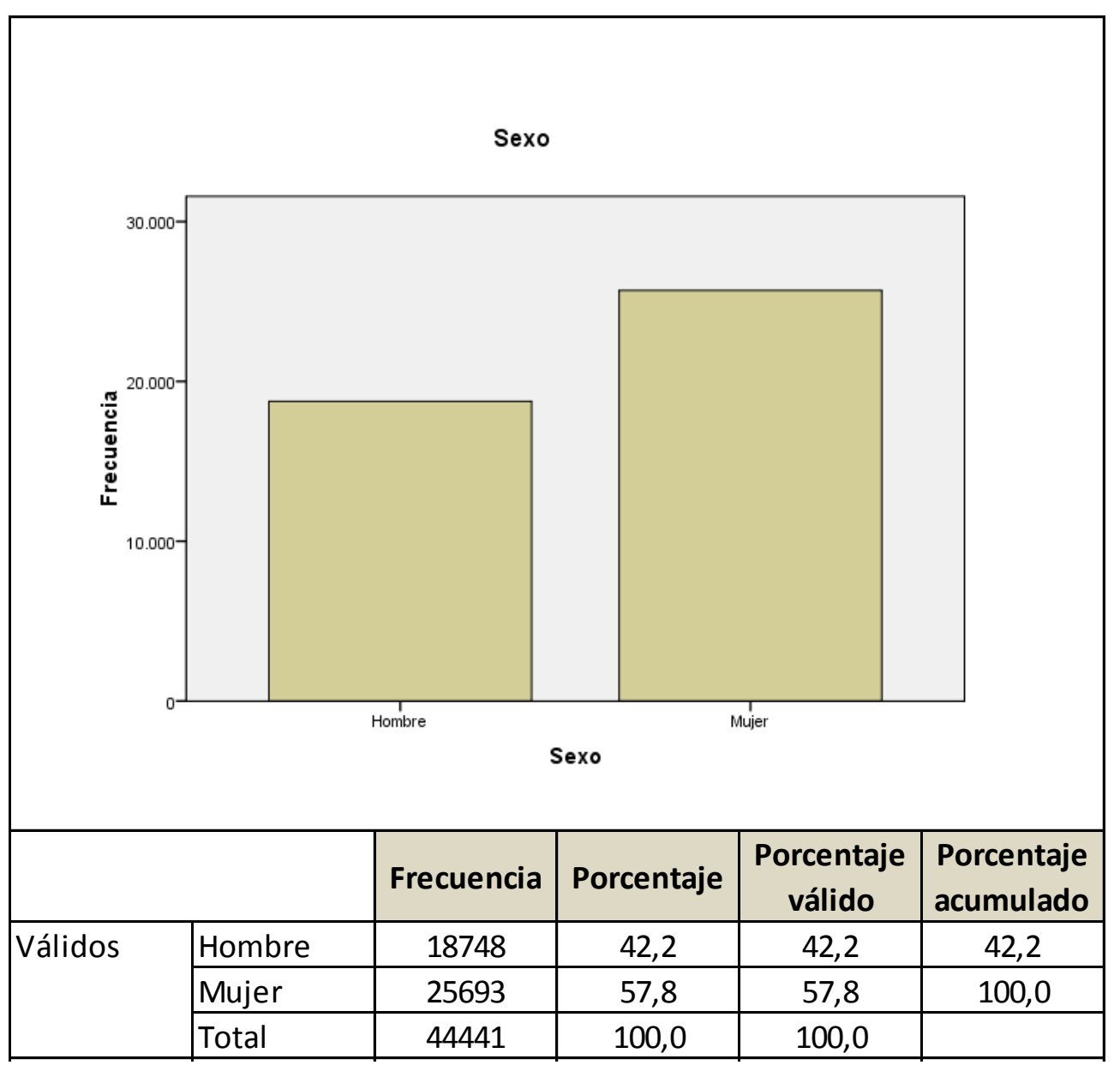

Figura 5. 2 Distribución de la muestra por sexo

El mayor porcentaje de graduados universitarios de Europa y Latinoamérica es de género femenino y en ese orden proceden de España, Francia, Reino Unido, Chile, México y Uruguay. En Alemania y Suiza hay mayoría de hombres con un 50,1\% y 58,7\% respectivamente. La Figura 5.3 refleja la distribución de hombres y mujeres para cada uno de los países referenciados. 


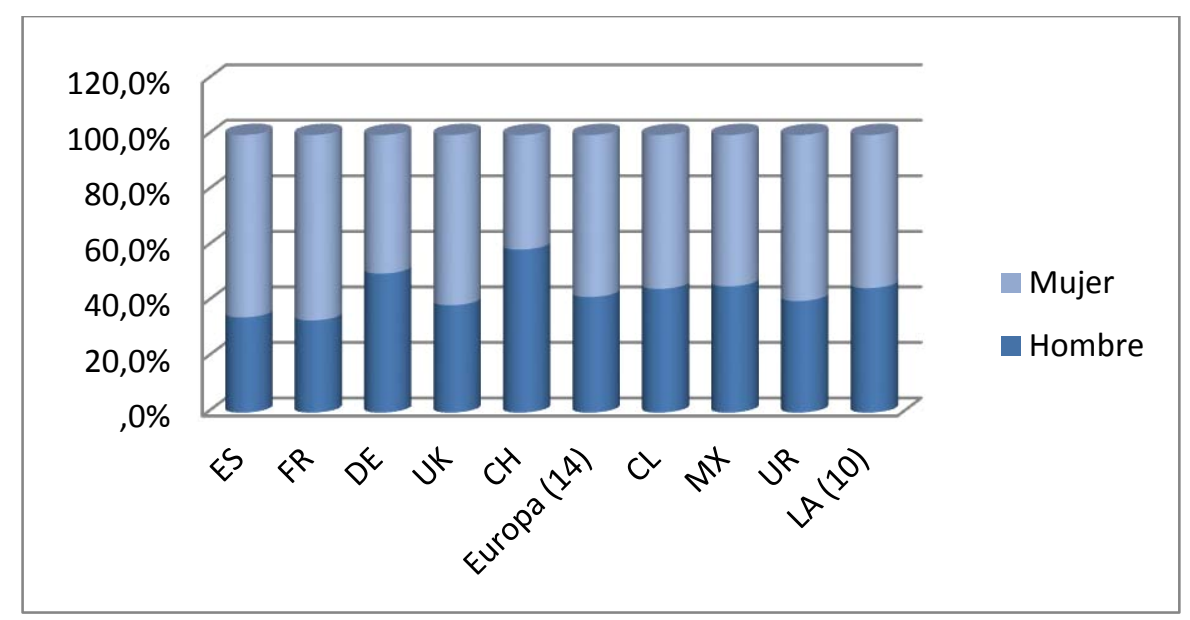

Figura 5. 3 \% de Graduadas Universitarias - País

En la comparativa por continente, los graduados/as de Europa estás distribuidos de la siguiente forma: $58,3 \%$ Mujeres y 41,7 \% hombres y los graduados/as de Latinoamérica se distribuye su participación en 55,1 \% Mujeres y 44,9\% hombres.

\subsubsection{Edad}

La media de edad de los graduados universitarios en el momento de la entrevista era de 31 años. La Figura 5.4 muestra la distribución de frecuencias del total de la muestra presentada por continente, en el que se destaca que la media de edad de los latinoamericanos (29 años) es menor que la de los europeos (32 años).
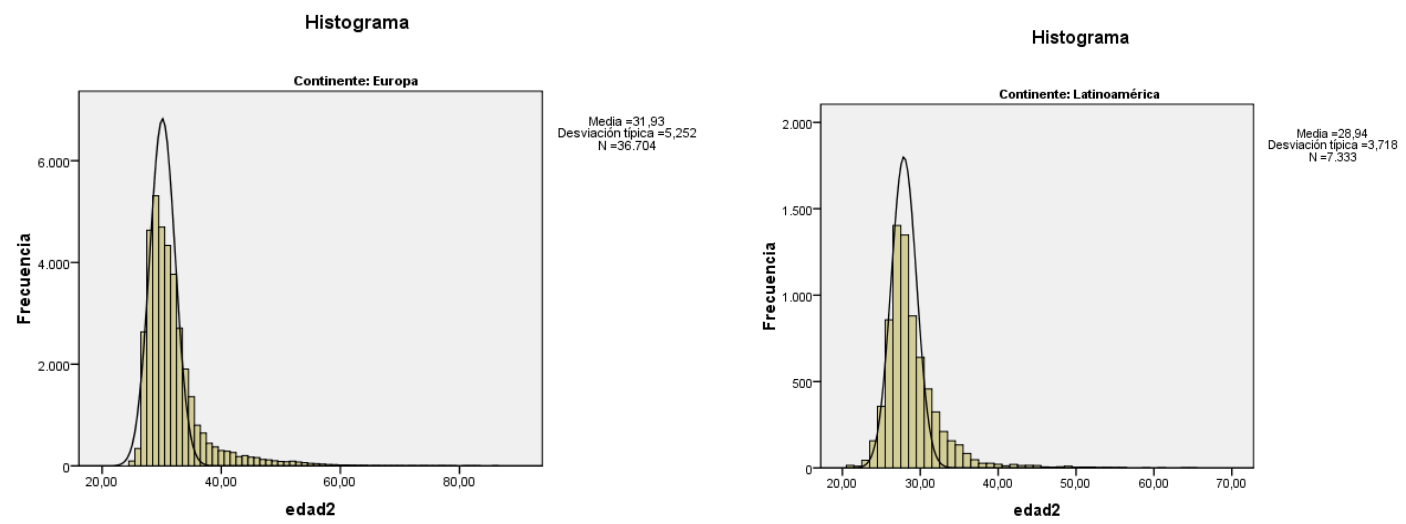

Figura 5. 4 Distribución de frecuencias (Edad) 


\subsubsection{Situación de Convivencia}

La mayoría de los graduados universitarios manifestaron convivir en pareja, el 60,5\% de los europeos y el $49,9 \%$ de los latinoamericanos. En el conjunto de la muestra total, le siguen los que viven solos (as) y los que viven con sus padres.

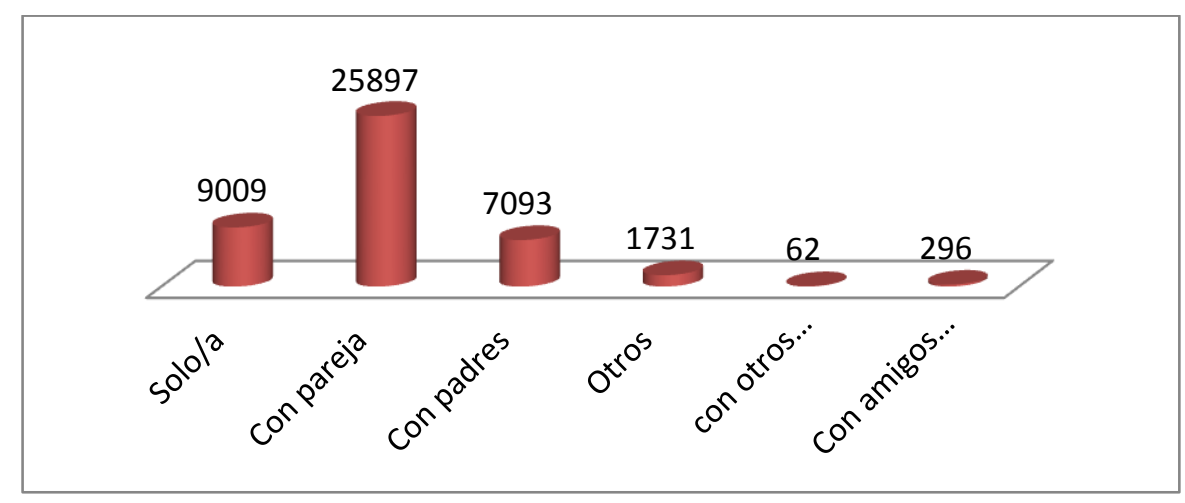

Figura 5. 5 Situación de convivencia (№ de graduados).

La tabla 5.2, muestra la proporción de graduados universitarios por país, según la situación de convivencia en el momento de la entrevista. Destaca el 30,5\% de los alemanes que manifestaron vivir solos/as y el $65,5 \%$ que viven en pareja, así como los suizos que lo manifiestan en un $63,7 \%$. La convivencia con los padres es mayor entre los españoles $(36,8 \%)$, seguidos de los mexicanos que lo manifiestan en un $30,8 \%$.

Tabla 5. 2 Situación de Convivencia de los Graduados Universitarios - País / (\%)

\begin{tabular}{|c|c|c|c|c|c|c|c|c|c|c|}
\hline & España & Francia & $\begin{array}{c}\text { Reino } \\
\text { Unido }\end{array}$ & Suiza & Alemania & $\begin{array}{c}\text { Europa } \\
(14)\end{array}$ & México & Chile & Uruguay & $\begin{array}{c}\text { Latinoamérica } \\
(10)\end{array}$ \\
\hline Solo/a & $13,8 \%$ & $29,6 \%$ & $21,3 \%$ & $28,1 \%$ & $30,5 \%$ & $21,2 \%$ & $14,4 \%$ & $18,9 \%$ & $15,9 \%$ & $16,6 \%$ \\
\hline Con pareja & $43,5 \%$ & $60,1 \%$ & $53,7 \%$ & $63,7 \%$ & $65,5 \%$ & $60,5 \%$ & $46,7 \%$ & $56,4 \%$ & $53,0 \%$ & $49,9 \%$ \\
\hline Con padres & $36,8 \%$ & $7,9 \%$ & $14,1 \%$ & $3,6 \%$ & $2,7 \%$ & $13,9 \%$ & $30,8 \%$ & $18,3 \%$ & $27,7 \%$ & $26,9 \%$ \\
\hline Otros & $5,9 \%$ & $0,3 \%$ & $1,6 \%$ & $4,6 \%$ & $0,1 \%$ & $3,4 \%$ & $8,0 \%$ & $6,4 \%$ & $3,3 \%$ & $6,6 \%$ \\
\hline $\begin{array}{c}\text { con otros } \\
\text { parientes }\end{array}$ & $0,0 \%$ & $0,0 \%$ & $0,8 \%$ & $0,0 \%$ & $0,2 \%$ & $0,2 \%$ & $0,0 \%$ & $0,0 \%$ & $0,0 \%$ & $0,0 \%$ \\
\hline $\begin{array}{c}\text { Con } \\
\text { amigos y/o } \\
\text { conocidos }\end{array}$ & $0,0 \%$ & $2,1 \%$ & $8,4 \%$ & $0,0 \%$ & $1,0 \%$ & $0,8 \%$ & $0,0 \%$ & $0,0 \%$ & $0,0 \%$ & $0,0 \%$ \\
\hline Total (N) & 5.180 & 1.598 & 1.543 & 4.738 & 1.642 & 36.777 & 3.149 & 2.402 & 541 & 7.311 \\
\hline
\end{tabular}

\subsubsection{Graduados con Hijos}

En este apartado la mayoría de los graduados universitarios, manifestaron no tener hijos (72,4\%), 7,156 graduados manifestaron tener un hijo (16,1\%). De idéntica forma, el 11,9\% manifestaron tener 2 o más hijos. 


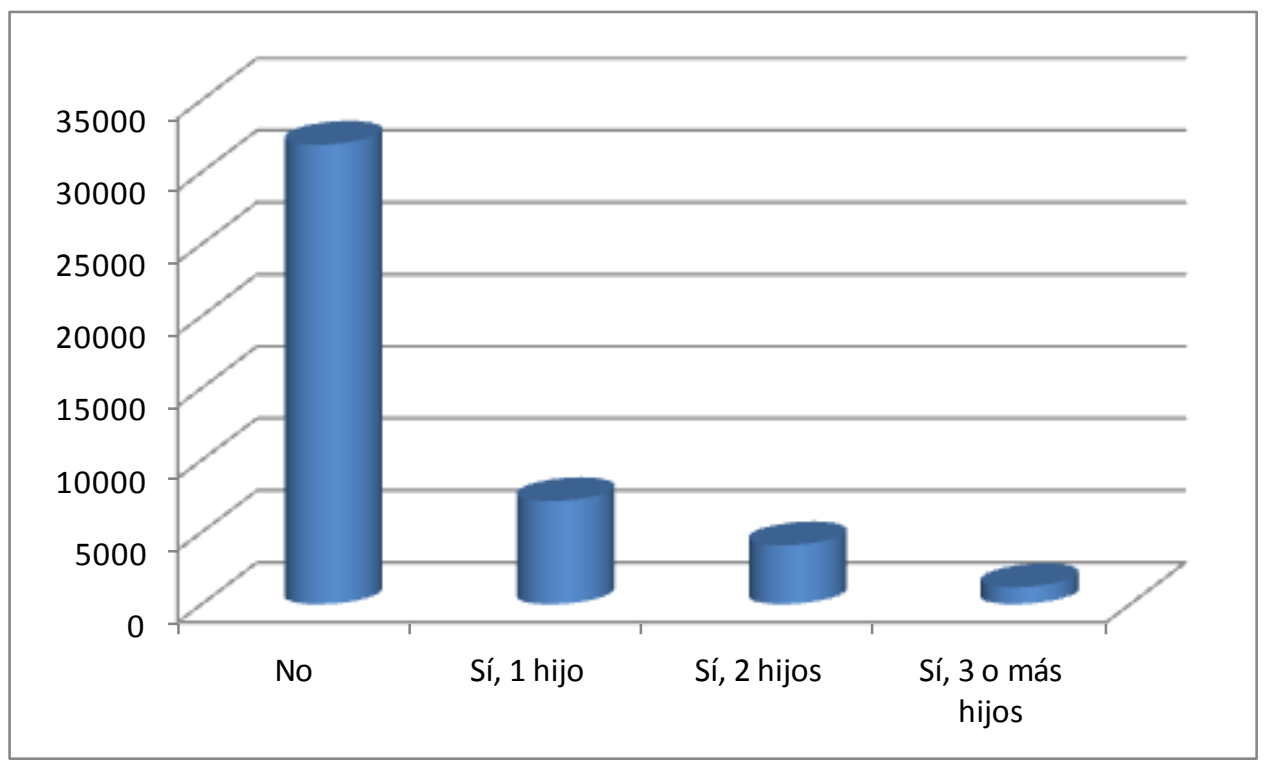

Figura 5. 6 Graduados Universitarios - № de Hijos

La tabla 5.3, muestra la proporción de graduados universitarios por país, según el número de hijos. Los graduados de Europa $(73,5 \%)$ y Latinoamérica $(64,2 \%)$ manifestaron en el momento de la entrevista que no tener hijos. Por países la cifra más alta se muestra en el caso de España con un 89,6\% el caso más alto del conjunto de países referenciados, seguido de los graduados de Uruguay con un $70,1 \%$, ambos datos superan las proporciones manifestadas por los graduados referenciados por continente.

Tabla 5. 3 Graduados Universitarios con hijos - País / (\%)

\begin{tabular}{|c|c|c|c|c|c|c|c|c|c|c|}
\hline & España & Francia & $\begin{array}{c}\text { Reino } \\
\text { Unido }\end{array}$ & Suiza & Alemania & $\begin{array}{c}\text { Europa } \\
(14)\end{array}$ & México & Chile & Uruguay & $\begin{array}{c}\text { Latinoamérica } \\
(10)\end{array}$ \\
\hline Sí, 1 hijo & $7,4 \%$ & $13,6 \%$ & $7,4 \%$ & $11,5 \%$ & $18,7 \%$ & $14,9 \%$ & $21,8 \%$ & $24,5 \%$ & $18,7 \%$ & $22,7 \%$ \\
\hline Sí, 2 hijos & $2,5 \%$ & $5,7 \%$ & $8,8 \%$ & $8,8 \%$ & $10,2 \%$ & $9,0 \%$ & $11,4 \%$ & $10,9 \%$ & $8,7 \%$ & $10,5 \%$ \\
\hline $\begin{array}{c}\text { Sí, 3 o } \\
\text { más hijos }\end{array}$ & $0,5 \%$ & $1,9 \%$ & $4,6 \%$ & $2,7 \%$ & $3,0 \%$ & $2,7 \%$ & $2,3 \%$ & $3,0 \%$ & $2,6 \%$ & $2,6 \%$ \\
\hline No & $89,6 \%$ & $78,8 \%$ & $79,2 \%$ & $77,0 \%$ & $68,1 \%$ & $73,5 \%$ & $64,5 \%$ & $61,6 \%$ & $70,1 \%$ & $64,2 \%$ \\
\hline Total (N) & 5.318 & 1.620 & 1.557 & 4.765 & 1.660 & 37.025 & 3.149 & 2.402 & 541 & 7.304 \\
\hline
\end{tabular}

\subsubsection{6. Área de Estudio}

El área de estudio hace referencia a la agrupación de las titulaciones de los encuestados en ocho campos de estudio, cuyo detalle puede consultarse en el anexo B: Referencia ISCED 5A (1997), que corresponde a la base para la clasificación de las áreas de estudio a partir de las titulaciones de primer nivel y segundo nivel. 
La clasificación se estructura mediante la agrupación del amplio conjunto de titulaciones universitarias de los países que participaron de la encuesta. Incluye ciclos cortos y ciclos largos. De esta forma se hace posible la comparación de los datos obtenidos alineados a criterios homogéneos.

El área de estudio de mayor participación de los graduados que respondieron la encuesta, corresponde al área de técnicas, y el área de economía y empresas, la Figura 5.7 muestra la distribución total de la muestra.

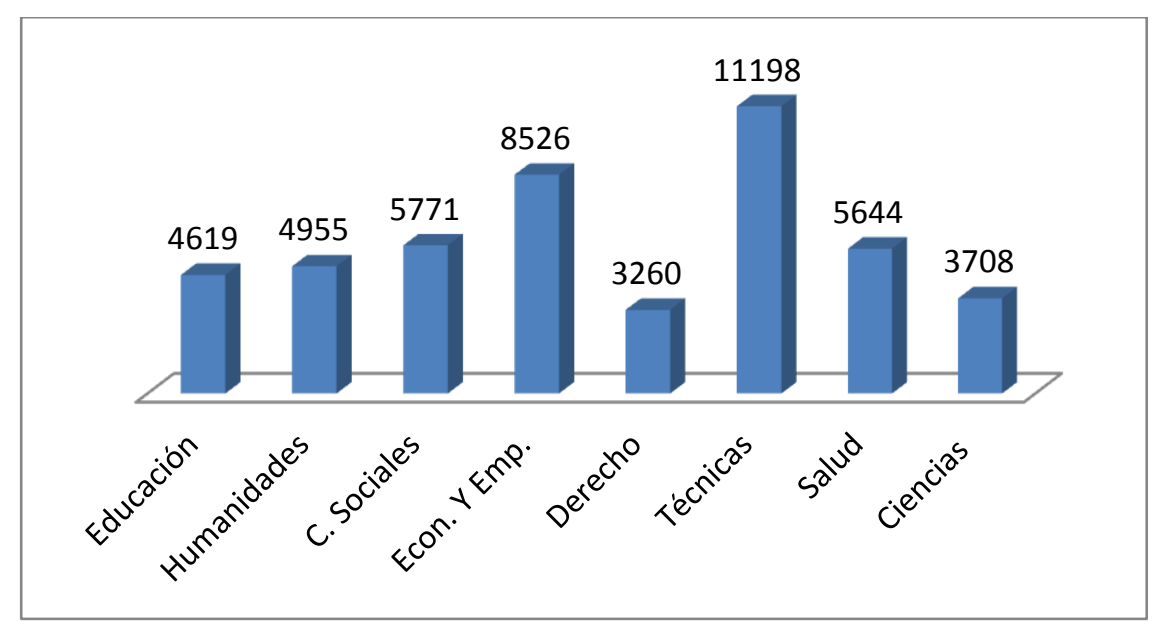

Figura 5. 7 Graduados Universitarios - Área de Estudio

La distribución es similar al comparar la información obtenida por países y continente, siendo las titulaciones que componen el área de técnicas las que tienen mayor participación (España, Alemania, Suiza, Chile, México). En el caso de Francia la mayor participación está en Ciencias, Reino Unido en Humanidades y en Salud los graduados de Uruguay. En Europa los graduados que pertenecen a carreras técnicas son el 21,7\% mientras que en Latinoamérica es de $30,6 \%$. En la tabla 5.4 se presenta la comparación entre los cinco países europeos de referencia, los tres países de Latinoamérica y la representación para Europa (14 países) y Latinoamérica (10 países). 
Tabla 5. $4 \%$ de Graduados según el área de estudio, país y continente

\begin{tabular}{|c|c|c|c|c|c|c|c|c|c|c|}
\hline $\begin{array}{c}\text { Área de } \\
\text { Estudio }\end{array}$ & ES & FR & DE & UK & CH & Europa & CL & Mx & UR & Latinoamérica \\
\hline Educación & $12,8 \%$ & $5,4 \%$ & $7,0 \%$ & $3,3 \%$ & $2,6 \%$ & $10,6 \%$ & $15,5 \%$ & $2,3 \%$ &, $9 \%$ & $6,1 \%$ \\
\hline Humanidades & $10,9 \%$ & $16,8 \%$ & $14,7 \%$ & $27,9 \%$ & $12,0 \%$ & $11,6 \%$ & $7,1 \%$ & $6,5 \%$ & $5,2 \%$ & $5,7 \%$ \\
\hline C. Sociales & $10,1 \%$ & $11,8 \%$ & $13,3 \%$ & $17,8 \%$ & $8,9 \%$ & $11,2 \%$ & $14,5 \%$ & $13,9 \%$ & $22,2 \%$ & $15,8 \%$ \\
\hline Econ. y Emp. & $16,7 \%$ & $14,4 \%$ & $13,9 \%$ & $13,1 \%$ & $14,7 \%$ & $17,6 \%$ & $15,2 \%$ & $21,2 \%$ & $18,1 \%$ & $18,9 \%$ \\
\hline Derecho & $9,6 \%$ & $10,2 \%$ & $5,7 \%$ & $4,2 \%$ & $9,6 \%$ & $6,5 \%$ & $4,6 \%$ & $9,8 \%$ & $3,0 \%$ & $8,3 \%$ \\
\hline Técnicas & $19,4 \%$ & $13,2 \%$ & $29,1 \%$ & $11,8 \%$ & $24,3 \%$ & $21,7 \%$ & $31,0 \%$ & $28,4 \%$ & $15,5 \%$ & $30,6 \%$ \\
\hline Salud & $9,1 \%$ & $8,2 \%$ & $7,5 \%$ & $7,3 \%$ & $17,3 \%$ & $12,5 \%$ & $5,7 \%$ & $12,2 \%$ & $26,7 \%$ & $9,4 \%$ \\
\hline Ciencias & $11,3 \%$ & $20,0 \%$ & $8,7 \%$ & $14,8 \%$ & $10,5 \%$ & $8,4 \%$ & $6,4 \%$ & $5,7 \%$ & $8,4 \%$ & $5,3 \%$ \\
\hline N & 5.410 & 1.671 & 1.692 & 1.566 & 4.882 & 37.948 & 2.968 & 4.620 & 670 & 9.733 \\
\hline
\end{tabular}

\subsubsection{Ocupación de los Profesionales Universitarios.}

El criterio de agrupación de las distintas ocupaciones, se realiza a partir de la clasificación internacional de ocupaciones $\mathrm{CIOU}-88$ que se puede consultar en el anexo C.

La clasificación se estructura mediante la agrupación del conjunto de cargos ejercidos por graduados de diversas titulaciones. Para establecer el tipo de ocupación se consideran aspectos que incluyen el tipo de función, responsabilidades, categoría, nivel de dificultad y el grado de especialización de la ocupación.

Este análisis de frecuencias responde a la pregunta sobre la ocupación de los graduados en el momento de la entrevista. El porcentaje mal alto corresponde a los que ocupan el cargo de profesional/científico (61\%), seguido por los que ocupan cargos de técnico de nivel medio $(19,6 \%)$ y empleados de oficina $(6,7 \%)$. La tabla 5.5 muestra la distribución de la muestra total de graduados teniendo como referencia los cinco amplios grupos de ocupación o cargos ocupados. 
Tabla 5. 5 Ocupación de los Graduados Universitarios

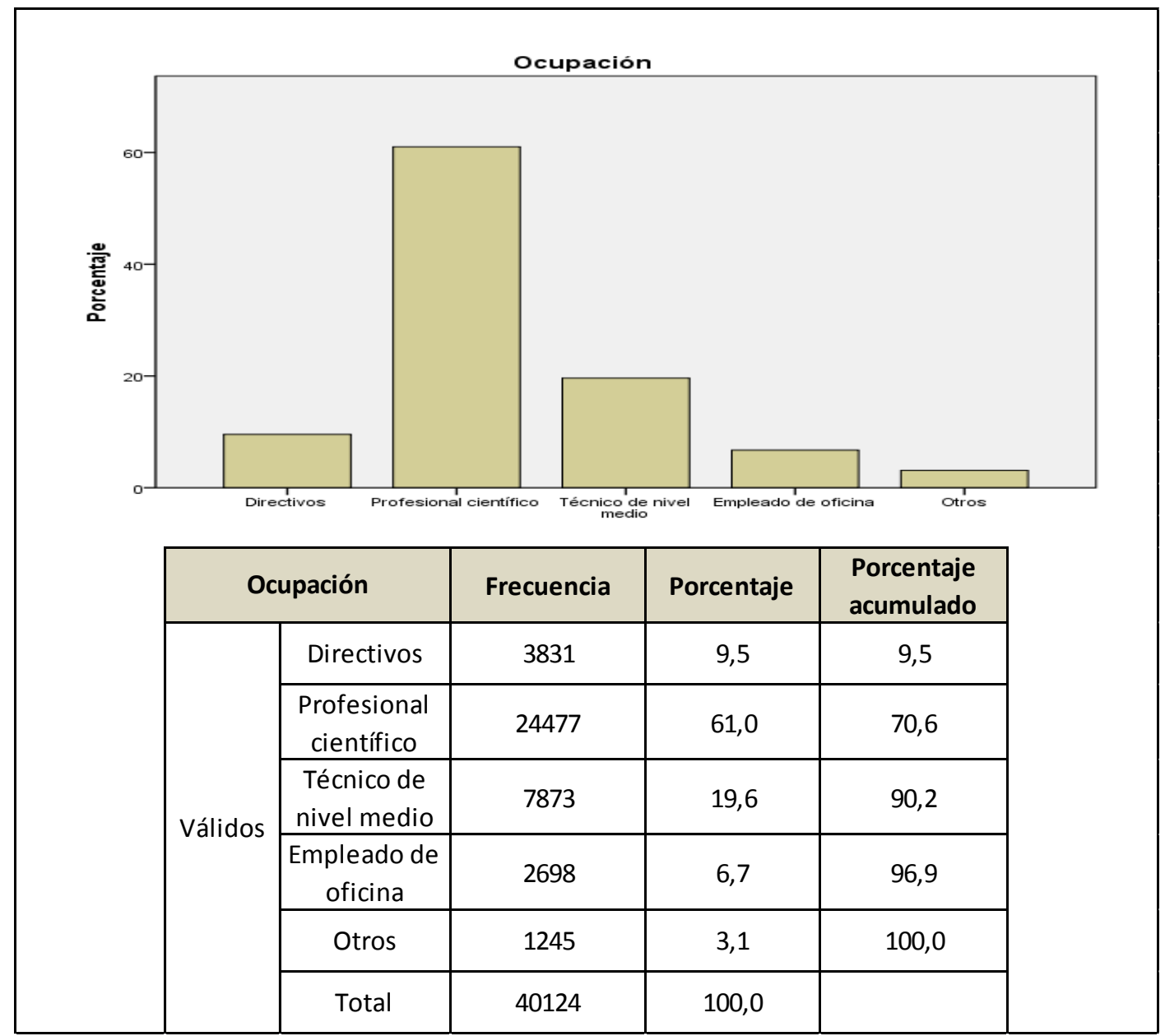

Las ocupaciones más representativas de la muestra están compuestas de la siguiente forma:

Directivos: En esta clasificación se incluyen los miembros del poder ejecutivo y de los cuerpos legislativos. Personal directivo de la administración pública y de empresas, directores de empresa, gerentes de empresa.

Profesional/científico: Agrupa profesionales científicos e intelectuales, en las diferentes áreas de conocimiento. Profesionales de nivel superior y otros profesionales científicos e intelectuales. Profesionales de las ciencias físicas, químicas, matemáticas, ingeniería y arquitectura. Profesionales de las ciencias biológicas, la medicina y la salud. Profesionales de la enseñanza. Incluye escritores, religiosos. 
Técnico de Nivel Medio: Técnicos y profesionales de nivel medio en las diferentes áreas de conocimiento (biológicas, medicina, químicas, ingeniería y afines). Otros técnicos y profesionales de nivel medio. Maestros e instructores de nivel medio, entre otras.

Empleados de Oficina: Oficinistas, empleados en trato directo con el público.

Otros: Agrupa trabajadores de los servicios de comercios y mercados, agricultores y trabajadores cualificados agropecuarios y pesqueros, oficiales operarios y artesanos de artes mecánicas y de otros oficios, operadores de instalaciones y máquinas y montadores, trabajadores no cualificados, otras ocupaciones / situaciones.

La ocupación de los graduados universitarios en el momento de la entrevista, en los países seleccionados y por continente se refleja en la tabla 5.6.

El 37,4\% de los españoles ocupan cargos de Técnico Medio y el 6,7\% cargos directivos, uno de los valores más bajos de la selección de países y por continente. En Francia El mayor porcentaje de respuestas corresponde a cargos de Profesional/científico $(67,5 \%)$ y el menor porcentaje corresponde a cargos de empleados de oficina $(2,8 \%)$.

El 78,9\% de los alemanes ocupan cargos de Profesional/científico y el 10,5\% ocupan cargos de Técnico de nivel medio. Los graduados del Reino Unido ocupan cargos de Profesional/científico $(50,8 \%)$ y el menor porcentaje corresponde a otros cargos $(5,2 \%)$. En el caso de los graduados de Suiza, el mayor porcentaje de respuestas corresponde a cargos de Profesional/científico $(63,7 \%)$ y el menor porcentaje corresponde a Empleados de oficina $(1,7 \%)$.

Tabla 5. 6 Ocupación de los Profesionales Universitarios (\% País)

\begin{tabular}{|c|c|c|c|c|c|c|c|c|c|c|}
\hline $\begin{array}{c}\text { País / } \\
\text { Ocupación }\end{array}$ & España & Francia & Alemania & $\begin{array}{c}\text { Reino } \\
\text { Unido }\end{array}$ & Suiza & $\begin{array}{c}\text { Europa } \\
(\mathbf{1 4})\end{array}$ & Chile & México & Uruguay & $\begin{array}{c}\text { Latinoamerica } \\
(\mathbf{1 0})\end{array}$ \\
\hline Directivos & $6,0 \%$ & $10,4 \%$ & $6,8 \%$ & $10,9 \%$ & $15,1 \%$ & $8,5 \%$ & $12,6 \%$ & $10,7 \%$ & $21,8 \%$ & $14,1 \%$ \\
\hline $\begin{array}{c}\text { Profesional } \\
\text { Científico }\end{array}$ & $30,4 \%$ & $67,5 \%$ & $78,9 \%$ & $50,8 \%$ & $63,7 \%$ & $63,1 \%$ & $59,6 \%$ & $53,9 \%$ & $36,2 \%$ & $51,8 \%$ \\
\hline $\begin{array}{c}\text { Técnico de } \\
\text { Nivel Medio }\end{array}$ & $37,4 \%$ & $15,9 \%$ & $10,5 \%$ & $22,2 \%$ & $15,6 \%$ & $20,5 \%$ & $17,5 \%$ & $14,3 \%$ & $19,9 \%$ & $16,0 \%$ \\
\hline $\begin{array}{c}\text { Empleado de } \\
\text { Oficina }\end{array}$ & $19,3 \%$ & $2,8 \%$ & $3,0 \%$ & $11,0 \%$ & $1,7 \%$ & $5,1 \%$ & $8,0 \%$ & $15,0 \%$ & $20,1 \%$ & $13,9 \%$ \\
\hline Otros & $6,9 \%$ & $3,4 \%$ &, $8 \%$ & $5,2 \%$ & $3,9 \%$ & $2,8 \%$ & $2,2 \%$ & $6,1 \%$ & $2,1 \%$ & $4,3 \%$ \\
\hline
\end{tabular}

Los graduados de Latinoamérica manifestaron ocupar cargos de Profesional/científico principalmente seguidos del cargo de directivos, esto puede ser un indicio de que la velocidad de ascenso es mayor para los graduados latinoamericanos que para los europeos. 
En el caso de Chile, el mayor porcentaje de respuestas corresponde a cargos de Profesional/científico (59,6\%), para los graduados de México es de 53,9\% y para los de Uruguay es $36,2 \%$.

En este apartado destaca que en todos los países de referencia excepto en España (Cargos de Técnico Medio) el cargo de profesional/científico es la ocupación con mayoría de respuestas tanto de Europa como de Latinoamérica. De igual forma los graduados españoles son los que en menor proporción ocupan cargos directivos $(6,0 \%)$, uno de los valores más bajos de la selección de países y por continente.

\subsubsection{Tipo de Contrato de los Profesionales Universitarios}

En Europa se definen tres tipos de contrato (Indefinido, duración limitada, honorarios) y en Latinoamérica se definen cuatro tipos de contrato (Indefinido, duración limitada, honorarios y otros). La Figura 5.8 muestra la distribución de los diferentes tipos de contrato.

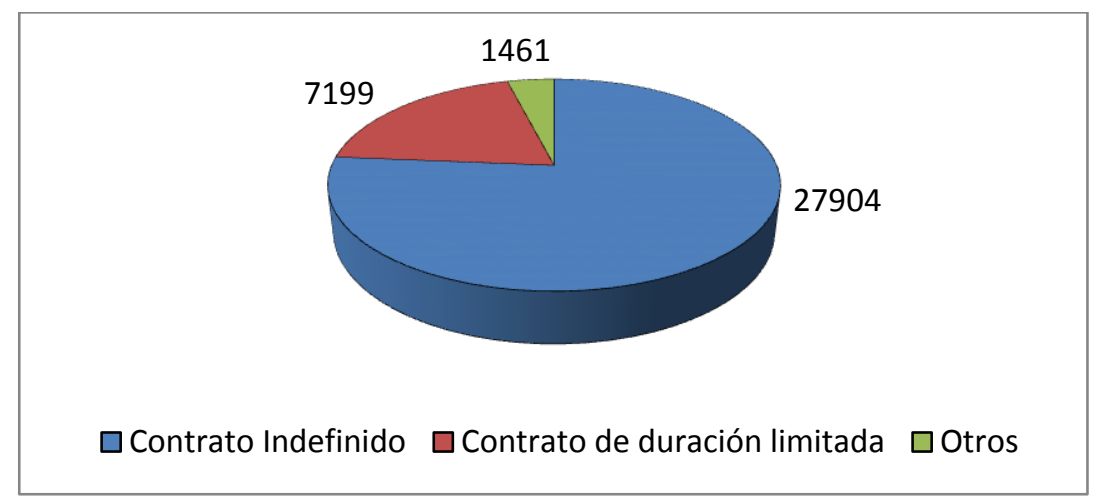

Figura 5. 8 Profesionales Universitarios - Tipo de Contrato

Los graduados de ambos continentes tienen mayoritariamente contratos de duración indefinida, seguidos por contratos de duración limitada.

Comparando las frecuencias entre países, destaca que Reino Unido (82,5\%, Suiza (79,5\%), Francia $(78,4 \%)$, Alemania $(76,7 \%)$, España $(60,4 \%)$ en este orden descendente, los graduados tienen contratos indefinidos.

Con respecto a contratos de duración determinada el mayor porcentaje de graduados que manifestaron tener esa modalidad pertenecen a España (31,3\%), así como de contratos en modalidad honorarios $(8,3 \%)$. 
En la tabla 5.7 se representa el porcentaje de graduados universitario para cada uno de los países seleccionados, así como el porcentaje para el conjunto de países de la muestra por Continente.

Tabla 5. 7 Tipo de Contrato de los Profesionales Universitarios (\% País - \% Continente)

\begin{tabular}{|c|c|c|c|c|c|c|c|c|c|c|}
\hline $\begin{array}{c}\text { País / } \\
\text { Tipo } \\
\text { Contrato }\end{array}$ & España & Francia & Alemania & $\begin{array}{l}\text { Reino } \\
\text { Unido }\end{array}$ & Suiza & $\begin{array}{c}\text { Europa } \\
\text { (14) }\end{array}$ & Chile & México & Uruguay & $\begin{array}{c}\text { L.América } \\
\text { (10) }\end{array}$ \\
\hline $\begin{array}{l}\text { Contrato } \\
\text { indefinido }\end{array}$ & $60,40 \%$ & $78,40 \%$ & $76,70 \%$ & $82,50 \%$ & $79,50 \%$ & $77,09 \%$ & $70,40 \%$ & $72,70 \%$ & $82,12 \%$ & $73,06 \%$ \\
\hline $\begin{array}{c}\text { Contrato } \\
\text { de } \\
\text { duración } \\
\text { limitada }\end{array}$ & $31,30 \%$ & $20,50 \%$ & $23,20 \%$ & $15,90 \%$ & $20,10 \%$ & $20,53 \%$ & $15,10 \%$ & $16,50 \%$ & $17,03 \%$ & $16,14 \%$ \\
\hline Otros & $8,30 \%$ & $1,10 \%$ & $0,20 \%$ & $1,60 \%$ & $0,40 \%$ & $2,38 \%$ & $14,50 \%$ & $10,80 \%$ & $0,85 \%$ & $10,80 \%$ \\
\hline
\end{tabular}

La categoría otros incluye los contratos en Europa correspondiente a becarios y contrato a honorarios. En Latinoamérica corresponde a contrato de obra y servicio.

Con relación a los países latinoamericanos, los graduados universitarios de Uruguay $(82,1 \%)$ son contratados mediante contrato indefinido, seguidos por los de México $(72,7 \%)$ y Chile $(70,4 \%)$. El contrato por honorarios y otros son modalidades de contratación de uso en Chile $(14,5 \%)$ y México $(10,8 \%)$, en el caso de Uruguay el porcentaje es de $0,85 \%$.

\subsubsection{Sector Económico}

Los graduados entrevistados en Europa y Latinoamérica, en su mayoría trabajaban en el momento de la entrevista principalmente en el sector servicios $(19,7 \%)$, seguidos del sector Educación $(19,4 \%)$, sector salud $(14,5 \%)$ y sector industria $(11,6 \%)$. La figura 5.9 muestra la distribución por continente para todos los sectores económicos en los que se distribuye la participación de los graduados de la muestra. 


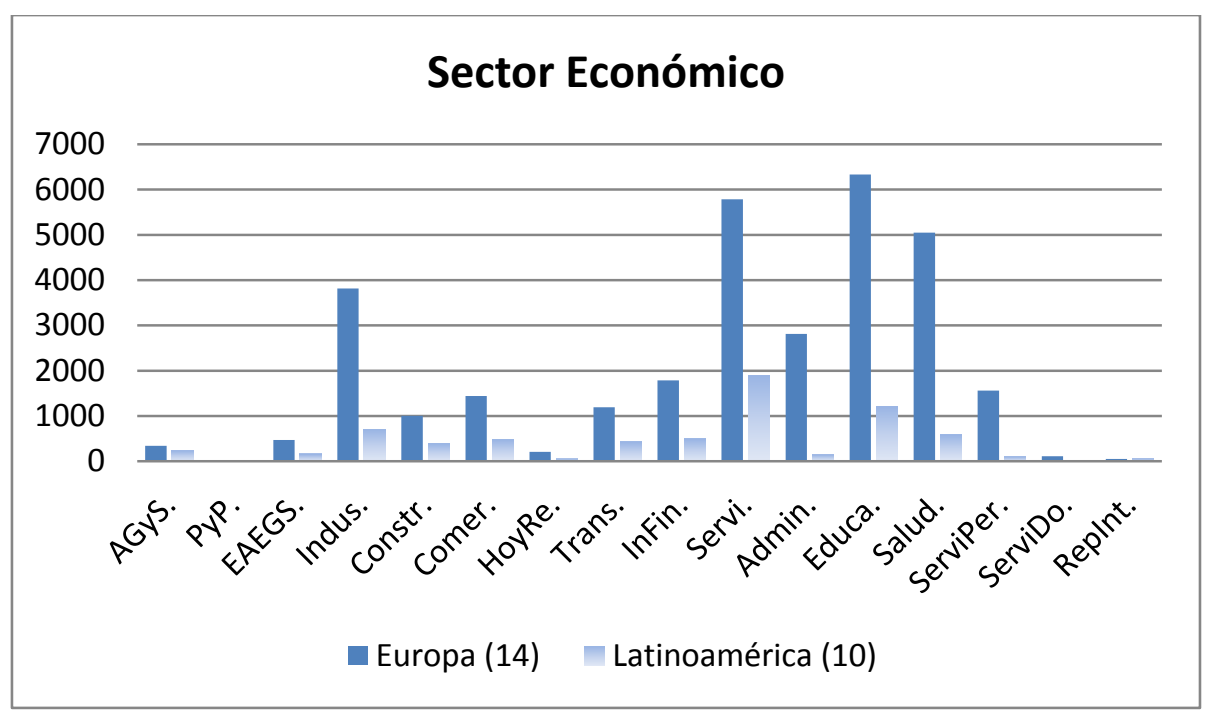

Figura 5. 9 Sector Económico en el que trabajan los Profesionales Universitarios

\section{a. Sector económico en el que trabajan los Profesionales por País}

En Europa la mayor participación de los graduados que respondieron la encuesta corresponde al sector Educación, es el caso de Francia, Alemania, Reino Unido y España. El $20,9 \%$ de los graduados de Suiza trabajan en el sector Servicios.

Para el grupo de Latinoamérica la mayor participación corresponde al sector servicios en México y Uruguay, mientras en Chile la mayor participación de los graduados está en el sector educación. La tabla 5.8 muestra la participación por número y porcentaje en cada uno de los sectores económicos. 
Tabla 5. 8 Sector Económico en el que trabajan los Profesionales Universitarios (\% y № /País)

\begin{tabular}{|c|c|c|c|c|c|c|c|c|c|c|}
\hline $\begin{array}{l}\text { País / Sec. } \\
\text { Económico }\end{array}$ & España & Francia & Alemania & $\begin{array}{l}\text { Reino } \\
\text { Unido }\end{array}$ & Suiza & $\begin{array}{c}\text { Europa } \\
\text { (14) }\end{array}$ & Chile & México & Uruguay & $\begin{array}{c}\text { Latinoamérica } \\
\text { (10) }\end{array}$ \\
\hline \multirow{2}{*}{$\begin{array}{l}\text { Agricultura, } \\
\text { ganadería y } \\
\text { silvicultura }\end{array}$} & 65 & 12 & 18 & 9 & 30 & 341 & 84 & 144 & 3 & 241 \\
\hline & $1,5 \%$ & ,9\% & $1,3 \%$ & ,7\% & ,8\% & $1,1 \%$ & $3,8 \%$ & $4,2 \%$ & ,6\% & $3,4 \%$ \\
\hline \multirow{2}{*}{$\begin{array}{c}\text { Pesca y } \\
\text { piscicultura }\end{array}$} & 13 & 1 & 3 & 0 & 0 & 24 & 18 & 4 & 2 & 24 \\
\hline & ,3\% & ,1\% & ,2\% &, $0 \%$ &, $0 \%$ & ,1\% &, $8 \%$ & ,1\% & ,4\% & ,3\% \\
\hline $\begin{array}{c}\text { Energía y agua. } \\
\text { Electricidad, gas } \\
\text { y suministros. }\end{array}$ & 130 & 9 & 12 & 17 & 21 & 471 & 46 & 84 & 8 & 161 \\
\hline \multirow{2}{*}{ Industria } & 350 & 168 & 195 & 129 & 406 & 3816 & 139 & 426 & 59 & 704 \\
\hline & $8,3 \%$ & $12,1 \%$ & $13,8 \%$ & $9,4 \%$ & $11,1 \%$ & $11,9 \%$ & $6,3 \%$ & $12,5 \%$ & $11,6 \%$ & $10,0 \%$ \\
\hline \multirow{2}{*}{ Construcción } & 302 & 21 & 53 & 35 & 33 & 1003 & 110 & 176 & 16 & 397 \\
\hline & $7,2 \%$ & $1,5 \%$ & $3,8 \%$ & $2,6 \%$ & ,9\% & $3,1 \%$ & $5,0 \%$ & $5,1 \%$ & $3,1 \%$ & $5,7 \%$ \\
\hline \multirow{2}{*}{ Transportes } & 222 & 76 & 34 & 35 & 115 & 1192 & 104 & 196 & 40 & 426 \\
\hline & $5,3 \%$ & $5,5 \%$ & $2,4 \%$ & $2,6 \%$ & $3,1 \%$ & $3,7 \%$ & $4,7 \%$ & $5,7 \%$ & $7,8 \%$ & $6,1 \%$ \\
\hline \multirow{2}{*}{$\begin{array}{c}\text { Instituciones } \\
\text { financieras }\end{array}$} & 279 & 78 & 58 & 80 & 324 & 1788 & 138 & 221 & 32 & 493 \\
\hline & $6,6 \%$ & $5,6 \%$ & $4,1 \%$ & $5,9 \%$ & $8,8 \%$ & $5,6 \%$ & $6,3 \%$ & $6,5 \%$ & $6,3 \%$ & $7,0 \%$ \\
\hline \multirow{2}{*}{ Servicios } & 425 & 201 & 277 & 262 & 765 & 5784 & 621 & 897 & 139 & 1902 \\
\hline & $10,1 \%$ & $14,5 \%$ & $19,6 \%$ & $19,2 \%$ & $20,9 \%$ & $18,1 \%$ & $28,4 \%$ & $26,2 \%$ & $27,3 \%$ & $27,1 \%$ \\
\hline \multirow{2}{*}{ Administración } & 353 & 87 & 85 & 154 & 408 & 2813 & 21 & 82 & 21 & 151 \\
\hline & $8,4 \%$ & $6,3 \%$ & $6,0 \%$ & $11,3 \%$ & $11,1 \%$ & $8,8 \%$ & $1,0 \%$ & $2,4 \%$ & $4,1 \%$ & $2,2 \%$ \\
\hline \multirow{2}{*}{ Educación } & 806 & 374 & 357 & 310 & 618 & 6330 & 648 & 404 & 91 & 1218 \\
\hline & $19,2 \%$ & $27,0 \%$ & $25,3 \%$ & $22,7 \%$ & $16,8 \%$ & $19,8 \%$ & $29,6 \%$ & $11,8 \%$ & $17,8 \%$ & $17,4 \%$ \\
\hline Salud & 497 & 186 & 201 & 213 & 561 & 5048 & 93 & 449 & 19 & 588 \\
\hline Total & 4208 & 1385 & 1413 & 1366 & 3668 & 31983 & 2190 & 3420 & 510 & 7017 \\
\hline País/Continente & $100,0 \%$ & $100,0 \%$ & $100,0 \%$ & $100,0 \%$ & $100,0 \%$ & $100,0 \%$ & $100,0 \%$ & $100,0 \%$ & $100,0 \%$ & $100,0 \%$ \\
\hline
\end{tabular}

\section{b. Sector al que pertenece la Organización donde trabajan los graduados}

En este apartado se hace una descripción del sector (público/privado) al que pertenecen las organizaciones donde trabajan los graduados de la muestra.(Figura 5.10).

Se consideraron cuatro tipos de organización: sector público, sector privado, sector privado sin fines de lucro y otros. En el momento de la entrevista se preguntó por la pertenencia al sector público o privado de la organización en que trabajaban: El 46,1\% de graduados que respondieron la encuesta en Francia y el 49\% del Reino Unido, manifestaron trabajar en organizaciones del sector público. 
En el sector privado trabajan mayoritariamente el 59,8\% de los graduados de España, el $50,8 \%$ de los alemanes y el $47,2 \%$ de los suizos. Para el conjunto de los 14 países de Europa trabajan en el sector privado el $49,7 \%$ y en el sector público el $41,2 \%$ de los graduados que respondieron a esta cuestión.

En el caso de los graduados latinoamericanos las respuestas mayoritarias corresponden a organizaciones del sector privado: Uruguay $(62,1 \%)$, Chile $(60,8 \%)$, México (60,6\%). La comparación para Latinoamérica (10 países), corresponde al sector privado (62,9\%) y en el sector público $(29,5 \%)$ que es marcadamente inferior que en los países europeos.

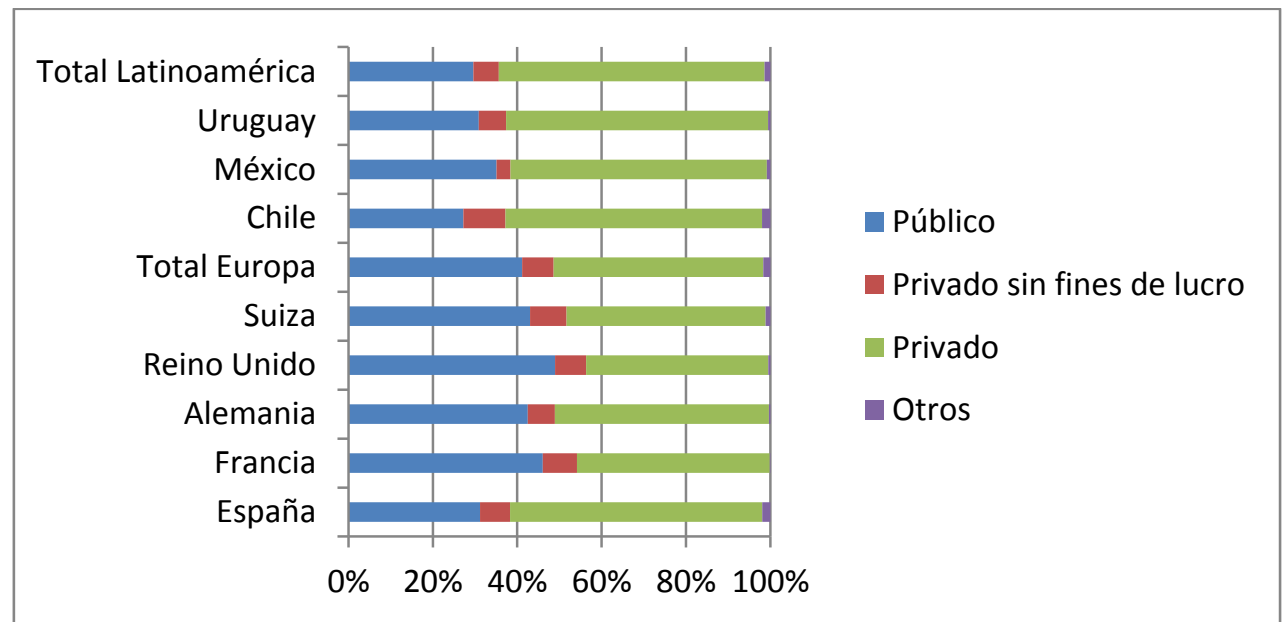

Figura 5. 10 Sector Económico donde trabajan los Graduados Universitarios

\subsubsection{Tamaño de la Organización}

Se preguntó a los graduados acerca del tamaño de la organización donde trabajaban. En Europa, el 33,90\% de los graduados manifestaron trabajar en empresas grandes (1000 o más trabajadores); mientras que el $17,3 \%$ lo hacen en empresas de tamaño mediano. En el caso de Latinoamérica, el $29,60 \%$ de los graduados manifestaron trabajar en empresas grandes y el $17,3 \%$ lo hacen en empresas de tamaño mediano. La Figura 5.11 muestra la distribución del porcentaje de los graduados universitarios según tamaño de la organización y por continente. 


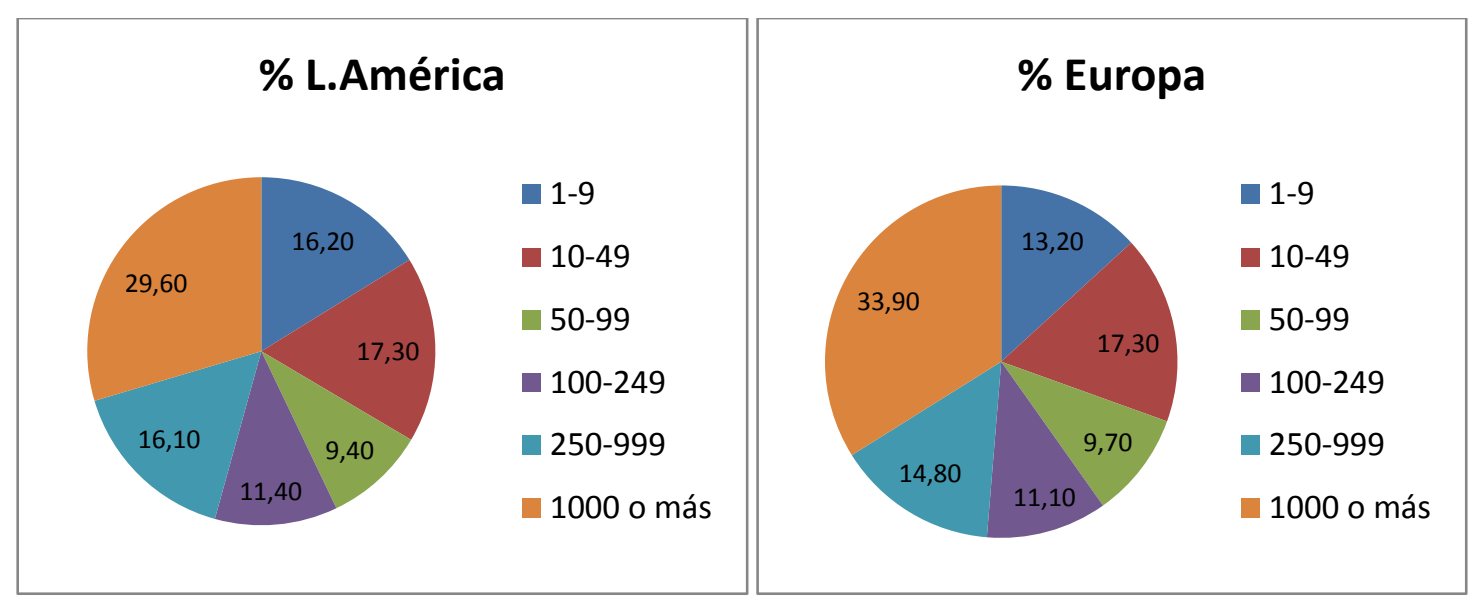

Figura 5. 11 Tamaño de las Organizaciones donde Trabajan los Graduados Universitarios

En el caso de las organizaciones que tienen una distribución por delegaciones territoriales, el número de trabajadores es menor. Es así como en Europa los graduados trabajan generalmente en delegaciones de tamaño mediano (10 a 49 trabajadores) con excepción de España, país en el que los graduados universitarios trabajan en delegaciones que suelen ser de tamaño pequeño (1 a 9 trabajadores). En Latinoamérica, la mayoría de graduados trabajan en organizaciones que solo tienen un establecimiento. En este apartado, el nivel de respuesta se redujo del $80,9 \%$ al $68 \%$.

\subsection{2.Éxito Laboral}

\subsubsection{Promedio de Horas de dedicación en el trabajo}

A los graduados universitarios se les preguntó cuántas horas semanales dedicaban al trabajo, según contrato en el trabajo principal, las horas extras, las horas dedicadas en otros trabajos y el total. Como puede verse en la Figura 5.12 la media de horas de dedicación de los graduados de Latinoamérica es un poco mayor que la de los graduados europeos, con especial diferencia en lo que corresponde a las horas extras y horas en otros trabajos. 


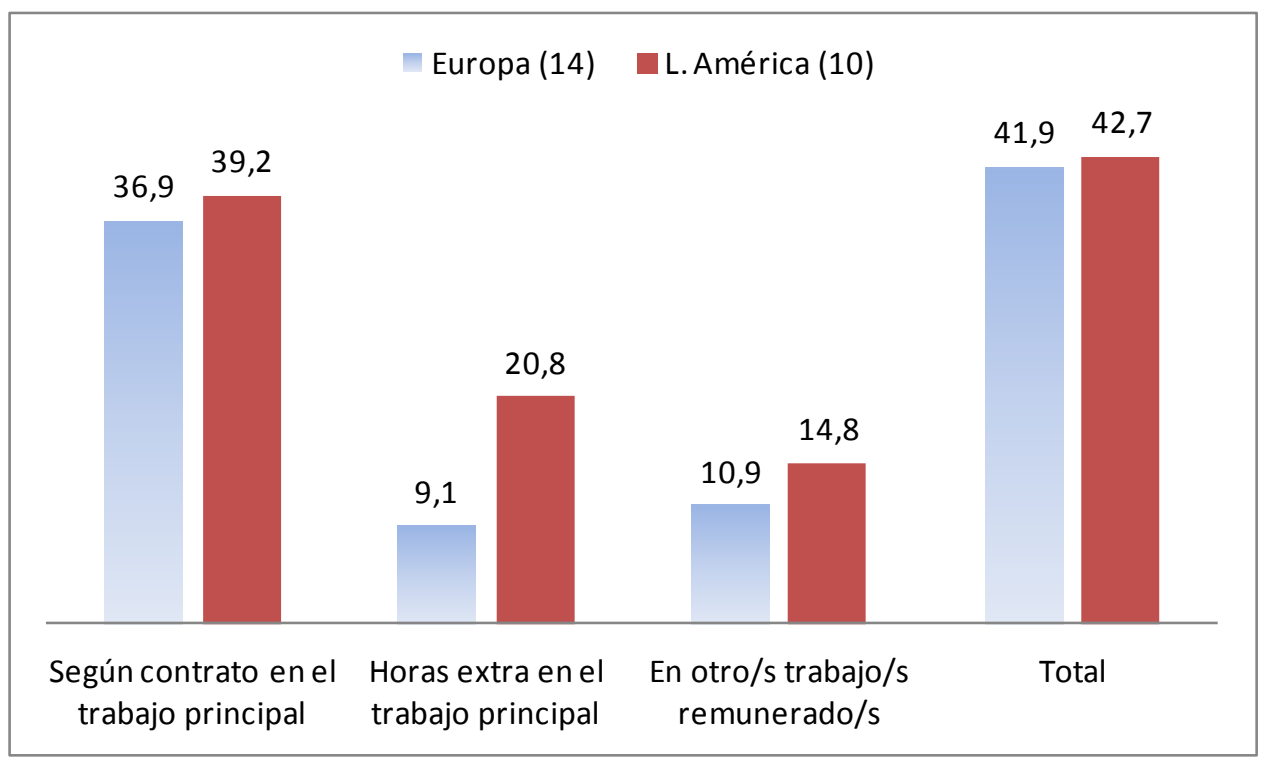

Figura 5. 12 Horas de dedicación semanal al trabajo por continente (Media aritmética)

Siguiendo la línea anterior, al realizar una comparación entre los países seleccionados de la muestra (tabla 5.9), los graduados de Chile y de Alemania son los que dedican más horas de trabajo. En el caso de los graduados de Uruguay hubo un problema en la codificación y por lo tanto no se considera fiable la información obtenida de esta variable (Informe PROFLEX, 2010).

Tabla 5. 9 Horas de dedicación semana al trabajo por País (Media aritmética)

\begin{tabular}{|c|c|c|c|c|c|c|c|c|c|c|}
\hline $\begin{array}{c}\text { Promedio de Horas } \\
\text { de Trabajo a la } \\
\text { Semana }\end{array}$ & España & Francia & Alemania & R. Unido & Suiza & Europa (14) & Chile & México & Uruguay & L. América (10) \\
\hline $\begin{array}{l}\text { Según contrato en el } \\
\text { trabajo principal }\end{array}$ & 36,4 & 33,8 & 37,4 & 37,5 & 37,6 & 36,9 & 40,3 & 36,3 & N.D. & 39,2 \\
\hline $\begin{array}{l}\text { Horas extra en el } \\
\text { trabajo principal }\end{array}$ & 10,1 & 12,0 & 10,1 & 9,7 & 8,3 & 9,1 & 28,7 & 20,4 & N.D & 20,8 \\
\hline $\begin{array}{c}\text { En otro/s trabajo/s } \\
\text { remunerado/s }\end{array}$ & 14,5 & 9,0 & 10,0 & 15,9 & 9,1 & 10,9 & 13,2 & 15,0 & N.D. & 14,8 \\
\hline Total & 40,2 & 39,5 & 43,8 & 43,2 & 42,6 & 41,9 & 44,2 & 38,6 & N.D. & 42,7 \\
\hline Número Total $(\mathrm{N})$ & 4561 & 1377 & 1508 & 1364 & 4270 & 33015 & 2456 & 3760 & 661 & 8054 \\
\hline
\end{tabular}

\subsubsection{Salario Mensual de las Profesionales Universitarios}

Se utilizan los valores elaborados en el informe Proflex (2010) que empleaban el índice de Paridad de Poder Adquisitivo (PPA) para homogeneizar los valores brutos de salario de los distintos países en Euros. Además, para obtener los valores finales de salario en dólares USD, se utilizaron los índices de precios al consumidor (IPC) para el año 2013. En el anexo G, se muestra el procedimiento realizado para la obtención de la información. 
La tabla 5.10 muestra el salario promedio mensual bruto por país en dólares americanos (USD) corregidos por el Índice de precios al consumidor (IPC), para los países considerados.

El salario total, está compuesto del sueldo según contrato, la realización de horas extras o comisiones y otro/s ingresos del trabajo. Los sueldos totales de los graduados europeos son superiores al conjunto de los graduados latinoamericanos.

El salario según contrato de los graduados de países europeos, registran valores elevados en comparación con el de los graduados de Latinoamérica. Los salarios más altos en Europa corresponden a los graduados de Alemania y Suiza, siendo el salario más bajo el de los graduados Españoles. En Latinoamérica los graduados de Chile, perciben los mayores salarios.

Tabla 5. 10 Salario Mensual Bruto según contrato y total en Dólares USD y Dólares USD (IPC) por país (Media aritmética)

\begin{tabular}{|l|c|c|c|c|}
\hline \multirow{2}{*}{\multicolumn{1}{|c|}{ PAISES }} & \multicolumn{2}{|c|}{ Salario según Contrato } & \multicolumn{2}{c|}{ Salario Total } \\
\cline { 2 - 5 } & USD & $\begin{array}{c}\text { USD } \\
\text { (IPC_2013) }\end{array}$ & USD & $\begin{array}{c}\text { USD } \\
\text { (IPC_2013) }\end{array}$ \\
\hline España - ES & 1750 & 1695 & 1815 & 1758 \\
\hline Francia - FR & 2576 & 2074 & 2618 & 2108 \\
\hline Alemania - DE & 3796 & 3444 & 4584 & 4158 \\
\hline Reino Unido - UK & 3229 & 2626 & 3343 & 2718 \\
\hline Suiza - CH & 5068 & 2776 & 5548 & 3039 \\
\hline Unión Europea- UE & 2757 & N.A. & 2940 & N.A. \\
\hline Chile - CL & 1698 & 2212 & 1863 & 2427 \\
\hline México - MX & 991 & 1538 & 1193 & 1853 \\
\hline Uruguay - UR & 1190 & 1212 & 1353 & 1377 \\
\hline Latinoamérica - LA & 1301 & N.A. & 1605 & N.A. \\
\hline
\end{tabular}

Fuente: Elaboración Propia a partir del Informe PROFLEX (2010)

A continuación se analiza la valoración que los graduados hicieron del trabajo que ocupaban en el momento de la entrevista, en tres aspectos concretos: El grado de uso de los conocimientos y habilidades, los requerimientos del trabajo y el grado de satisfacción con el 
trabajo. En la encuesta se utilizaron Escalas Likert, (1=Nada, 5=Mucho), por lo que se define a las variables del análisis como variables ordinales.

\subsubsection{Uso de conocimientos}

Al preguntar a los graduados universitarios de Europa y Latinoamérica: ¿En qué medida usas tus conocimientos y habilidades en tu trabajo actual?. La mayor parte de graduados de Latinoamérica $(79,40 \%)$ afirmaron que es alto o muy alto el uso que hacen de los conocimientos y habilidades, mientras que en Europa la proporción es algo menor (71,5\%). En la tabla 5.11 se refleja la comparativa para los ocho países de la selección y la proporción para Europa (14 países) y Latinoamérica (10 países).

Tabla 5. 11 Uso de Conocimientos y habilidades en el Trabajo actual (\%)

\begin{tabular}{|c|c|c|c|c|c|c|c|c|c|c|}
\hline & España & Francia & Alemania & $\begin{array}{l}\text { Reino } \\
\text { Unido }\end{array}$ & Suiza & $\begin{array}{c}\text { Europa } \\
(14)\end{array}$ & Chile & México & Uruguay & $\begin{array}{c}\text { L. América } \\
\text { (10) }\end{array}$ \\
\hline Nada: 1 & $6,8 \%$ & $2,9 \%$ &, $8 \%$ & $4,0 \%$ &, $9 \%$ & $2,4 \%$ &, $9 \%$ & $1,9 \%$ &, $7 \%$ & $1,3 \%$ \\
\hline 2 & $9,3 \%$ & $9,6 \%$ & $8,2 \%$ & $9,6 \%$ & $6,1 \%$ & $7,1 \%$ & $3,2 \%$ & $4,0 \%$ & $4,0 \%$ & $3,7 \%$ \\
\hline 3 & $19,6 \%$ & $19,8 \%$ & $18,3 \%$ & $19,9 \%$ & $19,0 \%$ & $19,0 \%$ & $12,9 \%$ & $17,7 \%$ & $18,8 \%$ & $15,7 \%$ \\
\hline 4 & $30,6 \%$ & $38,1 \%$ & $41,7 \%$ & $32,0 \%$ & $39,4 \%$ & $36,1 \%$ & $29,7 \%$ & $32,1 \%$ & $27,6 \%$ & $31,3 \%$ \\
\hline Mucho: 5 & $33,6 \%$ & $29,5 \%$ & $31,0 \%$ & $34,4 \%$ & $34,6 \%$ & $35,4 \%$ & $53,4 \%$ & $44,3 \%$ & $48,9 \%$ & $48,1 \%$ \\
\hline Total (N) & 4683 & 1392 & 1504 & 1379 & 4431 & 33666 & 2466 & 3930 & 554 & 8187 \\
\hline
\end{tabular}

\subsubsection{Conocimientos requeridos}

Para conocer los requerimientos del trabajo, los graduados universitarios respondieron a la pregunta: ¿En qué medida tu trabajo actual requiere más conocimientos y habilidades de los que tú puedes ofrecer?

El $45,9 \%$ de los graduados europeos y el al $29,6 \%$ de los graduados de Latinoamérica dieron una valoración baja (1 y 2 ) a esta pregunta. Estos resultados, podrían dar una pauta sobre la relación que puede tener el ajuste entre el área de conocimiento y el trabajo actual, el grado de uso de los conocimientos y habilidades y la posibilidad de responder a los requerimientos del trabajo. La tabla 5.12 refleja las frecuencias relativas obtenidas, para los ocho países de la selección. 
Tabla 5. 12 Requerimiento de conocimientos y habilidades (\%)

\begin{tabular}{|c|c|c|c|c|c|c|c|c|c|c|}
\hline & España & Francia & Alemania & $\begin{array}{l}\text { Reino } \\
\text { Unido }\end{array}$ & Suiza & $\begin{array}{c}\text { Europa } \\
\text { (14) }\end{array}$ & Chile & México & Uruguay & $\begin{array}{c}\text { L. } \\
\text { América } \\
(10)\end{array}$ \\
\hline Nada: 1 & $19,3 \%$ & $15,4 \%$ & $10,9 \%$ & $17,8 \%$ & $13,5 \%$ & $13,5 \%$ & $7,8 \%$ & $9,7 \%$ & $7,4 \%$ & $8,5 \%$ \\
\hline 2 & $29,1 \%$ & $35,9 \%$ & $32,3 \%$ & $28,9 \%$ & $37,8 \%$ & $32,4 \%$ & $23,2 \%$ & $18,4 \%$ & $23,0 \%$ & $21,1 \%$ \\
\hline 3 & $28,3 \%$ & $31,5 \%$ & $31,3 \%$ & $28,0 \%$ & $29,6 \%$ & $30,4 \%$ & $31,3 \%$ & $30,7 \%$ & $32,7 \%$ & $30,9 \%$ \\
\hline 4 & $17,3 \%$ & $13,4 \%$ & $21,6 \%$ & $19,7 \%$ & $15,9 \%$ & $18,7 \%$ & $21,1 \%$ & $24,5 \%$ & $21,8 \%$ & $23,3 \%$ \\
\hline Mucho: 5 & $6,0 \%$ & $3,8 \%$ & $3,8 \%$ & $5,6 \%$ & $3,1 \%$ & $4,9 \%$ & $16,6 \%$ & $16,6 \%$ & $15,1 \%$ & $16,1 \%$ \\
\hline Total (N) & 4683 & 1386 & 1503 & 1376 & 4431 & 33608 & 2467 & 3930 & 556 & 8188 \\
\hline
\end{tabular}

\subsubsection{Satisfacción con el trabajo actual}

A la pregunta, ¿En general, estás satisfecho con tu trabajo actual?. La mayoría de los graduados universitarios manifestaron estar satisfechos con el trabajo que tenían en el momento de la entrevista, aunque esa satisfacción es mayor en el caso de los latinoamericanos.

Tabla 5. 13 Grado de Satisfacción en el Trabajo actual (\%)

\begin{tabular}{|c|c|c|c|c|c|c|c|c|c|c|}
\hline & España & Francia & Alemania & $\begin{array}{l}\text { Reino } \\
\text { Unido }\end{array}$ & Suiza & $\begin{array}{c}\text { Europa } \\
(14)\end{array}$ & Chile & México & Uruguay & $\begin{array}{c}\text { L. América } \\
\text { (10) }\end{array}$ \\
\hline Muy Insatisfecho: 1 & $5,0 \%$ & $4,5 \%$ & $3,3 \%$ & $4,0 \%$ & $2,2 \%$ & $2,8 \%$ & $1,9 \%$ & $2,7 \%$ & $2,2 \%$ & $2,3 \%$ \\
\hline 2 & $9,8 \%$ & $7,8 \%$ & $8,8 \%$ & $10,4 \%$ & $8,2 \%$ & $8,0 \%$ & $4,8 \%$ & $5,1 \%$ & $4,3 \%$ & $5,1 \%$ \\
\hline 3 & $21,9 \%$ & $19,7 \%$ & $18,2 \%$ & $21,0 \%$ & $18,7 \%$ & $21,2 \%$ & $17,5 \%$ & $16,1 \%$ & $15,8 \%$ & $17,2 \%$ \\
\hline 4 & $37,3 \%$ & $36,1 \%$ & $41,4 \%$ & $37,1 \%$ & $38,5 \%$ & $40,8 \%$ & $39,0 \%$ & $32,2 \%$ & $38,7 \%$ & $35,4 \%$ \\
\hline Muy Satisfecho: 5 & $26,0 \%$ & $31,9 \%$ & $28,3 \%$ & $27,5 \%$ & $32,4 \%$ & $27,2 \%$ & $36,8 \%$ & $43,9 \%$ & $39,0 \%$ & $40,0 \%$ \\
\hline Total (N) & 4683 & 1403 & 1507 & 1380 & 4433 & 33633 & 2472 & 3923 & 557 & 8192 \\
\hline
\end{tabular}

\subsubsection{Rol - Funciones}

\subsubsection{1 Área de estudios apropiada al trabajo actual}

En este apartado se preguntó a los graduados si el área de estudio era la más apropiada para el trabajo que estaban realizando. Los graduados Europeos $(85,1 \%)$ y los graduados latinoamericanos $(90,8 \%)$, manifestaron realizar un trabajo que corresponde exclusivamente al área de estudio, la propia área de estudios o alguna relacionada. Ver figura 5.13. 


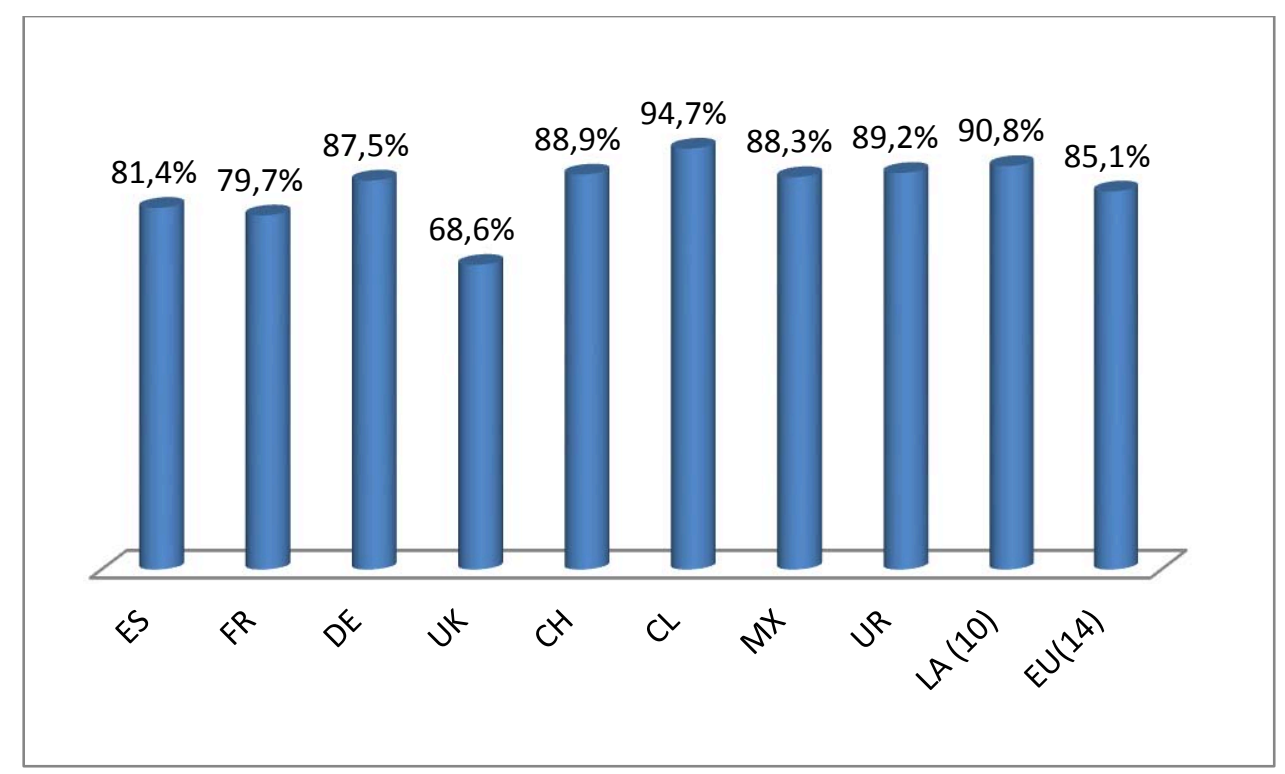

Figura 5. 13 Ajuste entre el área de estudio en la universidad y la requerida en el trabajo

Al realizar la comparación entre el conjunto de países seleccionados, la tabla 5.14 muestra que los graduados de los ocho países seleccionados ocupan trabajos relacionados con su propia área o alguna relacionada, seguidos por los que ocupan en su mayoría trabajos que corresponden exclusivamente a su propia área de estudios. En el otro extremo, destaca que el $20,1 \%$ de los graduados universitarios de Reino Unido manifestaron ocupar trabajos que no tienen que ver con ningún área en particular, un valor muy superior al manifestado por el conjunto de graduados europeos $(7,9 \%)$.

Tabla 5. 14 Ajuste entre el área de estudio en la universidad y la requerida en el trabajo por país (porcentaje)

\begin{tabular}{|c|c|c|c|c|c|c|c|c|c|c|}
\hline & España & Francia & Alemania & $\begin{array}{c}\text { Reino } \\
\text { Unido }\end{array}$ & Suiza & $\begin{array}{c}\text { Europa } \\
(14)\end{array}$ & Chile & México & Uruguay & $\begin{array}{c}\text { L. América } \\
(10)\end{array}$ \\
\hline $\begin{array}{c}\text { Exclusivamente tu } \\
\text { propia área de } \\
\text { estudios }\end{array}$ & $26,7 \%$ & $35,4 \%$ & $33,7 \%$ & $26,7 \%$ & $37,2 \%$ & $31,8 \%$ & $40,2 \%$ & $33,3 \%$ & $23,0 \%$ & $34,7 \%$ \\
\hline $\begin{array}{c}\text { Tu propia área o } \\
\text { alguna relacionada }\end{array}$ & $54,7 \%$ & $44,3 \%$ & $53,8 \%$ & $41,9 \%$ & $51,7 \%$ & $53,3 \%$ & $54,5 \%$ & $55,0 \%$ & $66,2 \%$ & $56,1 \%$ \\
\hline $\begin{array}{c}\text { Un área totalmente } \\
\text { diferente }\end{array}$ & $8,2 \%$ & $7,8 \%$ & $4,7 \%$ & $11,3 \%$ & $4,8 \%$ & $7,0 \%$ & $2,9 \%$ & $6,6 \%$ & $6,2 \%$ & $5,2 \%$ \\
\hline $\begin{array}{c}\text { Ningún área en } \\
\text { particular }\end{array}$ & $10,4 \%$ & $12,5 \%$ & $7,7 \%$ & $20,1 \%$ & $6,2 \%$ & $7,9 \%$ & $2,4 \%$ & $5,1 \%$ & $4,5 \%$ & $4,0 \%$ \\
\hline Total (N) & 4683 & 1383 & 1497 & 1362 & 4433 & 33571 & 2467 & 3920 & 551 & 8156 \\
\hline
\end{tabular}

\subsubsection{Relaciones de Responsabilidad}

En este apartado se muestran las tablas de frecuencia que muestran las relaciones de responsabilidad asociadas con el puesto de trabajo de los graduados universitarios. 
Las respuestas fueron obtenidas como escalas likert (1=Nada, 5=Mucho). La comparación de cada pregunta se hizo por país y continente.

Se preguntó a los graduados universitarios en qué medida eran responsables de establecer objetivos en la organización. Los graduados universitarios europeos manifestaron en general no tener ninguna responsabilidad (37,5\%), mientras que los latinoamericanos manifestaron tener mayor (4 sobre 5 ) responsabilidad $(25,7 \%)$. En la tabla 5.15 se muestra la distribución de frecuencias relativas para los países de la selección.

Tabla 5. 15 Responsabilidad para establecer objetivos en la organización

\begin{tabular}{|c|c|c|c|c|c|c|c|c|c|c|}
\hline & España & Francia & Alemania & $\begin{array}{c}\text { Reino } \\
\text { Unido }\end{array}$ & Suiza & $\begin{array}{c}\text { Europa } \\
(\mathbf{1 4 )}\end{array}$ & Chile & $\begin{array}{c}\text { México } \\
\text { Uruguay }\end{array}$ & $\begin{array}{c}\text { L. América } \\
(\mathbf{1 0 )}\end{array}$ \\
\hline 1: Nada & $39,3 \%$ & $51,4 \%$ & $43,7 \%$ & $47,7 \%$ & $46,9 \%$ & $37,5 \%$ & $16,6 \%$ & $9,6 \%$ & $18,4 \%$ & $13,1 \%$ \\
\hline 2 & $18,8 \%$ & $17,8 \%$ & $16,4 \%$ & $16,0 \%$ & $20,4 \%$ & $19,0 \%$ & $15,5 \%$ & $14,8 \%$ & $18,4 \%$ & $15,0 \%$ \\
\hline 3 & $18,1 \%$ & $15,8 \%$ & $18,4 \%$ & $19,6 \%$ & $16,4 \%$ & $19,7 \%$ & $24,3 \%$ & $25,0 \%$ & $23,7 \%$ & $24,3 \%$ \\
\hline 4 & $13,8 \%$ & $8,7 \%$ & $10,0 \%$ & $10,7 \%$ & $9,7 \%$ & $13,8 \%$ & $24,8 \%$ & $26,7 \%$ & $19,1 \%$ & $25,7 \%$ \\
\hline $5:$ Mucho & $10,0 \%$ & $6,2 \%$ & $11,5 \%$ & $6,0 \%$ & $6,6 \%$ & $10,0 \%$ & $18,9 \%$ & $24,0 \%$ & $20,4 \%$ & $21,9 \%$ \\
\hline Total (N) & 4534 & 1361 & 1481 & 1371 & 4386 & 33074 & 2399 & 3893 & 539 & 8018 \\
\hline
\end{tabular}

En los cinco países (Francia, Reino Unido, Suiza, Alemania, España) los graduados manifestaron mayoritariamente no tener responsabilidad en el establecimiento de objetivos para la organización.

En el caso de Latinoamérica, los graduados de México $(26,7 \%)$ y Chile $(24,8 \%)$ valoraron en la escala con cuatro, que si participan en el establecimiento de objetivos para la organización, mientras que para los graduados de Uruguay (23\%), la responsabilidad es intermedia (3 sobre 5$)$.

A la pregunta sobre el grado de responsabilidad que tenían los graduados universitarios para establecer objetivos sobre el propio trabajo, la mayoría de las respuestas corresponden a las valoraciones más altas de la escala (4 y 5). Del total de las respuestas obtenidas por continente, el $74,3 \%$ de los graduados de Europa y el $84,9 \%$ de Latinoamérica consideran alta la responsabilidad que tienen para establecer objetivos en su propio trabajo. La tabla 5.16 muestra las frecuencias relativas obtenidas para cada uno de los países de la selección. 
Tabla 5. 16 Responsabilidad para establecer objetivos del propio trabajo

\begin{tabular}{|c|c|c|c|c|c|c|c|c|c|c|}
\hline & España & Francia & Alemania & $\begin{array}{c}\text { Reino } \\
\text { Unido }\end{array}$ & Suiza & $\begin{array}{c}\text { Europa } \\
(\mathbf{1 4})\end{array}$ & Chile & México & $\begin{array}{c}\text { Uruguay } \\
\text { L. América } \\
(\mathbf{1 0})\end{array}$ \\
\hline $1:$ Nada & $9,8 \%$ & $8,3 \%$ & $2,6 \%$ & $3,5 \%$ & $2,8 \%$ & $4,4 \%$ & $1,0 \%$ & $1,0 \%$ & $1,5 \%$ & $1,1 \%$ \\
\hline 2 & $8,5 \%$ & $7,8 \%$ & $3,8 \%$ & $3,6 \%$ & $6,2 \%$ & $5,8 \%$ & $3,3 \%$ & $2,2 \%$ & $3,2 \%$ & $2,8 \%$ \\
\hline 3 & $17,6 \%$ & $21,7 \%$ & $13,2 \%$ & $14,3 \%$ & $16,4 \%$ & $15,5 \%$ & $11,5 \%$ & $10,6 \%$ & $11,9 \%$ & $11,1 \%$ \\
\hline 4 & $31,0 \%$ & $32,6 \%$ & $30,7 \%$ & $38,9 \%$ & $35,5 \%$ & $33,6 \%$ & $30,2 \%$ & $32,6 \%$ & $27,1 \%$ & $31,9 \%$ \\
\hline $5:$ Mucho & $33,1 \%$ & $29,6 \%$ & $49,7 \%$ & $39,7 \%$ & $39,0 \%$ & $40,7 \%$ & $54,0 \%$ & $53,5 \%$ & $56,4 \%$ & $53,0 \%$ \\
\hline Total (N) & 4562 & 1368 & 1490 & 1373 & 4402 & 33232 & 2400 & 3899 & 539 & 8026 \\
\hline
\end{tabular}

En cuanto a la responsabilidad para decidir estrategia de trabajo para la organización, los graduados de Europa $(25,0 \%)$, consideran tener responsabilidad para decidir estrategias de trabajo para la organización, siendo mayor la proporción para los latinoamericanos (52,6\%).

En los cinco países (Francia, Reino Unido, Suiza, Alemania, España) los graduados manifestaron no tener responsabilidad para decidir estrategias para la organización. Los graduados de México $(27,8 \%)$ y Chile $(28,1 \%)$ manifestaron con una escala de 4 , que tienen responsabilidad para decidir estrategias de trabajo para la organización. Los graduados de Uruguay $(25,2 \%)$ manifestaron un grado de responsabilidad media (3 sobre 5 ) para decidir estrategias de trabajo para la organización. La comparación de muestra en la tabla 5.17.

Tabla 5. 17 Responsabilidad de decidir estrategias de trabajo para la organización.

\begin{tabular}{|c|c|c|c|c|c|c|c|c|c|c|}
\hline & España & Francia & Alemania & $\begin{array}{l}\text { Reino } \\
\text { Unido } \\
\end{array}$ & Suiza & $\begin{array}{c}\text { Europa } \\
(14)\end{array}$ & Chile & México & Uruguay & $\begin{array}{c}\text { L. América } \\
(10)\end{array}$ \\
\hline 1: Nada & $30,7 \%$ & $40,1 \%$ & $33,1 \%$ & $39,5 \%$ & $38,7 \%$ & $32,1 \%$ & $12,8 \%$ & $8,4 \%$ & $14,9 \%$ & $10,5 \%$ \\
\hline 2 & $19,1 \%$ & $21,9 \%$ & $19,6 \%$ & $16,5 \%$ & $22,7 \%$ & $20,6 \%$ & $14,3 \%$ & $13,3 \%$ & $14,7 \%$ & $13,6 \%$ \\
\hline 3 & $21,4 \%$ & $17,7 \%$ & $22,0 \%$ & $23,5 \%$ & $20,1 \%$ & $22,3 \%$ & $23,2 \%$ & $23,8 \%$ & $25,2 \%$ & $23,3 \%$ \\
\hline 4 & $16,9 \%$ & $12,3 \%$ & $13,8 \%$ & $14,3 \%$ & $11,5 \%$ & $15,3 \%$ & $28,1 \%$ & $27,8 \%$ & $20,9 \%$ & $27,9 \%$ \\
\hline 5: Mucho & $11,8 \%$ & $8,0 \%$ & $11,5 \%$ & $6,3 \%$ & $7,0 \%$ & $9,7 \%$ & $21,5 \%$ & $26,7 \%$ & $24,3 \%$ & $24,7 \%$ \\
\hline Total $(\mathrm{N})$ & 4531 & 1361 & 1482 & 1373 & 4370 & 33036 & 2399 & 3888 & 536 & 8010 \\
\hline
\end{tabular}

A la pregunta sobre qué responsabilidad tenían para decidir cómo hacer el propio trabajo. Los graduados de Europa y de Latinoamérica evaluaron esta pregunta con la escala máxima (5). La tabla 5.18, muestra las frecuencias relativas por países y continente. 
Tabla 5. 18 Responsabilidad de decidir cómo hacer el trabajo propio

\begin{tabular}{|c|c|c|c|c|c|c|c|c|c|c|}
\hline & España & Francia & Alemania & $\begin{array}{c}\text { Reino } \\
\text { Unido }\end{array}$ & Suiza & $\begin{array}{c}\text { Europa } \\
(\mathbf{1 4})\end{array}$ & Chile & México & $\begin{array}{c}\text { Uruguay } \\
\text { L. América } \\
(\mathbf{1 0})\end{array}$ \\
\hline $1:$ Nada & $3,0 \%$ & $4,3 \%$ &, $9 \%$ & $3,0 \%$ & $2,0 \%$ & $1,9 \%$ &, $4 \%$ &, $7 \%$ &, $6 \%$ &, $7 \%$ \\
\hline 2 & $5,0 \%$ & $5,5 \%$ & $1,8 \%$ & $4,6 \%$ & $7,0 \%$ & $4,0 \%$ & $2,0 \%$ & $1,6 \%$ & $1,1 \%$ & $1,9 \%$ \\
\hline 3 & $12,2 \%$ & $14,6 \%$ & $7,3 \%$ & $14,5 \%$ & $17,6 \%$ & $12,3 \%$ & $7,5 \%$ & $6,8 \%$ & $9,9 \%$ & $7,5 \%$ \\
\hline 4 & $32,3 \%$ & $33,4 \%$ & $27,0 \%$ & $33,0 \%$ & $34,5 \%$ & $32,4 \%$ & $28,3 \%$ & $26,6 \%$ & $23,0 \%$ & $27,6 \%$ \\
\hline $5:$ Mucho & $47,6 \%$ & $42,2 \%$ & $63,0 \%$ & $44,8 \%$ & $38,9 \%$ & $49,4 \%$ & $61,8 \%$ & $64,3 \%$ & $65,4 \%$ & $62,4 \%$ \\
\hline Total (N) & 4564 & 1367 & 1487 & 1377 & 4394 & 33221 & 2401 & 3892 & 538 & 8024 \\
\hline
\end{tabular}

La parte final de este apartado, está relacionado con la valoración que los graduados dan a la pregunta relacionada con el perjuicio que ocasionarían a la organización, si cometieran un error grave en el puesto de trabajo. En la tabla 5.19 se presentan los resultados obtenidos.

Tabla 5. 19 Perjuicio a la organización por cometer errores graves en el trabajo

\begin{tabular}{|c|c|c|c|c|c|c|c|c|c|c|}
\hline & España & Francia & Alemania & $\begin{array}{c}\text { Reino } \\
\text { Unido }\end{array}$ & Suiza & $\begin{array}{c}\text { Europa } \\
(\mathbf{1 4 )}\end{array}$ & Chile & México & Uruguay & $\begin{array}{c}\text { L. América } \\
(\mathbf{1 0})\end{array}$ \\
\hline 1:Nada & $7,0 \%$ & $13,5 \%$ & $2,5 \%$ & $2,3 \%$ & $1,9 \%$ & $7,5 \%$ & $1,7 \%$ & $1,7 \%$ &, $9 \%$ & $1,6 \%$ \\
\hline 2 & $12,4 \%$ & $15,4 \%$ & $5,5 \%$ & $10,0 \%$ & $10,2 \%$ & $14,8 \%$ & $5,5 \%$ & $4,2 \%$ & $4,1 \%$ & $4,4 \%$ \\
\hline 3 & $24,3 \%$ & $29,3 \%$ & $17,6 \%$ & $20,2 \%$ & $22,1 \%$ & $23,1 \%$ & $14,7 \%$ & $18,1 \%$ & $27,4 \%$ & $16,7 \%$ \\
\hline 4 & $30,4 \%$ & $28,3 \%$ & $37,8 \%$ & $34,5 \%$ & $36,0 \%$ & $30,1 \%$ & $34,1 \%$ & $31,2 \%$ & $30,6 \%$ & $32,4 \%$ \\
\hline $5:$ Mucho & $26,0 \%$ & $13,6 \%$ & $36,6 \%$ & $33,0 \%$ & $29,9 \%$ & $24,5 \%$ & $44,0 \%$ & $44,7 \%$ & $37,0 \%$ & $45,0 \%$ \\
\hline Total & 4566 & 1343 & 1462 & 1374 & 4318 & 33099 & 2398 & 3900 & 540 & 8051 \\
\hline
\end{tabular}

En este apartado, los resultados muestran que para el $54,6 \%$ de los graduados europeos el perjuicio para la organización sería mayor si cometieran errores graves en el trabajo (escala 4 y 5). En particular esta escala fue valorada principalmente por los alemanes $(74,4 \%)$, los graduados del Reino Unido $(67,5 \%)$ y de Suiza $(65,9 \%)$. Idéntica valoración, aunque en mayor proporción, se obtuvo en Latinoamérica. El $77,4 \%$ de los graduados respondieron que perjudicarían a su organización si cometieran un error grave en su trabajo (escala 4 y 5 ). Por países destacan las valoración que dieron los graduados de Chile $(78,1 \%)$ y de México (75,9\%).

En el conjunto de Europa y Latinoamérica se puede identificar la tendencia a aumentar el grado de responsabilidad en lo relacionado al propio trabajo (figura $5.14 \mathrm{~b}$ y d) y como disminuye el grado de responsabilidad cuando las decisiones tienen que ver con la organización (figura 5.14 a y c). Sin embargo, en el caso de Latinoamérica se puede destacar que los graduados universitarios perciben una mayor responsabilidad en cuanto al establecimiento de objetivos y estrategias de trabajo para la organización (figura 5.14 a y c). 
Por último, para la pregunta relacionada con el nivel de perjuicio que se puede ocasionar a la organización por cometer errores en el trabajo, el patrón está cerca de las preguntas b) y d): los latinoamericanos declaran un mayor nivel de daño potencial que los europeos en concordancia con su mayor nivel de responsabilidad (figura 5.14 e).
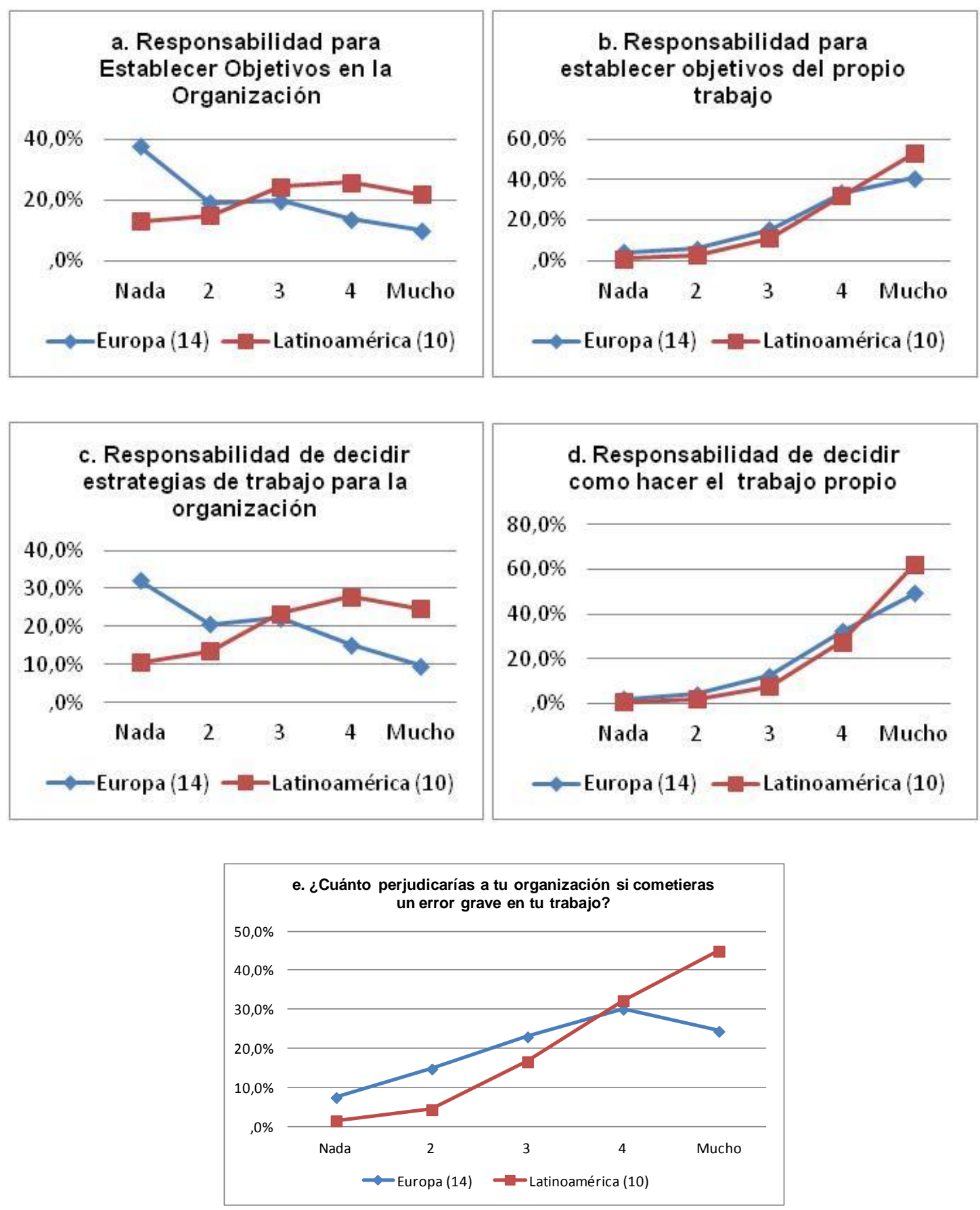

Figura 5. 14 Relaciones de Responsabilidad en el Trabajo

En resumen, como resultado del análisis se desprende que los graduados de Latinoamérica tienen una mayor responsabilidad en el proceso de toma de decisiones de sus 
organizaciones que sus colegas europeos, y, en consecuencia, potencialmente pueden causar un mayor daño a la organización. Los niveles de autonomía son similares en los dos grupos, o ligeramente mayor para los graduados de Latinoamérica.

\subsubsection{Relaciones en el Trabajo CIRE ${ }^{16}$}

En este apartado se analizan que tipo de relaciones establece el graduado universitario con sus compañeros de trabajo o con personas de otras organizaciones, en aspectos como el consejo entre compañeros, comunicación profesional, relaciones externas a la organización, ética, y la estimación del perjuicio a la organización por errores cometidos en el puesto de trabajo.

Las Tablas que a continuación se presentan, muestran las frecuencias relativas relacionadas con cuatro preguntas en las que se utilizan las escalas de Likert ( $1=$ Nada a $5=$ Mucho). La comparación se hizo por país y continente.

La percepción general de los graduados universitarios es alta, respecto a la siguiente afirmación: los compañeros, clientes, etc. Acuden a mí para pedirme consejo. La tabla 5.20 muestra la distribución, donde destaca una valoración alta (4), en España (36,6\%), Francia $(31,5 \%)$, Alemania $(45,6 \%)$, Reino Unido $(33,8 \%)$, Chile $(40,1 \%)$, México $(37,4 \%)$ y Uruguay $(36,7 \%)$.

Tabla 5. 20 Los compañeros, clientes, etc. acuden a mí para pedirme consejo

\begin{tabular}{|c|c|c|c|c|c|c|c|c|c|c|}
\hline & España & Francia & Alemania & $\begin{array}{c}\text { Reino } \\
\text { Unido }\end{array}$ & Suiza & $\begin{array}{c}\text { Europa } \\
(\mathbf{1 4})\end{array}$ & Chile & México & Uruguay & $\begin{array}{c}\text { L. América } \\
(\mathbf{1 0})\end{array}$ \\
\hline 1: Nada & $5,3 \%$ & $8,5 \%$ & $1,8 \%$ & $8,9 \%$ &, $6 \%$ & $3,8 \%$ & $2,2 \%$ & $3,0 \%$ & $1,8 \%$ & $2,6 \%$ \\
\hline 2 & $11,5 \%$ & $15,8 \%$ & $2,7 \%$ & $13,3 \%$ & $2,4 \%$ & $9,4 \%$ & $6,8 \%$ & $5,8 \%$ & $9,6 \%$ & $6,3 \%$ \\
\hline 3 & $28,7 \%$ & $31,1 \%$ & $17,0 \%$ & $27,2 \%$ & $16,0 \%$ & $27,2 \%$ & $19,5 \%$ & $21,8 \%$ & $19,2 \%$ & $21,1 \%$ \\
\hline 4 & $36,6 \%$ & $31,5 \%$ & $45,6 \%$ & $33,8 \%$ & $51,0 \%$ & $39,9 \%$ & $40,1 \%$ & $37,4 \%$ & $36,7 \%$ & $38,1 \%$ \\
\hline $5:$ Mucho & $17,9 \%$ & $13,1 \%$ & $32,9 \%$ & $16,9 \%$ & $30,0 \%$ & $19,8 \%$ & $31,4 \%$ & $32,0 \%$ & $32,7 \%$ & $31,9 \%$ \\
\hline Total & 4567 & 1358 & 1483 & 1373 & 4374 & 33057 & 2396 & 3904 & 542 & 8034 \\
\hline
\end{tabular}

Para conocer la percepción que los graduados universitarios acerca del grado de comunicación entre compañeros de profesión para compartir información sobre nuevos desarrollos, se obtuvieron los resultados que muestra la tabla 5.21 presentados en frecuencias relativas.

\footnotetext{
${ }^{16}$ Acrónimo de variables analizadas: consejo, información, relaciones externas, ética.
} 
Tabla 5. 21 Mantengo informados a mis compañeros de profesión sobre nuevos desarrollos en mi campo

\begin{tabular}{|c|c|c|c|c|c|c|c|c|c|c|}
\hline & España & Francia & Alemania & $\begin{array}{c}\text { Reino } \\
\text { Unido }\end{array}$ & Suiza & $\begin{array}{c}\text { Europa } \\
(\mathbf{1 4})\end{array}$ & Chile & México & Uruguay & $\begin{array}{c}\text { L. América } \\
(\mathbf{1 0})\end{array}$ \\
\hline 1: Nada & $12,4 \%$ & $13,4 \%$ & $3,5 \%$ & $10,4 \%$ & $2,7 \%$ & $7,6 \%$ & $7,6 \%$ & $8,8 \%$ & $8,7 \%$ & $7,9 \%$ \\
\hline 2 & $15,1 \%$ & $19,0 \%$ & $7,8 \%$ & $13,2 \%$ & $9,4 \%$ & $15,1 \%$ & $13,5 \%$ & $13,8 \%$ & $13,6 \%$ & $13,4 \%$ \\
\hline 3 & $28,6 \%$ & $28,7 \%$ & $22,3 \%$ & $29,4 \%$ & $26,7 \%$ & $29,2 \%$ & $25,2 \%$ & $26,4 \%$ & $23,6 \%$ & $25,8 \%$ \\
\hline 4 & $31,7 \%$ & $27,6 \%$ & $42,5 \%$ & $32,9 \%$ & $42,1 \%$ & $33,9 \%$ & $32,3 \%$ & $31,0 \%$ & $32,6 \%$ & $32,3 \%$ \\
\hline $5:$ Mucho & $12,2 \%$ & $11,3 \%$ & $23,9 \%$ & $14,1 \%$ & $19,1 \%$ & $14,3 \%$ & $21,5 \%$ & $20,0 \%$ & $21,5 \%$ & $20,5 \%$ \\
\hline Total & 4555 & 1355 & 1479 & 1372 & 4360 & 33000 & 2393 & 3891 & 543 & 8018 \\
\hline
\end{tabular}

A excepción de los graduados franceses (escala 3), los graduados de España, Alemania, R. Unido y Suiza valoraron en escala (4) el grado de información que ofrecen a los compañeros de profesión. En el conjunto del continente el nivel es idéntico (33,9\%). El 32,3\% de los graduados latinoamericanos valoraron en la escala (4) el grado de información que ofrecen a los compañeros de profesión. En Chile, México y Uruguay se mantiene idéntica escala de valoración de los graduados europeos.

Para la pregunta sobre relaciones profesionales de los graduados universitarios con profesionales ajenos a la organización, hay diversidad de respuestas por países. Los españoles $(53,0 \%)$ y franceses $(49,6 \%)$ indicaron que pocas veces o ninguna (escala 1 y 2 ), inician relaciones profesionales con expertos ajenos a la organización. Los alemanes $(27,3 \%)$ y suizos $(26,3 \%)$, valoraron en la escala cuatro su grado de implicación con profesionales de otras organizaciones. Los graduados del Reino Unido reparten su valoración en la escala tres en el $22,2 \%$ de las respuestas y en la escala cuatro en el $22,4 \%$. La tabla 5.22 resumen las valoraciones por país y continente.

Los tres países de Latinoamérica, Chile, México y Uruguay, dieron una valoración alta en sus respuestas $(4 \mathrm{y} 5)$. Estos resultados indican que los graduados universitarios latinoamericanos establecen con frecuencia relaciones con expertos ajenos a la organización en mayor proporción que la indicada por los europeos. 
Tabla 5. 22 Suelo iniciar relaciones profesionales con expertos ajenos a la organización

\begin{tabular}{|c|c|c|c|c|c|c|c|c|c|c|}
\hline & España & Francia & Alemania & $\begin{array}{c}\text { Reino } \\
\text { Unido }\end{array}$ & Suiza & $\begin{array}{c}\text { Europa } \\
(\mathbf{1 4})\end{array}$ & Chile & México & Uruguay & $\begin{array}{c}\text { L. América } \\
(\mathbf{1 0})\end{array}$ \\
\hline 1: Nada & $29,1 \%$ & $29,0 \%$ & $11,3 \%$ & $21,8 \%$ & $11,8 \%$ & $18,2 \%$ & $9,7 \%$ & $9,1 \%$ & $8,5 \%$ & $9,4 \%$ \\
\hline 2 & $23,9 \%$ & $20,6 \%$ & $20,3 \%$ & $21,5 \%$ & $21,8 \%$ & $22,8 \%$ & $18,7 \%$ & $14,3 \%$ & $14,0 \%$ & $15,5 \%$ \\
\hline 3 & $22,5 \%$ & $21,6 \%$ & $25,0 \%$ & $22,2 \%$ & $27,8 \%$ & $25,5 \%$ & $24,4 \%$ & $26,3 \%$ & $24,2 \%$ & $25,4 \%$ \\
\hline 4 & $18,1 \%$ & $18,3 \%$ & $27,3 \%$ & $22,4 \%$ & $26,3 \%$ & $22,7 \%$ & $28,1 \%$ & $29,3 \%$ & $30,7 \%$ & $28,9 \%$ \\
\hline $5:$ Mucho & $6,4 \%$ & $10,5 \%$ & $16,1 \%$ & $12,1 \%$ & $12,2 \%$ & $10,8 \%$ & $19,1 \%$ & $21,1 \%$ & $22,6 \%$ & $20,8 \%$ \\
\hline Total & 4537 & 1352 & 1482 & 1372 & 4357 & 32981 & 2398 & 3892 & 541 & 8021 \\
\hline
\end{tabular}

Para saber cómo perciben los graduados universitarios la valoración de la ética profesional en el puesto de trabajo. Se preguntó a los graduados universitarios que tan importante es la ética profesional como parte de sus funciones. La tabla 5.23 muestra los resultados en frecuencias relativas, por país y región.

Tabla 5. 23 Importancia de la ética profesional como parte importante de las funciones

\begin{tabular}{|c|c|c|c|c|c|c|c|c|c|c|}
\hline & España & Francia & Alemania & $\begin{array}{c}\text { Reino } \\
\text { Unido }\end{array}$ & Suiza & $\begin{array}{c}\text { Europa } \\
(\mathbf{1 4})\end{array}$ & Chile & México & Uruguay & $\begin{array}{c}\text { L. América } \\
(\mathbf{1 0})\end{array}$ \\
\hline 1: Nada & $10,9 \%$ & $9,2 \%$ & $7,3 \%$ & $8,4 \%$ & $4,1 \%$ & $5,0 \%$ & $2,5 \%$ & $1,0 \%$ & $1,5 \%$ & $1,5 \%$ \\
\hline 2 & $10,6 \%$ & $11,7 \%$ & $9,8 \%$ & $9,6 \%$ & $7,3 \%$ & $7,2 \%$ & $4,1 \%$ & $1,6 \%$ & $4,1 \%$ & $2,5 \%$ \\
\hline 3 & $21,3 \%$ & $20,2 \%$ & $25,0 \%$ & $21,1 \%$ & $20,3 \%$ & $18,1 \%$ & $10,0 \%$ & $9,0 \%$ & $9,4 \%$ & $9,0 \%$ \\
\hline 4 & $26,6 \%$ & $30,6 \%$ & $33,1 \%$ & $28,8 \%$ & $34,0 \%$ & $30,8 \%$ & $21,5 \%$ & $24,0 \%$ & $23,2 \%$ & $22,9 \%$ \\
\hline $5:$ Mucho & $30,5 \%$ & $28,2 \%$ & $24,7 \%$ & $32,0 \%$ & $34,2 \%$ & $38,9 \%$ & $61,9 \%$ & $64,4 \%$ & $61,8 \%$ & $64,2 \%$ \\
\hline Total & 4534 & 1354 & 1454 & 1367 & 4344 & 32952 & 2393 & 3893 & 542 & 8017 \\
\hline
\end{tabular}

Para los graduados de ambos continentes es muy importante (4 y 5 en la escala) la ética en el trabajo, siendo mayor para una alta proporción de graduados de Latinoamérica $(87,1 \%)$ si se compara con la proporción manifestada por los graduados europeos $(69,7 \%)$.

El 12,2\% de los graduados de Europa dan poca o ninguna importancia a la ética profesional como parte de su trabajo, frente a la proporción en que lo manifiestan los latinoamericanos $(4,0 \%)$. Por países, los españoles $(21,5 \%)$ seguidos de los franceses $(20,9 \%)$ son los que manifestaron con un alto porcentaje de valoración en la escala "poco o nada", situación que hace contraste con la valoración realizada por los mexicanos $(2,6 \%)$.

La Figura 5.15 agrupa una comparación entre los resultados obtenidos para los graduados de Europa y Latinoamérica en donde se identifican similitudes y diferencias de la percepción que tienen con respecto a las relaciones en el trabajo. Para la sección a y b los patrones son similares en ambos grupos, aunque los latinoamericanos manifestaron ser una mayor fuente de asesoría y consejo que los europeos. En las preguntas c y d las diferencias son 
claras. La iniciativa para establecer contactos fuera de la organización, es significativamente mayor entre los graduados latinoamericanos. A la pregunta relacionada con la relevancia de la ética en el trabajo el patrón es similar, pero nuevamente los latinoamericanos otorgan un alto porcentaje en la escala, dando más importancia que los colegas europeos.
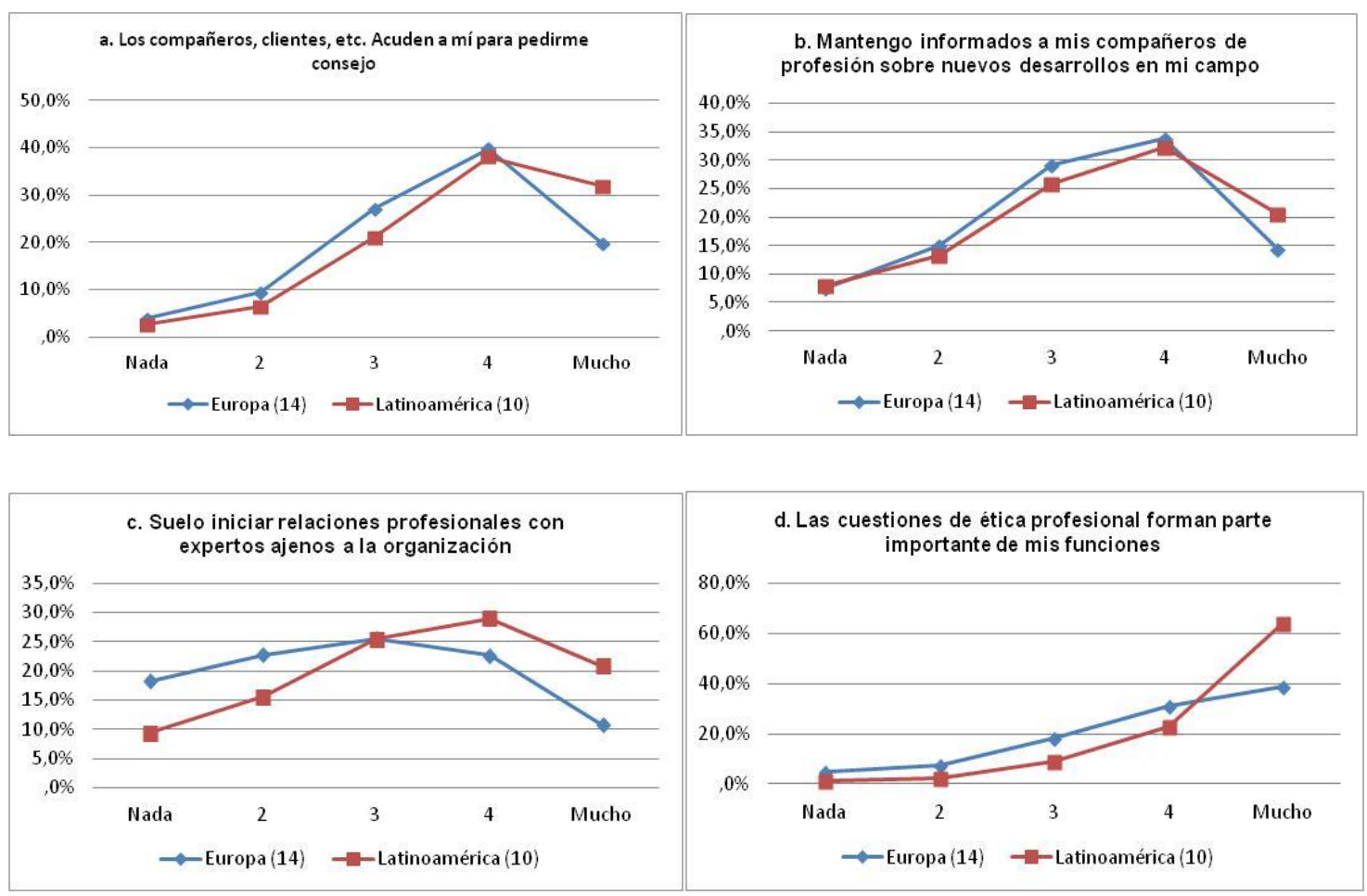

Figura 5. 15 Relaciones en el Trabajo CIRE

Los resultados sugieren que un alto porcentaje de los graduados europeos y latinoamericanos que trabajan, establecen frecuentes contactos y relaciones con otros colegas dentro y fuera de la organización. También la importancia de la ética en el trabajo es similar para ambos grupos o ligeramente mayor para los graduados de Latinoamérica.

\subsubsection{Las Competencias de los Profesionales Universitarios}

Se pretende analizar el nivel de competencias propias, el nivel de competencias requeridas en el trabajo, así como el ajuste entre ambos. A los graduados universitarios se les pidió que valoraran el nivel de competencias personal que tenían en el momento de la entrevista, así como la valoración de las competencias que les eran requeridas en el trabajo. 
Respecto a las competencias propias de los profesionales universitarios, en el cuestionario se les preguntó "¿Cómo valoras tu actual nivel de competencias? ". Las respuestas se midieron con escala Likert de 7 puntos, donde $1=$ Muy bajo y $7=$ Muy alto.

En la tabla 5.24 se muestra una perspectiva general del nivel de competencias propio según la percepción de los graduados cinco años después de finalizar los estudios universitarios.

Los resultados muestra el número de respuestas obtenidas de los graduados de Europa y Latinoamérica, la media de las puntuaciones de cada competencia en la escala Likert y la desviación típica.

Las competencias consideradas más fuertes son; capacidad para utilizar herramientas informáticas, capacidad para adquirir con rapidez nuevos conocimientos, Capacidad para trabajar en equipo. Las competencias consideradas más débiles son; capacidad para negociar de forma eficaz, conocimiento de otras áreas o disciplinas y capacidad para escribir y hablar en idiomas extranjeros. 
Tabla 5. 24 Competencias Personales

\begin{tabular}{|c|c|c|c|c|}
\hline & Competencias Personales & $\mathbf{N}$ & Media & Desv.típ \\
\hline 1 & $\begin{array}{l}\text { Capacidad para utilizar herramientas } \\
\text { informáticas }\end{array}$ & 44369 & 5,82 & 1,201 \\
\hline 2 & $\begin{array}{l}\text { Capacidad para adquirir con rapidez } \\
\text { nuevos conocimientos }\end{array}$ & 44413 & 5,75 & 1,035 \\
\hline 3 & Capacidad para trabajar en equipo & 44324 & 5,70 & 1,112 \\
\hline 4 & Capacidad para coodinar actividades & 44328 & 5,57 & 1,159 \\
\hline 5 & Capacidad para trabajar bajo presión & 44389 & 5,53 & 1,252 \\
\hline 6 & $\begin{array}{l}\text { Capacidad para redactar informes o } \\
\text { documentos }\end{array}$ & 44292 & 5,48 & 1,268 \\
\hline 7 & $\begin{array}{l}\text { Capacidad para usar el tiempo de forma } \\
\text { efectiva }\end{array}$ & 44361 & 5,46 & 1,193 \\
\hline 8 & Capacidad para hacerte entender & 44322 & 5,46 & 1,133 \\
\hline 9 & $\begin{array}{l}\text { Predisposición para cuestionar ideas } \\
\text { propias o ajenas }\end{array}$ & 44288 & 5,46 & 1,157 \\
\hline 10 & $\begin{array}{l}\text { Capacidad para encontrar nuevas ideas y } \\
\text { soluciones }\end{array}$ & 44237 & 5,44 & 1,130 \\
\hline 11 & Pensamiento analítico & 44336 & 5,42 & 1,193 \\
\hline 12 & Dominio de tu área o disciplina & 44544 & 5,40 & 1,033 \\
\hline 13 & $\begin{array}{l}\text { Capacidad para detectar nuevas } \\
\text { oportunidades }\end{array}$ & 44225 & 5,05 & 1,310 \\
\hline 14 & $\begin{array}{l}\text { Capacidad para movilizar las } \\
\text { capacidades de otros }\end{array}$ & 44239 & 5,01 & 1,286 \\
\hline 15 & $\begin{array}{l}\text { Capacidad para presentar en público } \\
\text { productos, ideas o informes }\end{array}$ & 44279 & 5,00 & 1,464 \\
\hline 16 & Capacidad para hacer valer tu autoridad & 44245 & 4,87 & 1,384 \\
\hline 17 & Capacidad para negociar de forma eficaz & 44280 & 4,84 & 1,427 \\
\hline 18 & $\begin{array}{l}\text { Conocimientos de otras áreas o } \\
\text { disciplinas }\end{array}$ & 44413 & 4,55 & 1,200 \\
\hline 19 & $\begin{array}{l}\text { Capacidad para escribir y hablar en } \\
\text { idiomas extranjeros }\end{array}$ & 44327 & 4,40 & 1,826 \\
\hline
\end{tabular}

Respecto a las competencias requeridas en el trabajo, en el cuestionario se les preguntó "¿Qué nivel de competencias necesitas en tu trabajo actual? ". Las respuestas se midieron mediante una escala Likert de 7 puntos donde $1=$ Muy bajo y $7=$ Muy alto.

Siguiendo el criterio de clasificación de las competencias propias, en la tabla 5.25 se muestra la valoración dada por los graduados universitarios, respecto al nivel de competencias requerido para desempeñar las tareas propias del puesto de trabajo. Para los graduados, las competencias más requeridas en el trabajo son: capacidad para usar el tiempo de forma efectiva, capacidad para trabajar bajo presión, capacidad para trabajar en equipo; en el lado 
contrario las competencias menos requeridas en el trabajo según la percepción de los graduados es: capacidad para detectar nuevas oportunidades, conocimiento de otras áreas o disciplinas y capacidad para escribir y hablar en idiomas extranjeros.

Tabla 5. 25 Competencias Requeridas en el Trabajo

\begin{tabular}{|c|c|c|c|c|}
\hline & Competencias Requeridas en el Trabajo & $\mathbf{N}$ & Media & Desv.típ \\
\hline 1 & $\begin{array}{l}\text { Capacidad para usar el tiempo de forma } \\
\text { efectiva }\end{array}$ & 39471 & 5,64 & 1,311 \\
\hline 2 & Capacidad para trabajar bajo presión & 39519 & 5,62 & 1,399 \\
\hline 3 & Capacidad para trabajar en equipo & 39443 & 5,51 & 1,430 \\
\hline 4 & Capacidad para hacerte entender & 39427 & 5,49 & 1,361 \\
\hline 5 & Dominio de tu área o disciplina & 39668 & 5,48 & 1,372 \\
\hline 6 & $\begin{array}{l}\text { Capacidad para utilizar herramientas } \\
\text { informáticas }\end{array}$ & 39457 & 5,47 & 1,457 \\
\hline 7 & $\begin{array}{l}\text { Capacidad para adquirir con rapidez } \\
\text { nuevos conocimientos }\end{array}$ & 39486 & 5,43 & 1,364 \\
\hline 8 & Capacidad para coodinar actividades & 39440 & 5,43 & 1,429 \\
\hline 9 & $\begin{array}{l}\text { Capacidad para encontrar nuevas ideas y } \\
\text { soluciones }\end{array}$ & 39388 & 5,27 & 1,460 \\
\hline 10 & $\begin{array}{l}\text { Capacidad para redactar informes o } \\
\text { documentos }\end{array}$ & 39392 & 5,24 & 1,583 \\
\hline 11 & Pensamiento analítico & 39426 & 5,20 & 1,455 \\
\hline 12 & $\begin{array}{l}\text { Predisposición para cuestionar ideas } \\
\text { propias o ajenas }\end{array}$ & 39373 & 5,03 & 1,491 \\
\hline 13 & $\begin{array}{l}\text { Capacidad para movilizar las } \\
\text { capacidades de otros }\end{array}$ & 39382 & 4,93 & 1,624 \\
\hline 14 & Capacidad para negociar de forma eficaz & 39417 & 4,87 & 1,749 \\
\hline 15 & Capacidad para hacer valer tu autoridad & 39360 & 4,87 & 1,659 \\
\hline 16 & $\begin{array}{l}\text { Capacidad para presentar en público } \\
\text { productos, ideas o informes }\end{array}$ & 39379 & 4,85 & 1,755 \\
\hline 17 & $\begin{array}{l}\text { Capacidad para detectar nuevas } \\
\text { oportunidades }\end{array}$ & 39308 & 4,82 & 1,646 \\
\hline 18 & $\begin{array}{l}\text { Conocimientos de otras áreas o } \\
\text { disciplinas }\end{array}$ & 39520 & 4,40 & 1,512 \\
\hline 19 & $\begin{array}{l}\text { Capacidad para escribir y hablar en } \\
\text { idiomas extranjeros }\end{array}$ & 38987 & 3,99 & 2,116 \\
\hline
\end{tabular}

Como se indicó al inicio de este apartado, es de interés para el objetivo de este trabajo, analizar como es el ajuste de competencias. Los resultados obtenidos acerca de la percepción que tienen los graduados universitarios del nivel propio de competencias y el nivel requerido en el trabajo, muestran que existen diferencias en las valoraciones que dan a las diecinueve competencias evaluadas. 
En adelante, el ajuste de las competencias será considerado para los análisis que son objetivo de este trabajo. Para obtener los valores del ajuste de las competencias, se han utilizado las escalas originales a partir de las valoraciones de competencias propias y requeridas dadas por los graduados universitarios (Figura 5.16).

El indicador de medida se ha obtenido a partir de las escalas Likert que miden el nivel de competencias propias y requeridas en el trabajo ( $1=$ Muy bajo y $7=$ Muy alto $)$.

La medida del ajuste de competencias, se define como el grado de cualificación que tiene un graduado universitario al evaluar su nivel de competencias propio menos el nivel de competencias requerido en el trabajo. El criterio que define la escala es:

- Valores Positivos en la escala: Sobrecualificado en la competencia X.

- Valor Cero: Ajuste en la cualificación de la competencia X.

- Valores Negativos en la escala: Infracualificado en la competencia X.

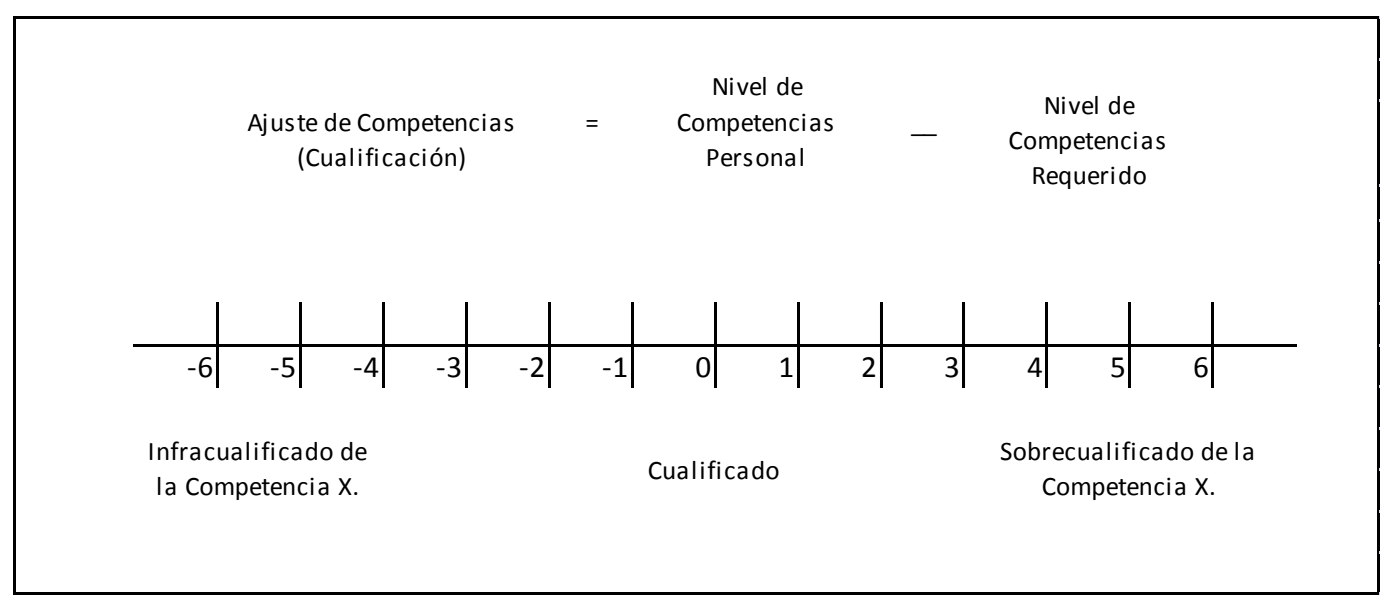

Figura 5. 16 Ajuste de Competencias (Cualificación)

En la figura 5.17, se puede ver una comparativa de los resultados obtenidos del ajuste de competencias, después de segmentar el análisis para los graduados de Europa, Latinoamérica y España. Se puede distinguir que los graduados de las tres áreas geográficas se sienten sobrecualificados en la mayoría de las competencias y en particular los españoles, seguidos de los Europeos y Latinoamericanos. 


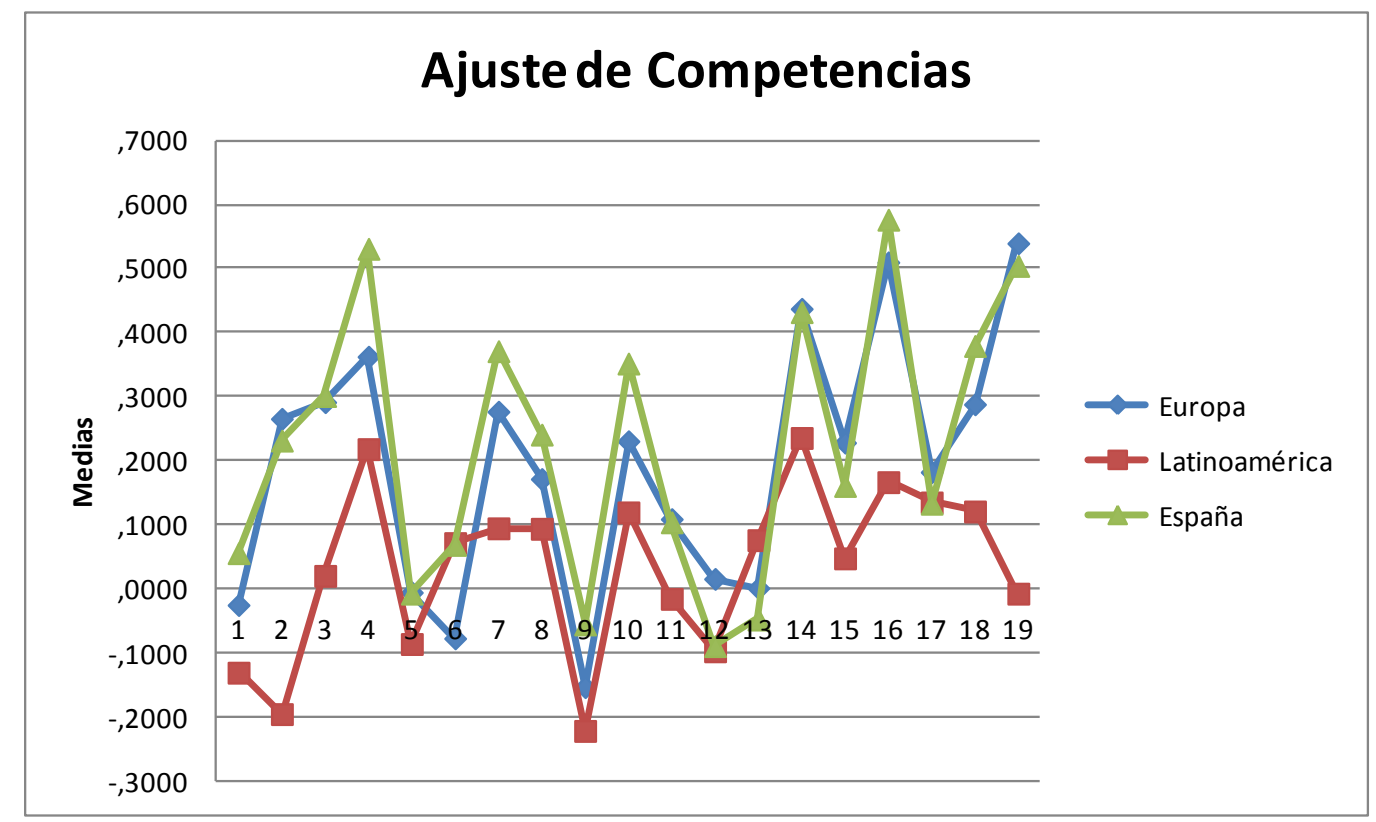

\begin{tabular}{|c|c|}
\hline \multicolumn{2}{|c|}{ Ajuste de Competencias - Descripción } \\
\hline 1. Dominio de tu área o disciplina & 11. Movilizar las capacidades de otros \\
\hline 2. Conocimientos de otras áreas o disciplinas & 12. Capacidad para hacerte entender \\
\hline 3. Pensamiento analítico & 13. Capacidad para hacervaler tu autoridad \\
\hline 4. Adquirir con rapidez nuevos conocimientos & 14. Utilizar herramientas informáticas \\
\hline 5. Negociar de forma eficaz & 15. Capacidad para encontrar nuevas ideas y soluciones \\
\hline 6. Trabajar bajo presión & 16. Predisposición para cuestionar ideas propias o ajenas \\
\hline 7. Detectar nuevas oportunidades & 17. Presentar en público productos, ideas o informes \\
\hline 8. Coodinar actividades & 18. Redactar informes o documentos \\
\hline 9. Usarel tiempo de forma efectiva & 19. Escribir y hablar en idiomas extranjeros \\
\hline 10. Trabajar en equipo & \\
\hline
\end{tabular}

Figura 5. 17

\subsubsection{Los Valores Laborales de los Profesionales Universitarios}

El objetivo de este apartado es conocer qué importancia personal dan los graduados universitarios a las características del trabajo y si hay ajuste entre los valores laborales y los que se aplican a la situación laboral.

Respecto a los valores laborales, en el cuestionario se les preguntó “¿Qué importancia tienen para ti las siguientes características del trabajo? ", cuyas respuestas se midieron mediante una escala Likert de 5 puntos donde $1=$ Ninguna importancia y $5=$ Mucha importancia (Tabla 5.26).

En ese orden, los graduados de Europa y Latinoamérica dan mayor importancia a la oportunidad para aprender cosas nuevas, la autonomía en el trabajo y la estabilidad laboral. Las características del trabajo a las que dieron menor importancia corresponden a la 
oportunidad de hacer algo útil para la sociedad, tener ingresos elevados y tener reconocimiento/prestigio social.

Tabla 5. 26 Valores Laborales. Importancia Personal

\begin{tabular}{|c|l|c|c|c|}
\hline \multicolumn{1}{|c|}{ Importancia Personal } & N & Media & Desv.típ \\
\hline 1 & $\begin{array}{l}\text { Oportunidad para aprender } \\
\text { cosas nuevas }\end{array}$ & 43157 & 4,48 & 0,698 \\
\hline 2 & Autonomía en el trabajo & 43068 & 4,31 & 0,796 \\
\hline 3 & Estabilidad laboral & 43149 & 4,28 & 0,911 \\
\hline 4 & Afrontar nuevos retos & 43117 & 4,16 & 0,850 \\
\hline 5 & $\begin{array}{l}\text { Tiempo para actividades } \\
\text { recreativas }\end{array}$ & 43135 & 4,13 & 0,923 \\
\hline 6 & $\begin{array}{l}\text { Facilidad para combinar trabajo } \\
\text { y familia }\end{array}$ & 43049 & 4,10 & 1,066 \\
\hline 7 & $\begin{array}{l}\text { Buenas Perspectivas } \\
\text { Profesionales }\end{array}$ & 43093 & 4,00 & 0,986 \\
\hline 8 & $\begin{array}{l}\text { Oportunidad de hacer algo útil } \\
\text { para la sociedad }\end{array}$ & 43120 & 3,86 & 1,038 \\
\hline 9 & Ingresos elevados & 36749 & 3,85 & 0,939 \\
\hline 10 & $\begin{array}{l}\text { Reconocimiento/prestigio } \\
\text { social }\end{array}$ & 43064 & 3,44 & 1,083 \\
\hline
\end{tabular}

La segunda parte de este apartado se interesa en conocer en qué medida las características del trabajo se aplican a la situación laboral en el momento de la entrevista. El resultado obtenido en la tabla 5.27, muestra diferencias entre la importancia dada a algunas características y el grado en que se cumplen en el trabajo. Las características que más se adecuan son, la autonomía en el trabajo, la oportunidad para aprender cosas nuevas y la estabilidad laboral. En el caso contrario, las características del trabajo que se consideran que menos aplican a la situación laboral son: Buenas perspectivas profesionales e ingresos elevados. 
Tabla 5. 27 Valores Laborales. Grado de aplicación a la situación laboral

\begin{tabular}{|c|l|c|c|c|}
\hline & \multicolumn{1}{|c|}{$\begin{array}{c}\text { Medida en que aplica a la } \\
\text { situación laboral }\end{array}$} & N & Media & Desv.típ \\
\hline 1 & Autonomía en el trabajo & 38775 & 4,06 & 0,949 \\
\hline 2 & $\begin{array}{l}\text { Oportunidad para aprender } \\
\text { cosas nuevas }\end{array}$ & 38838 & 3,83 & 1,040 \\
\hline 3 & Estabilidad laboral & 38868 & 3,75 & 1,197 \\
\hline 4 & Afrontar nuevos retos & 38823 & 3,63 & 1,082 \\
\hline 5 & $\begin{array}{l}\text { Oportunidad de hacer algo útil } \\
\text { para la sociedad }\end{array}$ & 38822 & 3,42 & 1,235 \\
\hline 6 & $\begin{array}{l}\text { Facilidad para combinar trabajo } \\
\text { familia }\end{array}$ & 38776 & 3,35 & 1,210 \\
\hline 7 & $\begin{array}{l}\text { Tiempo para actividades } \\
\text { recreativas }\end{array}$ & 38825 & 3,31 & 1,173 \\
\hline 8 & $\begin{array}{l}\text { Reconocimiento/prestigio } \\
\text { social }\end{array}$ & 38766 & 3,25 & 1,057 \\
\hline 9 & $\begin{array}{l}\text { Buenas Perspectivas } \\
\text { Profesionales }\end{array}$ & 38810 & 3,16 & 1,192 \\
\hline 10 & \begin{tabular}{l} 
Ingresos elevados \\
\hline
\end{tabular} & 2,95 & 1,107 \\
\hline
\end{tabular}

Como se apuntó al comienzo de este apartado, es de interés analizar cómo se ajustan los valores laborales de los graduados universitarios. Los resultados obtenidos en el descriptivo acerca de la importancia personal y el grado de aplicación a la situación laboral, muestra que existen diferencias en las valoraciones que los graduados universitarios dan a las diez características.

En adelante, el ajuste de los valores laborales será considerado para los análisis que son objetivo de este trabajo. El criterio para indicar el ajuste de los valores laborales, se construyó partiendo de las respuestas obtenidas de los graduados universitarios tal como se muestra a continuación (Figura 5.18).

El indicador de medida se ha obtenido a partir de las escalas Likert que miden la importancia personal de los valores laborales y la medida en que los valores laborales se cumplen en el trabajo ( 1 = Ninguna y $5=$ Mucha $)$.

La medida del ajuste de valores laborales, se define como el grado de conformidad que tiene un graduado universitario al evaluar en qué medida se cumple una característica del trabajo (valor laboral) frente a la importancia personal que da a la misma característica del trabajo. 
El criterio que define la escala es:

- Valores Positivos en la escala : La situación en el trabajo mejora las expectativas del graduado.

- Valores Negativos en la escala: La situación en el trabajo no alcanza las expectativas del graduado.

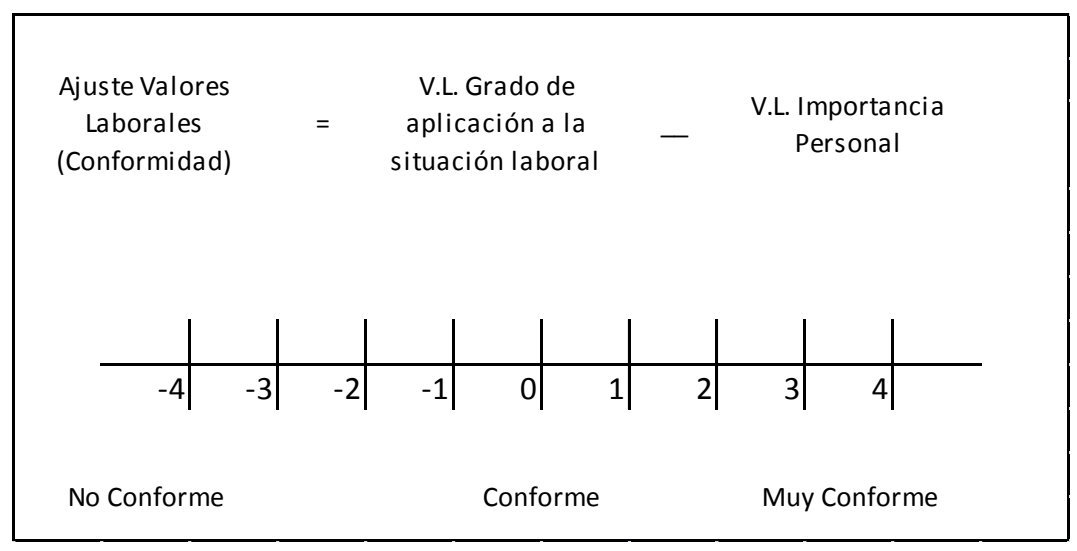

Figura 5. 18 Ajuste de Valores Laborales (Conformidad)

En la figura 5.19, se puede ver una comparativa de los resultados obtenidos del ajuste de los valores laborales, después de segmentar el análisis para los graduados de Europa, Latinoamérica y España.

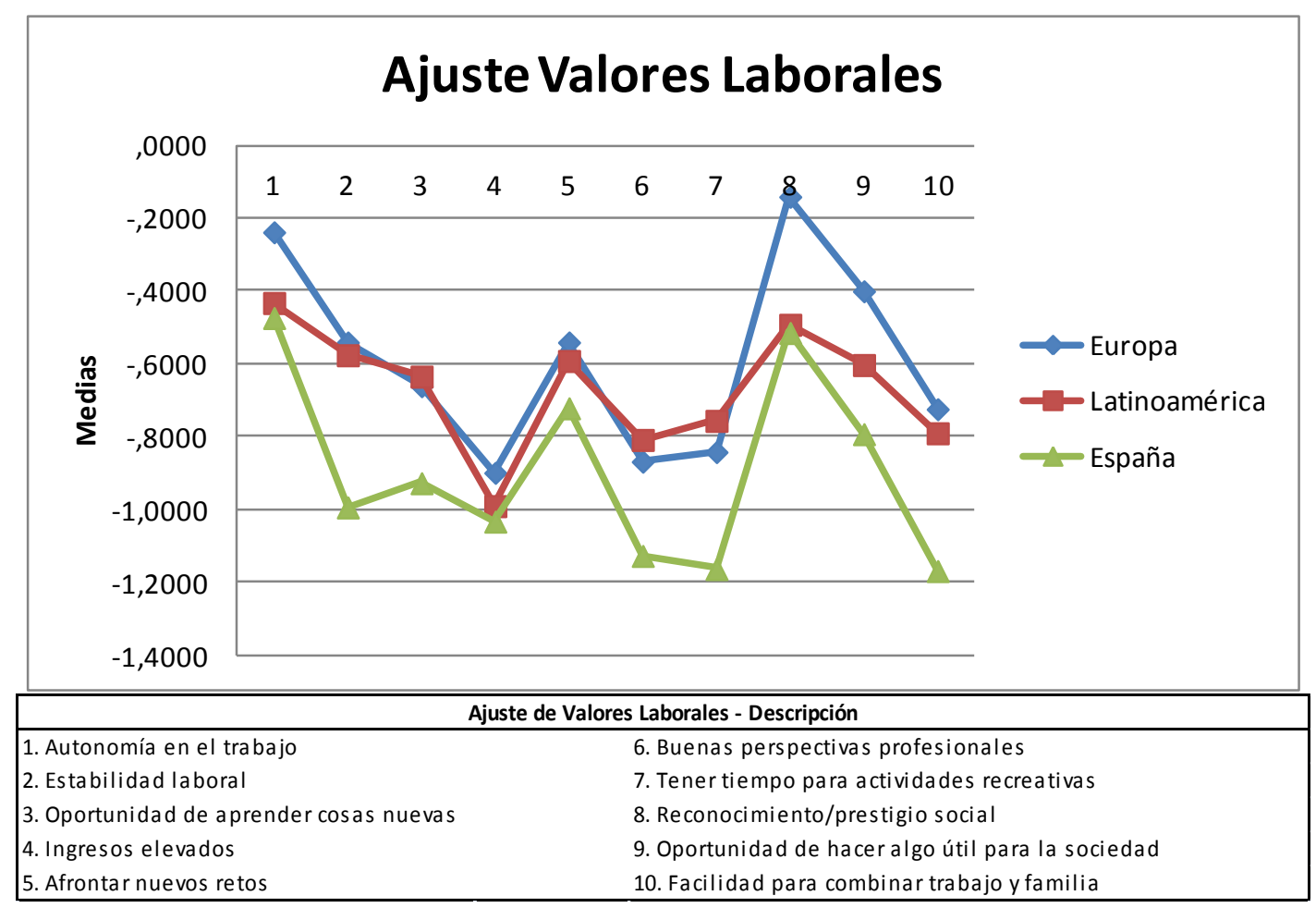

Figura 5. 19 
Se puede distinguir que para los graduados de las tres áreas geográficas los valores laborales no están conforme a sus expectativas. Los valores laborales que más se ajustan a sus expectativas son la autonomía, el reconocimiento/ prestigio social. En el conjunto de las áreas geográficas el ajuste de los valores laborales se da un poco mejor en Europa, seguido por Latinoamérica y España.

\subsection{Análisis de correlación y análisis de Fiabilidad}

\subsubsection{Análisis de Correlación}

El concepto de correlación entre las variables es una forma de valorar la asociación entre ellas, entendiendo la asociación como el hecho de que las variables que se consideran varíen conjuntamente. Cuando dos variables correlacionan o están asociadas, se dice que covarían. Quiere decir que varían de manera simultánea siguiendo una ley que rige la dependencia de dicha variación entre ellas.

Para analizar la correlación, la referencia de mayor utilización es el Coeficiente de Pearson, utilizado cuando las dos variables que se relacionan son medidas mediante escalas de intervalo, mientras que para las variables ordinales se utiliza el Coeficiente Rho de Spearman y el coeficiente de correlación de Kendall.

La correlación oscila cuantitativamente entre -1 y +1 , considerando el valor positivo como una correlación positiva y el signo negativo como una correlación negativa. Los valores obtenidos en las correlaciones solo se deben interpretar en términos de su intensidad (alta, media o moderada y baja), pero teniendo en cuenta siempre el $p$-valor que indica que el estadístico es significativamente distinto de cero y en consecuencia, considerado como científicamente válido.

Para el análisis de correlación inicial, utilizamos el coeficiente de correlación de Pearson, que mide la intensidad de la asociación lineal entre dos variables y el coeficiente Rho de Spearman para las variables ordinales.

El Anexo $\mathrm{H}$, muestra la matriz de correlaciones obtenida de cada conjunto de variables. En ellas se destaca que todas las correlaciones son significativas. Los valores de los coeficientes de correlación alcanzan valores moderados pero revelan que son apropiados para el análisis de los datos. 


\subsubsection{Análisis de fiabilidad}

Para la valoración de la fiabilidad de las escalas utilizadas en la encuesta, se ha utilizado el índice alfa de Cronbach, que es el indicador más ampliamente utilizado para este tipo de análisis. Este coeficiente determina la consistencia interna de una escala analizando la correlación media de una variable con todas las demás que integran dicha escala. Toma valores entre 0 y 1 , aunque también puede mostrar valores negativos (lo que indicaría que en la escala hay ítems que miden lo opuesto al resto). Cuanto más se acerque el coeficiente a la unidad, mayor será la consistencia interna de los indicadores en la escala evaluada, aunque no existe un acuerdo generalizado sobre cuál es el límite que demarca cuándo una escala puede ser considerada como fiable o no. Según George y Mallery (1995), el alfa de Cronbach por debajo de 0,5 muestra un nivel de fiabilidad no aceptable; si tomara un valor entre 0,5 y 0,6 se podría considerar como un nivel pobre; si se situara entre 0,6 y 0,7 se estaría ante un nivel débil; entre 0,7 y 0,8 haría referencia a un nivel aceptable; en el intervalo 0,8-0,9 se podría calificar como de un nivel bueno, y si tomara un valor superior a 0,9 sería excelente. La tabla 5.28 muestra los valores de fiabilidad obtenidos para el conjunto de la muestra de graduados universitarios de Europa y Latinoamérica. Los valores de la variables del constructo Éxito laboral subjetivo, reflejan un nivel bajo, mientras el nivel de significatividad de las variables de los constructos rol, competencias y valores laborales son superiores a 0,7 , por lo tanto se consideran fiables sus escalas de medida.

Tabla 5. 28 Resultados de los análisis de Fiabilidad para las escalas de medición

\begin{tabular}{|c|c|}
\hline Variable & Alfa de Cronbach \\
\hline Éxito Laboral & 0,649 \\
\hline Éxito Laboral Subjetivo & 0,581 \\
\hline Éxito Laboral Objetivo & 0,973 \\
\hline Rol (Funciones) & 0,782 \\
\hline Nivel de responsabilidad & 0,777 \\
\hline Relaciones personales & 0,705 \\
\hline Ética & N.A. \\
\hline Grado de Perjuicio & N.A. \\
\hline Competencias & 0,894 \\
\hline Competencias Personales & 0,916 \\
\hline Competencias Requeridas en el Trabajo & $*$ \\
\hline Valores Laborales & 0,769 \\
\hline Importancia Personal de los Valores Laborales & 0,762 \\
\hline Valores Laborales - Grado de aplicación en el trabajo & \\
\hline
\end{tabular}

* No se ha calculado por el número elevado de variables implicadas. 


\subsection{Análisis Factorial}

El análisis factorial exploratorio tiene como objetivo la reducción del número de variables. Se trata de agrupar la información que producen muchas variables empíricas correlacionadas en unas pocas variables teóricas o factores independientes entre sí.

Para el análisis se ha utilizado el modelo de Componentes Principales, que supone que la varianza se encuentra explicada en su totalidad por los factores comunes que resultan ser tantos como las variables que contiene el modelo. El modelo parte de una matriz de correlaciones en las que todos los elementos de la diagonal principal tienen un valor 1 (Castro y Galindo, 2000).

Como se expuso en el punto anterior y preparatorio a la realización de la técnica factorial, se llevó a cabo una revisión de las correlaciones entre las variables que componen los indicadores y se observó la fiabilidad de la escala. En el anexo I, se encuentra detallado el desarrollo del análisis factorial para el conjunto de variables que representan el modelo de investigación, cargas factoriales y la varianza total explicada.

Para determinar cómo se agrupan las variables de cada uno de los constructos del modelo de investigación, se realizaron diversas pruebas de análisis factorial utilizando la información de la muestra completa (48094 registros), segmentando la base de datos por continente (Europa y Latinoamérica) y con los ocho países seleccionados en el descriptivo (23664 registros).

A continuación se presentan los resultados correspondientes al conjunto de variables finales que se utilizarán en los análisis estadísticos para resolver las hipótesis planteadas a través del modelo de investigación para Europa, Latinoamérica y España. 


\subsubsection{Análisis Factorial Europa}

Se realizó el análisis factorial con las variables obtenidas a partir de los resultados de la encuesta a los graduados universitarios de Europa. En el Anexo I1, está detallado cada uno de los análisis realizados. Se muestran los resultados del análisis de fiabilidad, las pruebas confirmatorias para el uso del análisis factorial (como son el coeficiente KMO Kaiser-MeyerOlkin, la prueba de Esfericidad de Barlett) y la extracción de componentes principales con el método de rotación Varimax. Los resultados presentados representan el análisis factorial exploratorio.

La variable dependiente corresponde a la medida del éxito laboral entendida como éxito laboral objetivo y éxito laboral subjetivo. La medida del éxito laboral objetivo se realizó a partir de las variables sueldo contrato y sueldo total y se obtuvo un componente llamado Exlabob_E. El alfa de Cronbach obtenido de 0,97 corresponde a una buena escala de fiabilidad. El $K M O=0,500$ es mediocre pero la prueba de esfericidad de Barlett es significativa y el componente explica el $97,35 \%$ de la varianza total.

La medida del éxito laboral subjetivo, se realizó a partir de las variables uso de conocimientos y satisfacción en el trabajo. Como resultado se obtuvo un solo componente Ilamado Exlabsu_E. El alfa de Cronbach 0,574 corresponde a un resultado pobre, en cuanto a la fiabilidad de la escala de medición inicial. El KMO =0,500 es mediocre, la prueba de esfericidad de Barlett es significativa y el componente explica el 70,13\% de la varianza total.

La medición de las variables independientes, conformadas por los constructos de rol, competencias y valores laborales, se realizaron de la siguiente forma.

Para medir el rol en el trabajo se elaboró un indicador que está compuesto por la medida de la responsabilidad con la organización y con el puesto de trabajo, medida de las relaciones en el trabajo y el perjuicio a la organización. El alfa de Cronbach obtenido de 0,759 corresponde a una escala de fiabilidad aceptable. Se obtuvieron tres factores, con una varianza explicada de $61,381 \%$. La medida de adecuación $\mathrm{KMO}=0,762$ es buena y la prueba de esfericidad de Barlett es significativa. La tabla 5.29 muestra cómo se constituyen los factores. 
Tabla 5. 29 Interpretación de los Componentes Principales. Rol en el Trabajo (Europa)

\begin{tabular}{|c|c|c|c|}
\hline № & $\begin{array}{l}\text { Componentes } \\
\text { Interpretados }\end{array}$ & Variables & $\begin{array}{l}\text { \% Varianza } \\
\text { Explicada }\end{array}$ \\
\hline \multirow{4}{*}{1} & \multirow{4}{*}{ Responsabilidad } & Responsabilidad de establecer objetivos para la organización & \multirow{4}{*}{26,189} \\
\hline & & Responsabilidad de establecer objetivos para el propio trabajo & \\
\hline & & Responsabilidad de decidir estrategias de trabajo para la organización & \\
\hline & & Responsabilidad de decidir cómo hacer el trabajo & \\
\hline \multirow{4}{*}{2} & \multirow{4}{*}{$\begin{array}{l}\text { Relaciones en el } \\
\text { Trabajo }\end{array}$} & Los compañeros, clientes, etc. acuden a mí para pedirme consejo & \multirow{4}{*}{23,645} \\
\hline & & $\begin{array}{l}\text { Mantengo informados a mis compañeros de profesión sobre nuevos } \\
\text { desarrollos en mi campo }\end{array}$ & \\
\hline & & $\begin{array}{l}\text { Suelo iniciar relaciones profesionales con expertos ajenos a la } \\
\text { organización }\end{array}$ & \\
\hline & & $\begin{array}{l}\text { Las cuestiones de ética profesional forman parte importante de mis } \\
\text { funciones }\end{array}$ & \\
\hline 3 & Perjuicio & Perjuicio a la organización al cometer un error grave en el trabajo & 11,548 \\
\hline
\end{tabular}

Como resultado de la evaluación de las competencias propias de los graduados universitarios de Europa se obtuvo un Alfa de Cronbach de 0,880 siendo este, un valor adecuado. EI KMO = 0,932 y la prueba de esfericidad de Barlett resultó significativa. Se obtuvieron cuatro factores, con una varianza explicada de 51,817\%. La varianza total se explica en el primer factor $17,041 \%$, el segundo factor $12,32 \%$, el tercero $11,36 \%$ y el cuarto factor 11,094\%. La tabla 5.30 muestra la composición de los factores. 
Tabla 5. 30 Interpretación de los Componentes Principales. Competencias Propias (Europa)

\begin{tabular}{|c|c|c|c|}
\hline № & $\begin{array}{l}\text { Componentes } \\
\text { Interpretados }\end{array}$ & Variables & $\begin{array}{r}\text { \% Varianza } \\
\text { Explicada }\end{array}$ \\
\hline \multirow{6}{*}{1} & \multirow{6}{*}{$\begin{array}{l}\text { Competencias de } \\
\text { Liderazgo y } \\
\text { Comunicación }\end{array}$} & Negociar de forma eficaz & \multirow{6}{*}{17,041} \\
\hline & & Detectar nuevas oportunidades & \\
\hline & & Movilizar las capacidades de otros & \\
\hline & & Hacerte entender & \\
\hline & & Hacer valer tu autoridad & \\
\hline & & Presentar en público productos, ideas o informes & \\
\hline \multirow{4}{*}{2} & \multirow{4}{*}{$\begin{array}{l}\text { Competencias } \\
\text { Organizativas }\end{array}$} & Trabajar bajo presión & \multirow{4}{*}{12,32} \\
\hline & & Coordinar actividades & \\
\hline & & Usar el tiempo de forma efectiva & \\
\hline & & Trabajar en equipo & \\
\hline \multirow{5}{*}{3} & \multirow{5}{*}{$\begin{array}{l}\text { Competencias } \\
\text { Instrumentales y de } \\
\text { Innovación }\end{array}$} & Utilizar herramientas informáticas & \multirow{5}{*}{11,363} \\
\hline & & Encontrar nuevas ideas y soluciones & \\
\hline & & Predisposición para cuestionar ideas propias o ajenas & \\
\hline & & Redactar informes o documentos & \\
\hline & & Escribir y hablar idiomas extranjeros & \\
\hline \multirow{4}{*}{4} & Competencias de & Dominio de tu área o disciplina & \multirow{4}{*}{11,094} \\
\hline & Conocimiento y & Conocimiento de otras áreas o disciplinas & \\
\hline & Pensamiento & Pensamiento analítico & \\
\hline & Metacognitivo & Adquirir con rapidez nuevos conocimientos & \\
\hline
\end{tabular}

De la evaluación de las Competencia requeridas en el trabajo, se obtuvo un valor alto de fiabilidad en las escalas con Alfa de Cronbach de 0,906, KMO =0,942 y valores significativos en la prueba de esfericidad de Barlett. La varianza total explicada es 52,405\% distribuidas en los tres componentes resultantes. Al primer factor le corresponde un $19,99 \%$, al segundo factor le corresponde $17,783 \%$ y al tercer factor le corresponde el $14,631 \%$ de la varianza total explicada. La interpretación de los componentes se muestra en la tabla 5.31. 
Tabla 5. 31 Interpretación de los Componentes Principales. Competencias Requeridas en el Trabajo (Europa)

\begin{tabular}{|c|c|c|c|}
\hline № & $\begin{array}{l}\text { Componentes } \\
\text { Interpretados }\end{array}$ & Variables & $\begin{array}{c}\text { \% Varianza } \\
\text { Explicada }\end{array}$ \\
\hline \multirow{7}{*}{1} & \multirow{7}{*}{$\begin{array}{l}\text { Competencias } \\
\text { Organizativas y } \\
\text { Liderazgo }\end{array}$} & Negociar de forma eficaz & \multirow{7}{*}{19,99} \\
\hline & & Detectar nuevas oportunidades & \\
\hline & & Coordinar actividades & \\
\hline & & Trabajar en equipo & \\
\hline & & Movilizar las capacidades de otros & \\
\hline & & Hacerte entender & \\
\hline & & Hacer valer tu autoridad & \\
\hline \multirow{8}{*}{2} & \multirow{8}{*}{$\begin{array}{c}\text { Competencias de } \\
\text { Innovación, } \\
\text { Instrumentales y de } \\
\text { Comunicación }\end{array}$} & Conocimiento de otras áreas o disciplinas & \multirow{8}{*}{17,783} \\
\hline & & Pensamiento analítico & \\
\hline & & Utilizar herramientas informáticas & \\
\hline & & Encontrar nuevas ideas y soluciones & \\
\hline & & Predisposición para cuestionar ideas propias o ajenas & \\
\hline & & Presentar en público productos, ideas o informes & \\
\hline & & Redactar informes o documentos & \\
\hline & & Escribir y hablar idiomas extranjeros & \\
\hline \multirow{4}{*}{3} & \multirow{4}{*}{$\begin{array}{c}\text { Competencias de } \\
\text { Conocimiento, } \\
\text { organizativas }\end{array}$} & Dominio de tu área o disciplina & \multirow{4}{*}{14,631} \\
\hline & & Adquirir con rapidez nuevos conocimientos & \\
\hline & & Trabajar bajo presión & \\
\hline & & Usar el tiempo de forma efectiva & \\
\hline
\end{tabular}

Idéntico procedimiento se hizo para analizar la importancia personal que los graduados universitarios de Europa dan a los valores laborales. Se obtuvo un valor aceptable de la escala inicial: Alfa de Cronbach de 0,692. Se obtuvo tres componentes los cuales explican el 54,25\% de la varianza (El primer factor $19,27 \%$, el segundo $17,61 \%$ y el tercer factor $17,38 \%$ ), tal como se muestra en la tabla 5.32 . 
Tabla 5. 32 Interpretación de los Componentes Principales. Valores Laborales Personales (Europa)

\begin{tabular}{|c|c|c|c|}
\hline № & $\begin{array}{l}\text { Componentes } \\
\text { Interpretados }\end{array}$ & Variables & $\begin{array}{c}\text { \% Varianza } \\
\text { Explicada }\end{array}$ \\
\hline \multirow{3}{*}{1} & \multirow{3}{*}{$\begin{array}{c}\text { Ingresos y } \\
\text { Reconocimiento }\end{array}$} & Ingresos elevados & \multirow{3}{*}{19,27} \\
\hline & & Buenas perspectivas profesionales & \\
\hline & & Reconocimiento/prestigio social & \\
\hline \multirow{3}{*}{2} & \multirow{3}{*}{$\begin{array}{l}\text { Puesto de Trabajo } \\
\text { Enriquecido } \\
\text { "satisfactorio" }\end{array}$} & Autonomía en el trabajo & \multirow{3}{*}{17,606} \\
\hline & & Oportunidad de aprender cosas nuevas & \\
\hline & & Afrontar nuevos retos & \\
\hline \multirow{4}{*}{3} & \multirow{4}{*}{$\begin{array}{c}\text { Ocio, Familia y } \\
\text { Servicio a la sociedad }\end{array}$} & Estabilidad laboral & \multirow{4}{*}{17,376} \\
\hline & & Tener tiempo para actividades recreativas & \\
\hline & & Oportunidad de hacer algo útil para la sociedad & \\
\hline & & Facilidad para combinar trabajo y familia & \\
\hline
\end{tabular}

Como resultado de la medida del grado de cumplimiento de los valores laborales personales en el trabajo se obtuvo un valor de fiabilidad de la escala inicial, con un Alfa de Cronbach de 0,704 considerado aceptable, como ocurre con el valor del KMO 0,729 y la prueba de esfericidad de Barlett que resulta significativa. Los componentes interpretados para el análisis de los valores laborales en el trabajo que corresponden al primer factor son el puesto de trabajo enriquecido "satisfactorio". El segundo factor interpreta los ingresos, la estabilidad y el reconocimiento mientras que el tercer factor se interpreta al valor del ocio y la familia. La tabla 5.33 muestra cómo se constituyen estos factores.

Tabla 5. 33 Interpretación de los Componentes Principales. Valores Laborales en el Trabajo (Europa)

\begin{tabular}{|c|c|c|c|}
\hline № & $\begin{array}{l}\text { Componentes } \\
\text { Interpretados }\end{array}$ & Variables & $\begin{array}{c}\text { \% Varianza } \\
\text { Explicada }\end{array}$ \\
\hline \multirow{4}{*}{1} & \multirow{4}{*}{$\begin{array}{l}\text { Puesto de Trabajo } \\
\text { Enriquecido } \\
\text { "satisfactorio" }\end{array}$} & Autonomía en el trabajo & \multirow{4}{*}{20,308} \\
\hline & & Oportunidad de aprender cosas nuevas & \\
\hline & & Afrontar nuevos retos & \\
\hline & & Oportunidad de hacer algo útil para la sociedad & \\
\hline \multirow{4}{*}{2} & \multirow{4}{*}{$\begin{array}{c}\text { Ingresos, Estabilidad y } \\
\text { Reconocimiento }\end{array}$} & Estabilidad laboral & \multirow{4}{*}{19,68} \\
\hline & & Ingresos elevados & \\
\hline & & Buenas perspectivas profesionales & \\
\hline & & Reconocimiento/prestigio social & \\
\hline \multirow{2}{*}{3} & \multirow{2}{*}{ Ocio y Familia } & Tener tiempo para actividades recreativas & \multirow{2}{*}{17,613} \\
\hline & & Facilidad para combinar trabajo y familia & \\
\hline
\end{tabular}


Se realizaron dos pruebas adicionales para medir el ajuste de competencias y el ajuste de los valores laborales. El punto de partida para el análisis fueron las variables originales de competencias y valores laborales. El resumen de la prueba factorial del ajuste competencias mostró valores adecuados para la prueba. $\mathrm{KMO}=0,942$ y la prueba de esfericidad de Barlett significativa. Se obtuvo tres componentes los cuales explican el $48,42 \%$ de la varianza total. La tabla 5.34 muestra la composición de los factores.

Tabla 5. 34 Interpretación de los Componentes Principales. Ajuste de Competencias (Europa)

\begin{tabular}{|c|c|c|c|}
\hline № & $\begin{array}{l}\text { Componentes } \\
\text { Interpretados }\end{array}$ & Variables & $\begin{array}{r}\text { \% Varianza } \\
\text { Explicada }\end{array}$ \\
\hline \multirow{8}{*}{1} & \multirow{8}{*}{$\begin{array}{l}\text { C. de Liderazgo y } \\
\text { Organizativas }\end{array}$} & Negociar de forma eficaz & \multirow{8}{*}{18,93} \\
\hline & & Detectar nuevas oportunidades & \\
\hline & & Coordinar actividades & \\
\hline & & Usar el tiempo de forma efectiva & \\
\hline & & Trabajar en equipo & \\
\hline & & Movilizar las capacidades de otros & \\
\hline & & Hacerte entender & \\
\hline & & Hacer valer tu autoridad & \\
\hline \multirow{6}{*}{2} & \multirow{6}{*}{$\begin{array}{c}\text { Competencias } \\
\text { Instrumentales, de } \\
\text { Innovación y } \\
\text { Comunicación }\end{array}$} & Utilizar herramientas informáticas & \multirow{6}{*}{14,777} \\
\hline & & Encontrar nuevas ideas y soluciones & \\
\hline & & Predisposición para cuestionar ideas propias o ajenas & \\
\hline & & Presentar en público productos, ideas o informes & \\
\hline & & Redactar informes o documentos & \\
\hline & & Escribir y hablar idiomas extranjeros & \\
\hline \multirow{5}{*}{3} & \multirow{5}{*}{$\begin{array}{l}\text { Competencias de } \\
\text { Conocimiento y } \\
\text { Pensamiento } \\
\text { Metacognitivo }\end{array}$} & Dominio de tu área o disciplina & \multirow{5}{*}{14,714} \\
\hline & & Conocimiento de otras áreas o disciplinas & \\
\hline & & Pensamiento analítico & \\
\hline & & Adquirir con rapidez nuevos conocimientos. & \\
\hline & & Trabajar bajo presión & \\
\hline
\end{tabular}


El ajuste de valores laborales dio como resultado tres componentes que explican el $56,309 \%$ de la varianza (El primer factor $20,87 \%$, el segundo $18,49 \%$ y el tercer factor $16,95 \%$ ). El resumen de la prueba factorial mostró valores adecuados para la prueba: KMO = 0,759 y la prueba de Barlett resultó significativa. La interpretación de los componentes se muestra en la tabla 5.35 .

Tabla 5. 35 Interpretación de los Componentes Principales. Ajuste de Valores Laborales

(Europa)

\begin{tabular}{|c|c|c|c|}
\hline № & $\begin{array}{l}\text { Componentes } \\
\text { Interpretados }\end{array}$ & Variables & $\begin{array}{c}\text { \% Varianza } \\
\text { Explicada }\end{array}$ \\
\hline \multirow{4}{*}{1} & \multirow{4}{*}{$\begin{array}{l}\text { Puesto de Trabajo } \\
\text { Enriquecido } \\
\text { "satisfactorio" }\end{array}$} & Autonomía en el trabajo & \multirow{4}{*}{20,871} \\
\hline & & Oportunidad de aprender cosas nuevas & \\
\hline & & Afrontar nuevos retos & \\
\hline & & Oportunidad de hacer algo útil para la sociedad & \\
\hline \multirow{4}{*}{2} & \multirow{4}{*}{$\begin{array}{l}\text { Ingresos, Estabilidad y } \\
\text { Reconocimiento }\end{array}$} & Estabilidad laboral & \multirow{4}{*}{18,491} \\
\hline & & Ingresos elevados & \\
\hline & & Buenas perspectivas profesionales & \\
\hline & & Reconocimiento/prestigio social & \\
\hline \multirow{2}{*}{3} & \multirow{2}{*}{ Ocio y Familia } & Tener tiempo para actividades recreativas & \multirow{2}{*}{16,948} \\
\hline & & Facilidad para combinar trabajo y familia & \\
\hline
\end{tabular}

La tabla 5.36, presenta el resumen de las variables finales del modelo para Europa y el nombre que las identifica para posteriores análisis, el porcentaje de la varianza explicada, la fiabilidad de la escala.

Tabla 5. 36 Variables Modelo Final EUROPA. Porcentaje de la varianza explicada y fiabilidad de las escalas resultantes

\begin{tabular}{|c|c|c|c|}
\hline Variable Dependiente & Nombre & $\%$ Varianza & ALFA $\alpha$ \\
\hline Medidas del Éxito Laboral & Exlab & & \\
\hline Éxito Laboral Objetivo & Exlabob & 97,35 & 0,97 \\
\hline 1.Sueldo Contrato & \multirow{2}{*}{ Exlabob_E } & \multirow{2}{*}{97,35} & \\
\hline 2.Sueldo Total & & & \\
\hline Éxito Laboral Subjetivo & Exlabsu & 70,132 & 0,574 \\
\hline 3.Uso de conocimientos y habilidades & \multirow{2}{*}{ Exlabsu_E } & \multirow{2}{*}{70,132} & \\
\hline 4.Satisfacción en el trabajo & & & \\
\hline
\end{tabular}




\begin{tabular}{|c|c|c|c|}
\hline Variables Independientes & Nombre & \% Varianza & ALFA $\alpha$ \\
\hline Rol en el Trabajo & Rol & 61,381 & 0,759 \\
\hline 5. Responsabilidad en el trabajo & Responsa_E & 26,189 & \\
\hline 6. Relaciones en el trabajo & Relación_E & 23,645 & \\
\hline 7. Perjuicio a la organización & Perjuicio_E & 11,548 & \\
\hline Competencias Personales & CPE & 51,817 & 0,88 \\
\hline 8. C. Liderazgo y Comunicación & CPE_F1 & 17,041 & \\
\hline 9. C. Organizativas & CPE_F2 & 12,32 & \\
\hline 10. C. Instrumentales y de Innovación & CPE_F3 & 11,363 & \\
\hline $\begin{array}{l}\text { 11. C. de Conocimiento y Pensamiento } \\
\text { Metacognitivo }\end{array}$ & CPE_F4 & 11,094 & \\
\hline Competencias Requeridas en el Trabajo & CRE & 52,405 & 0,906 \\
\hline 12. C. Organizativas y Liderazgo & CRE_F1 & 19,99 & \\
\hline $\begin{array}{l}\text { 13. C. de Innovación, Instrumentales y de } \\
\text { Comunicación }\end{array}$ & CRE_F2 & 17,783 & \\
\hline 14. C. de Conocimiento, Organizativas & CRE_F3 & 14,631 & \\
\hline Valores Laborales Personales & Val_Lab_Pers & 54,251 & 0,692 \\
\hline 15. Ingresos y Reconocimiento & VPE_F1 & 19,27 & \\
\hline $\begin{array}{l}\text { 16. Puesto de Trabajo Enriquecido } \\
\text { "satisfactorio" }\end{array}$ & VPE_F2 & 17,606 & \\
\hline 17. Ocio, Familia y Servicio a la Sociedad & VPE_F3 & 17,376 & \\
\hline Valores Laborales en el Trabajo & Val_Lab_Trbj & 57,601 & 0,704 \\
\hline $\begin{array}{l}\text { 18. Puesto de Trabajo Enriquecido } \\
\text { "satisfactorio" }\end{array}$ & VLTE_F1 & 20,308 & \\
\hline 19. Ingresos, Estabilidad y Reconocimiento & VLTE_F2 & 19,68 & \\
\hline 20. Ocio y Familia & VLTE_F3 & 17,613 & \\
\hline $\begin{array}{l}\text { Ajuste de Competencias Propias y } \\
\text { Requeridas en el trabajo }\end{array}$ & AJC_E & 48,42 & N.A. \\
\hline 21. C. de liderazgo y organizativas & AJC_F1_E & 18,93 & \\
\hline $\begin{array}{l}\text { 22. C. Instrumentales, de innovación y } \\
\text { comunicación }\end{array}$ & AJC_F2_E & 14,777 & \\
\hline $\begin{array}{l}\text { 23. C. Conocimiento y pensamiento } \\
\text { metacognitivo }\end{array}$ & AJC_F3_E & 14,714 & \\
\hline \begin{tabular}{|l|} 
Ajuste de Valores Laborales Personales y \\
Valores Laborales en el Trabajo \\
\end{tabular} & AJVT_E & 56,309 & N.A. \\
\hline $\begin{array}{l}\text { 24.Puesto de Trabajo Enriquecido } \\
\text { "satisfactorio" } \\
\end{array}$ & AJVT_F1_E & 20,871 & \\
\hline 25 Ingresos, Estabilidad y Reconocimiento & AJVT_F2_E & 18,491 & \\
\hline 26. Ocio y Familia & AJVT_F3_E & 16,948 & \\
\hline
\end{tabular}




\subsubsection{Análisis Factorial Latinoamérica}

El segundo análisis factorial se realizó con las variables obtenidas a partir de los resultados de la encuesta a los graduados universitarios de Latinoamérica. En el Anexo 12, se detalla los análisis realizados.

La variable dependiente corresponde a la medida del éxito laboral entendida como éxito laboral objetivo y éxito laboral subjetivo. Para la medida del éxito laboral objetivo se obtuvo un componente llamado Exlabob_LA. El alfa de Cronbach obtenido de 0,959 corresponde a una buena escala de fiabilidad. EI KMO $=0,500$ es mediocre, la prueba de esfericidad de Barlett es significativa y el componente explica el 96,378\% de la varianza total.

La medida del éxito laboral subjetivo, se realizó a partir de las variables uso de conocimientos y satisfacción en el trabajo. Como resultado se obtuvo un solo componente Ilamado Exlabsu_LA. El alfa de Cronbach 0,533 corresponde a un resultado pobre, en cuanto a la fiabilidad de la escala de medición inicial. El KMO $=0,500$ es mediocre, la prueba de esfericidad de Barlett es significativa y el componente explica el $68,23 \%$ de la varianza total.

La medición de las variables independientes, conformadas por los constructos de rol, competencias y valores laborales, se realizaron de la siguiente forma.

El Alfa de Cronbach para el conjunto de las variables de rol en el trabajo es 0,798 , valor que verifica la fiabilidad de las escalas usadas. La varianza total explicada es del 62,13\% y está reflejada en cada uno de los factores obtenidos: relaciones en el trabajo (22,34\%), responsabilidad con la organización $(21,263 \%)$ y autonomía y responsabilidad en el puesto de trabajo (18,524\%). La tabla 5.37 muestra cómo se constituyen los factores. 
Tabla 5. 37 Interpretación de los Componentes Principales. Rol en el Trabajo (Latinoamérica)

\begin{tabular}{|c|c|c|c|}
\hline № & $\begin{array}{l}\text { Componentes } \\
\text { Interpretados }\end{array}$ & Variables & $\begin{array}{l}\text { Varianza } \\
\text { Explicada }\end{array}$ \\
\hline \multirow{4}{*}{1} & \multirow{4}{*}{ Relaciones en el trabajo } & $\begin{array}{l}\text { Los compañeros, clientes, etc. acuden a mí para pedirme } \\
\text { consejo }\end{array}$ & \multirow{4}{*}{22,344} \\
\hline & & $\begin{array}{l}\text { Mantengo informados a mis compañeros de profesión sobre } \\
\text { nuevos desarrollos en mi campo }\end{array}$ & \\
\hline & & $\begin{array}{l}\text { Suelo iniciar relaciones profesionales con expertos ajenos a la } \\
\text { organización }\end{array}$ & \\
\hline & & $\begin{array}{l}\text { Las cuestiones de ética profesional forman parte importante } \\
\text { de mis funciones }\end{array}$ & \\
\hline \multirow{3}{*}{2} & \multirow{3}{*}{$\begin{array}{l}\text { Responsabilidad con la } \\
\text { Organización }\end{array}$} & Responsabilidad de establecer objetivos para la organización & \multirow{3}{*}{21,263} \\
\hline & & $\begin{array}{l}\text { Responsabilidad de decidir estrategias de trabajo para la } \\
\text { organización }\end{array}$ & \\
\hline & & $\begin{array}{l}\text { Perjuicio a la organización al cometer un error grave en el } \\
\text { trabajo }\end{array}$ & \\
\hline \multirow[t]{2}{*}{3} & \multirow{2}{*}{$\begin{array}{c}\text { Autonomía / } \\
\text { Responsabilidad con el } \\
\text { Puesto de trabajo }\end{array}$} & $\begin{array}{l}\text { Responsabilidad de establecer objetivos para el propio } \\
\text { trabajo }\end{array}$ & \multirow[t]{2}{*}{18,524} \\
\hline & & Responsabilidad de decidir cómo hacer el trabajo & \\
\hline
\end{tabular}

El resumen de la prueba factorial del nivel de competencias personales de los graduados universitarios de Latinoamérica, muestra que la fiabilidad de la escala inicial es muy adecuada al arrojar un Alfa de Cronbach de 0,932, $\mathrm{KMO}=0,968$ y la prueba de esfericidad de Barlett significativa. Las competencias quedan agrupadas en tres factores resultantes con una varianza total explicada del $58,467 \%$. Las competencias organizativas, de liderazgo e innovación se agrupan en el primer factor (31,405\%). El segundo factor agrupa las competencias de conocimiento y pensamiento metacognitivo (14,949\%) y el tercer factor con una varianza explicada de $12,113 \%$ agrupa las competencias instrumentales y de comunicación. La composición de los factores se muestra en la tabla 5.38. 
Tabla 5. 38 Interpretación de los Componentes Principales. Competencias Personales (Latinoamérica)

\begin{tabular}{|c|c|c|c|}
\hline № & $\begin{array}{l}\text { Componentes } \\
\text { Interpretados }\end{array}$ & Variables & $\begin{array}{l}\text { Varianza } \\
\text { Explicada }\end{array}$ \\
\hline \multirow{11}{*}{1} & \multirow{11}{*}{$\begin{array}{c}\text { Competencias } \\
\text { Organizativas, Liderazgo, } \\
\text { Innovación }\end{array}$} & Negociar de forma eficaz & \multirow{11}{*}{31,405} \\
\hline & & Trabajar bajo presión & \\
\hline & & Detectar nuevas oportunidades & \\
\hline & & Coordinar actividades & \\
\hline & & Usar el tiempo de forma efectiva & \\
\hline & & Trabajar en equipo & \\
\hline & & Movilizar las capacidades de otros & \\
\hline & & Hacerte entender & \\
\hline & & Hacer valer tu autoridad & \\
\hline & & Encontrar nuevas ideas y soluciones & \\
\hline & & Predisposición para cuestionar ideas propias o ajenas & \\
\hline \multirow{4}{*}{2} & Competencias de & Dominio de tu área o disciplina & \multirow{4}{*}{14,949} \\
\hline & Conocimiento y & Conocimiento de otras áreas o disciplinas & \\
\hline & Pensamiento & Pensamiento analítico & \\
\hline & Metacognitivo & Adquirir con rapidez nuevos conocimientos & \\
\hline \multirow{4}{*}{3} & \multirow{4}{*}{$\begin{array}{c}\text { Competencias } \\
\text { Instrumentales y de } \\
\text { Comunicación }\end{array}$} & Utilizar herramientas informáticas & \multirow{4}{*}{12,113} \\
\hline & & Presentar en público productos, ideas o informes & \\
\hline & & Redactar informes o documentos & \\
\hline & & Escribir y hablar idiomas extranjeros & \\
\hline
\end{tabular}

Del análisis de las competencias requeridas en el trabajo, se obtuvo un valor alto del Alfa de Cronbach: 0,943, KMO de 0,969 y la prueba de esfericidad de Barlett significativa. Valores que indican la adecuación de los datos a la realización del análisis factorial exploratorio. Como resultado se obtuvieron dos componentes. El primer factor agrupa el mayor número de variables mientras que en el segundo factor agrupa el resto de variables, tal como se puede ver en la tabla 5.39. 
Tabla 5. 39 Interpretación de los Componentes Principales. Competencias Requeridas en el Trabajo (Latinoamérica)

\begin{tabular}{|c|c|c|c|}
\hline № & $\begin{array}{l}\text { Componentes } \\
\text { Interpretados }\end{array}$ & Variables & $\begin{array}{l}\text { Varianza } \\
\text { Explicada }\end{array}$ \\
\hline \multirow{15}{*}{1} & \multirow{15}{*}{$\begin{array}{l}\text { C. Organizativas, } \\
\text { Liderazgo, Innovación, } \\
\text { Pensamiento } \\
\text { Metacognitivo }\end{array}$} & Dominio de tu área o disciplina & \multirow{15}{*}{39,392} \\
\hline & & Pensamiento analítico & \\
\hline & & Adquirir con rapidez nuevos conocimientos & \\
\hline & & Negociar de forma eficaz & \\
\hline & & Trabajar bajo presión & \\
\hline & & Detectar nuevas oportunidades & \\
\hline & & Coordinar actividades & \\
\hline & & Usar el tiempo de forma efectiva & \\
\hline & & Trabajar en equipo & \\
\hline & & Movilizar las capacidades de otros & \\
\hline & & Hacerte entender & \\
\hline & & Hacer valer tu autoridad & \\
\hline & & Encontrar nuevas ideas y soluciones & \\
\hline & & Predisposición para cuestionar ideas propias o ajenas & \\
\hline & & Presentar en público productos, ideas o informes & \\
\hline \multirow{4}{*}{2} & Competencias & Conocimiento de otras áreas o disciplinas & \multirow{4}{*}{18,241} \\
\hline & Instrumentales, & Utilizar herramientas informáticas & \\
\hline & Comunicación y & Redactar informes o documentos & \\
\hline & Conocimiento & Escribir y hablar idiomas extranjeros & \\
\hline
\end{tabular}

El primer factor explica la mayor parte de la varianza asociada a las variables originales, efecto causado por la alta correlación entre las variables.

La prueba factorial para la medida de los valores laborales personales de los graduados universitarios de Latinoamérica, arrojó un buen indicador de la fiabilidad de las escalas (Alfa de Cronbach $=0,894$ ), la medida de adecuación $\mathrm{KMO}=0,917$ y la prueba de esfericidad de Barlett resulto significativa. La varianza total explicada es de 60,354\%, representada en dos componentes; el primer componente llamado puesto de trabajo enriquecido $(37,183 \%$ ) y el segundo componente llamado ocio, familia y servicio a la sociedad $(23,171 \%)$.La tabla 5.40 muestra cómo quedan constituidos los factores. 
Tabla 5. 40 Interpretación de los Componentes Principales. Valores Laborales Personales (Latinoamérica)

\begin{tabular}{|c|c|c|c|}
\hline № & $\begin{array}{l}\text { Componentes } \\
\text { Interpretados }\end{array}$ & Variables & $\begin{array}{l}\text { Varianza } \\
\text { Explicada }\end{array}$ \\
\hline \multirow{6}{*}{1} & \multirow{6}{*}{$\begin{array}{l}\text { Puesto de Trabajo } \\
\text { Enriquecido. Ingresos }\end{array}$} & Autonomía en el trabajo & \multirow{6}{*}{37,183} \\
\hline & & Estabilidad laboral & \\
\hline & & Oportunidad de aprender cosas nuevas & \\
\hline & & Ingresos elevados & \\
\hline & & Afrontar nuevos retos & \\
\hline & & Buenas perspectivas profesionales & \\
\hline \multirow{4}{*}{2} & \multirow{4}{*}{$\begin{array}{c}\text { Ocio, Familia y Servicio a } \\
\text { la Sociedad }\end{array}$} & Tener tiempo para actividades recreativas & \multirow{4}{*}{23,171} \\
\hline & & Reconocimiento/prestigio social & \\
\hline & & Oportunidad de hacer algo útil para la sociedad & \\
\hline & & Facilidad para combinar trabajo y familia & \\
\hline
\end{tabular}

Como resultado de la medida del grado de cumplimiento de los valores laborales en el trabajo se obtuvo un valor de fiabilidad de la escala inicial, con un Alfa de Cronbach de 0,875 considerado bueno, como ocurre con el valor del KMO 0,877 y la prueba de esfericidad de Barlett que resulta significativa. Se obtuvieron dos componentes que corresponden al 59,959\% de la varianza total explicada. La tabla 5.41 muestra la constitución de los factores.

Tabla 5. 41 Interpretación de los Componentes Principales. Valores Laborales en el Trabajo (Latinoamérica)

\begin{tabular}{|c|c|c|c|}
\hline № & $\begin{array}{l}\text { Componentes } \\
\text { Interpretados }\end{array}$ & Variables & $\begin{array}{l}\text { Varianza } \\
\text { Explicada }\end{array}$ \\
\hline \multirow{8}{*}{1} & \multirow{8}{*}{$\begin{array}{c}\text { Puesto de Trabajo } \\
\text { Enriquecido. Ingresos, } \\
\text { Reconocimiento, Servicio } \\
\text { a la Sociedad }\end{array}$} & Autonomía en el trabajo & \multirow{8}{*}{34,468} \\
\hline & & Estabilidad laboral & \\
\hline & & Oportunidad de aprender cosas nuevas & \\
\hline & & Ingresos elevados & \\
\hline & & Afrontar nuevos retos & \\
\hline & & Buenas perspectivas profesionales & \\
\hline & & Reconocimiento/prestigio social & \\
\hline & & Oportunidad de hacer algo útil para la sociedad & \\
\hline \multirow{2}{*}{2} & \multirow{2}{*}{ Ocio y Familia } & Tener tiempo para actividades recreativas & \multirow{2}{*}{21,491} \\
\hline & & Facilidad para combinar trabajo y familia & \\
\hline
\end{tabular}

De igual manera como en el caso de los graduados universitarios de Europa, se realizaron las pruebas para medir el ajuste de competencias y el ajuste de los valores laborales, Para el análisis se utilizaron las variables originales de competencias y valores laborales. El 
resumen de la prueba factorial del ajuste competencias mostró valores adecuados para la prueba $\mathrm{KMO}=0,936$ y la prueba de esfericidad de Barlett significativa. Se obtuvo tres componentes los cuales explican el $45,59 \%$ de la varianza total. El primero componente resultante llamado competencias organizativas, liderazgo e innovación. El segundo componente llamado competencias de conocimiento y pensamiento metacognitivo y el tercer componente llamado competencias instrumentales y de comunicación. La tabla 5.42 muestra la composición de los factores obtenidos.

Tabla 5. 42 Interpretación de los Componentes Principales. Ajuste de Competencias (Latinoamérica)

\begin{tabular}{|c|c|c|c|}
\hline № & $\begin{array}{l}\text { Componentes } \\
\text { Interpretados }\end{array}$ & Variables & $\begin{array}{l}\text { Varianza } \\
\text { Explicada }\end{array}$ \\
\hline \multirow{10}{*}{1} & \multirow{10}{*}{$\begin{array}{c}\text { Competencias } \\
\text { Organizativas, Liderazgo, } \\
\text { Innovación }\end{array}$} & Negociar de forma eficaz & \multirow{10}{*}{20,211} \\
\hline & & Trabajar bajo presión & \\
\hline & & Detectar nuevas oportunidades & \\
\hline & & Coordinar actividades & \\
\hline & & Usar el tiempo de forma efectiva & \\
\hline & & Trabajar en equipo & \\
\hline & & Movilizar las capacidades de otros & \\
\hline & & Hacerte entender & \\
\hline & & Hacer valer tu autoridad & \\
\hline & & Encontrar nuevas ideas y soluciones & \\
\hline \multirow{4}{*}{2} & \multirow{4}{*}{$\begin{array}{l}\text { Competencias de } \\
\text { Conocimiento y } \\
\text { Pensamiento } \\
\text { Metacognitivo }\end{array}$} & Dominio de tu área o disciplina & \multirow{4}{*}{12,77} \\
\hline & & Conocimiento de otras áreas o disciplinas & \\
\hline & & Pensamiento analítico & \\
\hline & & Adquirir con rapidez nuevos conocimientos. & \\
\hline & \multirow{5}{*}{$\begin{array}{l}\text { Competencias } \\
\text { Instrumentales y C. de } \\
\text { Comunicación }\end{array}$} & Utilizar herramientas informáticas & \multirow{5}{*}{12,609} \\
\hline & & Predisposición para cuestionar ideas propias o ajenas & \\
\hline & & Presentar en público productos, ideas o informes & \\
\hline & & Redactar informes o documentos & \\
\hline & & Escribir y hablar idiomas extranjeros & \\
\hline
\end{tabular}

El ajuste de valores laborales dio como resultado dos componentes que explican el $51,94 \%$ de la varianza total (El primer factor $31,99 \%$ y el segundo $19,948 \%$ ). El resumen de la prueba factorial mostró valores adecuados para la medida de adecuación muestral $\mathrm{KMO}=$ 0,855 y la prueba de Barlett resultó significativa. La composición de los factores se muestran en la tabla 5.43 . 
Tabla 5. 43 Interpretación de los Componentes Principales. Ajuste de Valores Laborales (Latinoamérica)

\begin{tabular}{|c|c|c|c|}
\hline № & $\begin{array}{l}\text { Componentes } \\
\text { Interpretados }\end{array}$ & Variables & $\begin{array}{l}\text { Varianza } \\
\text { Explicada }\end{array}$ \\
\hline \multirow{7}{*}{1} & \multirow{7}{*}{$\begin{array}{c}\text { Puesto de Trabajo } \\
\text { Enriquecido. Ingresos, } \\
\text { Estabilidad y } \\
\text { Reconocimiento }\end{array}$} & Autonomía en el trabajo & \multirow{7}{*}{31,993} \\
\hline & & Estabilidad laboral & \\
\hline & & Oportunidad de aprender cosas nuevas & \\
\hline & & Ingresos elevados & \\
\hline & & Afrontar nuevos retos & \\
\hline & & Buenas perspectivas profesionales & \\
\hline & & Reconocimiento/prestigio social & \\
\hline \multirow{3}{*}{2} & \multirow{3}{*}{$\begin{array}{c}\text { Ocio, Familia y Servicio a } \\
\text { la Sociedad }\end{array}$} & Tener tiempo para actividades recreativas & \multirow{3}{*}{19,948} \\
\hline & & Oportunidad de hacer algo útil para la sociedad & \\
\hline & & Facilidad para combinar trabajo y familia & \\
\hline
\end{tabular}

La tabla 5.44, presenta el resumen de las variables finales del modelo para Latinoamérica y el nombre que las identifica para posteriores análisis, el porcentaje de la varianza explicada, la fiabilidad de la escala. 
Tabla 5. 44 Variables Modelo Final LATINOAMÉRICA. Porcentaje de la varianza explicada y fiabilidad de las escalas resultantes

\begin{tabular}{|c|c|c|c|}
\hline Variable Dependiente & Nombre & $\begin{array}{c}\% \\
\text { Varianza }\end{array}$ & ALFA $\alpha$ \\
\hline Medidas del Éxito Laboral & Exlab & & \\
\hline Éxito Laboral Objetivo & Exlabob & 96,378 & 0,959 \\
\hline 1.Sueldo Contrato & \multirow{2}{*}{ Exlabob_LA } & \multirow{2}{*}{96,378} & \\
\hline 2.Sueldo Total & & & \\
\hline Éxito Laboral Subjetivo & Exlabsu & 68,228 & 0,533 \\
\hline 3.Uso de conocimientos y habilidades & \multirow{2}{*}{ Exlabsu_LA } & \multirow{2}{*}{68,228} & \\
\hline 4.Satisfacción en el trabajo & & & \\
\hline Variables Independientes & Nombre & $\begin{array}{c}\% \\
\text { Varianza }\end{array}$ & ALFA $\alpha$ \\
\hline Rol en el Trabajo & Rol & 62,132 & 0,798 \\
\hline 5. Relaciones en el trabajo & Relacion_LA & 22,344 & \\
\hline 6. Responsabilidad con la organización & Responsa_LA & 21,263 & \\
\hline 7. Autonomía / Responsabilidad & AutonomiaPT_LA & 18,524 & \\
\hline Competencias Personales & CPLA & 58,467 & 0,932 \\
\hline 8. C. Organizativas, Liderazgo, Innovación & CPLA_F1 & 31,405 & \\
\hline 9. C. de Conocimiento y Pensamiento Metacognitivo & CPLA_F2 & 14,949 & \\
\hline 10. Competencias Instrumentales y de Comunicación & CPLA_F3 & 12,113 & \\
\hline Competencias Requeridas en el Trabajo & CRLA & 57,633 & 0,943 \\
\hline $\begin{array}{l}\text { 11. C. Organizativas, Liderazgo, Innovación y } \\
\text { Pensamiento Metacognitivo }\end{array}$ & CRLA_F1 & 39,392 & \\
\hline 12. C. Instrumentales, Comunicación y Conocimiento & CRLA_F2 & 18,241 & \\
\hline Valores Laborales Personales & Val_Lab_Pers & 60,354 & 0,894 \\
\hline 13. Puesto de Trabajo Enriquecido. Ingresos & VPLA_F1 & 37,183 & \\
\hline 14. Ocio, Familia y Servicio a la Sociedad & VPLA_F2 & 23,171 & \\
\hline Valores Laborales en el Trabajo & Val_Lab_Trbj & 59,959 & 0,875 \\
\hline $\begin{array}{l}\text { 15. Puesto de Trabajo Enriquecido. Ingresos, } \\
\text { Reconocimiento, Servicio a la Sociedad }\end{array}$ & VLTLA_F1 & 34,468 & \\
\hline 16. Ocio y Familia & VLTLA_F2 & 21,491 & \\
\hline $\begin{array}{l}\text { Ajuste de Competencias Propias y Requeridas en el } \\
\text { trabajo }\end{array}$ & AJC_LA & 45,591 & N.A. \\
\hline 17. C. Organizativas, Liderazgo, Innovación & AJC_F1_LA & 20,211 & \\
\hline 18. C de Conocimiento y Pensamiento Metacognitivo & AJC_F2_LA & 12,77 & \\
\hline 19.C. Instrumentales y C. de Comunicación & AJC_F3_LA & 12,609 & \\
\hline $\begin{array}{l}\text { Ajuste de Valores Laborales Personales y Valores } \\
\text { Laborales en el Trabajo }\end{array}$ & AJVT_LA & 51,94 & N.A. \\
\hline $\begin{array}{l}\text { 20. Puesto de Trabajo Enriquecido. Ingresos, Estabilidad y } \\
\text { Reconocimiento }\end{array}$ & AJVT_F1_LA & 31,993 & \\
\hline 21. Ocio, Familia y Servicio a la Sociedad & AJVT_F2_LA & 19,948 & \\
\hline
\end{tabular}




\subsubsection{Análisis Factorial España}

El tercer análisis factorial exploratorio corresponde a los graduados universitarios de España. En el Anexo 13, está detallado cada uno de los análisis realizados.

La variable dependiente corresponde a la medida del éxito laboral entendida como, éxito laboral objetivo y éxito laboral subjetivo. Para la medida del éxito laboral objetivo se obtuvo un componente Ilamado Exlabob_Spn. El alfa de Cronbach obtenido de 0,965 corresponde a una buena escala de fiabilidad. EI KMO $=0,500$ es mediocre, la prueba de esfericidad de Barlett es significativa y el componente resultante explica el $96,71 \%$ de la varianza total.

La medida del éxito laboral subjetivo, se realizó a partir de las variables uso de conocimientos y satisfacción en el trabajo. Como resultado se obtuvo un solo componente Ilamado Exlabsu_Spn. El alfa de Cronbach 0,626 corresponde a un resultado aceptable, en cuanto a la fiabilidad de la escala de medición inicial. El KMO =0,500 es mediocre, la prueba de esfericidad de Barlett es significativa y el componente resultante explica el $72,87 \%$ de la varianza total.

La medición de las variables independientes, se realizaron de la siguiente forma.

Para medir el rol en el trabajo se elaboró un indicador que está compuesto por la medida de la responsabilidad con la organización y con el puesto de trabajo, medida de las relaciones en el trabajo y el perjuicio a la organización. El coeficiente Alfa Cronbach tomó un valor de 0,809 para los nueve ítems correspondientes a las variables sobre rol en el trabajo. La medida de adecuación muestral de Kaiser-Meyer-Olkin alcanzó el valor de 0,803 y el contraste de esfericidad de Barlett arrojó resultados significativos indicando la adecuación de los datos a la realización del análisis factorial exploratorio. La tabla 5.45 muestra cómo se constituyen estos factores. 
Tabla 5. 45 Interpretación de los Componentes Principales. Rol en el Trabajo (España)

\begin{tabular}{|c|c|c|c|}
\hline № & $\begin{array}{l}\text { Componentes } \\
\text { Interpretados }\end{array}$ & Variables & $\begin{array}{l}\text { \% Varianza } \\
\text { Explicada }\end{array}$ \\
\hline \multirow{4}{*}{1} & \multirow{4}{*}{ Responsabilidad } & Responsabilidad de establecer objetivos para la organización & \multirow{4}{*}{27,415} \\
\hline & & $\begin{array}{l}\text { Responsabilidad de establecer objetivos para el propio } \\
\text { trabajo }\end{array}$ & \\
\hline & & $\begin{array}{l}\text { Responsabilidad de decidir estrategias de trabajo para la } \\
\text { organización }\end{array}$ & \\
\hline & & Responsabilidad de decidir cómo hacer el trabajo & \\
\hline \multirow{4}{*}{2} & \multirow{4}{*}{ Relaciones en el Trabajo } & $\begin{array}{l}\text { Los compañeros, clientes, etc. acuden a mí para pedirme } \\
\text { consejo }\end{array}$ & \multirow{4}{*}{24,025} \\
\hline & & $\begin{array}{l}\text { Mantengo informados a mis compañeros de profesión sobre } \\
\text { nuevos desarrollos en mi campo }\end{array}$ & \\
\hline & & $\begin{array}{l}\text { Suelo iniciar relaciones profesionales con expertos ajenos a la } \\
\text { organización }\end{array}$ & \\
\hline & & $\begin{array}{l}\text { Las cuestiones de ética profesional forman parte importante } \\
\text { de mis funciones }\end{array}$ & \\
\hline 3 & Perjuicio & $\begin{array}{l}\text { Perjuicio a la organización al cometer un error grave en el } \\
\text { trabajo }\end{array}$ & 12,093 \\
\hline
\end{tabular}

Los componentes resultantes son tres: El primer factor con un \% de varianza explicada de $27,415 \%$ se ha interpretado como componente de responsabilidad, el segundo con un $24,025 \%$ de varianza explicada se ha interpretado como componente de relaciones en el trabajo y el tercero deja la variable perjuicio con una varianza explicada de $12,093 \%$. Se ha considerado que las descripciones de los ítems hacen referencia a algún tipo de rol en el trabajo previamente definido en la teoría. Por tanto ninguno de ellos fue excluido en la aplicación del análisis factorial

Como resultado de la valoración de las competencia propias por parte de los graduados universitarios Españoles se obtuvo un Alfa de Cronbach de 0,896 siendo un valor adecuado, así como el KMO de 0,942 una medida de la adecuación muestral y la prueba de esfericidad de Barlett significativa. Del análisis factorial, se obtuvieron cuatro componentes, que explican el 54,753\% de la varianza.: El primer factor con una varianza explicada de 17,348\%, agrupa competencias de liderazgo y comunicación. El segundo con una varianza de $13,713 \%$ agrupa competencias organizativas, el tercero (12,212\%) agrupa competencias de conocimiento y pensamiento metacognitivo y el cuarto factor $(11,481 \%)$ agrupa competencias instrumentales y de innovación. En la tabla 5.46 se muestran los componentes resultantes. 
Tabla 5. 46 Interpretación de los Componentes Principales. Competencias Personales (España)

\begin{tabular}{|c|c|c|c|}
\hline № & $\begin{array}{l}\text { Componentes } \\
\text { Interpretados }\end{array}$ & Variables & $\begin{array}{l}\text { \% Varianza } \\
\text { Explicada }\end{array}$ \\
\hline \multirow{7}{*}{1} & \multirow{7}{*}{$\begin{array}{l}\text { Competencias de } \\
\text { Liderazgo y comunicación }\end{array}$} & Negociar de forma eficaz & \multirow{7}{*}{17,348} \\
\hline & & Detectar nuevas oportunidades & \\
\hline & & Movilizar las capacidades de otros & \\
\hline & & Hacerte entender & \\
\hline & & Hacer valer tu autoridad & \\
\hline & & Encontrar nuevas ideas y soluciones & \\
\hline & & Presentar en público productos, ideas o informes & \\
\hline \multirow{4}{*}{2} & \multirow{4}{*}{$\begin{array}{l}\text { Competencias } \\
\text { Organizativas }\end{array}$} & Trabajar bajo presión & \multirow{4}{*}{13,713} \\
\hline & & Coordinar actividades & \\
\hline & & Usar el tiempo de forma efectiva & \\
\hline & & Trabajar en equipo & \\
\hline \multirow{4}{*}{3} & \multirow{4}{*}{$\begin{array}{c}\text { Competencias de } \\
\text { Conocimiento y } \\
\text { Pensamiento } \\
\text { Metacognitivo }\end{array}$} & Dominio de tu área o disciplina & \multirow{4}{*}{12,212} \\
\hline & & Conocimiento de otras áreas o disciplinas & \\
\hline & & Pensamiento analítico & \\
\hline & & Adquirir con rapidez nuevos conocimientos & \\
\hline \multirow{4}{*}{4} & \multirow{4}{*}{$\begin{array}{l}\text { Competencias } \\
\text { Instrumentales y de } \\
\text { Innovación }\end{array}$} & Utilizar herramientas informáticas & \multirow{4}{*}{11,481} \\
\hline & & Predisposición para cuestionar ideas propias o ajenas & \\
\hline & & Redactar informes o documentos & \\
\hline & & Escribir y hablar idiomas extranjeros & \\
\hline
\end{tabular}

Como resultado de la valoración de las competencias requeridas en el trabajo por parte de los graduados universitarios españoles, la medida de fiabilidad de la escala inicial, arrojó un Alfa de Cronbach de 0,921, KMO de 0,948 y la prueba de esfericidad de Barlett resultó significativa. Medidas adecuadas para la realización de la prueba. Se obtuvieron tres componentes los cuales explican el $55,234 \%$ de la varianza, como se puede visualizar en la tabla 5.47 . 
Tabla 5. 47 Interpretación de los Componentes Principales. Competencias Requeridas en el Trabajo (España)

\begin{tabular}{|c|c|c|c|}
\hline № & $\begin{array}{l}\text { Componentes } \\
\text { Interpretados }\end{array}$ & Variables & $\begin{array}{c}\text { \% Varianza } \\
\text { Explicada }\end{array}$ \\
\hline \multirow{9}{*}{1} & \multirow{9}{*}{$\begin{array}{c}\text { Competencias } \\
\text { Organizativas, Liderazgo e } \\
\text { Innovación }\end{array}$} & Negociar de forma eficaz & \multirow{9}{*}{22,46} \\
\hline & & Coordinar actividades & \\
\hline & & Usar el tiempo de forma efectiva & \\
\hline & & Trabajar en equipo & \\
\hline & & Movilizar las capacidades de otros & \\
\hline & & Hacerte entender & \\
\hline & & Hacer valer tu autoridad & \\
\hline & & Encontrar nuevas ideas y soluciones & \\
\hline & & Predisposición para cuestionar ideas propias o ajenas & \\
\hline \multirow{6}{*}{2} & \multirow{6}{*}{$\begin{array}{l}\text { Competencias de } \\
\text { Conocimiento y } \\
\text { Pensamiento } \\
\text { Metacognitivo }\end{array}$} & Dominio de tu área o disciplina & \multirow{6}{*}{18,128} \\
\hline & & Conocimiento de otras áreas o disciplinas & \\
\hline & & Pensamiento analitico & \\
\hline & & Adquirir con rapidez nuevos conocimientos & \\
\hline & & Trabajar bajo presión & \\
\hline & & Detectar nuevas oportunidades & \\
\hline \multirow{4}{*}{3} & \multirow{4}{*}{$\begin{array}{l}\text { Competencias } \\
\text { Instrumentales y de } \\
\text { Comunicación }\end{array}$} & Utilizar herramientas informáticas & \multirow{4}{*}{14,646} \\
\hline & & Presentar en público productos, ideas o informes & \\
\hline & & Redactar informes o documentos & \\
\hline & & Escribir y hablar idiomas extranjeros & \\
\hline
\end{tabular}

Como resultado de la evaluación de la importancia personal que los graduados universitarios de España dan a los valores laborales, se obtuvo un valor de fiabilidad de la escala inicial, con un alfa de Cronbach de $0,763, \mathrm{KMO}=0,793$ y la prueba de esfericidad de Barlett significativa. La varianza total explicada del $45,956 \%$ se distribuye en dos componentes que se interpretan en el caso del primer factor como el valor del puesto de trabajo enriquecido "satisfactorio" y el segundo factor que involucra las variables ocio y familia, ingresos y estabilidad. La tabla 5.48 muestra la composición de estos factores. 
Tabla 5. 48 Interpretación de los Componentes Principales. Valores Laborales Personales (España)

\begin{tabular}{|c|c|c|c|}
\hline № & $\begin{array}{l}\text { Componentes } \\
\text { Interpretados }\end{array}$ & Variables & $\begin{array}{r}\text { \% Varianza } \\
\text { Explicada }\end{array}$ \\
\hline \multirow{6}{*}{1} & \multirow{6}{*}{$\begin{array}{l}\text { Puesto de Trabajo } \\
\text { Enriquecido "satisfactorio" }\end{array}$} & Autonomía en el trabajo & \multirow{6}{*}{25,106} \\
\hline & & Oportunidad de aprender cosas nuevas & \\
\hline & & Afrontar nuevos retos & \\
\hline & & Buenas perspectivas profesionales & \\
\hline & & Reconocimiento/prestigio social & \\
\hline & & Oportunidad de hacer algo útil para la sociedad & \\
\hline \multirow{4}{*}{2} & \multirow{4}{*}{$\begin{array}{c}\text { Ocio y Familia - Ingresos y } \\
\text { Estabilidad }\end{array}$} & Estabilidad laboral & \multirow{4}{*}{20,85} \\
\hline & & Ingresos elevados & \\
\hline & & Tener tiempo para actividades recreativas & \\
\hline & & Facilidad para combinar trabajo y familia & \\
\hline
\end{tabular}

Como resultado de la medida del grado de cumplimiento de los valores laborales personales en el trabajo se obtuvo un buen valor de fiabilidad de la escala inicial, Alfa de Cronbach de $0,821, \mathrm{KMO}=0,824$ y la prueba de esfericidad de Barlett significativa. La tabla 5.49 muestra cómo están constituidos los factores.

Tabla 5. 49 Interpretación de los Componentes Principales. Valores Laborales en el Trabajo (España)

\begin{tabular}{|c|c|c|c|}
\hline № & $\begin{array}{l}\text { Componentes } \\
\text { Interpretados }\end{array}$ & Variables & $\begin{array}{r}\text { \% Varianza } \\
\text { Explicada }\end{array}$ \\
\hline \multirow{6}{*}{1} & \multirow{6}{*}{$\begin{array}{l}\text { Puesto de Trabajo } \\
\text { Enriquecido "satisfactorio" }\end{array}$} & Autonomía en el trabajo & \multirow{6}{*}{30,184} \\
\hline & & Oportunidad de aprender cosas nuevas & \\
\hline & & Afrontar nuevos retos & \\
\hline & & Buenas perspectivas profesionales & \\
\hline & & Reconocimiento/prestigio social & \\
\hline & & Oportunidad de hacer algo útil para la sociedad & \\
\hline \multirow{2}{*}{2} & \multirow{2}{*}{ Ocio y Familia } & Tener tiempo para actividades recreativas & \multirow{2}{*}{18,998} \\
\hline & & Facilidad para combinar trabajo y familia & \\
\hline \multirow{2}{*}{3} & \multirow{2}{*}{ Ingresos y Estabilidad } & Estabilidad laboral & \multirow{2}{*}{15,953} \\
\hline & & Ingresos elevados & \\
\hline
\end{tabular}

La varianza total explicada es $65,135 \%$ y está distribuida en los tres componentes resultantes: El primer factor con una varianza de 30,184\% agrupa variables de puesto de trabajo enriquecido "satisfactorio". El segundo factor tiene una varianza de 18,998\% y agrupa las variables de ocio y familia y el tercer factor agrupa las variables de ingresos y estabilidad. 
En la prueba factorial ajuste de competencias para los graduados universitarios de España, se utilizaron las variables originales. Se obtuvieron valores adecuados para la prueba $\mathrm{KMO}=0,947$ y la prueba de esfericidad de Barlett resultó significativa. Se obtuvo tres componentes los cuales explican el $51,366 \%$ de la varianza total. El primero componente resultante llamado competencias organizativas, liderazgo e innovación. El segundo componente llamado competencias de conocimiento y pensamiento metacognitivo y el tercer componente llamado competencias instrumentales y de comunicación. La constitución de los factores se muestra en la tabla 5.50 .

Tabla 5. 50 Interpretación de los Componentes Principales. Ajuste de Competencias (España)

\begin{tabular}{|c|c|c|c|}
\hline № & $\begin{array}{l}\text { Componentes } \\
\text { Interpretados }\end{array}$ & Variables & $\begin{array}{c}\text { \% Varianza } \\
\text { Explicada }\end{array}$ \\
\hline \multirow{10}{*}{1} & \multirow{10}{*}{$\begin{array}{c}\text { Competencias } \\
\text { Organizativas, Liderazgo, } \\
\text { Innovación }\end{array}$} & Negociar de forma eficaz & \multirow{10}{*}{21,788} \\
\hline & & Trabajar bajo presión & \\
\hline & & Detectar nuevas oportunidades & \\
\hline & & Coordinar actividades & \\
\hline & & Usar el tiempo de forma efectiva & \\
\hline & & Trabajar en equipo & \\
\hline & & Movilizar las capacidades de otros & \\
\hline & & Hacerte entender & \\
\hline & & Hacer valer tu autoridad & \\
\hline & & Encontrar nuevas ideas y soluciones & \\
\hline \multirow{4}{*}{2} & Competencias de & Dominio de tu área o disciplina & \multirow{4}{*}{14,792} \\
\hline & Conocimiento y & Conocimiento de otras áreas o disciplinas & \\
\hline & Pensamiento & Pensamiento analítico & \\
\hline & Metacognitivo & Adquirir con rapidez nuevos conocimientos & \\
\hline \multirow{5}{*}{3} & \multirow{5}{*}{$\begin{array}{c}\text { Competencias } \\
\text { Instrumentales y C. de } \\
\text { Comunicación }\end{array}$} & Utilizar herramientas informáticas & \multirow{5}{*}{14,786} \\
\hline & & Predisposición para cuestionar ideas propias o ajenas & \\
\hline & & Presentar en público productos, ideas o informes & \\
\hline & & Redactar informes o documentos & \\
\hline & & Escribir y hablar idiomas extranjeros & \\
\hline
\end{tabular}

El ajuste de valores laborales dio como resultado tres componentes que explican el $61,844 \%$ de la varianza total (El primer factor $29,278 \%$, el segundo $18,59 \%$ y el tercero 13,975\%). El resumen de la prueba factorial mostró valores adecuados para la medida de adecuación muestral KMO = 0,824 y la prueba de esfericidad de Barlett resultó significativa. La tabla 5.51 muestra cómo se constituyen estos factores. 
Tabla 5. 51 Interpretación de los Componentes Principales. Ajuste de Valores Laborales (España)

\begin{tabular}{|c|c|c|c|}
\hline № & $\begin{array}{l}\text { Componentes } \\
\text { Interpretados }\end{array}$ & Variables & $\begin{array}{c}\text { \% Varianza } \\
\text { Explicada }\end{array}$ \\
\hline \multirow{6}{*}{1} & \multirow{6}{*}{$\begin{array}{l}\text { Puesto de Trabajo } \\
\text { Enriquecido "satisfactorio" }\end{array}$} & Autonomía en el trabajo & \multirow{6}{*}{29,278} \\
\hline & & Oportunidad de aprender cosas nuevas & \\
\hline & & Afrontar nuevos retos & \\
\hline & & Buenas perspectivas profesionales & \\
\hline & & Reconocimiento/prestigio social & \\
\hline & & Oportunidad de hacer algo útil para la sociedad & \\
\hline \multirow{2}{*}{2} & \multirow{2}{*}{ Ocio y Familia } & Tener tiempo para actividades recreativas & \multirow{2}{*}{18,59} \\
\hline & & Facilidad para combinar trabajo y familia & \\
\hline \multirow{2}{*}{3} & \multirow{2}{*}{ Ingresos y Estabilidad } & Estabilidad laboral & \multirow{2}{*}{13,975} \\
\hline & & Ingresos elevados & \\
\hline
\end{tabular}

A modo de resumen, en la tabla 5.52, se muestra las variables finales del modelo para España y el nombre que las identifica para posteriores análisis, el porcentaje de la varianza explicada y la fiabilidad de la escala.

Tabla 5. 52 Variables Modelo Final ESPAÑA. Porcentaje de la varianza explicada y fiabilidad de las escalas resultantes

\begin{tabular}{|c|c|c|c|}
\hline Variable Dependiente & Nombre & \% Varianza & ALFA $\alpha$ \\
\hline Medidas del Éxito Laboral & Exlab & & \\
\hline Éxito Laboral Objetivo & Exlabob & 96,712 & 0,965 \\
\hline 1.Sueldo Contrato & \multirow{2}{*}{ Exlabob_Spn } & \multirow{2}{*}{96,712} & \\
\hline 2.Sueldo Total & & & \\
\hline Éxito Laboral Subjetivo & Exlabsu & 72,87 & 0,626 \\
\hline 3.Uso de conocimientos y habilidades & \multirow{2}{*}{ Exlabsu_Spn } & \multirow{2}{*}{72,87} & \\
\hline 4.Satisfacción en el trabajo & & & \\
\hline Variables Independientes & Nombre & \% Varianza & ALFA $\alpha$ \\
\hline Rol en el Trabajo & Rol & 63,533 & 0,809 \\
\hline 5. Responsabilidad en el trabajo & Responsa_Spn & 27,415 & \\
\hline 6. Relaciones en el trabajo & Relacion_Spn & 24,025 & \\
\hline 7. Perjuicio a la organización & Perjuicio_Spn & 12,093 & \\
\hline
\end{tabular}




\begin{tabular}{|l|c|c|c|}
\hline Competencias Personales & CPSPN & 54,753 & 0,896 \\
\hline 8. C. Liderazgo y Comunicación & CPSpn_F1 & 17,348 & \\
\hline 9. C. Organizativas & CPSpn_F2 & 13,713 & \\
\hline $\begin{array}{l}\text { 10. C. de Conocimiento y Pensamiento } \\
\text { Metacognitivo }\end{array}$ & CPSpn_F3 & 12,212 & \\
\hline 11. C. Instrumentales y de Innovación & CPSpn_F4 & 11,481 & \\
\hline Competencias Requeridas en el Trabajo & CRSPN & 55,234 & 0,921 \\
\hline 12. C. Organizativas, Liderazgo e innovación & CRSpn_F1 & 22,46 & \\
\hline $\begin{array}{l}\text { 13. C. de Conocimiento y Pensamiento } \\
\text { Metacognitivo }\end{array}$ & CRSpn_F2 & 18,128 & \\
\hline 14. C. Instrumentales y de Comunicación & CRSpn_F3 & 14,646 & \\
\hline Valores Laborales Personales & Val_Lab_Pers & 45,956 & 0,763 \\
\hline $\begin{array}{l}\text { 15. Puesto de Trabajo Enriquecido } \\
\text { "satisfactorio" }\end{array}$ & VPSpn_F1 & 25,106 & \\
\hline 16. Ocio y Familia - Ingresos y Estabilidad & VPSpn_F2 & 20,85 & \\
\hline Valores Laborales en el Trabajo & Val_Lab_Trbj & 65,135 & 0,821 \\
\hline $\begin{array}{l}\text { 17. Puesto de Trabajo Enriquecido } \\
\text { "satisfactorio" }\end{array}$ & VLTSpn_F1 & 30,184 & \\
\hline 18. Ocio y Familia & VLTSpn_F2 & 18,998 & \\
\hline 19. Ingresos y Estabilidad & VLTSpn_F3 & 15,953 & \\
\hline $\begin{array}{l}\text { Ajuste de Competencias Propias y } \\
\text { Requeridas en el trabajo }\end{array}$ & AJC_Spn & 51,366 & N.A. \\
\hline 20. C. Organizativas, liderazgo, innovación & AJC_F1_Spn & 21,788 & \\
\hline $\begin{array}{l}\text { 21 C. de Conocimiento y Pensamiento } \\
\text { Metacognitivo }\end{array}$ & AJC_F2_Spn & 14,792 & \\
\hline 22. C. Instrumentales y C. de Comunicación & AJC_F3_Spn & 14,786 & \\
\hline $\begin{array}{l}\text { Ajuste de Valores Laborales Personales y } \\
\text { Valores Laborales en el Trabajo }\end{array}$ & AJVT_Spn & 61,844 & N.A. \\
\hline $\begin{array}{l}\text { 23.Puesto de trabajo enriquecido } \\
\text { "Satisfactorio" }\end{array}$ & AJVT_F1_Spn & 29,278 & \\
\hline 24. Ocio y Familia & AJVT_F2_Spn & 18,59 & \\
\hline 25. Ingresos y estabilidad & AJVT_F3_Spn & 13,975 & \\
\hline
\end{tabular}

\subsection{Modelo Final de la investigación una vez se ha reducido el número de variables a}

\section{través del análisis factorial.}

Después de realizar análisis similares por continente y país, haciendo uso de la metodología de investigación propuesta, se decidió seguir adelante el presente trabajo a partir de los modelos finales de investigación obtenidos para una posterior comprobación de las hipótesis. Por representatividad y para delimitar la extensión de análisis similares, los modelos finales se reducen a tres grupos objetivos de interés: Los graduados universitarios de Europa, Latinoamérica y de España. 


\subsubsection{Modelo Final de Investigación para Europa}

En la Figura 5.20 se muestra el modelo de investigación y las variables de medida presentadas en la tabla 5.36. El conjunto de variables se compone por 24 nuevas variables obtenidas mediante el análisis factorial. Como se aprecia, las seis hipótesis están representadas por líneas de conexión entre los elementos del modelo.

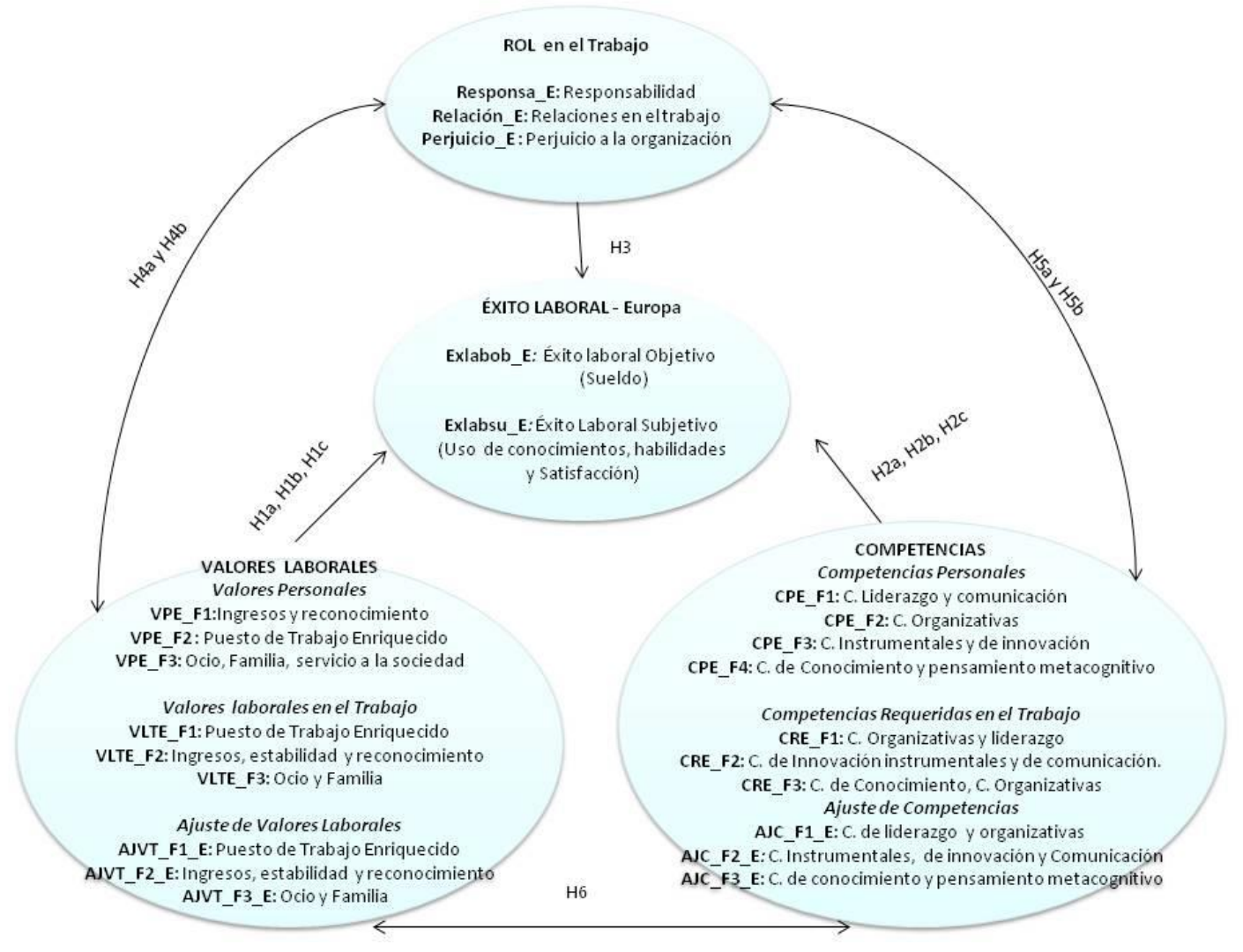

Figura 5. 20 Modelo final de Investigación - Europa 


\subsubsection{Modelo Final de Investigación para Latinoamérica}

En la Figura 5.21 se muestra el modelo de investigación y las variables de medida presentadas en la tabla 5.44. El conjunto de variables se compone por 19 nuevas variables obtenidas mediante el análisis factorial. Como se aprecia, las seis hipótesis están representadas por líneas de conexión entre los elementos del modelo.

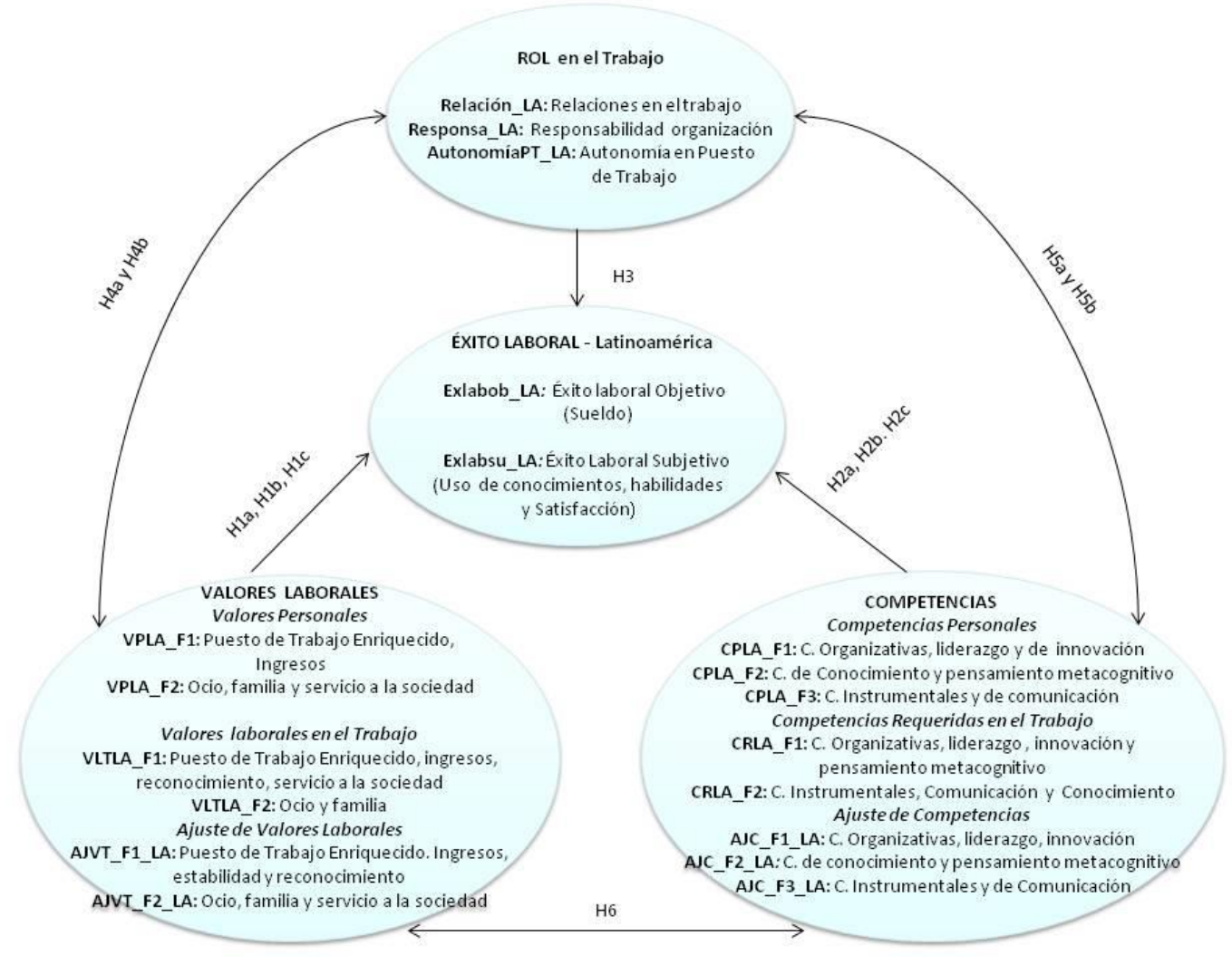

Figura 5. 21 Modelo final de Investigación - Latinoamérica 


\subsubsection{Modelo Final de Investigación para España}

En la Figura 5.22 se muestra el modelo de investigación y las variables de medida presentadas en la tabla 5.52. El conjunto de variables se compone por 23 nuevas variables obtenidas mediante el análisis factorial. Como se aprecia, las seis hipótesis están representadas por líneas de conexión entre los elementos del modelo.

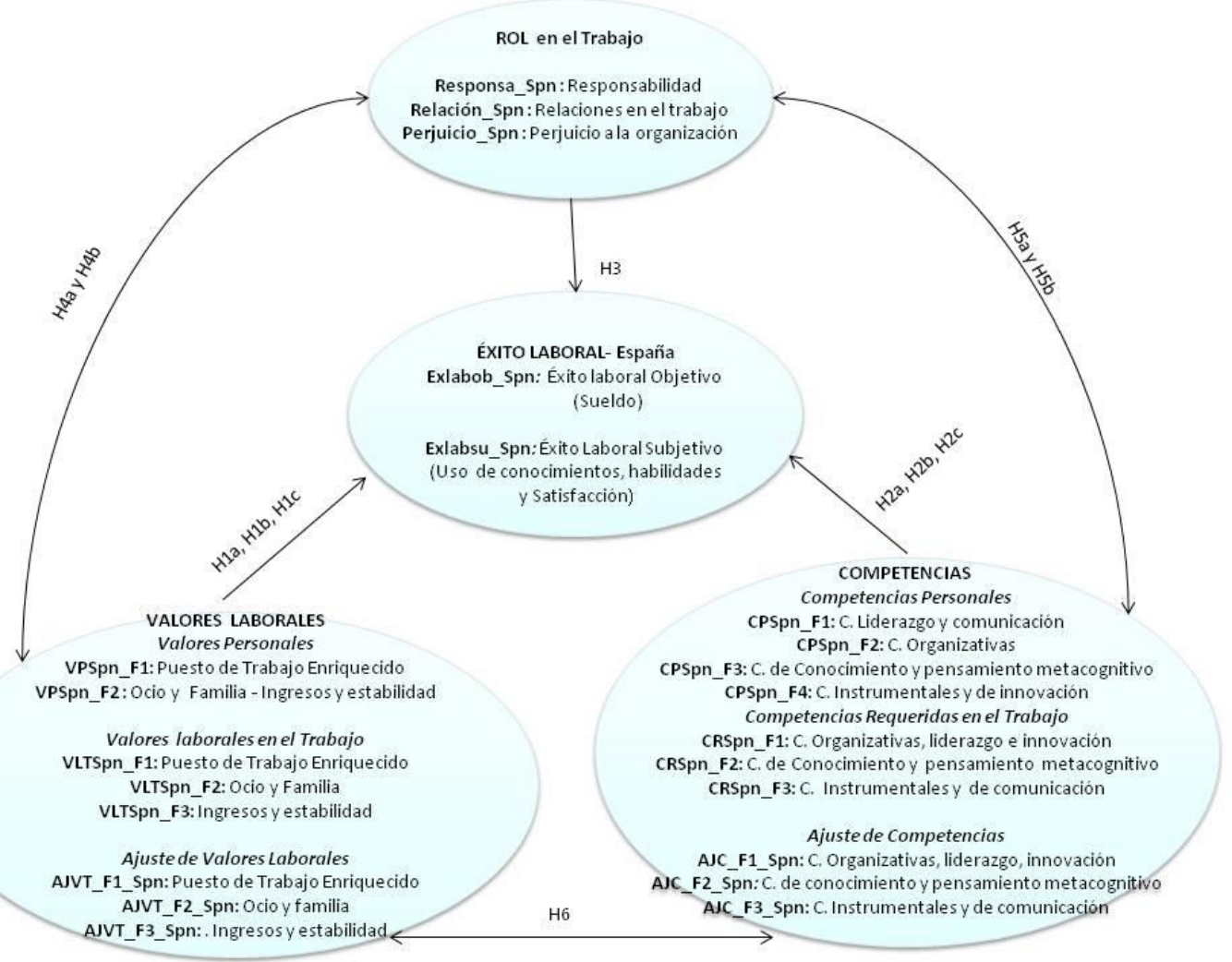

Figura 5. 22 Modelo final de Investigación - España

En este capítulo se ha realizado el análisis descriptivo de todas las variables que conforman el modelos general propuesto, así como la descripción de los resultados que han permitido obtener los tres modelos definitivos para el estudio del éxito laboral de los graduados universitarios de Europa, Latinoamérica y de España. Se ha podido identificar similitudes y las diferencias entre cada uno de ellos y sirven de marco de referencia para el capítulo siguiente, que corresponde a la discusión de los resultados. 


\section{CAPITULO 6}

\section{Discusión de Resultados}

El modelo teórico propuesto pretende analizar la relación entre el rol, las competencias y los valores laborales de los profesionales universitarios con el éxito laboral, en términos de éxito laboral objetivo y éxito laboral subjetivo. Se hizo una selección de preguntas a partir de la encuesta base que incluye nueve bloques de preguntas de los que se seleccionaron cinco: Información personal, información sobre el trabajo que ocupaban en el momento de la entrevista, información acerca de la organización, competencias y valores laborales.

Inicialmente se realizó un análisis previo de los datos para identificar datos ausentes o casos atípicos, posteriormente, para la caracterización de los graduados universitarios que respondieron al estudio se emplearon técnicas descriptivas. Se realizó el análisis de correlación y fiabilidad para las variables del modelo propuesto al conjunto de la muestra. A continuación, se utilizó la técnica de análisis factorial exploratorio con el objetivo de reducir el número original de variables y obtener un modelo final de investigación. La relación entre las variables para la comprobación de las hipótesis del modelo, se basó en un análisis de correlación bivariado. Los resultados obtenidos son la base para el análisis de comparación de los modelos finales resultantes que corresponden a los graduados universitarios de Europa, Latinoamérica y España.

\subsection{Análisis Descriptivo}

Los análisis descriptivos realizados permitieron conocer las características personales, el contexto familiar y laboral de los graduados. Inicialmente se realizaron al conjunto de los 48094 graduados universitarios. Posteriormente se hizo una segmentación por continente y por país con el objetivo de identificar similitudes y diferencias entre los graduados universitarios. Los países de referencia seleccionados son: España, Francia, Reino Unido, Suiza, Alemania, México, Chile y Uruguay. Los siguientes apartados recogen los aspectos más relevantes de cada uno de los análisis realizados en el capítulo cinco. 


\subsubsection{Datos demográficos y económicos}

En cuanto a las características generales de la muestra de $38286(79,6 \%)$ registros, son graduados universitarios de Europa y 9808 (20,4\%) son graduados universitarios de Latinoamérica. La distribución de la muestra por sexo corresponde a mujeres el 57,8\% y a hombres el $42,2 \%$. Valores similares de participación por sexo, se identificaron en la muestra por continente, en el que participaron $58,3 \%$ de graduadas universitarias procedentes de Europa y el $55,1 \%$ de mujeres procedentes de Latinoamérica.

La edad media de los graduados/as en el momento de la entrevista era de 31 años. La mayoría de ellos manifestaron convivir en pareja, $60,5 \%$ de los europeos y el $49,9 \%$ de los latinoamericanos. En este apartado, al comparar los ocho países seleccionados, la mayoría manifestaron vivir en pareja o solos, los graduados de México $(30,8 \%)$ y España $(36,8 \%)$ manifestaron en una proporción importante vivir con sus padres, con unas cifras que superan la media para Latinoamérica y Europa respectivamente. La mayoría de los graduados manifestaron no tener hijos $(72,4 \%)$. Los alemanes $(28,9 \%)$ y chilenos $(35,4 \%)$ manifestaron tener uno o dos hijos, cifra que supera la media de cada continente respectivamente.

Las áreas de estudio en las que se concentra el mayor número de graduados en general, por continente y país corresponde a los que estudiaron en aéreas de estudio técnicas.

La ocupación de los graduados universitarios corresponde en su mayoría a su nivel de formación, en su orden el cargo de profesional/científico, técnico de nivel medio, directivo, empleado de oficina y otros cargos. Aparecen dos diferencias: Mientras sólo el 8,5\% de los graduados europeos ocupan cargos directivos, este valor se incrementa al $14,1 \%$ en los graduados de Latinoamérica. En el otro lado de la escala solo el 7,9\% de los graduados europeos tienen bajas posiciones, como empleados de oficina y otros, mientras para los graduados de Latinoamérica este valor es $18,2 \%$. No son de fácil interpretación estos hechos, sino como una posibilidad provisional que requeriría posteriores investigaciones. La primera diferencia principal puede ser debido al hecho que la educación superior en Latinoamérica es aún limitada a una parte de la población con mayor nivel económico y con frecuencia los estudiantes tienen las relaciones que les facilitan alcanzar puestos de dirección más pronto que los graduados europeos. La estratificación social puede ser la base para el segundo hecho, los graduados de Latinoamérica procedentes de algunas universidades y entornos socioeconómicos pueden encontrar más dificultades para llegar a los puestos de trabajo de acuerdo con su grado. 
La mayoría de los graduados de ambos continentes indicaron en el momento de la entrevista tener contratos indefinidos $(76,31 \%)$, seguidos por contratos de duración limitada $(19,69 \%)$ y otro tipo de contrato $(4,0 \%)$.

Las organizaciones en las que trabajaban los graduados universitarios en el momento de la entrevista cubre todos los ámbitos de la clasificación CIUO-88, pero destaca su amplia participación en el sector servicios, sector de la educación y el sector de la salud. La mayoría de las organizaciones en las que trabajan son de carácter privado. Según tamaño de la organización, los graduados universitarios Europeos trabajan en organizaciones grandes (1000 o más) en mayor proporción que los Latinoamericanos. En ambos continentes, el 17,3\% trabajan en organizaciones de tamaño pequeño (10 a 49 trabajadores).

\subsubsection{Variables de Estudio}

Siguiendo el procedimiento del capítulo anterior se partió de la idea original de agrupar las variables según el modelo teórico inicial propuesto y a partir de los análisis mantener las variables originales o proceder a su eliminación.

\subsubsection{Variables de Éxito laboral}

Tomando de base la teoría actual sobre éxito laboral (Arthur, Khapova, y Wilderom, 2005), en la que se observan dos dimensiones, la dimensión objetiva y la dimensión subjetiva del éxito profesional, se analizaron las valoraciones y percepciones de los egresados universitarios a partir de su experiencia laboral.

Para el análisis descriptivo de las variables de éxito laboral objetivo, se consideraron dos variables originales: Promedio de horas de dedicación en el trabajo y el salario mensual. Para el análisis de las variables de éxito laboral subjetivo se consideraron tres variables originales: Uso de conocimientos y habilidades en el trabajo, conocimientos requeridos en el trabajo, y la satisfacción con el trabajo actual.

Al analizar las variables de éxito laboral objetivo, los resultados mostraron que los graduados latinoamericanos emplean más horas trabajando que los europeos. De igual manera, los latinoamericanos manifestaron tener una mayor dedicación en horas extraordinarias y en la realización de otros trabajos que los graduados europeos.

Para el análisis del sueldo, se tuvo en consideración, dos variables. El salario según contrato y el salario total que incluye los ingresos extras además del salario base. Esta información fue corregida inicialmente con el índice de Paridad de Poder Adquisitivo (PPA) para homogeneizar los valores brutos de salario de los distintos países en Euros. Para obtener 
los resultados por país en dólares americanos (USD), estos fueron corregidos por el índice de precios al consumidor (IPC), para los países considerados. De los resultados obtenidos destaca que el salario de los europeos es superior que el sueldo que perciben los latinoamericanos, si se compara país a país y en el conjunto del continente. Considerando los incrementos obtenidos por la realización de horas extras y dedicación a otros trabajos, los graduados europeos perciben un mayor incremento en el salario total que los graduados latinoamericanos.

Las tres variables que miden el éxito laboral subjetivo, uso de los conocimientos y habilidades en el trabajo, conocimientos requeridos en el trabajo y satisfacción en el trabajo fueron medidas utilizando una escala Likert de 1 a 5 , siendo 1 el valor correspondiente al nivel más bajo y 5 el más alto. En este análisis se destacan aspectos comparables entre los países de ambos continentes. El 71,5\% de los graduados Europeos y el 79,4\% de los Latinoamericanos indican que efectivamente usan en mayor grado sus conocimientos y habilidades en el trabajo. Sin embargo, los resultados obtenidos de la pregunta "En qué medida el trabajo requiere más conocimientos y habilidades de los que puede ofrecer" muestran que para el $32,4 \%$ de los graduados de Europa y el 30,9\% de los graduados de Latinoamérica el nivel de requerimiento de conocimientos y habilidades en el trabajo es más bajo del que podrían ofrecer.

Las dos respuestas hacen pensar que están indicando tener una adecuación entre el área de estudios y el puesto de trabajo ocupado. A la pregunta satisfacción con el trabajo actual, los graduados de Latinoamérica manifestaron en el conjunto del continente una mayor satisfacción que los graduados de Europa. En la comparación por países, la satisfacción con el trabajo es mucho mayor entre los graduados de Uruguay, México, Chile seguidos de los graduados de Suiza y Alemania.

\subsubsection{Variables de Rol - Funciones}

Las variables de análisis seleccionadas en el apartado de rol, buscan identificar qué rol desempeñan los graduados universitarios en el puesto de trabajo. De las referencias teóricas se tuvo en cuenta la consideración que existe acerca de que la adecuación entre el área de estudio y el área requerida en el puesto de trabajo es un factor determinante en la satisfacción de los graduados universitarios con sus trabajos (Informe Proflex, 2010). Los resultados obtenidos de la pregunta qué área de estudios era la más apropiada para el trabajo que realizaban, los graduados señalaron tener trabajos relacionados con su área de estudios, siendo mayor para los latinoamericanos $(90,8 \%)$, frente a los europeos $(85,1 \%)$. Sin embargo, al comparar entre países los graduados de Reino Unido $(31,4 \%)$, España $(20,6 \%)$ y Francia 
(20,3\%), manifestaron en una proporción importante trabajar en cargos que no tenían nada que ver con los estudios cursados en la universidad.

Al analizar cómo los graduados universitarios asumen la responsabilidad frente al puesto de trabajo, se marcan diferencias entre los europeos y los latinoamericanos. Los graduados europeos, manifestaron sentir alta responsabilidad para establecer objetivos del propio trabajo y para decidir cómo hacer su trabajo. Sin embargo no perciben tener mayor responsabilidad para establecer objetivos en la organización, ni para decidir estrategias para la organización. En contraste, los graduados latinoamericanos se sienten responsables de decidir cómo hacer el propio trabajo, establecer objetivos relacionados con el puesto de trabajo y con la organización. De igual manera se sienten responsables de decidir estrategias de trabajo para la organización. En resumen, los graduados de Latinoamérica tienen mayor responsabilidad para tomar decisiones en sus organizaciones que los colegas de Europa y en consecuencia ellos pueden potencialmente causar mayor perjuicio a la organización. Esto es coherente con la mayor frecuencia con que ocupan cargos directivos. Los niveles de autonomía son similares en los dos grupos o ligeramente mayor para los graduados de Latinoamérica.

Otro aspecto analizado en este apartado ha sido interpretar cómo perciben las relaciones interpersonales en el trabajo. En general los graduados universitarios de Europa y Latinoamérica sienten que son tenidos en cuenta por compañeros de trabajo, clientes, etc., para temas en los que se requiere consejo y mantienen canales de información sobre nuevos desarrollos en sus campos de actuación.

Las diferencias entre los graduados de Europa y Latinoamérica, muestran que existen diversas valoraciones cuando se les preguntó acerca del establecimiento de relaciones profesionales con expertos ajenos a la organización. Mientras los graduados de Chile, México y Uruguay manifestaron iniciar relaciones profesionales fuera de la organización, los de España y Francia manifestaron que no suelen iniciarlas.

Se puede afirmar que para los graduados universitarios, es importante la ética profesional como parte de las funciones en el puesto de trabajo, destacando la valoración que hace una mayor proporción de graduados latinoamericanos $(87,1 \%)$ frente a los graduados de Europa $(69,7 \%)$.

A la pregunta sobre cuánto perjudicarían a la organización si cometieran un error grave, los resultados arrojados muestran una alta percepción acerca del perjuicio que acarrearía para la organización una actuación errónea en el puesto de trabajo. 
El análisis realizado en este apartado es importante para resaltar las similitudes y diferencias marcadas para el conjunto de graduados de ambos continentes y la comparación realizada a los países seleccionados. Se puede añadir que los graduados latinoamericanos dan altas valoraciones a la percepción que tienen de los aspectos preguntados, en comparación con las valoraciones de los europeos que tienden a hacer evaluaciones más moderadas. Aunque algunos aspectos analizados mostraron diferencias entre europeos $y$ latinoamericanos, se puede percibir que valoran positivamente su trabajo, su rol en la organización y que reconocen la importancia de lo que hacen y lo que esto puede afectar a su trabajo y a la organización. Sus valoraciones indican que los latinoamericanos tienen mayor margen de maniobra para el desarrollo de sus funciones. Los resultados sugieren que un alto porcentaje de los graduados de ambos continentes trabajan en organizaciones en donde ellos establecen con frecuencia contactos y relaciones con otros colegas dentro y fuera de la organización. La relevancia de la ética en el trabajo es similar en ambos grupos, ligeramente mayor en los graduados de Latinoamérica.

\subsubsection{Las Competencias de los Profesionales Universitarios}

Se admite que quien dispone de los conocimientos, destrezas y aptitudes necesarios para ejercer una profesión, puede resolver los problemas profesionales de forma autónoma y flexible y está preparado para colaborar con su entorno profesional y en la organización del trabajo, tiene competencia profesional (Bunk, 1994). En el momento de evaluar las competencias en los graduados universitarios, se ha considerado que pasado un tiempo desde la graduación, las competencias pueden quedar obsoletas en unos casos y se puede ganar en la adquisición de nuevas competencias en otros casos. La entrevista directa a los graduados permite a los graduados universitarios reflexionar acerca del nivel de competencias que posee y las competencias que necesitan para desarrollar su trabajo.

En el análisis realizado, se identificó en el conjunto de los graduados universitarios, la evaluación personal del nivel que consideraban tener en cada una de las diecinueve competencias propuestas para su valoración y del nivel de competencias requerido en el puesto de trabajo. Los graduados universitarios de Europa y Latinoamérica consideraron tener un nivel personal medio alto al valorar cada una de las diecinueve competencias propuestas en la encuesta. Las competencias en las que se consideran más fuertes, no son las que más nivel de competencias les es requerido en el trabajo, siendo el nivel que exigen las competencias en el trabajo, ligeramente menor que el que manifestaron tener. Así pues los graduados perciben un cierto desajuste entre sus competencias personales y las requeridas en su trabajo. 
El conocimiento de otras áreas o disciplinas y la capacidad para escribir y hablar en idiomas extranjeros, competencias consideradas por los graduados universitarios como las competencias personales de menor nivel personal, son a la vez competencias poco requeridas en los puestos de trabajo.

La capacidad para usar el tiempo de forma efectiva, capacidad de hacerse entender y la capacidad para trabajar bajo presión son competencias requeridas en el puesto de trabajo y son algunas de las que más se ajustan al nivel personal indicado por los graduados de ambos continentes.

\subsubsection{Los Valores Laborales de los Profesionales Universitarios}

Tres décadas atrás, tener una carrera profesional y poder ocupar un cargo remunerado en una organización, era un buen indicador de éxito profesional. Sin embargo, en los últimos años hemos asistido a cambios sociales que están afectando esa visión, en donde el sueldo y la ocupación no son suficientes para tener una satisfacción en el trabajo o considerarse un profesional exitoso. Sin quitar la importancia que este aspecto objetivo del éxito laboral ocupa, aparecen en escena otros aspectos de carácter subjetivo pero muy importantes en la vida laboral. Características tales como la satisfacción en el trabajo, la autonomía, el poder conciliar el trabajo con la vida familiar, el prestar un servicio a la sociedad, entre otros pasan a ser importantes aspectos subjetivos del éxito laboral. En este apartado se analizó la importancia que dan los graduados universitarios de Europa y Latinoamérica a las características del trabajo y evaluaron el grado en que se aplican a su situación laboral. En general, el grado de aplicación de las características del trabajo con respecto a su valoración personal es menor. Es decir que ninguna se adecua plenamente en comparación a la importancia que los graduados universitarios de ambos continentes le dan. Las características del trabajo que más se ajustan para el conjunto de los graduados de Europa y Latinoamérica son, la autonomía en el trabajo, la oportunidad de aprender cosas nuevas y la estabilidad laboral. Los ingresos elevados y buenas perspectivas profesionales son las características del trabajo que menos se aplican a la situación laboral por ellos manifestada.

En este apartado 6.1 se han resumido los aspectos más relevantes del descriptivo de los graduados universitarios de Europa y Latinoamérica, así como de los países seleccionados para la comparación de resultados.

\subsection{Análisis de Correlación y fiabilidad}

Continuando con los análisis de los resultados obtenidos en el capítulo cinco, se realizaron dos pruebas a la muestra de graduados universitarios de Europa y Latinoamérica. La 
primera, fue un análisis de correlación entre las variables con el fin de ver la intensidad de la asociación lineal entre dos variables y la segunda fue el análisis de fiabilidad, con el fin de valorar la fiabilidad de las escalas utilizadas en los bloques de preguntas.

Para el análisis de correlación inicial se utilizó el coeficiente correlación de Pearson que mide la intensidad de asociación lineal entre dos variables. Se aplicó este análisis de correlación a las variables de éxito laboral objetivo; sueldo y horas promedio de trabajo a la semana. El grado de correlación entre variables es positivo y significativo. El coeficiente Rho de Spearman fue utilizado para el análisis de correlación de las variables ordinales agrupadas para los constructos rol (9 variables), competencias propias (19 variables), competencias requeridas en el trabajo (19 variables), valores laborales - importancia personal (10 variables) y valores laborales- grado de aplicación en el trabajo (10 variables). En la mayoría de las correlaciones se hallaron diferentes grados de asociación que resultaron estadísticamente significativos.

En el análisis de fiabilidad, se hicieron las mediciones mediante la agrupación de cada una de las variables inicialmente propuestas para cada uno de los constructos del modelo. Estas se verificaron para confirmar la fiabilidad de las escalas de medición: Éxito laboral (Alfa de Cronbach= 0,649), rol (Alfa de Cronbach= 0,782), competencias personales (Alfa de Cronbach $=0,894)$ competencias requeridas (Alfa de Cronbach $=0,916)$, valores laborales personales (Alfa de Cronbach $=0,769$ ) y valores laborales grado de aplicación en el trabajo (Alfa de Cronbach $=0,762$ ).

Para medir la fiabilidad de las escalas del constructo éxito laboral subjetivo fueron seleccionadas inicialmente las variables, "¿En qué medida usas tus conocimientos y habilidades en tu trabajo actual?”, “¿En qué medida tu trabajo actual requiere más conocimientos y habilidades de los que tú puedes ofrecer?”, “¿En general, estás satisfecho con tu trabajo actual?" Después de varias pruebas se decidió eliminar del análisis la variable, “¿En qué medida tu trabajo actual requiere más conocimientos y habilidades de los que tú puedes ofrecer?" al presentar menor grado de asociación con las otras dos variables del análisis. Aunque se obtuvo un Alfa de Cronbach de 0,581, se decidió seguir adelante con las dos variables enunciadas.

Un análisis similar se realizó con las variables de éxito laboral objetivo:

¿Cuál es aproximadamente tu sueldo mensual bruto? Sueldo base regular.

¿Cuál es aproximadamente tu sueldo mensual bruto? Total. 
¿Cuál es el promedio de horas que trabajas a la semana? Según contrato en el trabajo principal.

¿Cuál es el promedio de horas que trabajas a la semana? Total.

Se decidió continuar el análisis únicamente con las variables de sueldo y eliminar las variables promedio de horas de trabajo a la semana, por el carácter discreto de la variable horas promedio de trabajo a la semana y porque mejora el valor de fiabilidad si se utiliza solo las dos variables asociadas al sueldo.

\subsection{Análisis Factorial}

De la información obtenida en los análisis, se decidió estudiar la agrupación de las variables del modelo propuesto, utilizando la base conjunta, la base segmentada por continentes (Europa y Latinoamérica) y un país seleccionado del grupo de países analizados en el descriptivo (España). A partir de diferentes análisis realizados con la técnica del análisis factorial, se obtuvo una serie de factores que forman el modelo resultante para Europa, Latinoamérica y España.

El procedimiento general para el estudio de cada uno de los tres modelos consistió en nueve análisis hechos para la variable dependiente del modelo: éxito laboral y para las variables independientes del modelo: rol, competencias propias, competencias requeridas, valores laborales - importancia personal, valores laborales- grado de aplicación en el trabajo, ajuste de competencias y ajuste de valores laborales. Los nombres de las nuevas variables refleja la agrupación de las variables resultantes.

\subsubsection{Diferencias en el Comportamiento de Europa y Latinoamérica en cada una de los} Variables independientes. Análisis Gráfico de las Medias.

A modo exploratorio y para conocer la tendencia de comportamiento del conjunto de los graduados universitarios de ambos continentes, se realizó el análisis factorial para todas las variables que conforman las variables independientes del modelo. A partir de los factores obtenidos se realizó una comparación entre los mismos con los valores de media resultantes en el descriptivo y se obtuvieron diversos gráficos que se muestran a continuación. El proceso arrojó resultados que mostraron que los países se agrupan por un denominador común que corresponde al continente. Los siguientes gráficos muestran algunas de las comparaciones realizadas, por motivos de espacio no se incluyen todas, pero son representativas de cada variable. 
La figura 6.1 muestra la comparación entre las componentes resultantes del análisis factorial de la medida del rol en el trabajo. En la figura a, se muestra la comparación entre el primer factor resultante (Responsabilidad) frente al segundo factor (Relación). En la figura b. corresponde a la comparación entre el primero factor Responsabilidad frente al tercer factor resultante Perjuicio. Los valores de las medias obtenidas se agrupan entre países del mismo continente, en este caso Europa y Latinoamérica.
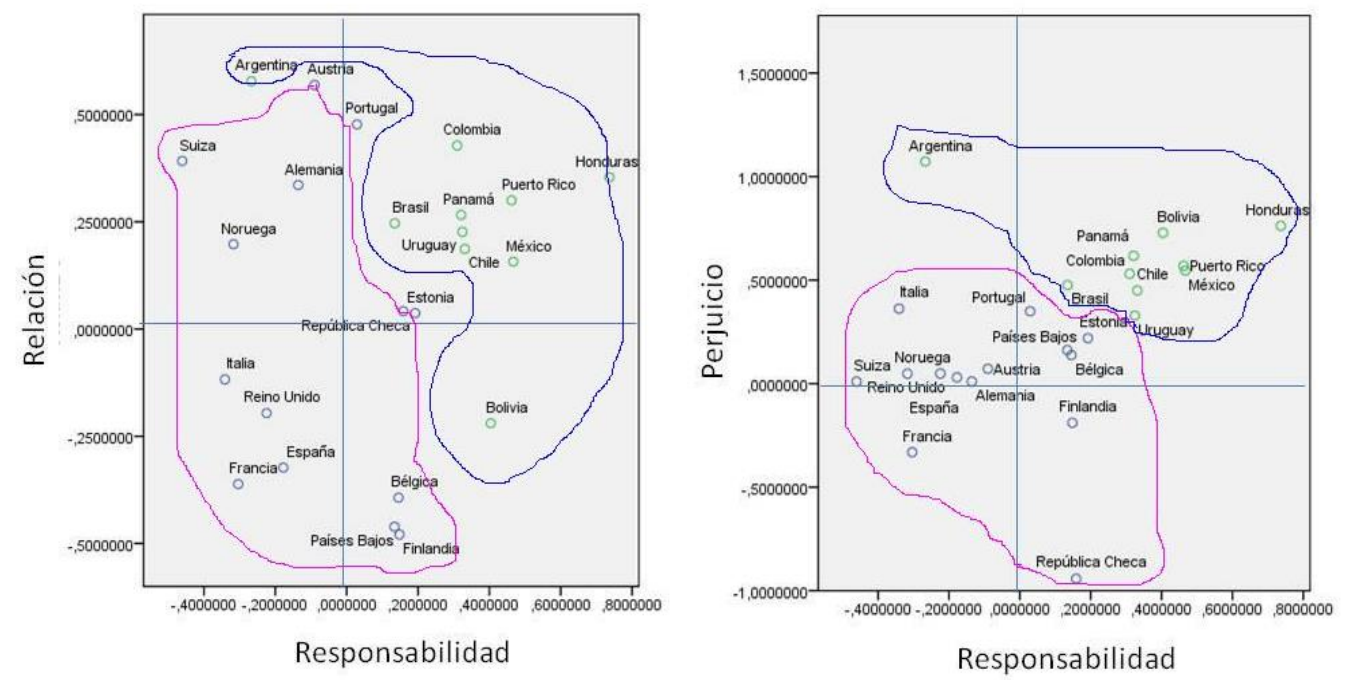

Figura 6.1 Variable Rol

a.(F1. Responsabilidad vs F2.Relación) y b.(F1. Responsabilidad vs F3. Perjuicio)

En ambas figuras se aprecia que los graduados de Latinoamérica tienden a tener mayor nivel de responsabilidad. También ambas muestran que tanto en relación como en perjuicio los graduados de Latinoamérica tienden a dar valores mayores. 
La figura 6.2 representa la comparación entre las componentes resultantes del análisis factorial de la medida de las competencias propias. La figura a. muestra la comparación entre el primer factor resultante (F1. Competencias de liderazgo, organizativas y de comunicación) frente al segundo factor (F2. Competencias instrumentales y de innovación). La figura b. muestra la comparación del primero y el tercer factor (F3. Competencias de conocimiento y pensamiento metacognitivo). Los valores de las medias obtenidas se agrupan entre países del mismo continente.

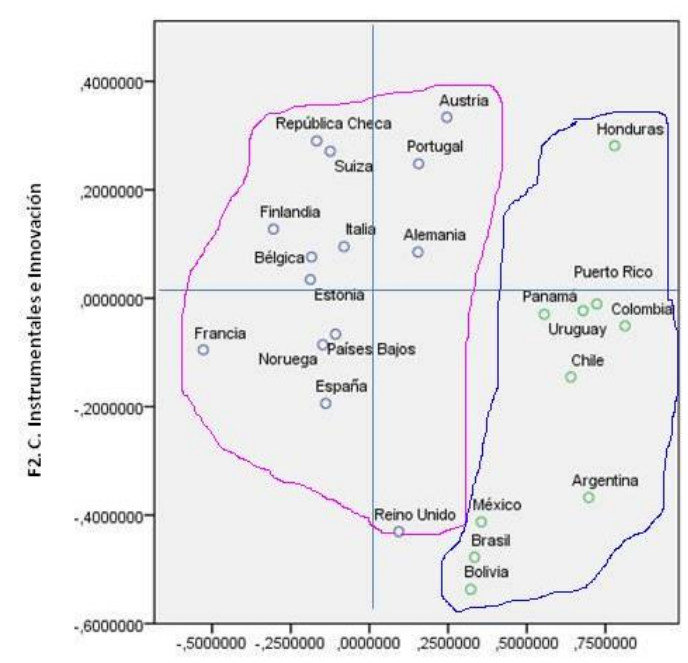

F1.C. Liderazgo, Organizativas y Comunicación

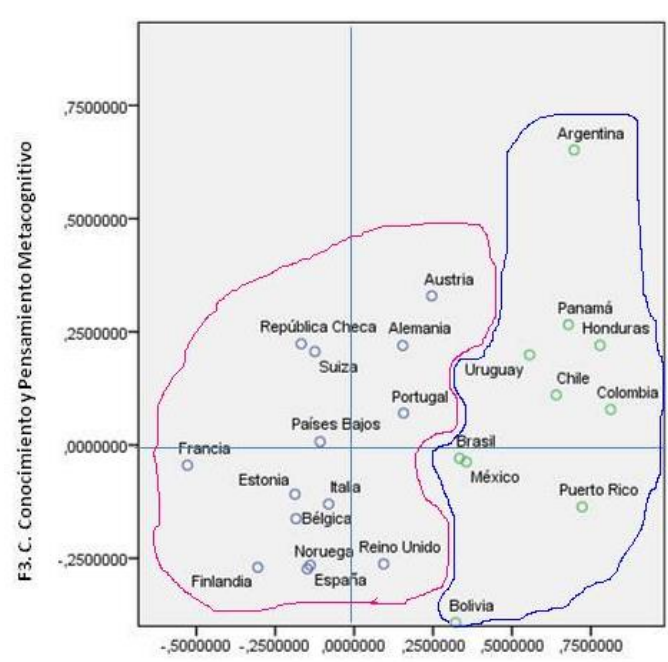

F1. C. Liderazgo, Organizativas y Comunicación

Figura 6. 2 Variable Competencias Propias a.(Factor 1 vs Factor 2 ) y b.(Factor 1 vs Factor 3)

Ambas figuras muestran que las diferencias por continente corresponden al factor 1 , competencias de liderazgo, organizativas y de comunicación y que sin embargo tanto en competencias instrumentales e innovación, como en competencias de conocimiento y pensamiento metacognitivo no hay diferencias. 
La figura 6.3 representa la comparación entre las componentes resultantes del análisis factorial de la medida del nivel de competencias requeridas en el puesto de trabajo. En la figura a. se muestra la comparación entre el primer factor resultante (F1. Competencias de liderazgo) frente al segundo factor (F2. Competencias instrumentales. Innovación y comunicación). En la figura b. aparece la comparación entre el primer factor y el tercero (F3. Competencias organizativas, conocimiento y pensamiento metacognitivo). Los valores de las medias obtenidas agrupan entre países del mismo continente.
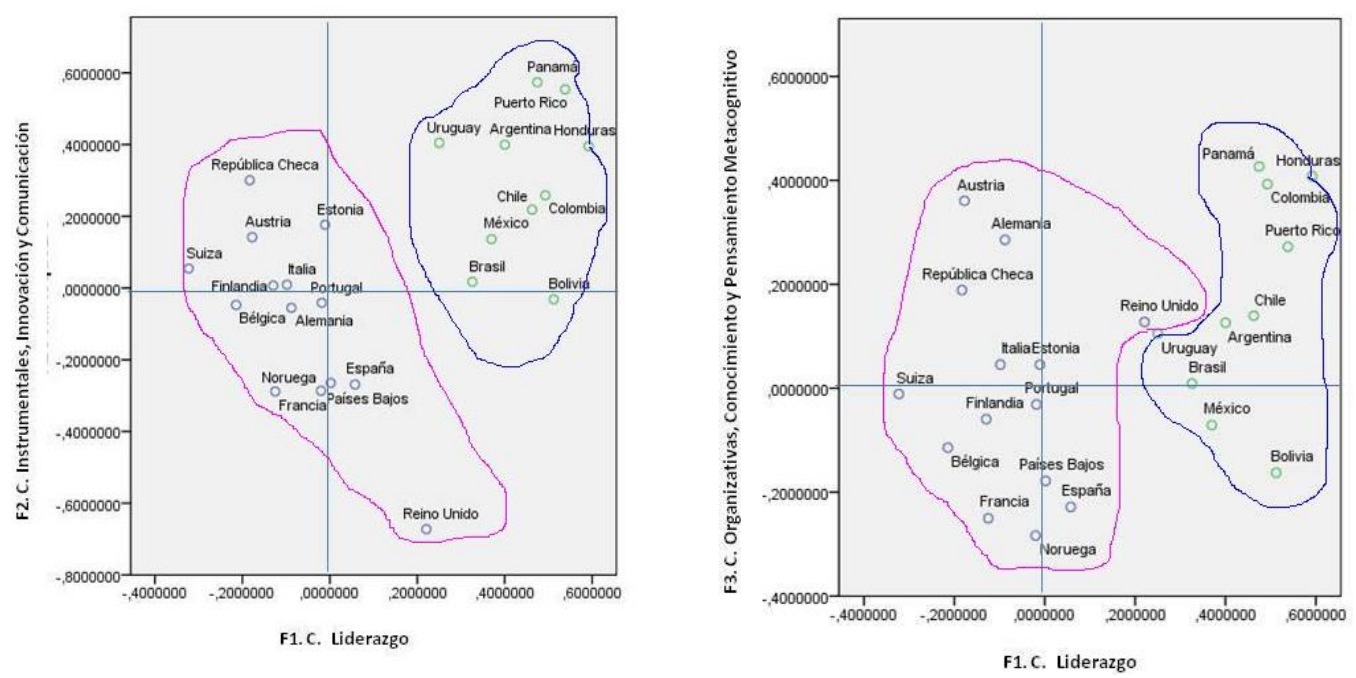

Figura 6. 3 Variable Competencias Requeridas a.(Factor 1 vs Factor 2) y b.(Factor 1 vs Factor 3)

En este caso se percibe también la diferencia por continente en el factor liderazgo de modo bastante claro, pero la menor diferencia se muestra en el factor 2 y sobre todo en el factor 3 . 
La figura 6.4 representa la comparación entre las componentes resultantes del análisis factorial de la medida los valores laborales personales. En la figura a. se muestra la comparación entre el primer factor resultante (F1. Ingresos y reconocimiento) frente al segundo factor (F2. Puesto de trabajo enriquecido). La figura b. corresponde a la comparación entre el primer y el tercer factor (F3. Estabilidad, ocio, familia y servicio a la sociedad).

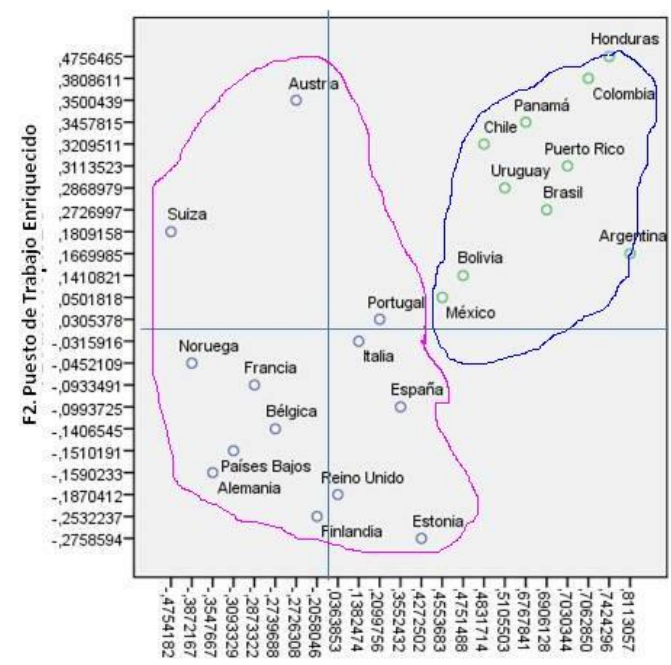

F1. Ingresos y Reconocimiento

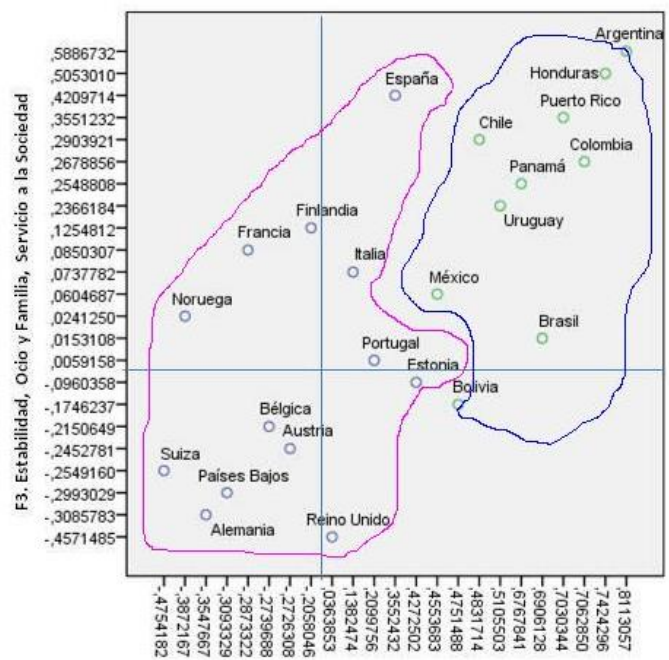

F1. Ingresos y Reconocimiento

Figura 6. 4 Valores Laborales Personales a.(Factor 1 vs Factor 2 ) y b.(Factor 1 vs Factor 3)

Nuevamente el F1 recoge la clara diferencia entre continentes en cuanto a la relevancia otorgada a los valores de ingresos y reconocimiento. También se percibe esa diferencia, aunque no tan nítida en F2 ( importancia de tener un puesto de trabajo enriquecido) y F3 (estabilidad, ocio y familia, servicio a la sociedad). 
La figura 6.5 representa la comparación entre las componentes resultantes del análisis factorial de la medida de los valores laborales en el trabajo. En la figura la comparación muestra el primer factor resultante (F1. Autonomía, puesto de trabajo enriquecido y servicio a la sociedad) frente al segundo factor (F2. Estabilidad, ingresos y reconocimiento). La figura b. muestra la comparación entre el factor 2 y el factor 3 (F3. Ocio y familia).
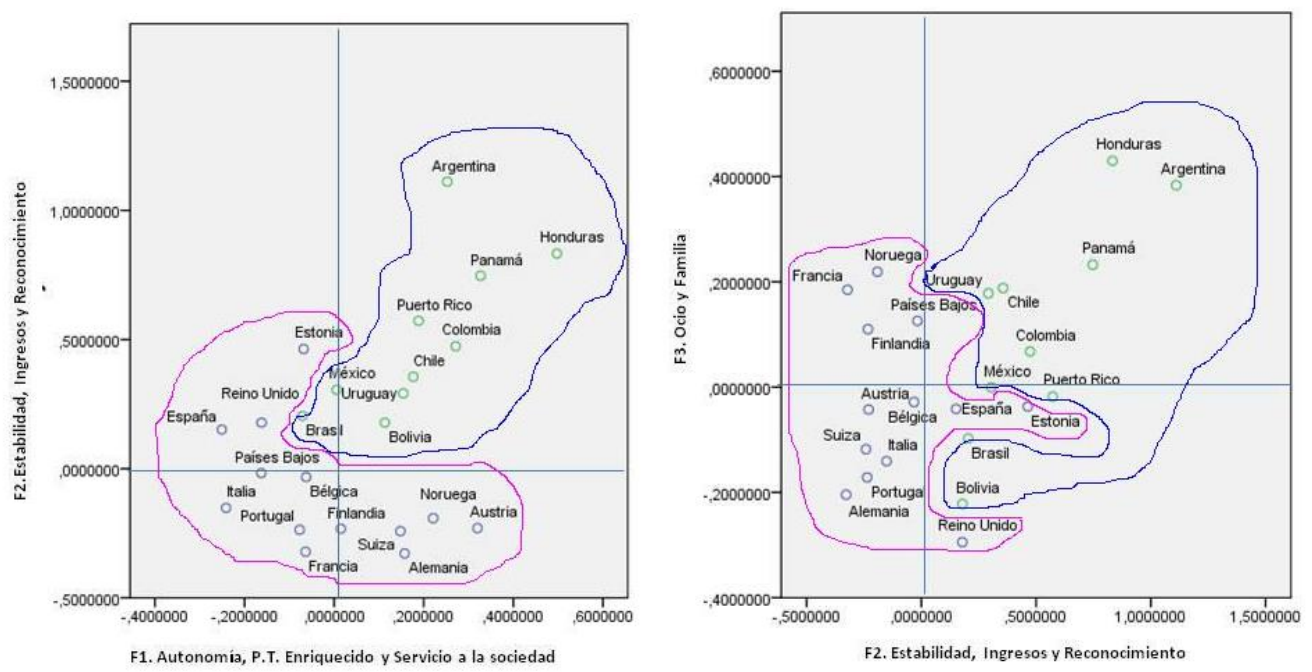

Figura 6. 5 Valores Laborales en el Trabajo a.(Factor 1 vs Factor 2) y b.(Factor 2 vs Factor 3)

En la figura 6.5 a y $b$ se aprecia la diferencia entre continentes en el Factor 2, importancia de la estabilidad, ingresos y reconocimiento (mayor para los graduados de Latinoamérica). En cambio la diferencia es menos clara en los F1 (importancia de la autonomía, tener un puesto de trabajo enriquecido y el servicio a la sociedad) y F3 (importancia del ocio y familia).

Los análisis gráficos muestran la existencia de diferencias entre los graduados de Europa y Latinoamérica. Refuerza el objetivo de los análisis, para continuar el estudio realizando una segmentación por continente.

\subsubsection{Análisis Factorial. Comparativa de la Variable Éxito Laboral}

En este apartado se hace una comparativa de la medida del éxito laboral que permite mostrar las similitudes y diferencias halladas. El punto de partida fue la segmentación de la muestra de los graduados universitarios para el análisis de Europa, Latinoamérica y España. La medida del éxito laboral se realiza a partir de las cuatro variables originales (sueldo contrato, sueldo total, uso de conocimientos y habilidades, satisfacción en el trabajo) después del 
análisis factorial, resultan dos nuevos componentes llamados éxito laboral objetivo (Exlabob) y éxito laboral subjetivo (Exlabsu). Los valores obtenidos se muestran en las secciones I1-A, I2-A, 13-A del apéndice. La comparativa se resume en la tabla 6.1.

Tabla 6. 1 Comparativa de la Prueba Factorial. Variable Éxito Laboral

\begin{tabular}{|c|c|c|c|}
\hline \multicolumn{4}{|c|}{ Éxito Laboral Objetivo } \\
\hline \multicolumn{4}{|c|}{ Sueldo Contrato, Sueldo Total } \\
\hline Prueba & Europa & Latinoamérica & España \\
\hline$\alpha$ Cronbach & 0,97 & 0,959 & 0,965 \\
\hline KMO & 0,500 & 0,500 & 0,500 \\
\hline E. Barlett & 0,000 & 0,000 & 0,000 \\
\hline \% Varianza Total Explicada & 97,35 & 96,38 & 96,71 \\
\hline \multicolumn{4}{|c|}{ Éxito Laboral Subjetivo } \\
\hline \multicolumn{4}{|c|}{ Uso de conocimientos y habilidades, Satisfacción en el trabajo } \\
\hline Prueba & Europa & Latinoamérica & España \\
\hline$\alpha$ Cronbach & 0,574 & 0,533 & 0,626 \\
\hline KMO & 0,500 & 0,500 & 0,500 \\
\hline E. Barlett & 0,000 & 0,000 & 0,000 \\
\hline \% Varianza Total Explicada & 70,13 & 68,23 & 72,87 \\
\hline
\end{tabular}

Con el fin de trabajar de un modo homogéneo a lo realizado con el resto de variables, el análisis factorial del éxito laboral objetivo y subjetivo, en el que se incluye un bajo número de variables, se ha forzado a pesar de los valores bajos de KMO que muestra la tabla 6.1. El coeficiente KMO es una comparación de la suma cuadrática de los coeficientes de correlación parcial entre todos los pares de variables y los coeficientes de correlación observados. Bajos valores de este coeficiente implican que las correlaciones entre cada pareja de variables no puede explicarse por otras, de modo que no sería aconsejable usar el análisis factorial (Vidal Díaz, 2002). El hecho de que la prueba de esfericidad de Bartlett sea significativa, nos da una cierta justificación para la realización de dicho análisis. Además, al menos para el caso del éxito laboral objetivo, los valores del alfa de Cronbach avalan este uso.

Los resultados son muy similares en los tres análisis de la medida del éxito laboral objetivo. El valor de $\mathrm{KMO}=0,500$ tiene un valor cercano al límite del umbral de aceptación predefinido, la mayoría de los test de verificación de la aplicación del análisis se cumplen y por tanto se decidió seguir adelante con el análisis factorial. 
La medida del éxito laboral subjetivo resultante, muestra valores del alfa de Cronbach en el límite de la fiabilidad de las escalas, así como el valor del KMO que también está en el umbral de aceptación. Sin embargo, la prueba de esfericidad de Barlett es significativa por lo tanto se puede confiar que el modelo factorial es adecuado para explicar los datos.

Para cada una de las pruebas, las variables que se encuentran en cada factor se han agrupado de manera lógica bajo una característica común, con el fin de encontrar y demostrar significado y sentido, tal como lo indica el análisis factorial. Para los casos de Europa, Latinoamérica y España las pruebas son admisibles y como lo muestra la tabla 6.1 se obtuvo un componente para cada análisis con un alto porcentaje de la varianza explicada en cada caso de la prueba éxito laboral objetivo y de la prueba éxito laboral subjetivo.

\subsubsection{Análisis Factorial. Comparativa de la Variable Rol en el Trabajo}

Los resultados obtenidos en la prueba factorial Rol en el trabajo para los modelos de Europa, Latinoamérica y España, se referencian en las secciones I1-B, 12-B, I3-B del apéndice y la comparativa se muestra en la Tabla 6.2. Los valores obtenidos para cada una de las pruebas, son adecuados para el análisis factorial, como se muestra en el alfa de Cronbach, el KMO, la prueba de esfericidad de Barlett que resultó significativa.

Tabla 6. 2 Comparativa de la Prueba Factorial. Variable Rol en el Trabajo

\begin{tabular}{|c|c|c|c|}
\hline \multicolumn{5}{|c|}{ Rol en El Trabajo } \\
\hline No & Europa & Latinoamérica & España \\
\hline 1 & $\begin{array}{c}\text { Responsabilidad en el } \\
\text { trabajo }\end{array}$ & Relaciones en el trabajo & $\begin{array}{c}\text { Responsabilidad en el } \\
\text { trabajo }\end{array}$ \\
\hline 2 & Relaciones en el trabajo & $\begin{array}{c}\text { Responsabilidad con la } \\
\text { organización }\end{array}$ & Relaciones en el trabajo \\
\hline 3 & Perjuicio a la organización & Autonomía/ Responsabilidad & Perjuicio a la organización \\
\hline \multicolumn{2}{|c|}{ Resultados de la Prueba } & 0,809 \\
\hline$\alpha$ Cronbach & 0,759 & 0,798 & 0,803 \\
\hline KMO & 0,762 & 0,788 & 0,000 \\
\hline E. Barlett & 0,000 & 0,000 & 63,53 \\
\hline Earianza Total & 61,38 & 61,13 & \\
\hline
\end{tabular}

El análisis factorial tiene en común que para cada análisis arrojó tres factores que explican niveles similares de varianza (el 61,38\% de la varianza para Europa, el 61,13\% para Latinoamérica y el 63,53\% para España). 
La agrupación de las variables originales en los nuevos componentes, resultaron similares para los graduados universitarios de Europa y España. Es así como el primero corresponde al factor responsabilidad $(26,18 \%)$, el segundo a las relaciones en el trabajo $(23,64 \%)$ y el tercer factor que corresponde al perjuicio a la organización $(11,54 \%)$.

En cuanto a la agrupación de los factores en el caso de los graduados latinoamericanos, el primer componente corresponde a las relaciones en el trabajo (22,34\%), el segundo a la responsabilidad con la organización $(21,26 \%)$ y el tercero corresponde a la autonomía y la responsabilidad en el puesto de trabajo (18,52\%).

Estos resultados hacen pensar que los graduados universitarios de Europa y España valoran las responsabilidades asociadas a la organización y al puesto de trabajo, más desde lo individual, mientras que los graduados latinoamericanos, valoran las relaciones que por razones de su trabajo establecen. Valoran la responsabilidad primero con la organización seguido por la autonomía y la responsabilidad en el puesto de trabajo.

\subsubsection{Análisis Factorial. Comparativa de la Variable Competencias Personales}

Al abordar la sección de competencias, es bueno recordar que a los graduados universitarios se les pidió que valoraran su percepción acerca del nivel de competencias personales que tenían respecto a diecinueve competencias propuestas, considerando que han pasado cinco años de la finalización de los estudios universitarios.

Antes de asignar el nombre a los nuevos componentes se realizó una clasificación de cada una de las competencias propuestas y de esta manera tener referencia para definir cada factor (Tabla 6.3). El criterio de asignación del nuevo nombre, fue considerar las variables que tuvieran la carga factorial más alta en el factor por ser las que más contribuyen a la denominación del mismo (Vidal, 2002). 
Tabla 6. 3 Clasificación de Competencias

\begin{tabular}{|c|c|}
\hline Competencia & Clasificación de la Competencia \\
\hline Dominio de tu área o disciplina. & Conocimientos \\
\hline Conocimientos de otras áreas o disciplinas. & Conocimientos \\
\hline Pensamiento analítico. & Pensamiento Metacognitivo \\
\hline Adquirir con rapidez nuevos conocimientos. & Pensamiento Metacognitivo \\
\hline Negociar de forma eficaz. & Liderazgo \\
\hline Trabajar bajo presión. & Organizativas \\
\hline Detectar nuevas oportunidades. & Liderazgo \\
\hline Coordinar actividades. & Organizativas \\
\hline Usar el tiempo de forma efectiva. & Organizativas \\
\hline Trabajar en equipo. & Liderazgo \\
\hline Movilizar las capacidades de otros. & Liderazgo \\
\hline Hacerte entender. & Comunicación \\
\hline Hacer valer tu autoridad. & Liderazgo \\
\hline Utilizar herramientas informáticas. & Instrumentales \\
\hline Encontrar nuevas ideas y soluciones. & Innovación \\
\hline $\begin{array}{l}\text { Predisposición para cuestionar ideas propias o } \\
\text { ajenas. }\end{array}$ & Innovación \\
\hline Presentar en público productos, ideas o informes. & Comunicación \\
\hline Redactar informes o documentos. & Comunicación \\
\hline Escribir y hablar en idiomas extranjeros. & Instrumentales \\
\hline
\end{tabular}

Fuente: Elaboración propia a partir de Conchado (2011)

Las pruebas de alfa de Cronbach, KMO y esfericidad de Barlett resultaron adecuadas y significativas, para seguir adelante con la prueba factorial. Como resultado para Europa y España se obtuvieron cuatro nuevas componentes que agruparon las variables originales, mientras que los factores resultantes en Latinoamérica fueron tres. Los resultados están referenciados en las secciones I1-C, I2-C, I3-C del apéndice. La comparativa de la prueba factorial de competencias propias para los tres grupos de graduados universitarios se muestra en la tabla 6.4. 
Tabla 6. 4 Comparativa de la Prueba Factorial. Variable Competencias Personales

\begin{tabular}{|c|c|c|c|}
\hline \multicolumn{4}{|c|}{ Competencias Personales } \\
\hline № & Europa & Latinoamérica & España \\
\hline 1 & $\begin{array}{l}\text { C. Liderazgo y } \\
\text { Comunicación }\end{array}$ & $\begin{array}{l}\text { C. Organizativas, } \\
\text { Liderazgo, } \\
\text { Innovación }\end{array}$ & $\begin{array}{l}\text { C. Liderazgo y } \\
\text { Comunicación }\end{array}$ \\
\hline 2 & C. Organizativas & $\begin{array}{l}\text { C. de Conocimiento y } \\
\text { Pensamiento } \\
\text { Metacognitivo }\end{array}$ & C. Organizativas \\
\hline 3 & $\begin{array}{l}\text { C. Instrumentales y } \\
\text { de Innovación }\end{array}$ & $\begin{array}{l}\text { C. Instrumentales y } \\
\text { de Comunicación }\end{array}$ & $\begin{array}{l}\text { C. de Conocimiento } \\
\text { y Pensamiento } \\
\text { Metacognitivo }\end{array}$ \\
\hline 4 & $\begin{array}{l}\text { C. de Conocimiento } \\
\text { y Pensamiento } \\
\text { Metacognitivo }\end{array}$ & & $\begin{array}{l}\text { C. Instrumentales y } \\
\text { de Innovación }\end{array}$ \\
\hline \multicolumn{4}{|c|}{ Resultados de la Prueba } \\
\hline$\alpha$ Cronbach & 0,880 & 0,932 & 0,896 \\
\hline KMO & 0,932 & 0,968 & 0,942 \\
\hline E. Barlett & 0,000 & 0,000 & 0,000 \\
\hline $\begin{array}{l}\text { \% Varianza } \\
\text { Total } \\
\text { Explicada }\end{array}$ & 51,81 & 58,47 & 54,75 \\
\hline
\end{tabular}

Como en el apartado anterior, la tendencia de agrupación de las variables originales en los nuevos componentes, resultan parecidas para los graduados universitarios de Europa y España. En el caso de Europa, el primer factor resultante corresponde a Competencias de liderazgo y comunicación con un $17,04 \%$ de la varianza total. El segundo factor ha sido llamado de Competencias organizativas, con un $12,32 \%$ de la varianza, el tercer factor agrupa competencias instrumentales y de innovación con un $11,36 \%$ de la varianza y el cuarto factor llamado de competencias de conocimiento y pensamiento metacognitivo con una varianza total explicada de $11,09 \%$.

De los factores obtenidos en España, el primero corresponde a competencias de liderazgo y comunicación (17,04\%), seguido de competencias organizativas (12,32\%). El tercer factor agrupa competencias de Conocimiento y Pensamiento Metacognitivo (12,21\%) y el cuarto factor llamado de Competencias Instrumentales y de Innovación (11,48\%).

El análisis factorial de las competencias propias de los graduados de Latinoamérica arrojó tres componentes. El primer factor agrupa las Competencias Organizativas, de Liderazgo 
y de Innovación con una varianza total explicada de 31,40\%. El segundo factor ha sido llamado competencias de conocimiento y pensamiento metacognitivo con una varianza de $14,94 \%$ y el tercer factor que agrupa competencias instrumentales y de Comunicación con una varianza total explicada de $12,11 \%$.

\subsubsection{Análisis Factorial. Comparativa de la Variable Competencias Requeridas}

Para la prueba factorial que mide la variable competencias requeridas en el puesto de trabajo, los valores obtenidos se referencian en las secciones I1-D, I2-D, I3-D del apéndice y la comparativa se muestra en la tabla 6.5. Las pruebas de alfa de Cronbach, KMO y esfericidad de Barlett resultaron adecuadas y significativas, para seguir adelante con la prueba factorial. Como resultado para Europa y España se obtuvieron tres nuevas componentes que agruparon las variables originales, mientras que los factores resultantes en Latinoamérica se reducen a dos componentes.

Tabla 6. 5 Comparativa de la Prueba Factorial. Variable Competencias Requeridas

\begin{tabular}{|c|c|c|c|}
\hline \multicolumn{4}{|c|}{ Competencias Requeridas } \\
\hline № & Europa & Latinoamérica & España \\
\hline 1 & $\begin{array}{l}\text { C. Organizativas y } \\
\text { Liderazgo }\end{array}$ & $\begin{array}{l}\text { C. Organizativas, } \\
\text { Liderazgo, } \\
\text { Innovación, y } \\
\text { Pensamiento } \\
\text { Metacognitivo }\end{array}$ & $\begin{array}{l}\text { C. Organizativas, } \\
\text { Liderazgo e } \\
\text { Innovación }\end{array}$ \\
\hline 2 & $\begin{array}{l}\text { C. de Innovación, } \\
\text { Instrumentales y de } \\
\text { Comunicación }\end{array}$ & $\begin{array}{l}\text { C. Instrumentales, } \\
\text { Comunicación y } \\
\text { Conocimiento }\end{array}$ & $\begin{array}{l}\text { C. de Conocimiento } \\
\text { y Pensamiento } \\
\text { Metacognitivo }\end{array}$ \\
\hline 3 & $\begin{array}{c}\text { C. de Conocimiento, } \\
\text { Organizativas }\end{array}$ & & $\begin{array}{l}\text { C. Instrumentales y } \\
\text { de Comunicación }\end{array}$ \\
\hline \multicolumn{4}{|c|}{ Resultados de la Prueba } \\
\hline$\alpha$ Cronbach & 0,906 & 0,943 & 0,921 \\
\hline KMO & 0,942 & 0,969 & 0,948 \\
\hline E. Barlett & 0,000 & 0,000 & 0,000 \\
\hline $\begin{array}{l}\text { \% Varianza } \\
\text { Total } \\
\text { Explicada }\end{array}$ & 52,4 & 57,63 & 55,23 \\
\hline
\end{tabular}

En el caso de Europa, el primer factor resultante corresponde a competencias organizativas y de liderazgo con un $19,99 \%$ de la varianza total explicada. El segundo factor ha sido llamado competencias de innovación, instrumentales y de comunicación, con un 17,78\% 
de la varianza, el tercer factor agrupa competencias de conocimiento y organizativas con un $14,63 \%$ de la varianza.

La prueba factorial para los graduados universitarios de España, el primer factor agrupa competencias organizativas, de liderazgo e Innovación (22,46\%), seguido de competencias de conocimiento y pensamiento metacognitivo (18,13\%). El tercer factor agrupa competencias instrumentales y de comunicación $(14,64 \%)$.

El análisis factorial de las competencias requeridas de los graduados de Latinoamérica arrojó dos nuevos componentes. El primer factor agrupa las competencias organizativas, de liderazgo, innovación y pensamiento metacognitivo con una varianza total explicada de 39,39\%. El segundo factor ha sido llamado competencias instrumentales, de comunicación y conocimiento con una varianza total explicada de $18,24 \%$.

De los resultados anteriores se desprende, que las competencias requeridas son las competencias organizativas y de liderazgo, por igual para los graduados universitarios de Europa, Latinoamérica y España.

\subsubsection{Análisis Factorial. Comparativa de la Variable Ajuste de Competencias}

Se realizó la prueba factorial para medir el ajuste de las competencias de los graduados universitarios y los resultados obtenidos se referencian en las secciones I1-G, 12-G, I3-G del apéndice. La comparativa de la prueba se muestra en la tabla 6.6.

Tabla 6. 6 Comparativa de la Prueba Factorial. Variable Ajuste de Competencias

\begin{tabular}{|c|c|c|c|}
\hline \multicolumn{4}{|c|}{ Ajuste de Competencias Personales y Requeridas en el trabajo } \\
\hline No & Europa & Latinoamérica & España \\
\hline 1 & $\begin{array}{c}\text { C. de Liderazgo y } \\
\text { Organizativas }\end{array}$ & $\begin{array}{c}\text { C. Organizativas, } \\
\text { Liderazgo, } \\
\text { Innovación }\end{array}$ & $\begin{array}{c}\text { C. Organizativas, } \\
\text { Liderazgo, } \\
\text { Innovación }\end{array}$ \\
\hline 2 & $\begin{array}{c}\text { C. Instrumentales, } \\
\text { de Innovación y } \\
\text { Comunicación }\end{array}$ & $\begin{array}{c}\text { C. de Conocimiento y } \\
\text { Pensamiento } \\
\text { Metacognitivo }\end{array}$ & $\begin{array}{c}\text { C. de Conocimiento } \\
\text { y Pensamiento } \\
\text { Metacognitivo }\end{array}$ \\
\hline 3 & $\begin{array}{c}\text { C. de Conocimiento } \\
\text { y Pensamiento } \\
\text { Metacognitivo }\end{array}$ & $\begin{array}{c}\text { C. Instrumentales y } \\
\text { C. de Comunicación }\end{array}$ & $\begin{array}{c}\text { C. Instrumentales y } \\
\text { C. de comunicación }\end{array}$ \\
\hline \multicolumn{4}{|c|}{ Resultados de la Prueba } \\
\hline KMO & 0,942 & 0,936 & 0,947 \\
\hline E. Barlett & 0,000 & 0,000 & 0,000 \\
\hline $\begin{array}{c}\text { Total } \\
\text { Explicada }\end{array}$ & 48,42 & 45,59 & 51,36 \\
\hline
\end{tabular}


Los valores obtenidos para cada una de las pruebas, son adecuados para el análisis factorial, como se muestra en los valores de KMO superiores a 0,9 y la prueba de esfericidad de Barlett resultó significativa y por lo tanto el modelo factorial explica los datos adecuadamente. El alfa de Cronbach no fue calculado para esta prueba porque en este caso se tuvo en consideración los valores de fiabilidad obtenidos al analizar las competencias personales y requeridas de manera individual.

El análisis factorial de los tres análisis tiene en común que arrojó tres factores que explican el $48,42 \%$ de la varianza para Europa, el 45,59\% para Latinoamérica y el 51,36\% para España.

Para los graduados universitarios de Europa, el primer factor del ajuste de competencias resultante corresponde a Competencias de Liderazgo y Organizativas con un 18,93\% de la varianza total explicada. El segundo factor ha sido Ilamado Competencias Instrumentales, de Innovación y Comunicación, con un 14,77\% de la varianza, el tercer factor agrupa Competencias de Conocimiento y Pensamiento Metacognitivo con un $14,71 \%$ de la varianza.

El resultado obtenido en la prueba factorial del ajuste de competencias de los graduados de Latinoamérica arrojó tres nuevos componentes. El primer factor agrupa las Competencias Organizativas, de liderazgo e innovación con una varianza total explicada de $20,21 \%$. El segundo factor ha sido Ilamado competencias de conocimiento y pensamiento Metacognitivo con una varianza total explicada de $12,77 \%$ y el tercer factor agrupa competencias instrumentales y de Comunicación con una varianza de 12,61\%.

En la prueba factorial para los graduados universitarios de España, el primer factor agrupa competencias Organizativas, de liderazgo e innovación (21,79\%), seguido de competencias de conocimiento y pensamiento metacognitivo $(14,79 \%)$ y el tercer factor agrupa competencias instrumentales y de comunicación (14,78\%).

En el conjunto del análisis es común la composición del primer factor, pues agrupa para Europa, Latinoamérica y España que el ajuste de competencias corresponde a las competencias de liderazgo organizativas. En el caso de Europa no incluye las competencias de innovación.

Al analizar el segundo componente resultante en cada uno, hay similitudes de agrupación en España y Latinoamérica en las competencias de Conocimiento y pensamiento metacognitivo, mientras que en Europa la agrupación es de competencias de innovación, 
instrumentales y de comunicación y que a la vez corresponden a la agrupación de competencias del tercer factor resultante en España y Latinoamérica.

\subsubsection{Análisis Factorial. Comparativa de la Variable Valores Laborales Personales}

En este apartado se comparan los resultados obtenidos en la prueba factorial en las que los graduados universitarios valoran la importancia de diez características del trabajo consideradas como parte de la dimensión subjetiva del éxito laboral. En las secciones I1-E, I2-E, I3-E del apéndice se puede ver cada uno de los análisis realizados.

Las pruebas de alfa de Cronbach, KMO y esfericidad de Barlett resultaron adecuadas y significativas, para seguir adelante con la prueba factorial. Como resultado, para Europa se obtuvieron tres componentes que explican el $54,25 \%$ de la varianza, mientras que para Latinoamérica y España se obtuvieron dos nuevas componentes que agruparon las variables originales con una varianza total explicada del 60,35\% y $45,96 \%$ respectivamente. Los resultados obtenidos se muestran en la tabla 6.7.

Tabla 6. 7 Comparativa de la Prueba Factorial. Variable Valores Laborales Personales

\begin{tabular}{|c|c|c|c|}
\hline \multicolumn{4}{|c|}{ Valores Laborales Personales } \\
\hline № & Europa & Latinoamérica & España \\
\hline 1 & $\begin{array}{l}\text { Ingresos y } \\
\text { Reconocimiento }\end{array}$ & $\begin{array}{c}\text { Puesto de Trabajo } \\
\text { Enriquecido. Ingresos }\end{array}$ & $\begin{array}{c}\text { Puesto de Trabajo } \\
\text { Enriquecido } \\
\text { "satisfactorio" }\end{array}$ \\
\hline 2 & $\begin{array}{l}\text { Puesto de Trabajo } \\
\text { Enriquecido } \\
\text { "satisfactorio" }\end{array}$ & $\begin{array}{c}\text { Ocio, Familia y } \\
\text { Servicio a la sociedad }\end{array}$ & $\begin{array}{l}\text { Ocio y Familia - } \\
\text { Ingresos y } \\
\text { Estabilidad }\end{array}$ \\
\hline 3 & $\begin{array}{l}\text { Ocio, Familia y } \\
\text { Servicio a la } \\
\text { sociedad }\end{array}$ & & \\
\hline \multicolumn{4}{|c|}{ Resultados de la Prueba } \\
\hline$\alpha$ Cronbach & 0,692 & 0,894 & 0,763 \\
\hline KMO & 0,729 & 0,917 & 0,793 \\
\hline E. Barlett & 0,000 & 0,000 & 0,000 \\
\hline $\begin{array}{c}\text { \% Varianza } \\
\text { Total } \\
\text { Explicada }\end{array}$ & 54,25 & 60,35 & 45,96 \\
\hline
\end{tabular}

Los factores obtenidos reciben nombres representativos de las variables que los integran, es el caso del factor Puesto de Trabajo Enriquecido "satisfactorio", formado por algunas características que en conjunto hacen atractivo el puesto de trabajo, como la autonomía, la oportunidad de aprender cosas nuevas y la oportunidad de afrontar nuevos retos. 
Los factores resultantes en Europa corresponden, el primero a ingresos y reconocimientos, el segundo ha sido llamado puesto de trabajo enriquecido "satisfactorio" y el tercero corresponde al factor llamado ocio, familia y servicio a la sociedad.

En Latinoamérica resultaron dos factores que agrupan en el primer componente el puesto de trabajo enriquecido "satisfactorio" e ingresos. El segundo componente agrupa las variables de ocio, familia y servicio a la sociedad.

Para España la prueba factorial arrojó como resultados dos componentes. El primer factor llamado puesto de trabajo enriquecido "satisfactorio" y el segundo factor llamado ocio, familia, ingresos y estabilidad, iguales a los de Latinoamérica.

Mientras para la mayoría de los europeos el primer factor corresponde a tener ingresos elevados y reconocimiento, para los latinoamericanos y españoles el primer factor agrupa aquellas características que en conjunto hacen que el trabajo sea enriquecido "satisfactorio".

En el conjunto de la prueba factorial, destacan dos aspectos: El factor ocio, familia y servicio a la sociedad se agrupan en el tercer factor para Europa mientras en el caso de Latinoamérica y España se agrupa en el segundo. Además, en el caso de España están incluidos los ingresos y la estabilidad. 


\subsubsection{Análisis Factorial. Comparativa de la Variable Valores Laborales en el Trabajo}

Considerando los resultados observados en el descriptivo del capítulo cinco, acerca de los valores laborales de los graduados universitarios en el trabajo, se puede afirmar que existe una diferencia entre la importancia que los graduados universitarios dan a las características del trabajo y la evaluación que hacen del grado de cumplimiento de las mismas en sus puestos de trabajo. La mayoría de los graduados considera que en su trabajo las características evaluadas no se le da la importancia que tiene para ellos.

Los resultados del análisis factorial está referenciado en las secciones I1-F, I2-F, I3-F del apéndice. En este apartado se comparan los resultados de la prueba factorial, que aparecen reflejados en la tabla 6.8. Los valores de fiabilidad de las escalas utilizadas son aceptables, el KMO de cada una de las pruebas es adecuado y la prueba de esfericidad de Barlett resulta significativa, por lo tanto son la base para afirmar que la técnica es adecuada.

Tabla 6. 8 Comparativa de la Prueba Factorial. Variable Valores Laborales en el Trabajo

\begin{tabular}{|c|c|c|c|}
\hline \multicolumn{4}{|c|}{ Valores Laborales en el Trabajo } \\
\hline № & Europa & Latinoamérica & España \\
\hline 1 & $\begin{array}{l}\text { Puesto de Trabajo } \\
\text { Enriquecido } \\
\text { "satisfactorio" }\end{array}$ & $\begin{array}{l}\text { Puesto de Trabajo } \\
\text { Enriquecido. } \\
\text { Ingresos, } \\
\text { Reconocimiento, } \\
\text { Servicio a la Sociedad }\end{array}$ & $\begin{array}{c}\text { Puesto de Trabajo } \\
\text { Enriquecido } \\
\text { "satisfactorio" }\end{array}$ \\
\hline 2 & $\begin{array}{l}\text { Ingresos, Estabilidad } \\
\text { y Reconocimiento }\end{array}$ & Ocio y Familia & Ocio y Familia \\
\hline 3 & Ocio y Familia & & $\begin{array}{l}\text { Ingresos y } \\
\text { Estabilidad }\end{array}$ \\
\hline \multicolumn{4}{|c|}{ Resultados de la Prueba } \\
\hline$\alpha$ Cronbach & 0,704 & 0,875 & 0,821 \\
\hline KMO & 0,729 & 0,877 & 0,824 \\
\hline E. Barlett & 0,000 & 0,000 & 0,000 \\
\hline $\begin{array}{l}\text { \% Varianza } \\
\text { Total } \\
\text { Explicada }\end{array}$ & 57,6 & 59,96 & 65,14 \\
\hline
\end{tabular}

De los factores resultantes en Europa, corresponde, el primero a puesto de trabajo enriquecido "satisfactorio", el segundo corresponde al factor llamado de ingresos, estabilidad y reconocimiento y el tercero corresponde al factor ocio y familia. 
En Latinoamérica resultaron dos factores que agrupan en el primer componente el puesto de trabajo enriquecido "satisfactorio", ingresos, reconocimiento y servicio a la sociedad. El segundo componente agrupa las variables de ocio y familia.

Para España la prueba factorial arrojó como resultados tres componentes. El primer factor llamado puesto de trabajo enriquecido "satisfactorio", el segundo factor llamado ocio, familia, y el tercero llamado de ingresos y estabilidad.

En este análisis se mide el grado de cumplimiento de los valores laborales en el trabajo, el primer factor que incluye variables comunes en los tres análisis, corresponde al factor trabajo enriquecido "satisfactorio".

El segundo factor común corresponde al factor Ocio y Familia y aplica para Latinoamérica y España, mientras que este factor es el tercero para los Europeos, pues para ellos el segunda factor corresponde a ingresos, estabilidad y reconocimiento. En el caso de España, el tercer factor corresponde a los ingresos y estabilidad.

\subsubsection{Análisis Factorial. Comparativa de la Variable Ajuste de Valores Laborales Personales y}

\section{Valores Laborales en el Trabajo}

Se realizó la prueba factorial para comparar el ajuste de los valores laborales de los graduados universitarios. Los resultados obtenidos de la prueba factorial se referencian en las secciones I1-H, I2-H, I3-H del apéndice y la comparativa se muestra en la tabla 6.9.

Tabla 6. 9 Comparativa de la Prueba Factorial. Variable Ajuste de Valores Laborales

\begin{tabular}{|c|c|c|c|}
\hline \multicolumn{4}{|c|}{ Ajuste de Valores Laborales Personales y Valores Laborales en el Trabajo } \\
\hline № & Europa & Latinoamérica & España \\
\hline 1 & $\begin{array}{l}\text { Puesto de Trabajo } \\
\text { Enriquecido } \\
\text { "satisfactorio" }\end{array}$ & $\begin{array}{l}\text { Puesto de Trabajo } \\
\text { Enriquecido. } \\
\text { Ingresos, Estabilidad } \\
\text { y Reconocimiento. }\end{array}$ & $\begin{array}{c}\text { Puesto de Trabajo } \\
\text { Enriquecido } \\
\text { "satisfactorio" }\end{array}$ \\
\hline 2 & $\begin{array}{l}\text { Ingresos, Estabilidad } \\
\text { y Reconocimiento }\end{array}$ & $\begin{array}{c}\text { Ocio, Familia y } \\
\text { Servicio a la Sociedad }\end{array}$ & Ocio y Familia \\
\hline 3 & Ocio y Familia & & $\begin{array}{l}\text { Ingresos y } \\
\text { Estabilidad }\end{array}$ \\
\hline \multicolumn{4}{|c|}{ Resultados de la Prueba } \\
\hline KMO & 0,759 & 0,855 & 0,824 \\
\hline E. Barlett & 0,000 & 0,000 & 0,000 \\
\hline $\begin{array}{l}\% \text { Varianza } \\
\text { Total } \\
\text { Explicada }\end{array}$ & 56,31 & 51,94 & 61,84 \\
\hline
\end{tabular}


Los estadísticos obtenidos para cada una de las pruebas, son adecuados para el análisis factorial, como se muestra en los valores de KMO superiores a 0,759 y la prueba de esfericidad de Barlett es significativa y por lo tanto el modelo factorial explica los datos apropiadamente. El alfa de Cronbach no fue calculado para esta prueba porque en este caso se tuvo en consideración los valores de fiabilidad obtenidos al analizar los valores laborales personales y valores laborales en el trabajo de manera individual.

Para los graduados universitarios de Europa, el primer factor del ajuste de los valores laborales resultante corresponde a Puesto de Trabajo Enriquecido "satisfactorio" con un 20,87\% de la varianza total explicada. El segundo factor ha sido llamado Ingresos, Estabilidad y reconocimiento, con un $18,49 \%$ de la varianza, el tercer factor agrupa los valores de ocio y familia con un $16,95 \%$ de la varianza total explicada.

La prueba factorial del ajuste de valores laborales de los graduados de Latinoamérica arrojó dos componentes. El primer factor agrupa los valores del trabajo relacionados con el puesto de trabajo enriquecido, ingresos, estabilidad y reconocimiento con una varianza total explicada de 31,99\%. El segundo factor llamado Ocio, Familia y Servicio a la sociedad con una varianza total explicada de $19,95 \%$.

En la prueba factorial para los graduados universitarios de España, el primer factor agrupa los valores relacionados con el puesto de trabajo enriquecido "satisfactorio" con una varianza total explicada de $29,28 \%$, el segundo corresponde a los valores relacionados con el ocio y la familia con una varianza de $18,59 \%$ y el tercer factor corresponde a ingresos y estabilidad con una varianza total explicada de $13,97 \%$.

El resultado obtenido y común a los tres análisis factoriales, corresponde al primer factor que agrupa valores laborales relacionados con el puesto de trabajo enriquecido "satisfactorio". En el caso de Latinoamérica además agrupa variables relacionadas con los ingresos, la estabilidad y el reconocimiento. El segundo factor corresponde a los valores relacionados con el ocio, familia y servicio a la sociedad.

En el caso de los graduados de España, el tercer factor agrupa las variables relacionadas con los ingresos y la estabilidad laboral. Esta agrupación podría tener relación con las circunstancias particulares del mercado laboral español. 


\subsection{Correlaciones Bivariadas y Comprobación de hipótesis}

\subsubsection{Correlaciones Bivariadas}

Con la finalidad de analizar la existencia de relaciones estadísticamente significativas entre las diferentes variables del modelo identificadas en el punto 5.3.1, 5.3.2., 5.3.3 y realizar una comprobación preliminar de las hipótesis, se realizó el análisis bivariado a cada uno de los modelos finales de investigación obtenidos. Las Tablas 6.10, 6.11 y 6.12 resumen las correlaciones bivariadas (coeficiente de correlación Rho de Spearman) de los modelos obtenidos. Los análisis completos se presentan en el anexo J.

En la Tabla 6.10 a.: Se muestran las correlaciones bivariadas para Europa, entre éxito laboral, rol en el trabajo, competencias personales y requeridas en el trabajo, valores laborales personales y valores laborales en el trabajo.

En la Tabla 6.10 b.: Se muestran las correlaciones bivariadas para Europa, entre éxito laboral, rol en el trabajo, ajuste de competencias y ajuste de los valores laborales.

En la Tabla 6.11 a.: Se muestran las correlaciones bivariadas para Latinoamérica, entre éxito laboral, rol en el trabajo, competencias personales y requeridas en el trabajo, valores laborales personales y valores laborales en el trabajo.

En la Tabla 6.11 b.: Se muestran las correlaciones bivariadas para Latinoamérica, entre éxito laboral, rol en el trabajo, ajuste de competencias y ajuste de los valores laborales.

En la Tabla 6.12 a.: Se muestran las correlaciones bivariadas para España, entre éxito laboral, rol en el trabajo, competencias personales y requeridas en el trabajo, valores laborales personales y valores laborales en el trabajo.

En la Tabla 6.12 b.: Se muestran las correlaciones bivariadas para España, entre éxito laboral, rol en el trabajo, ajuste de competencias y ajuste de los valores laborales. 
Tabla 6. 10 Correlaciones Bivariadas - Europa

(a)

\begin{tabular}{|c|c|c|c|c|c|c|c|c|c|c|c|c|c|c|c|c|c|c|}
\hline \multicolumn{19}{|c|}{ CORRELACIONES BIVARIADAS EUROPA } \\
\hline \multirow{2}{*}{ Rho de Spearman } & \multicolumn{2}{|c|}{ Éxito Laboral } & \multicolumn{3}{|c|}{ Rol en el Trabajo } & \multicolumn{4}{|c|}{ Competencias Personales } & \multicolumn{3}{|c|}{ Competencias Requeridas en el Trabajo } & \multicolumn{3}{|c|}{$\begin{array}{l}\text { Valores Laborales Personales } \\
\end{array}$} & \multicolumn{3}{|c|}{ Valores Laborales en el Trabajo } \\
\hline & Exlabob_E_1 & Exlabsu_E_1 & Responsa_E_1 & Relación_E_1 & Perjuicio_E_1 & CPE_F1_1 & CPE_F2_1 & CPE_F3_1 & CPE_F4_1 & CRE_F1_1 & CRE_F2_1 & CRE_F3_1 & VPE_F1_1 & VPE_F2_1 & VPE_F3_1 & VLTE_F1_1 & VLTE_F2_1 & VLTE_F3_1 \\
\hline $\begin{array}{l}\text { Exlabob_E_1: Éxito } \\
\text { laboral objetivo }\end{array}$ & 1,000 & ,102" &,$- 056^{*}$ & , 147" & ,296" & $040^{\circ}$ & ,004 & ,050" & ,027" & , 000 &,- 009 & 001 & $-100^{*}$ & ,021“ & $-262^{*}$ & , 078" & , 185" &,$- 115^{\prime \prime}$ \\
\hline $\begin{array}{l}\text { Exlabsu_E_1: Éxito } \\
\text { Laboral Subjetivo }\end{array}$ & & 1,000 & ,237" & ,246" &,- 002 & ,126“ & ,106" & , $045^{*}$ & , $088 "$ & , 153“" & ,215" & , 148" & $-041^{*}$ & , 178" & ,022" & ,466" & ,227" & , 073" \\
\hline Responsa_E_1 & & & 1,000 & 008 & ,030" & ,256" & ,020" &,- 006 & ,098“ & $315^{*}$ & ,109" & ,059" & ,018" & ,114" &,- 005 & 287" & ,115" & ,041“ \\
\hline Relación_E_1 & & & & 1,000 & ,010 &, $273^{*}$ & , 125" & , 192" & ,259" & , 181" & ,226" & , 144" & ,026" & ,277" &,$- 057^{*}$ & , 270" & ,079" & $-026 "$ \\
\hline Perjuicio_E_1 & & & & & 1,000 & ,089" & ,036" & $-080 "$ &,- 003 & ,062" & $-100^{\circ}$ & ,089" & $092^{\circ}$ & ,023" &,$- 066^{*}$ & ,006 & ,122" & $-144^{\prime \prime}$ \\
\hline CPE_F1_1 1 & & & & & & 1,000 &, $012^{\circ}$ & -004 & ,027“" & ,507" & $013^{\circ}$ & ,032" & ,126“ & ,229" & $040^{\circ}$ & ,198" & ,095" & ,031" \\
\hline CPE_F2_1 1 & & & & & & & 1,000 & ,007 & ,007 & , 112" & -039" & , 397" & , 144" & , 141" & ,071" & ,056" & ,087" & ,011 \\
\hline CPE_F3_1 & & & & & & & & 1,000 &, $012^{\circ}$ & 002 & ,461" & -,027" & ,033“ & ,215" &,$- 071^{*}$ & ,138" & ,010 &,$- 064^{*}$ \\
\hline CPE_F4_-1 & & & & & & & & & 1,000 & $-071^{\prime \prime}$ & ,190" & , 186" & ,057" & ,191" & $-104^{*}$ & ,091" & ,026" &,- 009 \\
\hline CRE_F1_1 & & & & & & & & & & 1,000 & $025^{\prime \prime}$ & ,037" & ,097" & ,168" & ,105" & ,250" & ,151" & $014^{\circ}$ \\
\hline CRE_F2_1 & & & & & & & & & & & 1,000 & ,026" & ,086" & , 186" & $-0071^{*}$ & ,341" & ,144" & -107" \\
\hline CRE_F3_1 & & & & & & & & & & & & 1,000 & , 100" & , 120" & ,026" & , 173" & , 118" & -,166" \\
\hline VPE_F1_1 & & & & & & & & & & & & & 1,000 & $015^{\circ}$ & ,021" & $-082^{\prime \prime}$ & ,322" & -093" \\
\hline VPE_F2_1 & & & & & & & & & & & & & & 1,000 & , 029" & ,397" & -010 & ,021" \\
\hline VPE_F3_1 & & & & & & & & & & & & & & & 1,000 & , 064" &,$- 032^{*}$ & , 339" \\
\hline VLTE_F1_1 & & & & & & & & & & & & & & & & 1,000 & ,002 & ,008 \\
\hline VLTE_F2_1 & & & & & & & & & & & & & & & & & 1,000 &,- 001 \\
\hline VLTE_F3_1 & & & & & & & & & & & & & & & & & & 1,000 \\
\hline
\end{tabular}

**. La correlación es significativa al nivel 0,01 (bilateral).

" La correlación es significativa al nivel 0,05 (bilateral).

$\mathrm{N}=31,701$ 
Tabla 6.10 Correlaciones Bivariadas - Europa (b)

\begin{tabular}{|c|c|c|c|c|c|c|c|c|c|c|c|}
\hline \multicolumn{12}{|c|}{ CORRELACIONES BIVARIADAS - EUROPA (2) } \\
\hline \multirow{2}{*}{ Rho de Spearman } & \multicolumn{2}{|c|}{ Éxito Laboral } & \multicolumn{3}{|c|}{ Rol en el Trabajo } & \multicolumn{3}{|c|}{ Ajuste de Competencias } & \multicolumn{3}{|c|}{ Ajuste de los Valores Laborales } \\
\hline & Exlabob_E_1 & Exlabsu_E_1 & Responsa_E_1 & Relación_E_1 & Perjuicio_E_1 & AJC_F1_E_1 & AJC_F2_E_1 & AJC_F3_E_1 & AJVT_F1_E_1 & AJVT_F2_E_1 & AJVT_F3_E_1 \\
\hline $\begin{array}{c}\text { Exlabob_E_1:Éxito } \\
\text { Laboral Objetivo }\end{array}$ & 1,000 & $102^{* *}$ &,$- 056^{* *}$ & $147^{* *}$ &, $296^{* *}$ & $018^{* *}$ & $026^{* *}$ &, $046^{* *}$ & $075^{* *}$ & $267^{* *}$ & $031^{* *}$ \\
\hline $\begin{array}{l}\text { Exlabsu_E_1: Éxito } \\
\text { Laboral Subjetivo }\end{array}$ & & 1,000 &, $237^{* *}$ & $246^{* *}$ &,- 002 &,$- 020^{* *}$ &,$- 167^{* *}$ &,$- 117^{* *}$ &, $354^{* *}$ &, $199^{* *}$ & $054^{* *}$ \\
\hline Responsa_E_1 & & & 1,000 & ,008 &, $030^{* *}$ &,$- 117^{* *}$ &,$- 100^{* *}$ &,$- 024^{* *}$ &, $192^{* *}$ &, $090^{* *}$ &, $040^{* *}$ \\
\hline Relación_E_1 & & & & 1,000 & 010 & $026^{* *}$ &,$- 026^{* *}$ & ,008 & $066^{* *}$ & $072^{* *}$ & 011 \\
\hline Perjuicio_E_1 & & & & & 1,000 &,$- 029^{* *}$ &, $056^{* *}$ &,$- 029^{* *}$ &,- 004 &, $058^{* *}$ &,$- 094^{* *}$ \\
\hline AJC_F1_E_1 & & & & & & 1,000 &,- 004 &,$- 017^{* *}$ &,$- 093^{* *}$ &,$- 057^{* *}$ &, $099^{* *}$ \\
\hline AJC_F2_E_1 & & & & & & & 1,000 &,$- 013^{*}$ &,$- 217^{* *}$ &,$- 035^{* *}$ &, $028^{* *}$ \\
\hline AJC_F3_E_1 & & & & & & & & 1,000 &,$- 227^{* *}$ &,$- 027^{* *}$ &, $156^{* *}$ \\
\hline AJVT_F1_E_1 & & & & & & & & & 1,000 &,$- 016^{*}$ &,$- 017^{* *}$ \\
\hline AJVT_F2_E_1 & & & & & & & & & & 1,000 &,- 002 \\
\hline AJVT_F3_E_1 & & & & & & & & & & & 1,000 \\
\hline
\end{tabular}

**. La correlación es significativa al nivel 0,01 (bilateral).

*. La correlación es significativa al nivel 0,05 (bilateral).

$\mathrm{N}=31,701$ 


\section{Tabla 6. 11 Correlaciones Bivariadas - Latinoamérica}

(a)

\begin{tabular}{|c|c|c|c|c|c|c|c|c|c|c|c|c|c|c|}
\hline \multicolumn{15}{|c|}{ CORRELACIONES BIVARIADAS LATINOAMÉRICA } \\
\hline \multirow{2}{*}{ Rho de Spearman } & \multicolumn{2}{|c|}{ Éxito Laboral } & \multicolumn{3}{|c|}{ Rol en el Trabajo } & \multicolumn{3}{|c|}{ Competencias Personales } & \multicolumn{2}{|c|}{ Competencias Requeridas } & \multicolumn{2}{|c|}{ Valores Laborales Personales } & \multicolumn{2}{|c|}{ Valores Laborales en el Trabajo } \\
\hline & Exlabob_LA_2 & Exlabsu_LA_2 & Relación_LA_2 & Responsa-LA_2 & Autonomía_LA_2 & CPLA_F1_2 & CPLA_F2_2 & CPLA_F3_2 & CRLA_F1_2 & CRLA_F2_2 & VPLA_F1_2 & VPLA_F2_2 & VLTLA_F1_2 & VLTLA_F2_2 \\
\hline $\begin{array}{l}\text { Exlabob_LA_2: Éxito } \\
\text { laboral objetivo }\end{array}$ & 1,000 &, $085^{* *}$ & ,121" &,$- 071^{*}$ & ,062" & ,039" & $165^{*}$ &, $105^{* *}$ & $090^{* *}$ &, $124^{*}$ &, $113^{*}$ &,$- 121^{* *}$ &, $114^{* *}$ &,$- 065^{* \prime}$ \\
\hline $\begin{array}{l}\text { Exlabsu_LA_2: Éxito } \\
\text { Laboral Subjetivo }\end{array}$ & & 1,000 &, $285^{* \prime}$ &, $226^{* \prime}$ & $108^{* *}$ & $167^{* *}$ & ,189" & $095^{* *}$ &, $185^{* *}$ &, $237^{* *}$ & $097^{* *}$ & , $118^{* *}$ &, $406^{* \prime}$ & ,109" \\
\hline Relación_LA_2 & & & 1,000 & 021 &,$- 066^{* \prime}$ & ,251" & ,251" & $147^{* *}$ & ,262" & ,242* & $142^{* *}$ & $137^{* *}$ & $279^{* *}$ & ,062* \\
\hline Responsa-LA_2 & & & & 1,000 &,- 006 & ,137" & $067^{* *}$ &,- 013 & $175^{*}$ & $095^{*}$ & ,037" & $104^{* *}$ & ,294** & ,074* \\
\hline Autonomía_LA_2 & & & & & 1,000 & , 168" & ,080" &, $052^{* *}$ & ,204" & ,041" & $128^{* \prime}$ & 011 & ,068** & ,079** \\
\hline CPLA_F1_2 & & & & & & 1,000 & ,007 &,- 002 & $625^{*}$ & ,080" & , 262" & ,205" & ,239** & ,110** \\
\hline CPLA_F2_2 & & & & & & & 1,000 & ,051" & ,193" & ,273" & $155^{*}$ & ,062" & ,163" & ,087"* \\
\hline CPLA_F3_2 & & & & & & & & 1,000 & ,073" & ,452** & ,150"* & ,081" & ,149" & ,109" \\
\hline CRLA_F1_2 & & & & & & & & & 1,000 & -022 & ,286" & ,157"* & ,301* & ,025 \\
\hline CRLA_F2_2 & & & & & & & & & & 1,000 & ,119" & ,102* & ,290** & , $088^{* *}$ \\
\hline VPLA_F1_2 & & & & & & & & & & & 1,000 & -147" &, $255^{* *}$ & ,059" \\
\hline VPLA_F2_2 & & & & & & & & & & & & 1,000 & ,191" & , 270" \\
\hline VLTLA_F1_2 & & & & & & & & & & & & & 1,000 & -,008 \\
\hline VLTLA_F2_2 & & & & & & & & & & & & & & 1,000 \\
\hline
\end{tabular}

**. La correlación es significativa al nivel 0,01 (bilateral).

$\mathrm{N}=9808$ 
Tabla 6.11 Correlaciones Bivariadas - Latinoamérica (b)

\begin{tabular}{|c|c|c|c|c|c|c|c|c|c|c|}
\hline \multicolumn{11}{|c|}{ CORRELACIONES BIVARIADAS LATINOAMÉRICA (2) } \\
\hline \multirow{2}{*}{ Rho de Spearman } & \multicolumn{2}{|c|}{ Éxito Laboral } & \multicolumn{3}{|c|}{ Rol en el Trabajo } & \multicolumn{3}{|c|}{ Ajuste de Competencias } & \multicolumn{2}{|c|}{ Ajuste de Valores Laborales } \\
\hline & Exlabob_LA_2 & Exlabsu_LA_2 & Relación_LA_2 & Responsa_LA_2 & Autonomía_LA_2 & AJC_F1_LA_2 & AJC_F2_LA_2 & AJC_F3_LA_2 & AJVT_F1_LA_2 & AJVT_F2_LA_2 \\
\hline $\begin{array}{c}\text { Exlabob_LA_2: Éxito } \\
\text { laboral objetivo }\end{array}$ & 1,000 &, $085^{* *}$ &, $121^{* *}$ &,$- 071^{* *}$ &, $062^{* *}$ &,$- 041^{* *}$ &,- 018 & 022 & , 084 &,$- 060^{* *}$ \\
\hline $\begin{array}{l}\text { Exlabsu_LA_2: Éxito } \\
\text { Laboral Subjetivo }\end{array}$ & & 1,000 & $285^{* *}$ &, $226^{* *}$ & $108^{* *}$ & ,009 &,$- 094^{* *}$ &,$- 099^{* *}$ &, $301^{* *}$ &, $055^{* *}$ \\
\hline Relación_LA_2 & & & 1,000 & ,021 &,$- 066^{* *}$ &,- 001 &,$- 040^{* *}$ &,$- 040^{* *}$ &, $122^{* *}$ &,- 003 \\
\hline Responsa_LA_2 & & & & 1,000 &,- 006 &,$- 036^{* *}$ &,$- 036^{* *}$ &,$- 096^{* *}$ &, $245^{* *}$ &, $048^{* *}$ \\
\hline Autonomía_LA_2 & & & & & 1,000 &,$- 065^{* *}$ &,- 011 &,- 012 &,- 001 &, $027^{*}$ \\
\hline AJC_F1_LA_2 & & & & & & 1,000 &,$- 074^{* *}$ &,$- 051^{* *}$ &,$- 058^{* *}$ &, $085^{* *}$ \\
\hline AJC_F2_LA_2 & & & & & & & 1,000 & -015 &,$- 090^{* *}$ &, $070^{* *}$ \\
\hline AJC_F3_LA_2 & & & & & & & & 1,000 &,$- 137^{* *}$ &,$- 030^{*}$ \\
\hline AJVT_F1_LA_2 & & & & & & & & & 1,000 & 016 \\
\hline AJVT_F2_LA_2 & & & & & & & & & & 1,000 \\
\hline
\end{tabular}

**. La correlación es significativa al nivel 0,01 (bilateral).

*. La correlación es significativa al nivel 0,05 (bilateral).

$\mathrm{N}=9,808$ 
Tabla 6. 12 Correlaciones Bivariadas - España

(a)

\begin{tabular}{|c|c|c|c|c|c|c|c|c|c|c|c|c|c|c|c|c|c|}
\hline \multicolumn{18}{|c|}{ CORRELACIONES BIVARIADAS ESPAÑA } \\
\hline \multirow{2}{*}{ Rho de Spearman } & \multicolumn{2}{|c|}{ Éxito Laboral } & \multicolumn{3}{|c|}{ Rol en el Trabajo } & \multicolumn{4}{|c|}{ Competencias Personales } & \multicolumn{3}{|c|}{ Competencias Requeridas en el Trabajo } & \multicolumn{2}{|c|}{ Valores Laborales Personales } & \multicolumn{3}{|c|}{ Valores Laborales en el Trabajo } \\
\hline & Exlabob_Spn_3 & Exlabsu_Spn__3 & Responsa_Spn_3 & Relación_Spn_3 & Perjuicio_Spn_3 & CPSpn_F1_3 & CPSpn_F2_3 & CPSpn_F3_3 & CPSpn_F4_3 & CRSpn_F1_3 & CRSpn_F2_3 & CRSpn_F3_3 & VPESP_F1_3 & VPEsp_F2_3 & VLTSpn_F1_3 & VLTSpn_F2_3 & VLTSpn_F3_3 \\
\hline $\begin{array}{l}\text { Exlabob_Spn_3: Éxito } \\
\text { Laboral Objetivo }\end{array}$ & 1,000 & ,281" & , 104" & , 175" &, $034^{*}$ & , 075" &,$- 062^{*}$ & ,083" & ,114" &, $120^{*}$ & ,117" & ,158" & ,010 & -018 & , 163" & 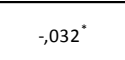 & ,265" \\
\hline $\begin{array}{l}\text { Exlabsu_Spn_3: Exxito } \\
\text { Laboral Subjetivo }\end{array}$ & & 1,000 & ,317" & , 306" & , 039" & ,141" & ,096" & , 088" & , 076" & ,201" & ,221" & ,238" & , 170" & ,004 & ,514" & , 162" & , 124" \\
\hline Responsa_Spn_3 3 & & & 1,000 & ,001 & ,051" & , 263" & ,002 & ,096" & ,032* & , 292" & ,075" & , 182" & ,117" &,$- 056 "$ & ,342" & ,070" & ,091" \\
\hline Relación_Spn_3 & & & & 1,000 & -001 & ,239" & ,108" & , 188" & ,158" & ,249" & ,242" & ,198" & ,223" &,- 004 &, $323^{\prime \prime}$ &,- 016 & ,021 \\
\hline Perjuicio_Spn_3 & & & & & 1,000 & ,141" & ,006 & ,043" & $-063{ }^{*}$ & ,115" & , 179" & $-064 "$ & , 072" &,- 011 & ,105" &,$- 085^{*}$ & ,082" \\
\hline CPSpn_F1_3 & & & & & & 1,000 &,- 012 & $034^{\circ}$ &,- 003 & ,437" & ,000 & ,054" & $263^{\prime \prime}$ & -002 & ,223" & $031^{\circ}$ & ,044" \\
\hline CPSpn_F2_3 & & & & & & & 1,000 & ,007 & 001 &, $223^{\prime \prime}$ & ,217" &,$- 062^{\prime \prime}$ & ,194" & ,139" & $088^{\prime \prime}$ & 018 & ,059" \\
\hline CPSpn_F3_3 & & & & & & & & 1,000 & 017 & $-031^{\circ}$ & ,321" & ,064" &, $138^{*}$ &, $030^{\circ}$ & ,074" &,- 023 & ,052" \\
\hline CPSPn_F4_3 & & & & & & & & & 1,000 &,- 007 & , 048" & , 460" & , 129" & -,067" & , 121" & -031 & -,015 \\
\hline CRSpn_F1_3 & & & & & & & & & & 1,000 & ,010 & ,010 & , 208" & ,053" & , 290" & ,003 & , 070" \\
\hline CRSpn_F2_3 & & & & & & & & & & & 1,000 & ,017 & , 157" & ,041 & , 313" & - 141" & , 091" \\
\hline CRSpn_F3_3 & & & & & & & & & & & & 1,000 & , 139" & $-059^{* \prime}$ & ,321" & 年, &, $035^{\circ}$ \\
\hline VPEsp_F1_3 & & & & & & & & & & & & & 1,000 & ,015 & ,349" & ,022 &,- 028 \\
\hline VPESp_F2_3 & & & & & & & & & & & & & & 1,000 &,$- 033^{*}$ & , 182" & , 106" \\
\hline VLTSpn_F1_3 & & & & & & & & & & & & & & & 1,000 & ,020 & 019 \\
\hline VLTSpn_F2_3 & & & & & & & & & & & & & & & & 1,000 & ,026 \\
\hline VLTSpn_F3_3 & & & & & & & & & & & & & & & & & 1,000 \\
\hline
\end{tabular}

**. La correlación es significativa al nivel 0,01 (bilateral).

*. La correlación es significativa al nivel 0,05 (bilateral) 
Tabla 6.12 Correlaciones Bivariadas - España (b)

\begin{tabular}{|c|c|c|c|c|c|c|c|c|c|c|c|}
\hline \multicolumn{12}{|c|}{ CORRELACIONES BIVARIADAS ESPAÑA (2) } \\
\hline \multirow{2}{*}{ Rho de Spearman } & \multicolumn{2}{|c|}{ Éxito Laboral } & \multicolumn{3}{|c|}{ Rol en el Trabajo } & \multicolumn{3}{|c|}{ Ajuste de Competencias } & \multicolumn{3}{|c|}{ Ajuste de Valores Laborales } \\
\hline & Exlabob_Spn_3 & Exlabsu_Spn_3 & Responsa_Spn_3 & Relación_Spn_3 & Perjuicio_Spn_3 & AJC_F1_Spn_3 & AJC_F2_Spn_3 & AJC_F3_Spn_3 & AJVT_F1_Spn_3 & AJVT_F2_Spn_3 & AJVT_F3_Spn_3 \\
\hline $\begin{array}{c}\text { Exlabob_Spn_3: } \\
\text { Éxito Laboral }\end{array}$ & 1,000 &, $281^{* *}$ &, $104^{* *}$ &, $175^{* *}$ &, $034^{*}$ &,$- 098^{* *}$ &,$- 084^{* *}$ &,$- 070^{* *}$ & $168^{* *}$ &,- 002 &, $213^{* *}$ \\
\hline $\begin{array}{c}\text { Exlabsu_Spn_3: } \\
\text { Éxito Laboral }\end{array}$ & & 1,000 &, $317^{* *}$ &, $306^{* *}$ &, $039^{* *}$ &,$- 057^{* *}$ &,$- 197^{* *}$ &,$- 174^{* *}$ &, $403^{* *}$ &, $137^{* *}$ &, $115^{* *}$ \\
\hline Responsa_Spn_3 & & & 1,000 & 001 & ,051* &,$- 102^{* *}$ &,$- 063^{* *}$ &,$- 139^{* *}$ & $260^{* *}$ & $083^{* *}$ & $125^{* *}$ \\
\hline Relación_Spn_3 & & & & 1,000 &,- 001 &,$- 074^{* *}$ &,$- 099^{* *}$ &,$- 073^{* *}$ & $173^{* *}$ &,- 025 & $039^{*}$ \\
\hline Perjuicio_Spn_3 & & & & & 1,000 &,$- 069^{* *}$ &,$- 127^{* *}$ & 029 &, $067^{* *}$ &,$- 070^{* *}$ & $073^{* *}$ \\
\hline AJC_F1_Spn_3 & & & & & & 1,000 &,$- 039^{*}$ &,- 018 &,$- 123^{* *}$ & $083^{* *}$ &,$- 042^{*}$ \\
\hline AJC_F2_Spn_3 & & & & & & & 1,000 &,- 015 &,$- 253^{* *}$ &, $059^{* *}$ &,- 018 \\
\hline AJC_F3_Spn_3 & & & & & & & & 1,000 &,$- 204^{* *}$ &,- 005 &,$- 046^{* *}$ \\
\hline AJVT_F1_Spn_3 & & & & & & & & & 1,000 &, 006 &,- 002 \\
\hline AJVT_F2_Spn_3 & & & & & & & & & & 1,000 & 021 \\
\hline AJVT_F3_Spn_3 & & & & & & & & & & & 1,000 \\
\hline
\end{tabular}

**. La correlación es significativa al nivel 0,01 (bilateral).

*. La correlación es significativa al nivel 0,05 (bilateral).

$\mathrm{N}=5,474$ 


\subsubsection{Verificación de hipótesis - Europa}

Evaluar la validez de los coeficientes de correlación, como muestra de la relación existente entre las variables consideradas, tiene dos aspectos relevantes que deben ser abordados.

El primero se refiere a la significación del coeficiente, es decir a la confianza que podemos tener en que su valor sea realmente distinto de cero. Este aspecto no ofrece mayor duda que el nivel de confianza que debemos exigir y es un criterio generalmente aceptado el usar una confianza de al menos el 95\%, así como indicar el nivel alcanzado (99,0\%, 99,9\%).

El segundo aspecto a considerar se refiere al valor del propio coeficiente de correlación y a la intensidad de la relación detectada. Aquí hay una considerable disparidad de criterios, que varían según el campo de estudio. En concreto, en el campo de las ciencias sociales en el que se enmarca este estudio, resulta de especial interés lo comentado por Cohen (1981 y 1988) o Morales (2008). Basándonos en ellos, se ha establecido el criterio de considerar las correlaciones de acuerdo con la siguiente escala (siempre refiriéndonos a coeficientes de correlación significativamente distintos de cero).

$$
\begin{aligned}
& \text { Un valor de r: Indica una correlación: }
\end{aligned}
$$

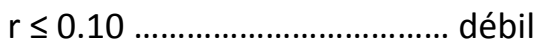

$$
\begin{aligned}
& 0.10<r \leq 0.30 \ldots \ldots \ldots \ldots \ldots \ldots \ldots . . . \text { baja }
\end{aligned}
$$

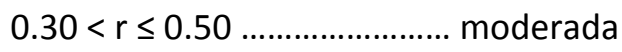

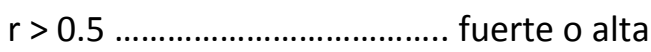

En el apartado 2.3.3.3 se ha discutido esta cuestión con más detalle.

A continuación se presenta el análisis de correlación bivariado para cada una de las hipótesis planteadas (Tablas 6.13 a 6.24). 


\subsubsection{Relación entre Éxito laboral y Valores - Hipótesis 1.}

Tabla 6. 13 Correlaciones bivariadas

\begin{tabular}{|} 
Éxito laboral_Valores Personales_E - H1a \\
\begin{tabular}{|c|c|c|c|c|}
\hline \multicolumn{2}{|c|}{ Rho de Spearman } & VPE_F1_1 & VPE_F2_1 & VPE_F3_1 \\
\hline Exlabob_E_1 & $\begin{array}{c}\text { Coeficiente } \\
\text { de } \\
\text { correlación }\end{array}$ &,- 100 &, 021 &,- 262 \\
\cline { 2 - 5 } & $\begin{array}{c}\text { Sig. } \\
\text { (bilateral) }\end{array}$ &, 000 &, 001 &, 000 \\
\hline Exlabsu_E_1 & $\begin{array}{c}\text { Coeficiente } \\
\text { de } \\
\text { correlación }\end{array}$ &,- 041 &, 178 &, 022 \\
\cline { 2 - 5 } & $\begin{array}{c}\text { Sig. } \\
\text { (bilateral) }\end{array}$ &, 000 &, 000 &, 000 \\
\hline
\end{tabular}
\end{tabular}

Dónde:

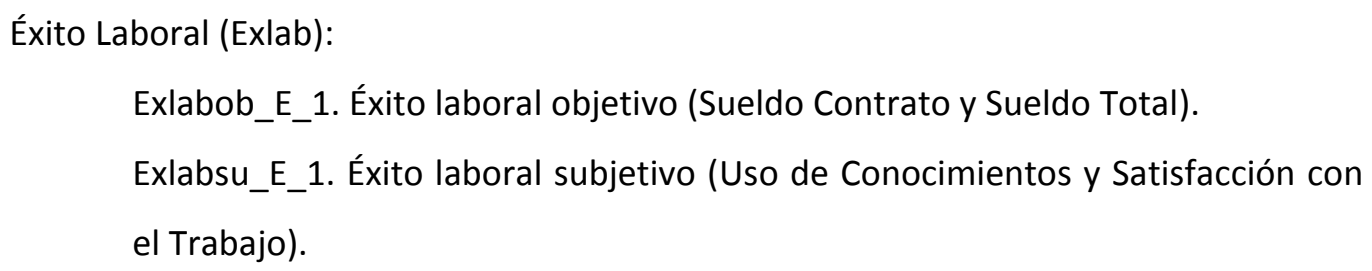

Interpretación de los resultados:

En general se presentan correlaciones positivas y negativas que son estadísticamente significativas $(p<, 01)$, entre las variables que miden la importancia personal de los valores laborales y las variables que miden el éxito laboral. En general presentan una correlación baja, $r<=.30$.

Se tiene la percepción que existe contraposición entre el éxito objetivo y la dedicación al ocio, la familia y el servicio a la sociedad. Mientras que éxito laboral subjetivo está relacionado positivamente con tener un puesto de trabajo enriquecido "satisfactorio". 
En conjunto se puede decir que en Europa, para los profesionales universitarios su percepción de éxito laboral tiene relación con la importancia personal que dan a los valores laborales. Por lo anterior, se encuentra evidencia que soporta H1a: El éxito laboral de los profesionales universitarios está condicionado por la importancia personal que dan a los valores laborales.

Tabla 6. 14 Correlaciones bivariadas Éxito Laboral_Valores Laborales en el Trabajo_E - H1b

\begin{tabular}{|c|c|c|c|c|}
\hline \multicolumn{2}{|c|}{ Rho de Spearman } & VLTE_F1_1 & VLTE_F2_1 & VLTE_F3_1 \\
\hline Exlabob_E_1 & $\begin{array}{c}\text { Coeficiente } \\
\text { de } \\
\text { correlación }\end{array}$ &, 078 &, 185 &,- 115 \\
\cline { 2 - 5 } & $\begin{array}{c}\text { Sig. } \\
\text { (bilateral) }\end{array}$ &, 000 &, 000 &, 000 \\
\hline Exlabsu_E_1 & $\begin{array}{c}\text { Coeficiente } \\
\text { de } \\
\text { correlación }\end{array}$ &, 466 &, 227 &, 073 \\
\cline { 2 - 5 } & $\begin{array}{c}\text { Sig. } \\
\text { (bilateral) }\end{array}$ &, 000 &, 000 &, 000 \\
\hline
\end{tabular}

Dónde:

Éxito Laboral (Exlab):

Exlabob_E_1. Éxito laboral objetivo (Sueldo Contrato y Sueldo Total).

Exlabsu_E_1 Éxito laboral subjetivo (Uso de Conocimientos y Satisfacción con el Trabajo).

Valores laborales en el trabajo (VLTE):

VLTE_F1_1. Puesto de Trabajo Enriquecido "satisfactorio".

VLTE_F2_1. Ingresos, Estabilidad y Reconocimiento.

VLTE_F3_1. Ocio y Familia.

Interpretación de los resultados:

En general se presentan relaciones positivas que son estadísticamente significativas $(p<, 01)$, entre las variables que miden el grado de aplicación de los valores laborales en el trabajo y las variables que miden el éxito laboral. Presentan correlaciones entre moderadas ( $r$ $<=.50)$ y débiles $(r<=.10)$. 
De un lado, se tiene la percepción que el uso de conocimientos y la satisfacción en el trabajo (éxito laboral subjetivo), correlaciona positivamente con un puesto de trabajo enriquecido "satisfactorio", como se tiene en relación a los ingresos, la estabilidad y el reconocimiento con el éxito laboral en general. De otro lado, nuevamente aparece la percepción de que existe contraposición entre el éxito objetivo y la dedicación al ocio y la familia.

Debido a la presencia de mayoría de correlaciones estadísticamente positivas y significativas, se puede decir que en Europa, para los profesionales universitarios su percepción de éxito laboral tiende a ser mayor en la medida en que los valores laborales personales tienen mayor aplicación en su situación laboral. Por lo anterior, se encuentra evidencia que soporta H1b: El éxito laboral de los profesionales universitarios está condicionado por el grado de aplicación de los valores laborales en el trabajo.

Tabla 6. 15 Correlaciones bivariadas Éxito laboral_Ajuste Valores Laborales (AJVTE) - H1c

\begin{tabular}{|c|c|c|c|c|}
\hline \multicolumn{2}{|c|}{ Rho de Spearman } & AJVT_F1_E_1 & AJVT_F2_E_1 & AJVT_F3_E_1 \\
\hline Exlabob_E_1 & $\begin{array}{c}\text { Coeficiente } \\
\text { de } \\
\text { correlación }\end{array}$ &, 075 &, 267 &, 031 \\
\cline { 2 - 5 } & $\begin{array}{c}\text { Sig. } \\
\text { (bilateral) }\end{array}$ &, 000 &, 000 &, 000 \\
\hline Exlabsu_E_1 & $\begin{array}{c}\text { Coeficiente } \\
\text { de } \\
\text { correlación }\end{array}$ &, 354 &, 199 &, 054 \\
\cline { 2 - 5 } & $\begin{array}{c}\text { Sig. } \\
\text { (bilateral) }\end{array}$ &, 000 &, 000 &, 000 \\
\hline
\end{tabular}

Dónde:

Éxito Laboral (Exlab):

Exlabob_E_1. Éxito laboral objetivo (Sueldo Contrato y Sueldo Total).

Exlabsu_E_1 Éxito laboral subjetivo (Uso de Conocimientos y Satisfacción con el Trabajo).

Ajuste de los Valores laborales (AJVTE):

AJVT_F1_E_1. Puesto de Trabajo Enriquecido "satisfactorio".

AJVT_F2_E_1. Ingresos, Estabilidad y Reconocimiento.

AJVT_F3_E_1. Ocio y Familia. 
Interpretación de los resultados:

Se presentan relaciones positivas que son estadísticamente significativas $(p<, 01)$, entre las variables que miden el ajuste entre los valores laborales personales y los valores laborales en el trabajo con las variables que miden el éxito laboral. Presentan una fuerza de relación entre moderada $(r<=.50)$ y débil $(r<=.10)$

Para los profesionales universitarios de Europa la percepción de ajuste de los valores laborales y el éxito laboral objetivo, se relaciona positiva y significativamente a través de los ingresos, estabilidad y reconocimiento, mientras que él éxito laboral subjetivo se relaciona positiva y significativamente a través de un puesto de trabajo enriquecido "satisfactorio". Se encuentra evidencia que soporta H1c: El éxito laboral de los profesionales universitarios está relacionado con el ajuste entre los valores laborales personales y los valores laborales en el trabajo. 
6.4.2.2 Relación entre Éxito Laboral y Competencias - Hipótesis 2.

Tabla 6. 16 Correlaciones bivariadas Éxito laboral_Competencias Personales (CPE) H2a

\begin{tabular}{|c|c|c|c|c|c|}
\hline \multicolumn{2}{|c|}{ Rho de Spearman } & CPE_F1_1 & CPE_F2_1 & CPE_F3_1 & CPE_F4_1 \\
\hline Exlabob_E_1 & $\begin{array}{c}\text { Coeficiente } \\
\text { de } \\
\text { correlación }\end{array}$ &, 040 &, 004 &, 050 &, 027 \\
\cline { 2 - 6 } & $\begin{array}{c}\text { Sig. } \\
\text { (bilateral) }\end{array}$ &, 000 &, 462 &, 000 &, 000 \\
\hline Exlabsu_E_1 & $\begin{array}{c}\text { Coeficiente } \\
\text { de } \\
\text { correlación }\end{array}$ &, 126 &, 106 &, 045 &, 088 \\
\cline { 2 - 6 } & $\begin{array}{c}\text { Sig. } \\
\text { (bilateral) }\end{array}$ &, 000 &, 000 &, 000 &, 000 \\
\hline
\end{tabular}

Dónde:

Éxito Laboral (Exlab):

Exlabob_E_1. Éxito laboral objetivo (Sueldo Contrato y Sueldo Total).

Exlabsu_E_1. Éxito laboral subjetivo (Uso de Conocimientos y Satisfacción con el Trabajo).

Competencias Personales (CPE):

CPE_F1_1. Competencias de Liderazgo y Comunicación.

CPE_F2_1. Competencias Organizativas.

CPE_F3_1. Competencias Instrumentales y de Innovación.

CPE_F4_1. Competencias de Conocimiento y Pensamiento Metacognitivo.

Interpretación de los resultados:

En general se presentan relaciones positivas que son estadísticamente significativas $(p<, 01)$, entre las variables que miden las competencias personales y las variables que miden el éxito laboral objetivo y subjetivo, con una correlación baja, $r<=.30$.

Las variables CPE_F2_1 (Competencias organizativas), no presentan relación con las variables de Éxito laboral objetivo (Sueldo Contrato y Sueldo Total). 
Se puede decir que para los profesionales universitarios las competencias personales tienden a aumentar su percepción del éxito laboral objetivo (representado en las variables de sueldo) y el éxito laboral subjetivo (uso de conocimientos y en la satisfacción laboral). Por lo anterior, se encuentra evidencia que soporta H2a: El éxito laboral de los profesionales universitarios se ve favorecido por sus competencias personales.

Tabla 6. 17 Correlaciones bivariadas Éxito laboral _C Competencias requeridas en el trabajo (CRE) - H2b

\begin{tabular}{|c|c|c|c|c|}
\hline \multicolumn{2}{|c|}{ Rho de Spearman } & CRE_F1_1 & CRE_F2_1 & CRE_F3_1 \\
\hline Exlabob_E_1 & $\begin{array}{c}\text { Coeficiente } \\
\text { de } \\
\text { correlación }\end{array}$ &, 000 &,- 009 &, 001 \\
\cline { 2 - 5 } & $\begin{array}{c}\text { Sig. } \\
\text { (bilateral) }\end{array}$ &, 991 &, 145 &, 902 \\
\hline Exlabsu_E_1 & $\begin{array}{c}\text { Coeficiente } \\
\text { de } \\
\text { correlación }\end{array}$ &, 153 &, 215 &, 148 \\
\cline { 2 - 5 } & $\begin{array}{c}\text { Sig. } \\
\text { (bilateral) }\end{array}$ &, 000 &, 000 &, 000 \\
\hline
\end{tabular}

Dónde:

Éxito Laboral (Exlab):

Exlabob_E_1. Éxito laboral objetivo (Sueldo Contrato y Sueldo Total).

Exlabsu_E_1. Éxito laboral subjetivo (Uso de Conocimientos y Satisfacción con el Trabajo).

Competencias requeridas en el trabajo (CRE):

CRE_F1_1. Competencias Organizativas y Liderazgo.

CRE_F2_1. Competencias de Innovación, Instrumentales y de Comunicación.

CRE_F3_1. Competencias de Conocimiento, Organizativas.

Interpretación de los resultados:

En general se presentan relaciones positivas que son estadísticamente significativas $(p<, 01)$, entre las variables que miden las competencias requeridas en el trabajo y las variables que miden el éxito laboral subjetivo (uso de conocimientos y satisfacción con el trabajo), con una fuerza de relación baja, $r<=.30$. 
El conjunto de las competencias requeridas en el trabajo (CRE), representadas en CRE_F1_1, CRE_F2_1, CRE_F3_1. No presentan relación con las variables de Éxito laboral objetivo (Sueldo Contrato y Sueldo Total).

Se puede decir que las competencias requeridas en trabajo afectan positivamente la percepción que tienen los profesionales del éxito laboral subjetivo (uso de conocimientos y la satisfacción con el trabajo).

Los profesionales universitarios de Europa no perciben que haya relación entre su éxito laboral objetivo (remuneración) y el nivel de competencia requerido en el puesto de trabajo. En cambio, un mayor requerimiento de competencias sí que afecta positivamente al éxito subjetivo (satisfacción y uso de conocimientos) de los profesionales. Por lo anterior, se encuentra evidencia que soporta $\mathrm{H} 2 \mathrm{~b}$ : El éxito laboral de los profesionales universitarios tiene relación con el nivel de competencias requeridas en el trabajo, si bien esta relación se orienta hacia el componente subjetivo del éxito.

Tabla 6. 18 Correlaciones bivariadas Éxito laboral_Ajuste de Competencias (AJCE) - H2c

\begin{tabular}{|c|c|c|c|c|}
\hline \multicolumn{2}{|c|}{ Rho de Spearman } & AJC_F1_E_1 & AJC_F2_E_1 & AJC_F3_E_1 \\
\hline \multirow{2}{*}{ Exlabob_E_1 } & $\begin{array}{c}\text { Coeficiente } \\
\text { de } \\
\text { correlación }\end{array}$ &, 018 &, 026 &, 046 \\
\cline { 2 - 5 } & $\begin{array}{c}\text { Sig. } \\
\text { (bilateral) }\end{array}$ &, 004 &, 000 &, 000 \\
\hline \multirow{2}{*}{ Exlabsu_E_1 } & $\begin{array}{c}\text { Coeficiente } \\
\text { de } \\
\text { correlación }\end{array}$ &,- 020 &,- 167 &,- 117 \\
\cline { 2 - 5 } & $\begin{array}{c}\text { Sig. } \\
\text { (bilateral) }\end{array}$ &, 001 &, 000 &, 000 \\
\hline
\end{tabular}

Dónde:

Éxito Laboral (Exlab):

Exlabob_E_1. Éxito laboral objetivo (Sueldo Contrato y Sueldo Total).

Exlabsu_E_1. Éxito laboral subjetivo (Uso de Conocimientos y Satisfacción con el Trabajo). 
Ajuste de Competencias (AJCE):

AJC_F1_E_1. Competencias Organizativas y de Liderazgo.

AJC_F2_E_1. Competencias instrumentales, de Innovación y Comunicación.

AJC_F3_E_1. Competencias de Conocimiento y Pensamiento Metacognitivo.

Interpretación de los resultados:

Se presentan relaciones positivas y negativas que son estadísticamente significativas $(p<, 05)$, entre las variables que miden el ajuste entre las competencias propias y las competencias requeridas en el trabajo frente a las variables que miden el éxito laboral con una fuerza de relación baja, $r<=.30$ a débil $(r<0.10)$.

El ajuste de competencias representadas en AJC_F1_E_1, AJC_F2_E_1, AJC_F3_E_1. Presentan relación positiva y débil con las variables de éxito laboral objetivo (sueldo). Se puede decir que el ajuste entre las competencias propias y las requeridas en el trabajo afectan muy levemente la percepción que tienen los profesionales del éxito laboral objetivo representado en la remuneración.

Las variables del ajuste de competencias, presentan una correlación negativa y baja con las variables de éxito laboral subjetivo. Se puede interpretar que el estar sobre cualificado reduce la percepción de éxito subjetivo.

El ajuste de competencias afecta positiva o negativamente la percepción que tienen los profesionales europeos acerca del uso de conocimientos y la satisfacción en el trabajo. De lo anterior se puede aceptar la hipótesis H2c: El éxito laboral de los profesionales universitarios se ve favorecido por el ajuste entre las competencias propias y las requeridas por las organizaciones, nuevamente centrado en el éxito subjetivo. 


\subsubsection{Relación entre Éxito laboral y Rol - Hipótesis 3.}

Tabla 6. 19 Correlaciones bivariadas Éxito laboral_Rol - H3

\begin{tabular}{|c|c|c|c|c|}
\hline \multicolumn{2}{|c|}{ Rho de Spearman } & Responsa_E_1 & Relacion_E_1 & Perjuicio_E_1 \\
\hline Exlabob_E_1 & $\begin{array}{c}\text { Coeficiente } \\
\text { de } \\
\text { correlación }\end{array}$ &,- 056 &, 147 &, 296 \\
\cline { 2 - 5 } & $\begin{array}{c}\text { Sig. } \\
\text { (bilateral) }\end{array}$ &, 000 &, 000 &, 000 \\
\hline Exlabsu_E_1 & $\begin{array}{c}\text { Coeficiente } \\
\text { de } \\
\text { correlación }\end{array}$ &, 237 &, 246 &,- 002 \\
\cline { 2 - 5 } & $\begin{array}{c}\text { Sig. } \\
\text { (bilateral) }\end{array}$ &, 000 &, 000 &, 682 \\
\hline
\end{tabular}

Dónde:

Éxito Laboral (Exlab):

Exlabob_E_1. Éxito laboral objetivo (Sueldo Contrato y Sueldo Total).

Exlabsu_E_1. Éxito laboral subjetivo (Uso de Conocimientos y Satisfacción con el Trabajo).

Rol en el trabajo (Rol):

$$
\begin{aligned}
& \text { Responsa_E_1. Responsabilidad. } \\
& \text { Relacion_E_1. Relaciones en el trabajo. } \\
& \text { Perjuicio_E_1. Perjuicio a la organización. }
\end{aligned}
$$

Interpretación de los resultados:

La mayoría de las relaciones son positivas y estadísticamente significativas $(p<, 01)$, entre las variables que miden el rol en el trabajo y las variables que miden el éxito laboral objetivo y subjetivo, con una fuerza de relación débil, $r<=.30$.

La variable Perjuicio_E_1 (perjuicio a la organización), no presenta relación con las variables de éxito laboral subjetivo (uso de conocimientos y satisfacción con el trabajo).

Se puede decir que para los profesionales universitarios el rol en el trabajo se relaciona positivamente con el éxito laboral subjetivo (uso de conocimientos y la satisfacción con el trabajo), a través de las variables de responsabilidad y las variables de relaciones en el trabajo. 
Por lo anterior, se encuentra evidencia que soporta H3: La satisfacción laboral de los graduados universitarios está relacionada con el rol que desempeñan dentro de las organizaciones.

6.4.2.4 Relación entre Rol y Valores - Hipótesis 4.

Tabla 6. 20 Correlaciones bivariadas Rol_Valores Personales_E H4a

\begin{tabular}{|l|c|c|c|c|}
\hline \multicolumn{2}{|c|}{ Rho de Spearman } & VPE_F1_1 & VPE_F2_1 & VPE_F3_1 \\
\hline Responsa_E_1 & $\begin{array}{c}\text { Coeficiente } \\
\text { de } \\
\text { correlación }\end{array}$ &, 018 &, 114 &,- 005 \\
\cline { 2 - 5 } & $\begin{array}{c}\text { Sig. } \\
\text { (bilateral) }\end{array}$ &, 005 &, 000 &, 409 \\
\hline Relacion_E_1 & $\begin{array}{c}\text { Coeficiente } \\
\text { de } \\
\text { correlación }\end{array}$ &, 026 &, 277 &,- 057 \\
\cline { 2 - 5 } & $\begin{array}{c}\text { Sig. } \\
\text { (bilateral) }\end{array}$ &, 000 &, 000 &, 000 \\
\hline Perjuicio_E_1 & $\begin{array}{c}\text { Coeficiente } \\
\text { de } \\
\text { correlación }\end{array}$ &, 092 &, 023 &,- 066 \\
\cline { 2 - 5 } & $\begin{array}{c}\text { Sig. } \\
\text { (bilateral) }\end{array}$ &, 000 &, 000 &, 000 \\
\hline
\end{tabular}

Dónde:

Rol en el trabajo (Rol):

Responsa_E_1. Responsabilidad.

Relacion_E_1. Relaciones en el trabajo.

Perjuicio_E_1. Perjuicio a la organización.

Valores Laborales Personales (VPE):

VPE_F1_1. Ingresos y reconocimiento.

VPE_F2_1. Puesto de Trabajo Enriquecido "satisfactorio".

VPE_F3_1. Ocio, Familia y Servicio a la Sociedad.

Interpretación de los resultados:

La mayoría de las relaciones son positivas y estadísticamente significativas $(p<, 01)$, entre las variables que miden el rol en el trabajo y las variables que miden la importancia personal de los valores laborales con una fuerza de relación baja, $r<=.30$ o débil $(r<0.10)$. 
La variable VPE_F3_1 (Ocio, Familia y Servicio a la sociedad), no presenta relación con la variable del rol en el trabajo, Responsa_E_1 (responsabilidad).

El valorar el puesto de trabajo satisfactorio, se correlaciona más con asumir responsabilidades y tener relaciones laborales. Quienes tienen valores laborales personales ligados a los ingresos, son más conscientes del perjuicio que pueden causar a la empresa.

Existe además una relación significativa y negativa entre las variables del rol, relaciones en el trabajo y perjuicio a la organización, frente a las variables de los valores personales relacionados con el ocio, familia y servicio a la sociedad.

Por lo anterior, se encuentra evidencia que soporta H4a: El rol de los profesionales universitarios está relacionado con la importancia que dan a sus valores laborales.

Tabla 6. 21 Correlaciones bivariadas Rol_Valores Laborales en el Trabajo_E - H4b

\begin{tabular}{|c|c|c|c|c|}
\hline \multicolumn{2}{|c|}{ Rho de Spearman } & \multirow{2}{*}{$\begin{array}{c}\text { VLTE_F1_1 } \\
\text {,287 }\end{array}$} & \multirow{2}{*}{$\begin{array}{c}\text { VLTE_F2_1 } \\
\text { 115 }\end{array}$} & \multirow{2}{*}{$\begin{array}{c}\text { VLTE_F3_1 } \\
, 041\end{array}$} \\
\hline Responsa_E_1 & \begin{tabular}{|c|} 
Coeficiente \\
de \\
correlación
\end{tabular} & & & \\
\hline & $\begin{array}{c}\text { Sig. } \\
\text { (bilateral) }\end{array}$ & ,000 & ,000 & ,000 \\
\hline \multirow[t]{2}{*}{ Relacion_E_1 } & $\begin{array}{c}\text { Coeficiente } \\
\text { de } \\
\text { correlación }\end{array}$ & ,270 & ,079 &,- 026 \\
\hline & \begin{tabular}{|c|} 
Sig. \\
(bilateral)
\end{tabular} & ,000 & , 000 & ,000 \\
\hline \multirow[t]{2}{*}{ Perjuicio_E_1 } & \begin{tabular}{|c|} 
Coeficiente \\
de \\
correlación
\end{tabular} & ,006 & 122 &,- 144 \\
\hline & $\begin{array}{c}\text { Sig. } \\
\text { (bilateral) }\end{array}$ & ,320 & ,000 & ,000 \\
\hline
\end{tabular}

Dónde:

Rol en el trabajo (Rol):

Responsa_E_1. Responsabilidad.

Relacion_E_1. Relaciones en el trabajo.

Perjuicio_E_1. Perjuicio a la organización. 
Valores laborales en el trabajo (VLTE):

VLTE_F1_1. Puesto de Trabajo Enriquecido "satisfactorio".

VLTE_F2_1. Ingresos, Estabilidad y Reconocimiento.

VLTE_F3_1. Ocio y Familia.

Interpretación de los resultados:

La mayoría de las relaciones son positivas y estadísticamente significativas $(p<, 01)$, entre las variables que miden el rol en el trabajo y las variables que miden el grado de aplicación de los valores laborales en el trabajo, con una fuerza de relación débil, $r<=.30$.

La variable VLTE_F1_1 (Puesto de Trabajo Enriquecido "satisfactorio"), presenta una positiva aunque débil relación con las variables de rol correspondientes a responsabilidad y relaciones en el trabajo. No presenta relación significativa con la variable perjuicio a la organización.

Se puede decir que para los profesionales universitarios de Europa el rol en el trabajo se relaciona positivamente en la medida en que aplican los valores laborales en el trabajo, (Puesto de Trabajo Enriquecido "satisfactorio", Ingresos, Estabilidad y Reconocimiento). Existe además una relación significativa y negativa entre las variables del rol (relaciones en el trabajo y perjuicio a la organización), frente a las variables que miden el grado de aplicación de los valores laborales en el trabajo (ocio y familia). Por lo anterior, se encuentra evidencia que soporta H4b: El rol de los profesionales universitarios está relacionado con la importancia personal que dan a sus valores laborales en el trabajo. 
6.4.2.5 Relación Rol y Competencias - Hipótesis 5.

Tabla 6. 22 Correlaciones bivariadas Rol_Competencias Personales_E-H5a

\begin{tabular}{|l|c|c|c|c|c|}
\hline \multicolumn{2}{|c|}{ Rho de Spearman } & CPE_F1_1 & CPE_F2_1 & CPE_F3_1 & CPE_F4_1 \\
\hline Responsa_E_1 & $\begin{array}{c}\text { Coeficiente } \\
\text { de } \\
\text { correlación }\end{array}$ &, 256 &, 020 &,- 006 &, 098 \\
\cline { 2 - 5 } & $\begin{array}{c}\text { Sig. } \\
\text { (bilateral) }\end{array}$ &, 000 &, 001 &, 313 &, 000 \\
\hline Relacion_E_1 & $\begin{array}{c}\text { Coeficiente } \\
\text { de } \\
\text { correlación }\end{array}$ &, 273 &, 125 &, 192 &, 259 \\
\cline { 2 - 6 } & $\begin{array}{c}\text { Sig. } \\
\text { (bilateral) }\end{array}$ &, 000 &, 000 &, 000 &, 000 \\
\hline Perjuicio_E_1 & $\begin{array}{c}\text { Coeficiente } \\
\text { de } \\
\text { correlación }\end{array}$ &, 089 &, 036 &,- 080 &,- 003 \\
\cline { 2 - 6 } & $\begin{array}{c}\text { Sig. } \\
\text { (bilateral) }\end{array}$ &, 000 &, 000 &, 000 &, 581 \\
\hline
\end{tabular}

Dónde:

Rol en el trabajo (Rol):

Responsa_E_1. Responsabilidad.

Relacion_E_1. Relaciones en el trabajo.

Perjuicio_E_1. Perjuicio a la organización.

Competencias Personales (CPE):

CPE_F1_1. Competencias de Liderazgo y Comunicación.

CPE_F2_1. Competencias Organizativas.

CPE_F3_1. Competencias Instrumentales y de Innovación.

CPE_F4_1. Competencias de Conocimiento y Pensamiento Metacognitivo.

Interpretación de los resultados:

En general se presenta mayoría de relaciones positivas que son estadísticamente significativas $(p<, 01)$, entre las variables que miden las competencias personales y las variables que miden el rol en el trabajo, con una fuerza de relación débil, $r<=.30$. 
La variable CPE_F1_1 (Competencias de Liderazgo y Comunicación) presenta relación positiva y significativa con las variables de rol a través de la responsabilidad $(r=, 256)$ y relaciones en el trabajo $(r=, 273)$.

Las variables CPE_F3_1 (Competencias Instrumentales y de Innovación) y las variables CPE_F4_1 (Competencias de Conocimiento y Pensamiento Metacognitivo) no presentan relación con las variables de rol en el trabajo (responsabilidad y perjuicio respectivamente).

Se puede decir que para los profesionales universitarios de Europa, sus competencias personales, favorecen el rol en el trabajo a través de las variables de responsabilidad y relaciones en el trabajo. Por tanto se encuentra evidencia que soporta H5a: El rol de los profesionales universitarios en las organizaciones está relacionado con las competencias personales.

Tabla 6. 23 Correlaciones bivariadas Rol_Competencias Requeridas_E - H5b

\begin{tabular}{|l|c|c|c|c|}
\hline \multicolumn{2}{|c|}{ Rho de Spearman } & CRE_F1_1 & CRE_F2_1 & CRE_F3_1 \\
\hline Responsa_E_1 & $\begin{array}{c}\text { Coeficiente } \\
\text { de } \\
\text { correlación }\end{array}$ &, 315 &, 109 &, 059 \\
\cline { 2 - 5 } & $\begin{array}{c}\text { Sig. } \\
\text { (bilateral) }\end{array}$ &, 000 &, 000 &, 000 \\
\hline Relacion_E_1 & $\begin{array}{c}\text { Coeficiente } \\
\text { de } \\
\text { correlación }\end{array}$ &, 181 &, 226 &, 144 \\
\cline { 2 - 5 } & $\begin{array}{c}\text { Sig. } \\
\text { (bilateral) }\end{array}$ &, 000 &, 000 &, 000 \\
\hline Perjuicio_E_1 & $\begin{array}{c}\text { Coeficiente } \\
\text { de } \\
\text { correlación }\end{array}$ &, 062 &,- 100 &, 089 \\
\cline { 2 - 5 } & $\begin{array}{c}\text { Sig. } \\
\text { (bilateral) }\end{array}$ &, 000 &, 000 &, 000 \\
\hline
\end{tabular}

Dónde:

Rol en el trabajo (Rol):

Responsa_E_1. Responsabilidad.

Relacion_E_1. Relaciones en el trabajo.

Perjuicio_E_1. Perjuicio a la organización. 
Competencias requeridas en el trabajo (CRE):

CRE_F1_1. Competencias Organizativas y Liderazgo.

CRE_F2_1. Competencias de Innovación, Instrumentales y de Comunicación.

CRE_F3_1. Competencias de Conocimiento, Organizativas.

Interpretación de los resultados:

En general se presenta mayoría de relaciones positivas que son estadísticamente significativas $(p<, 01)$, entre las variables que miden las competencias requeridas en el trabajo y las variables que miden el rol en el trabajo, con una fuerza de relación moderada $(r<=.40$ ) y baja $(r<.30)$ con alguna débil $(r<.10)$.

La variable CRE_F2_1 (Competencias de Innovación, Instrumentales y de Comunicación), presenta una débil relación significativa y negativa con la variable Perjuicio_E_1 (perjuicio a la organización), similar a lo ocurrido en el apartado con las competencias personales.

Se puede decir que para los profesionales universitarios de Europa, las competencias requeridas en el trabajo (Competencias Organizativas y Liderazgo, Competencias de Innovación, Instrumentales y de Comunicación) favorecen el rol en el trabajo principalmente a través de las variables de responsabilidad y relaciones en el trabajo. Se encuentra evidencia que soporta H5b: El rol de los profesionales universitarios en las organizaciones está relacionado con el nivel de competencias requerido en el trabajo. 
6.4.2.6 Relación entre Competencias y Valores - Hipótesis 6.

Tabla 6. 24 Correlaciones bivariadas Competencias Requeridas_E_Valores Laborales en el Trabajo_E-H6

\begin{tabular}{|c|c|c|c|c|}
\hline \multicolumn{2}{|c|}{ Rho de Spearman } & VLTE_F1_1 & VLTE_F2_1 & VLTE_F3_1 \\
\hline CRE_F1_1 & $\begin{array}{c}\text { Coeficiente } \\
\text { de } \\
\text { correlación }\end{array}$ &, 250 &, 151 &, 014 \\
\cline { 2 - 5 } & $\begin{array}{c}\text { Sig. } \\
\text { (bilateral) }\end{array}$ &, 000 &, 000 &, 042 \\
\hline CRE_F2_1 & $\begin{array}{c}\text { Coeficiente } \\
\text { de } \\
\text { correlación }\end{array}$ &, 341 &, 144 &,- 107 \\
\cline { 2 - 5 } & $\begin{array}{c}\text { Sig. } \\
\text { (bilateral) }\end{array}$ &, 000 &, 000 &, 000 \\
\hline CRE_F3_1 & $\begin{array}{c}\text { Coeficiente } \\
\text { de } \\
\text { correlación }\end{array}$ &, 173 &, 118 &,- 166 \\
\cline { 2 - 5 } & $\begin{array}{c}\text { Sig. } \\
\text { (bilateral) }\end{array}$ &, 000 &, 000 &, 000 \\
\hline
\end{tabular}

Dónde:
Competencias requeridas en el trabajo (CRE):
CRE_F1_1. Competencias Organizativas y Liderazgo.
CRE_F2_1. Competencias de Innovación, Instrumentales y de Comunicación.
CRE_F3_1. Competencias de Conocimiento, Organizativas.
Valores laborales en el trabajo (VLTE):
VLTE_F1_1. Puesto de Trabajo Enriquecido "satisfactorio".
VLTE_F2_1. Ingresos, Estabilidad y Reconocimiento.
VLTE_F3_1. Ocio y Familia.

Interpretación de los resultados:

Se presentan relaciones en su mayoría positivas y estadísticamente significativas $(p<, 01 ; p<, 05)$, entre algunas de las variables que miden las competencias requeridas en el trabajo y las variables que miden los valores laborales en el trabajo, con una fuerza de relación entre moderada $(r<=.40)$ y baja $(r<=.30)$. 
Las competencias requeridas en el trabajo a través de las variables CRE_F1_1 (Competencias Organizativas y Liderazgo), CRE_F2_1 (Competencias de Innovación, Instrumentales y de Comunicación) y CRE_F3_1 (Competencias de Conocimiento y Organizativas) presentan una positiva aunque débil relación con la variable VLTE_F1_1 (Puesto de Trabajo Enriquecido "satisfactorio").

Las competencias requeridas en el trabajo a través de las variables CRE_F2_1 (Competencias de Innovación, Instrumentales y de Comunicación) y CRE_F3_1 (Competencias de Conocimiento y Organizativas) presentan una relación negativa y estadísticamente significativa con la variable VLTE_F3_1 (Ocio y Familia) con una fuerza de relación baja $(r<.30)$.

Se puede afirmar que el nivel de competencias requerido en el trabajo, está relacionado con la percepción que tienen los profesionales universitarios de Europa sobre la medida en que se cumplen los valores laborales en el trabajo (puesto de trabajo Enriquecido "satisfactorio", ingresos, estabilidad y reconocimiento). De lo anterior se encuentra evidencia que soporta H6: Los valores laborales de los profesionales universitarios en el trabajo están relacionados con las competencias requeridas por la organización. 


\subsubsection{Verificación de hipótesis- Latinoamérica}

A continuación se presenta el análisis de correlación bivariado para cada una de las hipótesis planteadas (Tabla 6.25 a la 6.36).

\subsubsection{Relación entre Éxito laboral y Valores - Hipótesis 1.}

Tabla 6. 25 Correlaciones bivariadas Éxito laboral_Valores laborales personales (VPLA) - H1a

\begin{tabular}{|c|c|c|c|}
\hline \multicolumn{2}{|c|}{ Rho de Spearman } & VPLA_F1_2 & VPLA_F2_2 \\
\hline \multirow{2}{*}{ Exlabob_LA_2 } & $\begin{array}{c}\text { Coeficiente } \\
\text { de } \\
\text { correlación }\end{array}$ &, 113 &,- 121 \\
\cline { 2 - 4 } & $\begin{array}{c}\text { Sig. } \\
\text { (bilateral) }\end{array}$ &, 000 &, 000 \\
\hline \multirow{2}{*}{ Exlabsu_LA_2 } & $\begin{array}{c}\text { Coeficiente } \\
\text { de } \\
\text { correlación }\end{array}$ &, 097 &, 118 \\
\cline { 2 - 4 } & $\begin{array}{c}\text { Sig. } \\
\text { (bilateral) }\end{array}$ &, 000 &, 000 \\
\hline
\end{tabular}

Dónde:

Éxito Laboral (Exlab):

Exlabob_LA_2. Éxito laboral objetivo (Sueldo Contrato y Sueldo Total).

Exlabsu_LA_2. Éxito laboral subjetivo (Uso de Conocimientos y Satisfacción con el Trabajo).

Valores Laborales Personales (VPLA):

VPLA_F1_2. Puesto de Trabajo Enriquecido. Ingresos.

VPLA_F2_2. Ocio, Familia y Servicio a la sociedad.

Interpretación de los resultados:

En general se presentan relaciones positivas y negativas que son estadísticamente significativas $(p<, 01)$, entre las variables que miden la importancia personal de los valores laborales y las variables que miden el éxito laboral. En general presentan una fuerza de relación baja, $r<=.30$. 
Se tiene la percepción que existe contraposición entre el éxito objetivo y la dedicación al ocio, familia y servicio a la sociedad.

Se puede decir que en Latinoamérica, para los profesionales universitarios su percepción de éxito laboral subjetivo y objetivo tiende a ser mayor en la medida que tienen un puesto de trabajo enriquecido "satisfactorio", tienen ingresos y tiempo para disfrutar de la familia, el ocio y prestar servicio a la sociedad. Por lo anterior, se encuentra evidencia que soporta H1a: El éxito laboral de los profesionales universitarios está condicionado por la importancia personal que dan a los valores laborales.

Tabla 6. 26 Correlaciones bivariadas Éxito laboral_ Valores laborales en el trabajo (VLTLA) H1b

\begin{tabular}{|c|c|c|c|}
\hline \multicolumn{2}{|c|}{ Rho de Spearman } & VLTLA_F1_2 & VLTLA_F2_2 \\
\hline \multirow{2}{*}{ Exlabob_LA_2 } & $\begin{array}{c}\text { Coeficiente } \\
\text { de } \\
\text { correlación }\end{array}$ &, 114 &,- 065 \\
\cline { 2 - 4 } & $\begin{array}{c}\text { Sig. } \\
\text { (bilateral) }\end{array}$ &, 000 &, 000 \\
\hline \multirow{2}{*}{ Exlabsu_LA_2 } & $\begin{array}{c}\text { Coeficiente } \\
\text { de } \\
\text { correlación }\end{array}$ &, 406 &, 109 \\
\cline { 2 - 4 } & $\begin{array}{r}\text { Sig. } \\
\text { (bilateral) }\end{array}$ &, 000 &, 000 \\
\hline
\end{tabular}

Dónde:

Éxito Laboral (Exlab):

Exlabob_LA_2. Éxito laboral objetivo (Sueldo Contrato y Sueldo Total).

Exlabsu_LA_2. Éxito laboral subjetivo (Uso de Conocimientos y Satisfacción con el Trabajo).

Valores laborales en el trabajo (VLTLA):

VLTLA_F1_2. Puesto de Trabajo Enriquecido. Ingresos, Reconocimiento, Servicio a la Sociedad.

VLTLA_F2_2. Ocio y Familia. 
Interpretación de los resultados:

En general se presentan relaciones positivas que son estadísticamente significativas $(p<, 01)$, entre las variables que miden el grado de aplicación de los valores laborales en el trabajo y las variables que miden el éxito laboral. Presentan una fuerza de relación moderada $(r<=.50)$ tendiendo a débil $(r<=.10)$

Se evidencia una percepción contraria entre el éxito laboral objetivo y la dedicación al ocio y la familia, sin embargo hay una correlación moderada y positiva entre el éxito laboral subjetivo (uso de conocimientos y satisfacción con el trabajo) y el tener un puesto enriquecido, ingresos y prestar un servicio a la sociedad.

Debido a la presencia de correlaciones estadísticamente positivas y significativas, se puede decir que en Latinoamérica, para los profesionales universitarios su percepción de Éxito laboral tiende a ser mayor en la medida en que los valores laborales personales se aplican a su situación laboral. Por lo anterior, se encuentra evidencia que soporta H1b: El éxito laboral de los profesionales universitarios está condicionado por el grado de aplicación de los valores laborales en el trabajo.

Tabla 6. 27 Correlaciones bivariadas Éxito laboral_Ajuste Valores Laborales (AJVTLA) - H1c

\begin{tabular}{|c|c|c|c|}
\hline \multicolumn{2}{|c|}{ Rho de Spearman } & AJVT_F1_LA_2 & AJVT_F2_LA_2 \\
\hline Exlabob_LA_2 & $\begin{array}{c}\text { Coeficiente } \\
\text { de } \\
\text { correlación }\end{array}$ &, 084 &,- 060 \\
\cline { 2 - 4 } & $\begin{array}{c}\text { Sig. } \\
\text { (bilateral) }\end{array}$ &, 000 &, 000 \\
\hline \multirow{2}{*}{ Exlabsu_LA_2 } & $\begin{array}{c}\text { Coeficiente } \\
\text { de } \\
\text { correlación }\end{array}$ &, 301 &, 055 \\
\cline { 2 - 4 } & $\begin{array}{c}\text { Sig. } \\
\text { (bilateral) }\end{array}$ &, 000 &, 000 \\
\hline
\end{tabular}

Dónde:

Éxito Laboral (Exlab):

Exlabob_LA_2. Éxito laboral objetivo (Sueldo Contrato y Sueldo Total).

Exlabsu_LA_2. Éxito laboral subjetivo (Uso de Conocimientos y Satisfacción con el Trabajo). 
Ajuste de Valores laborales (AJVTLA):

AJVT_F1_LA_2. Puesto de Trabajo Enriquecido. Ingresos, Estabilidad y Reconocimiento.

AJVT_F2_LA_2. Ocio Familia y Servicio a la Sociedad.

Interpretación de los resultados:

Se presentan relaciones positivas que son estadísticamente significativas $(p<, 01)$, entre las variables que miden el ajuste entre los valores laborales personales y los valores laborales en el trabajo con las variables que miden el éxito laboral. Presentan una fuerza de relación entre moderada $(r<=.50)$ y débil $(r<=.10)$.

Para los profesionales universitarios de Latinoamérica la percepción de ajuste de los valores laborales frente al éxito laboral objetivo $(r=084)$ y el éxito laboral subjetivo $(r=, 301)$, se relaciona positiva y significativamente a través del puesto de trabajo enriquecido, los ingresos, estabilidad y reconocimiento. Se evidencia una percepción contraria entre el éxito laboral objetivo y la dedicación al Ocio Familia y Servicio a la Sociedad. De lo anterior se halla evidencia que soporta H1c: El éxito laboral de los profesionales universitarios está relacionado con el ajuste entre los valores laborales personales y los valores laborales en el trabajo. 
6.4.3.2 Relación entre Éxito laboral y Competencias - Hipótesis 2.

Tabla 6. 28 Correlaciones bivariadas Éxito laboral_Competencias Personales (CPLA) - H2a

\begin{tabular}{|c|c|c|c|c|}
\hline \multicolumn{2}{|c|}{ Rho de Spearman } & CPLA_F1-2 & CPLA_F2_2 & CPLA_F3_2 \\
\hline Exlabob_LA_2 & $\begin{array}{c}\text { Coeficiente } \\
\text { de } \\
\text { correlación }\end{array}$ &, 039 &, 165 &, 105 \\
\cline { 2 - 5 } & $\begin{array}{c}\text { Sig. } \\
\text { (bilateral) }\end{array}$ &, 002 &, 000 &, 000 \\
\hline Exlabsu_LA_2 & $\begin{array}{c}\text { Coeficiente } \\
\text { de } \\
\text { correlación }\end{array}$ &, 167 &, 189 &, 095 \\
\cline { 2 - 5 } & $\begin{array}{c}\text { Sig. } \\
\text { (bilateral) }\end{array}$ &, 000 &, 000 &, 000 \\
\hline
\end{tabular}

Dónde:

Éxito Laboral (Exlab):

Exlabob_LA_2. Éxito laboral objetivo (Sueldo Contrato y Sueldo Total).

Exlabsu_LA_2. Éxito laboral subjetivo (Uso de Conocimientos y Satisfacción con el Trabajo).

Competencias Personales (CPLA):

CPLA_F1-2. Competencias Organizativas, Liderazgo, Innovación.

CPLA_F2-2. Competencias de Conocimiento y Pensamiento Metacognitivo.

CPLA_F3-2. Competencias de Comunicación.

Interpretación de los resultados:

Se presentan relaciones positivas que son estadísticamente significativas $(p<, 01)$, entre las variables que miden las competencias personales y las variables que miden el éxito laboral objetivo y subjetivo, con una fuerza de relación baja, $r<=.30$.

Se puede decir que las competencias personales de los profesionales universitarios aumentan la percepción sobre el éxito laboral objetivo (representado en las variables de sueldo) y el éxito laboral subjetivo (uso de conocimientos y en la satisfacción laboral). Por lo anterior, se encuentra evidencia que soporta H2a: El éxito laboral de los profesionales universitarios se ve favorecido por sus competencias personales. 
Tabla 6. 29 Correlaciones bivariadas Éxito laboral_Competencias requeridas en el trabajo (CRLA) - H2b

\begin{tabular}{|c|c|c|c|}
\hline \multicolumn{2}{|c|}{ Rho de Spearman } & CRLA_F1_2 & CRLA_F2_2 \\
\hline Exlabob_LA_2 & $\begin{array}{c}\text { Coeficiente } \\
\text { de } \\
\text { correlación }\end{array}$ &, 090 &, 124 \\
\cline { 2 - 4 } & $\begin{array}{c}\text { Sig. } \\
\text { (bilateral) }\end{array}$ &, 000 &, 000 \\
\hline Exlabsu_LA_2 & $\begin{array}{c}\text { Coeficiente } \\
\text { de } \\
\text { correlación }\end{array}$ &, 185 &, 237 \\
\cline { 2 - 4 } & $\begin{array}{c}\text { Sig. } \\
\text { (bilateral) }\end{array}$ &, 000 &, 000 \\
\hline
\end{tabular}

Dónde:

Éxito Laboral (Exlab):

Exlabob_LA_2. Éxito laboral objetivo (Sueldo Contrato y Sueldo Total).

Exlabsu_LA_2. Éxito laboral subjetivo (Uso de Conocimientos y Satisfacción con el Trabajo).

Competencias requeridas en el trabajo (CRLA)

CRLA_F1_2. Pensamiento Metacognitivo, Organizativas, Liderazgo, Innovación.

CRLA_F2_2. Competencias de Conocimiento y de Comunicación.

Interpretación de los resultados:

En general se presentan relaciones positivas que son estadísticamente significativas $(p<, 01)$, entre las variables que miden las competencias requeridas en el trabajo y las variables que miden el éxito laboral subjetivo (uso de conocimientos y satisfacción con el trabajo) y el éxito laboral objetivo (sueldo contrato y sueldo total) con una fuerza de relación débil, $r<=.30$.

Se puede decir que las competencias requeridas en trabajo afectan positivamente la percepción que tienen los profesionales universitarios de Latinoamérica sobre el éxito laboral (Exlab).

Por lo anterior, se encuentra evidencia que soporta H2b: El éxito laboral de los profesionales universitarios tiene relación con el nivel de competencias requeridas en el trabajo. 
Tabla 6. 30 Correlaciones bivariadas Éxito laboral_Ajuste de Competencias (AJCLA) - H2c

\begin{tabular}{|c|c|c|c|c|}
\hline \multicolumn{2}{|c|}{ Rho de Spearman } & AJC_F1_LA_2 & AJC_F2_LA_2 & AJC_F3_LA_2 \\
\hline \multirow{2}{*}{ Exlabob_LA_2 } & $\begin{array}{c}\text { Coeficiente } \\
\text { de } \\
\text { correlación }\end{array}$ &,- 041 &,- 018 &, 022 \\
\cline { 2 - 5 } & $\begin{array}{c}\text { Sig. } \\
\text { (bilateral) }\end{array}$ &, 001 &, 162 &, 077 \\
\hline \multirow{2}{*}{ Exlabsu_LA_2 } & $\begin{array}{c}\text { Coeficiente } \\
\text { de } \\
\text { correlación }\end{array}$ &, 009 &,- 094 &,- 099 \\
\cline { 2 - 5 } & $\begin{array}{c}\text { Sig. } \\
\text { (bilateral) }\end{array}$ &, 457 &, 000 &, 000 \\
\hline
\end{tabular}

Dónde:

Éxito Laboral (Exlab):

Exlabob_LA_2. Éxito laboral objetivo (Sueldo Contrato y Sueldo Total).

Exlabsu_LA_2. Éxito laboral subjetivo (Uso de Conocimientos y Satisfacción con

el Trabajo).

Ajuste de Competencias (AJCLA):

AJC_F1_LA_2. Competencias Organizativas, Liderazgo, Innovación.

AJC_F2_LA_2. Competencias de Conocimiento y de Pensamiento Metacognitivo.

AJC_F3_LA_2. Competencias Instrumentales y C. de Comunicación.

Interpretación de los resultados:

Se presentan relaciones negativas que son estadísticamente significativas $(p<, 05)$, entre las variables que miden el ajuste entre las competencias propias y las competencias requeridas en el trabajo frente a las variables que miden el éxito laboral con una fuerza de relación débil, $r<=.10$.

No existe relación entre las variables de éxito laboral objetivo y las variables AJC_F2_LA_2 y - AJC_F3_LA_2. Así como entre las variables de éxito laboral subjetivo y las variables AJC_F1_LA_2. 
De un parte se desprende que el ajuste de competencias representadas en las variables AJC_F1_LA_2 (Competencias Organizativas, Liderazgo, Innovación), presentan relación muy débil y negativa con las variables de éxito laboral objetivo (remuneración). Las variables AJC_F2_LA_2 (Competencias de Conocimiento y de Pensamiento Metacognitivo), AJC_F3_LA_2 (Competencias Instrumentales y C. de Comunicación), presentan una relación muy débil y negativa frente a las variables relacionadas con el éxito laboral subjetivo (Uso de conocimientos y satisfacción con el trabajo).

La sobrecualificación en competencias reduce la percepción del éxito laboral subjetivo y de forma menos clara, en el éxito laboral objetivo. Se puede decir que el ajuste de competencias afecta la percepción que tienen los profesionales latinoamericanos acerca del éxito laboral. De lo anterior se puede aceptar la hipótesis H2c: El éxito laboral de los profesionales universitarios se ve favorecido por el ajuste entre las competencias propias y las requeridas por las organizaciones. 


\subsubsection{Relación entre Éxito laboral y Rol - Hipótesis 3.}

Tabla 6. 31 Correlaciones bivariadas Éxito laboral_Rol - H3

\begin{tabular}{|c|c|c|c|c|}
\hline \multicolumn{2}{|c|}{ Rho de Spearman } & Relacion_LA_2 & Responsa_LA_2 & Autonomia_LA_2 \\
\hline Exlabob_LA_2 & $\begin{array}{c}\text { Coeficiente } \\
\text { de } \\
\text { correlación }\end{array}$ &, 121 &,- 071 &, 062 \\
\cline { 2 - 5 } & $\begin{array}{c}\text { Sig. } \\
\text { (bilateral) }\end{array}$ &, 000 &, 000 &, 000 \\
\hline Exlabsu_LA_2 & $\begin{array}{c}\text { Coeficiente } \\
\text { de } \\
\text { correlación }\end{array}$ &, 285 &, 226 &, 108 \\
\cline { 2 - 5 } & $\begin{array}{c}\text { Sig. } \\
\text { (bilateral) }\end{array}$ &, 000 &, 000 &, 000 \\
\hline
\end{tabular}

Dónde:

Éxito Laboral (Exlab):

Exlabob_LA_2. Éxito laboral objetivo (Sueldo Contrato y Sueldo Total).

Exlabsu_LA_2. Éxito laboral subjetivo (Uso de Conocimientos y Satisfacción con el Trabajo).

Rol en el trabajo (Rol):

Relacion_LA_2. Relaciones en el trabajo.

Responsa_LA_2. Responsabilidad con la organización.

Autonomia_LA_2. Autonomía trabajo/Responsabilidad en el puesto de trabajo.

Interpretación de los resultados:

La mayoría de las relaciones son positivas y estadísticamente significativas $(p<, 01)$, entre las variables que miden el rol en el trabajo y las variables que miden el éxito laboral objetivo y subjetivo, con una fuerza de relación baja, $r<=.30$.

Se puede decir que para los profesionales universitarios el rol en el trabajo se relaciona positivamente con el éxito laboral subjetivo (uso de conocimientos y la satisfacción con el trabajo), a través de las variables de relaciones en el trabajo, responsabilidad y autonomía. Por lo anterior, se encuentra evidencia que soporta H3: La satisfacción laboral de los graduados universitarios está relacionada con el rol que desempeñan dentro de las organizaciones. 


\subsubsection{Relación entre Rol y Valores - Hipótesis 4.}

Tabla 6. 32 Correlaciones bivariadas Rol_Valores Personales_LA - H4a

\begin{tabular}{|c|c|c|c|}
\hline \multicolumn{2}{|c|}{ Rho de Spearman } & VPLA_F1_2 & VPLA_F2_2 \\
\hline \multirow{2}{*}{ Relacion_LA_2 } & Coeficiente de correlación & 142 & 137 \\
\hline & Sig. (bilateral) & ,000 & ,000 \\
\hline \multirow{2}{*}{ Responsa_LA_2 } & Coeficiente de correlación & ,037 & 104 \\
\hline & Sig. (bilateral) & ,003 & ,000 \\
\hline \multirow{2}{*}{ Autonomia_LA_2 } & Coeficiente de correlación & 128 & 011 \\
\hline & Sig. (bilateral) & ,000 & ,374 \\
\hline
\end{tabular}

Dónde:

Rol en el trabajo (Rol):

Relacion_LA_2. Relaciones en el trabajo.

Responsa_LA_2. Responsabilidad con la organización.

Autonomia_LA_2. Autonomía trabajo/Responsabilidad en el puesto de trabajo.

Valores Laborales Personales (VPLA):

VPLA_F1_2. Puesto de Trabajo Enriquecido. Ingresos.

VPLA_F2_2. Ocio, Familia y Servicio a la Sociedad.

Interpretación de los resultados:

Las relaciones son positivas y estadísticamente significativas $(p<, 01)$, entre las variables que miden el rol en el trabajo y las variables que miden la importancia personal de los valores laborales con una fuerza de relación baja, $r<=.30$.

La variable VPLA_F2_2 (Ocio, Familia y Servicio a la Sociedad), no presenta relación con la variable del rol en el trabajo, Autonomia_LA_2 (autonomía/responsabilidad en el puesto de 
trabajo). La dedicación al ocio, la familia y el servicio a la sociedad, se correlaciona más con las relaciones en el trabajo y la responsabilidad con la organización.

Se puede decir que para los profesionales universitarios el rol en el trabajo se relaciona positivamente con la importancia personal dada a los valores laborales, a través de las variables de relación, responsabilidad con la organización y autonomía en el puesto de trabajo.

Por lo anterior, se encuentra evidencia que soporta H4a: El rol de los profesionales universitarios está relacionado con la importancia que dan a sus valores laborales.

Tabla 6. 33 Correlaciones bivariadas Rol_Valores Laborales en el Trabajo_LA - H4b

\begin{tabular}{|c|c|c|c|}
\hline \multicolumn{2}{|c|}{ Rho de Spearman } & VLTLA_F1_2 & VLTLA_F2_2 \\
\hline \multirow{2}{*}{ Relacion_LA_2 } & Coeficiente de correlación & 279 & ,062 \\
\hline & Sig. (bilateral) & ,000 & ,000 \\
\hline \multirow{2}{*}{ Responsa_LA_2 } & Coeficiente de correlación & 294 & ,074 \\
\hline & Sig. (bilateral) & ,000 & ,000 \\
\hline \multirow{2}{*}{ Autonomia_LA_2 } & Coeficiente de correlación & ,068 & 079 \\
\hline & Sig. (bilateral) & ,000 & ,000 \\
\hline
\end{tabular}

Dónde:

Rol en el trabajo (Rol):

Relacion_LA_2. Relaciones en el trabajo.

Responsa_LA_2. Responsabilidad con la organización.

Autonomia_LA_2. Autonomía trabajo/Responsabilidad en el puesto de trabajo.

Valores laborales en el trabajo (VLTLA):

VLTLA_F1_2. Puesto de Trabajo Enriquecido. Ingresos, Reconocimiento, Servicio a la Sociedad.

VLTLA_F2_2. Ocio y Familia. 
Interpretación de los resultados:

Las relaciones son positivas y estadísticamente significativas $(p<, 01)$, entre las variables que miden el rol en el trabajo y las variables que miden el grado de aplicación de los valores laborales en el trabajo, con una fuerza de relación baja, $r<=.30$.

Se puede decir que para los profesionales universitarios de Latinoamérica el rol en el trabajo (relaciones en el trabajo, responsabilidad con la organización y autonomía) se relaciona positivamente en la medida en que aplican sus valores laborales en el trabajo. Por lo anterior, se encuentra evidencia que soporta H4b: El rol de los profesionales universitarios está relacionado con la importancia personal que dan a sus valores laborales en el trabajo. 
6.4.3.5 Relación entre Rol y Competencias - Hipótesis 5.

Tabla 6. 34 Correlaciones bivariadas Rol_Competencias Personales_LA - H5a

\begin{tabular}{|l|c|c|c|c|}
\hline \multicolumn{2}{|c|}{ Rho de Spearman } & CPLA_F1-2 & CPLA_F2_2 & CPLA_F3_2 \\
\hline \multirow{2}{*}{ Relacion_LA_2 } & Coeficiente de correlación &, 251 &, 251 &, 147 \\
\cline { 2 - 5 } & Sig. (bilateral) &, 000 &, 000 &, 000 \\
\hline \multirow{2}{*}{ Responsa_LA_2 } & Coeficiente de correlación &, 137 &, 067 &,- 013 \\
\cline { 2 - 5 } & Sig. (bilateral) &, 000 &, 000 &, 266 \\
\hline \multirow{2}{*}{ Autonomia_LA_2 } & Coeficiente de correlación &, 168 &, 080 &, 052 \\
\cline { 2 - 5 } & Sig. (bilateral) &, 000 &, 000 &, 000 \\
\hline
\end{tabular}

Dónde:

Rol en el trabajo (Rol):

Relacion_LA_2. Relaciones en el trabajo.

Responsa_LA_2. Responsabilidad con la organización.

Autonomia_LA_2. Autonomía trabajo/Responsabilidad en el puesto de trabajo.

Competencias personales (CPLA):

CPLA_F1_2. Competencias Organizativas, liderazgo, innovación.

CPLA_F2_2. Competencias de Conocimiento y Pensamiento Metacognitivo.

CPLA_F3_2. Competencias de Comunicación.

Interpretación de los resultados:

En general se presenta mayoría de relaciones positivas que son estadísticamente significativas $(p<, 01)$, entre las variables que miden las competencias personales y las variables que miden el rol en el trabajo, con una fuerza de relación baja $(r<=.30)$ a débil $(r<0.10)$.

Las variables CPLA_F3-2 (Competencias de Comunicación) no presentan relación con las variables de rol en el trabajo a través de la responsabilidad con la organización. 
Se puede decir que para los profesionales universitarios de Latinoamérica, sus competencias personales favorecen el rol en el trabajo a través de las variables relaciones en el trabajo, responsabilidad con la organización y Autonomía / Responsabilidad en el puesto de trabajo. Por tanto se encuentra evidencia que soporta H5a: El rol de los profesionales universitarios en las organizaciones está relacionado con las competencias personales.

Tabla 6. 35 Correlaciones bivariadas Rol_Competencias Requeridas_LA - H5b

\begin{tabular}{|c|c|c|c|}
\hline \multirow{2}{*}{ Rho de Spearman } & CRLA_F1_2 & CRLA_F2_2 \\
\hline \multirow{2}{*}{ Relacion_LA_2 } & Coeficiente de correlación &, 262 &, 242 \\
\cline { 2 - 4 } & Sig. (bilateral) &, 000 &, 000 \\
\hline \multirow{2}{*}{ Autonomia_LA_2 } & Coeficiente de correlación &, 175 &, 095 \\
\cline { 2 - 4 } & Coeficiente de correlación &, 204 &, 000 \\
\cline { 2 - 4 } & Sig. (bilateral) &, 000 &, 001 \\
\hline
\end{tabular}

Dónde:

Rol en el trabajo (Rol):

Relacion_LA_2. Relaciones en el trabajo.

Responsa_LA_2. Responsabilidad con la organización.

Autonomia_LA_2. Autonomía trabajo/Responsabilidad en el puesto de trabajo.

Competencias requeridas en el trabajo (CRLA):

CRLA_F1_2. Pensamiento Metacognitivo, Organizativas, Liderazgo, Innovación.

CRLA_F2_2. Competencias de Conocimiento y de Comunicación. 
Interpretación de los resultados:

En general se presentan relaciones positivas que son estadísticamente significativas $(p<, 01)$, entre las variables que miden las competencias requeridas en el trabajo y las variables que miden el rol en el trabajo, con una fuerza de relación baja $(r<=.30)$.

Se puede decir que para los profesionales universitarios de Latinoamérica, las competencias requeridas en el trabajo favorecen el rol en el trabajo a través de las variables Relacion_LA_2, Responsa_LA_2, Autonomia_LA_2. Por tanto se encuentra evidencia que soporta H5b: El rol de los profesionales universitarios en las organizaciones está relacionado con el nivel de competencias requerido en el trabajo.

\subsubsection{Relación entre Competencias y Valores - Hipótesis 6.}

Tabla 6. 36 Correlaciones bivariadas Competencias Requeridas_LA_Valores Laborales en el Trabajo_LA - H6

\begin{tabular}{|c|c|c|c|}
\hline \multicolumn{2}{|c|}{ Rho de Spearman } & VLTLA_F1_2 & VLTLA_F2_2 \\
\hline \multirow{2}{*}{ CRLA_F1_2 } & Coeficiente de correlación &, 301 &, 025 \\
\cline { 2 - 4 } & Sig. (bilateral) &, 000 &, 057 \\
\hline \multirow{2}{*}{ CRLA_F2_2 } & Coeficiente de correlación &, 290 &, 088 \\
\cline { 2 - 4 } & Sig. (bilateral) &, 000 &, 000 \\
\hline
\end{tabular}

Dónde:

Competencias requeridas en el trabajo (CRLA):

CRLA_F1_2. Pensamiento Metacognitivo, Organizativas, Liderazgo, Innovación.

CRLA_F2_2. Competencias Instrumentales, de Conocimiento y de Comunicación.

Valores laborales en el trabajo (VLTLA):

VLTLA_F1_2. Puesto de Trabajo Enriquecido. Ingresos, Reconocimiento, Servicio a la Sociedad.

VLTLA_F2_2. Ocio y Familia. 
Interpretación de los resultados:

Se presentan relaciones en su mayoría positivas y estadísticamente significativas $(p<, 01)$, entre algunas de las variables que miden las competencias requeridas en el trabajo y las variables que miden el grado de aplicación de los valores laborales en el trabajo, con una fuerza de relación baja $(r<=.30)$.

Las variables de valores laborales en el trabajo VLTLA_F2_2 (Ocio y Familia) no presentan relación con las variables de competencias requeridas en el trabajo CRLA_F1_2 (Competencias de Pensamiento Metacognitivo, Organizativas, Liderazgo, Innovación).

Se puede decir que para los profesionales universitarios de Latinoamérica, el nivel de competencias requerido en el trabajo, está relacionado con la percepción que tienen de la medida en que se cumplen los valores laborales en el trabajo (puesto de trabajo enriquecido, ingresos, reconocimiento, servicio a la sociedad. Se encuentra evidencia que soporta H6: Los valores laborales de los profesionales universitarios en el trabajo están relacionados con las competencias requeridas por la organización. 


\subsubsection{Verificación de hipótesis- España}

A continuación se presenta el análisis de correlación bivariado para cada una de las hipótesis planteadas (Tabla 6.37 a la 6.48).

\subsubsection{Relación entre Éxito laboral y Valores - Hipótesis 1.}

Tabla 6. 37 Correlaciones bivariadas Éxito laboral _ Valores laborales personales (VPSPN) _ H1a

\begin{tabular}{|c|c|c|c|}
\hline \multicolumn{2}{|c|}{ Rho de Spearman } & VPSpn_F1_3 & VPSpn_F2_3 \\
\hline \multirow{2}{*}{ Exlabob_Spn_3 } & Coeficiente de correlación &, 010 &,- 018 \\
\cline { 2 - 4 } & Sig. (bilateral) &, 543 &, 255 \\
\hline \multirow{2}{*}{ Exlabsu_Spn_3 } & Coeficiente de correlación &, 170 &, 004 \\
\cline { 2 - 4 } & Sig. (bilateral) &, 000 &, 819 \\
\hline
\end{tabular}

Dónde:

Éxito Laboral (Exlab):

Exlabob_Spn_3. Éxito laboral objetivo (Sueldo Contrato y Sueldo Total).

Exlabsu_Spn_3. Éxito laboral subjetivo (Uso de Conocimientos y Satisfacción con el Trabajo).

Valores Laborales Personales (VPSPN):

VPSpn_F1_3. Puesto de Trabajo Enriquecido "satisfactorio".

VPSpn_F2_3. Ocio y Familia - Ingresos y Estabilidad.

Interpretación de los resultados:

Se presenta relación positiva y estadísticamente significativa $(p<, 01)$, entre las variables que miden la importancia personal de los valores laborales, a través del Puesto de 
trabajo enriquecido "satisfactorio" (VPSpn_F1_3) y las variables que miden el éxito laboral subjetivo (Exlabsu_Spn_3), con una fuerza de relación baja, $r<=.30$.

Las variables VPSpn_F1_3 (Puesto de Trabajo Enriquecido "satisfactorio"), VPSpn_F2_3 (Ocio y Familia - Ingresos y Estabilidad) no presentan relación con las variables de éxito laboral objetivo. Las variables VPSpn_F2_3 no presentan relación con las variables de éxito laboral subjetivo.

Se puede decir que en España, para los profesionales universitarios su percepción de Éxito laboral tiene relación con la importancia personal que dan a los valores laborales a través de un puesto de trabajo enriquecido "satisfactorio". Por lo anterior, se encuentra evidencia parcial que soporta H1a: El éxito laboral de los profesionales universitarios está condicionado por la importancia personal que dan a los valores laborales, si bien este solo se orienta hacia el componente subjetivo del éxito.

Tabla 6. 38 Correlaciones bivariadas Éxito laboral _ Valores laborales en el trabajo (VLTSPN) $-\mathrm{H} 1 \mathrm{~b}$

\begin{tabular}{|c|c|c|c|c|}
\hline \multicolumn{2}{|c|}{ Rho de Spearman } & VLTSpn_F1_3 & VLTSpn_F2_3 & VLTSpn_F3_3 \\
\hline Exlabob_Spn_3 & $\begin{array}{c}\text { Coeficiente } \\
\text { de } \\
\text { correlación }\end{array}$ &, 163 &,- 032 &, 265 \\
\cline { 2 - 5 } & $\begin{array}{c}\text { Sig. } \\
\text { (bilateral) }\end{array}$ &, 000 &, 048 &, 000 \\
\hline \multirow{2}{*}{ Exlabsu_Spn_3 } & $\begin{array}{c}\text { Coeficiente } \\
\text { de } \\
\text { correlación }\end{array}$ &, 514 &, 162 &, 124 \\
\cline { 2 - 5 } & $\begin{array}{c}\text { Sig. } \\
\text { (bilateral) }\end{array}$ &, 000 &, 000 &, 000 \\
\hline
\end{tabular}

Dónde:

Éxito Laboral (Exlab):

Exlabob_Spn_3. Éxito laboral objetivo (Sueldo Contrato y Sueldo Total).

Exlabsu_Spn_3. Éxito laboral subjetivo (Uso de Conocimientos y Satisfacción con el Trabajo). 
Valores Laborales en el trabajo (VLTSPN):

VLTSpn_F1_3. Puesto de Trabajo Enriquecido "satisfactorio".

VLTSpn_F2_3. Ocio y Familia.

VLTSpn_F3_3. Ingresos y Estabilidad.

Interpretación de los resultados:

En general la mayoría de relaciones son positivas y estadísticamente significativas $(p<, 01$ y $p<, 05)$, entre las variables que miden el grado de aplicación de los valores laborales en el trabajo y las variables que miden el éxito laboral presentando una fuerza de relación moderada $(r<=.50)$ a baja $(r<=.30)$.

La variable VLTSpn_F2_3 (ocio y familia) presenta una correlación negativa y significativa con una fuerza de relación débil con la variable Exlabob_Spn_3 (sueldos contrato y sueldo total), en línea con lo que ocurría en Europa y en Latinoamérica, aquí se percibe más débilmente.

La variable que presenta una correlación más alta $(r>=, 50)$ es VLTSpn_F1_3 (Puesto de trabajo enriquecido "satisfactorio") con el Exlabsu_Spn_3 (uso de conocimientos y satisfacción en el trabajo).

Debido a la presencia de correlaciones estadísticamente positivas y significativas, se puede decir que en España, para los profesionales universitarios su percepción de éxito laboral tiende a ser mayor en la medida en que los valores laborales personales tienen mayor aplicación en su situación laboral, con mayor valoración de la percepción del éxito laboral subjetivo. Por lo anterior, se encuentra evidencia que soporta H1b: El éxito laboral de los profesionales universitarios está condicionado por el grado de aplicación de los valores laborales en el trabajo. 
Tabla 6. 39 Correlaciones bivariadas Éxito laboral_Ajuste Valores Laborales (AJVTSpn) - H1c

\begin{tabular}{|c|c|c|c|c|}
\hline \multicolumn{2}{|c|}{ Rho de Spearman } & AJVT_F1_Spn_3 & AJVT_F2_Spn_3 & AJVT_F3_Spn_3 \\
\hline \multirow{2}{*}{ Exlabob_Spn_3 } & $\begin{array}{c}\text { Coeficiente } \\
\text { de } \\
\text { correlación }\end{array}$ &, 168 &,- 002 &, 213 \\
\cline { 2 - 5 } & $\begin{array}{c}\text { Sig. } \\
\text { (bilateral) }\end{array}$ &, 000 &, 878 &, 000 \\
\hline \multirow{2}{*}{ Exlabsu_Spn_3 } & $\begin{array}{c}\text { Coeficiente } \\
\text { de } \\
\text { correlación }\end{array}$ &, 403 &, 137 &, 115 \\
\cline { 2 - 5 } & $\begin{array}{c}\text { Sig. } \\
\text { (bilateral) }\end{array}$ &, 000 &, 000 &, 000 \\
\hline
\end{tabular}

Dónde:

Éxito Laboral (Exlab):

Exlabob_Spn_3. Éxito laboral objetivo (Sueldo Contrato y Sueldo Total).

Exlabsu_Spn_3. Éxito laboral subjetivo (Uso de Conocimientos y Satisfacción con el Trabajo).

Ajuste Valores Laborales (AJVTSpn):

AJVT_F1_Spn_3. Puesto de Trabajo Enriquecido "satisfactorio".

AJVT_F2_Spn_3. Ocio y Familia.

AJVT_F3_Spn_3. Ingresos y Estabilidad

Interpretación de los resultados:

Se presentan relaciones positivas que son estadísticamente significativas $(p<, 01)$, entre las variables que miden el ajuste entre los valores laborales personales y los valores laborales en el trabajo con las variables que miden el éxito laboral. Presentan una fuerza de correlación moderada $(r<=.50)$ tendiendo a baja $(r<=.30)$.

Nuevamente, no se evidencia relación entre las variables asociadas al éxito laboral objetivo (sueldo) y las variables AJVT_F2_Spn_3 (Ocio y familia). 
Para los profesionales universitarios de España la percepción de ajuste de los valores laborales y el éxito laboral objetivo, se relaciona positiva y significativamente a través del puesto de Trabajo Enriquecido "satisfactorio", Ingresos y Estabilidad mientras que él éxito laboral subjetivo se relaciona positiva y significativamente a través de las variables asociadas al ajuste de los valores laborales, principalmente a la variable Puesto de Trabajo Enriquecido "satisfactorio" ( $r=.403)$.

Se encuentra evidencia que soporta H1c: El éxito laboral de los profesionales universitarios está relacionado con el ajuste entre los valores laborales personales y los valores laborales en el trabajo. 
6.4.4.2 Relación entre Éxito laboral y Competencias - Hipótesis 2.

Tabla 6. 40 Correlaciones bivariadas Éxito laboral_Competencias Personales (CPSPN) - H2a

\begin{tabular}{|c|c|c|c|c|c|}
\hline \multicolumn{2}{|c|}{ Rho de Spearman } & CPSpn_F1_3 & CPSpn_F2_3 & CPSpn_F3_3 & CPSpn_F4_3 \\
\hline Exlabob_Spn_3 & $\begin{array}{c}\text { Coeficiente } \\
\text { de } \\
\text { correlación }\end{array}$ &, 075 &,- 062 &, 083 &, 114 \\
\cline { 2 - 6 } & $\begin{array}{c}\text { Sig. } \\
\text { (bilateral) }\end{array}$ &, 000 &, 000 &, 000 &, 000 \\
\hline \multirow{2}{*}{ Exlabsu_Spn_3 } & $\begin{array}{c}\text { Coeficiente } \\
\text { de } \\
\text { correlación }\end{array}$ &, 141 &, 096 &, 088 &, 076 \\
\cline { 2 - 6 } & $\begin{array}{c}\text { Sig. } \\
\text { (bilateral) }\end{array}$ &, 000 &, 000 &, 000 &, 000 \\
\hline
\end{tabular}

Dónde:

Éxito Laboral (Exlab):

Exlabob_Spn_3. Éxito laboral objetivo (Sueldo Contrato y Sueldo Total).

Exlabsu_Spn_3. Éxito laboral subjetivo (Uso de Conocimientos y Satisfacción con el Trabajo).

Competencias Personales (CPSPN):

CPSpn_F1_3. Competencias de Liderazgo y Comunicación.

CPSpn_F2_3. Competencias Organizativas.

CPSpn_F3_3. Competencias de Conocimiento y Pensamiento Metacognitivo.

CPSpn_F4_3. Competencias Instrumentales y de Innovación.

Interpretación de los resultados:

En general se presentan relaciones positivas que son estadísticamente significativas $(p<, 01)$, entre las variables que miden las competencias personales y las variables que miden el éxito laboral objetivo y subjetivo, con una fuerza de relación baja $(r<=.30)$ o débil $(r<.10)$.

Las variables CPSpn_F2_3 (competencias organizativas), presentan relación significativa y negativa con las variables de Éxito laboral objetivo (Sueldo). 
Se puede decir que el nivel de competencias personales de los profesionales universitarios favorece positivamente el éxito laboral objetivo (representado en las variables de sueldo) y el éxito laboral subjetivo (uso de conocimientos y en la satisfacción laboral). Por lo anterior, se encuentra evidencia que soporta H2a: El éxito laboral de los profesionales universitarios se ve favorecido por sus competencias personales.

Tabla 6. 41 Correlaciones bivariadas Éxito laboral__ Competencias requeridas en el trabajo (CRSPN) - H2b

\begin{tabular}{|c|c|c|c|c|}
\hline \multicolumn{2}{|c|}{ Rho de Spearman } & CRSpn_F1_3 & CRSpn_F2_3 & CRSpn_F3_3 \\
\hline \multirow[t]{2}{*}{ Exlabob_Spn_3 } & $\begin{array}{c}\text { Coeficiente } \\
\text { de } \\
\text { correlación }\end{array}$ & ,120 & 117 & , 158 \\
\hline & $\begin{array}{c}\text { Sig. } \\
\text { (bilateral) }\end{array}$ & ,000 & ,000 & ,000 \\
\hline \multirow[t]{2}{*}{ Exlabsu_Spn_3 } & $\begin{array}{c}\text { Coeficiente } \\
\text { de } \\
\text { correlación }\end{array}$ & 201 & ,221 & ,238 \\
\hline & $\begin{array}{c}\text { Sig. } \\
\text { (bilateral) }\end{array}$ & ,000 & ,000 & ,000 \\
\hline
\end{tabular}

Dónde:

Éxito Laboral (Exlab):

Exlabob_Spn_3. Éxito laboral objetivo (Sueldo Contrato y Sueldo Total).

Exlabsu_Spn_3. Éxito laboral subjetivo (Uso de Conocimientos y Satisfacción con el Trabajo).

Competencias requeridas en el trabajo (CRSPN):

CRSpn_F1_3. Competencias Organizativas y Liderazgo e Innovación.

CRSpn_F2_3. Competencias de Conocimiento y Pensamiento Metacognitivo.

CRSpn_F3_3. Competencias Instrumentales y de Comunicación.

Interpretación de los resultados:

Se presentan relaciones positivas que son estadísticamente significativas $(p<, 01)$, entre las variables que miden las competencias requeridas en el trabajo y las variables que miden el éxito laboral (Exlab), con una fuerza de relación baja, $r<=.30$. 
Se puede decir que el nivel de competencias requerido en el trabajo afecta positivamente la percepción que tienen los profesionales del éxito laboral objetivo (sueldo) y el éxito laboral subjetivo (uso de conocimientos y la satisfacción con el trabajo).

Por lo anterior, se encuentra evidencia que soporta $\mathbf{H 2 b}$ : El éxito laboral de los profesionales universitarios tiene relación con el nivel de competencias requeridas en el trabajo.

Tabla 6. 42 Correlaciones bivariadas Éxito laboral_Ajuste de Competencias (AJCSpn) - H2c

\begin{tabular}{|c|c|c|c|c|}
\hline \multicolumn{2}{|c|}{ Rho de Spearman } & AJC_F1_Spn_3 & AJC_F2_Spn_3 & AJC_F3_Spn_3 \\
\hline \multirow{2}{*}{ Exlabob_Spn_3 } & $\begin{array}{c}\text { Coeficiente } \\
\text { de } \\
\text { correlación }\end{array}$ &,- 098 &,- 084 &,- 070 \\
\cline { 2 - 5 } & $\begin{array}{c}\text { Sig. } \\
\text { (bilateral) }\end{array}$ &, 000 &, 000 &, 000 \\
\hline \multirow{2}{*}{ Exlabsu_Spn_3 } & $\begin{array}{c}\text { Coeficiente } \\
\text { de } \\
\text { correlación }\end{array}$ &,- 057 &,- 197 &,- 174 \\
\cline { 2 - 5 } & $\begin{array}{c}\text { Sig. } \\
\text { (bilateral) }\end{array}$ &, 000 &, 000 &, 000 \\
\hline
\end{tabular}

Dónde:

Éxito Laboral (Exlab):

Exlabob_Spn_3. Éxito laboral objetivo (Sueldo Contrato y Sueldo Total).

Exlabsu_Spn_3. Éxito laboral subjetivo (Uso de Conocimientos y Satisfacción con el Trabajo).

Ajuste de Competencias (AJCSpn):

AJC_F1_Spn_3. Competencias Organizativas, Liderazgo e Innovación.

AJC_F2_Spn_3. Competencias de Conocimiento y Pensamiento Metacognitivo.

AJC_F3_Spn_3. Competencias Instrumentales y C. de Comunicación.

Interpretación de los resultados:

Se presentan relaciones negativas que son estadísticamente significativas $(p<, 01)$, entre las variables que miden el ajuste entre las competencias propias y las competencias 
requeridas en el trabajo frente a las variables que miden el éxito laboral con una fuerza de relación baja $(r<=.30)$ a débil $(r<.10)$.

El ajuste de competencias representado en las variables AJC_F1_Spn_3, AJC_F2_Spn_3, AJC_F3_Spn_3. Presentan relación negativa con las variables de éxito laboral objetivo (sueldo) y las variables de éxito laboral subjetivo (uso de conocimientos y satisfacción con el trabajo). Para los graduados universitarios de España, estar sobrecualificado en competencias organizativas, de liderazgo e innovación reduce la percepción de éxito objetivo. La sobrecualificación en competencias de conocimiento y pensamiento Metacognitivo, competencias instrumentales y de comunicación, reduce la percepción de éxito subjetivo.

Se puede decir que existe una relación contraria entre el ajuste de competencias y la percepción que tienen los profesionales españoles acerca del éxito laboral, a través del sueldo, el uso de conocimientos y la satisfacción en el trabajo. De lo anterior se puede aceptar la hipótesis H2c: El éxito laboral de los profesionales universitarios se ve favorecido por el ajuste entre las competencias propias y las requeridas por las organizaciones. 
6.4.4.3 Relación entre Éxito laboral y Rol - Hipótesis 3.

Tabla 6. 43 Correlaciones bivariadas Éxito laboral_Rol - H3

\begin{tabular}{|c|c|c|c|c|}
\hline \multicolumn{2}{|c|}{ Rho de Spearman } & Responsa_Spn_3 & Relacion_Spn_3 & Perjuicio_Spn_3 \\
\hline Exlabob_Spn_3 & $\begin{array}{c}\text { Coeficiente } \\
\text { de } \\
\text { correlación }\end{array}$ &, 104 &, 175 &, 034 \\
\cline { 2 - 5 } & $\begin{array}{c}\text { Sig. } \\
\text { (bilateral) }\end{array}$ &, 000 &, 000 &, 030 \\
\hline \multirow{2}{*}{ Exlabsu_Spn_3 } & $\begin{array}{c}\text { Coeficiente } \\
\text { de } \\
\text { correlación }\end{array}$ &, 317 &, 306 &, 039 \\
\cline { 2 - 5 } & $\begin{array}{c}\text { Sig. } \\
\text { (bilateral) }\end{array}$ &, 000 &, 000 &, 009 \\
\hline
\end{tabular}

Dónde:

Éxito Laboral (Exlab):

Exlabob_Spn_3. Éxito laboral objetivo (Sueldo Contrato y Sueldo Total).

Exlabsu_Spn_3. Éxito laboral subjetivo (Uso de Conocimientos y Satisfacción con el Trabajo).

Rol en el trabajo (Rol):

Responsa_Spn_3. Responsabilidad.

Relacion_Spn_3. Relaciones en el Trabajo.

Perjuicio_Spn_3. Perjuicio a la organización.

Interpretación de los resultados:

Las relaciones son positivas y estadísticamente significativas $(p<, 01$ y $p<, 05)$, entre las variables que miden el rol en el trabajo y las variables que miden el éxito laboral objetivo y subjetivo, con una fuerza de relación moderada $(r<=, 50)$ a débil $(r<=, 10)$.

La variable Responsa_Spn_3 (responsabilidad) y la variable Relacion_Spn_3 (relaciones en el trabajo) tienen una correlación positiva con la variable con la variable éxito laboral subjetivo (Uso de conocimientos y Satisfacción con el trabajo).

Se puede decir que para los profesionales universitarios de España, el rol en el trabajo se relaciona positivamente con el éxito laboral objetivo y subjetivo, a través de las variables de responsabilidad y relaciones en el trabajo. Por lo anterior, se encuentra evidencia que soporta H3: La satisfacción laboral de los graduados universitarios está relacionada con el rol que desempeñan dentro de las organizaciones. 


\subsubsection{Relación entre Rol y Valores - Hipótesis 4.}

Tabla 6. 44 Correlaciones bivariadas Rol_Valores Laborales Personales (VPSPN) - H4a

\begin{tabular}{|c|c|c|c|}
\hline \multicolumn{2}{|c|}{ Rho de Spearman } & VPSpn_F1_3 & VPSpn_F2_3 \\
\hline \multirow{2}{*}{ Responsa_Spn_3 } & Coeficiente de correlación &, 117 &,- 056 \\
\cline { 2 - 4 } & Sig. (bilateral) &, 000 &, 000 \\
\hline \multirow{2}{*}{ Relacion_Spn_3 } & Coeficiente de correlación &, 223 &,- 004 \\
\cline { 2 - 4 } & Sig. (bilateral) &, 000 &, 779 \\
\hline \multirow{2}{*}{ Perjuicio_Spn_3 } & Coeficiente de correlación &, 072 &,- 011 \\
\cline { 2 - 4 } & Sig. (bilateral) &, 000 &, 495 \\
\hline
\end{tabular}

Dónde:

Rol en el trabajo (Rol):

Responsa_Spn_3. Responsabilidad.

Relacion_Spn_3. Relaciones en el Trabajo.

Perjuicio_Spn_3.Perjuicio a la organización.

Valores Laborales Personales (VPSPN):

VPSpn_F1_3. Puesto de Trabajo Enriquecido "satisfactorio".

VPSpn_F2_3. Ocio y Familia - Ingresos y Estabilidad.

Interpretación de los resultados:

La mayoría de las correlaciones son positivas y estadísticamente significativas $(p<, 01)$, entre las variables que miden el rol en el trabajo y las variables que miden la importancia personal de los valores laborales con una fuerza de relación baja, $r<=.30$.

Valorar el puesto de trabajo enriquecido "satisfactorio", se correlaciona más con asumir responsabilidades y tener relaciones laborales. 
Existe una relación significativa y negativa entre la variable Responsa_Spn_3 (responsabilidad) y la variable VPSpn_F2_3 (ocio y familia - Ingresos y Estabilidad).

La variable VPSpn_F2_3 (Ocio y Familia - Ingresos y Estabilidad), no presenta relación con las variables del rol en el trabajo, Relacion_Spn_3 (Relaciones en el Trabajo) y Perjuicio_Spn_3 (Perjuicio a la organización).

Se puede afirmar que para los profesionales universitarios de España, los valores laborales personales están relacionados positivamente con el rol en el trabajo a través de la variable puesto de Trabajo enriquecido "satisfactorio". Por lo anterior, se encuentra evidencia que soporta H4a: El rol de los profesionales universitarios está relacionado con la importancia que dan a sus valores laborales.

Tabla 6. 45 Correlaciones bivariadas Rol_Valores Laborales en el Trabajo (VLTSPN) - H4b

\begin{tabular}{|c|c|c|c|c|}
\hline \multicolumn{2}{|c|}{ Rho de Spearman } & VLTSpn_F1_3 & VLTSpn_F2_3 & VLTSpn_F3_3 \\
\hline Responsa_Spn_3 & $\begin{array}{c}\text { Coeficiente } \\
\text { de } \\
\text { correlación }\end{array}$ &, 342 &, 070 &, 091 \\
\cline { 2 - 5 } & $\begin{array}{c}\text { Sig. } \\
\text { (bilateral) }\end{array}$ &, 000 &, 000 &, 000 \\
\hline Relacion_Spn_3 & $\begin{array}{c}\text { Coeficiente } \\
\text { de } \\
\text { correlación }\end{array}$ &, 323 &,- 016 &, 021 \\
\cline { 2 - 5 } & $\begin{array}{c}\text { Sig. } \\
\text { (bilateral) }\end{array}$ &, 000 &, 312 &, 171 \\
\hline Perjuicio_Spn_3 & $\begin{array}{c}\text { Coeficiente } \\
\text { de } \\
\text { correlación }\end{array}$ &, 105 &,- 085 &, 082 \\
\cline { 2 - 5 } & $\begin{array}{c}\text { Sig. } \\
\text { (bilateral) }\end{array}$ &, 000 &, 000 &, 000 \\
\hline
\end{tabular}

Dónde:

Rol en el trabajo (Rol):

Responsa_Spn_3. Responsabilidad.

Relacion_Spn_3. Relaciones en el Trabajo.

Perjuicio_Spn_3. Perjuicio a la organización.

Valores Laborales en el trabajo (VLTSPN):

VLTSpn_F1_3. Puesto de Trabajo Enriquecido "satisfactorio".

VLTSpn_F2_3. Ocio y Familia.

VLTSpn_F3_3. Ingresos y Estabilidad. 
Interpretación de los resultados:

La mayoría de las correlaciones son positivas y estadísticamente significativas $(p<, 01)$, entre las variables que miden el rol en el trabajo y las variables que miden el grado de aplicación de los valores laborales en el trabajo, con una fuerza de relación moderada $(r<=$ $.50)$ a débil $(r<=.10)$. Existe además, una relación significativa y contraria entre la variable Perjuicio_Spn_3 (Perjuicio a la organización) y la variable VLTSpn_F2_3 (ocio y familia). Las variables VLTSpn_F2_3 (Ocio y Familia), VLTSpn_F3_3 (Ingresos y Estabilidad) no presentan relación con la variable Relacion_Spn_3 (Relaciones en el Trabajo).

Se puede decir que para los profesionales universitarios de España el rol en el trabajo se relaciona positivamente en la medida en que aplican sus valores laborales en el trabajo, principalmente a través de un puesto de trabajo Enriquecido "satisfactorio". Por lo anterior, se encuentra evidencia que soporta $\mathrm{H} 4 \mathrm{~b}$ : El rol de los profesionales universitarios está relacionado con la importancia personal que dan a sus valores laborales en el trabajo. 
6.4.4.5 Relación entre Rol y Competencias - Hipótesis 5.

Tabla 6. 46 Correlaciones bivariadas Rol_Competencias Personales (CPSPN) - H5a

\begin{tabular}{|c|c|c|c|c|c|}
\hline \multicolumn{2}{|c|}{ Rho de Spearman } & CPSpn_F1_3 & CPSpn_F2_3 & CPSpn_F3_3 & CPSpn_F4_3 \\
\hline \multirow[t]{2}{*}{ Responsa_Spn_3 } & $\begin{array}{l}\text { Coeficiente } \\
\text { de } \\
\text { correlación }\end{array}$ & ,263 & ,002 & ,096 & ,032 \\
\hline & $\begin{array}{c}\text { Sig. } \\
\text { (bilateral) }\end{array}$ & ,000 & 907 & ,000 & ,045 \\
\hline \multirow[t]{2}{*}{ Relacion_Spn_3 } & $\begin{array}{l}\text { Coeficiente } \\
\text { de } \\
\text { correlación }\end{array}$ & 239 & 108 & 188 & 158 \\
\hline & $\begin{array}{c}\text { Sig. } \\
\text { (bilateral) }\end{array}$ & ,000 & ,000 & ,000 & ,000 \\
\hline \multirow[t]{2}{*}{ Perjuicio_Spn_3 } & $\begin{array}{l}\text { Coeficiente } \\
\text { de } \\
\text { correlación }\end{array}$ & 141 & ,006 & ,043 &,- 063 \\
\hline & $\begin{array}{c}\text { Sig. } \\
\text { (bilateral) }\end{array}$ & , 000 & 687 - - & ,007 - - & ,000 \\
\hline
\end{tabular}

Dónde:

Rol en el trabajo (Rol):

Responsa_Spn_3. Responsabilidad.

Relacion_Spn_3. Relaciones en el Trabajo.

Perjuicio_Spn_3. Perjuicio a la organización.

Competencias Personales (CPSPN):

CPSpn_F1_3. Competencias de Liderazgo y Comunicación.

CPSpn_F2_3. Competencias Organizativas.

CPSpn_F3_3. Competencias de Conocimiento y Pensamiento Metacognitivo.

CPSpn_F4_3. Competencias Instrumentales y de Innovación.

Interpretación de los resultados:

En general se presenta mayoría de relaciones positivas que son estadísticamente significativas $(p<, 01$ y $p<, 05)$, entre las variables que miden las competencias personales y las variables que miden el rol en el trabajo, con una fuerza de relación baja, $r<=.30$. 
Existe una correlación significativa y contraria entre la variable CPSpn_F4_3 (competencias instrumentales y de innovación) y la variable Perjuicio_Spn_3 (perjuicio a la organización).

La variable CPSpn_F2_3 (Competencias Organizativas) no presentan relación significativa con las variables de rol en el trabajo (responsabilidad y perjuicio a la organización).

Se puede decir que para los profesionales universitarios de España, el nivel de competencias personales favorece el rol en el trabajo. Por tanto se encuentra evidencia que soporta H5a: El rol de los profesionales universitarios en las organizaciones está relacionado las competencias personales.

Tabla 6. 47 Correlaciones bivariadas Rol_Competencias Requeridas (CRSPN) - H5b

\begin{tabular}{|l|c|c|c|c|}
\hline \multicolumn{2}{|c|}{ Rho de Spearman } & CRSpn_F1_3 & CRSpn_F2_3 & CRSpn_F3_3 \\
\hline Responsa_Spn_3 & $\begin{array}{c}\text { Coeficiente } \\
\text { de } \\
\text { correlación }\end{array}$ &, 292 &, 075 &, 182 \\
\cline { 2 - 5 } & $\begin{array}{c}\text { Sig. } \\
\text { (bilateral) }\end{array}$ &, 000 &, 000 &, 000 \\
\hline Relacion_Spn_3 & $\begin{array}{c}\text { Coeficiente } \\
\text { de } \\
\text { correlación }\end{array}$ &, 249 &, 242 &, 198 \\
\cline { 2 - 5 } & $\begin{array}{c}\text { Sig. } \\
\text { (bilateral) }\end{array}$ &, 000 &, 000 &, 000 \\
\hline Perjuicio_Spn_3 & $\begin{array}{c}\text { Coeficiente } \\
\text { de } \\
\text { correlación }\end{array}$ &, 115 &, 179 &,- 064 \\
\cline { 2 - 5 } & $\begin{array}{c}\text { Sig. } \\
\text { (bilateral) }\end{array}$ &, 000 &, 000 &, 000 \\
\hline
\end{tabular}

Dónde:

Rol en el trabajo (Rol):

Responsa_Spn_3. Responsabilidad.

Relacion_Spn_3. Relaciones en el Trabajo.

Perjuicio_Spn_3. Perjuicio a la organización. 
Competencias requeridas en el trabajo (CRSPN):

CRSpn_F1_3. Competencias Organizativas, Liderazgo e Innovación.

CRSpn_F2_3. Competencias de Conocimiento y Pensamiento Metacognitivo.

CRSpn_F3_3.Competencias Instrumentales y de Comunicación.

Interpretación de los resultados:

En general se presenta mayoría de correlaciones positivas que son estadísticamente significativas $(p<, 01)$, entre las variables que miden las competencias requeridas en el trabajo y las variables que miden el rol en el trabajo, con una fuerza de relación baja $(r<=.30)$.

La variable CRSpn_F3_3 (Competencias Instrumentales y de Comunicación), presenta una débil relación significativa y contraria con la variable Perjuicio_E_1 (perjuicio a la organización).

Se puede decir que para los profesionales universitarios de España, el nivel de competencias requeridas en el trabajo afecta positivamente la percepción que tienen sobre el rol en el trabajo principalmente a través de las variables de responsabilidad y relaciones en el trabajo. Por tanto se encuentra evidencia que soporta H5b: El rol de los profesionales universitarios en las organizaciones está relacionado con el nivel de competencias requerido en el trabajo. 
6.4.4.6 Relación entre Competencias y Valores - Hipótesis 6.

Tabla 6. 48 Correlaciones bivariadas Competencias Requeridas (CRSPN)_Valores Laborales en el Trabajo (VLTSPN) - H6

\begin{tabular}{|c|c|c|c|c|}
\hline \multicolumn{2}{|c|}{ Rho de Spearman } & VLTSpn_F1_3 & VLTSpn_F2_3 & VLTSpn_F3_3 \\
\hline \multirow[t]{2}{*}{ CRSpn_F1_3 } & $\begin{array}{l}\text { Coeficiente } \\
\text { de } \\
\text { correlación }\end{array}$ & , 290 & ,003 & ,070 \\
\hline & $\begin{array}{c}\text { Sig. } \\
\text { (bilateral) }\end{array}$ & ,000 & ,843 & ,000 \\
\hline \multirow[t]{2}{*}{ CRSpn_F2_3 } & $\begin{array}{c}\text { Coeficiente } \\
\text { de } \\
\text { correlación }\end{array}$ & ,313 &,- 141 & ,091 \\
\hline & $\begin{array}{c}\text { Sig. } \\
\text { (bilateral) }\end{array}$ & ,000 & ,000 & ,000 \\
\hline \multirow[t]{2}{*}{ CRSpn_F3_3 } & $\begin{array}{c}\text { Coeficiente } \\
\text { de } \\
\text { correlación }\end{array}$ & ,321 &,- 006 & ,035 \\
\hline & $\begin{array}{c}\text { Sig. } \\
\text { (bilateral) }\end{array}$ & ,000 & ,712 & ,028 \\
\hline
\end{tabular}

Dónde:

Competencias requeridas en el trabajo (CRSPN):

CRSpn_F1_3. Competencias Organizativas, Liderazgo e Innovación.

CRSpn_F2_3. Competencias de Conocimiento y Pensamiento Metacognitivo.

CRSpn_F3_3. Competencias Instrumentales y de Comunicación.

Valores Laborales en el trabajo (VLTSPN):

VLTSpn_F1_3. Puesto de Trabajo Enriquecido "satisfactorio".

VLTSpn_F2_3. Ocio y Familia.

VLTSpn_F3_3. Ingresos y Estabilidad. 
Interpretación de los resultados:

Se presentan relaciones en su mayoría positivas y estadísticamente significativas $(p<, 01$ y $p<, 05)$, entre algunas de las variables que miden las competencias requeridas en el trabajo y las variables que miden los valores laborales en el trabajo, con una fuerza de relación moderada $(r<=.50)$ tendiendo a débil $(r<=.30)$.

La variable VLTSpn_F2_3 (Ocio y Familia), no presenta relación con la variable CRSpn_F1_3(Competencias Organizativas, Liderazgo e Innovación) y con la variable CRSpn_F3_3 (Competencias Instrumentales y de Comunicación).

La variable VLTSpn_F2_3 (Ocio y Familia) presenta correlación significativa y negativa con la variable CRSpn_F2_3 (Competencias de Conocimiento y Pensamiento Metacognitivo).

Se puede decir que para los profesionales universitarios de España, el nivel de competencias requerido en el trabajo, favorece la percepción que tienen acerca del grado de aplicación de los valores laborales en el trabajo principalmente a través de un puesto de trabajo enriquecido "satisfactorio".

Se encuentra evidencia que soporta H6: Los valores laborales de los profesionales universitarios en el trabajo están relacionados con las competencias requeridas por la organización.

\subsubsection{Comparativa de la evaluación de las hipótesis por área geográfica}

La hipótesis sobre la que se ha desarrollado la investigación es la siguiente:

La existencia de relación entre los valores laborales, las competencias y el rol desempeñado, en conjunto favorecen el éxito de los profesionales universitarios en las organizaciones donde ejercen su actividad.

Como se expuso en el capítulo 3, la hipótesis general está formada por 6 hipótesis específicas, para dar respuesta a un mismo problema. En la tabla 6.49 se presenta la comparativa de las hipótesis planteadas para cada una de las áreas geográficas de estudio; Europa, Latinoamérica y España. De forma resumida se comentan aquellos factores que al ser analizados marcaron diferencias en la evaluación y comparación de cada una de las hipótesis. 
Como resultado de la evaluación global, las hipótesis: H1b, H1c, H2a, H3, H4a, H4b, H5a, H5b y H6a se aceptan para Europa, Latinoamérica y España. La hipótesis H1a en España, la hipótesis H2b en Europa y la hipótesis H2c en Latinoamérica, se aceptan de forma parcial, en el sentido que una parte de los factores analizados no presentaron relación significativa.

La hipótesis H1a se acepta parcialmente en España. Para los graduados universitarios españoles, el éxito laboral subjetivo (uso de conocimientos y satisfacción con el trabajo) esta positiva y significativamente correlacionado con la importancia personal que dan a los valores laborales a través de un puesto de trabajo enriquecido "satisfactorio".

No se aprecia relación entre el éxito laboral objetivo, (remuneración) y los valores laborales personales de los graduados universitarios españoles. Los resultados no mostraron relación entre el éxito laboral subjetivo y los valores laborales tiempo para el ocio y la familia, tener ingresos elevados y estabilidad.

La hipótesis H2b se acepta parcialmente en Europa. En el conjunto de los graduados universitarios europeos, el éxito laboral objetivo subjetivo (uso de conocimientos y satisfacción con el trabajo) esta correlacionado de forma positiva y significativa con el nivel de competencias requerido en el trabajo. Sin embargo, no mostraron tener relación significativa con el éxito laboral objetivo (remuneración).

La hipótesis H2c se acepta parcialmente en Latinoamérica. Para los graduados universitarios el aumento de la sobre cualificación implica una reducción en la percepción de éxito laboral (objetivo y subjetivo según el caso).

Los resultados de las pruebas no muestran relación entre éxito laboral objetivo y el ajuste de las competencias de conocimiento y pensamiento metacognitivo, competencias instrumentales y de comunicación. Tampoco se evidencia relación entre el éxito laboral subjetivo y el ajuste de competencias organizativas, de liderazgo y de innovación.

En el conjunto del global de la Hipótesis general, se puede concluir que evidentemente existen relaciones asociadas al rol en el trabajo, las competencias y los valores laborales de los graduados universitarios que apoyan la percepción que ellos tiene del éxito laboral evaluado desde las dimensiones objetiva y subjetiva. 
Tabla 6. 49 Comparativa de la Evaluación de las Hipótesis por Área Geográfica

\begin{tabular}{|c|c|c|c|c|c|c|c|c|}
\hline \multirow{2}{*}{$\begin{array}{c}\text { Hipótesis } \\
\text { № }\end{array}$} & \multirow{2}{*}{$\begin{array}{l}\text { Hipótesis } \\
\text { Específica }\end{array}$} & \multirow{2}{*}{ Enunciado Hipótesis } & EUROPA & LATINOAMÉRICA & ESPAÑA & EUROPA & LATINOAMERICA & ESPAÑA \\
\hline & & & Acepta/Rechazo & Acepta/Rechazo & Acepta/Rechazo & Comentarios & Comentarios & Comentarios \\
\hline \multirow{3}{*}{ H1 } & $\mathrm{H} 1 \mathrm{a}$ & $\begin{array}{l}\text { El éxito laboral está condicionado } \\
\text { por la percepción que se tiene de } \\
\text { los valores laborales personales. }\end{array}$ & Acepta & Acepta & $\begin{array}{l}\text { Aceptación } \\
\text { parcial }\end{array}$ & $\begin{array}{l}\text { El éxito laboral objetivo asociado a los } \\
\text { ingresos, está negativamente } \\
\text { correlacionado con tener tiempo para } \\
\text { dedicar al ocio, la familia y el servicio a la } \\
\text { sociedad. }\end{array}$ & $\begin{array}{l}\text { El éxito laboral objetivo asociado a los } \\
\text { ingresos, está negativamente } \\
\text { correlacionado con tener tiempo para } \\
\text { dedicar al ocio, la familia y el servicio a } \\
\text { la sociedad. }\end{array}$ & $\begin{array}{l}\text { Los valores puesto de trabajo } \\
\text { enriquecido, ocio y familia, ingresos y } \\
\text { estabilidad no presentan relación con } \\
\text { las variables de éxito laboral } \\
\text { objetivo. Los valores ocio y familia, } \\
\text { ingresos y estabilidad no presentan } \\
\text { relación con el éxito laboral } \\
\text { subjetivo. }\end{array}$ \\
\hline & $\mathrm{H} 1 \mathrm{~b}$ & $\begin{array}{l}\text { El éxito laboral está condicionado } \\
\text { por el grado de aplicación de los } \\
\text { valores laborales en el trabajo. }\end{array}$ & Acepta & Acepta & Acepta & $\begin{array}{l}\text { El éxito laboral objetivo asociado a los } \\
\text { ingresos, está negativamente } \\
\text { correlacionado con tener tiempo para } \\
\text { dedicar al ocio, la familia. }\end{array}$ & $\begin{array}{l}\text { El éxito laboral objetivo asociado a los } \\
\text { ingresos, está negativamente } \\
\text { correlacionado con tener tiempo para } \\
\text { dedicar al ocio, la familia. }\end{array}$ & $\begin{array}{l}\text { El éxito laboral objetivo, está } \\
\text { positivamente correlacionado con } \\
\text { tener un puesto de trabajo } \\
\text { enriquecido "satisfactorio", ingresos } \\
\text { elevados y estabilidad, sin embargo } \\
\text { tener tiempo para el ocio y la familia } \\
\text { está negativamente correlacionado. }\end{array}$ \\
\hline & $\mathrm{H} 1 \mathrm{c}$ & $\begin{array}{c}\text { El éxito laboral está relacionado } \\
\text { con el ajuste entre los valores } \\
\text { laborales personales y los valores } \\
\text { laborales en el trabajo. }\end{array}$ & Acepta & Acepta & Acepta & $\begin{array}{l}\text { El éxito laboral esta positivamente } \\
\text { correlacionado con el ajuste de los } \\
\text { valores laborales en el trabajo. }\end{array}$ & $\begin{array}{l}\text { El éxito laboral objetivo asociado a los } \\
\text { ingresos, está negativamente } \\
\text { correlacionado con dedicar tiempo al } \\
\text { ocio, la familia y servicio a la sociedad. }\end{array}$ & $\begin{array}{l}\text { El éxito laboral objetivo y subjetivo } \\
\text { se relacionan de forma positiva y } \\
\text { significativa a través del ajuste de los } \\
\text { valores laborales en el trabajo. el } \\
\text { valor laboral tener tiempo para el } \\
\text { ocio y familia no presenta relación } \\
\text { con el éxito laboral objetivo. }\end{array}$ \\
\hline \multirow{3}{*}{ H2 } & $\mathrm{H} 2 \mathrm{a}$ & $\begin{array}{c}\text { El éxito laboral de los } \\
\text { profesionales universitarios se ve } \\
\text { favorecido por sus competencias } \\
\text { personales. }\end{array}$ & Acepta & Acepta & Acepta & $\begin{array}{l}\text { Las competencias organizativas no tienen } \\
\text { relación significativa con el éxito laboral } \\
\text { objetivo. }\end{array}$ & $\begin{array}{l}\text { Las competencias personales } \\
\text { correlacionan de forma positiva y } \\
\text { significativa con el éxito laboral. }\end{array}$ & $\begin{array}{l}\text { Las competencias organizativas estan } \\
\text { correlacionadas de forma negativa y } \\
\text { significativa con el éxito laboral } \\
\text { objetivo. }\end{array}$ \\
\hline & $\mathrm{H} 2 \mathrm{~b}$ & $\begin{array}{c}\text { El éxito laboral de los } \\
\text { profesionales universitarios tiene } \\
\text { relación con el nivel de } \\
\text { competencias requeridas en el } \\
\text { trabajo. }\end{array}$ & Aceptación parcial & Acepta & Acepta & $\begin{array}{l}\text { Las competencias requeridas no son } \\
\text { significativas con el éxito laboral } \\
\text { objetivo. La correlación entre éxito } \\
\text { laboral subjetivo y las competencias es } \\
\text { significativa. }\end{array}$ & $\begin{array}{l}\text { El éxito laboral se correlaciona positiva } \\
\text { y significativamente con las } \\
\text { competencias requeridas. }\end{array}$ & $\begin{array}{l}\text { el éxito Laboral se relaciona } \\
\text { positivamente con las competencias } \\
\text { requeridas en el puesto de trabajo. }\end{array}$ \\
\hline & $\mathrm{H} 2 \mathrm{C}$ & $\begin{array}{c}\text { El éxito laboral se ve favorecido } \\
\text { por el ajuste entre las } \\
\text { competencias propias y las } \\
\text { requeridas por las organizaciones. }\end{array}$ & Acepta & $\begin{array}{l}\text { Aceptación } \\
\text { parcial }\end{array}$ & Acepta & $\begin{array}{l}\text { El aumento de la sobrecualificación } \\
\text { implica la reducción en la percepción de } \\
\text { éxito (objetivo y subjetivo, según el } \\
\text { caso). }\end{array}$ & $\begin{array}{l}\text { El éxito laboral objetivo no tiene } \\
\text { relación significativa con las } \\
\text { competencias de conocimiento y } \\
\text { pensamiento metacognitivo, las } \\
\text { competencias instrumentales y de } \\
\text { comunicación. El éxito laboral subjetivo } \\
\text { no tiene relación significativa con las } \\
\text { competencias organizativas, de } \\
\text { liderazgo y de comunicación. }\end{array}$ & $\begin{array}{l}\text { Las variables de ajuste de } \\
\text { competencias tienen correlación } \\
\text { negativa y significativa con las } \\
\text { variables de éxito laboral. Estar } \\
\text { sobrecualificado en competencias } \\
\text { reduce la percepción de éxito } \\
\text { objetivo y éxito subjetivo. }\end{array}$ \\
\hline
\end{tabular}


Tabla 6.49 Comparativa de la Evaluación de las Hipótesis por Área Geográfica

\begin{tabular}{|c|c|c|c|c|c|c|c|c|}
\hline \multirow{2}{*}{\begin{tabular}{|c|}
$\begin{array}{c}\text { Hipótesis } \\
\text { № }\end{array}$ \\
\end{tabular}} & \multirow{2}{*}{$\begin{array}{l}\text { Hipótesis } \\
\text { Especifica }\end{array}$} & \multirow{2}{*}{ Enunciado Hipótesis } & \multirow{2}{*}{$\begin{array}{c}\text { EUROPA } \\
\text { Acepta/Rechazo } \\
\end{array}$} & \multirow{2}{*}{\begin{tabular}{|l|} 
LATINOAMÉRICA \\
Acepta/Rechazo \\
\end{tabular}} & \multirow{2}{*}{\begin{tabular}{|c|} 
ESPAÑA \\
Acepta/Rechazo
\end{tabular}} & \multirow{2}{*}{$\begin{array}{l}\text { EUROPA } \\
\text { Comentarios }\end{array}$} & \multirow{2}{*}{$\begin{array}{l}\text { LATINOAMERICA } \\
\text { Comentarios }\end{array}$} & \multirow{2}{*}{$\begin{array}{l}\text { ESPAÑA } \\
\text { Comentarios }\end{array}$} \\
\hline & & & & & & & & \\
\hline н3 & H3 & $\begin{array}{l}\text { La satisfacción laboral está } \\
\text { relacionada con el rol que se } \\
\text { desempeña dentro de las } \\
\text { organizaciones. }\end{array}$ & Acepta & Acepta & Acepta & $\begin{array}{l}\text { El rol en el trabajo (responsabilidad y } \\
\text { relaciones en el trabajo) correlacionan } \\
\text { positivamente con el éxito laboral } \\
\text { subjetivo (satisfacción en el trabajo y uso } \\
\text { de conocimientos). }\end{array}$ & $\begin{array}{l}\text { El rol en el trabajo (relaciones en el } \\
\text { trabajo, responsabilidad con la } \\
\text { organización y autonomía en el puesto } \\
\text { de trabajo) correlaciona positivamente } \\
\text { con el éxito laboral subjetivo } \\
\text { (satisfacción con el trabajo y uso de } \\
\text { conocimientos). }\end{array}$ & $\begin{array}{l}\text { El rol en el trabajo (responsabilidad, } \\
\text { relaciones en el trabajo y perjuicio) } \\
\text { correlacionan positivamente con el } \\
\text { éxito laboral subjetivo (satisfacción } \\
\text { en el trabajo y uso de } \\
\text { conocimientos). }\end{array}$ \\
\hline \multirow{2}{*}{ H4 } & $\mathrm{H} 4 \mathrm{a}$ & $\begin{array}{l}\text { El rol de está relacionado con la } \\
\text { importancia que se da a los } \\
\text { valores laborales personales. }\end{array}$ & Acepta & Acepta & Acepta & $\begin{array}{l}\text { El rol en el trabajo a través de la variable } \\
\text { responsabilidad no presenta relación con } \\
\text { los valores personales de ocio, familia y } \\
\text { servicio a la sociedad. }\end{array}$ & $\begin{array}{l}\text { El rol en el trabajo a través de la variable } \\
\text { autonomia/responsabilidad en el } \\
\text { puesto de trabajo no presenta relación } \\
\text { con los valores laborales personales } \\
\text { ocio, familia y servicio a la sociedad. }\end{array}$ & $\begin{array}{l}\text { El rol en el trabajo a través de las } \\
\text { variables relación y perjuicio no } \\
\text { presenta relación con los valores } \\
\text { laborales personales de ocio y } \\
\text { familia, ingresos y estabilidad. }\end{array}$ \\
\hline & H4b & $\begin{array}{c}\text { El rol está relacionado con la } \\
\text { importancia personal que se da a } \\
\text { los valores laborales en el } \\
\text { trabajo. }\end{array}$ & Acepta & Acepta & Acepta & $\begin{array}{l}\text { El rol en el trabajo a través de la variable } \\
\text { perjuicio no presenta relación con el } \\
\text { valor laboral, tener un puesto de trabajo } \\
\text { enriquecido "satisfactorio". }\end{array}$ & $\begin{array}{l}\text { El rol (relaciones en el trabajo, } \\
\text { responsabilidad con la organización y } \\
\text { autonomía) tiene una relación positiva y } \\
\text { significativa con los valores laborales en } \\
\text { el trabajo. }\end{array}$ & $\begin{array}{l}\text { El rol en el trabajo a través de la } \\
\text { variable relacionenen en el trabajo no } \\
\text { presenta relación con los valores } \\
\text { laborales en el trabajo ocio y familia, } \\
\text { ingresos y estabilidad. }\end{array}$ \\
\hline \multirow[b]{2}{*}{ H5 } & H5a & $\begin{array}{c}\text { El rol en el trabajo esta } \\
\text { relacionado con las competencias } \\
\text { personales. }\end{array}$ & Acepta & Acepta & Acepta & $\begin{array}{l}\text { El rol en el trabajo (responsabilidad y } \\
\text { perjuicio a la organización) no presenta } \\
\text { relación con las competencias personales } \\
\text { (competencias instrumentales y de } \\
\text { innovación, competencias de } \\
\text { conocimiento y pensamiento } \\
\text { metacognitivo). }\end{array}$ & $\begin{array}{l}\text { El rol en el trabajo a través de la variable } \\
\text { responsabilidad con la organización no } \\
\text { presenta relación con las competencias } \\
\text { personales a través de las competencias } \\
\text { de comunicación. }\end{array}$ & $\begin{array}{l}\text { el rol en el trabajo a través de las } \\
\text { variables de responsabilidady } \\
\text { perjuicio a la organización no } \\
\text { presenta relación significativa con las } \\
\text { competencias personales a través de } \\
\text { las competencias organizativas. }\end{array}$ \\
\hline & H5b & $\begin{array}{c}\text { El rol en el trabajo está } \\
\text { relacionado con las competencias } \\
\text { requeridas }\end{array}$ & Acepta & Acepta & Acepta & $\begin{array}{l}\text { El rol en el trabajo (responsabilidad y } \\
\text { relaciones en el trabajo) correlaciona de } \\
\text { forma positiva y significativa con las } \\
\text { competencias requeridas. El rol a través } \\
\text { de la variable perjuicio presenta } \\
\text { correlación muy débil y negativa con las } \\
\text { competencias de innovación, } \\
\text { instrumentales y de comunicación. }\end{array}$ & $\begin{array}{l}\text { El rol en el trabajo se correlaciona } \\
\text { positiva y significativamente con las } \\
\text { competencias requeridas en el trabajo. }\end{array}$ & $\begin{array}{l}\text { El rol en el trabajo a través de la } \\
\text { variable perjuicio a la organización } \\
\text { presenta una débil correlación } \\
\text { negativa y significativa con las } \\
\text { competencias instrumentales y de } \\
\text { comunicación. }\end{array}$ \\
\hline H6 & H6 & $\begin{array}{c}\text { Los valores laborales en el trabajo } \\
\text { están relacionados con las } \\
\text { competencias requeridas. }\end{array}$ & Acepta & Acepta & Acepta & $\begin{array}{l}\text { El valor laboral en el trabajo ocio y } \\
\text { familia presenta una correlación debil y } \\
\text { negativa con las competencias } \\
\text { requeridas (innovación, instrumentales, } \\
\text { comunicación, conocimiento y } \\
\text { organizativas). }\end{array}$ & $\begin{array}{l}\text { El valor laboral en el trabajo ocio y } \\
\text { familia no presenta relación con con las } \\
\text { competencias requeridas } \\
\text { (instrumentales, conocimiento y } \\
\text { comunicación). }\end{array}$ & $\begin{array}{l}\text { El valor laboral en el trabajo ocio y } \\
\text { familia, no presenta relación con las } \\
\text { competencias requeridas } \\
\text { (organizativas, liderazgo e } \\
\text { innovación, instrumentales y de } \\
\text { comunicación). }\end{array}$ \\
\hline
\end{tabular}





\section{CAPITULO 7}

\section{Conclusiones y Líneas Futuras de Investigación}

Este último capítulo presenta las conclusiones obtenidas de acuerdo con los objetivos de la investigación, así como un sumario de los resultados obtenidos. También se señalan las limitaciones de la investigación y se proponen futuras líneas de investigación.

\subsection{Sumario}

En esta investigación se han analizado las relaciones entre el rol en el trabajo, las competencias y los valores laborales, con el éxito laboral de los graduados universitarios de Europa, Latinoamérica y España. El estudio se realizó a partir de la base de datos de 48,094 graduados universitarios de catorce países de Europa y diez de Latinoamérica, obtenidas a partir de los proyectos internacionales REFLEX en Europa y PROFLEX en Latinoamérica. Se han considerado aquellos individuos que ocupaban un puesto de trabajo en una organización cinco años después de su graduación.

Para construir el marco teórico planteado en esta tesis doctoral, se dedicó un apartado a las teorías de gestión y su evolución en el tiempo. Una síntesis que, en el marco de esta investigación, ayuda a entender su influencia histórica en el papel del recurso humano dentro de las organizaciones. Aunque éstas se han adaptado para satisfacer las nuevas necesidades actuales, existen prácticas que provienen del pasado y que siguen teniendo vigencia y aplicación en las organizaciones de hoy en día. El acelerado desarrollo tecnológico ha llevado a los trabajadores y a las organizaciones a tratar con aspectos intangibles como las ideas y la información, influyendo sobre la gestión, el funcionamiento y las relaciones de las organizaciones y empresas con el entorno.

Las investigaciones orientadas al análisis del éxito laboral de los profesionales se han centrado en aquellos factores explicativos que hacen que los profesionales se sientan exitosos con su trabajo, como lo exponen Arthur, Khapova y Wilderom (2005) basados en la teoría de la profesión y después de analizar diversos trabajos relacionados. Los hallazgos mostraron tres 
grupos de factores. Los factores objetivos de la carrera (ingresos, ascensos, nivel jerárquico), la carrera subjetiva (satisfacción laboral, satisfacción con la vida, desarrollo, compromiso ocupacional) y un tercer factor que considera una interacción entre los dos anteriores.

La dinámica del ámbito laboral actual, hace más difícil alcanzar el éxito profesional tal como se ha entendido tradicionalmente, ingresos altos y buena promoción (Sturges, 1999). Los esfuerzos que hacen las empresas por identificar factores personales y laborales que influyen en la obtención del éxito profesional (Boudreau, Boswell y Judge, 2001) y los proyectos internacionales que han estudiado la experiencia académica y laboral de graduados universitarios, nos llevó a platearnos una revisión de aquellos factores que pudieran influir en el logro del éxito profesional en las organizaciones a través del rol en el trabajo, las competencias y los valores laborales.

A partir del marco teórico y la revisión de la literatura se desarrolló y se cumplió con el primer objetivo de la investigación, el cual apuntaba a plantear definiciones de trabajo sobre el rol, las competencias, los valores laborales y el éxito laboral en sus dos dimensiones: el éxito laboral objetivo y el éxito laboral subjetivo.

El segundo objetivo de la investigación fue plantear un modelo teórico a partir de la definición de seis hipótesis específicas de investigación. Para ello se planteó la existencia de relaciones entre los valores laborales, las competencias y el rol desempeñado en el trabajo, con el éxito laboral de los profesionales universitarios en las organizaciones donde ejercían su actividad.

A partir de lo anterior se trató de demostrar si el rol, las competencias y los valores laborales contribuían al éxito laboral de los profesionales universitarios. Para esto se analizó la influencia de cada una de estas variables sobre un constructo de éxito laboral formado a través de las variables sueldo, uso de conocimientos, habilidades y la satisfacción en el trabajo.

En las encuestas utilizadas se propone a los graduados que evalúen su situación laboral, la organización donde trabajan, el nivel de competencias propio y requerido en el trabajo, la importancia de ciertas características del trabajo (valores laborales) y la medida que estas se aplican en su situación laboral.

El tercer objetivo de este estudio consistió en identificar las características de los puestos de trabajo que ocupan los profesionales universitarios en las organizaciones y las funciones que desempeñan. Para ello se decidió realizar un amplio análisis descriptivo general y una comparación por área geográfica, cinco países de Europa y tres de Latinoamérica. Para 
las conclusiones que se presentarán a continuación, se tuvo en consideración que los graduados universitarios proceden de países con diferentes estructuras económicas y sociales, además de tener diferencias profundamente arraigadas entre los sistemas nacionales de educación superior:

- $\quad$ Se puede decir que los graduados de educación superior en la mayoría de los países europeos están bien posicionados dentro del mercado laboral, aunque es mayor esa proporción en los latinoamericanos, ocupando cargos relacionados con sus áreas de estudio. Solo una pequeña proporción de los graduados de Europa $(8,5 \%)$ y Latinoamérica $(14,1 \%)$, alcanzan una posición directiva tras cinco años desde la graduación. En todo caso, a la mayoría les es requerida una formación de nivel superior general o especializada. Por otra parte, hay países y campos de estudio donde a los graduados universitarios les resulta especialmente difícil encontrar una buena posición.

- $\quad$ El porcentaje de graduados con contrato permanente es ligeramente superior en Europa $(77,09 \%)$ que en Latinoamérica $(73,06 \%)$. Existen diferencias entre cada uno de los países analizados, pero destaca la situación de los españoles que supera la media de Europa (20,53\%) en contrataciones de duración limitada (31,3\%).

- La mayoría de los graduados de ambos continentes manifestaron trabajar principalmente en el sector de servicios, educación, salud y la industria. El 49,7\% de los graduados europeos trabajan en el sector privado y en organizaciones grandes el $33,9 \%$. La mayoría de los graduados de Latinoamérica $(62,9 \%)$ trabajan en el sector privado y el $26,9 \%$ trabajan en empresas grandes. La participación de los europeos en el sector público es mayor que la de los latinoamericanos.

- Los resultados indican que los latinoamericanos emplean más horas trabajando a la semana que los europeos.

- Los salarios más elevados corresponden a los graduados europeos y de estos, los más bajos son los salarios de los españoles, mientras que los chilenos manifestaron tener los mayores ingresos en Latinoamérica.

- Los latinoamericanos afirman hacer mucho uso de sus conocimientos y habilidades, mientras que los graduados europeos afirman hacer menos uso de los mismos. Del otro lado, el conjunto de los graduados consideran que el nivel de requerimiento de conocimientos y habilidades es más bajo del que ellos pueden ofrecer en su trabajo. siendo esta percepción mayor en los graduados de Europa. 
- La percepción de responsabilidad para establecer objetivos y decisiones sobre el propio trabajo es alta entre los graduados de ambos continentes. Para los europeos la responsabilidad de establecer objetivos y decidir estrategias para la organización es menor frente a la percepción que tienen los graduados de Latinoamérica.

- Un alto porcentaje de los graduados europeos y latinoamericanos establecen frecuentes contactos y relaciones con otros compañeros de trabajo, tanto dentro como fuera de la organización. Las respuestas son similares en ambos continentes. También la importancia de la ética en el trabajo es similar para ambos grupos o ligeramente mayor para los graduados de Latinoamérica.

- Los graduados de ambos continentes valoraron tener un nivel medio-alto de sus competencias personales. Existe un desajuste entre competencias personales y requeridas: Hay una serie de competencias en las que el nivel de los profesionales es superior a lo requerido, y otras competencias en las que ocurre lo contrario, siendo menor el nivel personal que el requerido.

Es interesante comprobar que las percepciones de los graduados sobre sus competencias es muy similar independientemente del país.

- En el conjunto de los graduados, los resultados muestran que las competencias requeridas en el puesto de trabajo son principalmente: La capacidad para usar el tiempo de forma efectiva, capacidad de hacerse entender y la capacidad para trabajar bajo presión. Las menos requeridas son la capacidad para escribir y hablar en idiomas extranjeros y el conocimiento de otras áreas o disciplinas.

- Para los graduados universitarios de Europa y Latinoamérica existen diferencias entre la importancia que ellos le dan a determinadas características del trabajo y lo que perciben en los puestos de trabajo (ajuste valores laborales). La mayoría coinciden en que no se les concede la importancia que para ellos tienen. Las características que tienen más adecuación en cuanto a importancia son: el reconocimiento y prestigio social, autonomía en el trabajo y la oportunidad de hacer algo útil a la sociedad. Las características con menor adecuación en cuanto a importancia son, la facilidad para combinar trabajo y familia y los ingresos elevados.

- Finalmente, en el conjunto de los graduados universitarios de Europa y Latinoamérica los resultados muestran que los latinoamericanos son los más satisfechos con sus trabajos, seguidos de los suizos y alemanes. 
Para la validación del modelo, se realizaron tres análisis paralelos teniendo como objeto de estudio los graduados universitarios de Europa, los graduados universitarios de Latinoamérica y los graduados universitarios de España.

La aplicación del análisis de componentes principales permitió reducir el conjunto inicial de nueve indicadores de rol a cuatro dimensiones agrupadas de forma diferente en cada una de las tres áreas geográficas estudiadas: Responsabilidad, Relaciones en el trabajo, Perjuicio, Autonomía.

Sobre las competencias se realizaron tres análisis idénticos para reducir diecinueve indicadores sobre competencias personales, 19 sobre competencias requeridas y 19 sobre el ajuste de competencias. Para definir la dimensión de competencias en este trabajo se tomó como referencia, la agrupación de competencias de Conchado (2011). Los resultados de los análisis de componentes principales muestran que es posible distinguir siete dimensiones en el análisis factorial exploratorio correspondiente: Competencias de Conocimiento, Pensamiento Metacognitivo, Organizativas, Instrumentales, Comunicación, Innovación y Liderazgo. Su relevancia y ordenación varía según la región geográfica.

Del mismo modo se han identificado cinco dimensiones principales para el conjunto de diez indicadores de valores laborales personales, diez de valores laborales en el trabajo y diez de ajuste de los valores laborales: Puesto de trabajo enriquecido -"satisfactorio", Ingresos, Estabilidad y reconocimiento, Ocio y familia, Servicio a la sociedad.

A partir del análisis de correlación bivariado, se realizó una aproximación a la contrastación de las hipótesis planteadas en el modelo. El resultado obtenido muestra que las relaciones bivariadas correlacionan en su mayoría de forma positiva, lo que probó la existencia de evidencia estadística para apoyar las hipótesis. Posteriormente se hizo una comparación de los tres modelos resultantes para Europa, Latinoamérica y España.

De estos hallazgos se puede afirmar que el rol en el trabajo, las competencias y los valores laborales, tienen una correlación positiva y significativa con el éxito laboral a través de sus dos factores, éxito laboral objetivo y éxito laboral subjetivo.

Hay que precisar algunas diferencias que se observan en algunas relaciones en las tres muestras:

- Para los europeos y latinoamericanos, el éxito laboral objetivo asociado a los ingresos esta correlacionado de forma negativa y significativa con tener 
tiempo para dedicar al ocio, la familia y el servicio a sociedad. En el caso de los españoles solo existe correlación positiva y significativa entre el éxito laboral subjetivo y los valores laborales personales asociados a tener un trabajo enriquecido "satisfactorio". El éxito laboral objetivo no tiene relación con los valores laborales personales.

- El estudio de la relación entre el éxito laboral y las competencias personales, muestran que para los graduados europeos no existe correlación entre el éxito laboral objetivo y las competencias organizativas, mientras que para los españoles existe una relación que es negativa y significativa. Para los graduados de Latinoamérica la correlación es positiva y significativa entre las competencias personales y el éxito laboral en sus dos dimensiones.

- Para los graduados europeos, no existe correlación significativa entre las competencias requeridas en el trabajo y el éxito laboral objetivo. La correlación es positiva y significativa para los latinoamericanos y los españoles.

- Al analizar la correlación entre el éxito laboral objetivo y el ajuste de competencias propias y las requeridas en el trabajo, se obtuvieron correlaciones significativas y positivas, que muestran que el ajuste de competencias afecta positivamente la percepción que se tiene del éxito laboral objetivo representado en la remuneración. El análisis del éxito laboral subjetivo y el ajuste de competencias muestra que un aumento de la sobrecualificación reduce la percepción del éxito laboral subjetivo representado en el uso de los conocimientos y la satisfacción con el trabajo. Además de lo anterior, para los graduados latinoamericanos, no hay correlación significativa entre algunas variables del ajuste de competencias y el éxito laboral.

- Para los graduados universitarios de Europa, Latinoamérica y España, el éxito laboral subjetivo medido a través de las variables de satisfacción en el trabajo y el uso de conocimientos y habilidades, correlacionan de forma positiva y significativa a través de las variables de responsabilidad con la organización, responsabilidad en el puesto de trabajo, y las relaciones en el trabajo.

\subsection{Conclusiones finales}

El modelo empírico que se ha analizado en esta investigación se apoya en las teorías e investigaciones recientes del éxito laboral y considera la situación de las organizaciones que actúan desde cada uno de sus ámbitos en un entorno global y dinámico. 
Desde este enfoque y de los resultados obtenidos a partir del estudio empírico de la experiencia laboral de titulados de la educación superior de veinticuatro países, existen evidencias para afirmar que el éxito laboral objetivo y el éxito laboral subjetivo están relacionados y que su análisis conjunto con el rol en el puesto de trabajo, las competencias personales y requeridas, y los valores laborales, amplía la visión del éxito laboral.

Los resultados obtenidos muestran similitudes en las percepciones que tienen los profesionales universitarios acerca de su experiencia laboral a pesar de las diferencias esperadas ya sea por el país de procedencia, la conformación de cada mercado laboral, la cultura y las normas que rigen el funcionamiento de las organizaciones en las que se desempeñan. Los indicadores evaluados muestran aspectos objetivos y subjetivos que son muy importantes para ellos en su trabajo.

Se puede afirmar que los titulados universitarios de Europa y Latinoamérica, desempeñan su rol profesional y que están bien posicionados en el mercado laboral de cada uno de sus países. Para ambos grupos las posiciones que ocupan son muy similares, matizadas por algunas diferencias que resultan interesantes. Los graduados de Latinoamérica no solo tienen mayor probabilidad de ocupar cargos ejecutivos (directivos), sino también de oficinista y otras posiciones de bajo nivel. Las diferencias en las características socioeconómicas de los graduados en ambos continentes, probablemente puede explicar este hecho.

El nivel de correspondencia entre el área de estudio de los graduados y el área de conocimientos requeridos por la organización tienen una distribución similar, con pequeñas diferencias. Una mayoría muy importante de más del $85 \%$ considera que en su trabajo realiza funciones propias de su área de conocimiento o uno relacionado.

Al comparar a los titulados universitarios de Europa y Latinoamérica se hallan más similitudes que diferencias, destacando en los últimos una visión más optimista de su rol en el puesto de trabajo y en la organización.

Los graduados de Latinoamérica dan mayor importancia a las relaciones con otros profesionales dentro y fuera de la organización seguida de la responsabilidad con la organización y la autonomía en el puesto de trabajo. Para los graduados de Europa el aspecto principal del rol en el trabajo es la responsabilidad y la autonomía. Es interesante decir que, una parte de la diferencia está en la importancia que dan a los distintos factores. Para los latinoamericanos la responsabilidad y la posibilidad de daños a la organización están 
vinculadas en el mismo factor, mientras que para los graduados de Europa ambas preguntas son independientes. Esta es una diferencia importante en la percepción.

Se han hallado evidencias en los grupos analizados para afirmar que la responsabilidad frente al trabajo propio y a la organización, la autonomía y la posibilidad de establecer relaciones profesionales dentro y fuera de la organización son aspectos del rol que favorecen la percepción del éxito laboral subjetivo asociado en este trabajo con la satisfacción laboral y el uso de los conocimientos.

Para los graduados universitarios tener un buen nivel de competencias, favorece positivamente la percepción del éxito laboral objetivo asociado a los ingresos así como el éxito laboral subjetivo asociado a la satisfacción con el trabajo y el uso de los conocimientos. Sin embargo cabe destacar que para ellos no todas las competencias son valoradas en términos de éxito laboral objetivo, es decir monetario.

Frente a la percepción personal que se tiene del nivel de competencias, está la evaluación del nivel de competencias requerido en el trabajo. Llegados a este punto se puede afirmar que las organizaciones tienen un papel fundamental, puesto que son ellas las que demandan una serie de competencias a sus trabajadores y lo que se puede concluir en particular de los graduados de Latinoamérica y España es que para ellos un nivel adecuado de competencias favorecen la percepción de éxito laboral objetivo y subjetivo. En el caso del conjunto de los europeos, el requerimiento de competencias favorece solo el éxito laboral subjetivo.

La sobre-cualificación en competencias afecta la percepción que se tiene del éxito laboral desde sus dos componentes el éxito objetivo y subjetivo. Desde lo objetivo afecta porque hay competencias que son más valoradas que otras y siguen dependiendo de otras variables, las áreas de conocimiento, el cargo ocupado, el sector, tamaño y entorno de la organización. La remuneración puede no reflejar la valoración que el profesional universitario tenga de su nivel competencial. Desde lo subjetivo porque afecta la satisfacción con el trabajo y la intensidad de uso de conocimientos.

Los valores laborales se definieron como las características asociadas al puesto de trabajo que intervienen directamente en la evaluación de la calidad de vida en el trabajo, formando parte del concepto de éxito laboral. Los profesionales universitarios los evaluaron según la importancia personal y según el grado de cumplimiento en el trabajo. El análisis del ajuste de los valores laborales muestra que el cumplimiento de los valores laborales en el 
trabajo es menor del que desearían tener. De los resultados obtenidos y las diferencias existentes entre los graduados de Europa, Latinoamérica y España, los valores laborales que más se ajustan son los que tienen que ver con tener un puesto de trabajo enriquecido "satisfactorio", es decir aquel que ofrezca autonomía, estabilidad, nuevos retos, oportunidad de aprender etc., así como los ingresos, la estabilidad y el reconocimiento. En conjunto favorecen la percepción del éxito laboral subjetivo y objetivo.

Siguiendo la teoría se podría afirmar que los valores laborales están relacionados positivamente con el logro del éxito laboral objetivo y subjetivo, sin embargo la realidad es más imperfecta. Los resultados muestran que por ejemplo, existen aún muchas dificultades para conciliar el trabajo con el tiempo de dedicación al ocio y la familia.

El mercado laboral actual viene presentando una serie de acontecimientos que están cambiando el concepto tradicional del empleo estable y para toda la vida, por el de un empleo en donde al profesional se le pide ser competitivo, autónomo, que tenga capacidad de asumir riesgos y que sea flexible. Por lo tanto, el éxito profesional no puede entenderse solamente como un aspecto de la posición en la escala jerárquica de una organización o como las ganancias percibidas por el trabajo realizado, sino que, como se ha mostrado, es el resultado de la interacción de numerosos factores.

\subsection{Aportaciones del estudio}

A la comunidad académica, las aportaciones de carácter científico aportadas por esta investigación son de carácter teórico, metodológico y práctico:

La revisión bibliográfica que incluye diversas y significativas fuentes, expone un marco de referencia de los aportes teóricos y empíricos presentes en la literatura científica relacionada con el estudio del éxito laboral.

El planteamiento y análisis de un modelo de investigación que permite explorar el éxito laboral medido por el éxito laboral objetivo (remuneración) y el éxito laboral subjetivo (uso de conocimientos y habilidades, satisfacción con el trabajo) a través del rol en el trabajo, las competencias y los valores laborales.

Aporta la realización de una investigación empírica y el contraste de un conjunto de hipótesis en una amplia muestra de graduados universitarios de dos áreas geográficas Europa, Latinoamérica y un país como España. 
La investigación realizada puede ser punto de partida de otros estudios conducentes a complementar y profundizar el modelo propuesto, que permitan hacer inferencias estadísticas en las poblaciones de interés.

A nivel metodológico, la investigación presenta una opción metodológica para realizar estudios exploratorios y comparativos en diferentes regiones.

A la comunidad empresarial, la investigación realizada puede ser una aportación para el análisis y reflexión de los gestores de las organizaciones de cualquier sector, tanto público como privado. De los resultados obtenidos en el estudio, se deduce que las organizaciones tienen una importante proporción de capital humano procedente de la educación superior, que no es utilizado plenamente a pesar de tenerlo a su disposición. Independiente del tamaño o sector económico en el que se sitúen las organizaciones, podrían aplicar políticas y estrategias para la definición de los puestos de trabajo de manera que permita ajustarlos a sus necesidades reales y al aprovechamiento del capital humano del que disponen para lograr una relación de equilibrio entre lo que la organización está dispuesta a ofrecer y lo que espera recibir.

Por último, está la difusión de resultados de este estudio a través de publicaciones y comunicaciones en congresos. Son resultados que en sí mismos evidencian un aporte al estudio del rol de los profesionales universitarios que trabajan en las organizaciones del siglo XXI y al reto que enfrentan para lograr el éxito profesional.

\subsection{Limitaciones}

Para el estudio del éxito Laboral y el rol de los graduados universitarios en las organizaciones se tuvo como criterio de análisis la segmentación geográfica por continente y país. Se consideraron en un sentido amplio algunas variables que siendo muy importantes (género, ocupación, área de estudio) no fueron objetivo específico de análisis en esta tesis.

Sobre las conclusiones es importante puntualizar acerca de algunos aspectos relativos a las limitaciones del trabajo realizado. En primer lugar, la investigación se basa en un estudio de corte transversal en el cual se aplica una sola herramienta de investigación, el cuestionario. No se dispone de otras fuentes de información que complementen o maticen las valoraciones de los encuestados. Por otro lado se plantea a los graduados que evalúen de forma subjetiva diversas características de su puesto de trabajo y la organización donde trabajan. Ambas limitaciones pueden ser aceptadas, dado que el objetivo de estudio es el análisis del rol en el 
trabajo de los titulados universitarios, que en gran medida se trata de una cuestión personal. En cualquier caso, se ha de tener siempre presente que los resultados de la encuesta proceden de valoraciones personales y teniendo en cuenta el enfoque internacional con que se ha planteado la investigación, las limitaciones en este sentido resultan ineludibles.

\subsection{Futuros Estudios}

Las investigaciones asociadas al éxito laboral y la relación con el rol profesional, las competencias y valores laborales pueden dar paso a estudios individuales de estos conceptos. Los resultados obtenidos llevan a proponer la continuación de esta investigación en la siguientes líneas de estudio:

- A partir del modelo propuesto y a efectos comparativos, ahondar en el estudio del éxito laboral de los profesionales universitarios mediante la aplicación de otras técnicas estadísticas de análisis multivariante ampliando el estudio considerando el género, la ocupación, tipos de contrato y el tamaño de la organización.

- Profundizar en el estudio del ajuste de competencias desde las organizaciones. Si bien esta investigación se ha centrado en el estudio del éxito laboral de los profesionales universitarios, los resultados han mostrado que la sobrecualificación reduce la percepción de éxito laboral. La preocupación del ajuste de competencias no solo es cuestión de los profesionales universitarios sino de las organizaciones y empresas al que pueden aportar haciendo uso de estrategias de planificación y selección consecuentes con la realidad del capital humano del que disponen y de las instituciones educativas donde los profesionales adquieren esas competencias.

- Actualización de las encuestas, para evaluar los cambios que las variaciones en el entorno económico (p.e., efectos de la crisis) y académico (p.e., aplicación de titulaciones ajustadas a Bolonia) están provocando en el mercado laboral. 



\section{CAPITULO 8}

\section{Referencias}

- Abbott, A. (1988). The System of professions. An essay on the division of expert labor. Chicago: University of Chicago Press.

- Ackoff, R.L. (1969). A concept of corporate planning. In Ackoff. Edition, illustrated. Publisher, Wiley-Interscience.

- Adams, J.S. (1965). Inequity in social exchange. En L. Berkowitz (ed.), Advances in Experimental Social Psychology (pp. 276-299). Nueva York: Academic Press.

- Agarwal, N. (1981). Determinants of executive compensation. Industrial Relations, 1, 3645.

- Agencia Nacional de Acreditación ANECA y Centro de Estudios en Gestión de la Educación Superior CEGES. (2007). El profesional flexible en la sociedad del conocimiento REFLEX Informe ejecutivo (versión 2.0 - 28 de junio). Madrid, Valencia: ANECA - CEGES.

- Aguirre, A., Castillo, A. y Tous, D. (1999). Administración de organizaciones: Fundamentos y aplicaciones. Madrid: Pirámide.

- Al-Zoubi, M. (2008). Job design and employees well-being and performance. A future perspective. Milton Keynes UK: Verlag Dr. Müller.

- Allen, J. \& Van der Velden, R. (2011). The flexible professional in the knowledge society: New challenges for higher education. Dordrecht: Springer.

- Allen, J. y de Weert, E. (2007). What do educational mismatches tell us about skill mismatches? A cross-country analysis. European Journal of Education, 42(1), 59-73.

- Allen, J., \& Van der Velden, R. (2001). Educational mismatches versus skill mismatches: Effects on wages, job satisfaction, and on-the-job search. Oxford Economic Papers, 53(3), 434-452.

- Allen, J., Arnesen, C.Å., Calmand, J., Frontini, M., Paul, J.- J., Rostan, M., Schomburg, H., Storen, L.A., Teichler, U. y Van der Velden, R. (2007). The flexible professional in the knowledge society: General results of the REFLEX project. Maastricht: Open Access publications from Maastricht University.

- Allen, J., Ramaekers, G. \& van der Velden, R. (2003). La medición de las competencias de los titulados superiores. En J. Vidal (Ed.), Métodos de análisis de la inserción laboral de los 
universitarios (pp. 31-54). Madrid: Consejo de Coordinación Universitaria. Ministerio de Educación, Cultura y Deporte.

- Alvesson, M. (2001). Knowledge Work: Ambiguity, image and identity. Human Relations, $547,863-86$.

- Andolfatto, D. \& Gervais, M. (2006). Human capital investment and debt constraints. Review of Economic Dynamics, 9(1), 52-67.

- Ansoff, H.I. (1976). La Estrategia de la Empresa, Pamplona: EUNSA.

- Ansoff, H.I. (1984). Implanting Strategic Management. Englewood Cliffs, N.J.: Prentice/Hall International.

- Aranowitz, S. \& Difazio, W. (1994).The jobless future: Sci-tech and the dogma of work. Minneapolis. M.N.: University Minneapolis Press.

- Arrow, K. (1997). The benefits of education and the formation of preferences. En J.R. Behrman and N. Stacy (Eds.), The social benefits of education. University of Michigan Press Ann Arbor.

- Arthur, L. (2006). Higher Education and the Area of Work: Issues, Challenges and Responses in Norway and Germany (REFLEX Working paper 3). Recuperado el 31 de enero de 2012, de http://www.wwords.co.uk/RCIE.

- Arthur, M.B. \& Sullivan S.E (2006). The evolution of the boundaryless career concept: Examining physical and psychological mobility. Journal of Vocational Behavior, 69, 19-29.

- Arthur, L., Brennan, J., Hick, R., y Kimura, M. (2008). The context of higher education and employment: Comparisons between different European countries (REFLEX Report 2). London, England: Centre for higher education, research and information. The Open University.

- Arthur, M. B., Hall, D. T. \& Lawrence, B. S. (1989). Generating new directions in career theory: The case for a transdisciplinary approach. En M. B. Arthur, D. T. Hall, \& B. S. Lawrence (Eds.), Handbook of career theory (pp. 7-25). New York, N.Y.: Cambridge University Press.

- Arthur, M. B., Khapova, S. N., y Wilderom, C. P. M. (2005). Career success in a boundaryless career world. Journal of Organizational Behavior, 26(2), 177-202.

- Arthur, M., Claman, P. \& Defillipi, R. (1995). Intelligent enterprise, intelligent career. The Academy of Management Executive, 9(4), 7-22.

- Aryee, S., Chay, Y.W. \& Tom, H.H. (1994). An examination of the antecedents of subjective career success among a managerial sample in Singapore. Human Relations, 47(5), 487-509. 
- Atchley, R. (1975). The life course, age grading, and age-linked demands for decision making. In D. Natan y L. Ginsberg (Eds.), Life-span developmental psychology. Normative life crises (pp.261-278). Nueva York: Academic Press.

- Ballout, H. (2007). Career success: The effects of human capital, person-environment fit and organizational support. Journal of Managerial Psychology, 22(8), 741-765.

- Becker, G. (1993). Human Capital: A theoretical and empirical analysis with special relevance to education. New York: National Bureau of Economic Research, Columbia University Press.

- Becker, G.S. (1964). Human Capital, A theoretical and empirical analysis, with special reference to education. New York: National Bureau of Economic Research.

- Bennis, W.G. (1969). Organization development: Its nature, origins and prospects. Reading, Mass: Addison-Wesley.

- Berings, D., De fruyt, F.D. \& Bouwen, R. (2004). Work values and personality traits as predictors of enterprising and social vocational interest. Personality and Individual Differences, 36, 349-364.

- Bermeo, H. (2007). Rendimiento y colaboración científica en la investigación académica: Estudio del caso de los grupos de investigación de la UPV. Tesis doctoral, Departamento de Proyectos de Ingeniería, Innovación, Desarrollo y Diseño Industrial y Rural, Universidad Politécnica de Valencia, España.

- Bertalanffy, L. (1924). Einführung in Spenglers Werk. Litaraturblatt, Kölnische Zeitung, (May).

- Bertalanffy, L. (1951). General system theory: A new approach to unity of science human biology.

- Block, Fred (1990). Postindustrial possibilities: a critique of economic discourse. Berkeley, CA: University California Press.

- Borjas, G. J. (1979). Job satisfaction, wages, and unions. Journal of Human Resources, 14(1), 21-40.

- Boudreau, J.W., Boswell, W.R. \& Judge, T.A. (2001). Effects of personality on executive career success in the United States and Europe. Journal of Vocational Behavior, 58, 53-81.

- Bounds, G., Dobbins, G. y Fowler, O. (1995). Management: A total quality perspective. Cincinnati, US: South Western Publishing.

- Bourdieu, P. \& Passeron, J. C. (1977). Reproduction in education, society and culture. London: Sage. 
- Boyatzis, R.E. (1982). The Competent Manager: A model for Effective Managers. New York: Willey \& Sons.

- Bravo, M., Peiró, JM. y Rodríguez, I. (2002). Satisfacción laboral. En JM. Peiró y F. Prieto (Eds.), Tratado de psicología del trabajo. Vol. I: La actividad laboral en su contexto (pp. 343-394). Madrid: Síntesis.

- Brennan, J. (2008). It's not always what you know: Why graduates get jobs. In B. Kehm (Ed.), Hochschule im Wandel. Die Universität als Forschungsgegenstand. Festschrift für Ulrich Teichler. Frankfurt: Campus Publisher.

- Brennan, J., Johnston, B., Little, B., Shah, T., \& Woodley, A. (2001). The employment of UK graduates: comparisons with Europe and Japan. London: CHERI/HEFCE.

- Brennan, J., Kogan, M. Teichler, U. (1996). Higher education and work. Great Britain: Jessica Kingsley Publishers.

- Brief, Arthur. \& Weiss, Howard (2002). Organizational Behavior: Affect in the Workplace. Annual Review of Psychology, 53, 279-307.

- Bromley, D. (1966). The Psychology of human aging. Baltimore: Penguin.

- Brunetto, Y. (2001). Mediating change for public sector professionals. The International Journal of Public Sector Management, 146, 465-81.

- Bunk, G.P. (1994). La transmisión de las competencias en la formación y perfeccionamiento profesionales de la RFA. Revista Europea de Formación Profesional, 1, 8-14.

- Burrell, G. (2002). Twentieth century quadrilles: Aristocracy, owners, managers and professionals. International Studies of Management and Organization, 322, 25-50.

- Cabral, J. A.(2005). Skill mismatches and job satisfaction. Economics Letters, 89(1), 39-47.

- Caicedo, M.A. (2007). Éxito Profesional. Códice - Universidad de La Salle, 3(1), 41-47.

- Cain, L. (1976). La vida humana y la estructura social. En R. Faris (Ed.), La vida social. Tratado de Sociología, Vol. III (pp. 515-582). Barcelona: Hispano Europea.

- Campbell, A., Converse, P. E. \& Rodgers, W.L. (1976). The quality of American life: perceptions, evaluations and satisfaction. Russel Sage Foundation, New York: Wiley.

- Carrera, F. (2003). Desarrollo de competencias profesionales en el área de tecnología. Universidad de Lleida. Departamento de Pedagogía y Psicología.

- Carr-Saunders \& Wilson, P.A. (1964). The Professions. London: Frank Cass and Co.

- Castelló, M. \& Iñesta, A. (2007). Escribir y comunicarse en contextos científicos y académicos: Conocimientos y estrategias. Barcelona, España: Editorial GRAÓ. 
- Castro, J. A. \& Galindo, Mạ P. (2000). Estadística multivariante. Análisis de correlaciones. Salamanca, España: Amarú Ediciones.

- Cavalcante, J.J. (2004). Satisfacción en el trabajo de los directores de las escuelas secundarias públicas de la región de jacobina (Bahía, Brasil). Tesis doctoral, Universidad Autónoma de Barcelona, España.

- Chandler, A.D. (1962). Strategy and Structure. Boston, Mass: MIT Press.

- Chiavenato, I. ( 2006). Introducción a la teoría general de la administración. México: McGraw Hill / Interamericana.

- Clark, A. E. \& Oswald, A. J. (1996). Satisfaction and comparison income. Journal of Public Economics, 61(3), 359-381.

- Clark, A. E. (1996). Job satisfaction in Britain. British Journal of Industrial Relations, 34(2), 189-217.

- Claver, E., Gascó, J.L. y Llopis, J. (1996). Los recursos humanos en la empresa: un enfoque directivo. Madrid: Cívitas.

- Cohen, J. (1988). Statistical power analysis for the behavioral sciences (2a Ed.). New Jersey: Lawrence Erlbaum Associates, Inc.

- Cohen, L., Finn R., Wilkinson, A. \& Arnold, J. (2002). Professional work and management. International Studies of Management and Organization, 322, 3-24.

- Conchado, A. (2011). Modelización multivariante de los procesos de enseñanzaaprendizaje basados en competencias en educación superior. Tesis Doctoral, Departamento de Estadística e Investigación Operativa Aplicadas y Calidad, Universitat Politècnica de València, España.

- Conchado, A., Cortés, A., Mora, J-G. y Carot, J.M. (2012). Los valores laborales de los graduados en educación en España. Revista de Educación, septiembre-diciembre, 359.

- Cortés, A. (2009). The work values of teacher training students in a spanish university. Symbiosis between Schwartz and meaning of work (MOW) study group. European Journal of Education, 44(3), 441-453.

- Cummings, Th. y Worley, C.G. (2008). Organization development and change (9a Ed.). Mason OH, USA: Cengage Learning.

- Daft, R.L. (1988). Management. N.Y.: The Dryden Press.

- Daft, R.L. y Marcic, D. (2006). Introducción a la administración (4ạ Ed.). México: International Thomson Editores.

- De Lucas, R. (1979). La dirección y la estructura de la empresa. Madrid: Editorial Index. 
- De Miguel, E. (1993). Introducción a la Gestión. Management I (9 Ed.). Valencia, España: Universidad Politécnica de Valencia.

- De Miguel, E. (2005). Introducción a la Gestión (Management). Valencia, España: Editorial UPV.

- Dent, M. (2002). Professional predicaments: comparing the professionalisation projects of German and Italian nurses. The International Journal of Public Sector Management, 152, 151-62.

- Díaz de R., V. (2002). Técnicas de análisis multivariante para investigación social y comercial. Madrid: Ra-Ma Editorial.

- Drucker, P. (2001, November 1st). The near future. The Economist.

- Echeverría, B. (2002). Gestión de la competencia de acción profesional. Revista de Investigación Educativa, 20(1), 7-43.

- Etzioni, A. (1961). Complex organizations. N.Y., USA: Holt, Rinehart \& Winston.

- Etzioni, A. (1969). The semi-professions and their organization. London: Collier-Macmillan Ed.

- European Higher Education Area EHEA (2012). Making the most of our potential: Consolidating the European Higher Education. Final Version. Bucharest: EHEA Ministerial Conference.

- Evetts, J. (2002). New directions in state and international professional occupations: Discretionary decision making and acquired regulation. Work, Employment and Society, $162,341-53$.

- Exworthy, M. \& Halford, S. (1999). Professionals and the new managerialism in the public sector. Buckingham: Open University Press.

- Fernández, J. (2005). Gestión por competencias. Madrid: FT. Prentice Hall.

- Fernández, J.A., Barajas, G. y Barroso, L. (2007). Profesión, ocupación y trabajo. Eliot Freidson y la conformación del campo. Barcelona: Ediciones Pomares.

- Fernández-Losa, N. (2002). El desarrollo profesional de los trabajadores como ventaja competitiva de las empresas. Revista Cuadernos de Gestión, 2(1).

- Filippi, G. (2008). El significado y el valor del trabajo en distintos grupos socio-laborales de Argentina en los albores del siglo XXI. Tesis, Universidad de Buenos Aires, Argentina.

- Foucault, M. (1977). The archaeology of knowledge. London: Tavistock.

- Freidson, E. (2001). La Teoría de las Profesiones. Estado del Arte. Perfiles Educativos, 23(93), 28-43. 
- Friedson, E. (1988). Profession of Medicine - A Study of the Sociology of Applied Knowledge. Chicago: University of Chicago Press.

- Gamero, C. (2005). Análisis microeconómico de la satisfacción laboral. Madrid: Consejo Económico y Social.

- García, A. (2003). Labour market analysis for european graduates. Tesis doctoral, Facultat $d^{\prime}$ Economía, Departament d'Anàlisi Econòmica, Universitat de València, España.

- García-Aracil, A., Gabaldón, D., Mora, J-G. \& Vila, L. (2007). The relationship between life goals and fields of study among young European graduates. Higher Education, 53, 843865.

- García-Aracil, A., Mora, J-G. \& Vila, L. (2004). The rewards of human capital competences for young european higher education graduates. Tertiary Education and Management, 10, 287-305.

- García-Montalvo, J., Peiró, J. Ma y Soro, A. (2003). Capital Humano, observatorio de la inserción laboral de los jóvenes: 1996-2002. Valencia: Fundación Bancaja.

- Garrido, S. (2006). Dirección estratégica (2ª Ed.). España: McGraw Hill / Interamericana.

- Gattiker, U. \& Larwood, L. (1988). 'Predictors for managers' career mobility, success, and satisfaction. Human Relations, 41(8), 569-591.

- Gelabert, M. P. (2008). Recursos Humanos. Dirigir y gestionar personas en las organizaciones. Pozuelo de Alarcón, Madrid, España: ESIC editorial.

- Genescá, E. (1977). Motivación y enriquecimiento del trabajo. Barcelona: Hispano Europea.

- Gervais, M., Livshits, I. \& Meh, C. (2008). Uncertainty and the specificity of human capital. Journal of Economic Theory. 143(1), 469-498.

- Gimeno, J., Folta, T. B., Cooper, A. C., \& Woo, C. Y. (1997). Survival of the fittest? Entrepreneurial human capital and the persistence of underperforming firms. Administrative Science Quarterly, 750-783.

- Glazer, N. (1974). Schools of the Minor Professions. New York: Minerva.

- Godet, M. (1985). Prospective et Planification Stratégique. Paris: Economica.

- González, J. \& Wagenaar, R. (2003). Tuning educational structures in Europe. Informe Final Proyecto Piloto, Fase 1. Bilbao: Universidad de Deusto.

- González, J., Wagenaar, R., \& Beneitone, P. (2004). Tuning-América Latina: un proyecto de las universidades. Revista iberoamericana de educación, 35, 151-164.

- Goode, W. J. (1969). The Theoretical Limits of Professionalization. In A. Etzioni (Ed.), The Semi-Professions and their Organization. London: Collier-Macmillan. 
- Gould, G. \& Penley, L.E. (1984). Career strategies and salary progression: a study of their relationships in a municipal bureaucracy. Organizational Behavior and Human Performance, 34, 244-265.

- Greenhaus, J.H., Collanan, G. \& Godshalk, V.M. (2000). Career Management. Mason,OH: Thompson-South Western.

- Greenwood, R., Suddaby R. \& Hinings C. R. (2002). Theorizing change: The Role of associations in the transformation of institutionalized fields. Academy of Management Journal, 451, 58-80.

- Gunz, H.P. \& Jalland, R.M. (1996). Managerial careers and business strategies. Academy of Management Review, 21, 718-756.

- Gunz, H.P. \& Heslin, P. A. (2005). Reconceptualizing career success. Journal of Organizational Behavior, 26, 105-111.

- Gunz, H.P., Jalland, R. \& Evans, M.G. (1998). New strategy, wrong managers? What you need to know about career streams. Academy of Management Executive, 12, 21-37.

- Hair, J.F., Anderson, R.E., Tatham, R.L. \& Black, W.C. (2008). Análisis multivariante (5a Ed.). Madrid: Prentice Hall Iberia.

- Hall, D. \& Moss, J.E. (1998). The new protean career contract: helping organizations and employees adapt. Organizational Dynamics, 26(3), 22-37.

- Hall, D. T., \& Chandler, D. E. (2005). Psychological success: When the career is a calling. Journal of Organizational Behavior, 26(2), 155-176.

- Hallam, J. (2002). Vocation to profession: Changing images of nursing in Britain. Journal of Organizational Change Management, 151, 35-47.

- Hamermesh, D. S. (2001). The changing distribution of job satisfaction. Journal of Human Resources, 36(1), 1-30.

- Hamilton, B. H. (2000). Does entrepreneurship pay? An empirical analysis of the returns of self-employment. The Journal of Political Economy, 108(3), 604-631.

- Harrison, B. (1994). Lean and mean: the changing landscape of corporate power in the age of flexibility. New York: Basic Books.

- Harpaz, I. (1990). The Importance of Work Goals. An International Perspective. Journal of International Business Studies.

- Harpaz, I., Depolo, M., Claes, R. \& Ruiz-Quintanilla, S. (1992). The Meaning of Work of Career Starters. Revue Internationale de Psychology Sociale - International Review of Social Psichology, 5(1), 81-104.

- Hartog, J. (1992). Capabilities, allocation and earnings. Boston: Kluwer. 
- Havighurst, R. J. (1982). The world of work. En B. Wolman (Ed.), Handbook of Developmental Psychology. Englewood Cliffs, N.J.: Prentice-Hall.

- Hax, A,C. (1981). Organizational Design: A Survey and an Approach. Operations Research, 29(3), 417-447.

- Heijke, H., Meng, C. \& Ramaekers, G. (2003). An investigation into the role of human capital competences and their pay-off. International Journal of Manpower, 24, 750-773.

- Heijke, H., Meng, C. \& Ris, C. (2003). Fitting to the job: the role of generic and vocational competencies in adjustement and performance. Labour Economics, 10(2), 215-229.

- Hernández, R., Fernández, C. y Baptista, P. (2010). Metodología de la Investigación (5ạ Ed.). México: McGraw-Hill/ Interamericana.

- Heslin, P. A. (2005). Conceptualizing and evaluating career success. Journal of Organizational Behavior, 26(2), 113-136.

- Hofstede, G. (1991). Culture and Organizations: Software of the mind. London: Mc Graw Hill International.

- Hontagas, P.M. y Peiró, J.M. (2002). Ajuste persona-trabajo. En JM. Peiró y F. Prieto (Eds.), Tratado de Psicología del Trabajo. Vol. I: La actividad laboral en su contexto (pp. 251-281). Madrid: Síntesis.

- Hoppock, R. y Super, D. E. (1950). Vocational and educational satisfaction. En D.H. Fryer y E.R. Henry (Eds.), Handbook of applied Psychology (pp 126-134). New York: Rinehart.

- Hughes, E.C. (1937). Institutional office and the person. American Journal of Sociology, 43, 404-413.

- Huse, E., y Cummings, Th. (1985). Organization development and change (3a Ed.). St. Paul, Minn: West Publ.

- Idson, T. L. (1990). Establishment size, job satisfaction and the structure of work. Applied Economics, 22(8), 1007-1018.

- Illich, I. (1977). Disabling Professions. In I. Illich, I. K. Zola, J. McKnight, J. Caplan and H. Sharken (Eds.), Disabling Professions. London: Marion Boyars.

- Jahoda, M. (1987). Empleo y desempleo: un análisis psico_sociológico. Madrid: Morata.

- Johnson, T. J. (1972). Professions and Power. London: MacMillan.

- Jones, G. R. \& George, J.M. (2003). Contemporary Administration. McGraw-Hill Companies, Inc.

- Jones, G. R. y George, J.M. (2006). Administración contemporánea (4ạ Ed.). México: McGraw Hill. 
- Jones, G. R. (2008). Teoría organizacional: Diseño y cambio en las organizaciones (5a Ed.). México: Pearson Educación.

- Judge, T. A., \& Bretz, R. D., Jr. (1991). The effects of work values on job choice decisions (CAHRS Working Paper \#91-23). Ithaca, NY: Cornell University, School of Industrial and Labor Relations, Center for Advanced Human Resource Studies. Recuperado el 10 de octubre de 2012, de http://digitalcommons.ilr.cornell.edu/cahrswp/355

- Judge, T., Thoresen, C., Bono, J. y Patton, G. (2001). The job satisfaction-job performance relationships: A qualitative and quantitative review. Psychological Bulletin, 127, 376-407.

- Judge, T.A., Cable, D.M., Boudreau, J.W. y Bretz, R.D. Jr. (1995). An empirical investigation of the predictors of executive career success. Personnel Psychology, 48, 485-519.

- Kanungo, R. (1979). The Concepts of Alienation and Involvement Revisited. Psychological Bulletin.

- Kanungo, R. (1982). Measurement of Job and Work Involvement. Journal of Applied Psychology.

- Kärreman, D., Sveningsson, S. \& Alvesson, M. (2002). The Return of the machine bureaucracy? Management control in the work settings of professionals. International Studies of Management and Organization, 322, 70-92.

- Katz, D., \& Kahn, R. (1966). The Social Psychology of Organization. New York: John Wiley.

- Kellerman, P. (2001). Las competencias de los graduados y los requerimientos del trabajo. [aut. libro] Antonio Sáenz de Miera. En torno al trabajo universitario: reflexiones y datos (pp. 137-164). Madrid : Secretaría General Técnica.

- Kellermann, P. (2003). Acquired and required competencies of graduates. En U. Teichler (Ed.), Careers of university graduates: Views and experiences in comparative perspectives. Dordrecht, The Netherlands: Kluwer.

- Kitchener, M., Kirkpatrick, I. y Whipp, R. (2000). Supervising professional work under new public management: Evidence from an 'Invisible Trade'. British Journal of Management, $11,213-266$.

- Knorr-Cetina, K. (1997). Sociality with objects. Social relations in post social knowledge societies. Theory, Culture and Society, 14(4), 1-30.

- Koontz, H. y Weihrich, H. (1998). Administración: una perspectiva global. México: McGrawHill.

- Korman, A.K., Wittig-Berman, U. y Lang, D. (1981). Career success and personal failure: Alienation in professionals and managers. Academy of Management Journal, 24(2), 342360. 
- Laffaldano, M. \& Muchinsky, P. (1985). Job satisfaction and job performance: A metaanalysis. Psychological Bulletin, 97, 251-273.

- Leal, A., Román, M., Alfaro, A. y Rodríguez, L. (2004). El factor humano en las relaciones laborales. Manual de dirección y gestión. Madrid: Pirámide.

- Leidner, D. \& Kayworth, T. (2006). A review of culture in information systems research: Toward a theory of information technology culture conflict. MIS Quarterly, 30(2), 357-399.

- Leontief, W. (1951). Input-Output Economics. Scientific American.

- Levinson, D. (1977). Middle adulthood in modern society: A sociopsychological view. In D. Di Renzo (Ed.), We the people: Social change and social character. Wesport, Conn.: Greenwood Press.

- Lévy - Leboyer, C. (1997). Gestión de las competencias. Madrid: Ediciones Gestión 2000.

- Lévy-Garboua, L. \& Montmarquette, C. (2004). Reported job satisfaction: What does it mean? Journal of Socio-Economics, 33(2), 135-151.

- Lévy-Leboyer, C. (2003). La motivación de la empresa: modelos y estrategias. Madrid: Ediciones Gestión 2000.

- Lewin, K. (1951). Field theory in social science: Selected theoretical papers.D. Cartwright (ed.) New York: Harper \& Row.

- Liacqua, J. A., Schumacher, P. \& Li, H. C. (1995). Factors contributing to job satisfaction in higher education. Education, 116(1).

- Little, B. \& Tang, W. (2008). Age differences in graduate employment across Europe (Report 5). Bristol, U.K.: Higher Education Funding Council for England.

- Locke, E.A. (1976). The nature and causes of job satisfaction. En M.D. Dunnette (Ed.), Handbook of industrial and organizational psychology. New York: John Wiley \& Sons.

- Locke, E.A. y Henne, D. (1986). Work motivation theories. En Cooper, C.L. y Robertson I.T. (Eds.), International Review of Industrial and Organizational Psychology, Vol. 7, pp. 1- 35. Nueva York: John Wiley and Sons.

- Locke, E.A. y Latham, G.P. (1990). A theory of goal-setting and task performance. Prentice Hall, Englewood Cliffs.

- Lucas, A. y Garcia, P. (2002). Sociología de las organizaciones, Madrid: McGrawHill Interamericana de España.

- Luce, R.D. \& Raiffa, H. (1957). Games and Decisions. N.Y.: John Wiley \& Sons.

- Lyon, E. S. (1996). Success with qualifications: Comparative perspectives on women graduates in the labour market. Higher education, 31(3), 301-323.

- Lyotard, J.F. (1994): La condición posmoderna. Madrid: Catedra. 
- Macdonald, K. M. \& Ritzer, G. (1988). The Sociology of the professions: dead or alive? Work and Occupations, 153, 251-72.

- Macdonald, K. M. (1995). The Sociology of the Professions. London: Sage.

- Machin, S. y Vignoles, A. (2005). What's the good of education? United Kingdom. Princeton University Press.

- Mackenzie, K. I. \& Harris, F. C. (1984). “Money the only motivator?" Building Technology and Management, Vol. 22, pp. 25-29.

- Manville, B. (2001). Learning in the new economy. Leader to Leader, vol. 20, 36-45.

- Marginson, S. y van der Wende, M. (2007). Globalisation and higher education (Working paper number 8). Paris, France: Organisation for Economic Cooperation and Development, OECD.

- Martínez, B. y Rocabert, E. (2000). Comparación de las diferentes escalas de valores de trabajo. Revista de Psicología del Trabajo y de las Organizaciones, 16(1), 45-61.

- Mayo, E. (1933). The human problems of an industrial civilization. New York: The MacMillan Co.

- McDonald, P., Brown, K. \& Bradely, L. (2005). Have traditional career paths given way to protean ones?. Career Development International, 10(2), 109-129.

- McDougall, W. (1908). An introduction to social psychology. London: Methuen.

- McLaughlin, J. (2001). EBM and risk: Rhetorical resources in the articulation of professional identity. Journal of Management in Medicine, 15 (5), 352-63.

- Meng, C. \& Heijke, H. (2005). Student time allocation, the learning environment and the acquisition of competencies. ROA Research Memorandum 2005/1E.

- Michael, R. T. (1982). Measuring non-monetary benefits of education: A survey. Financing education: Overcoming inefficiency and inequity, 119-149.

- Mincer, J. (1958). Investment in Human Capital and Personal Income Distribution. Journal Political Economics, 66, 281-302.

- Mincer, J. (1962). On-the-Job Training: Costs, Returns and Some Implications. Journal of Political Economy, 70, 50-79.

- Mincer, J. (1974). Schooling, experience and earnings. New York: National Bureau of Economic Research, Columbia University Press.

- Moncaleano, G. I. (2002). La tecnología de la información en organizaciones cooperativas: influencia sobre el aprendizaje, la creación de valor, y cultura. Tesis doctoral. España: Departamento de Organización de Empresas, Universidad Politécnica de Valencia. 
- Montoro, J. (2004). Apuntes sobre metodología social. Departamento de Organización de Empresas: Universidad Politécnica de Valencia, España.

- Mora, J-G. (2003). Competencias y empleo de los jóvenes graduados universitarios. Revista de educación, 330, 157-170.

- Mora, J.G., García-Aracil, A. \& Vila, L. (2006). Cómo recompensa el mercado laboral europeo las competencias de los jóvenes graduados universitarios. En AA.VV., Flexibilidad y competencias profesionales en las universidades iberoamericanas (pp. 161 - 176). Barcelona: Ediciones Pomares.

- Mora, J-G. y CEGES-LMPF (2008). El éxito laboral de los jóvenes graduados universitarios europeos. Revista de Educación, número extraordinario, 41-58.

- Mora, J-G., Carot, J.M. y Conchado, A. (2010). Informe resumen del proyecto ALFA PROFLEX en Latinoamérica. Comparativa con el proyecto REFLEX en Europa. Valencia: Centro de Gestión de la Calidad y del Cambio, Universitat Politècnica de València, España.

- Mora, J-G., Vila, L. \& Garcia-Aracil, A. (2005). European higher education graduates and job satisfaction. European Journal of Education, 40(1), 35-44.

- Morales V., P. (2008). Estadística aplicada a las ciencias sociales. Madrid: Universidad Pontificia de Comillas.

- Morgenstern \& Von Neumann (1944). Theory of Games and Economic Behavior. Princeton University Press.

- Morrell, K. (2004). Analysing professional work in the public sector: The Case of NHS Nurses. Preliminary paper 2004:1. Loughborough University: Business School Research Series.

- MOW International Research Team (1987). The meaning of working. London: Academic Press.

- Muchinsky, P.M. (2000). Psicología aplicada al trabajo. Madrid: Paraninfo Thomson Learning.

- Münsterberg`s, H. (1913) Psychology and Industrial Efficiency. London: Constable.

- Nabi, G. (2003). Situational characteristics and subjective career success. International Journal of Manpower, 24(6), 653-671.

- Nadler, D.A. (1977). Feedback and organization development: Using data-based methods. Reading, Mass: Addison-Wesley.

- Neal, M. \& Morgan, J. (2000). The professionalization of everyone? A comparative study of the development of the professions in the United Kingdom and Germany. European Sociological Review, 16, 9-26. 
- Neugarten, B. \& Hagestad, G. (1976). Age and life course. In R. Binstork y E. Shanes (Eds.), Handbook of aging and social sciences. New York: Van Nostrand.

- $\quad \mathrm{Ng}, \mathrm{T} .$, Eby, L., Sorensen, D. \& Feldman, D. (2005). Predictors of objective and subjective career success: a meta-analysis. Personnel Psychology, 58(2), 367-408.

- Nordhaug, O. \& Gronhaug, K. (1994). Competences as resources in firms. The International Journal of Human Resource Management, 5(1), 89-106.

- Núñez Rodríguez, J.A., Díaz Vilela, L., Leal, L., Rodríguez Hernández, L. \& Chams-El-Dim Delgado, A. (1995). El significado del trabajo. Un estudio sobre la población de Tenerife. Tenerife: Cabildo de Tenerife.

- O'Shea, D.P., Betsinger, A.M., y King, C.T. (1999). Successful career progression: Exploratory findings from a study of selected occupations. Center for the Study of Human Resources, Univ.Austin, Texas.

- Oliver, J. (1997). The new-look fast track. Management Today, March, 86-89.

- Organización de las Naciones Unidas para la Educación, la Ciencia y la Cultura (2012). Tercer congreso internacional sobre educación y formación técnica y profesional. Shanghái: UNESCO.

- Parsons, T. (1960). Structure and Process in Modern Societies. N.Y., USA: Free Press.

- Parsons, T. (1968). Professions. International Encyclopedia of the Social Sciences 12, 536547.

- Pereda, S. y Barrachina, M.P. (1987). Satisfacción y rendimiento laboral en empleadas en escuelas infantiles. Revista de Psicología del Trabajo y de las Organizaciones, Vol. 6, pp. 2028.

- Pérez, C. (1991). Nuevo patrón tecnológico y educación superior: Una aproximación desde la empresa. En G. López-Ospina( Ed.), Retos científicos y tecnológicos Vol.3 (pp.23-49). Caracas: UNESCO.

- Pérezgonzález, J. y Díaz, L. (2005). La centralidad del trabajo. USA: Lulu, Inc.

- Pérez Quintana, F., Diaz Vilela, L. \& Leal, L. (1993). Work Centrality and Work Goals in the population of Tenerife (Canary Islands). A replication of the Mow Research. Comunicación presentada en el VI West European Congress on Work and Organizational Psychology, Alicante.

- Perkin, H. (1989). The Rise of Professional Society: England since 1880. Great Britain: Routledge.

- Perkin, H. (1996). The Third Revolution: Professional elites in the modern world. London: Routledge. 
- Phillips, J. (2005). Investing in your company's human capital: strategies to avoid spending too little or too much. N.Y. USA: AMACON.

- Pilbeam \& Corbridge (2006). People Resourcing: Contemporary HRM in Practice (Third edition). England: Prentice Hall.

- Porret, M. (2008). Recursos humanos. Gestión de personas. Madrid: ESIC.

- Porter, M.E. (1980). Competitive strategy: techniques for analyzing industries and competitors. New York : Free Press.

- Pryor, R.G. (1981). Interest and values as preferences. Australian Psychologist, 16, 258272.

- Pryor, R.G. (1983). Manual for the work aspect preference scale. Sidney, Australia: NSW Department of Industrial Relations.

- Psacharopoulos, G. (1994). Returns to investment in education: A global update. World Development, 22(9), 1325-1343.

- Pümpin, C. \& García, S. (1988). Cultura Empresarial. Madrid: Díaz de Santos

- Purcell, K. \& Elias, P. (2004). Seven years on: Graduate careers in a changing labour market. Manchester: Higher Education Careers Services Unit.

- Reich, R.B. (1991). The work of nations. New York: Alfred A. Knopf.

- Ribes, Á. (2000). La antropología de la misión. Harvard Deusto Business Review, 97, 48-53.

- Robotham, D. \& Jubb, R. (1996). Competences: Measuring the unmeasurable. Management Development Review, 9(5), 25-29.

- Rodríguez, D. (2001). Gestión Organizacional. Santiago: Ediciones Universidad Católica de Chile.

- Roethlisberger, F.J. y Dickson, W.J. (1939). Management and the worker. Cambridge: Harvard University Press.

- Romero, M. G. (2002). Tendencias organizacionales de las empresas. Revista Venezolana de Gerencia (RVG), 7(19), 355-374.

- Romero, R. y Zúnica, L.(2005). Métodos estadísticos en ingeniería. Valencia: Editorial Universidad Politécnica de Valencia.

- Rosenbaum, J.E. (1989). Organizational career systems and employee misperceptions. En M. B. Arthur, D. T. Hall, \& B. S. Lawrence (Eds.), Handbook of career theory (pp. 329-353). New York, N.Y.: Cambridge University Press.

- Ruiz Quintanilla, S.A. \& Wilpert, B. (1991). ¿Are Work Meanings changing?. European World and Organizational Psychologist. 
- Salanova, M., Gracia, F. J. y Peiró, J.M. (1996). Significado del trabajo y valores laborales. En J.M. Peiró y F. Prieto (Eds.), Tratado de Psicología del Trabajo. Vol. II. Madrid: Síntesis Psicología.

- Salanova, M., Hontagas, P.M. y Peiró, J.M. (2002). Motivación laboral. En J.M. Peiró y F. Prieto (Eds.), Tratado de Psicología del Trabajo. Vol. I: La actividad laboral en su contexto (pp. 215-249). Madrid: Síntesis.

- Salas, M. (2003). Educación superior y mercado de trabajo. Granada: Grupo Editorial Universitario.

- Sarabia, F.J. (2013). Métodos de investigación social y de la empresa. Madrid: Pirámide Ediciones.

- Sarfatti, M. (1977). The rise of professionalism. Berkeley, Los Angeles, London: University of California Press.

- Schein, E. (1988). La Cultura empresarial y el liderazgo: Una visión dinámica. Barcelona, España: Plaza \& Janes.

- Schomburg, H. (2007). The professional success of higher education graduates. European Journal of Education, 42(1), 35-57.

- Schomburg, H., \& Teichler, U. (2006). Higher Education and Graduate Employment in Europe: Results of graduates surveys from twelve countries. Dordrecht, The Netherlands: Springer.

- Schultz, T.W. (1961). Investment in Human Capital. American Economic Review, 51, 1-17.

- Schultz, T.W. (1962). Reflections on investment in man. The Journal of Political Economy, 1-8.

- Schwartz, S. (1992). Universals in the content and structure of values: Theoretical advances and empirical tests in 20 countries. Advances in Experimental Social Psychology, 25, 1-65.

- Schwartz, S. (2001). ¿Existen Aspectos Universales en la Estructura de los Valores Humanos? En Ros, M. \& Gouveia, V. Psicología social de los Valores Humanos. Desarrollos teóricos, metodológicos y aplicados. Madrid: Biblioteca Nueva.

- Seibert, S., Crant, J.M. \& Kraimer, M.L. (1999). Proactive personality and career success. Journal of Applied Psychology, 84(3), 416-427.

- Seibert, S., Kraimer, M. \& Liden, R. (2001). A social capital theory of career success. Academy of Management Journal, 44(2), 219-237.

- Seibert, S.E., Kraimer, M.L. y Crant, J.M. (2001). What do proactive people do? A longitudinal model linking proactive personality and career success. Personnel Psychology, $54,845-874$. 
- Semejin, J. H., Van der Velden, R., Heijke, H., Van der Vleuten, C. \& Boshuizen, H.P.A. (2005). Competence indicators in academic education and early labour market success of graduates in health sciences (ROA-RM-2005/2E). Maastricht: Maastricht University. Faculty of Economics and Business Administration. Research Centre for Education and the Labour Market.

- Senge, P. (1990). La Quinta Disciplina: El arte y práctica de la organización inteligente. Buenos Aires: Granica.

- Sennett, R. (1998). La corrosión del carácter. Las consecuencias personales del trabajo en el nuevo capitalismo. Barcelona: Anagrama.

- Smith, A. (1776). An Inquiry into the Nature and Causes of the Wealth of Nations. London: W. Strahan \& T. Cadell.

- Smith, V. (1996). Employee involvement, involved employees: participative work arrangements in a white-collar service occupation. Social Problems, 43(2), 166-179.

- Soto Berenguel, A. (2002.) La gestión por competencias: Una revisión crítica. Capital Humano, 159, 30-42.

- Spector, P. (1997). Job Satisfaction: Application, assessment, causes, and consequences. Thousand Oaks, C.A.: Sage.

- Squires, G. (2001). Management as a professional discipline. Journal of Management Studies, 38(4), 473-487.

- Steiner, G.A. (1979). Planificación de la Alta Dirección. Pamplona, España: Eunsa.

- Sturges, J. (1999). What it means to succeed: personal conceptions of career success held by male and female managers at different ages. British Journal of Management, 10(3), 239-252.

- Suarez, E. y Hernández, B. (2008). La consistencia entre los valores, las actitudes y el comportamiento. Notas desde la psicología ambiental. En Icaria (Ed.), ¿En qué estamos fallando? Cambio social para ecologizar el mundo. (pp. 129-160). Barcelona: Icaria y Antrazyt.

- Sullivan, S.E. (1999). The changing nature of careers: a review and research agenda. Journal of Management. 25(3), 457-484.

- Sullivan, W. M. (2000). Medicine under threat: professionalism and professional identity. Canadian Medical Association Journal, 1625, 673-675.

- Super, D.E. (1968). Work values inventory. Boston: Houghton Mifflin.

- Super, D.E. (1970). Work values inventory. Boston: Houghton Mifflin. 
- Tamayo, A., de Oliveira de Borges, L. (2001). Valores del trabajo y valores de las organizaciones. En M. Ros y V. Gouveia. Psicología Social de los Valores Humanos. Desarrollos Teóricos, Metodológicos y Aplicados. Madrid: Biblioteca Nueva.

- Tead, O. (1918). Instincts in Industry. Maynard, Boston: Small.

- Teichler, U. (1999). Higher education policy and the world of work: Changing conditions and challenges. Higher Education Policy, 12, 285-312.

- Teichler, U. (2000). Perspectives on the relationship between higher education and employment. Tertiary Education and Management, 6(2).

- Teichler, U. (2003). Careers of higher education graduates. View and experiences in comparative perspectives. Kluwer Pub.

- Teichler, U. (2005). Graduados y empleo: Investigación, metodología y resultados. Los casos de Europa, Japón, Argentina y Uruguay. Buenos Aires: Miño y Dávila.

- Teichler, U. (2007). Careers of University Graduates. Views and Experiences in Comparative Perspectives. The Netherlands: Springer.

- Teichler, U. \& Schomburg, H. (2007). Careers of Higher Education Graduates, View and Experiences in Comparative Perspectives. New York: Springer.

- Teichler, U. (2009). Higher education and the world of work. Conceptual frameworks, comparative perspectives, empirical findings. Rotterdam, The Netherlands: Sense Publishers.

- Tejada, C., Tobón, S., Martínez, J., Mendo, C., Moreiro, J. y Ramos, L. (2006). El diseño del plan docente en información y documentación acorde con el espacio europeo de educación superior: Un enfoque por competencias. Madrid: Facultad de Ciencias de la Documentación, Universidad Complutense de Madrid.

- Tharenou, P. (2001). Going up? Do traits and informal social processes predict advancing in management?. Academy of Management Journal, 37(5), 105-107.

- Thompson, J. D. (1966). Models of Organization and Administrative Systems. Paris: UNESCO.

- Thompson, J. D. (1967). Organizations in Action: Social Science Bases of Administrative Theory. New York: McGraw-Hill.

- Tobón, S. (2005). Formación basada en competencias. Pensamiento complejo, diseño curricular y didáctica. Madrid: Universidad Complutense de Madrid.

- Tosi, H.L., Werner, S., Katz, J.P. \& Gomez-Meja, L. (2000). How much does performance matter? A meta-analysis of CEO pay studies. Journal of Management, 26, 301-339. 
- Tracey, J.B. \& Charpentier, A. (2004). Professionalizing the HR function: Functional, industry, and firm-specific approaches for enhancing HR competencies. Cornell Quarterly, 45, 388-397.

- Valderrey, P. (2010). Estadística SPSS 17: Extracción del conocimiento a partir del análisis de datos. Madrid: Ra-Ma Editorial.

- Valls, F. y Martínez, J.M. (2004). La centralidad y el valor del trabajo en el proceso de inserción laboral de personas desempleadas. Revista de Psicología del Trabajo y de las Organizaciones, 20(3), 338-354.

- Van Damme, D. (2001). Quality issues in the internationalization of higher education. Higher Education, 41(11), 415-441.

- Van Maanen, J. (1977). Experiencing organization: notes on the meaning of careers and socialization. En J. Van Maanen (Eds.), Organizational careers: Some new perspectives. New York: Wiley.

- Vila, L. E., Garcia-Aracil, A. \& Mora, J-G. (2007). The distribution of job satisfaction among young european graduates: Does the choice of study field matter? The Journal of Higher Education, 78(1), 97-118.

- Vroom, V. H. (1964). Work and Motivation. New York: John Wiley.

- Watson, T. (2002). Professions and professionalism: Should we jump off the bandwagon, better to understand where it is going? International Studies of Management and Organization, 322, 93-105.

- Weber, M. (1968). The theory of social and economic organization. New York: T. Parsons, Free Press

- World Bank (2002). Constructing knowledge societies: New challenges for tertiary education. A World Bank Report, Washington, DC: The World Bank.

- Wright, T. (2006). The emergente of job satisfaction in organizational behavior: A historical overview of the dawn of job attitude research. Journal of Management History, 12, 262271.

- Wright, T., y Douglas, G. (2007). Job satisfaction and psychological well-being as nonadditive predictors of workplace turnover. Journal of management, 33, 141-60.

- Young, B. (1991). Reasons for changing jobs within a career structure. Leadership and Organization Development Journal, 12(1), 12-16.

- Zhao, X. R., \& Namasivayam, K. (2012). The relationship of chronic regulatory focus to work-family conflict and job satisfaction. International Journal of Hospitality Management, $31(2), 458-467$. 


\section{Páginas Web consultadas:}

- HEGESCO (2013). Higher Education as a Generator of Strategic Competences. Recuperado el 9 de junio de 2013, a partir de http://www.hegesco.org/content/view/8/10/

- INCHER - Kassel University. (2000). Careers after Higher Education: a European Research Study - CHEERS. Recuperado el 17 de Julio de 2014, a partir de http://www.unikassel.de/wz1/TSEREGS/publi e.htm

- International Labour Organization - ILO. (2013). World of Work Report 2013: Repairing the economic and social fabric. Recuperado 1 de octubre de 2013, a partir de http://www.ilo.org/global/research/global-reports/world-ofwork/2013/WCMS 214476/lang--es/index.htm

- Numbeo. (2013). Cost of Living Index by Country. Recuperado 18 de marzo de 2013, a partir de http://www.numbeo.com/cost-of-living/rankings by country.jsp

- OANDA: http://www.oanda.com/lang/es/currency/converter/

- OECD StatExtracts: http://stats.oecd.org/Index.aspx?DatasetCode=SNA TABLE4

- Proyecto Proflex. (2010). El profesional flexible en la sociedad del conocimiento: Nuevas exigencias en la Educación Superior. Recuperado el 17 de Julio de 2014, a partir de http://www.seguimientoegresados.com/

- University of Twente. (2007). The Flexible Professional in the Knowledge Society New Demands on Higher Education in Europe, REFLEX Project. Recuperado el 17 de Julio de 2014, a partir de http://www.utwente.nl/mb/cheps/research/projects/flexibleproefessional/ 



\section{APÉNDICES}

Anexo A. Preguntas seleccionadas del cuestionario PROFLEX (2007).

Anexo B. Referencia ISCED 5A (1997).

Anexo C. Lista de Ocupaciones.

Anexo D. Lista de Sector Económico Encuesta Proflex.

Anexo E. Codificación de Variables.

Anexo F. Resumen del Análisis Exploratorio: Éxito Laboral Objetivo y Subjetivo, Rol (Funciones), Competencias, Valores Laborales.

Anexo G. Ajuste de los Valores Monetarios.

Anexo H. Análisis de Correlaciones.

Anexo I. Análisis Factorial.

Anexo J. Correlaciones Bivariadas. 

Anexo A. Preguntas seleccionadas del cuestionario PROFLEX (2007) 
Anexo A. Preguntas seleccionadas del cuestionario PROFLEX (2007)

\section{CARRERA QUE TERMINASTE}

Nombre de la Carrera / Denominación de la Titulación

¿De qué Universidad Egresaste?

\section{CARACTERÍSTICAS DEL TRABAJO ACTUAL}

¿Cuál es tu ocupación o puesto?

* Anexo C. Lista de Ocupaciones

¿Qué tipo de contrato tienes actualmente?

* Contrato indefinido

* Contrato a término fijo durante Meses

* Otros, especifica

¿Cuál es el promedio de horas que trabajas a la semana?

* Según contrato en el trabajo principal

* Horas extras remuneradas en el trabajo principal

* Horas extras no remuneradas en el trabajo principal

* En otro/s trabajo/s remunerados

¿Cuál es aproximadamente tu sueldo mensual bruto?

* Sueldo base regular

* Horas extra o comisiones

* Otros ingresos del trabajo

Según tu opinión ¿Cuál es el área de estudio más apropiada para este trabajo?

* Exclusivamente tu propia área de estudios

* Tu propia área o alguna relacionada

* Un área totalmente diferente

* Ningún área en particular

¿En qué medida usas tus conocimientos y habilidades en tu trabajo actual?

* (1= Nada, 5 = Mucho)

¿En qué medida tu trabajo actual requiere más conocimientos y habilidades de los que tú puedes ofrecer?

* (1= Nada,...., 5 = Mucho $)$

En general, estás satisfecho con tu trabajo actual?

* (1= Nada,...., $5=$ Mucho $)$ 


\section{ORGANIZACIÓN EN LA QUE TRABAJAS}

¿Cuándo empezaste a trabajar con tu empleador actual?

* Mes__ Año

¿A qué sector económico pertenece la organización en que trabajas?

* Anexo D. Lista de Sector Económico

¿Tu organización pertenece al sector:

* Público

* Privado sin fines de lucro

* Privado

* Otros

\section{¿Dónde Trabajas?}

* Municipio /ciudad

* Departamento/estado

* País

¿Cuántas personas trabajan en tu organización y, si corresponde, en el lugar, establecimiento o sucursal donde trabajas?

* Organización: 1-9, 10-49, 50-99, 100-249, 250-999, >=1000

* Establecimiento o sucursal: 1-9, 10-49, 50-99, 100-249, 250-999, >=1000, No aplicable, solo un establecimiento.

En qué medida eres responsable de...

- Establecer objetivos para la organización? (1= Nada,...., 5 = Mucho)

* Establecer objetivos para tu propio trabajo? (1=Nada,...., $5=$ Mucho)

- Decidir estrategias de trabajo para la organización? (1= Nada,...., $5=$ Mucho)

* Decidir cómo hacer tu trabajo? (1= Nada,...., 5 = Mucho)

¿En qué medida son aplicables a tu trabajo las siguientes afirmaciones?

* Los compañeros, clientes, etc. acuden a mí para pedirme consejo: (1= Nada,...., 5 = Mucho)

* Mantengo informados a mis compañeros de profesión sobre nuevos desarrollos en mi campo: (1= Nada,...., 5 = Mucho)

* Suelo iniciar relaciones profesionales con expertos ajenos a la organización: (1= Nada,...., 5 = Mucho)

- Las cuestiones de ética profesional forman parte importante de mis funciones: (1= Nada,...., 5 = Mucho)

¿Cuánto perjudicarías a tu organización si cometieras un error grave en tu trabajo?

* (1= Nada,...., $5=$ Mucho $)$ 


\section{COMPETENCIAS}

\section{C.1. ¿Cómo valoras tu actual nivel de competencias?}

* En todos los casos: (1 = Muy bajo,...., 7 = Muy alto $)$

\section{C.2. ¿Qué nivel de competencias necesitas en tu trabajo actual?}

- En todos los casos: (1 = Muy bajo,...., 7 = Muy alto)

a. Dominio de tu área o disciplina

b. Conocimientos de otras áreas o disciplinas

c. Pensamiento analítico

d. Capacidad para adquirir con rapidez nuevos conocimientos

e. Capacidad para negociar de forma eficaz

f. Capacidad para rendir bajo presión

g. Capacidad para detectar nuevas oportunidades

h. Capacidad para coordinar actividades

i. Capacidad para usar el tiempo de forma efectiva

j. Capacidad para trabajar en equipo

k. Capacidad para movilizar las capacidades de otros

I. Capacidad para hacerte entender

m. Capacidad para hacer valer tu autoridad

n. Capacidad para utilizar herramientas informáticas

o. Capacidad para encontrar nuevas ideas y soluciones

p. Predisposición para cuestionar ideas propias o ajenas

q. Capacidad para presentar en público productos, ideas o informes

r. Capacidad para redactar informes o documentos

s. Capacidad para escribir y hablar en idiomas extranjeros

\section{VALORES LABORALES}

Indica la importancia que las siguientes características tienen para ti y en qué medida se aplican a tu situación laboral actual.

- D.1. Importancia para ti.

En todos los casos: $(1=$ Ninguna,...., $5=$ Mucha $)$

- D.2. En qué medida se aplica a tu situación laboral actual.

En todos los casos: $(1=$ Ninguna,..., $5=$ Mucha $)$

1. Autonomía en el trabajo

2. Estabilidad Laboral

3. Oportunidad de aprender cosas nuevas

4. Ingresos elevados

5. Afrontar nuevos retos

6. Buenas perspectivas profesionales 
7. Tener tiempo para actividades recreativas

8. Reconocimiento/prestigio social

9. Oportunidad de hacer algo útil para la sociedad

10. Facilidad para combinar trabajo y familia

\section{INFORMACIÓN PERSONAL}

\section{Género}

* Masculino

* Femenino

Año de Nacimiento:

¿Cómo vives actualmente?

* Solo (incl. Familia monoparental)

* Con tu pareja (con o sin hijos)

* Con tus padres

* Otros

¿Tienes hijos?
* Sí, 1 hijo
- Sí, 2 hijos
* Sí, 3 hijos o más
* No 

Anexo B. Referencia ISCED 5A (1997) 
Anexo B. Referencia ISCED 5A (1997)

\section{Base para la Clasificación de las áreas de estudio a partir de las titulaciones de primer nivel y segundo nivel. ${ }^{17}$}

\section{Educación \\ Formación de personal docente y ciencias de la educación}

Formación de personal docente para: educación preescolar; jardines de infancia; escuelas elementales; asignaturas profesionales, prácticas y no profesionales; educación de adultos; formación de personal docente; formación de maestros de niños minusválidos. Programas generales y especializados de formación de personal docente.

Ciencias de la educación: elaboración de programas de estudio de materias no profesionales y profesionales. Evaluación de conocimientos, pruebas y mediciones, investigaciones sobre educación; otros programas relacionados con las ciencias de la educación.

\section{Humanidades y artes}

\section{Artes}

Bellas artes: dibujo, pintura y escultura; Artes del espectáculo: música, arte dramático, danza, circo; Artes gráficas y audiovisuales: fotografía, cinematografía, producción musical, producción de radio y televisión, impresión y publicación; Diseño; artesanía.

\section{Humanidades}

Religión y teología; Lenguas y culturas extranjeras: lenguas vivas o muertas y sus respectivas literaturas, estudios regionales interdisciplinarios; Lenguas autóctonas: lenguas corrientes 0 vernáculas y su literatura; Otros programas de humanidades: interpretación y traducción, lingüística, literatura comparada, historia, arqueología, filosofía, ética.

\section{Ciencias sociales, educación comercial y derecho}

\section{Ciencias sociales y del comportamiento}

Economía, historia de la economía, ciencias políticas, sociología, demografía, antropología (excepto antropología física), etnología, futurología, psicología, geografía (excepto geografía física), estudios sobre paz y conflictos, derechos humanos.

\section{Periodismo e información}

Periodismo; bibliotecología y personal técnico de bibliotecas; personal técnico de museos y establecimientos similares; Técnicas de documentación; Archivología.

\section{Educación comercial y administración}

Comercio al por menor, comercialización, ventas, relaciones públicas, asuntos inmobiliarios; Gestión financiera, administración bancaria, seguros, análisis de inversiones; Contabilidad,

\footnotetext{
${ }^{17}$ Primer Nivel: Graduados que hacen 3-4 años de Educación superior. No dan acceso directo a doctorado Segundo nivel: Graduados con 4 años de Educación superior o más. Dan acceso directo a doctorado.
} 
auditoría, teneduría de libros; Gestión, administración pública, administración institucional, administración de personal; Secretariado y trabajo de oficina.

38 Derecho

Magistrados locales, notarios, derecho (general, internacional, laboral, marítimo, etc.), jurisprudencia, historia del derecho.

\section{Ciencias}

\section{Ciencias de la vida}

Biología, botánica, bacteriología, toxicología, microbiología, zoología, entomología, ornitología, genética, bioquímica, biofísica, otras ciencias afines, excepto medicina y veterinaria.

\section{Ciencias físicas}

Astronomía y ciencias espaciales, física y asignaturas afines, química y asignaturas afines, geología, geofísica, mineralogía, antropología física, geografía física y demás ciencias de la tierra, meteorología y demás ciencias de la atmósfera, comprendida la investigación sobre el clima, las ciencias marinas, vulcanología, paleoecología.

\section{Matemáticas y estadística}

Matemáticas, investigación de operaciones, análisis numérico, ciencias actuariales, estadística y otros sectores afines.

\section{Informática}

Informática: Concepción de sistemas, programación informática, procesamiento de datos, redes, sistemas operativos - elaboración de programas informáticos solamente (el material y equipo se deben clasificar en el sector de la ingeniería).

\section{Ingeniería, industria y construcción}

\section{Ingeniería y profesiones afines}

Dibujo técnico, mecánica, metalistería, electricidad, electrónica, telecomunicaciones, ingeniería energética y química, mantenimiento de vehículos, topografía.

\section{Industria y producción}

Alimentación y bebidas, textiles, confección, calzado, cuero, materiales (madera, papel, plástico, vidrio, etc.), minería e industrias extractivas.

\section{Arquitectura y construcción}

Arquitectura y urbanismo: arquitectura estructural, arquitectura paisajística, planificación comunitaria, cartografía; Edificación, construcción; Ingeniería civil.

\section{Agricultura}

\section{Agricultura, silvicultura y pesca}

Agricultura, producción agropecuaria, agronomía, ganadería, horticultura y jardinería, silvicultura y técnicas forestales, parques naturales, flora y fauna, pesca, ciencia y tecnología pesqueras.

\section{Veterinaria}

Veterinaria, auxiliar de veterinaria.

\section{Salud y servicios sociales}




\section{Medicina}

Medicina: anatomía, epidemiología, citología, fisiología, inmunología e inmunohematología, patología, anestesiología, pediatría, obstetricia y ginecología, medicina interna, cirugía, neurología, psiquiatría, radiología, oftalmología; Servicios médicos: servicios de salud pública, higiene, farmacia, farmacología, terapéutica, rehabilitación, prótesis, optometría, nutrición; Enfermería: enfermería básica, partería; Servicios dentales: auxiliar de odontología, higienista dental, técnico de laboratorio dental, odontología.

\section{Servicios sociales}

Asistencia social: asistencia a minusválidos, asistencia a la infancia, servicios para jóvenes, servicios de gerontología; Trabajo social: orientación, asistencia social.

\section{Servicios}

\section{Servicios personales}

Hotelería y restaurantes, viajes y turismo, deportes y actividades recreativas, peluquería, tratamientos de belleza y otros servicios personales: lavandería y tintorería, servicios cosméticos, ciencias del hogar.

\section{Servicios de transporte}

Formación de marinos, oficiales de marina, náutica, tripulación de aviones, control del tráfico aéreo, transporte ferroviario, transporte por carretera, servicios postales.

\section{Protección del medio ambiente}

Conservación, vigilancia y protección del medio ambiente, control de la contaminación atmosférica y del agua, ergonomía y seguridad.

\section{Servicios de seguridad}

Protección de personas y bienes: servicios de policía y orden público, criminología, prevención y extinción de incendios, seguridad civil; Educación militar. 
Anexo C. Lista de Ocupaciones. 
Anexo C. Lista de Ocupaciones

Según Clasificación Internacional Uniforme de Ocupaciones (CIUO-88), Organización Internacional del Trabajo OIT.

Grandes grupos, subgrupos principales y subgrupos

Gran grupo 1: Miembros del poder ejecutivo y de los cuerpos legislativos y personal directivo de la administración pública y de empresas

11 Miembros del poder ejecutivo y de los cuerpos legislativos y personal directivo de la administración Pública.

111 Miembros del poder ejecutivo y de los cuerpos legislativos.

112 Personal directivo de la administración pública.

113 Jefes de pequeñas poblaciones.

114 Dirigentes y administradores de organizaciones especializadas.

12 Directores de empresas.

121 Directores generales y gerentes generales de empresa.

122 Directores de departamentos de producción y operaciones.

123 Otros directores de departamentos.

13 Gerentes de empresa.

131 Gerentes de empresa.

Gran grupo 2: Profesionales científicos e intelectuales.

21 Profesionales de las ciencias físicas, químicas y matemáticas y de la ingeniería.

211 Físicos, químicos y afines.

212 Matemáticos, estadísticos y afines.

213 Profesionales de la informática.

214 Arquitectos, ingenieros y afines. 
22 Profesionales de las ciencias biológicas, la medicina y la salud.

221 Profesionales en ciencias biológicas y otras disciplinas relativas a los seres orgánicos.

222 Médicos y profesionales afines (excepto el personal de enfermería y partería).

223 Personal de enfermería y partería de nivel superior.

23 Profesionales de la enseñanza.

231 Profesores de universidades y otros establecimientos de la enseñanza superior.

232 Profesores de la enseñanza secundaria.

233 Maestros de nivel superior de la enseñanza primaria y preescolar.

234 Maestros e instructores de nivel superior de la enseñanza especial.

235 Otros profesionales de la enseñanza.

24 Otros profesionales cientificos e intelectuales.

241 Especialistas en organización y administración de empresas y afines.

242 Profesionales del derecho.

243 Archiveros, bibliotecarios, documentalistas y afines.

244 Especialistas en ciencias sociales y humanas.

245 Escritores, artistas creativos y ejecutantes.

246 Sacerdotes de distintas religiones.

Gran grupo 3: Técnicos y profesionales de nivel medio.

31 Técnicos y profesionales de nivel medio de las ciencias físicas y químicas, la ingeniería y afines.

311 Técnicos en ciencias físicas y químicas y en ingeniería.

312 Técnicos en programación y control informáticos.

313 Operadores de equipos ópticos y electrónicos.

314 Técnicos en navegación marítima y aeronáutica. 
315 Inspectores de obras, seguridad y salud y control de calidad.

32 Técnicos y profesionales de nivel medio de las ciencias biológicas, la medicina y la salud.

321 Técnicos de nivel medio en ciencias biológicas, agronomía, zootecnia y afines.

322 Profesionales de nivel medio de la medicina moderna y la salud (excepto el personal de enfermería y partería).

323 Personal de enfermería y partería de nivel medio.

324 Practicantes de la medicina tradicional y curanderos.

33 Maestros e instructores de nivel medio.

331 Maestros de nivel medio de la enseñanza primaria.

332 Maestros de nivel medio de la enseñanza preescolar.

333 Maestros de nivel medio de la enseñanza especial.

334 Otros maestros e instructores de nivel medio.

34 Otros técnicos y profesionales de nivel medio.

341 Profesionales de nivel medio en operaciones financieras y comerciales.

342 Agentes comerciales y corredores.

343 Profesionales de nivel medio de servicios de administración.

344 Agentes de las administraciones públicas de aduanas, impuestos y afines.

345 Inspectores de policía y detectives.

346 Trabajadores y asistentes sociales de nivel medio.

347 Profesionales de nivel medio de actividades artísticas, espectáculos y deportes.

348 Auxiliares laicos de los cultos.

Gran grupo 4: Empleados de oficina.

\section{Oficinistas.}

411 Secretarios y operadores de máquinas de oficina.

412 Auxiliares contables y financieros. 
413 Empleados encargados del registro de materiales y de transportes.

414 Empleados de bibliotecas y servicios de correos y afines.

419 Otros oficinistas.

42 Empleados en trato directo con el público.

421 Cajeros, taquilleros y afines.

422 Empleados de servicios de información a la clientela.

Gran grupo 5: Trabajadores de los servicios y vendedores de comercios y mercados.

51 Trabajadores de los servicios personales y de los servicios de protección y seguridad.

511 Personal al servicio directo de los pasajeros.

512 Personal de intendencia y de restauración.

513 Trabajadores de los cuidados personales y afines.

514 Otros trabajadores de servicios personales a particulares.

515 Astrólogos, adivinadores y afines.

516 Personal de los servicios de protección y seguridad.

52 Modelos, vendedores y demostradores.

521 Modelos de modas, arte y publicidad.

522 Vendedores y demostradores de tiendas y almacenes.

523 Vendedores de quioscos y de puestos de mercado.

Gran grupo 6: Agricultores y trabajadores calificados agropecuarios y pesqueros.

61 Agricultores y trabajadores calificados de explotaciones agropecuarias, forestales $y$ pesqueras con destino al mercado.

611 Agricultores y trabajadores calificados de cultivos para el mercado.

612 Criadores y trabajadores pecuarios calificados de la cría de animales para el mercado y afines.

613 Productores y trabajadores agropecuarios calificados cuya producción se destina al mercado. 
614 Trabajadores forestales calificados y afines.

615 Pescadores, cazadores y tramperos.

62 Trabajadores agropecuarios y pesqueros de subsistencia.

621 Trabajadores agropecuarios y pesqueros de subsistencia.

Gran grupo 7: Oficiales, operarios y artesanos de artes mecánicas y de otros oficios.

71 Oficiales y operarios de las industrias extractivas y de la construcción.

711 Mineros, canteros, pegadores y labrantes de piedra.

712 Oficiales y operarios de la construcción (obra gruesa) y afines.

713 Oficiales y operarios de la construcción (trabajos de acabado) y afines.

714 Pintores, limpiadores de fachadas y afines.

72 Oficiales y operarios de la metalurgia, la construcción mecánica y afines.

721 Moldeadores, soldadores, chapistas, caldereros, montadores de estructuras metálicas y afines.

722 Herreros, herramientitas y afines.

723 Mecánicos y ajustadores de máquinas.

724 Mecánicos y ajustadores de equipos eléctricos y electrónicos.

73 Mecánicos de precisión, artesanos, operarios de las artes gráficas y afines.

731 Mecánicos de precisión en metales y materiales similares.

732 Alfareros, operarios de cristalerías y afines.

733 Artesanos de la madera, tejidos, cuero y materiales similares.

734 Oficiales y operarios de las artes gráficas y afines.

74 Otros oficiales, operarios y artesanos de artes mecánicas y de otros oficios.

741 Oficiales y operarios del procesamiento de alimentos y afines.

742 Oficiales y operarios del tratamiento de la madera, ebanistas y afines.

743 Oficiales y operarios de los textiles y de la confección y afines. 
744 Oficiales y operarios de las pieles, cuero y calzado.

Gran grupo 8: Operadores de instalaciones y máquinas y montadores.

\section{Operadores de instalaciones fijas y afines.}

811 Operadores de instalaciones mineras y de extracción y procesamiento de minerales.

812 Operadores de instalaciones de procesamiento de metales.

813 Operadores de instalaciones de vidriería, cerámica y afines.

814 Operadores de instalaciones de procesamiento de la madera y de la fabricación de papel.

815 Operadores de instalaciones de tratamientos químicos.

816 Operadores de instalaciones de producción de energía y afines.

817 Operadores de cadenas de montaje automatizadas y de robots industriales.

\section{Operadores de máquinas y montadores.}

821 Operadores de máquinas para trabajar metales y productos minerales.

822 Operadores de máquinas para fabricar productos químicos.

823 Operadores de máquinas para fabricar productos de caucho y de material plástico.

824 Operadores de máquinas para fabricar productos de madera.

825 Operadores de máquinas de imprenta, encuadernación y fabricación de productos de papel.

826 Operadores de máquinas para fabricar productos textiles y artículos de piel y cuero.

827 Operadores de máquinas para elaborar alimentos y productos afines.

828 Montadores.

829 Otros operadores de máquinas y montadores.

83 Conductores de vehículos y operadores de equipos pesados móviles.

831 Maquinistas de locomotoras y afines.

832 Conductores de vehículos de motor.

833 Operadores de maquinaria agrícola móvil y de otras máquinas móviles. 
834 Marineros de cubierta y afines.

Gran grupo 9: Trabajadores no calificados

91 Trabajadores no calificados de ventas y servicios.

911 Vendedores ambulantes y afines.

912 Limpiabotas y otros trabajadores callejeros.

913 Personal doméstico y afines, limpiadores, lavanderos y planchadores.

914 Conserjes, lavadores de ventanas y afines.

915 Mensajeros, porteadores, porteros y afines.

916 Recolectores de basura y afines.

92 Peones agropecuarios, forestales, pesqueros y afines.

921 Peones agropecuarios, forestales, pesqueros y afines.

93 Peones de la minería, la construcción, la industria manufacturera y el transporte.

931 Peones de la minería y la construcción.

932 Peones de la industria manufacturera.

933 Peones del transporte.

Gran grupo 0: Fuerzas armadas.

01 Fuerzas armadas. 
Anexo D. Lista de Sector Económico Encuesta Proflex 
Anexo D. Lista de Sector Económico Encuesta Proflex

Según Clasificación Nacional de Actividades Económicas

\section{SECTOR PRIMARIO}

01 - Agricultura, ganadería y silvicultura

02 - Pesca y piscicultura

\section{SECTOR INDUSTRIAL}

03 - Energía y agua ("Extracción y transformación de minerales energéticos" y "Captación, depuración y distribución de agua”)

04 - Industria de bienes intermedios ("Extracción y transformación de minerales no energéticos" $y$ "Productos químicos")

05 - Industria de bienes de capital ("Fabricación de productos metálicos, máquinas, equipos mecánicos y material de transporte")

06 - Industria de bienes de consumo ("Producción de manufacturas, alimentos, textiles, madera, papel, etc.")

07 - Construcción

\section{SECTOR SERVICIOS}

08 - Transportes

09 - Correo y telecomunicaciones

$10-$ Comercio

11 - Servicios de recuperación y reparación

12 - Hostelería y restauración

13 - Instituciones financieras

$14-$ Seguros

15 - Servicios a Empresas

16 - Servicios de alquiler de bienes muebles

17 - Servicios de alquiler de bienes inmuebles

18 - Educación e investigación

19 - Sanidad 
20 - Administración

21 - Servicios públicos

22 - Servicios sociales

23 - Servicios recreativos y culturales

24 - Servicios personales

25 - Servicios domésticos

26 - Representación internacional 

Anexo E. Codificación de Variables 


\section{Anexo E. Codificación de Variables}

\begin{tabular}{|c|c|}
\hline PREGUNTA & NOMBRE DE LA VARIABLE \\
\hline \multicolumn{2}{|c|}{ Muestra Reflex y Proflex } \\
\hline 1.Procedencia de la Muestra & Muestra \\
\hline 3.Continente de referencia & Continente \\
\hline 4.Ponderación país & Pond \\
\hline 6. ¿Cuál es tu ocupación o Puesto? & Ocupación \\
\hline \multicolumn{2}{|l|}{ 7. ¿Qué tipo de Contrato Tienes Actualmente? } \\
\hline Contrato Indefinido & Contrato \\
\hline
\end{tabular}




\begin{tabular}{|c|c|}
\hline \multicolumn{2}{|l|}{ Trabajo Actual } \\
\hline Contrato Temporal & CTemporal \\
\hline 8. ¿Cuál es el promedio de horas que trabajas a la semana? & \\
\hline Horas Según contrato & HContrato \\
\hline Horas Total & HTotal \\
\hline 9. ¿Cuál es aproximadamente tu sueldo mensual bruto? & \\
\hline Sueldo o base regular & SContrato \\
\hline Sueldo Total & STotal \\
\hline 10. Paridad de Poder Adquisitivo (PPA) & F7PPP \\
\hline $\begin{array}{l}\text { 11. Según tu opinión ¿Cuál es el área de estudios más apropiado para este trabajo? } \\
\text { Exclusivamente tu propia área de estudios, Tu propia área o alguna relacionada, Un área totalmente } \\
\text { diferente, Ningún área en particular. }\end{array}$ & AHorizontal \\
\hline
\end{tabular}




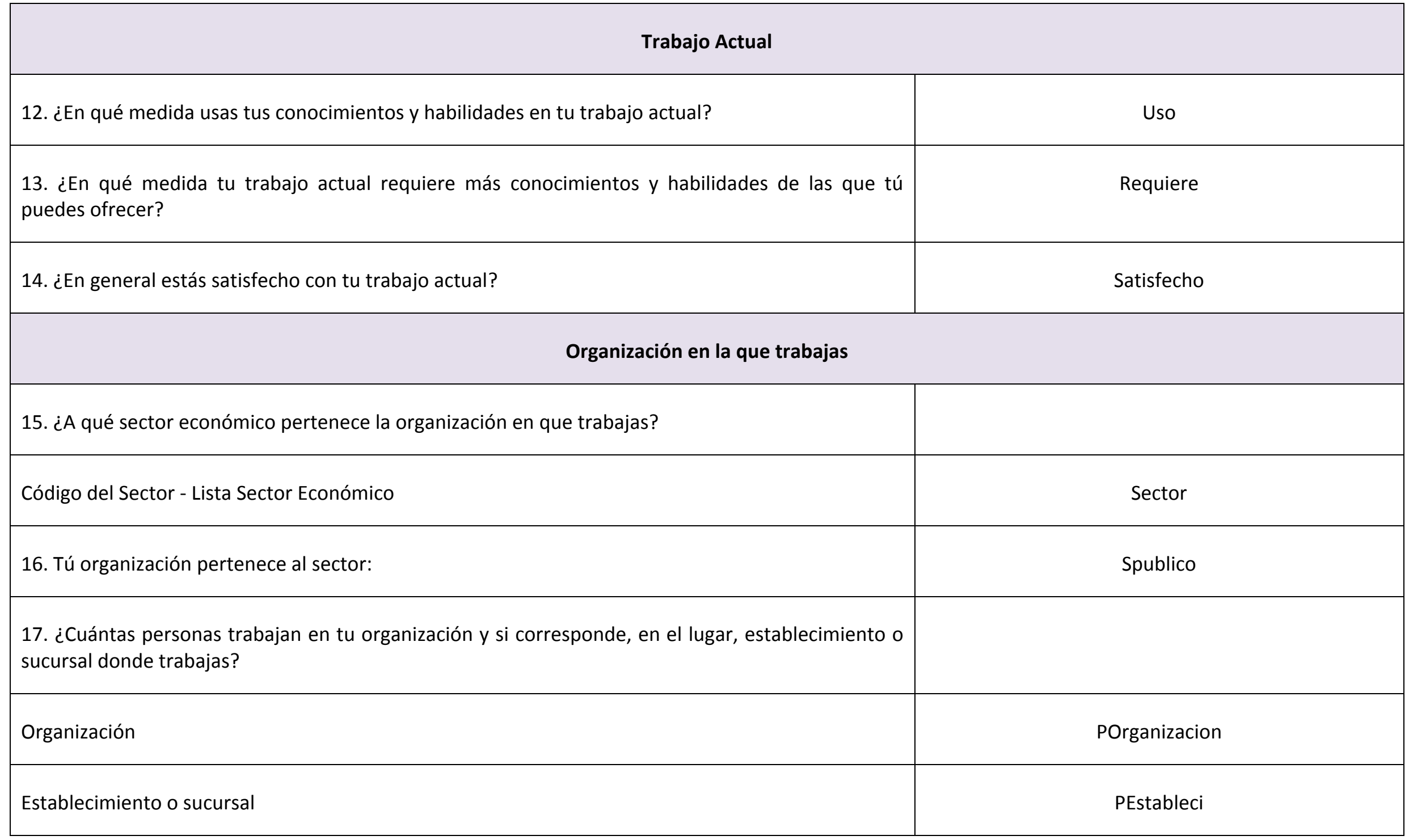




\begin{tabular}{|c|c|}
\hline \multicolumn{2}{|l|}{ Organización en la que trabajas } \\
\hline 18. En qué medida eres responsable de... & \\
\hline ¿Establecer objetivos para la organización? & ObjetivosOrg \\
\hline ¿Decidir estrategias de trabajo para la organización? & Estrategias \\
\hline ¿Decidir cómo hacer tu trabajo? & Decidir \\
\hline Mantengo informados a mis compañeros de profesión sobre nuevos desarrollos en mi campo & Información \\
\hline Suelo iniciar relaciones profesionales con expertos ajenos a la organización & Relación \\
\hline Las cuestiones de ética profesional forman parte importante de mis funciones & Ética \\
\hline
\end{tabular}




\section{Organización en la que trabajas}

20. ¿Cuánto Perjudicarías a tu organización si cometieras un error grave en tu trabajo?

Perjuicio

\begin{tabular}{|l|l|}
\hline \multicolumn{2}{|c|}{ Competencias (Conocimientos, habilidades y destrezas) Parte A } \\
\hline \multicolumn{1}{|c|}{ PREGUNTA } & NOMBRE DE LA VARIABLE \\
\hline 21. A Cómo Valoras tu actual nivel de competencias? & H1OWNFO \\
\hline a. Dominio de tu área o disciplina. & H1OTHFO \\
\hline b. Conocimientos de otras áreas o disciplinas. & H1ANALYO \\
\hline c. Pensamiento analítico. & H1ACKNOO \\
\hline d. Capacidad para adquirir con rapidez nuevos conocimientos. & H1NEGOTO \\
\hline e. Capacidad para negociar de forma eficaz. & \\
\hline
\end{tabular}




\begin{tabular}{|c|c|}
\hline \multicolumn{2}{|c|}{ Competencias (Conocimientos, habilidades y destrezas) Parte A } \\
\hline PREGUNTA & NOMBRE DE LA VARIABLE \\
\hline f. Capacidad para trabajar bajo presión. & H1PRESSO \\
\hline g. Capacidad para detectar nuevas oportunidades. & H1ALERTO \\
\hline h. Capacidad para coordinar actividades. & H1COORDO \\
\hline i. Capacidad para usar el tiempo de forma efectiva. & H1UTIMEO \\
\hline j. $\quad$ Capacidad para trabajar en equipo. & H1WWOTHO \\
\hline k. Capacidad para movilizar las capacidades de otros. & Н1МОВото \\
\hline I. Capacidad para hacerte entender. & H1CMEANO \\
\hline m. Capacidad para hacer valer tu autoridad. & H1AUTHOO \\
\hline n. Capacidad para utilizar herramientas informáticas. & H1COMPUO \\
\hline
\end{tabular}




\begin{tabular}{|c|c|}
\hline \multicolumn{2}{|c|}{ Competencias (Conocimientos, habilidades y destrezas) Parte A } \\
\hline PREGUNTA & NOMBRE DE LA VARIABLE \\
\hline o. Capacidad para encontrar nuevas ideas y soluciones. & H1SOLUTO \\
\hline q. Capacidad para presentar en público productos, ideas o informes. & H1PRESEO \\
\hline r. Capacidad para redactar informes o documentos. & H1WRITEO \\
\hline PREGUNTA & NOMBRE DE LA VARIABLE \\
\hline \multicolumn{2}{|l|}{ 21. B Que nivel de competencias necesitas en tu trabajo actual? } \\
\hline a. Dominio de tu área o disciplina. & H1OWNFR \\
\hline
\end{tabular}




\begin{tabular}{|c|c|}
\hline \multicolumn{2}{|c|}{ Competencias (Conocimientos, habilidades y destrezas) Parte B } \\
\hline PREGUNTA & NOMBRE DE LA VARIABLE \\
\hline b. Conocimientos de otras áreas o disciplinas. & H1OTHFR \\
\hline c. Pensamiento analítico. & H1ANALYR \\
\hline d. Capacidad para adquirir con rapidez nuevos conocimientos. & H1ACKNOR \\
\hline e. Capacidad para negociar de forma eficaz. & H1NEGOTR \\
\hline f. Capacidad para trabajar bajo presión. & H1PRESSR \\
\hline g. Capacidad para detectar nuevas oportunidades. & H1ALERTR \\
\hline h. Capacidad para coordinar actividades. & H1COORDR \\
\hline i. Capacidad para usar el tiempo de forma efectiva. & H1UTIMER \\
\hline j. $\quad$ Capacidad para trabajar en equipo. & H1WWOTHR \\
\hline
\end{tabular}




\begin{tabular}{|c|c|}
\hline \multicolumn{2}{|c|}{ Competencias (Conocimientos, habilidades y destrezas) Parte B } \\
\hline PREGUNTA & NOMBRE DE LA VARIABLE \\
\hline k. Capacidad para movilizar las capacidades de otros. & H1MOВOTR \\
\hline m. Capacidad para hacer valer tu autoridad. & H1AUTHOR \\
\hline n. Capacidad para utilizar herramientas informáticas. & H1COMPUR \\
\hline q. Capacidad para presentar en público productos, ideas o informes. & H1PRESER \\
\hline r. Capacidad para redactar informes o documentos. & H1WRITER \\
\hline s. Capacidad para escribir y hablar en idiomas extranjeros. & H1FLANGR \\
\hline
\end{tabular}




\begin{tabular}{|c|c|}
\hline \multicolumn{2}{|c|}{ Valores Laborales Parte A. } \\
\hline PREGUNTA & NOMBRE DE LA VARIABLE \\
\hline 22. A Indica la importancia que las siguientes características del tra & \\
\hline a. Autonomía en el trabajo & J1AUTONI \\
\hline b. Estabilidad laboral & J1SECURE \\
\hline c. Oportunidad de aprender cosas nuevas & J1LEARNI \\
\hline d. Ingresos elevados & J1EARNI1 \\
\hline e. Afrontar nuevos retos & J1CHALLI \\
\hline f. Buenas perspectivas profesionales & J1CAREEI \\
\hline g. Tener tiempo para actividades recreativas & J1LEISUI \\
\hline h. Reconocimiento/prestigio social & J1STATUI \\
\hline
\end{tabular}




\begin{tabular}{|c|c|}
\hline PREGUNTA & NOMBRE DE LA VARIABLE \\
\hline i. Oportunidad de hacer algo útil para la sociedad & J1USEFUI \\
\hline \multicolumn{2}{|c|}{ Valores Laborales Parte B. } \\
\hline \multicolumn{2}{|l|}{ 22. B En qué medida se aplican a tu situación laboral actual. } \\
\hline c. Oportunidad de aprender cosas nuevas & J1LEARNA \\
\hline d. Ingresos elevados & J1EARNIA \\
\hline e. Afrontar nuevos retos & J1CHALLA \\
\hline
\end{tabular}




\begin{tabular}{|c|c|}
\hline f. Buenas perspectivas profesionales & J1CAREEA \\
\hline g. Tener tiempo para actividades recreativas & J1LEISUA \\
\hline h. Reconocimiento/prestigio social & J1STATUA \\
\hline i. Oportunidad de hacer algo útil para la sociedad & J1USEFUA \\
\hline j. Facilidad para combinar trabajo y familia & J1FAMILA \\
\hline \multicolumn{2}{|c|}{ Información Personal } \\
\hline 23. Género & Sexo \\
\hline 24. Año de Nacimiento & Año \\
\hline 25. Edad & Edad \\
\hline 26. ¿Cómo vives actualmente? & Vive \\
\hline 27. ¿Tienes hijos? & Hijos \\
\hline
\end{tabular}



Anexo F. Resumen del Análisis Exploratorio: Éxito Laboral Objetivo y Subjetivo, Rol, Competencias, Valores Laborales 
Anexo F: Resumen del Análisis Exploratorio: Éxito Laboral Objetivo y Subjetivo, Rol (Funciones), Competencias, Valores Laborales.

\begin{tabular}{|c|c|c|c|c|c|c|c|c|c|c|}
\hline \multicolumn{11}{|c|}{ Éxito Laboral (Exlab) } \\
\hline Variable & Tipo & Min & Max & Media & Mediana & $\begin{array}{c}\text { Desviación } \\
\text { Típica }\end{array}$ & Asimetría & Curtosis & $\begin{array}{c}\text { Sig. } \\
\text { (Normalidad) }\end{array}$ & $\begin{array}{c}\text { Estimador } \\
\text { M-Huber }\end{array}$ \\
\hline HContrato & Escala & 1 & 98 & 37,28 & 40 & 10,00 & $-0,602$ & 3,920 & 0,00 & 38,78 \\
\hline HTotal & Escala & 1 & 98 & 41,99 & 41 & 12,61 & 0,185 & 2,788 & 0,00 & 41,98 \\
\hline SContrato & Escala & 0 & 14677 & 1924 & 1594 & 1401 & 1,147 & 1,762 & 0,00 & 1689 \\
\hline STotal & Escala & 0 & 14677 & 2059 & 1670 & 1553 & 1,633 & 4,841 & 0,00 & 1776 \\
\hline Variable & Tipo & \multicolumn{2}{|c|}{ Moda } & Mediana & Mínimo & Máximo & Recorrido & $\begin{array}{c}\text { Percentil } \\
25\end{array}$ & Percentil 50 & $\begin{array}{c}\text { Percentil } \\
75\end{array}$ \\
\hline Uso & Ordinal & \multicolumn{2}{|r|}{5} & 4 & 1 & 5 & 4 & 3 & 4 & 5 \\
\hline Requiere & Ordinal & \multicolumn{2}{|r|}{3} & 3 & 1 & 5 & 4 & 2 & 3 & 4 \\
\hline Satisfecho & Ordinal & \multicolumn{2}{|r|}{4} & 4 & 1 & 5 & 4 & 3 & 4 & 5 \\
\hline \multicolumn{11}{|c|}{ Rol (Funciones) } \\
\hline Variable & Tipo & \multicolumn{2}{|c|}{ Moda } & Mediana & Mínimo & Máximo & Recorrido & $\begin{array}{l}\text { Percentil } \\
25\end{array}$ & Percentil 50 & $\begin{array}{c}\text { Percentil } \\
75\end{array}$ \\
\hline AHorizontal & Ordinal & \multicolumn{2}{|r|}{2} & 2 & 1 & 4 & 3 & 1 & 2 & 2 \\
\hline
\end{tabular}




\begin{tabular}{|c|c|c|c|c|c|c|c|c|c|}
\hline \multicolumn{10}{|c|}{ Rol (Funciones) } \\
\hline Variable & Tipo & Moda & Mediana & Mínimo & Máximo & Recorrido & $\begin{array}{c}\text { Percentil } \\
25\end{array}$ & Percentil 50 & $\begin{array}{c}\text { Percentil } \\
75\end{array}$ \\
\hline ObjetivosOrg & Ordinal & 1 & 2 & 1 & 5 & 4 & 1 & 2 & 4 \\
\hline ObjetivosTrab & Ordinal & 5 & 4 & 1 & 5 & 4 & 4 & 4 & 5 \\
\hline Estrategias & Ordinal & 1 & 3 & 1 & 5 & 4 & 1 & 3 & 4 \\
\hline Decidir & Ordinal & 5 & 5 & 1 & 5 & 4 & 4 & 5 & 5 \\
\hline Consejo & Ordinal & 4 & 4 & 1 & 5 & 4 & 3 & 4 & 4 \\
\hline Información & Ordinal & 4 & 3 & 1 & 5 & 4 & 3 & 3 & 4 \\
\hline Relación & Ordinal & 3 & 3 & 1 & 5 & 4 & 2 & 3 & 4 \\
\hline Ética & Ordinal & 5 & 4 & 1 & 5 & 4 & 3 & 4 & 5 \\
\hline Perjuicio & Ordinal & 4 & 4 & 1 & 5 & 4 & 3 & 4 & 5 \\
\hline \multicolumn{10}{|c|}{ Competencias Nivel Propio y Requerido en el Puesto de trabajo } \\
\hline Variable & Tipo & Moda & Mediana & Mínimo & Máximo & Recorrido & $\begin{array}{c}\text { Percentil } \\
25\end{array}$ & Percentil 50 & $\begin{array}{c}\text { Percentil } \\
75\end{array}$ \\
\hline H1OWNFO & Ordinal & 6 & 5 & 1 & 7 & 6 & 5 & 5 & 6 \\
\hline H1OTHFO & Ordinal & 5 & 5 & 1 & 7 & 6 & 4 & 5 & 5 \\
\hline H1ANALYO & Ordinal & 6 & 6 & 1 & 7 & 6 & 5 & 6 & 6 \\
\hline
\end{tabular}




\begin{tabular}{|c|c|c|c|c|c|c|c|c|c|}
\hline \multicolumn{10}{|c|}{ Competencias Nivel Propio y Requerido en el Puesto de trabajo } \\
\hline Variable & Tipo & Moda & Mediana & Mínimo & Máximo & Recorrido & $\begin{array}{l}\text { Percentil } \\
25\end{array}$ & Percentil 50 & $\begin{array}{c}\text { Percentil } \\
75\end{array}$ \\
\hline H1ACKNOO & Ordinal & 6 & 6 & 1 & 7 & 6 & 5 & 6 & 7 \\
\hline H1NEGOTO & Ordinal & 5 & 5 & 1 & 7 & 6 & 4 & 5 & 6 \\
\hline H1PRESSO & Ordinal & 6 & 6 & 1 & 7 & 6 & 5 & 6 & 6 \\
\hline H1ALERTO & Ordinal & 5 & 5 & 1 & 7 & 6 & 4 & 5 & 6 \\
\hline H1COORDO & Ordinal & 6 & 6 & 1 & 7 & 6 & 5 & 6 & 6 \\
\hline H1UTIMEO & Ordinal & 6 & 6 & 1 & 7 & 6 & 5 & 6 & 6 \\
\hline H1WWOTHO & Ordinal & 6 & 6 & 1 & 7 & 6 & 5 & 6 & 6 \\
\hline Н1MOBOTO & Ordinal & 5 & 5 & 1 & 7 & 6 & 4 & 5 & 6 \\
\hline H1CMEANO & Ordinal & 6 & 6 & 1 & 7 & 6 & 5 & 6 & 6 \\
\hline H1AUTHOO & Ordinal & 5 & 5 & 1 & 7 & 6 & 4 & 5 & 6 \\
\hline H1COMPUO & Ordinal & 7 & 6 & 1 & 7 & 6 & 5 & 6 & 7 \\
\hline H1SOLUTO & Ordinal & 6 & 6 & 1 & 7 & 6 & 5 & 6 & 6 \\
\hline H1QUESTO & Ordinal & 6 & 6 & 1 & 7 & 6 & 5 & 6 & 6 \\
\hline H1PRESEO & Ordinal & 6 & 5 & 1 & 7 & 6 & 4 & 5 & 6 \\
\hline H1WRITEO & Ordinal & 6 & 6 & 1 & 7 & 6 & 5 & 6 & 6 \\
\hline
\end{tabular}




\begin{tabular}{|c|c|c|c|c|c|c|c|c|c|}
\hline \multicolumn{10}{|c|}{ Competencias Nivel Propio y Requerido en el Puesto de trabajo } \\
\hline Variable & Tipo & Moda & Mediana & Mínimo & Máximo & Recorrido & $\begin{array}{c}\text { Percentil } \\
25\end{array}$ & Percentil 50 & $\begin{array}{c}\text { Percentil } \\
75\end{array}$ \\
\hline H1LANGO & Ordinal & 6 & 5 & 1 & 7 & 6 & 3 & 5 & 6 \\
\hline H1OWNFR & Ordinal & 6 & 6 & 1 & 7 & 6 & 5 & 6 & 7 \\
\hline H1OTHFR & Ordinal & 4 & 4 & 1 & 7 & 6 & 3 & 4 & 6 \\
\hline H1ANALYR & Ordinal & 6 & 5 & 1 & 7 & 6 & 4 & 5 & 6 \\
\hline H1ACKNOR & Ordinal & 6 & 6 & 1 & 7 & 6 & 5 & 6 & 7 \\
\hline H1NEGOTR & Ordinal & 6 & 5 & 1 & 7 & 6 & 4 & 5 & 6 \\
\hline H1PRESSR & Ordinal & 7 & 6 & 1 & 7 & 6 & 5 & 6 & 7 \\
\hline H1ALERTR & Ordinal & 6 & 5 & 1 & 7 & 6 & 4 & 5 & 6 \\
\hline H1COORDR & Ordinal & 6 & 6 & 1 & 7 & 6 & 5 & 6 & 7 \\
\hline H1UTIMER & Ordinal & 7 & 6 & 1 & 7 & 6 & 5 & 6 & 7 \\
\hline H1WWOTHR & Ordinal & 7 & 6 & 1 & 7 & 6 & 5 & 6 & 7 \\
\hline H1MOBOTR & Ordinal & 6 & 5 & 1 & 7 & 6 & 4 & 5 & 6 \\
\hline H1CMEANR & Ordinal & 6 & 6 & 1 & 7 & 6 & 5 & 6 & 7 \\
\hline H1AUTHOR & Ordinal & 6 & 5 & 1 & 7 & 6 & 4 & 5 & 6 \\
\hline H1COMPUR & Ordinal & 7 & 6 & 1 & 7 & 6 & 5 & 6 & 7 \\
\hline
\end{tabular}




\begin{tabular}{|l|c|c|c|c|c|c|c|c|}
\hline \multicolumn{1}{|c|}{ Variable } & Tipo & Moda & Mediana & Mínimo & Máximo & Recorrido & $\begin{array}{c}\text { Percentil } \\
\mathbf{2 5}\end{array}$ & $\begin{array}{c}\text { Percentil 50 } \\
\text { Percentil } \\
\mathbf{7 5}\end{array}$ \\
\hline H1SOLUTR & Ordinal & 6 & 6 & 1 & 7 & 6 & 4 & 6 \\
\hline H1QUESTR & Ordinal & 6 & 5 & 1 & 7 & 6 & 4 & 5 \\
\hline H1PRESER & Ordinal & 6 & 5 & 1 & 7 & 6 & 4 & 5 \\
\hline H1WRITER & Ordinal & 6 & 6 & 1 & 7 & 6 & 4 & 6 \\
\hline H1FLANGR & Ordinal & 1 & 4 & 1 & 7 & 6 & 2 & 4 \\
\hline
\end{tabular}

\begin{tabular}{|l|c|c|c|c|c|c|c|c|c|}
\hline \multicolumn{1}{|c|}{ Variable } & Tipo & Moda & Mediana & Mínimo & Máximo & Recorrido & $\begin{array}{c}\text { Percentil } \\
\mathbf{2 5}\end{array}$ & $\begin{array}{c}\text { Percentil 50 } \\
\text { Percentil } \\
\mathbf{7 5}\end{array}$ \\
\hline J1AUTONI & Ordinal & 5 & 4 & 1 & 5 & 4 & 4 & 4 & 5 \\
\hline J1SECURE & Ordinal & 5 & 5 & 1 & 5 & 4 & 4 & 5 & 5 \\
\hline J1LEARNI & Ordinal & 5 & 5 & 1 & 5 & 4 & 4 & 5 \\
\hline J1EARNI1 & Ordinal & 4 & 4 & 1 & 5 & 4 & 3 & 4 & 5 \\
\hline J1CHALLI & Ordinal & 4 & 4 & 1 & 5 & 4 & 4 & 4 \\
\hline
\end{tabular}




\begin{tabular}{|c|c|c|c|c|c|c|c|c|c|}
\hline \multicolumn{10}{|c|}{ Valores Laborales } \\
\hline Variable & Tipo & Moda & Mediana & Mínimo & Máximo & Recorrido & $\begin{array}{c}\text { Percentil } \\
25\end{array}$ & Percentil 50 & $\begin{array}{c}\text { Percentil } \\
75\end{array}$ \\
\hline J1CAREEI & Ordinal & 5 & 4 & 1 & 5 & 4 & 3 & 4 & 5 \\
\hline J1LEISUI & Ordinal & 5 & 4 & 1 & 5 & 4 & 4 & 4 & 5 \\
\hline J1STATUI & Ordinal & 4 & 3 & 1 & 5 & 4 & 3 & 3 & 4 \\
\hline J1USEFUI & Ordinal & 4 & 4 & 1 & 5 & 4 & 3 & 4 & 5 \\
\hline J1FAMILI & Ordinal & 5 & 4 & 1 & 5 & 4 & 4 & 4 & 5 \\
\hline J1AUTONA & Ordinal & 5 & 4 & 1 & 5 & 4 & 4 & 4 & 5 \\
\hline JISECURA & Ordinal & 5 & 4 & 1 & 5 & 4 & 3 & 4 & 5 \\
\hline J1LEARNA & Ordinal & 4 & 4 & 1 & 5 & 4 & 3 & 4 & 5 \\
\hline J1EARNIA & Ordinal & 3 & 3 & 1 & 5 & 4 & 2 & 3 & 4 \\
\hline J1CHALLA & Ordinal & 4 & 4 & 1 & 5 & 4 & 3 & 4 & 4 \\
\hline J1CAREEA & Ordinal & 3 & 3 & 1 & 5 & 4 & 2 & 3 & 4 \\
\hline J1LEISUA & Ordinal & 3 & 3 & 1 & 5 & 4 & 3 & 3 & 4 \\
\hline J1STATUA & Ordinal & 3 & 3 & 1 & 5 & 4 & 3 & 3 & 4 \\
\hline J1USEFUA & Ordinal & 4 & 4 & 1 & 5 & 4 & 3 & 4 & 4 \\
\hline J1FAMILA & Ordinal & 3 & 3 & 1 & 5 & 4 & 3 & 3 & 4 \\
\hline
\end{tabular}




\begin{tabular}{|l|c|c|c|c|c|c|c|c|c|}
\hline \multicolumn{10}{|c|}{ Información General } \\
\hline Variable & Tipo & Min & Max & Media & Mediana & $\begin{array}{c}\text { Desviación } \\
\text { Típica }\end{array}$ & Asimetría & Curtosis & $\begin{array}{c}\text { Sig. } \\
\text { (Normalidad) }\end{array}$ \\
\hline EDAD2 & Escala & 22 & 66 & 31,39 & 30 & 4,946 & 2,746 & 11,761 & 0,00 \\
\hline
\end{tabular}


Anexo G. Ajuste de los Valores Monetarios 
Anexo G: Ajuste de los valores monetarios

Tasas utilizadas en el cálculo del salario promedio mensual bruto según contrato y salario promedio total

El Salario promedio mensual bruto según contrato y el salario promedio calculado para los países de referencia en Dólares USD, están corregidos según el índice de precios al consumidor (IPC)* para el año 2013. Los coeficientes utilizados en la base de datos, tienen como país de referencia a España. Las tasas de la tabla se utilizaron en los resultados que se presentan en la tabla 5.10 del capítulo 5 de este documento.

A partir de los resultados obtenidos en Euros, se hicieron los cambios a dólares americanos, tomando como referencia los promedios de las tasas de cambio para el año 2005 en el caso de los graduados europeos y el promedio de la tasa de cambios del año 2007 para los graduados latinoamericanos.

Valores de referencia para elaborar la tabla de Salarios basada en IPC para L.A. y Europa

\begin{tabular}{|c|c|c|c|}
\hline \multicolumn{4}{|c|}{ Tasas Comparativas por Países según Indice de Precios. } \\
\hline Paises & IPC 2013 & $\begin{array}{c}\text { Razón Referencia a EEUU } \\
80,54\end{array}$ & $\begin{array}{c}\text { Razón Referencia España } \\
83,14\end{array}$ \\
\hline España & 83,14 & 1,032282096 & 1 \\
\hline Estados Unidos & 80,54 & 1 & 0,968727448 \\
\hline Argentina & 70,44 & 0,874596474 & 0,84724561 \\
\hline Bolivia & 41,50 & 0,515271915 & 0,499158047 \\
\hline Brasil & 70,00 & 0,86913335 & 0,841953332 \\
\hline Chile & 63,83 & 0,792525453 & 0,767741159 \\
\hline Colombia & 58,44 & 0,725602185 & 0,702910753 \\
\hline Honduras & 48,00 & 0,595977154 & 0,577339427 \\
\hline México & 53,56 & 0,665011175 & 0,644214578 \\
\hline \begin{tabular}{|l|} 
Puerto Rico \\
\end{tabular} & 80,54 & 1 & 0,968727448 \\
\hline Uruguay & 81,66 & 1,013906134 & 0,982198701 \\
\hline Panamá & 53,38 & 0,66277626 & 0,642049555 \\
\hline Latinoamérica & 61,735 & 0,766513534 & 0,742542699 \\
\hline España & 83,14 & 1,032282096 & 1 \\
\hline Francia & 103,24 & 1,281847529 & 1,241760885 \\
\hline Alemania & 91,64 & 1,137819717 & 1,10223719 \\
\hline R. Unido & 102,24 & 1,269431338 & 1,229732981 \\
\hline Suiza & 151,77 & 1,884405264 & 1,825475102 \\
\hline Paises Bajos & 103,9 & 1,290042215 & 1,249699302 \\
\hline Italia & 101,42 & 1,259250062 & 1,219870099 \\
\hline Austria & 97,88 & 1,215296747 & 1,177291316 \\
\hline Finlandia & 106,99 & 1,328408244 & 1,286865528 \\
\hline Noruega & 173,85 & 2,158554755 & 2,091051239 \\
\hline Rep.Checa & 63,35 & 0,786565682 & 0,761967765 \\
\hline Bélgica & 108,04 & 1,341445245 & 1,299494828 \\
\hline Estonia & 70,75 & 0,878445493 & 0,85097426 \\
\hline Unión Europea & 104,48 & 1,297243606 & 1,256675487 \\
\hline
\end{tabular}

Fuente: Elaboración Propia a partir de Indice de Precios al Consumo 2013.

http://www.numbeo.com/cost-of-living/gmaps_rankings_country.jsp?year=2013 
* CPI: Cost of Living Index by Country

Las tasas de Cambio de euros a dólares americanos USD utilizadas como referencia ${ }^{18}$ :

\begin{tabular}{|l|l|}
\hline OANDA: Euros a USD - Europa & $\begin{array}{l}\text { Tasa de Cambio promedio 2005: } \\
0.8043\end{array}$ \\
\hline OANDA: Euros a USD - L. América & $\begin{array}{l}\text { Tasa de Cambio promedio 2007: } \\
0.7306\end{array}$ \\
\hline
\end{tabular}

${ }^{18}$ OANDA: http://www.oanda.com/lang/es/currency/converter/ OECD StatExtracts: http://stats.oecd.org/Index.aspx?DatasetCode=SNA TABLE4 CPI: Cost of Living Index by Country: http://www.numbeo.com/cost-of-living/rankings by country.jsp 

Anexo H. Análisis de Correlaciones 
Anexo H: Análisis de Correlaciones

Tabla H.1. Correlaciones entre las variables de Éxito Laboral Objetivo

\begin{tabular}{|c|c|c|c|c|c|}
\hline Correlación & e Pearson & $\begin{array}{l}\text { Sueldo } \\
\text { Contrato } \\
\text { Igualado }\end{array}$ & $\begin{array}{l}\text { Sueldo } \\
\text { Total } \\
\text { Igualado }\end{array}$ & $\begin{array}{l}\text { ¿Cuál es el } \\
\text { promedio de } \\
\text { horas que } \\
\text { trabajas a la } \\
\text { semana? Según } \\
\text { contrato en el } \\
\text { trabajo principal }\end{array}$ & $\begin{array}{l}\text { ¿Cuál es el } \\
\text { promedio de } \\
\text { horas que } \\
\text { trabajas a la } \\
\text { semana? } \\
\text { Total }\end{array}$ \\
\hline $\begin{array}{l}\text { Sueldo } \\
\text { Contrato }\end{array}$ & $\begin{array}{c}\text { Correlación } \\
\text { de Pearson } \\
\text { Sig. } \\
\text { (bilateral) } \\
\mathrm{N}\end{array}$ & 25333 & $\begin{array}{l}, 910^{* *} \\
, 000 \\
25333\end{array}$ & $\begin{array}{l}, 314^{* *} \\
, 000 \\
25333\end{array}$ & $\begin{array}{l}, 286^{* *} \\
, 000 \\
25333\end{array}$ \\
\hline Sueldo Total & $\begin{array}{c}\text { Correlación } \\
\text { de Pearson } \\
\text { Sig. } \\
\text { (bilateral) } \\
\mathrm{N}\end{array}$ & $\begin{array}{l}, 910^{* *} \\
, 000 \\
25333 \\
\end{array}$ & 25333 & $\begin{array}{l}, 280^{* *} \\
, 000 \\
25333 \\
\end{array}$ & $\begin{array}{l}, 317^{* *} \\
, 000 \\
25333 \\
\end{array}$ \\
\hline $\begin{array}{l}\text { ¿Cuál es el } \\
\text { promedio de } \\
\text { horas que } \\
\text { trabajas a la } \\
\text { semana? } \\
\text { Según } \\
\text { contrato en el } \\
\text { trabajo } \\
\text { principal }\end{array}$ & $\begin{array}{c}\text { Correlación } \\
\text { de Pearson } \\
\text { Sig. } \\
\text { (bilateral) }\end{array}$ & $\begin{array}{l}, 314^{* *} \\
, 000\end{array}$ & $\begin{array}{l}, 280^{* *} \\
, 000\end{array}$ & 36449 & $\begin{array}{l}, 777^{* *} \\
, 000\end{array}$ \\
\hline $\begin{array}{l}\text { ¿Cuál es el } \\
\text { promedio de } \\
\text { horas que } \\
\text { trabajas a la } \\
\text { semana? } \\
\text { Total } \\
\end{array}$ & $\begin{array}{c}\text { Correlación } \\
\text { de Pearson } \\
\text { Sig. } \\
\text { (bilateral) } \\
\text { N }\end{array}$ & $\begin{array}{l}, 286^{* *} \\
, 000 \\
25333\end{array}$ & $\begin{array}{l}, 317^{* *} \\
, 000 \\
25333\end{array}$ & $\begin{array}{l}, 777^{* *} \\
, 000 \\
36449\end{array}$ & 36449 \\
\hline
\end{tabular}

**. La correlación es significativa al nivel 0,01 (bilateral). 
Tabla H2. Correlaciones entre las variables de Éxito Laboral Subjetivo

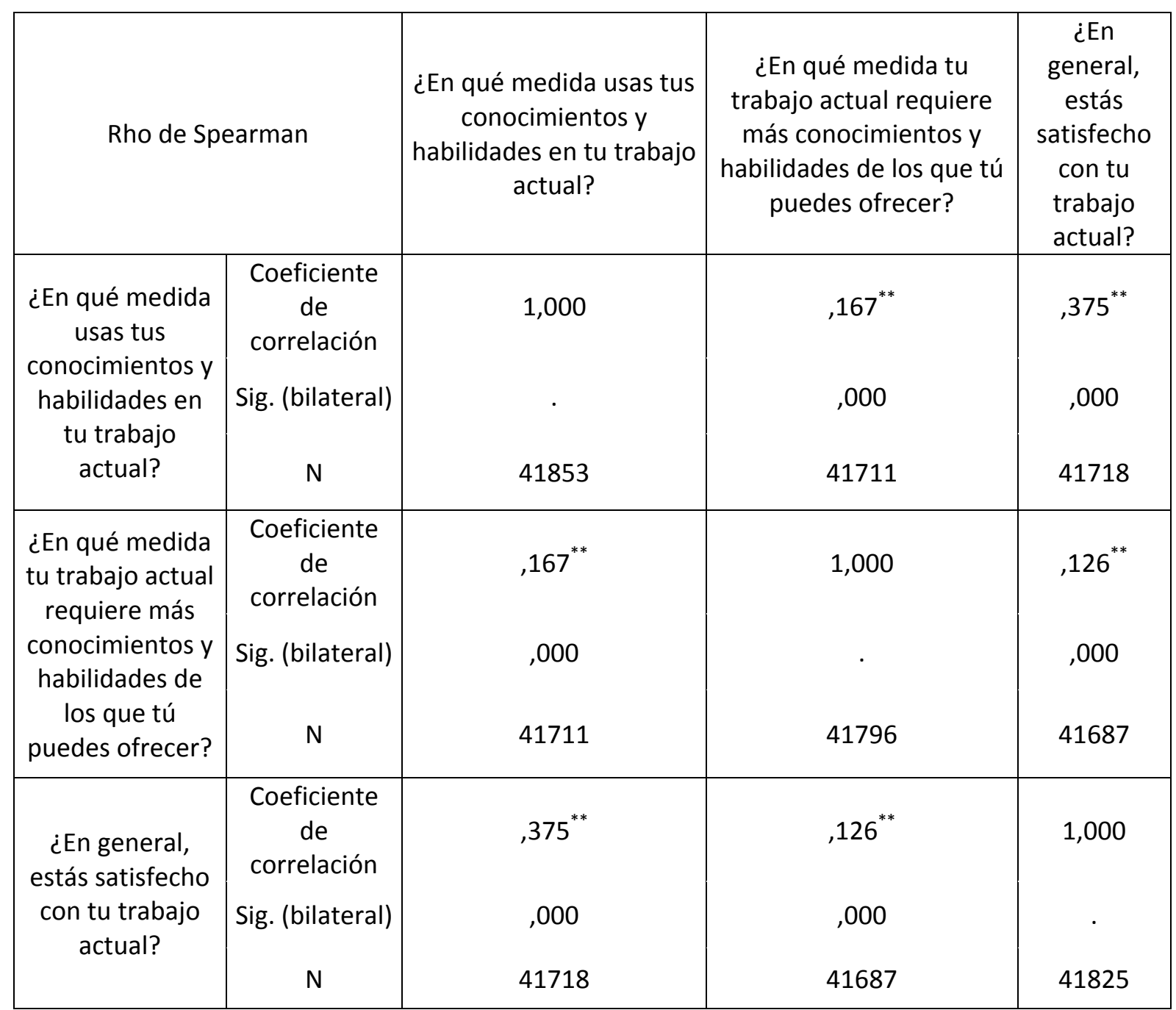

**. La correlación es significativa al nivel 0,01 (bilateral). 
Tabla H3. Correlaciones entre las variables del factor Rol (Funciones)

\begin{tabular}{|c|c|c|c|c|c|c|c|c|c|c|}
\hline Rho de Spearm & & $\begin{array}{c}\text { ¿En qué } \\
\text { medida eres } \\
\text { responsable } \\
\text { de establecer } \\
\text { objetivos para } \\
\text { la } \\
\text { organización? }\end{array}$ & $\begin{array}{c}\text { ¿En qué } \\
\text { medida eres } \\
\text { responsable } \\
\text { de establecer } \\
\text { objetivos para } \\
\text { tu propio } \\
\text { trabajo? }\end{array}$ & \begin{tabular}{|c|} 
¿En qué \\
medida eres \\
responsable \\
de decidir \\
estrategias de \\
trabajo para la \\
organización?
\end{tabular} & $\begin{array}{c}\text { ¿En qué } \\
\text { medida eres } \\
\text { responsable } \\
\text { de decidir } \\
\text { cómo hacer tu } \\
\text { trabajo? }\end{array}$ & $\begin{array}{c}\text { Los } \\
\text { compañeros, } \\
\text { clientes, etc. } \\
\text { acuden a mí } \\
\text { para pedirme } \\
\text { consejo }\end{array}$ & $\begin{array}{c}\text { Mantengo } \\
\text { informados a } \\
\text { mis } \\
\text { compañeros } \\
\text { de profesión } \\
\text { sobre nuevos } \\
\text { desarrollos en } \\
\text { mi campo }\end{array}$ & $\begin{array}{l}\text { Suelo iniciar } \\
\text { relaciones } \\
\text { profesionales } \\
\text { con expertos } \\
\text { ajenos a la } \\
\text { organización }\end{array}$ & $\begin{array}{l}\text { Las cuestiones } \\
\text { de ética } \\
\text { profesional } \\
\text { forman parte } \\
\text { importante de } \\
\text { mis funciones }\end{array}$ & $\begin{array}{c}\text { ¿Cuánto } \\
\text { perjudicarías a } \\
\text { tu } \\
\text { organización } \\
\text { si cometieras } \\
\text { un error grave } \\
\text { en tu trabajo? }\end{array}$ \\
\hline $\begin{array}{c}\text { ¿En qué medida eres } \\
\text { responsable de establecer } \\
\text { objetivos para la } \\
\text { organización? }\end{array}$ & $\begin{array}{c}\text { Coeficiente de } \\
\text { correlación } \\
\text { Sig. (bilateral) } \\
\mathrm{N}\end{array}$ & $\begin{array}{c}1,000 \\
. \\
41092\end{array}$ & $\begin{array}{l}, 446^{* *} \\
, 000 \\
40996\end{array}$ & $\begin{array}{c}, 727^{* *} \\
, 000 \\
40876\end{array}$ & $\begin{array}{c}, 305^{* *} \\
, 000 \\
40956\end{array}$ & $\begin{array}{c}, 246^{* *} \\
, 000 \\
40712\end{array}$ & $\begin{array}{c}, 253^{* *} \\
, 000 \\
40657\end{array}$ & $\begin{array}{c}, 361^{* *} \\
, 000 \\
40658\end{array}$ & $\begin{array}{c}, 209^{* *} \\
, 000 \\
40603\end{array}$ & $\begin{array}{c}188^{* *} \\
, 000 \\
40705\end{array}$ \\
\hline $\begin{array}{c}\text { ¿En qué medida eres } \\
\text { responsable de establecer } \\
\text { objetivos para tu propio } \\
\text { trabajo? }\end{array}$ & $\begin{array}{c}\text { Coeficiente de } \\
\text { correlación } \\
\text { Sig. (bilateral) } \\
\mathrm{N} \\
\end{array}$ & $\begin{array}{c}, 446^{* *} \\
, 000 \\
40996 \\
\end{array}$ & $\begin{array}{c}1,000 \\
. \\
41258 \\
\end{array}$ & $\begin{array}{l}, 394^{* *} \\
, 000 \\
40960 \\
\end{array}$ & $\begin{array}{l}, 554^{* *} \\
, 000 \\
41116 \\
\end{array}$ & $\begin{array}{c}, 265^{* *} \\
, 000 \\
40856 \\
\end{array}$ & $\begin{array}{c}, 266^{* *} \\
, 000 \\
40794 \\
\end{array}$ & $\begin{array}{c}, 317^{* *} \\
, 000 \\
40783 \\
\end{array}$ & $\begin{array}{c}, 239^{* *} \\
, 000 \\
40741 \\
\end{array}$ & $\begin{array}{c}103^{* *} \\
, 000 \\
40856 \\
\end{array}$ \\
\hline $\begin{array}{c}\text { ¿En qué medida eres } \\
\text { responsable de decidir } \\
\text { estrategias de trabajo para } \\
\text { la organización? }\end{array}$ & $\begin{array}{c}\text { Coeficiente de } \\
\text { correlación } \\
\text { Sig. (bilateral) } \\
\mathrm{N} \\
\end{array}$ & $\begin{array}{c}, 727^{* *} \\
, 000 \\
40876 \\
\end{array}$ & $\begin{array}{c}, 394^{* *} \\
, 000 \\
40960 \\
\end{array}$ & $\begin{array}{c}1,000 \\
. \\
41046 \\
\end{array}$ & $\begin{array}{l}, 345^{* *} \\
, 000 \\
40947 \\
\end{array}$ & $\begin{array}{c}, 275^{* *} \\
, 000 \\
40674 \\
\end{array}$ & $\begin{array}{c}, 273^{* *} \\
, 000 \\
40615 \\
\end{array}$ & $\begin{array}{c}, 359^{* *} \\
, 000 \\
40613 \\
\end{array}$ & $\begin{array}{c}, 205^{* *} \\
, 000 \\
40561 \\
\end{array}$ & $\begin{array}{c}, 205^{* *} \\
, 000 \\
40659 \\
\end{array}$ \\
\hline $\begin{array}{l}\text { ¿En qué medida eres } \\
\text { responsable de decidir } \\
\text { cómo hacer tu trabajo? }\end{array}$ & $\begin{array}{c}\text { Coeficiente de } \\
\text { correlación } \\
\text { Sig. (bilateral) } \\
\text { N }\end{array}$ & $\begin{array}{r}, 305^{* *} \\
, 000 \\
40956 \\
\end{array}$ & $\begin{array}{l}, 554^{* *} \\
, 000 \\
41116 \\
\end{array}$ & $\begin{array}{c}, 345^{* *} \\
, 000 \\
40947 \\
\end{array}$ & $\begin{array}{c}1,000 \\
\cdot \\
41245 \\
\end{array}$ & $\begin{array}{c}, 246^{* *} \\
, 000 \\
40849 \\
\end{array}$ & $\begin{array}{c}, 217^{* *} \\
, 000 \\
40774 \\
\end{array}$ & $\begin{array}{c}, 247^{* *} \\
, 000 \\
40766 \\
\end{array}$ & $\begin{array}{c}, 203^{* *} \\
, 000 \\
40727 \\
\end{array}$ & $\begin{array}{c}, 065^{* *} \\
, 000 \\
40844 \\
\end{array}$ \\
\hline $\begin{array}{l}\text { Los compañeros, clientes, } \\
\text { etc. acuden a mí para } \\
\text { pedirme consejo }\end{array}$ & $\begin{array}{c}\text { Coeficiente de } \\
\text { correlación } \\
\text { Sig. (bilateral) } \\
\mathrm{N} \\
\end{array}$ & $\begin{array}{c}, 246^{* *} \\
, 000 \\
40712 \\
\end{array}$ & $\begin{array}{c}, 265^{* *} \\
, 000 \\
40856 \\
\end{array}$ & $\begin{array}{l}, 275^{* *} \\
, 000 \\
40674 \\
\end{array}$ & $\begin{array}{c}, 246^{* *} \\
, 000 \\
40849 \\
\end{array}$ & $\begin{array}{c}1,000 \\
\cdot \\
41091 \\
\end{array}$ & $\begin{array}{c}, 494^{* *} \\
, 000 \\
40859 \\
\end{array}$ & $\begin{array}{c}, 363^{* *} \\
, 000 \\
40831 \\
\end{array}$ & $\begin{array}{c}, 225^{* *} \\
, 000 \\
40766 \\
\end{array}$ & $\begin{array}{c}131^{* *} \\
, 000 \\
40766 \\
\end{array}$ \\
\hline $\begin{array}{c}\text { Mantengo informados a mis } \\
\text { compañeros de profesión } \\
\text { sobre nuevos desarrollos en } \\
\text { mi campo }\end{array}$ & $\begin{array}{c}\text { Coeficiente de } \\
\text { correlación } \\
\text { Sig. (bilateral) } \\
\mathrm{N}\end{array}$ & $\begin{array}{l}, 253^{* *} \\
, 000 \\
40657\end{array}$ & $\begin{array}{l}, 266^{* *} \\
, 000 \\
40794\end{array}$ & $\begin{array}{l}, 273^{* *} \\
, 000 \\
40615\end{array}$ & $\begin{array}{l}, 217^{* *} \\
, 000 \\
40774\end{array}$ & $\begin{array}{l}, 494^{* *} \\
, 000 \\
40859\end{array}$ & $\begin{array}{c}1,000 \\
. \\
41018\end{array}$ & $\begin{array}{l}, 457^{* *} \\
, 000 \\
40812\end{array}$ & $\begin{array}{l}, 233^{* *} \\
, 000 \\
40707\end{array}$ & $\begin{array}{l}, 123^{* *} \\
, 000 \\
40700\end{array}$ \\
\hline $\begin{array}{l}\text { Suelo iniciar relaciones } \\
\text { profesionales con expertos } \\
\text { ajenos a la organización }\end{array}$ & $\begin{array}{c}\text { Coeficiente de } \\
\text { correlación } \\
\text { Sig. (bilateral) } \\
N\end{array}$ & $\begin{array}{l}, 361^{* *} \\
, 000 \\
40658\end{array}$ & $\begin{array}{l}, 317^{* *} \\
, 000 \\
40783\end{array}$ & $\begin{array}{l}, 359^{* *} \\
, 000 \\
40613\end{array}$ & $\begin{array}{l}, 247^{* *} \\
, 000 \\
40766\end{array}$ & $\begin{array}{l}, 363^{* *} \\
, 000 \\
40831\end{array}$ & $\begin{array}{l}, 457^{* *} \\
, 000 \\
40812\end{array}$ & $\begin{array}{l}1,000 \\
. \\
41002\end{array}$ & $\begin{array}{l}, 264^{* *} \\
, 000 \\
40719\end{array}$ & $\begin{array}{l}, 134^{* *} \\
, 000 \\
40688\end{array}$ \\
\hline $\begin{array}{l}\text { Las cuestiones de ética } \\
\text { profesional forman parte } \\
\text { importante de mis } \\
\text { funciones }\end{array}$ & $\begin{array}{c}\text { Coeficiente de } \\
\text { correlación } \\
\text { Sig. (bilateral) } \\
\mathrm{N} \\
\end{array}$ & $\begin{array}{c}, 209^{* *} \\
, 000 \\
40603 \\
\end{array}$ & $\begin{array}{c}, 239^{* *} \\
, 000 \\
40741 \\
\end{array}$ & $\begin{array}{c}, 205^{* *} \\
, 000 \\
40561 \\
\end{array}$ & $\begin{array}{c}, 203^{* *} \\
, 000 \\
40727 \\
\end{array}$ & $\begin{array}{c}, 225^{* *} \\
, 000 \\
40766 \\
\end{array}$ & $\begin{array}{c}, 233^{* *} \\
, 000 \\
40707 \\
\end{array}$ & $\begin{array}{c}, 264^{* *} \\
, 000 \\
40719 \\
\end{array}$ & $\begin{array}{c}1,000 \\
\cdot \\
40969 \\
\end{array}$ & $\begin{array}{c}124^{* *} \\
, 000 \\
40651 \\
\end{array}$ \\
\hline $\begin{array}{l}\text { ¿Cuánto perjudicarías a tu } \\
\text { organización si cometieras } \\
\text { un error grave en tu trabajo? }\end{array}$ & $\begin{array}{c}\text { Coeficiente de } \\
\text { correlación } \\
\text { Sig. (bilateral) } \\
\text { N }\end{array}$ & $\begin{array}{l}, 188^{* *} \\
, 000 \\
40705\end{array}$ & $\begin{array}{l}, 103^{* *} \\
, 000 \\
40856\end{array}$ & $\begin{array}{l}, 205^{* *} \\
, 000 \\
40659\end{array}$ & $\begin{array}{l}, 065^{* *} \\
, 000 \\
40844\end{array}$ & $\begin{array}{l}, 131^{* *} \\
, 000 \\
40766\end{array}$ & $\begin{array}{l}, 123^{* *} \\
, 000 \\
40700\end{array}$ & $\begin{array}{l}, 134^{* *} \\
, 000 \\
40688\end{array}$ & $\begin{array}{l}, 124^{* *} \\
, 000 \\
40651\end{array}$ & $\begin{array}{c}1,000 \\
\cdot \\
41150\end{array}$ \\
\hline
\end{tabular}


Tabla.H4a Correlaciones entre las variables del Factor Competencia Propias.

\begin{tabular}{|c|c|c|c|c|c|c|c|c|c|c|c|c|c|c|c|c|c|c|c|c|}
\hline \multicolumn{2}{|c|}{ Rho de Spearman } & a. & b. & c. & $\mathrm{d}$. & e. & f. & g. & h. & i. & $\mathrm{j}$. & $\mathrm{k}$. & $\mathrm{I}$. & $\mathrm{m}$. & $\mathrm{n}$. & 0. & p. & $\mathrm{q}$. & $\mathrm{r}$. & $\mathrm{s}$. \\
\hline \multirow[t]{3}{*}{$\begin{array}{l}\text { a. Dominio de tu } \\
\text { área o disciplina }\end{array}$} & $\begin{array}{l}\text { Coeficiente de } \\
\text { correlación }\end{array}$ & 1,000 &, $361 "$ & ,379" &, 374 & ,288" & ,312" &, 284 &, $317^{*}$ & $304^{* *}$ & ,268* & ,262" & $320^{* *}$ & ,294" & ,259" &, 356 &, 276 & 290 & ,278* & , 159" \\
\hline & Sig. (bilateral) & &, 000 & ,000 & ,000 &, 000 & , 000 & , 000 & , 000 & ,000 & , 000 & , 000 & ,000 & , 000 & ,000 & ,000 & ,000 & , 000 & , 000 & 000 \\
\hline & $\mathrm{N}$ & 444544 & 44312 & 44223 & 44300 & 44169 & 44269 & 44106 & 444207 & 44242 & 44208 & 44124 & 44208 & 44129 & 44248 & 44123 & 44177 & 44163 & 444173 & 44200 \\
\hline \multirow{2}{*}{$\begin{array}{l}\text { de otras áreas o } \\
\text { disciplinas }\end{array}$} & Sig. (bilateral) & 000 & & 000 & , 000 & ,000 & , 000 & , 000 & ,000 & ,000 & ,000 & , 000 & ,000 & , 000 &, 000 & ,000 & ,000 & ,000 & , 000 & 000 \\
\hline & $\bar{N}$ & 44312 & 444413 & 444163 & 44227 & 44103 & 44192 & 44040 & 44142 & 44169 & 44140 & 44056 & 444134 & 44059 & 44169 & 44046 & \begin{tabular}{|l|}
44098 \\
\end{tabular} & 44088 & 44099 & 44128 \\
\hline \multirow[t]{2}{*}{$\begin{array}{l}\text { c. Pensamiento } \\
\text { analítico }\end{array}$} & \begin{tabular}{|l}
$\begin{array}{l}\text { Coeficiente de } \\
\text { correlación }\end{array}$ \\
\end{tabular} & ,379" & $365^{\prime \prime}$ & 1,000 &, 476 & ,283" & $323^{\prime \prime}$ & ,310" & 327 & 262 & ,252" & $277^{\prime \prime}$ & ,312" & 264 & $318^{*}$ & ,417" & ,352" & ,307" & $326^{\prime \prime}$ & ,215" \\
\hline & $\mathrm{N}$ & 44223 & 44163 & 44336 & 44181 & 44063 & 44153 & 44002 & 44102 & 44120 & 44087 & 44014 & 44083 & 44017 & 44122 & 43994 & 44049 & 44043 & 44050 & 44075 \\
\hline \multirow{3}{*}{$\begin{array}{l}\text { d. Capacidad } \\
\text { para adquirir con } \\
\text { rapidez nuevos } \\
\text { conocimientos }\end{array}$} & $\begin{array}{l}\text { Coeficiente de } \\
\text { correlación }\end{array}$ & ,374" & ,336" &, $476^{*+1}$ & 1,000 & ,348" & ,414" & $365^{* *}$ & , 400" & ,367" & , 347" & ,306"t & $365^{* *}$ & ,308" & $355^{* *}$ &, $424^{* *}$ & ,344" & ,332" & ,352" & ,225" \\
\hline & \begin{tabular}{|l} 
Sig. (bilateral) \\
\end{tabular} &, 000 & ,000 & ,000 & & ,000 & , 000 & ,000 & , 000 & ,000 & ,000 & , 000 & 000 & , 000 & ,000 & ,000 & ,000 & ,000 & , 000 &, 000 \\
\hline & $\bar{N}$ & 44300 & 44227 & 44181 & 44413 & 44130 & 44235 & 44075 & 44180 & 44206 & 44172 & 44089 & 44165 & 44091 & 44202 & 44078 & 44133 & 44121 & 44129 & 44162 \\
\hline \multirow{3}{*}{\begin{tabular}{|l|} 
e. Capacidad \\
para negociar de \\
forma eficaz
\end{tabular}} & \begin{tabular}{|l}
$\begin{array}{l}\text { Coeficiente de } \\
\text { correlación }\end{array}$ \\
\end{tabular} & ,288" & ,292" & ,283" & ,348" & 1,000 & ,412" & ,434" & ,434 & $321^{\prime \prime}$ & 322 &, 416 & ,396" & ,466" & ,161" & , 362" & ,289" & $388^{\prime \prime}$ & $280^{\circ}$ & , 106" \\
\hline & Sig. (bilateral) & ,000 & , 000 & , 000 & , 000 & & , 000 & , 000 & , 000 & , 000 & , 000 & , 000 & ,000 & , 000 & , 000 & , 000 & , 000 & , 000 & , 000 & ,000 \\
\hline & $\mathrm{N}$ & 44169 & |44103 & 44063 & 44130 & 44280 & 44143 & 44031 & 44087 & 44105 & 444070 & 44007 & 44058 & 43996 & 44094 & 43982 & 44030 & 44032 & 44030 & 44055 \\
\hline \multirow{2}{*}{$\begin{array}{l}\text { f. Capacidad para } \\
\text { trabajar bajo } \\
\text { presión }\end{array}$} & Sig. (bilateral) &, 000 & ,000 & ,000 & ,000 & ,000 & & ,000 & ,000 & ,000 & ,000 & ,000 & ,000 & ,000 & ,000 & ,000 & ,000 & ,000 & ,000 &, 000 \\
\hline & $\bar{N}$ & 44269 & 44192 & 44153 & 44235 & |44143 & 44389 & 44094 & 44183 & 44211 & 44173 & 44094 & 44165 & 44093 & 44204 & 44086 & 44133 & 44123 & 44136 & 44158 \\
\hline \multirow{3}{*}{\begin{tabular}{|l|} 
g. Capacidad \\
para detectar \\
nuevas \\
oportunidades
\end{tabular}} & \begin{tabular}{|l} 
Coeficiente de \\
correlación
\end{tabular} & ,284" & ,305" & ,310" & ,365" & ,434" &, $430^{\circ}$ & 1,000 & ,454" & ,336" & ,337" & ,431" &, $350^{\circ}$ & ,379" & ,207" & ,472" & $324^{*}$ & $384^{*}$ & ,286" & , 175" \\
\hline & \begin{tabular}{|l} 
Sig. (bilateral) \\
\end{tabular} &, 000 & ,000 & ,000 & ,000 & ,000 & ,000 & & ,000 & ,000 & ,000 & ,000 & ,000 & ,000 & ,000 & ,000 & ,000 & ,000 & ,000 &, 000 \\
\hline & $\bar{N}$ & 44106 & 44040 & 44002 & 44075 & 44031 & 44094 & 44225 & 44058 & 44066 & 44034 & 43965 & 44023 & 43964 & 44061 & 43950 & 43996 & 43987 & 43991 & 44017 \\
\hline \multirow{3}{*}{\begin{tabular}{|l|} 
h. Capacidad \\
para coordinar \\
actividades
\end{tabular}} & \begin{tabular}{|l} 
Coeficiente de \\
correlación
\end{tabular} & ,317" & ,275" & ,327" & $400^{*}$ & ,434" & $459^{*}$ & ,454" & 1,000 &, $516^{* *}$ &, $441^{*}$ & ,451" & ,413" &, $431^{*}$ & ,236** & ,412" & ,330" & ,381" & $354^{* *}$ & ,135" \\
\hline & Sig. (bilateral) & ,000 & ,000 & ,000 & ,000 & ,000 & ,000 & ,000 & & ,000 & ,000 & ,000 & ,000 & ,000 & ,000 & ,000 & ,000 & ,000 & ,000 & ,000 \\
\hline & $\mathrm{N}$ & 44207 & 44142 & 44102 & 44180 & 44087 & 44183 & 44058 & 44328 & 44170 & 44135 & 44064 & 44130 & 44062 & 44162 & 44044 & 44093 & 44089 & 44091 & 44124 \\
\hline \multirow{3}{*}{$\begin{array}{l}\text { i. Capacidad para } \\
\text { usar el tiempo de } \\
\text { forma efectiva }\end{array}$} & $\begin{array}{l}\text { Coeficiente de } \\
\text { correlación }\end{array}$ & ,304"* & ,206" & ,262*t & , $367^{\prime \prime}$ & ,321" & ,403"+ & ,336"t &, $516^{*}$ & 1,000 &, $423^{*}$ & , 338* & ,361" & , 337" & ,208*t & ,322"*t & ,259"t & ,257*t & ,302*t & ,097" \\
\hline & \begin{tabular}{|l} 
Sig. (bilateral) \\
\end{tabular} &, 000 & ,000 & ,000 & ,000 & ,000 & ,000 & , 000 & , 000 & & ,000 & ,000 & ,000 & , 000 & ,000 & ,000 & ,000 & ,000 & ,000 &, 000 \\
\hline & $\mathrm{N}$ & 44242 & 44169 & 44120 & 44206 & 44105 & 44211 & 44066 & 44170 & 44361 & 444180 & 444103 & 444175 & 44106 & 44210 & 44087 & 44135 & 44128 & 44132 & 44163 \\
\hline \multirow[t]{3}{*}{\begin{tabular}{|l|} 
j. Capacidad para \\
trabajar en equipo
\end{tabular}} & $\begin{array}{l}\text { Coeficiente de } \\
\text { correlación }\end{array}$ & ,268" & ,203" & ,252") & ,347" & ,322" & ,370 & , 337" & ,441" & , 423 & 1,000 & ,481" & ,416" & ,339" & ,233"* & ,342 & ,313" & ,301" & ,300" & , 107" \\
\hline & \begin{tabular}{|l} 
Sig. (bilateral) \\
\end{tabular} & ,000 & ,000 & ,000 & , 000 & ,000 & ,000 & ,000 & ,000 & ,000 & & , 000 & ,000 & ,000 & ,000 & ,000 & ,000 & ,000 & , 000 & 000 \\
\hline & $\mathrm{N}$ & 44208 & 44140 & 44087 & 44172 & 44070 & 44173 & 44034 & 44135 & 44180 & 44324 & 44086 & |44144 & 44081 & 44179 & 44057 & 44105 & 44098 & 44111 & 44134 \\
\hline
\end{tabular}


Tabla H4b. Correlaciones entra las variables del Factor Competencias Propias.

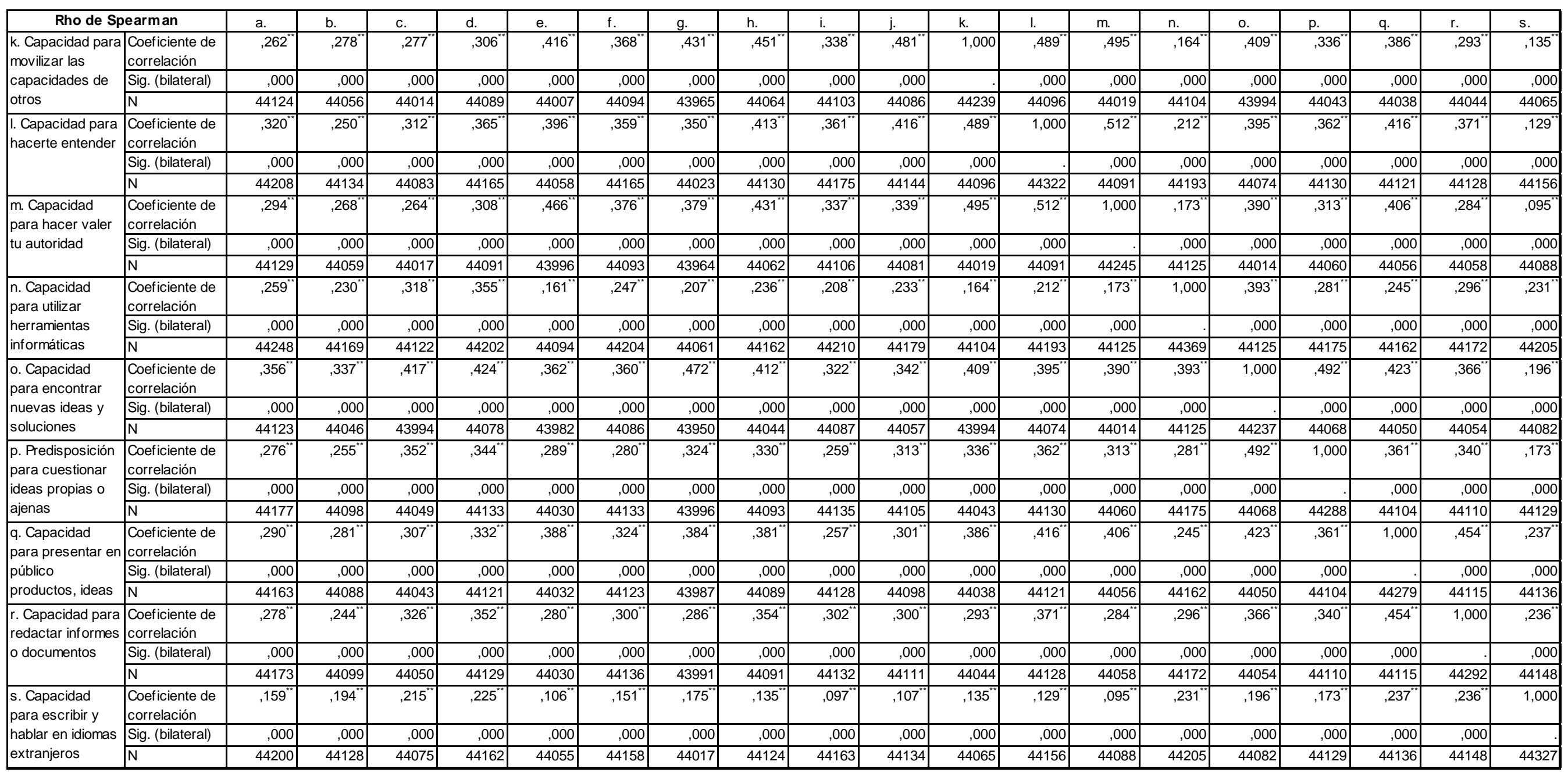

**. La correlación es significativa al nivel 0,01 (bilateral). 


\section{Tabla H5a. Correlaciones entre las variables del Factor Competencias Requeridas}

\begin{tabular}{|c|c|c|c|c|c|c|c|c|c|c|c|c|c|c|c|c|c|c|c|c|}
\hline \multicolumn{2}{|c|}{ Rho de Spearman } & a. & b. & c. & d. & e. & f. & g. & h. & i. & j. & k. & I. & $\mathrm{m}$. & $\mathrm{n}$. & 0. & & q. & $r$. & $\mathrm{s}$. \\
\hline \multirow{3}{*}{$\begin{array}{l}\text { a. Dominio de } \\
\text { tu área o } \\
\text { disciplina }\end{array}$} & $\begin{array}{l}\text { Coeficiente de } \\
\text { correlación }\end{array}$ & 1,000 & ,316" &, $436^{\circ}$ & $449^{* \prime}$ & ,291" & ,343" & ,316" & $345^{\circ}$ & , 377" & ,328" & ,283" &, $335^{* \prime}$ & $284^{*}$ & ,285" & , 367" &, $345^{* \prime}$ & , 307" & $331^{\prime \prime}$ &, $181^{\prime \prime}$ \\
\hline & Sig. (bilateral) & & ,000 & ,000 &, 000 & ,000 & ,000 & ,000 & ,000 & ,000 &, 000 & , 000 & , 000 & ,000 & ,000 &, 000 & , 000 & ,000 &, 000 &, 000 \\
\hline & $\mathrm{N}$ & $\begin{array}{ll}39668 \\
\end{array}$ & 39330 & 39227 & 39286 & 39215 & 39313 & 39106 & 39233 & 39267 & 39237 & 39184 & 39220 & 39152 & 39247 & 39176 & 39166 & 39171 & 39182 & 38769 \\
\hline \multirow{3}{*}{$\begin{array}{l}\text {. } \\
\text { Conocimientos } \\
\text { de otras áreas } \\
\text { o disciplinas }\end{array}$} & $\begin{array}{l}\text { Coeficiente de } \\
\text { correlación }\end{array}$ & ,316" & 1,000 & ,396" & ,392" & ,342" & ,258 & ,369" & 328 & ,277" & 276 & $330^{\circ}$ & $300^{\circ}$ & ,298" & ,260" & , 357" & $340^{*}$ & , 323" &, $310^{* \prime}$ & ,233" \\
\hline & Sig. (bilateral) & , 000 & & ,000 & , 000 & ,000 & ,000 & , 000 & ,000 & ,000 & , 000 & ,000 & ,000 & , 000 & ,000 & , 000 & , 000 & ,000 & , 000 &, 000 \\
\hline & $\mathrm{N}$ & 39330 & 39520 & 39176 & 39214 & 39139 & 39225 & 39030 & 39157 & 39180 & 39150 & 39098 & 39134 & 39073 & 39154 & 39095 & 39084 & 39091 & 39101 & 38690 \\
\hline \multirow[t]{3}{*}{$\begin{array}{l}\text { c. Pensamiento } \\
\text { analítico }\end{array}$} & $\begin{array}{l}\text { Coeficiente de } \\
\text { correlación }\end{array}$ &, $436 "$ &, $396 *$ & 1,000 &, $550^{*+}$ & , 345 & $365^{*}$ &, $381^{* *}$ &, 376 & $366^{*}$ & ,339" & ,323" &, 374 & ,299" & ,365" & ,456" & ,438* & , 369" & ,411" & ,281* \\
\hline & Sig. (bilateral) & , 000 & ,000 & & ,000 & 000 & 000 & ,000 & ,000 & 000 & ,000 & ,000 & ,000 & ,000 & ,000 & , 000 & ,000 & 000 & 000 &, 000 \\
\hline & $\mathrm{N}$ & 39227 & 39176 & 39426 & 39161 & 39089 & 39164 & 38983 & 39099 & 39131 & 39091 & 39049 & 39071 & 39006 & 39097 & 39032 & 39033 & 39027 & 39030 & 38622 \\
\hline \multirow{3}{*}{$\begin{array}{l}\text { d. Capacidad } \\
\text { para adquirir } \\
\text { con rapidez } \\
\text { nuevos }\end{array}$} & \begin{tabular}{|l} 
Coeficiente de \\
correlación
\end{tabular} & ,449*" & ,392" &, $550^{*}$ & 1,000 & , 393" & ,452" & ,433" &, $437^{*}$ & $455^{\prime \prime}$ & ,403" & ,341" & ,409" & $315^{* 1}$ & $418^{\prime \prime \prime}$ & ,475" & ,435" & ,390" & ,406" & ,281*t \\
\hline & Sig. (bilateral) & ,000 & , 000 & ,000 & & ,000 & ,000 & , 000 & , 000 & 000 & ,000 & 000 & 000 & , 000 & 000 & , 000 & 000 & , 000 & ,000 & , 000 \\
\hline & $\mathrm{N}$ & 39286 & 39214 & 39161 & 39486 & 39148 & 39236 & 39035 & 39159 & 39191 & 39160 & 39117 & 39143 & 39090 & 39165 & 39104 & 39093 & 39096 & 39108 & 38696 \\
\hline \multirow{3}{*}{$\begin{array}{l}\text { e. Capacidad } \\
\text { para negociar } \\
\text { de forma } \\
\text { eficaz } \\
\end{array}$} & \begin{tabular}{|l|}
$\begin{array}{l}\text { Coeficiente de } \\
\text { correlación }\end{array}$ \\
\end{tabular} & ,291" &, $342^{*+1}$ &, $345^{*}$ & ,393" & 1,000 & ,457" &, $507^{*}$ & , 472 & $390^{\circ}$ & ,370" & ,425" &, $405^{* *}$ & ,437" & ,234" & ,389" & ,365" & ,411" & ,330" &, $167^{*+}$ \\
\hline & Sig. (bilateral) & , 000 & , 000 & ,000 & ,000 & & ,000 & ,000 & ,000 & ,000 & , 000 & , 000 & ,000 & ,000 & ,000 & ,000 & , 000 & ,000 & ,000 & ,000 \\
\hline & $\mathrm{N}$ & 39215 & 39139 & 39089 & 39148 & 39417 & 39233 & 39067 & 39149 & 39161 & 39129 & 39103 & 39115 & 39060 & 39135 & 39084 & 39066 & 39081 & 39080 & 38659 \\
\hline \multirow{2}{*}{$\begin{array}{l}\text { f. Capacidad } \\
\text { para trabajar } \\
\text { bajo presión }\end{array}$} & Sig. (bilateral) & , 000 & ,000 & , 000 & , & ,000 & & , 000 & , 000 & , 000 & ,000 & , 000 & , 000 & , 000 & ,000 & ,000 & , 000 & , 000 & ,000 & , \\
\hline & $\mathrm{N}$ & 39313 & 39225 & 39164 & 39236 & 39233 & 39519 & 39130 & 39245 & 39271 & 39237 & 39185 & 39216 & 39158 & 39242 & 39180 & 39160 & 39174 & 39174 & 38761 \\
\hline \multirow{3}{*}{$\begin{array}{l}\text { g. Capacidad } \\
\text { para detectar } \\
\text { nuevas } \\
\text { oportunidades }\end{array}$} & $\begin{array}{l}\text { Coeficiente de } \\
\text { correlación }\end{array}$ & ,316" & , 369" & ,381" & ,433" & ,507 & ,432" & 1,000 &, 496 & ,414 & ,395" & $459^{\prime \prime}$ & , 398" & , 377" & ,286" &, 522 & ,458" & ,452" & ,346" & ,254" \\
\hline & Sig. (bilateral) & , 000 & ,000 & , 000 & ,000 & ,000 & ,000 & & ,000 & ,000 & ,000 & ,000 & ,000 & ,000 & ,000 & , 000 & , 000 & ,000 & ,000 & , 000 \\
\hline & $\mathrm{N}$ & 39106 & 39030 & 38983 & 39035 & 39067 & 39130 & 39308 & 39085 & 39086 & 39059 & 39033 & 39044 & 38993 & 39060 & 39010 & 39001 & 38999 & 38993 & 38589 \\
\hline \multirow{3}{*}{\begin{tabular}{|l|}
. Capacidad \\
para coordinar \\
actividades
\end{tabular}} & \begin{tabular}{|l}
$\begin{array}{l}\text { Coeficiente de } \\
\text { correlación }\end{array}$ \\
\end{tabular} & $345^{* *}$ & ,328*t &, $376^{*}$ & ,437" &, 472 & ,488* & ,496" & 1,000 & ,561" &, $508^{*+}$ & ,525" & ,469" & ,465" & ,307" &, $466^{* *}$ &, $426 *$ &, $414^{\prime \prime}$ & ,385" & ,183" \\
\hline & Sig. (bilateral) & , 000 & , 000 & ,000 & , 000 & ,000 & ,000 & , 000 & & ,000 & ,000 & ,000 & ,000 & , 000 & ,000 & , 000 & , 000 & ,000 & ,000 & ,000 \\
\hline & $\mathrm{N}$ & 39233 & 39157 & 39099 & 39159 & 39149 & 39245 & 39085 & 39440 & 39229 & 39193 & 39151 & \begin{tabular}{|l|}
39176 \\
\end{tabular} & 39115 & 39190 & 39132 & 39118 & \begin{tabular}{|l|}
39127 \\
\end{tabular} & 39130 & 38715 \\
\hline \multirow{3}{*}{$\begin{array}{l}\text { i. Capacidad } \\
\text { para usar el } \\
\text { tiempo de } \\
\text { forma efectiva }\end{array}$} & \begin{tabular}{|l|}
$\begin{array}{l}\text { Coeficiente de } \\
\text { correlación }\end{array}$ \\
\end{tabular} & ,377" & ,277 & ,366" &, $455^{\circ}$ & ,390" &, $525^{*}$ & ,414" &, $561^{\circ}$ & 1,000 & ,529" & $431^{\prime \prime}$ & ,474" & ,392 & ,325" & ,425" & ,388" & ,352" & 360 & ,169" \\
\hline & Sig. (bilateral) &, 000 & , 000 & , 000 & ,000 & , 000 & , 000 & , 000 &, 000 & & ,000 & , 000 & ,000 & , 000 & ,000 & , 000 & , 000 & ,000 & ,000 &, 000 \\
\hline & $\mathrm{N}$ & 39267 & 39180 & 39131 & 39191 & 39161 & 39271 & 39086 & 39229 & 39471 & 39234 & 39192 & 39223 & 39155 & 39225 & 39171 & 39154 & 39161 & 39157 & 38746 \\
\hline \multirow{3}{*}{$\begin{array}{l}\text { j. Capacidad } \\
\text { para trabajar } \\
\text { en equipo }\end{array}$} & \begin{tabular}{|l|}
$\begin{array}{l}\text { Coeficiente de } \\
\text { correlación }\end{array}$ \\
\end{tabular} & ,328*t & ,276 & ,339" & ,403" & , 370 & ,432" & ,395" & ,508 &, $529^{*}$ & 1,000 & ,558" & ,474 & ,397" & ,316" & ,433" & ,412 & $354^{* 1}$ & ,341" & ,166" \\
\hline & Sig. (bilateral) & , 000 & , 000 & ,000 & , & ,000 & ,000 & , 000 & , 000 & , 000 & & ,000 & 000 & ,000 & 000 & , 000 & ,000 & , 000 & ,000 & , 000 \\
\hline & $\mathrm{N}$ & 39237 & 39150 & 39091 & 39160 & 39129 & 39237 & 39059 & 39193 & 39234 & 39443 & 39167 & 39195 & 39130 & 39210 & 39147 & 39124 & 39136 & 39140 & 38728 \\
\hline
\end{tabular}




\section{Tabla H5b. Correlaciones entre las variables del Factor Competencias Requeridas}

\begin{tabular}{|c|c|c|c|c|c|c|c|c|c|c|c|c|c|c|c|c|c|c|c|c|}
\hline \multicolumn{2}{|c|}{ Rho de Spearman } & a. & b. & c. & d. & e. & f. & g. & h. & i. & & k. & $\mathrm{I}$. & $\mathrm{m}$. & $\mathrm{n}$. & o. & p. & q. & r. & s. \\
\hline \multirow{3}{*}{$\begin{array}{l}\text { k. Capacidad } \\
\text { para movilizar } \\
\text { las } \\
\text { capacidades } \\
\end{array}$} & \begin{tabular}{|l|} 
Coeficiente de \\
correlación
\end{tabular} & ,283" & ,330" & ,323" & ,341" & ,425" & ,371" & ,459" & ,525" & $4,431^{\prime \prime}$ &, $558^{\prime \prime}$ & 1,000 & ,541" & ,539" & ,224" &, $455^{*}$ & ,444" &, $411^{*}$ & ,330" & ,172" \\
\hline & \begin{tabular}{|l|l|} 
Sig. (bilateral) \\
\end{tabular} & ,000 & ,000 & ,000 & ,000 & ,000 & ,000 & ,000 & , 000 & ,000 & ,000 & & ,000 & , 000 & ,000 & ,000 & , 000 & ,000 & ,000 &, 000 \\
\hline & $\bar{N}$ & 39184 & 39098 & 39049 & 39117 & 39103 & 39185 & 39033 & 39151 & 39192 & 39167 & 39382 & 39170 & 39107 & 39155 & 39103 & 39085 & 39099 & 39102 & 38687 \\
\hline \multirow{2}{*}{$\begin{array}{l}\text { para hacerte } \\
\text { entender }\end{array}$} & Sig. (bilateral) & ,000 & ,000 & , 000 & ,000 & ,000 & ,000 & ,000 & ,000 & ,000 & ,000 & ,000 & & , 000 & ,000 & ,000 & ,000 & ,000 & ,000 & ,000 \\
\hline & $\mathrm{N}$ & 39220 & 39134 & 39071 & 39143 & 39115 & 39216 & 39044 & 39176 & 39223 & 39195 & 39170 & 39427 & 39146 & 39208 & 39152 & 39133 & $\begin{array}{ll}39146 \\
\end{array}$ & 39143 & 38731 \\
\hline \multirow{3}{*}{$\begin{array}{l}\text { m. Capacidad } \\
\text { para hacer } \\
\text { valer tu } \\
\text { autoridad } \\
\end{array}$} & \begin{tabular}{|l|}
$\begin{array}{l}\text { Coeficiente de } \\
\text { correlación }\end{array}$ \\
\end{tabular} & ,284" & ,298" & ,299" & ,315" & ,437" & $350^{\prime \prime \prime}$ & ,377" &, $465^{* \prime}$ & ,392" & $397^{* *}$ & ,539" &, $543^{* \prime}$ & 1,000 & ,207" &, $408^{\prime \prime}$ &, $407^{*}$ & ,409" & ,321" & ,139" \\
\hline & Sig. (bilateral) & ,000 & ,000 & ,000 & ,000 & ,000 & ,000 & ,000 & ,000 & ,000 & ,000 & ,000 & ,000 & & ,000 & ,000 & , 000 & ,000 & ,000 & ,000 \\
\hline & $\mathrm{N}$ & 39152 & 39073 & 39006 & 39090 & 39060 & 39158 & 38993 & 39115 & 39155 & 39130 & 39107 & 39146 & 39360 & 39151 & 39092 & 39081 & 39089 & 39088 & 38670 \\
\hline \multirow{3}{*}{$\begin{array}{l}\text { n. Capacidad } \\
\text { para utilizar } \\
\text { herramientas } \\
\text { informáticas }\end{array}$} & \begin{tabular}{|l|}
$\begin{array}{l}\text { Coeficiente de } \\
\text { correlación }\end{array}$ \\
\end{tabular} & ,285" & ,260" & ,365" & ,418" & ,234" & ,298" &, $2866^{\prime \prime}$ & $307^{* *}$ &, $325^{\prime \prime}$ & 316 "* & , 224" & ,277" & ,207" & 1,000 & ,449" & ,378" & ,322" & ,389" & ,316" \\
\hline & Sig. (bilateral) & ,000 & ,000 & ,000 & ,000 & ,000 & ,000 & ,000 & ,000 & ,000 & ,000 & , 000 & , 000 & , 000 & & ,000 & ,000 & ,000 & ,000 &, 000 \\
\hline & $\mathrm{N}$ & 39247 & 39154 & 39097 & 39165 & 39135 & 39242 & 39060 & 39190 & 39225 & 39210 & 39155 & 39208 & 39151 & 39457 & 39195 & \begin{tabular}{|l|}
39177 \\
\end{tabular} & \begin{tabular}{l|l}
39171 \\
\end{tabular} & 39181 & 38776 \\
\hline \multirow{3}{*}{$\begin{array}{l}\text { o. Capacidad } \\
\text { para encontrar } \\
\text { nuevas ideas y } \\
\text { soluciones }\end{array}$} & \begin{tabular}{|l|} 
Coeficiente de \\
correlación
\end{tabular} & ,367" & ,357" & ,456" &, $475^{* \prime}$ & , 389" & ,364" & ,522" &, $4666^{\prime \prime}$ & ,425" & ,433" & ,455" & ,472" & ,408" & ,449"| & 1,000 & ,636" & ,502" & ,444" & ,287" \\
\hline & Sig. (bilateral) & ,000 & ,000 & ,000 & ,000 & ,000 & ,000 & ,000 & ,000 & ,000 & ,000 & ,000 & ,000 & ,000 & ,000 & & ,000 & ,000 & ,000 & ,000 \\
\hline & $N$ & 39176 & 39095 & 39032 & 39104 & 39084 & 39180 & 39010 & 39132 & 39171 & 39147 & 39103 & 39152 & 39092 & 39195 & 39388 & 39129 & 39131 & 39132 & 38716 \\
\hline \multirow{2}{*}{$\begin{array}{l}\text { para } \\
\text { cuestionar }\end{array}$} & Sig. (bilateral) & ,000 & ,000 & ,000 & ,000 & ,000 & ,000 & ,000 & ,000 & ,000 & ,000 & ,000 & ,000 & ,000 & ,000 & ,000 & & ,000 & , 000 & ,000 \\
\hline & $\bar{N}$ & 39166 & 39084 & 39033 & 39093 & 39066 & 39160 & 39001 & 39118 & 39154 & 39124 & 39085 & 39133 & 39081 & 39177 & 39129 & 39373 & \begin{tabular}{l|l}
39113 \\
\end{tabular} & 39111 & 38701 \\
\hline \multirow{3}{*}{$\begin{array}{l}\text { q. Capacidad } \\
\text { para presentar } \\
\text { en público } \\
\text { productos, }\end{array}$} & \begin{tabular}{|l} 
Coeficiente de \\
correlación
\end{tabular} & ,307" & ,323" &, $369^{*+1}$ & ,390" & ,411" & $311^{* *}$ & ,452" &, $414^{* *}$ & ,352*t & ,354" & ,411" &, $438^{*+1}$ & ,409" & ,322" &, $502^{*+}$ &, $490^{*+}$ & 1,000 &, 536 & 3017 \\
\hline & Sig. (bilateral) & , 000 & ,000 & , 000 & ,000 & ,000 & ,000 & ,000 & , 000 & , 000 & ,000 & ,000 & ,000 & , 000 & , 000 & ,000 & ,000 & & , 000 & , 000 \\
\hline & $\mathrm{N}$ & 39171 & 39091 & 39027 & 39096 & 39081 & 39174 & 38999 & 39127 & 39161 & 39136 & 39099 & 39146 & 39089 & 39171 & 39131 & 39113 & 39379 & 39164 & 38733 \\
\hline \multirow{3}{*}{$\begin{array}{l}\text { r. Capacidad } \\
\text { para redactar } \\
\text { informes } 0 \\
\text { documentos } \\
\end{array}$} & \begin{tabular}{|l|}
$\begin{array}{l}\text { Coeficiente de } \\
\text { correlación }\end{array}$ \\
\end{tabular} & ,331" & $310^{* *}$ & ,411" & ,406" & $330^{* *}$ & $318^{* *}$ &, 346 & $385^{* *}$ & ,360" & ,341" & $330^{*+}$ &, $406^{* *}$ & ,321" & ,389" &, $444^{* *}$ & ,448*t &, $536^{\prime \prime}$ & 1,000 & 284 \\
\hline & Sig. (bilateral) & ,000 & ,000 & ,000 & ,000 & ,000 & ,000 & ,000 & ,000 & ,000 & ,000 & ,000 & ,000 & ,000 & ,000 & ,000 & ,000 & ,000 & &, 000 \\
\hline & $\mathrm{N}$ & 39182 & 39101 & 39030 & 39108 & 39080 & 39174 & 38993 & 39130 & 39157 & 39140 & 39102 & 39143 & 39088 & 39181 & 39132 & 39111 & 39164 & 39392 & 38744 \\
\hline \multirow{3}{*}{$\begin{array}{l}\text { s. Capacidad } \\
\text { para escribir y } \\
\text { hablar en } \\
\text { idiomas }\end{array}$} & \begin{tabular}{|l|}
$\begin{array}{l}\text { Coeficiente de } \\
\text { correlación }\end{array}$ \\
\end{tabular} & ,181" & ,233" & ,281" & $281^{\prime \prime}$ & ,167" & , 186" & ,254" & ,183" & ,169" & ,166" & ,172" &, $150^{\circ}$ & ,139" & ,316" & ,287" & ,273" & ,301" & $284^{*}$ & 1,000 \\
\hline & Sig. (bilateral) & ,000 & ,000 & , 000 & ,000 & ,000 & ,000 & ,000 & ,000 & ,000 & ,000 & ,000 & ,000 & ,000 & ,000 & ,000 & ,000 & ,000 & ,000 & \\
\hline & $\mathrm{N}$ & 38769 & 38690 & 38622 & 38696 & 38659 & 38761 & 38589 & 38715 & 38746 & 38728 & 38687 & 38731 & 38670 & 38776 & 38716 & 38701 & 38733 & 38744 & 38987 \\
\hline
\end{tabular}

**. La correlación es significativa al nivel 0,01 (bilateral). 
Tabla H6. Correlaciones entre las variables del Factor Valores Laborales - Importancia Personal

\begin{tabular}{|c|c|c|c|c|c|c|c|c|c|c|c|}
\hline \multicolumn{2}{|c|}{ Rho de Spearman } & \multirow{2}{*}{$\begin{array}{c}\begin{array}{c}\text { Autonomía en } \\
\text { el trabajo }\end{array} \\
1,000 \\
43068\end{array}$} & \multirow{2}{*}{$\begin{array}{c}\begin{array}{c}\text { Estabilidad } \\
\text { laboral }\end{array} \\
, 141^{* *} \\
, 000 \\
42904\end{array}$} & \multirow{2}{*}{\begin{tabular}{|c}
$\begin{array}{c}\text { Oportunidad de } \\
\text { aprender } \\
\text { cosas nuevas }\end{array}$ \\
, $279^{* *}$ \\
, 000 \\
42911
\end{tabular}} & \multirow{2}{*}{$\begin{array}{c}\begin{array}{c}\text { Ingresos } \\
\text { elevados }\end{array} \\
, 163^{* *} \\
, 000 \\
36518\end{array}$} & \multirow{2}{*}{$\begin{array}{c}\begin{array}{c}\text { Afrontar } \\
\text { nuevos retos }\end{array} \\
, 265^{* *} \\
000 \\
42872\end{array}$} & \multirow{2}{*}{$\begin{array}{c}\begin{array}{c}\text { Buenas } \\
\text { perspectivas } \\
\text { profesionales }\end{array} \\
, 176^{* *} \\
, 000 \\
42850\end{array}$} & \multirow{2}{*}{$\begin{array}{c}\begin{array}{c}\text { Tener tiempo } \\
\text { para } \\
\text { actividades } \\
\text { recreativas }\end{array} \\
, 132^{* *} \\
, 000 \\
42885\end{array}$} & \multirow{2}{*}{\begin{tabular}{|c}
$\begin{array}{c}\text { Reconocimient } \\
\text { o/prestigio } \\
\text { social }\end{array}$ \\
, $139^{* *}$ \\
, 000 \\
42822
\end{tabular}} & \multirow{2}{*}{\begin{tabular}{|c|}
$\begin{array}{c}\text { Oportunidad de } \\
\text { hacer algo útil } \\
\text { para la } \\
\text { sociedad }\end{array}$ \\
, $171^{* *}$ \\
, 000 \\
42869
\end{tabular}} & \multirow{2}{*}{\begin{tabular}{|c}
$\begin{array}{c}\text { Facilidad para } \\
\text { combinar } \\
\text { trabajo y familia }\end{array}$ \\
, $144^{* *}$ \\
, 000 \\
42804
\end{tabular}} \\
\hline $\begin{array}{c}\text { Autonomía en el } \\
\text { trabajo }\end{array}$ & $\begin{array}{c}\text { Coeficiente de } \\
\text { correlación } \\
\text { Sig. (bilateral) } \\
\mathrm{N}\end{array}$ & & & & & & & & & & \\
\hline $\begin{array}{l}\text { Estabilidad } \\
\text { laboral }\end{array}$ & $\begin{array}{c}\text { Coeficiente de } \\
\text { correlación } \\
\text { Sig. (bilateral) } \\
\text { N }\end{array}$ & $\begin{array}{l}, 141^{* *} \\
, 000 \\
42904\end{array}$ & $\begin{array}{c}1,000 \\
\cdot \\
43149\end{array}$ & $\begin{array}{c}, 192^{* *} \\
, 000 \\
43018\end{array}$ & $\begin{array}{l}, 336^{* *} \\
, 000 \\
36619\end{array}$ & $\begin{array}{c}, 085^{* *} \\
, 000 \\
42983\end{array}$ & $\begin{array}{l}, 273^{* *} \\
, 000 \\
42953\end{array}$ & $\begin{array}{c}, 268^{* *} \\
, 000 \\
42997\end{array}$ & $\begin{array}{l}, 263^{* *} \\
, 000 \\
42928\end{array}$ & $\begin{array}{c}, 206^{* *} \\
, 000 \\
42983\end{array}$ & $\begin{array}{l}, 318^{* *} \\
, 000 \\
42912\end{array}$ \\
\hline $\begin{array}{c}\text { Oportunidad de } \\
\text { aprender cosas } \\
\text { nuevas }\end{array}$ & $\begin{array}{c}\text { Coeficiente de } \\
\text { correlación } \\
\text { Sig. (bilateral) } \\
\text { N }\end{array}$ & $\begin{array}{l}, 279^{* *} \\
, 000 \\
42911\end{array}$ & $\begin{array}{l}, 192^{* *} \\
, 000 \\
43018\end{array}$ & $\begin{array}{c}1,000 \\
\cdot \\
43157\end{array}$ & $\begin{array}{l}239^{* *} \\
, 000 \\
36635\end{array}$ & $\begin{array}{l}, 495^{* *} \\
, 000 \\
42999\end{array}$ & $\begin{array}{l}, 350^{* *} \\
, 000 \\
42975\end{array}$ & $\begin{array}{l}, 173^{* *} \\
, 000 \\
43008\end{array}$ & $\begin{array}{l}180^{* *} \\
, 000 \\
42945\end{array}$ & $\begin{array}{l}, 273^{* *} \\
, 000 \\
42995\end{array}$ & $\begin{array}{l}195^{* *} \\
, 000 \\
42922\end{array}$ \\
\hline $\begin{array}{l}\text { Ingresos } \\
\text { elevados }\end{array}$ & $\begin{array}{c}\text { Coeficiente de } \\
\text { correlación } \\
\text { Sig. (bilateral) } \\
\mathrm{N} \\
\end{array}$ & $\begin{array}{l}163^{* *} \\
, 000 \\
36518 \\
\end{array}$ & $\begin{array}{c}, 336^{* *} \\
, 000 \\
36619 \\
\end{array}$ & $\begin{array}{c}, 239^{* *} \\
000 \\
36635 \\
\end{array}$ & $\begin{array}{c}1,000 \\
\cdot \\
36749 \\
\end{array}$ & $\begin{array}{l}, 296^{* *} \\
, 000 \\
36617 \\
\end{array}$ & $\begin{array}{c}, 509^{* *} \\
, 000 \\
36582 \\
\end{array}$ & $\begin{array}{l}234^{* *} \\
, 000 \\
36622 \\
\end{array}$ & $\begin{array}{l}, 401^{* *} \\
, 000 \\
36573 \\
\end{array}$ & $\begin{array}{l}120^{* *} \\
, 000 \\
36601 \\
\end{array}$ & $\begin{array}{c}, 227^{* *} \\
, 000 \\
36544 \\
\end{array}$ \\
\hline $\begin{array}{c}\text { Afrontar nuevos } \\
\text { retos }\end{array}$ & $\begin{array}{c}\text { Coeficiente de } \\
\text { correlación } \\
\text { Sig. (bilateral) } \\
\mathrm{N} \\
\end{array}$ & $\begin{array}{c}, 265^{* *} \\
, 000 \\
42872 \\
\end{array}$ & $\begin{array}{c}, 085^{* *} \\
, 000 \\
42983 \\
\end{array}$ & $\begin{array}{l}.495^{* *} \\
, 000 \\
42999 \\
\end{array}$ & $\begin{array}{l}, 296 * * \\
, 000 \\
36617\end{array}$ & $\begin{array}{c}1,000 \\
43117 \\
\end{array}$ & $\begin{array}{l}.435^{* *} \\
, 000 \\
42945 \\
\end{array}$ & $\begin{array}{l}.125^{* *} \\
, 000 \\
42987 \\
\end{array}$ & $\begin{array}{l}, 214^{* *} \\
, 000 \\
42921 \\
\end{array}$ & $\begin{array}{c}, 247^{* *} \\
, 000 \\
42966 \\
\end{array}$ & $\begin{array}{l}, 122^{* *} \\
, 000 \\
42893\end{array}$ \\
\hline $\begin{array}{c}\text { Buenas } \\
\text { perspectivas } \\
\text { profesionales }\end{array}$ & $\begin{array}{c}\text { Coeficiente de } \\
\text { correlación } \\
\text { Sig. (bilateral) } \\
\mathrm{N}\end{array}$ & $\begin{array}{c}, 176^{* *} \\
, 000 \\
42850 \\
\end{array}$ & $\begin{array}{l}, 273^{* *} \\
, 000 \\
42953\end{array}$ & $\begin{array}{c}, 350^{* *} \\
, 000 \\
42975 \\
\end{array}$ & $\begin{array}{c}, 509^{* *} \\
, 000 \\
36582 \\
\end{array}$ & $\begin{array}{c}, 435^{* *} \\
, 000 \\
42945 \\
\end{array}$ & $\begin{array}{c}1,000 \\
. \\
43093 \\
\end{array}$ & $\begin{array}{c}, 176^{* *} \\
, 000 \\
42966 \\
\end{array}$ & $\begin{array}{c}, 406{ }^{* *} \\
, 000 \\
42904 \\
\end{array}$ & $\begin{array}{l}, 217^{* *} \\
, 000 \\
42947 \\
\end{array}$ & $\begin{array}{c}, 208^{* *} \\
, 000 \\
42877 \\
\end{array}$ \\
\hline $\begin{array}{l}\text { Tener tiempo } \\
\text { para actividades } \\
\text { recreativas }\end{array}$ & $\begin{array}{c}\text { Coeficiente de } \\
\text { correlación } \\
\text { Sig. (bilateral) } \\
\text { N }\end{array}$ & $\begin{array}{l}, 132^{* *} \\
, 000 \\
42885\end{array}$ & $\begin{array}{l}, 268^{* *} \\
, 000 \\
42997\end{array}$ & $\begin{array}{l}, 173^{* *} \\
, 000 \\
43008\end{array}$ & $\begin{array}{l}, 234^{* *} \\
, 000 \\
36622\end{array}$ & $\begin{array}{c}, 125^{* *} \\
, 000 \\
42987\end{array}$ & $\begin{array}{l}, 176^{* *} \\
, 000 \\
42966\end{array}$ & $\begin{array}{c}1,000 \\
\cdot \\
43135\end{array}$ & $\begin{array}{l}, 201^{* *} \\
, 000 \\
42937\end{array}$ & $\begin{array}{l}, 223^{* *} \\
, 000 \\
42991\end{array}$ & $\begin{array}{l}, 430^{* *} \\
, 000 \\
42924\end{array}$ \\
\hline $\begin{array}{l}\text { Reconocimiento/ } \\
\text { prestigio social }\end{array}$ & $\begin{array}{c}\text { Coeficiente de } \\
\text { correlación } \\
\text { Sig. (bilateral) } \\
\mathrm{N}\end{array}$ & $\begin{array}{c}139^{* *} \\
, 000 \\
42822\end{array}$ & $\begin{array}{l}, 263^{* *} \\
, 000 \\
42928\end{array}$ & $\begin{array}{l}180^{* *} \\
, 000 \\
42945\end{array}$ & $\begin{array}{l}, 401^{* *} \\
, 000 \\
36573\end{array}$ & $\begin{array}{l}, 214^{* *} \\
, 000 \\
42921\end{array}$ & $\begin{array}{l}, 406^{* *} \\
, 000 \\
42904\end{array}$ & $\begin{array}{l}, 201^{* *} \\
, 000 \\
42937\end{array}$ & $\begin{array}{c}1,000 \\
. \\
43064\end{array}$ & $\begin{array}{l}, 296^{* *} \\
, 000 \\
42930\end{array}$ & $\begin{array}{l}, 218^{* *} \\
, 000 \\
42860\end{array}$ \\
\hline $\begin{array}{c}\text { Oportunidad de } \\
\text { hacer algo útil } \\
\text { para la sociedad }\end{array}$ & $\begin{array}{c}\text { Coeficiente de } \\
\text { correlación } \\
\text { Sig. (bilateral) } \\
\mathrm{N} \\
\end{array}$ & $\begin{array}{l}, 171^{* *} \\
, 000 \\
42869 \\
\end{array}$ & $\begin{array}{l}, 206^{* *} \\
, 000 \\
42983 \\
\end{array}$ & $\begin{array}{l}, 273^{* *} \\
, 000 \\
42995 \\
\end{array}$ & $\begin{array}{c}, 120^{* *} \\
, 000 \\
36601 \\
\end{array}$ & $\begin{array}{c}, 247^{* *} \\
, 000 \\
42966 \\
\end{array}$ & $\begin{array}{l}, 217^{* *} \\
, 000 \\
42947 \\
\end{array}$ & $\begin{array}{c}, 223^{* *} \\
, 000 \\
42991 \\
\end{array}$ & $\begin{array}{c}, 296 * \\
, 000 \\
42930 \\
\end{array}$ & $\begin{array}{c}1,000 \\
. \\
43120 \\
\end{array}$ & $\begin{array}{c}, 324^{* *} \\
, 000 \\
42917 \\
\end{array}$ \\
\hline $\begin{array}{c}\text { Facilidad para } \\
\text { combinar trabajo } \\
\text { y familia }\end{array}$ & $\begin{array}{c}\text { Coeficiente de } \\
\text { correlación } \\
\text { Sig. (bilateral) } \\
N\end{array}$ & $\begin{array}{l}, 144^{* *} \\
, 000 \\
42804\end{array}$ & $\begin{array}{l}, 318^{* *} \\
, 000 \\
42912\end{array}$ & $\begin{array}{l}195^{* *} \\
, 000 \\
42922\end{array}$ & $\begin{array}{l}, 227^{* *} \\
, 000 \\
36544\end{array}$ & $\begin{array}{l}122^{* *} \\
, 000 \\
42893\end{array}$ & $\begin{array}{l}208^{* *} \\
, 000 \\
42877\end{array}$ & $\begin{array}{l}, 430^{* *} \\
, 000 \\
42924\end{array}$ & $\begin{array}{l}218^{* *} \\
, 000 \\
42860\end{array}$ & $\begin{array}{l}.324^{* *} \\
, 000 \\
42917\end{array}$ & $\begin{array}{c}1,000 \\
\cdot \\
43049\end{array}$ \\
\hline
\end{tabular}

**. La correlación es significativa al nivel 0,01 (bilateral). 


\section{Tabla H7. Correlaciones entre las variables del Factor Valores Laborales - Grado de aplicación en el trabajo}

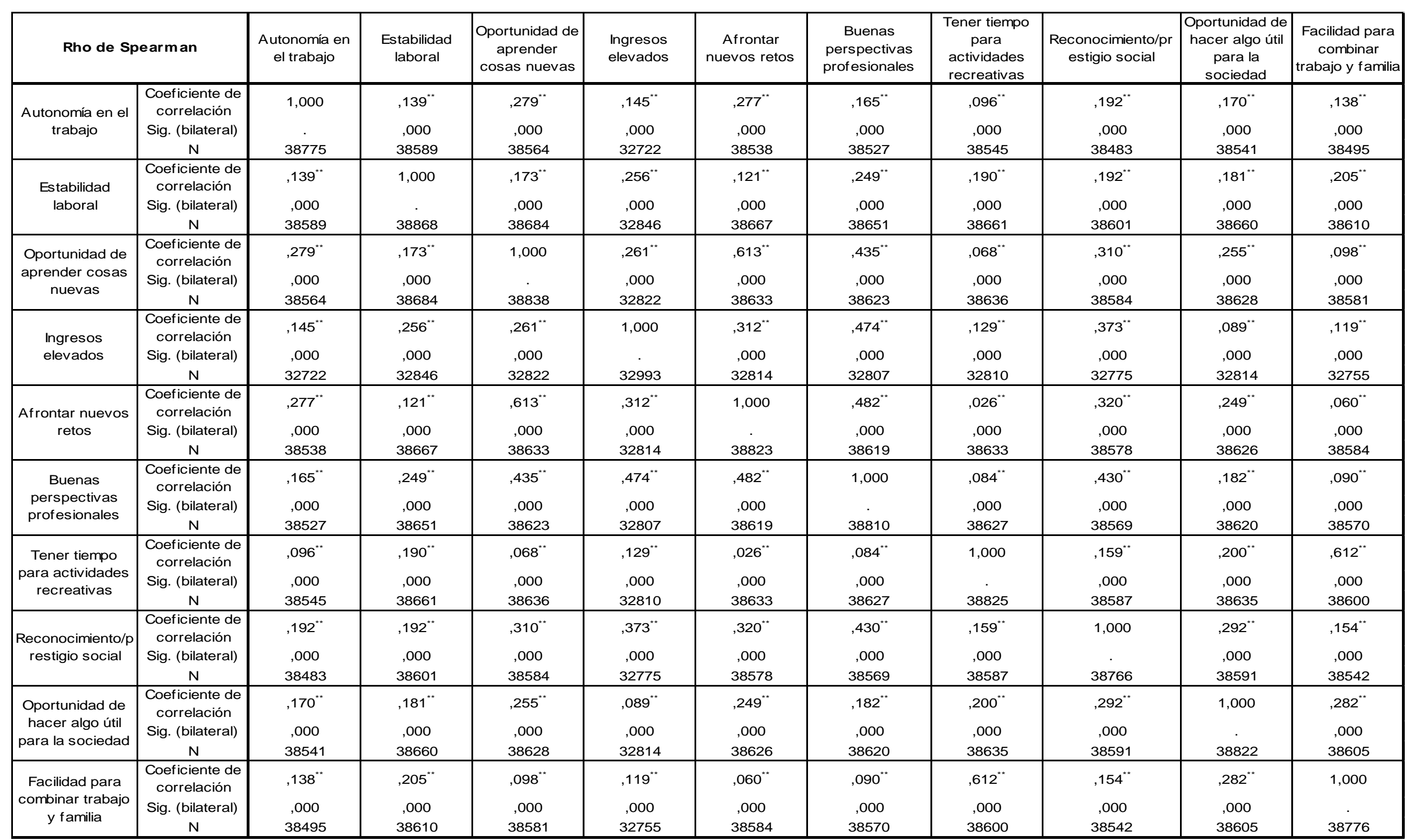

**. La correlación es significativa al nivel 0,01 (bilateral). 
Anexo I. Análisis Factorial 
Anexo I: Análisis Factorial

\section{Sección I1: Análisis Factorial de las variables para EUROPA}

\section{I1-A Medida del Éxito Laboral}

La medida del Éxito laboral entendida como, Éxito laboral objetivo y Éxito Laboral Subjetivo.

\section{I1-A1 Medida del Éxito Laboral Objetivo}

Tabla I1-1 Resumen de la Prueba Factorial

\begin{tabular}{|l|c|}
\hline \multicolumn{1}{|c|}{ Prueba } & Resultado \\
\hline Alfa de Cronbach & 0,970 \\
\hline Medida de adecuación muestral de Kaiser-Meyer-Olkin (KMO) & 0,500 \\
\hline Prueba de esfericidad de Barlett (sig) & 0,000 \\
\hline Varianza total explicada (\%) & 97,350 \\
\hline
\end{tabular}

Los resultados de cargas factoriales del factor obtenido, se presenta en la siguiente tabla:

Tabla I1-2 Resultados de las cargas factoriales: Éxito Laboral Objetivo Europa

\begin{tabular}{|c|c|c|c|c|c|}
\hline IdVariable & Variables & № & $\begin{array}{l}\text { Componentes } \\
\text { Interpretados }\end{array}$ & $\begin{array}{c}\text { Cargas } \\
\text { Factoriales }\end{array}$ & $\begin{array}{c}\text { \% Varianza } \\
\text { Explicada }\end{array}$ \\
\hline Sueldo Contrato & $\begin{array}{l}\text { ¿Cuál es aproximadamente tu } \\
\text { sueldo mensual bruto? Según } \\
\text { contrato }\end{array}$ & \multirow{2}{*}{1} & \multirow{2}{*}{ Exlabob_E } & 0,987 & \multirow[t]{2}{*}{97,350} \\
\hline Sueldo Total & $\begin{array}{l}\text { ¿Cuál es aproximadamente tu } \\
\text { sueldo Total bruto? Según } \\
\text { contrato }\end{array}$ & & & 0,987 & \\
\hline
\end{tabular}

\section{I1-A2 Medida del Éxito Laboral Subjetivo}

Tabla I1-3 Resumen de la Prueba Factorial

\begin{tabular}{|l|c|}
\hline \multicolumn{1}{|c|}{ Prueba } & Resultado \\
\hline Alfa de Cronbach & 0,574 \\
\hline Medida de adecuación muestral de Kaiser-Meyer-Olkin (KMO) & 0,500 \\
\hline Prueba de esfericidad de Barlett (sig) & 0,000 \\
\hline Varianza total explicada (\%) & 70,132 \\
\hline
\end{tabular}


Los resultados de cargas factoriales del factor obtenido, se presenta en la siguiente tabla:

Tabla I1-4 Resultados de las cargas factoriales: Éxito Laboral Subjetivo Europa

\begin{tabular}{|c|l|c|c|c|c|}
\hline IdVariable & \multicolumn{1}{|c|}{ Variables } & No & $\begin{array}{c}\text { Componentes } \\
\text { Interpretados }\end{array}$ & $\begin{array}{c}\text { Cargas } \\
\text { Factoriales }\end{array}$ & $\begin{array}{c}\text { \% Varianza } \\
\text { Explicada }\end{array}$ \\
\hline Uso & $\begin{array}{l}\text { ¿En qué medida usas tus } \\
\text { conocimientos y habilidades? }\end{array}$ & \multirow{2}{*}{1} & Exlabsu_E & 0,837 & \multirow{2}{*}{70,132} \\
\cline { 1 - 2 } Satisfacción & $\begin{array}{l}\text { ¿En general, estás satisfecho con tu } \\
\text { trabajo actual? }\end{array}$ & & 0,837 & \\
\hline
\end{tabular}

\section{I1-B Medida del Rol en el Trabajo}

Tabla 11-5 Resumen de la Prueba Factorial

\begin{tabular}{|l|c|}
\hline \multicolumn{1}{|c|}{ Prueba } & Resultado \\
\hline Alfa de Cronbach & 0,759 \\
\hline Medida de adecuación muestral de Kaiser-Meyer-Olkin (KMO) & 0,762 \\
\hline Prueba de esfericidad de Barlett (sig) & 0,000 \\
\hline Varianza total explicada (\%) & 61,381 \\
\hline
\end{tabular}

Los resultados de las cargas factoriales de los factores obtenidos, se presenta en la tabla I1-6. 
Tabla I1-6 Resultados de las cargas factoriales: Rol en el Trabajo Europa

\begin{tabular}{|c|c|c|c|c|c|}
\hline IdVariable & Variables & № & $\begin{array}{l}\text { Componentes } \\
\text { Interpretados }\end{array}$ & $\begin{array}{l}\text { Cargas } \\
\text { Factoriales }\end{array}$ & $\begin{array}{l}\text { \% Varianza } \\
\text { Explicada }\end{array}$ \\
\hline R1 & $\begin{array}{l}\text { ¿En qué medida eres responsable de } \\
\text { establecer objetivos para la } \\
\text { organización? }\end{array}$ & \multirow{4}{*}{1} & \multirow{4}{*}{ Responsabilidad } & 0,818 & \multirow{4}{*}{26,189} \\
\hline R2 & $\begin{array}{l}\text { ¿En qué medida eres responsable de } \\
\text { establecer objetivos para tu propio } \\
\text { trabajo? }\end{array}$ & & & 0,708 & \\
\hline R3 & $\begin{array}{l}\text { ¿En qué medida eres responsable de } \\
\text { decidir estrategias de trabajo para la } \\
\text { organización? }\end{array}$ & & & 0,800 & \\
\hline R4 & $\begin{array}{l}\text { ¿En qué medida eres responsable de } \\
\text { decidir cómo hacer tu trabajo? }\end{array}$ & & & 0,639 & \\
\hline R5 & $\begin{array}{l}\text { Los compañeros, clientes, etc. } \\
\text { acuden a mí para pedirme consejo. }\end{array}$ & \multirow{4}{*}{2} & \multirow{4}{*}{$\begin{array}{l}\text { Relaciones en el } \\
\text { Trabajo }\end{array}$} & 0,775 & \multirow{4}{*}{23,645} \\
\hline R6 & $\begin{array}{l}\text { Mantengo informados a mis } \\
\text { compañeros de profesión sobre } \\
\text { nuevos desarrollos en mi campo. }\end{array}$ & & & 0,820 & \\
\hline R7 & $\begin{array}{l}\text { Suelo iniciar relaciones profesionales } \\
\text { con expertos ajenos a la } \\
\text { organización. }\end{array}$ & & & 0,654 & \\
\hline R8 & $\begin{array}{l}\text { Las cuestiones de ética profesional } \\
\text { forman parte importante de mis } \\
\text { funciones. }\end{array}$ & & & 0,503 & \\
\hline R9 & $\begin{array}{l}\text { ¿Cuánto perjudicarías a tu } \\
\text { organización si cometieras un error } \\
\text { grave en tu trabajo? }\end{array}$ & 3 & Perjuicio & 0,871 & 11,548 \\
\hline
\end{tabular}

Método de extracción: Análisis de componentes principales

Método de Rotación: Normalización Varimax con Kaiser

Continente= Europa

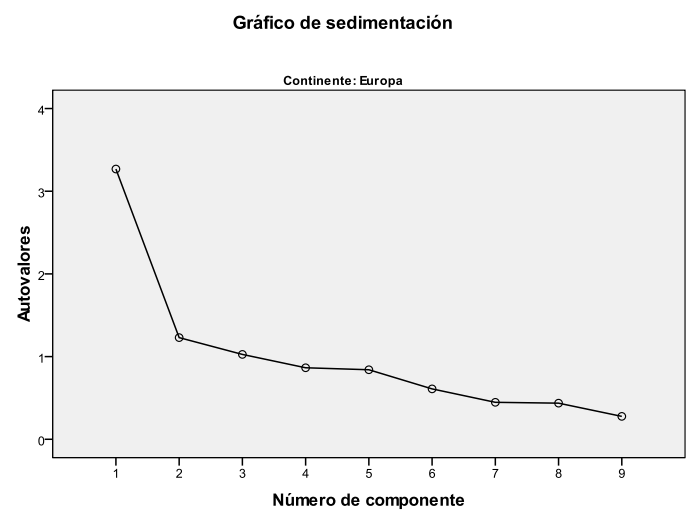

Fig I1-1 


\section{I1-C Medida de las Competencia Propias}

En la tabla I1-7 se presenta el resumen del análisis.

Tabla I1-7 Resumen de la Prueba Factorial

\begin{tabular}{|l|c|}
\hline \multicolumn{1}{|c|}{ Prueba } & Resultado \\
\hline Alfa de Cronbach & 0,880 \\
\hline Medida de adecuación muestral de Kaiser-Meyer-Olkin (KMO) & 0,932 \\
\hline Prueba de esfericidad de Barlett (sig) & 0,000 \\
\hline Varianza total explicada (\%) & 51,817 \\
\hline
\end{tabular}

En la tabla I1-8, se muestran los resultados obtenidos de las cargas factoriales y los componentes interpretados. 
Tabla I1-8 Resultados de las cargas factoriales: Competencias Propias Europa

\begin{tabular}{|c|c|c|c|c|c|}
\hline IdVariable & Variables & № & $\begin{array}{l}\text { Componentes } \\
\text { Interpretados }\end{array}$ & $\begin{array}{c}\text { Cargas } \\
\text { Factoriales }\end{array}$ & $\begin{array}{l}\text { \% Varianza } \\
\text { Explicada }\end{array}$ \\
\hline CPE & $\begin{array}{l}\text { Capacidad para negociar de } \\
\text { forma eficaz }\end{array}$ & \multirow{6}{*}{1} & \multirow{6}{*}{$\begin{array}{c}\text { Competencias de Liderazgo } \\
\text { y Comunicación }\end{array}$} & 0,606 & \multirow{6}{*}{17,041} \\
\hline CPG & $\begin{array}{l}\text { Capacidad para detectar } \\
\text { nuevas oportunidades }\end{array}$ & & & 0,489 & \\
\hline CPK & $\begin{array}{l}\text { Capacidad para movilizar las } \\
\text { capacidades de otros }\end{array}$ & & & 0,679 & \\
\hline CPL & $\begin{array}{l}\text { Capacidad para hacerte } \\
\text { entender }\end{array}$ & & & 0,631 & \\
\hline CPM & $\begin{array}{l}\text { Capacidad para hacer valer } \\
\text { tu autoridad }\end{array}$ & & & 0,724 & \\
\hline $\mathrm{CPQ}$ & $\begin{array}{l}\text { Capacidad para presentar } \\
\text { en público productos, ideas } \\
\text { o informes }\end{array}$ & & & 0,589 & \\
\hline $\mathrm{CPF}$ & $\begin{array}{l}\text { Capacidad para trabajar } \\
\text { bajo presión }\end{array}$ & \multirow{4}{*}{2} & \multirow{4}{*}{$\begin{array}{l}\text { Competencias } \\
\text { Organizativas }\end{array}$} & 0,545 & \multirow{4}{*}{12,32} \\
\hline $\mathrm{CPH}$ & $\begin{array}{l}\text { Capacidad para coordinar } \\
\text { actividades }\end{array}$ & & & 0,608 & \\
\hline CPI & $\begin{array}{l}\text { Capacidad para usar el } \\
\text { tiempo de forma efectiva }\end{array}$ & & & 0,781 & \\
\hline CPJ & $\begin{array}{l}\text { Capacidad para trabajar en } \\
\text { equipo }\end{array}$ & & & 0,627 & \\
\hline CPN & $\begin{array}{l}\text { Capacidad para utilizar } \\
\text { herramientas informáticas }\end{array}$ & \multirow{5}{*}{3} & \multirow{5}{*}{$\begin{array}{l}\text { Competencias } \\
\text { Instrumentales y de } \\
\text { Innovación }\end{array}$} & 0,624 & \multirow{5}{*}{11,363} \\
\hline $\mathrm{CPO}$ & $\begin{array}{l}\text { Capacidad para encontrar } \\
\text { nuevas ideas y soluciones }\end{array}$ & & & 0,442 & \\
\hline CPP & $\begin{array}{l}\text { Predisposición para } \\
\text { cuestionar ideas propias o } \\
\text { ajenas }\end{array}$ & & & 0,467 & \\
\hline CPR & $\begin{array}{l}\text { Capacidad para redactar } \\
\text { informes o documentos }\end{array}$ & & & 0,608 & \\
\hline CPS & $\begin{array}{l}\text { Capacidad para escribir y } \\
\text { hablar idiomas extranjeros }\end{array}$ & & & 0,624 & \\
\hline CPA & $\begin{array}{l}\text { Dominio de tu área o } \\
\text { disciplina }\end{array}$ & \multirow{4}{*}{4} & \multirow{4}{*}{$\begin{array}{l}\text { Competencias de } \\
\text { Conocimiento y } \\
\text { Pensamiento } \\
\text { Metacognitivo }\end{array}$} & 0,642 & \multirow{4}{*}{11,094} \\
\hline CPB & $\begin{array}{l}\text { Conocimiento de otras } \\
\text { áreas o disciplinas }\end{array}$ & & & 0,705 & \\
\hline CPC & Pensamiento analítico & & & 0,596 & \\
\hline CPD & $\begin{array}{l}\text { Capacidad para adquirir con } \\
\text { rapidez nuevos } \\
\text { conocimientos. }\end{array}$ & & & 0,489 & \\
\hline
\end{tabular}

Método de extracción: Análisis de componentes principales

Método de Rotación: Normalización Varimax con Kaiser

Continente=Europa 


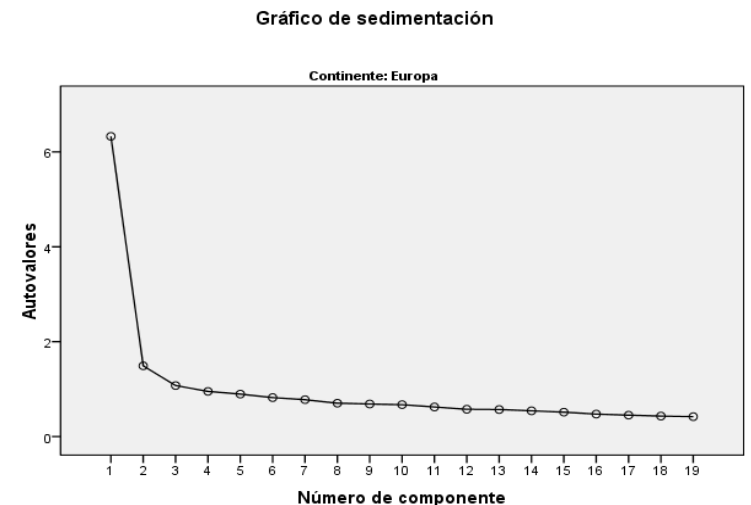

Fig $11-2$

\section{I1-D Medida de las Competencia Requeridas en el Trabajo}

Tabla I1-9 Resumen de la prueba Factorial

\begin{tabular}{|l|c|}
\hline \multicolumn{1}{|c|}{ Prueba } & Resultado \\
\hline Alfa de Cronbach & 0,906 \\
\hline Medida de adecuación muestral de Kaiser-Meyer-Olkin (KMO) & 0,942 \\
\hline Prueba de esfericidad de Barlett (sig) & 0,000 \\
\hline Varianza total explicada (\%) & 52,405 \\
\hline
\end{tabular}

En la tabla I1-10 se muestra el resumen de la prueba factorial resultante. 
Tabla I1-10 Resultados de las cargas factoriales: Competencias Requeridas en el Trabajo Europa

\begin{tabular}{|c|c|c|c|c|c|}
\hline IdVariable & Variables & № & $\begin{array}{l}\text { Componentes } \\
\text { Interpretados }\end{array}$ & $\begin{array}{c}\text { Cargas } \\
\text { Factoriales }\end{array}$ & $\begin{array}{c}\text { \% Varianza } \\
\text { Explicada }\end{array}$ \\
\hline CRE & $\begin{array}{l}\text { Capacidad para negociar de } \\
\text { forma eficaz }\end{array}$ & \multirow{7}{*}{1} & \multirow{7}{*}{$\begin{array}{c}\text { Competencias } \\
\text { Organizativas y Liderazgo }\end{array}$} & 0,488 & \multirow{7}{*}{19,99} \\
\hline CRG & $\begin{array}{l}\text { Capacidad para detectar } \\
\text { nuevas oportunidades }\end{array}$ & & & 0,462 & \\
\hline $\mathrm{CRH}$ & $\begin{array}{l}\text { Capacidad para coordinar } \\
\text { actividades }\end{array}$ & & & 0,540 & \\
\hline CRJ & $\begin{array}{l}\text { Capacidad para trabajar en } \\
\text { equipo }\end{array}$ & & & 0,518 & \\
\hline CRK & $\begin{array}{l}\text { Capacidad para movilizar las } \\
\text { capacidades de otros }\end{array}$ & & & 0,754 & \\
\hline CRL & $\begin{array}{l}\text { Capacidad para hacerte } \\
\text { entender }\end{array}$ & & & 0,682 & \\
\hline CRM & $\begin{array}{l}\text { Capacidad para hacer valer } \\
\text { tu autoridad }\end{array}$ & & & 0,738 & \\
\hline CRB & $\begin{array}{l}\text { Conocimiento de otras } \\
\text { áreas o disciplinas }\end{array}$ & \multirow{8}{*}{2} & \multirow{8}{*}{$\begin{array}{c}\text { Competencias de } \\
\text { Innovación, Instrumentales } \\
\text { y de Comunicación }\end{array}$} & 0,439 & \multirow{8}{*}{17,783} \\
\hline CRC & Pensamiento analítico & & & 0,599 & \\
\hline CRN & $\begin{array}{l}\text { Capacidad para utilizar } \\
\text { herramientas informáticas }\end{array}$ & & & 0,639 & \\
\hline CRO & $\begin{array}{l}\text { Capacidad para encontrar } \\
\text { nuevas ideas y soluciones }\end{array}$ & & & 0,585 & \\
\hline CRP & $\begin{array}{l}\text { Predisposición para } \\
\text { cuestionar ideas propias o } \\
\text { ajenas }\end{array}$ & & & 0,559 & \\
\hline CRQ & $\begin{array}{l}\text { Capacidad para presentar } \\
\text { en público productos, ideas } \\
\text { o informes }\end{array}$ & & & 0,548 & \\
\hline CRR & $\begin{array}{l}\text { Capacidad para redactar } \\
\text { informes o documentos }\end{array}$ & & & 0,622 & \\
\hline CRS & $\begin{array}{l}\text { Capacidad para escribir y } \\
\text { hablar idiomas extranjeros }\end{array}$ & & & 0,619 & \\
\hline CRA & $\begin{array}{l}\text { Dominio de tu área o } \\
\text { disciplina }\end{array}$ & \multirow{4}{*}{3} & \multirow{4}{*}{$\begin{array}{l}\text { Competencias de } \\
\text { Conocimiento, } \\
\text { organizativas }\end{array}$} & 0,493 & \multirow{4}{*}{14,631} \\
\hline CRD & $\begin{array}{l}\text { Capacidad para adquirir con } \\
\text { rapidez nuevos } \\
\text { conocimientos. }\end{array}$ & & & 0,567 & \\
\hline CRF & $\begin{array}{l}\text { Capacidad para trabajar } \\
\text { bajo presión }\end{array}$ & & & 0,727 & \\
\hline CRI & $\begin{array}{l}\text { Capacidad para usar el } \\
\text { tiempo de forma efectiva }\end{array}$ & & & 0,672 & \\
\hline
\end{tabular}

Método de extracción: Análisis de componentes principales Método de Rotación: Normalización Varimax con Kaiser Continente=Europa

\section{I1-E Medida de Los Valores Laborales Personales}

En la tabla I1-11 se puede apreciar el resumen del análisis. 
Tabla I1-11 Resumen de la prueba Factorial

\begin{tabular}{|l|c|}
\hline \multicolumn{1}{|c|}{ Prueba } & Resultado \\
\hline Alfa de Cronbach & 0,692 \\
\hline Medida de adecuación muestral de Kaiser-Meyer-Olkin (KMO) & 0,729 \\
\hline Prueba de esfericidad de Barlett (sig) & 0,000 \\
\hline Varianza total explicada (\%) & 54,251 \\
\hline
\end{tabular}

Las cargas factoriales se representan en la tabla I1-12

Tabla I1-12 Resultados de las cargas factoriales: Valores laborales Personales Europa

\begin{tabular}{|c|c|c|c|c|c|}
\hline IdVariable & Variables & № & $\begin{array}{l}\text { Componentes } \\
\text { Interpretados }\end{array}$ & $\begin{array}{c}\text { Cargas } \\
\text { Factoriales }\end{array}$ & $\begin{array}{l}\text { \% Varianza } \\
\text { Explicada }\end{array}$ \\
\hline VP4 & Ingresos elevados & \multirow{3}{*}{1} & \multirow{3}{*}{$\begin{array}{c}\text { Ingresos y } \\
\text { Reconocimiento }\end{array}$} & 0,820 & \multirow{3}{*}{19,27} \\
\hline VP6 & $\begin{array}{l}\text { Buenas perspectivas } \\
\text { profesionales }\end{array}$ & & & 0,747 & \\
\hline VP8 & $\begin{array}{l}\text { Reconocimiento/prestigio } \\
\text { social }\end{array}$ & & & 0,619 & \\
\hline VP1 & Autonomía en el trabajo & \multirow{3}{*}{2} & \multirow{3}{*}{$\begin{array}{l}\text { Puesto de Trabajo } \\
\text { Enriquecido } \\
\text { "satisfactorio" }\end{array}$} & 0,570 & \multirow{3}{*}{17,606} \\
\hline VP3 & $\begin{array}{l}\text { Oportunidad de aprender cosas } \\
\text { nuevas }\end{array}$ & & & 0,753 & \\
\hline VP5 & Afrontar nuevos retos & & & 0,747 & \\
\hline VP2 & Estabilidad laboral & \multirow{4}{*}{3} & \multirow{4}{*}{$\begin{array}{l}\text { Ocio, Familia y Servicio } \\
\text { a la sociedad }\end{array}$} & 0,520 & \multirow{4}{*}{17,376} \\
\hline VP7 & $\begin{array}{l}\text { Tener tiempo para actividades } \\
\text { recreativas }\end{array}$ & & & 0,700 & \\
\hline VP9 & $\begin{array}{l}\text { Oportunidad de hacer algo útil } \\
\text { para la sociedad }\end{array}$ & & & 0,545 & \\
\hline VP10 & $\begin{array}{l}\text { Facilidad para combinar trabajo } \\
\text { y familia }\end{array}$ & & & 0,769 & \\
\hline
\end{tabular}

Método de extracción: Análisis de componentes principales

Método de Rotación: Normalización Varimax con Kaiser

Continente=Europa

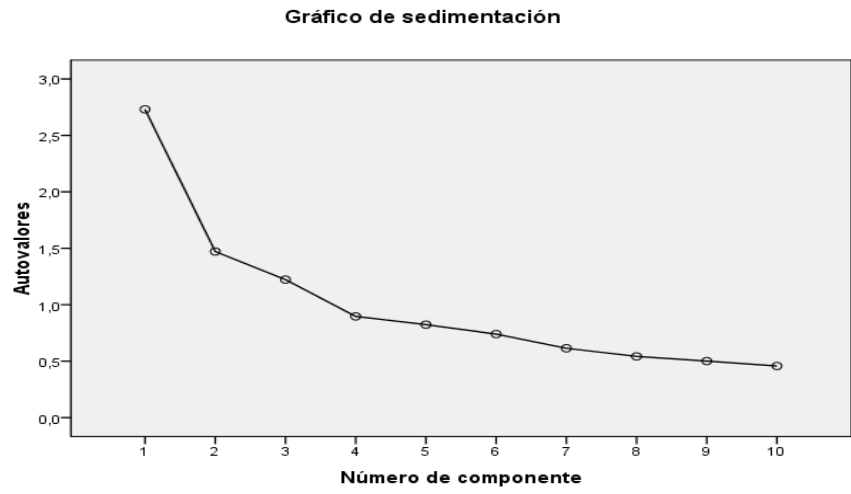

Fig. I1-3 


\section{I1-F Medida de Los Valores Laborales en el Trabajo}

La tabla I1-13 muestra el resumen de la prueba.

Tabla I1-13 Resumen de la prueba factorial

\begin{tabular}{|l|c|}
\hline \multicolumn{1}{|c|}{ Prueba } & Resultado \\
\hline Alfa de Cronbach & 0,704 \\
\hline Medida de adecuación muestral de Kaiser-Meyer-Olkin (KMO) & 0,729 \\
\hline Prueba de esfericidad de Barlett (sig) & 0,000 \\
\hline Varianza total explicada (\%) & 57,601 \\
\hline
\end{tabular}

Tabla I1-14 Tabla Resultados de las cargas factoriales: Valores laborales en el trabajo Europa

\begin{tabular}{|c|c|c|c|c|c|}
\hline IdVariable & Variables & № & $\begin{array}{l}\text { Componentes } \\
\text { Interpretados }\end{array}$ & $\begin{array}{c}\text { Cargas } \\
\text { Factoriales }\end{array}$ & $\begin{array}{l}\text { \% Varianza } \\
\text { Explicada }\end{array}$ \\
\hline VT1 & Autonomía en el trabajo & \multirow{4}{*}{1} & \multirow{4}{*}{$\begin{array}{l}\text { Puesto de Trabajo } \\
\text { Enriquecido } \\
\text { "satisfactorio" }\end{array}$} & 0,596 & \multirow{4}{*}{20,308} \\
\hline VT3 & $\begin{array}{l}\text { Oportunidad de aprender cosas } \\
\text { nuevas }\end{array}$ & & & 0,752 & \\
\hline VT5 & Afrontar nuevos retos & & & 0,760 & \\
\hline VT9 & $\begin{array}{l}\text { Oportunidad de hacer algo útil } \\
\text { para la sociedad }\end{array}$ & & & 0,531 & \\
\hline VT2 & Estabilidad laboral & \multirow{4}{*}{2} & \multirow{4}{*}{$\begin{array}{l}\text { Ingresos, Estabilidad y } \\
\text { Reconocimiento }\end{array}$} & 0,552 & \multirow{4}{*}{19,68} \\
\hline VT4 & Ingresos elevados & & & 0,796 & \\
\hline VT6 & $\begin{array}{l}\text { Buenas perspectivas } \\
\text { profesionales }\end{array}$ & & & 0,723 & \\
\hline VT8 & $\begin{array}{l}\text { Reconocimiento/prestigio } \\
\text { social }\end{array}$ & & & 0,552 & \\
\hline VT7 & $\begin{array}{l}\text { Tener tiempo para actividades } \\
\text { recreativas }\end{array}$ & \multirow{2}{*}{3} & \multirow{2}{*}{ Ocio y Familia } & 0,839 & \multirow{2}{*}{17,613} \\
\hline VT10 & $\begin{array}{l}\text { Facilidad para combinar trabajo } \\
\text { y familia }\end{array}$ & & & 0,858 & \\
\hline
\end{tabular}

Método de extracción: Análisis de componentes principales

Método de Rotación: Normalización Varimax con Kaiser

Continente=Europa 
I1-G Medida del ajuste de las competencias

Tabla I1-15 Resumen de la prueba Factorial

\begin{tabular}{|l|c|}
\hline \multicolumn{1}{|c|}{ Prueba } & Resultado \\
\hline Medida de adecuación muestral de Kaiser-Meyer-Olkin (KMO) & 0,942 \\
\hline Prueba de esfericidad de Barlett (sig) & 0,000 \\
\hline Varianza total explicada (\%) & 48,42 \\
\hline
\end{tabular}

Los resultados de cargas factoriales del factor obtenido, se presenta en la tabla I1 - 16 . 
Tabla I1-16 Tabla Resultados de las cargas factoriales: Ajuste de las competencias Europa

\begin{tabular}{|c|c|c|c|c|c|}
\hline $\begin{array}{l}\text { Id } \\
\text { Variable }\end{array}$ & Variables & № & $\begin{array}{l}\text { Componentes } \\
\text { Interpretados }\end{array}$ & $\begin{array}{l}\text { Cargas } \\
\text { Factoriales }\end{array}$ & $\begin{array}{l}\text { \% Varianza } \\
\text { Explicada }\end{array}$ \\
\hline CAJE & $\begin{array}{l}\text { Capacidad para negociar de forma } \\
\text { eficaz }\end{array}$ & \multirow{8}{*}{1} & \multirow{8}{*}{$\begin{array}{l}\text { C. de Liderazgo y } \\
\text { Organizativas }\end{array}$} & 0,555 & \multirow{8}{*}{18,93} \\
\hline CAJG & $\begin{array}{l}\text { Capacidad para detectar nuevas } \\
\text { oportunidades }\end{array}$ & & & 0,428 & \\
\hline CAJH & $\begin{array}{l}\text { Capacidad para coordinar } \\
\text { actividades }\end{array}$ & & & 0,602 & \\
\hline CAJI & $\begin{array}{l}\text { Capacidad para usar el tiempo de } \\
\text { forma efectiva }\end{array}$ & & & 0,530 & \\
\hline CAJJ & Capacidad para trabajar en equipo & & & 0,620 & \\
\hline CAJK & $\begin{array}{l}\text { Capacidad para movilizar las } \\
\text { capacidades de otros }\end{array}$ & & & 0,728 & \\
\hline CAJL & Capacidad para hacerte entender & & & 0,624 & \\
\hline CAJM & $\begin{array}{l}\text { Capacidad para hacer valer tu } \\
\text { autoridad }\end{array}$ & & & 0,670 & \\
\hline CAJN & $\begin{array}{l}\text { Capacidad para utilizar } \\
\text { herramientas informáticas }\end{array}$ & \multirow{6}{*}{2} & \multirow{6}{*}{$\begin{array}{l}\text { Competencias } \\
\text { Instrumentales, de } \\
\text { Innovación y } \\
\text { Comunicación }\end{array}$} & 0,511 & \multirow{6}{*}{14,777} \\
\hline CAJO & $\begin{array}{l}\text { Capacidad para encontrar nuevas } \\
\text { ideas y soluciones }\end{array}$ & & & 0,556 & \\
\hline CAJAP & $\begin{array}{l}\text { Predisposición para cuestionar } \\
\text { ideas propias o ajenas }\end{array}$ & & & 0,583 & \\
\hline CAJQ & $\begin{array}{l}\text { Capacidad para presentar en } \\
\text { público productos, ideas o informes }\end{array}$ & & & 0,627 & \\
\hline CAJR & $\begin{array}{l}\text { Capacidad para redactar informes o } \\
\text { documentos }\end{array}$ & & & 0,652 & \\
\hline CAJS & $\begin{array}{l}\text { Capacidad para escribir y hablar } \\
\text { idiomas extranjeros }\end{array}$ & & & 0,600 & \\
\hline CAJA & Dominio de tu área o disciplina & \multirow{5}{*}{3} & \multirow{5}{*}{$\begin{array}{c}\text { Competencias de } \\
\text { Conocimiento y } \\
\text { Pensamiento } \\
\text { Metacognitivo }\end{array}$} & 0,606 & \multirow{5}{*}{14,714} \\
\hline CAJB & $\begin{array}{l}\text { Conocimiento de otras áreas o } \\
\text { disciplinas }\end{array}$ & & & 0,530 & \\
\hline CAJC & Pensamiento analítico & & & 0,648 & \\
\hline CAJD & $\begin{array}{l}\text { Capacidad para adquirir con } \\
\text { rapidez nuevos conocimientos. }\end{array}$ & & & 0,685 & \\
\hline CAJF & $\begin{array}{l}\text { Capacidad para trabajar bajo } \\
\text { presión }\end{array}$ & & & 0,538 & \\
\hline
\end{tabular}

Método de extracción: Análisis de componentes principales Método de Rotación: Normalización Varimax con Kaiser Continente=Europa 


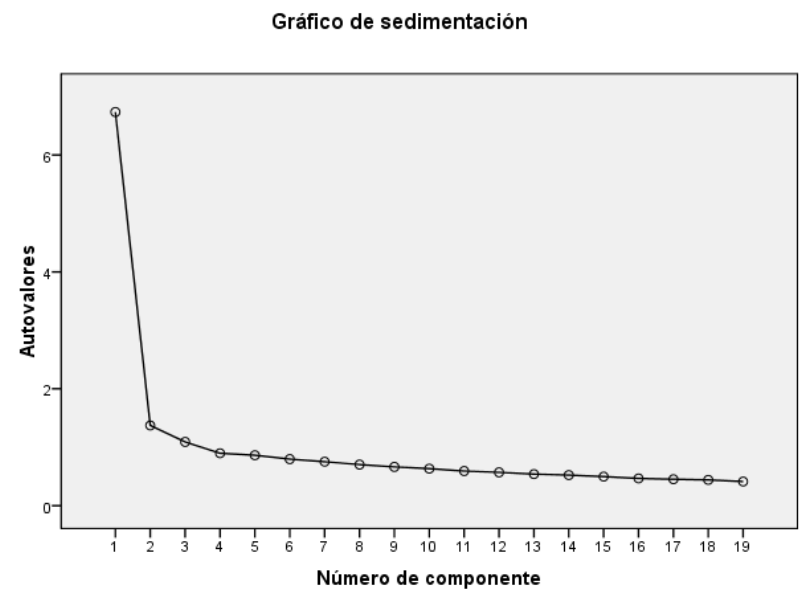

Fig. I1-4

\section{I1-H Medida del ajuste de los Valores Laborales}

Tabla I1-17 Resumen de la prueba Factorial

\begin{tabular}{|l|c|}
\hline \multicolumn{1}{|c|}{ Prueba } & Resultado \\
\hline Medida de adecuación muestral de Kaiser-Meyer-Olkin (KMO) & 0,759 \\
\hline Prueba de esfericidad de Barlett (sig) & 0,000 \\
\hline Varianza total explicada (\%) & 56,309 \\
\hline
\end{tabular}

Los resultados de cargas factoriales del factor obtenido, se presenta en la tabla I1 - 18 . 
Tabla I1-18 Tabla Resultados de las cargas factoriales: Ajuste de los Valores Laborales Europa

\begin{tabular}{|c|c|c|c|c|c|}
\hline $\begin{array}{l}\text { Id } \\
\text { Variable }\end{array}$ & Variables & № & $\begin{array}{l}\text { Componentes } \\
\text { Interpretados }\end{array}$ & $\begin{array}{l}\text { Cargas } \\
\text { Factoriales }\end{array}$ & $\begin{array}{l}\text { \% Varianza } \\
\text { Explicada }\end{array}$ \\
\hline AJVT1 & Autonomía en el trabajo & \multirow{4}{*}{1} & \multirow{4}{*}{$\begin{array}{l}\text { Puesto de Trabajo } \\
\text { Enriquecido } \\
\text { "satisfactorio" }\end{array}$} & 0,519 & \multirow{4}{*}{20,871} \\
\hline AJVT3 & $\begin{array}{l}\text { Oportunidad de aprender cosas } \\
\text { nuevas }\end{array}$ & & & 0,773 & \\
\hline AJVT5 & Afrontar nuevos retos & & & 0,795 & \\
\hline AJVT9 & $\begin{array}{l}\text { Oportunidad de hacer algo útil } \\
\text { para la sociedad }\end{array}$ & & & 0,496 & \\
\hline AJVT2 & Estabilidad laboral & \multirow{4}{*}{2} & \multirow{4}{*}{$\begin{array}{l}\text { Ingresos, Estabilidad y } \\
\text { Reconocimiento }\end{array}$} & 0,652 & \multirow{4}{*}{18,491} \\
\hline AJVT4 & Ingresos elevados & & & 0,758 & \\
\hline AJVT6 & Buenas perspectivas profesionales & & & 0,648 & \\
\hline AJVT8 & Reconocimiento/prestigio social & & & 0,562 & \\
\hline AJVT7 & $\begin{array}{l}\text { Tener tiempo para actividades } \\
\text { recreativas }\end{array}$ & \multirow{2}{*}{3} & \multirow{2}{*}{ Ocio y Familia } & 0,837 & \multirow{2}{*}{16,948} \\
\hline AJVT10 & $\begin{array}{l}\text { Facilidad para combinar trabajo y } \\
\text { familia }\end{array}$ & & & 0,844 & \\
\hline
\end{tabular}

Método de extracción: Análisis de componentes principales

Método de Rotación: Normalización Varimax con Kaiser

Continente=Europa

Gráfico de sedimentación

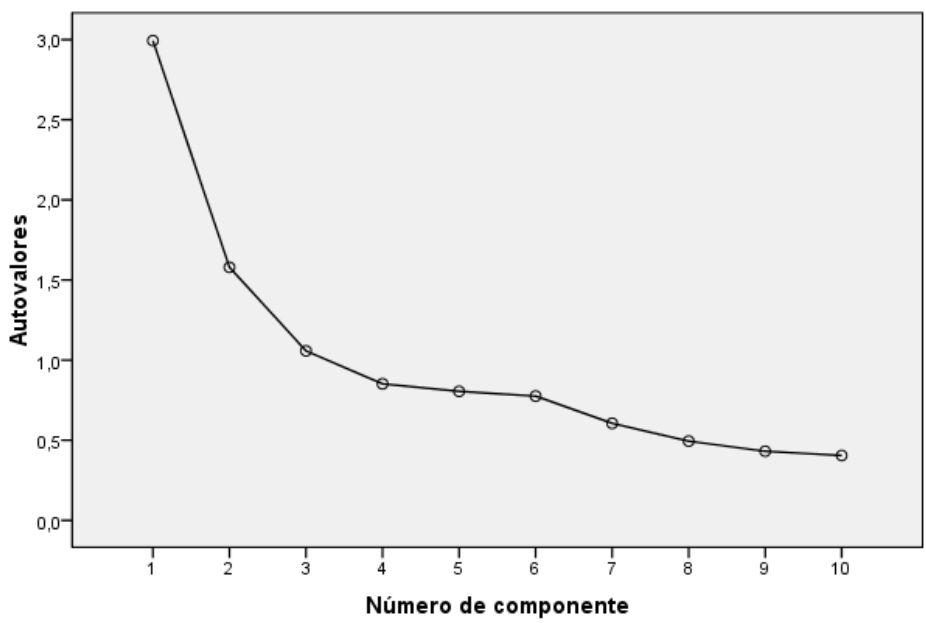

Fig. I1-5 
Sección 12: Análisis Factorial de las variables para LATINOAMÉRICA

\section{2-A Medida del Éxito Laboral}

La medida del Éxito laboral entendida como, Éxito laboral objetivo y Éxito Laboral Subjetivo.

\section{2-A1 Medida del Éxito Laboral Objetivo}

Tabla I2-1 Resumen de la Prueba Factorial

\begin{tabular}{|l|c|}
\hline \multicolumn{1}{|c|}{ Prueba } & Resultado \\
\hline Alfa de Cronbach & 0,959 \\
\hline Medida de adecuación muestral de Kaiser-Meyer-Olkin (KMO) & 0,500 \\
\hline Prueba de esfericidad de Barlett (sig) & 0,000 \\
\hline Varianza total explicada (\%) & 96,378 \\
\hline
\end{tabular}

Los resultados de cargas factoriales del factor obtenido, se presenta en la siguiente tabla:

Tabla 12-2 Resultados de las cargas factoriales: Éxito Laboral Objetivo. Latinoamérica

\begin{tabular}{|c|l|c|c|c|c|}
\hline IdVariable & \multicolumn{1}{|c|}{ Variables } & No & $\begin{array}{c}\text { Componentes } \\
\text { Interpretados }\end{array}$ & $\begin{array}{c}\text { Cargas } \\
\text { Factoriales }\end{array}$ & $\begin{array}{c}\text { \% Varianza } \\
\text { Explicada }\end{array}$ \\
\hline Sueldo Contrato & $\begin{array}{l}\text { ¿Cuál es aproximadamente tu } \\
\text { sueldo mensual bruto? Según } \\
\text { contrato }\end{array}$ & \multirow{2}{*}{1} & Exlabob_LA & 0,982 & \multirow{2}{*}{$0,36,378$} \\
\cline { 1 - 2 } Sueldo Total & $\begin{array}{l}\text { ¿Cuál es aproximadamente tu } \\
\text { sueldo Total bruto? Según } \\
\text { contrato }\end{array}$ & & & 0,982 & \\
\hline
\end{tabular}

\section{2-A2 Medida del Éxito Laboral Subjetivo}

Tabla 12-3 Resumen de la Prueba Factorial

\begin{tabular}{|l|c|}
\hline \multicolumn{1}{|c|}{ Prueba } & Resultado \\
\hline Alfa de Cronbach & 0,533 \\
\hline Medida de adecuación muestral de Kaiser-Meyer-Olkin (KMO) & 0,500 \\
\hline Prueba de esfericidad de Barlett (sig) & 0,000 \\
\hline Varianza total explicada (\%) & 68,228 \\
\hline
\end{tabular}


Los resultados de cargas factoriales del factor obtenido, se presenta en la siguiente tabla:

Tabla 12-4 Resultados de las cargas factoriales: Éxito Laboral Subjetivo. Latinoamérica

\begin{tabular}{|c|l|c|c|c|c|}
\hline IdVariable & \multicolumn{1}{|c|}{ Variables } & No & $\begin{array}{c}\text { Componentes } \\
\text { Interpretados }\end{array}$ & $\begin{array}{c}\text { Cargas } \\
\text { Factoriales }\end{array}$ & $\begin{array}{c}\text { \% Varianza } \\
\text { Explicada }\end{array}$ \\
\cline { 1 - 2 } Uso & $\begin{array}{l}\text { ¿En qué medida usas tus } \\
\text { conocimientos y habilidades? }\end{array}$ & \multirow{2}{*}{1} & Exlabsu_LA & 0,826 & \multirow{2}{*}{68,228} \\
\cline { 1 - 2 } Satisfacción & $\begin{array}{l}\text { ¿En general, estás satisfecho con tu } \\
\text { trabajo actual? }\end{array}$ & & 0,826 & \\
\hline
\end{tabular}

\section{I2-B Medida del Rol en el Trabajo}

Tabla 12-5 Resumen de la Prueba Factorial

\begin{tabular}{|l|c|}
\hline \multicolumn{1}{|c|}{ Prueba } & Resultado \\
\hline Alfa de Cronbach & 0,798 \\
\hline Medida de adecuación muestral de Kaiser-Meyer-Olkin (KMO) & 0,788 \\
\hline Prueba de esfericidad de Barlett (sig) & 0,000 \\
\hline Varianza total explicada (\%) & 62,132 \\
\hline
\end{tabular}

Se obtuvieron tres factores y sus cargas factoriales resultantes, se presentan en la siguiente tabla. 
Tabla 12-6 Resultados de las cargas factoriales: Rol en el Trabajo. Latinoamérica

\begin{tabular}{|c|c|c|c|c|c|}
\hline IdVariable & Variables & № & $\begin{array}{l}\text { Componentes } \\
\text { Interpretados }\end{array}$ & $\begin{array}{c}\text { Cargas } \\
\text { Factoriales }\end{array}$ & $\begin{array}{l}\text { \% Varianza } \\
\text { Explicada }\end{array}$ \\
\hline R5 & $\begin{array}{l}\text { Los compañeros, clientes, etc. } \\
\text { acuden a mí para pedirme } \\
\text { consejo. }\end{array}$ & \multirow{4}{*}{1} & \multirow{4}{*}{ Relaciones en el trabajo } & 0,647 & \multirow{4}{*}{22,344} \\
\hline R6 & $\begin{array}{l}\text { Mantengo informados a mis } \\
\text { compañeros de profesión sobre } \\
\text { nuevos desarrollos en mi campo. }\end{array}$ & & & 0,783 & \\
\hline R7 & $\begin{array}{l}\text { Suelo iniciar relaciones } \\
\text { profesionales con expertos } \\
\text { ajenos a la organización. } \\
\end{array}$ & & & 0,728 & \\
\hline R8 & $\begin{array}{l}\text { Las cuestiones de ética } \\
\text { profesional forman parte } \\
\text { importante de mis funciones. }\end{array}$ & & & 0,501 & \\
\hline $\mathrm{R} 1$ & $\begin{array}{l}\text { ¿En qué medida eres responsable } \\
\text { de establecer objetivos para la } \\
\text { organización? }\end{array}$ & \multirow{3}{*}{2} & \multirow{3}{*}{$\begin{array}{l}\text { Responsabilidad con la } \\
\text { organización }\end{array}$} & 0,84 & \multirow{3}{*}{21,263} \\
\hline R3 & $\begin{array}{l}\text { ¿En qué medida eres responsable } \\
\text { de decidir estrategias de trabajo } \\
\text { para la organización? }\end{array}$ & & & 0,827 & \\
\hline R9 & $\begin{array}{l}\text { ¿Cuánto perjudicarías a tu } \\
\text { organización si cometieras un } \\
\text { error grave en tu trabajo? }\end{array}$ & & & 0,587 & \\
\hline $\mathrm{R} 2$ & $\begin{array}{l}\text { ¿En qué medida eres responsable } \\
\text { de establecer objetivos para tu } \\
\text { propio trabajo? }\end{array}$ & \multirow{2}{*}{3} & \multirow{2}{*}{$\begin{array}{c}\text { Autonomía } \\
\text { trabajo/Responsabilidad PT. }\end{array}$} & 0,799 & \multirow{2}{*}{18,524} \\
\hline R4 & $\begin{array}{l}\text { ¿En qué medida eres responsable } \\
\text { de decidir cómo hacer tu trabajo? }\end{array}$ & & & 0,865 & \\
\hline
\end{tabular}

Método de extracción: Análisis de componentes principales

Método de Rotación: Normalización Varimax con Kaiser

Continente $=$ Latinoamérica

\section{2-C Medida de las Competencia Propias}

Tabla 12-7 Resumen de la Prueba Factorial

\begin{tabular}{|l|c|}
\hline \multicolumn{1}{|c|}{ Prueba } & Resultado \\
\hline Alfa de Cronbach & 0,932 \\
\hline Medida de adecuación muestral de Kaiser-Meyer-Olkin (KMO) & 0,968 \\
\hline Prueba de esfericidad de Barlett (sig) & 0,000 \\
\hline Varianza total explicada (\%) & 58,467 \\
\hline
\end{tabular}

Los resultados de las cargas factoriales se observan en la Tabla I2-8. 
Tabla 12-8 Resultados de las cargas factoriales: Competencias Propias. Latinoamérica

\begin{tabular}{|c|c|c|c|c|c|}
\hline IdVariable & Variables & № & $\begin{array}{l}\text { Componentes } \\
\text { Interpretados }\end{array}$ & $\begin{array}{l}\text { Cargas } \\
\text { Factoriales }\end{array}$ & $\begin{array}{c}\text { \% Varianza } \\
\text { Explicada }\end{array}$ \\
\hline CPE & $\begin{array}{l}\text { Capacidad para negociar de } \\
\text { forma eficaz }\end{array}$ & \multirow{11}{*}{1} & \multirow{11}{*}{$\begin{array}{l}\text { Competencias Organizativas, } \\
\text { liderazgo, innovación }\end{array}$} & 0,603 & \multirow{11}{*}{31,405} \\
\hline $\mathrm{CPF}$ & $\begin{array}{l}\text { Capacidad para trabajar bajo } \\
\text { presión }\end{array}$ & & & 0,620 & \\
\hline CPG & $\begin{array}{l}\text { Capacidad para detectar nuevas } \\
\text { oportunidades }\end{array}$ & & & 0,622 & \\
\hline $\mathrm{CPH}$ & $\begin{array}{l}\text { Capacidad para coordinar } \\
\text { actividades }\end{array}$ & & & 0,748 & \\
\hline $\mathrm{CPI}$ & $\begin{array}{l}\text { Capacidad para usar el tiempo } \\
\text { de forma efectiva }\end{array}$ & & & 0,713 & \\
\hline $\mathrm{CPJ}$ & $\begin{array}{l}\text { Capacidad para trabajar en } \\
\text { equipo }\end{array}$ & & & 0,713 & \\
\hline CPK & $\begin{array}{l}\text { Capacidad para movilizar las } \\
\text { capacidades de otros }\end{array}$ & & & 0,715 & \\
\hline CPL & $\begin{array}{l}\text { Capacidad para hacerte } \\
\text { entender }\end{array}$ & & & 0,675 & \\
\hline CPM & $\begin{array}{l}\text { Capacidad para hacer valer tu } \\
\text { autoridad }\end{array}$ & & & 0,718 & \\
\hline CPO & $\begin{array}{l}\text { Capacidad para encontrar } \\
\text { nuevas ideas y soluciones }\end{array}$ & & & 0,619 & \\
\hline CPP & $\begin{array}{l}\text { Predisposición para cuestionar } \\
\text { ideas propias o ajenas }\end{array}$ & & & 0,462 & \\
\hline CPA & Dominio de tu área o disciplina & \multirow{4}{*}{2} & \multirow{4}{*}{$\begin{array}{c}\text { Competencias de Conocimiento } \\
\text { y Pensamiento Metacognitivo }\end{array}$} & 0,704 & \multirow{4}{*}{14,949} \\
\hline CPB & $\begin{array}{l}\begin{array}{l}\text { Conocimiento de otras áreas o } \\
\text { disciplinas }\end{array} \\
\end{array}$ & & & 0,780 & \\
\hline $\mathrm{CPC}$ & Pensamiento analítico & & & 0,645 & \\
\hline CPD & $\begin{array}{l}\text { Capacidad para adquirir con } \\
\text { rapidez nuevos conocimientos }\end{array}$ & & & 0,530 & \\
\hline CPN & $\begin{array}{l}\text { Capacidad para utilizar } \\
\text { herramientas informáticas }\end{array}$ & \multirow{4}{*}{3} & \multirow{4}{*}{$\begin{array}{l}\text { Competencias instrumentales y } \\
\text { de Comunicación }\end{array}$} & 0,458 & \multirow{4}{*}{12,113} \\
\hline $\mathrm{CPQ}$ & $\begin{array}{l}\text { Capacidad para presentar en } \\
\text { público productos, ideas o } \\
\text { informes }\end{array}$ & & & 0,566 & \\
\hline CPR & $\begin{array}{l}\text { Capacidad para redactar } \\
\text { informes o documentos }\end{array}$ & & & 0,617 & \\
\hline CPS & $\begin{array}{l}\text { Capacidad para escribir y hablar } \\
\text { idiomas extranjeros }\end{array}$ & & & 0,770 & \\
\hline
\end{tabular}

Método de extracción: Análisis de componentes principales Método de Rotación: Normalización Varimax con Kaiser Continente $=$ Latinoamérica 


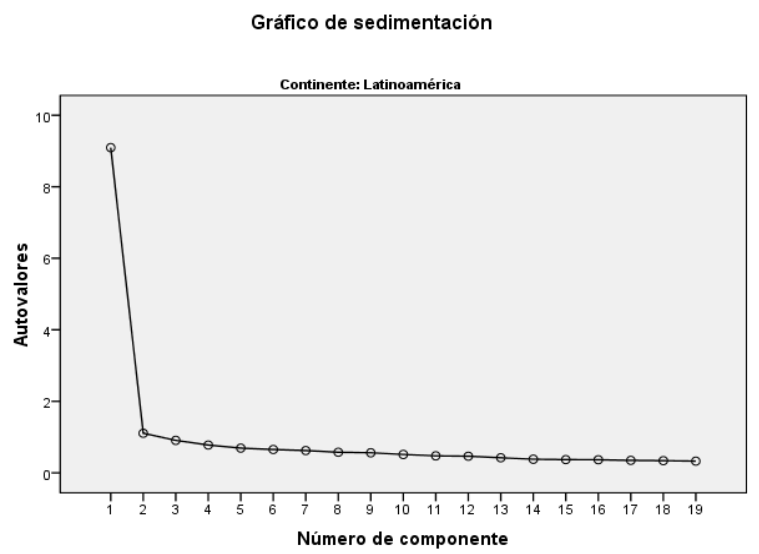

Fig. 12-1

\section{I2-D Medida de las Competencias Requeridas en el Trabajo}

Tabla 12-9 Resumen de la Prueba Factorial

\begin{tabular}{|l|c|}
\hline \multicolumn{1}{|c|}{ Prueba } & Resultado \\
\hline Alfa de Cronbach & 0,943 \\
\hline Medida de adecuación muestral de Kaiser-Meyer-Olkin (KMO) & 0,969 \\
\hline Prueba de esfericidad de Barlett (sig) & 0,000 \\
\hline Varianza total explicada (\%) & 57,633 \\
\hline
\end{tabular}

Resultado de las cargas factoriales, representados en la tabla I2-10. 
Tabla 12-10 Resultados de las cargas factoriales.

Competencias Requeridas en el Trabajo. Latinoamérica

\begin{tabular}{|c|c|c|c|c|c|}
\hline IdVariable & Variables & № & $\begin{array}{l}\text { Componentes } \\
\text { Interpretados }\end{array}$ & $\begin{array}{c}\text { Cargas } \\
\text { Factoriales }\end{array}$ & $\begin{array}{l}\text { \% Varianza } \\
\text { Explicada }\end{array}$ \\
\hline CRA & $\begin{array}{l}\text { Dominio de tu área o } \\
\text { disciplina }\end{array}$ & \multirow{15}{*}{1} & \multirow{15}{*}{$\begin{array}{c}\text { C. Organizativas, liderazgo, } \\
\text { innovación, Pensamiento } \\
\text { Metacognitivo }\end{array}$} & 0,507 & \multirow{15}{*}{39,392} \\
\hline CRC & Pensamiento analítico & & & 0,594 & \\
\hline CRD & $\begin{array}{l}\text { Capacidad para adquirir } \\
\text { con rapidez nuevos } \\
\text { conocimientos. }\end{array}$ & & & 0,623 & \\
\hline CRE & $\begin{array}{l}\text { Capacidad para negociar de } \\
\text { forma eficaz }\end{array}$ & & & 0,697 & \\
\hline CRF & $\begin{array}{l}\text { Capacidad para trabajar } \\
\text { bajo presión }\end{array}$ & & & 0,730 & \\
\hline CRG & $\begin{array}{l}\text { Capacidad para detectar } \\
\text { nuevas oportunidades }\end{array}$ & & & 0,693 & \\
\hline $\mathrm{CRH}$ & $\begin{array}{l}\text { Capacidad para coordinar } \\
\text { actividades }\end{array}$ & & & 0,790 & \\
\hline CRI & $\begin{array}{l}\text { Capacidad para usar el } \\
\text { tiempo de forma efectiva }\end{array}$ & & & 0,756 & \\
\hline CRJ & $\begin{array}{l}\text { Capacidad para trabajar en } \\
\text { equipo }\end{array}$ & & & 0,755 & \\
\hline CRK & $\begin{array}{l}\text { Capacidad para movilizar } \\
\text { las capacidades de otros }\end{array}$ & & & 0,759 & \\
\hline CRL & $\begin{array}{l}\text { Capacidad para hacerte } \\
\text { entender }\end{array}$ & & & 0,748 & \\
\hline CRM & $\begin{array}{l}\text { Capacidad para hacer valer } \\
\text { tu autoridad }\end{array}$ & & & 0,706 & \\
\hline CRO & $\begin{array}{l}\text { Capacidad para encontrar } \\
\text { nuevas ideas y soluciones }\end{array}$ & & & 0,672 & \\
\hline CRP & $\begin{array}{l}\text { Predisposición para } \\
\text { cuestionar ideas propias o } \\
\text { ajenas }\end{array}$ & & & 0,536 & \\
\hline CRQ & $\begin{array}{l}\text { Capacidad para presentar } \\
\text { en público productos, ideas } \\
\text { o informes }\end{array}$ & & & 0,563 & \\
\hline CRB & $\begin{array}{l}\text { Conocimiento de otras } \\
\text { áreas o disciplinas }\end{array}$ & \multirow{4}{*}{2} & \multirow{4}{*}{$\begin{array}{l}\text { Competencias } \\
\text { instrumentales, } \\
\text { Comunicación y } \\
\text { Conocimiento }\end{array}$} & 0,556 & \multirow{4}{*}{18,241} \\
\hline CRN & $\begin{array}{l}\text { Capacidad para utilizar } \\
\text { herramientas informáticas }\end{array}$ & & & 0,571 & \\
\hline CRR & $\begin{array}{l}\text { Capacidad para redactar } \\
\text { informes o documentos }\end{array}$ & & & 0,564 & \\
\hline CRS & $\begin{array}{l}\text { Capacidad para escribir y } \\
\text { hablar idiomas extranjeros }\end{array}$ & & & 0,811 & \\
\hline
\end{tabular}

Método de extracción: Análisis de componentes principales

Método de Rotación: Normalización Varimax con Kaiser

Continente $=$ Latinoamérica 


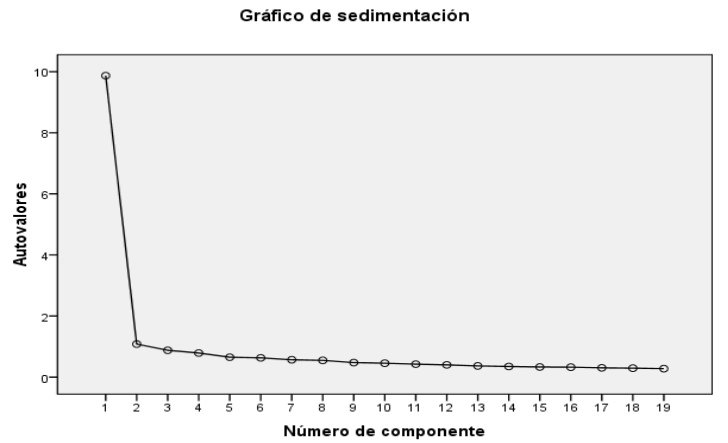

Fig. 12-2

El gráfico de sedimentación (figura 12-2), muestra el comportamiento del primer componente donde el autovalor es más elevado con respecto a los demás. De igual manera ocurre con la varianza total explicada (39,39\%).

\section{2-E Medida de los Valores Laborales Personales}

Tabla I2-11 Resumen de la Prueba Factorial

\begin{tabular}{|l|c|}
\hline \multicolumn{1}{|c|}{ Prueba } & Resultado \\
\hline Alfa de Cronbach & 0,894 \\
\hline Medida de adecuación muestral de Kaiser-Meyer-Olkin (KMO) & 0,917 \\
\hline Prueba de esfericidad de Barlett (sig) & 0,000 \\
\hline Varianza total explicada (\%) & 60,354 \\
\hline
\end{tabular}

Las cargas factorial se muestran en la tabla I2-12. 
Tabla 12-12 Resultados de las cargas factoriales: Valores Laborales Personales. Latinoamérica

\begin{tabular}{|c|c|c|c|c|c|}
\hline IdVariable & Variables & № & $\begin{array}{l}\text { Componentes } \\
\text { Interpretados }\end{array}$ & $\begin{array}{c}\text { Cargas } \\
\text { Factoriales }\end{array}$ & $\begin{array}{l}\text { \% Varianza } \\
\text { Explicada }\end{array}$ \\
\hline VP1 & Autonomía en el trabajo & \multirow{6}{*}{1} & \multirow{6}{*}{$\begin{array}{l}\text { Puesto de Trabajo } \\
\text { Enriquecido. Ingresos }\end{array}$} & 0,660 & \multirow{6}{*}{37,183} \\
\hline VP2 & Estabilidad laboral & & & 0,717 & \\
\hline VP3 & $\begin{array}{l}\text { Oportunidad de aprender cosas } \\
\text { nuevas }\end{array}$ & & & 0,777 & \\
\hline VP4 & Ingresos elevados & & & 0,701 & \\
\hline VP5 & Afrontar nuevos retos & & & 0,741 & \\
\hline VP6 & $\begin{array}{l}\text { Buenas perspectivas } \\
\text { profesionales }\end{array}$ & & & 0,754 & \\
\hline VP7 & $\begin{array}{l}\text { Tener tiempo para actividades } \\
\text { recreativas }\end{array}$ & \multirow{4}{*}{2} & \multirow{4}{*}{$\begin{array}{l}\text { Ocio, Familia y } \\
\text { Servicio a la sociedad }\end{array}$} & 0,568 & \multirow{4}{*}{23,171} \\
\hline VP8 & Reconocimiento/prestigio social & & & 0,788 & \\
\hline VP9 & $\begin{array}{l}\text { Oportunidad de hacer algo útil } \\
\text { para la sociedad }\end{array}$ & & & 0,763 & \\
\hline VP10 & $\begin{array}{l}\text { Facilidad para combinar trabajo } \\
\text { y familia }\end{array}$ & & & 0,565 & \\
\hline
\end{tabular}

Método de extracción: Análisis de componentes principales

Método de Rotación: Normalización Varimax con Kaiser

Continente $=$ Latinoamérica

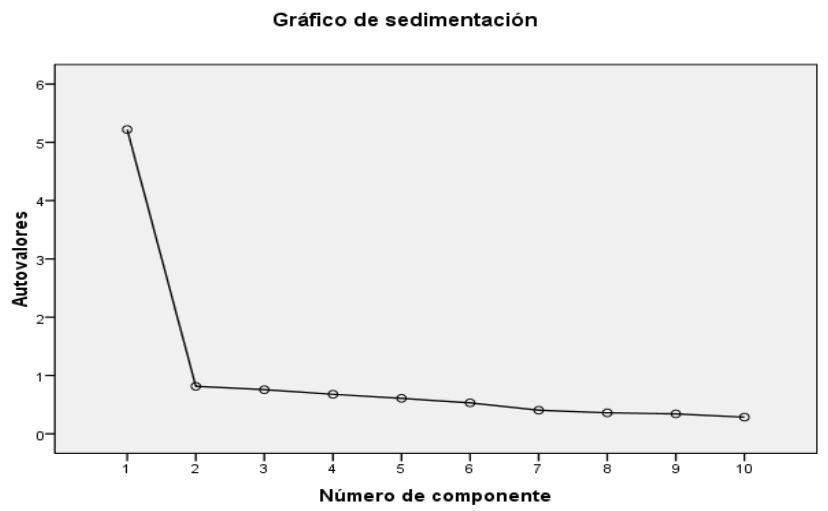

Fig 12-3

I2-F Medida de los Valores Laborales en el Trabajo

Tabla 12-13 Resumen de la Prueba Factorial

\begin{tabular}{|l|c|}
\hline \multicolumn{1}{|c|}{ Prueba } & Resultado \\
\hline Alfa de Cronbach & 0,875 \\
\hline Medida de adecuación muestral de Kaiser-Meyer-Olkin (KMO) & 0,877 \\
\hline Prueba de esfericidad de Barlett (sig) & 0,000 \\
\hline Varianza total explicada (\%) & 59,959 \\
\hline
\end{tabular}


Las cargas factorial que se muestran en la tabla 12-14, corresponde a los dos factores obtenidos

Tabla 12-14 Resultados de las cargas factorial: Valores laborales en el Trabajo. Latinoamérica

\begin{tabular}{|c|c|c|c|c|c|}
\hline IdVariable & Variables & № & $\begin{array}{l}\text { Componentes } \\
\text { Interpretados }\end{array}$ & $\begin{array}{c}\text { Cargas } \\
\text { Factoriales }\end{array}$ & $\begin{array}{l}\text { \% Varianza } \\
\text { Explicada }\end{array}$ \\
\hline VT1 & Autonomía en el trabajo & & \multirow{8}{*}{$\begin{array}{c}\text { Puesto de Trabajo } \\
\text { Enriquecido. Ingresos, } \\
\text { Reconocimiento, Servicio a } \\
\text { la sociedad }\end{array}$} & 0,533 & \multirow{8}{*}{34,468} \\
\hline VT2 & Estabilidad laboral & & & 0,592 & \\
\hline VT3 & $\begin{array}{l}\text { Oportunidad de aprender } \\
\text { cosas nuevas }\end{array}$ & & & 0,793 & \\
\hline VT4 & Ingresos elevados & & & 0,687 & \\
\hline VT5 & Afrontar nuevos retos & & & 0,840 & \\
\hline VT6 & $\begin{array}{l}\text { Buenas perspectivas } \\
\text { profesionales }\end{array}$ & & & 0,838 & \\
\hline VT8 & $\begin{array}{l}\text { Reconocimiento/prestigio } \\
\text { social }\end{array}$ & & & 0,642 & \\
\hline VT9 & $\begin{array}{l}\text { Oportunidad de hacer algo } \\
\text { útil para la sociedad }\end{array}$ & & & 0,469 & \\
\hline VT7 & $\begin{array}{l}\text { Tener tiempo para } \\
\text { actividades recreativas }\end{array}$ & & \multirow{2}{*}{ Ocio y Familia } & 0,875 & \multirow{2}{*}{21,491} \\
\hline VT10 & $\begin{array}{l}\text { Facilidad para combinar } \\
\text { trabajo y familia }\end{array}$ & & & 0,902 & \\
\hline
\end{tabular}

Método de extracción: Análisis de componentes principales Método de Rotación: Normalización Varimax con Kaiser Continente $=$ Latinoamérica

Gráfico de sedimentación

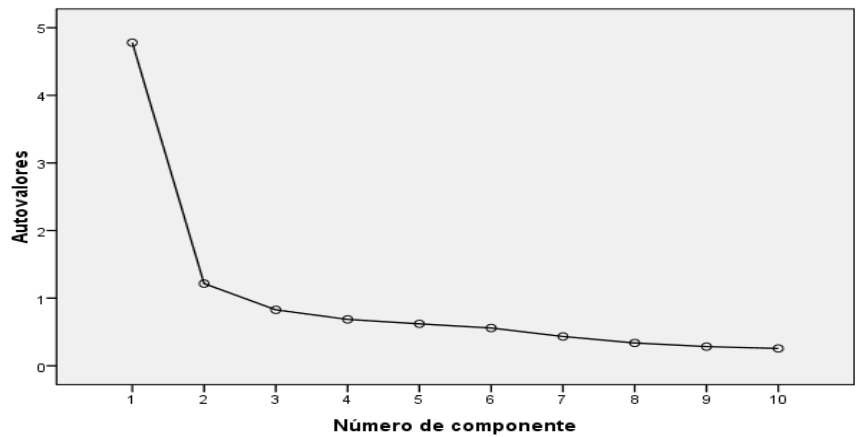

Fig.12-4 
12-G Medida del ajuste de las competencias

Tabla I2-15 Resumen de la Prueba Factorial

\begin{tabular}{|l|c|}
\hline \multicolumn{1}{|c|}{ Prueba } & Resultado \\
\hline Medida de adecuación muestral de Kaiser-Meyer-Olkin (KMO) & 0,936 \\
\hline Prueba de esfericidad de Barlett (sig) & 0,000 \\
\hline Varianza total explicada (\%) & 45,591 \\
\hline
\end{tabular}

Las cargas factorial que se muestran en la tabla 12-16, corresponde a los tres factores obtenidos. 
Tabla 12-16 Resultados de las cargas factorial: Ajuste de Competencias. Latinoamérica

\begin{tabular}{|c|c|c|c|c|c|}
\hline IdVariable & Variables & № & $\begin{array}{l}\text { Componentes } \\
\text { Interpretados }\end{array}$ & $\begin{array}{c}\text { Cargas } \\
\text { Factoriales }\end{array}$ & $\begin{array}{c}\% \\
\text { Varianza } \\
\text { Explicada }\end{array}$ \\
\hline CAJE & $\begin{array}{l}\text { Capacidad para negociar de } \\
\text { forma eficaz }\end{array}$ & \multirow{10}{*}{1} & \multirow{10}{*}{$\begin{array}{c}\text { Competencias } \\
\text { Organizativas, liderazgo, } \\
\text { innovación }\end{array}$} & 0,532 & \multirow{10}{*}{20,211} \\
\hline CAJF & $\begin{array}{l}\text { Capacidad para trabajar bajo } \\
\text { presión }\end{array}$ & & & 0,539 & \\
\hline CAJG & $\begin{array}{l}\text { Capacidad para detectar nuevas } \\
\text { oportunidades }\end{array}$ & & & 0,542 & \\
\hline CAJH & $\begin{array}{l}\text { Capacidad para coordinar } \\
\text { actividades }\end{array}$ & & & 0,675 & \\
\hline CAJI & $\begin{array}{l}\text { Capacidad para usar el tiempo de } \\
\text { forma efectiva }\end{array}$ & & & 0,625 & \\
\hline CAJJ & $\begin{array}{l}\text { Capacidad para trabajar en } \\
\text { equipo }\end{array}$ & & & 0,628 & \\
\hline CAJK & $\begin{array}{l}\text { Capacidad para movilizar las } \\
\text { capacidades de otros }\end{array}$ & & & 0,673 & \\
\hline CAJL & Capacidad para hacerte entender & & & 0,561 & \\
\hline CAJM & $\begin{array}{l}\text { Capacidad para hacer valer tu } \\
\text { autoridad }\end{array}$ & & & 0,585 & \\
\hline CAJO & $\begin{array}{l}\text { Capacidad para encontrar nuevas } \\
\text { ideas y soluciones }\end{array}$ & & & 0,462 & \\
\hline CAJA & Dominio de tu área o disciplina & \multirow{4}{*}{2} & \multirow{4}{*}{$\begin{array}{l}\text { Competencias de } \\
\text { Conocimiento y } \\
\text { Pensamiento } \\
\text { Metacognitivo }\end{array}$} & 0,691 & \multirow{4}{*}{12,77} \\
\hline CAJB & $\begin{array}{l}\text { Conocimiento de otras áreas o } \\
\text { disciplinas }\end{array}$ & & & 0,633 & \\
\hline CAJC & Pensamiento analítico & & & 0,682 & \\
\hline CAJD & $\begin{array}{l}\text { Capacidad para adquirir con } \\
\text { rapidez nuevos conocimientos. }\end{array}$ & & & 0,618 & \\
\hline CAJN & $\begin{array}{l}\text { Capacidad para utilizar } \\
\text { herramientas informáticas }\end{array}$ & \multirow{5}{*}{3} & \multirow{5}{*}{$\begin{array}{l}\text { Competencias } \\
\text { Instrumentales y C. de } \\
\text { Comunicación }\end{array}$} & 0,518 & \multirow{5}{*}{12,609} \\
\hline CAJAP & $\begin{array}{l}\text { Predisposición para cuestionar } \\
\text { ideas propias o ajenas }\end{array}$ & & & 0,546 & \\
\hline CAJQ & $\begin{array}{l}\text { Capacidad para presentar en } \\
\text { público productos, ideas o } \\
\text { informes }\end{array}$ & & & 0,648 & \\
\hline CAJR & $\begin{array}{l}\text { Capacidad para redactar informes } \\
\text { o documentos }\end{array}$ & & & 0,642 & \\
\hline CAJS & $\begin{array}{l}\text { Capacidad para escribir y hablar } \\
\text { idiomas extranjeros }\end{array}$ & & & 0,634 & \\
\hline
\end{tabular}

Método de extracción: Análisis de componentes principales Método de Rotación: Normalización Varimax con Kaiser Continente $=$ Latinoamérica 


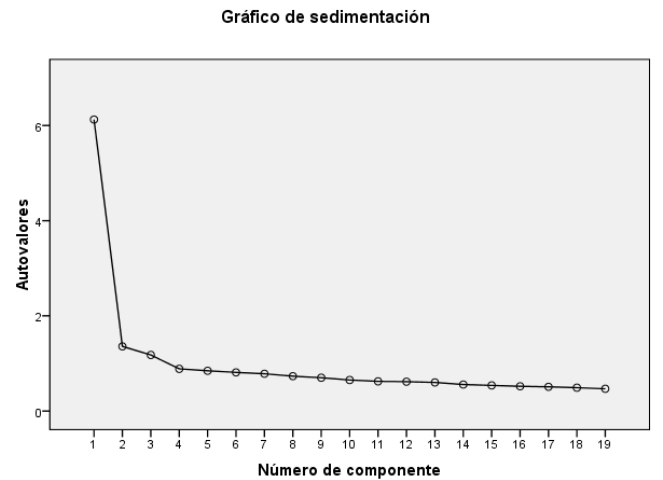

Fig.12-5

12-H Medida del ajuste de los Valores Laborales

Tabla 12-17 Resumen de la Prueba Factorial

\begin{tabular}{|l|c|}
\hline \multicolumn{1}{|c|}{ Prueba } & Resultado \\
\hline Medida de adecuación muestral de Kaiser-Meyer-Olkin (KMO) & 0,855 \\
\hline Prueba de esfericidad de Barlett (sig) & 0,000 \\
\hline Varianza total explicada (\%) & 51,94 \\
\hline
\end{tabular}

La tabla 12-18 muestra los resultados de las cargas factoriales obtenidas. 
Tabla 12-18 Resultados de las cargas factorial: Ajuste de los Valores Laborales. Latinoamérica

\begin{tabular}{|c|c|c|c|c|c|}
\hline IdVariable & Variables & № & $\begin{array}{l}\text { Componentes } \\
\text { Interpretados }\end{array}$ & $\begin{array}{c}\text { Cargas } \\
\text { Factoriales }\end{array}$ & $\begin{array}{c}\% \\
\text { Varianza } \\
\text { Explicada } \\
\end{array}$ \\
\hline AJVT1 & Autonomía en el trabajo & \multirow{7}{*}{1} & \multirow{7}{*}{$\begin{array}{l}\text { Puesto de Trabajo Enriquecido. } \\
\text { Ingresos, Estabilidad y } \\
\text { Reconocimiento }\end{array}$} & 0,426 & \multirow{7}{*}{31,993} \\
\hline AJVT2 & Estabilidad laboral & & & 0,515 & \\
\hline AJVT3 & $\begin{array}{l}\text { Oportunidad de } \\
\text { aprender cosas nuevas }\end{array}$ & & & 0,738 & \\
\hline AJVT4 & Ingresos elevados & & & 0,664 & \\
\hline AJVT5 & Afrontar nuevos retos & & & 0,779 & \\
\hline AJVT6 & $\begin{array}{l}\text { Buenas perspectivas } \\
\text { profesionales }\end{array}$ & & & 0,783 & \\
\hline AJVT8 & $\begin{array}{l}\text { Reconocimiento/prestigi } \\
\text { o social }\end{array}$ & & & 0,571 & \\
\hline AJVT7 & $\begin{array}{l}\text { Tener tiempo para } \\
\text { actividades recreativas }\end{array}$ & \multirow{3}{*}{2} & \multirow{3}{*}{$\begin{array}{c}\text { Ocio, Familia y Servicio a la } \\
\text { sociedad }\end{array}$} & 0,848 & \multirow{3}{*}{19,948} \\
\hline AJVT9 & $\begin{array}{l}\text { Oportunidad de hacer } \\
\text { algo útil para la sociedad }\end{array}$ & & & 0,436 & \\
\hline AJVT10 & $\begin{array}{l}\text { Facilidad para combinar } \\
\text { trabajo y familia }\end{array}$ & & & 0,88 & \\
\hline
\end{tabular}

Método de extracción: Análisis de componentes principales

Método de Rotación: Normalización Varimax con Kaiser

Continente $=$ Latinoamérica

Gráfico de sedimentación

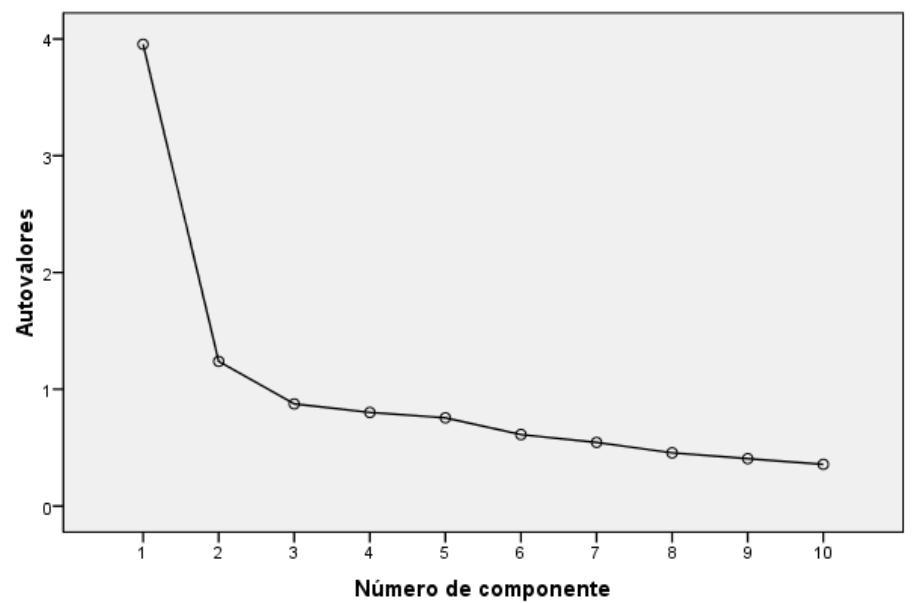

Fig.12-6 
Sección 13: Análisis Factorial de las Variables Para País: ESPAÑA

\section{3-A Medida del Éxito Laboral}

La medida del Éxito laboral entendida como, Éxito laboral objetivo y Éxito Laboral Subjetivo.

\section{3-A1 Medida del Éxito Laboral Objetivo}

Tabla I3-1 Resumen de la Prueba Factorial

\begin{tabular}{|l|c|}
\hline \multicolumn{1}{|c|}{ Prueba } & Resultado \\
\hline Alfa de Cronbach & 0,965 \\
\hline Medida de adecuación muestral de Kaiser-Meyer-Olkin (KMO) & 0,500 \\
\hline Prueba de esfericidad de Barlett (sig) & 0,000 \\
\hline Varianza total explicada (\%) & 96,712 \\
\hline
\end{tabular}

Los resultados de cargas factoriales del factor obtenido, se presenta en la siguiente tabla:

Tabla 13-2 Resultados de las cargas factoriales: Éxito Laboral Objetivo España

\begin{tabular}{|c|c|c|c|c|c|}
\hline IdVariable & Variables & № & $\begin{array}{l}\text { Componentes } \\
\text { Interpretados }\end{array}$ & $\begin{array}{c}\text { Cargas } \\
\text { Factoriales }\end{array}$ & $\begin{array}{c}\text { \% Varianza } \\
\text { Explicada }\end{array}$ \\
\hline Sueldo Contrato & $\begin{array}{l}\text { ¿Cuál es aproximadamente tu } \\
\text { sueldo mensual bruto? Según } \\
\text { contrato }\end{array}$ & \multirow[b]{2}{*}{1} & \multirow{2}{*}{ Exlabob_Spn } & 0,983 & \multirow{2}{*}{96,712} \\
\hline Sueldo Total & $\begin{array}{l}\text { ¿Cuál es aproximadamente tu } \\
\text { sueldo Total bruto? Según } \\
\text { contrato }\end{array}$ & & & 0,983 & \\
\hline
\end{tabular}

\section{3-A2 Medida del Éxito Laboral Subjetivo}

Tabla 13-3 Resumen de la Prueba Factorial

\begin{tabular}{|l|c|}
\hline \multicolumn{1}{|c|}{ Prueba } & Resultado \\
\hline Alfa de Cronbach & 0,626 \\
\hline Medida de adecuación muestral de Kaiser-Meyer-Olkin (KMO) & 0,500 \\
\hline Prueba de esfericidad de Barlett (sig) & 0,000 \\
\hline Varianza total explicada (\%) & 72,870 \\
\hline
\end{tabular}


Los resultados de cargas factoriales del factor obtenido, se presenta en la siguiente tabla:

Tabla 13-4 Resultados de las cargas factoriales: Éxito Laboral Subjetivo España

\begin{tabular}{|c|l|c|c|c|c|}
\hline IdVariable & \multicolumn{1}{|c|}{ Variables } & No & $\begin{array}{c}\text { Componentes } \\
\text { Interpretados }\end{array}$ & $\begin{array}{c}\text { Cargas } \\
\text { Factoriales }\end{array}$ & $\begin{array}{c}\text { \% Varianza } \\
\text { Explicada }\end{array}$ \\
\hline \multirow{2}{*}{ Uso } & $\begin{array}{l}\text { ¿En qué medida usas tus } \\
\text { conocimientos y habilidades? }\end{array}$ & \multirow{2}{*}{1} & Exlabsu_Spn & 0,854 & \multirow{2}{*}{72,870} \\
\cline { 1 - 2 } Satisfacción & $\begin{array}{l}\text { ¿En general, estás satisfecho con tu } \\
\text { trabajo actual? }\end{array}$ & & 0,854 & \\
\hline
\end{tabular}

\section{I3-B Medida del Rol en el Trabajo}

Los resultados obtenidos para el Rol en el trabajo aparecen resumidos en las tablas $13-5$ y I3-6

Tabla 13-5 Resumen de la Prueba factorial

\begin{tabular}{|l|c|}
\hline \multicolumn{1}{|c|}{ Prueba } & Resultado \\
\hline Alfa de Cronbach & 0,809 \\
\hline Medida de adecuación muestral de Kaiser-Meyer-Olkin (KMO) & 0,803 \\
\hline Prueba de esfericidad de Barlett (sig) & 0,000 \\
\hline Varianza total explicada (\%) & 63,533 \\
\hline
\end{tabular}

Los resultados de las cargas factoriales resultantes aparecen en la Tabla I3-6. 
Tabla 13-6 Resultados de las cargas factoriales: Rol en el Trabajo España

\begin{tabular}{|c|c|c|c|c|c|}
\hline IdVariable & Variables & № & $\begin{array}{l}\text { Componentes } \\
\text { Interpretados }\end{array}$ & $\begin{array}{c}\text { Cargas } \\
\text { Factoriales }\end{array}$ & $\begin{array}{c}\text { \% Varianza } \\
\text { Explicada }\end{array}$ \\
\hline R1 & $\begin{array}{l}\text { ¿En qué medida eres responsable de } \\
\text { establecer objetivos para la } \\
\text { organización? }\end{array}$ & \multirow{4}{*}{1} & \multirow{4}{*}{ Responsabilidad } & 0,803 & \multirow{4}{*}{27,415} \\
\hline $\mathrm{R} 2$ & $\begin{array}{l}\text { ¿En qué medida eres responsable de } \\
\text { establecer objetivos para tu propio } \\
\text { trabajo? }\end{array}$ & & & 0,759 & \\
\hline R3 & $\begin{array}{l}\text { ¿En qué medida eres responsable de } \\
\text { decidir estrategias de trabajo para la } \\
\text { organización? }\end{array}$ & & & 0,808 & \\
\hline R4 & $\begin{array}{l}\text { ¿En qué medida eres responsable de } \\
\text { decidir cómo hacer tu trabajo? }\end{array}$ & & & 0,656 & \\
\hline R5 & $\begin{array}{l}\text { Los compañeros, clientes, etc. } \\
\text { acuden a mí para pedirme consejo. }\end{array}$ & \multirow{4}{*}{2} & \multirow{4}{*}{$\begin{array}{l}\text { Relaciones en el } \\
\text { Trabajo }\end{array}$} & 0,727 & \multirow{4}{*}{24,025} \\
\hline R6 & $\begin{array}{l}\text { Mantengo informados a mis } \\
\text { compañeros de profesión sobre } \\
\text { nuevos desarrollos en mi campo. }\end{array}$ & & & 0,795 & \\
\hline R7 & $\begin{array}{l}\text { Suelo iniciar relaciones profesionales } \\
\text { con expertos ajenos a la } \\
\text { organización. }\end{array}$ & & & 0,59 & \\
\hline R8 & $\begin{array}{l}\text { Las cuestiones de ética profesional } \\
\text { forman parte importante de mis } \\
\text { funciones. }\end{array}$ & & & 0,603 & \\
\hline R9 & $\begin{array}{l}\text { ¿Cuánto perjudicarías a tu } \\
\text { organización si cometieras un error } \\
\text { grave en tu trabajo? }\end{array}$ & 3 & Perjuicio & 0,844 & 12,093 \\
\hline
\end{tabular}

Método de extracción: Análisis de componentes principales

Método de Rotación: Normalización Varimax con Kaiser

País = España

\section{I3-C Medida de las Competencias Propias}

Tabla 13-7 Resumen de la Prueba factorial

\begin{tabular}{|l|c|}
\hline \multicolumn{1}{|c|}{ Prueba } & Resultado \\
\hline Alfa de Cronbach & 0,896 \\
\hline Medida de adecuación muestral de Kaiser-Meyer-Olkin (KMO) & 0,942 \\
\hline Prueba de esfericidad de Barlett (sig) & 0,000 \\
\hline Varianza total explicada (\%) & 54,753 \\
\hline
\end{tabular}


Los resultados de las cargas factoriales resultantes aparecen en la Tabla I3-8.

Tabla I3-8 Resultados de las cargas factoriales: Competencias Propias España

\begin{tabular}{|c|c|c|c|c|c|}
\hline IdVariable & Variables & № & $\begin{array}{l}\text { Componentes } \\
\text { Interpretados }\end{array}$ & $\begin{array}{c}\text { Cargas } \\
\text { Factoriales }\end{array}$ & $\begin{array}{c}\text { \% Varianza } \\
\text { Explicada }\end{array}$ \\
\hline CPE & $\begin{array}{l}\text { Capacidad para negociar de } \\
\text { forma eficaz }\end{array}$ & \multirow{7}{*}{1} & \multirow{7}{*}{$\begin{array}{c}\text { Competencias de Liderazgo } \\
\text { y comunicación }\end{array}$} & 0,715 & \multirow{7}{*}{17,348} \\
\hline CPG & $\begin{array}{l}\text { Capacidad para detectar } \\
\text { nuevas oportunidades }\end{array}$ & & & 0,564 & \\
\hline CPK & $\begin{array}{l}\text { Capacidad para movilizar las } \\
\text { capacidades de otros }\end{array}$ & & & 0,609 & \\
\hline $\mathrm{CPL}$ & $\begin{array}{l}\text { Capacidad para hacerte } \\
\text { entender }\end{array}$ & & & 0,525 & \\
\hline CPM & $\begin{array}{l}\text { Capacidad para hacer valer } \\
\text { tu autoridad }\end{array}$ & & & 0,722 & \\
\hline $\mathrm{CPO}$ & $\begin{array}{l}\text { Capacidad para encontrar } \\
\text { nuevas ideas y soluciones }\end{array}$ & & & 0,389 & \\
\hline $\mathrm{CPQ}$ & $\begin{array}{l}\text { Capacidad para presentar } \\
\text { en público productos, ideas } \\
\text { o informes }\end{array}$ & & & 0,575 & \\
\hline CPF & $\begin{array}{l}\text { Capacidad para trabajar } \\
\text { bajo presión }\end{array}$ & \multirow{4}{*}{2} & \multirow{4}{*}{$\begin{array}{l}\text { Competencias } \\
\text { Organizativas }\end{array}$} & 0,426 & \multirow{4}{*}{13,713} \\
\hline $\mathrm{CPH}$ & $\begin{array}{l}\text { Capacidad para coordinar } \\
\text { actividades }\end{array}$ & & & 0,537 & \\
\hline CPI & $\begin{array}{l}\text { Capacidad para usar el } \\
\text { tiempo de forma efectiva }\end{array}$ & & & 0,693 & \\
\hline CPJ & $\begin{array}{l}\text { Capacidad para trabajar en } \\
\text { equipo }\end{array}$ & & & 0,722 & \\
\hline CPA & $\begin{array}{l}\text { Dominio de tu área o } \\
\text { disciplina }\end{array}$ & \multirow{4}{*}{3} & \multirow{4}{*}{$\begin{array}{l}\text { Competencias de } \\
\text { Conocimiento y } \\
\text { Pensamiento } \\
\text { Metacognitivo }\end{array}$} & 0,658 & \multirow{4}{*}{12,212} \\
\hline CPB & $\begin{array}{l}\text { Conocimiento de otras } \\
\text { áreas o disciplinas }\end{array}$ & & & 0,723 & \\
\hline $\mathrm{CPC}$ & Pensamiento analítico & & & 0,592 & \\
\hline CPD & $\begin{array}{l}\text { Capacidad para adquirir con } \\
\text { rapidez nuevos } \\
\text { conocimientos. }\end{array}$ & & & 0,518 & \\
\hline CPN & $\begin{array}{l}\text { Capacidad para utilizar } \\
\text { herramientas informáticas }\end{array}$ & \multirow{4}{*}{4} & \multirow{4}{*}{$\begin{array}{l}\text { Competencias } \\
\text { Instrumentales y de } \\
\text { Innovación }\end{array}$} & 0,531 & \multirow{4}{*}{11,481} \\
\hline CPP & $\begin{array}{l}\text { Predisposición para } \\
\text { cuestionar ideas propias o } \\
\text { ajenas }\end{array}$ & & & 0,465 & \\
\hline CPR & $\begin{array}{l}\text { Capacidad para redactar } \\
\text { informes o documentos }\end{array}$ & & & 0,619 & \\
\hline CPS & $\begin{array}{l}\text { Capacidad para escribir y } \\
\text { hablar idiomas extranjeros }\end{array}$ & & & 0,712 & \\
\hline
\end{tabular}

Método de extracción: Análisis de componentes principales Método de Rotación: Normalización Varimax con Kaiser País = España 


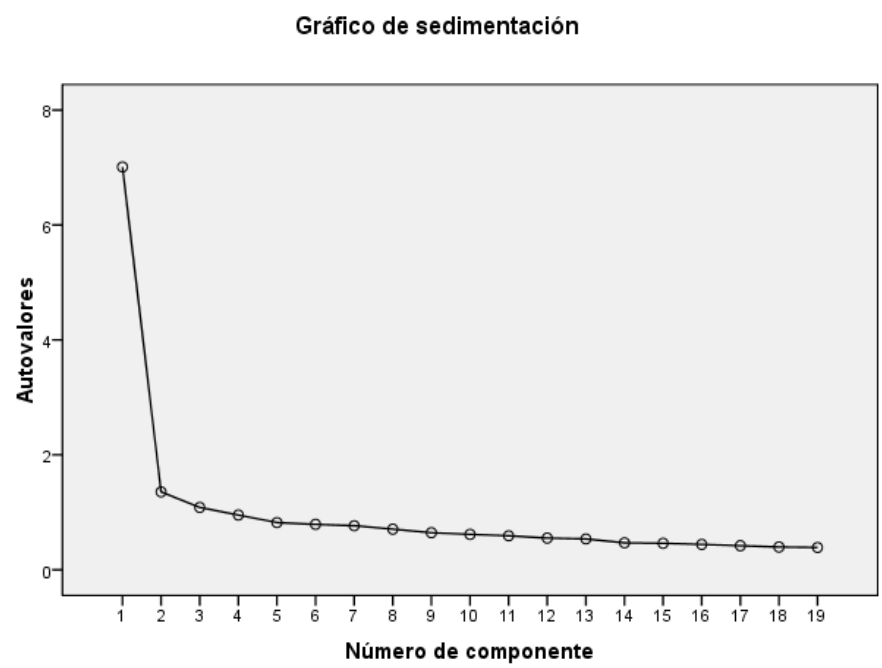

Fig. 13-1

I3-D Medida de las Competencias Requeridas en el Trabajo

Tabla 13-9 Resumen de la Prueba Factorial

\begin{tabular}{|l|c|}
\hline \multicolumn{1}{|c|}{ Prueba } & Resultado \\
\hline Alfa de Cronbach & 0,921 \\
\hline Medida de adecuación muestral de Kaiser-Meyer-Olkin (KMO) & 0,948 \\
\hline Prueba de esfericidad de Barlett (sig) & 0,000 \\
\hline Varianza total explicada (\%) & 55,234 \\
\hline
\end{tabular}

Los resultados de las cargas factoriales resultantes aparecen en la Tabla I3-10. 
Tabla 13-10 Resultados de las cargas factoriales

Competencias Requeridas en el Trabajo España

\begin{tabular}{|c|c|c|c|c|c|}
\hline IdVariable & Nombre Variable & № & $\begin{array}{l}\text { Componentes } \\
\text { Interpretados }\end{array}$ & $\begin{array}{c}\text { Cargas } \\
\text { Factoriales }\end{array}$ & $\begin{array}{c}\text { \% Varianza } \\
\text { Explicada }\end{array}$ \\
\hline CRE & $\begin{array}{l}\text { Capacidad para negociar de } \\
\text { forma eficaz }\end{array}$ & \multirow{9}{*}{1} & \multirow{9}{*}{$\begin{array}{c}\text { Competencias } \\
\text { Organizativas, Liderazgo e } \\
\text { Innovación }\end{array}$} & 0,504 & \multirow{9}{*}{22,46} \\
\hline $\mathrm{CRH}$ & $\begin{array}{l}\text { Capacidad para coordinar } \\
\text { actividades }\end{array}$ & & & 0,662 & \\
\hline CRI & $\begin{array}{l}\text { Capacidad para usar el } \\
\text { tiempo de forma efectiva }\end{array}$ & & & 0,539 & \\
\hline CRJ & $\begin{array}{l}\text { Capacidad para trabajar en } \\
\text { equipo }\end{array}$ & & & 0,587 & \\
\hline CRK & $\begin{array}{l}\text { Capacidad para movilizar las } \\
\text { capacidades de otros }\end{array}$ & & & 0,764 & \\
\hline CRL & $\begin{array}{l}\text { Capacidad para hacerte } \\
\text { entender }\end{array}$ & & & 0,657 & \\
\hline CRM & $\begin{array}{l}\text { Capacidad para hacer valer } \\
\text { tu autoridad }\end{array}$ & & & 0,756 & \\
\hline CRO & $\begin{array}{l}\text { Capacidad para encontrar } \\
\text { nuevas ideas y soluciones }\end{array}$ & & & 0,497 & \\
\hline CRP & $\begin{array}{l}\text { Predisposición para } \\
\text { cuestionar ideas propias o } \\
\text { ajenas }\end{array}$ & & & 0,526 & \\
\hline CRA & $\begin{array}{l}\text { Dominio de tu área o } \\
\text { disciplina }\end{array}$ & \multirow{6}{*}{2} & \multirow{6}{*}{$\begin{array}{l}\text { Competencias de } \\
\text { Conocimiento y } \\
\text { Pensamiento } \\
\text { Metacognitivo }\end{array}$} & 0,576 & \multirow{6}{*}{18,128} \\
\hline CRB & $\begin{array}{l}\text { Conocimiento de otras } \\
\text { áreas o disciplinas }\end{array}$ & & & 0,532 & \\
\hline CRC & Pensamiento analítico & & & 0,595 & \\
\hline CRD & $\begin{array}{l}\text { Capacidad para adquirir con } \\
\text { rapidez nuevos } \\
\text { conocimientos. }\end{array}$ & & & 0,751 & \\
\hline CRF & $\begin{array}{l}\text { Capacidad para trabajar } \\
\text { bajo presión }\end{array}$ & & & 0,619 & \\
\hline CRG & $\begin{array}{l}\text { Capacidad para detectar } \\
\text { nuevas oportunidades }\end{array}$ & & & 0,506 & \\
\hline CRN & $\begin{array}{l}\text { Capacidad para utilizar } \\
\text { herramientas informáticas }\end{array}$ & \multirow{4}{*}{3} & \multirow{4}{*}{$\begin{array}{l}\text { Competencias } \\
\text { Instrumentales y de } \\
\text { Comunicación }\end{array}$} & 0,535 & \multirow{4}{*}{14,646} \\
\hline CRQ & $\begin{array}{l}\text { Capacidad para presentar } \\
\text { en público productos, ideas } \\
\text { o informes }\end{array}$ & & & 0,619 & \\
\hline CRR & $\begin{array}{l}\text { Capacidad para redactar } \\
\text { informes o documentos }\end{array}$ & & & 0,648 & \\
\hline CRS & $\begin{array}{l}\text { Capacidad para escribir y } \\
\text { hablar idiomas extranjeros }\end{array}$ & & & 0,690 & \\
\hline
\end{tabular}

Método de extracción: Análisis de componentes principales Método de Rotación: Normalización Varimax con Kaiser País = España 
Gráfico de sedimentación

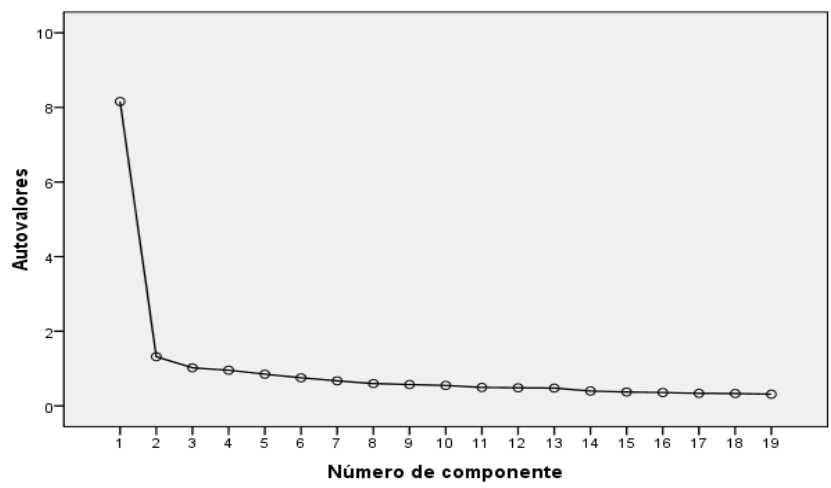

Fig. 13-2

I3-E Medida de los Valores Laborales Personales

Tabla I3-11 Resumen de la Prueba Factorial

\begin{tabular}{|l|c|}
\hline \multicolumn{1}{|c|}{ Prueba } & Resultado \\
\hline Alfa de Cronbach & 0,763 \\
\hline Medida de adecuación muestral de Kaiser-Meyer-Olkin (KMO) & 0,793 \\
\hline Prueba de esfericidad de Barlett (sig) & 0,000 \\
\hline Varianza total explicada (\%) & 45,956 \\
\hline
\end{tabular}


Los resultados de las cargas factoriales resultantes aparecen en la Tabla I3-12.

Tabla I3-12 Resultados de las cargas factoriales: Valores Laborales Personales España

\begin{tabular}{|c|c|c|c|c|c|}
\hline IdVariable & Nombre Variable & № & $\begin{array}{l}\text { Componentes } \\
\text { Interpretados }\end{array}$ & $\begin{array}{c}\text { Cargas } \\
\text { Factoriales }\end{array}$ & $\begin{array}{c}\text { \% Varianza } \\
\text { Explicada }\end{array}$ \\
\hline VP1 & Autonomía en el trabajo & \multirow{6}{*}{1} & \multirow{6}{*}{$\begin{array}{l}\text { Puesto de Trabajo } \\
\text { Enriquecido } \\
\text { "satisfactorio" }\end{array}$} & 0,474 & \multirow{6}{*}{25,106} \\
\hline VP3 & $\begin{array}{l}\text { Oportunidad de aprender cosas } \\
\text { nuevas }\end{array}$ & & & 0,737 & \\
\hline VP5 & Afrontar nuevos retos & & & 0,818 & \\
\hline VP6 & $\begin{array}{l}\text { Buenas perspectivas } \\
\text { profesionales }\end{array}$ & & & 0,671 & \\
\hline VP8 & Reconocimiento/prestigio social & & & 0,452 & \\
\hline VP9 & $\begin{array}{l}\text { Oportunidad de hacer algo útil } \\
\text { para la sociedad }\end{array}$ & & & 0,503 & \\
\hline VP2 & Estabilidad laboral & \multirow{4}{*}{2} & \multirow{4}{*}{$\begin{array}{l}\text { Ocio y Familia - } \\
\text { Ingresos y Estabilidad }\end{array}$} & 0,590 & \multirow{4}{*}{20,85} \\
\hline VP4 & Ingresos elevados & & & 0,481 & \\
\hline VP7 & $\begin{array}{l}\text { Tener tiempo para actividades } \\
\text { recreativas }\end{array}$ & & & 0,770 & \\
\hline VP10 & $\begin{array}{l}\text { Facilidad para combinar trabajo } \\
\text { y familia }\end{array}$ & & & 0,790 & \\
\hline
\end{tabular}

Método de extracción: Análisis de componentes principales

Método de Rotación: Normalización Varimax con Kaiser

País = España

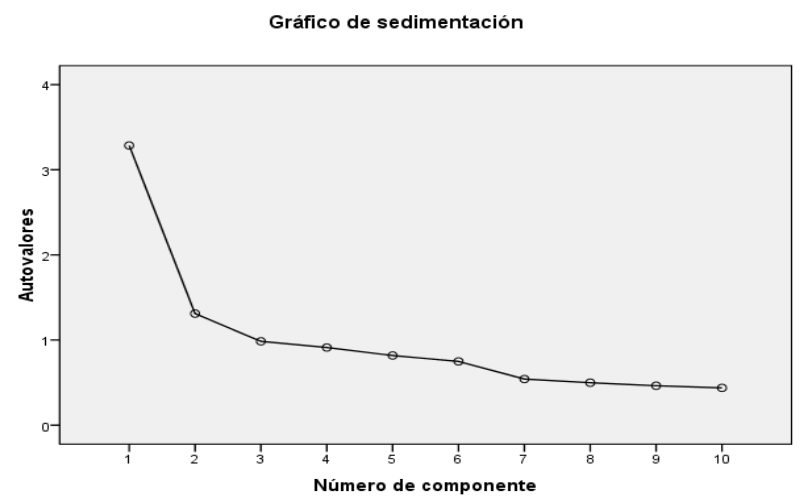

Fig. 13-3 


\section{I3-F Medida de los Valores Laborales en el Trabajo}

Tabla 13-13 Resumen de la Prueba Factorial

\begin{tabular}{|l|c|}
\hline \multicolumn{1}{|c|}{ Prueba } & Resultado \\
\hline Alfa de Cronbach & 0,821 \\
\hline Medida de adecuación muestral de Kaiser-Meyer-Olkin (KMO) & 0,824 \\
\hline Prueba de esfericidad de Barlett (sig) & 0,000 \\
\hline Varianza total explicada (\%) & 65,135 \\
\hline
\end{tabular}

En la tabla I3-14 se muestran los resultados obtenidos.

Tabla I3-14 Resultados de las cargas factorial: Valores Laborales en el Trabajo España

\begin{tabular}{|c|c|c|c|c|c|}
\hline IdVariable & Nombre Variable & № & $\begin{array}{l}\text { Componentes } \\
\text { Interpretados }\end{array}$ & $\begin{array}{l}\text { Cargas } \\
\text { Factoriales }\end{array}$ & $\begin{array}{l}\text { \% Varianza } \\
\text { Explicada }\end{array}$ \\
\hline VT1 & Autonomía en el trabajo & \multirow{6}{*}{1} & \multirow{6}{*}{$\begin{array}{l}\text { Puesto de Trabajo } \\
\text { Enriquecido } \\
\text { "satisfactorio" }\end{array}$} & 0,516 & \multirow{6}{*}{30,184} \\
\hline VT3 & $\begin{array}{l}\text { Oportunidad de aprender } \\
\text { cosas nuevas }\end{array}$ & & & 0,799 & \\
\hline VT5 & Afrontar nuevos retos & & & 0,833 & \\
\hline VT6 & $\begin{array}{l}\text { Buenas perspectivas } \\
\text { profesionales }\end{array}$ & & & 0,669 & \\
\hline VT8 & $\begin{array}{l}\text { Reconocimiento/prestigio } \\
\text { social }\end{array}$ & & & 0,639 & \\
\hline VT9 & $\begin{array}{l}\text { Oportunidad de hacer algo } \\
\text { útil para la sociedad }\end{array}$ & & & 0,600 & \\
\hline VT7 & $\begin{array}{l}\text { Tener tiempo para actividades } \\
\text { recreativas }\end{array}$ & \multirow{2}{*}{2} & \multirow{2}{*}{ Ocio y Familia } & 0,872 & \multirow{2}{*}{18,998} \\
\hline VT10 & $\begin{array}{l}\text { Facilidad para combinar } \\
\text { trabajo y familia }\end{array}$ & & & 0,889 & \\
\hline VT2 & Estabilidad laboral & \multirow{2}{*}{3} & \multirow{2}{*}{ Ingresos y Estabilidad } & 0,832 & \multirow{2}{*}{15,953} \\
\hline VT4 & Ingresos elevados & & & 0,649 & \\
\hline
\end{tabular}

Método de extracción: Análisis de componentes principales Método de Rotación: Normalización Varimax con Kaiser País = España 


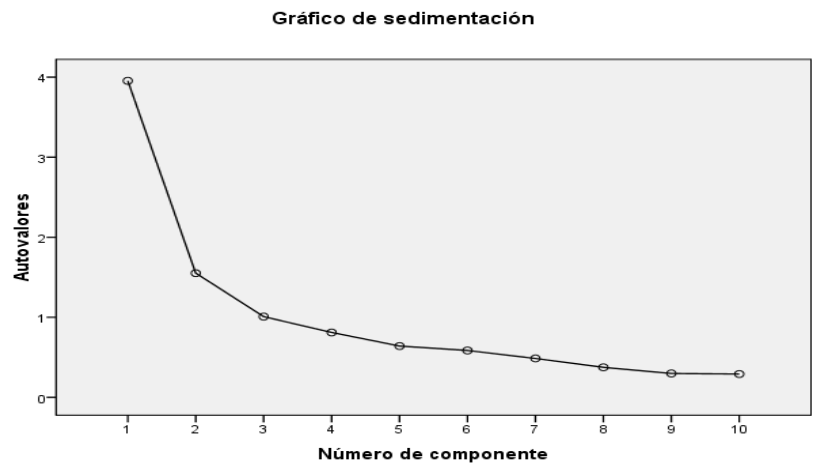

Fig. 13-4

\section{I3-G Medida del ajuste de Competencias}

Tabla I3-15 Resumen de la Prueba Factorial

\begin{tabular}{|l|c|}
\hline \multicolumn{1}{|c|}{ Prueba } & Resultado \\
\hline Medida de adecuación muestral de Kaiser-Meyer-Olkin (KMO) & 0,947 \\
\hline Prueba de esfericidad de Barlett (sig) & 0,000 \\
\hline Varianza total explicada (\%) & 51,366 \\
\hline
\end{tabular}

En la tabla I3-16 se muestran los resultados obtenidos. 
Tabla I3-16 Resultados de las cargas factorial: Ajuste de Competencias España

\begin{tabular}{|c|c|c|c|c|c|}
\hline IdVariable & Nombre Variable & № & $\begin{array}{l}\text { Componentes } \\
\text { Interpretados }\end{array}$ & $\begin{array}{l}\text { Cargas } \\
\text { Factoriales }\end{array}$ & $\begin{array}{l}\text { \% Varianza } \\
\text { Explicada }\end{array}$ \\
\hline CAJE & $\begin{array}{l}\text { Capacidad para negociar de } \\
\text { forma eficaz }\end{array}$ & \multirow{10}{*}{1} & \multirow{10}{*}{$\begin{array}{c}\text { Competencias } \\
\text { Organizativas, liderazgo, } \\
\text { innovación }\end{array}$} & 0,572 & \multirow{10}{*}{21,788} \\
\hline CAJF & $\begin{array}{l}\text { Capacidad para trabajar } \\
\text { bajo presión }\end{array}$ & & & 0,573 & \\
\hline CAJG & $\begin{array}{l}\text { Capacidad para detectar } \\
\text { nuevas oportunidades }\end{array}$ & & & 0,485 & \\
\hline CAJH & $\begin{array}{l}\text { Capacidad para coordinar } \\
\text { actividades }\end{array}$ & & & 0,631 & \\
\hline CAJI & $\begin{array}{l}\text { Capacidad para usar el } \\
\text { tiempo de forma efectiva }\end{array}$ & & & 0,607 & \\
\hline CAJJ & $\begin{array}{l}\text { Capacidad para trabajar en } \\
\text { equipo }\end{array}$ & & & 0,591 & \\
\hline CAJK & $\begin{array}{l}\text { Capacidad para movilizar las } \\
\text { capacidades de otros }\end{array}$ & & & 0,729 & \\
\hline CAJL & $\begin{array}{l}\text { Capacidad para hacerte } \\
\text { entender }\end{array}$ & & & 0,616 & \\
\hline CAJM & $\begin{array}{l}\text { Capacidad para hacer valer } \\
\text { tu autoridad }\end{array}$ & & & 0,672 & \\
\hline CAJO & $\begin{array}{l}\text { Capacidad para encontrar } \\
\text { nuevas ideas y soluciones }\end{array}$ & & & 0,490 & \\
\hline CAJA & $\begin{array}{l}\text { Dominio de tu área o } \\
\text { disciplina }\end{array}$ & \multirow{4}{*}{2} & \multirow{4}{*}{$\begin{array}{l}\text { Competencias de } \\
\text { Conocimiento y } \\
\text { Pensamiento } \\
\text { Metacognitivo }\end{array}$} & 0,695 & \multirow{4}{*}{14,792} \\
\hline CAJB & $\begin{array}{l}\text { Conocimiento de otras } \\
\text { áreas o disciplinas }\end{array}$ & & & 0,661 & \\
\hline CAJC & Pensamiento analítico & & & 0,706 & \\
\hline CAJD & $\begin{array}{l}\text { Capacidad para adquirir con } \\
\text { rapidez nuevos } \\
\text { conocimientos. }\end{array}$ & & & 0,688 & \\
\hline CAJN & $\begin{array}{l}\text { Capacidad para utilizar } \\
\text { herramientas informáticas }\end{array}$ & \multirow{3}{*}{3} & \multirow{5}{*}{$\begin{array}{l}\text { Competencias } \\
\text { Instrumentales y C. de } \\
\text { Comunicación }\end{array}$} & 0,549 & \multirow{5}{*}{14,786} \\
\hline CAJAP & $\begin{array}{l}\text { Predisposición para } \\
\text { cuestionar ideas propias o } \\
\text { ajenas }\end{array}$ & & & 0,569 & \\
\hline CAJQ & $\begin{array}{l}\text { Capacidad para presentar } \\
\text { en público productos, ideas } \\
\text { o informes }\end{array}$ & & & 0,647 & \\
\hline CAJR & $\begin{array}{l}\text { Capacidad para redactar } \\
\text { informes o documentos }\end{array}$ & & & 0,688 & \\
\hline CAJS & $\begin{array}{l}\text { Capacidad para escribir y } \\
\text { hablar idiomas extranjeros }\end{array}$ & & & 0,674 & \\
\hline
\end{tabular}

Método de extracción: Análisis de componentes principales

Método de Rotación: Normalización Varimax con Kaiser

País = España 


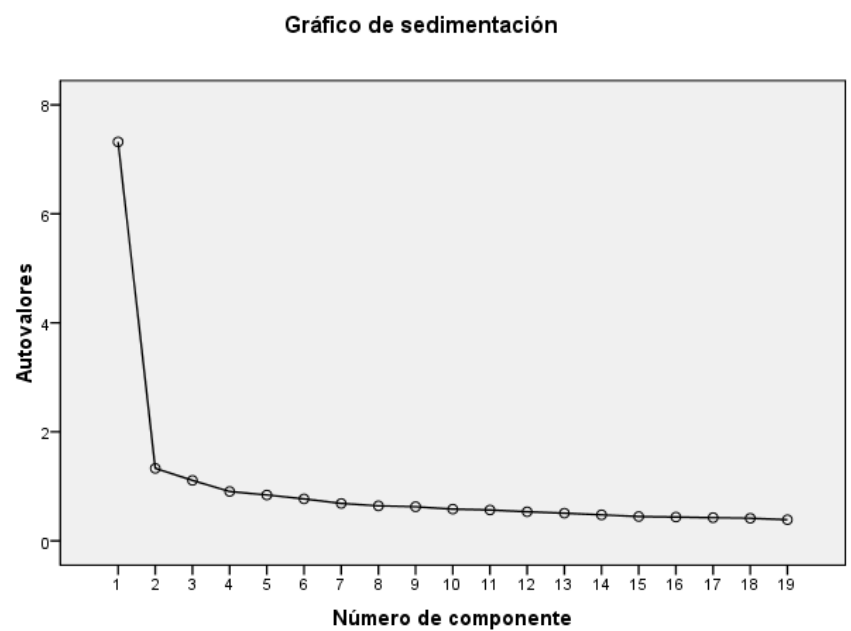

Fig. 13-5

\section{3-H Medida del ajuste de los Valores Laborales}

Tabla 13-17 Resumen de la Prueba Factorial

\begin{tabular}{|l|c|}
\hline \multicolumn{1}{|c|}{ Prueba } & Resultado \\
\hline Medida de adecuación muestral de Kaiser-Meyer-Olkin (KMO) & 0,824 \\
\hline Prueba de esfericidad de Barlett (sig) & 0,000 \\
\hline Varianza total explicada (\%) & 61,844 \\
\hline
\end{tabular}

En la tabla I3-18 se muestran los resultados obtenidos. 
Tabla 13-18 Resultados de las cargas factorial: Ajuste de Valores laborales España

\begin{tabular}{|c|c|c|c|c|c|}
\hline IdVariable & Nombre Variable & № & $\begin{array}{l}\text { Componentes } \\
\text { Interpretados }\end{array}$ & $\begin{array}{c}\text { Cargas } \\
\text { Factoriales }\end{array}$ & $\begin{array}{c}\text { \% Varianza } \\
\text { Explicada }\end{array}$ \\
\hline AJVT1 & Autonomía en el trabajo & \multirow{6}{*}{1} & \multirow{6}{*}{$\begin{array}{l}\text { Puesto de Trabajo } \\
\text { Enriquecido } \\
\text { "satisfactorio" }\end{array}$} & 0,486 & \multirow{6}{*}{29,278} \\
\hline AJVT3 & $\begin{array}{l}\text { Oportunidad de aprender cosas } \\
\text { nuevas }\end{array}$ & & & 0,765 & \\
\hline AJVT5 & Afrontar nuevos retos & & & 0,809 & \\
\hline AJVT6 & $\begin{array}{l}\text { Buenas perspectivas } \\
\text { profesionales }\end{array}$ & & & 0,677 & \\
\hline AJVT8 & Reconocimiento/prestigio social & & & 0,611 & \\
\hline AJVT9 & $\begin{array}{l}\text { Oportunidad de hacer algo útil } \\
\text { para la sociedad }\end{array}$ & & & 0,590 & \\
\hline AJVT7 & $\begin{array}{l}\text { Tener tiempo para actividades } \\
\text { recreativas }\end{array}$ & \multirow{2}{*}{2} & \multirow{2}{*}{ Ocio y Familia } & 0,877 & \multirow{2}{*}{18,59} \\
\hline AJVT10 & $\begin{array}{l}\text { Facilidad para combinar trabajo } \\
\text { y familia }\end{array}$ & & & 0,881 & \\
\hline AJVT2 & Estabilidad laboral & \multirow{2}{*}{3} & \multirow{2}{*}{ Ingresos y Estabilidad } & 0,884 & \multirow{2}{*}{13,975} \\
\hline AJVT4 & Ingresos elevados & & & 0,517 & \\
\hline
\end{tabular}

Método de extracción: Análisis de componentes principales Método de Rotación: Normalización Varimax con Kaiser País = España

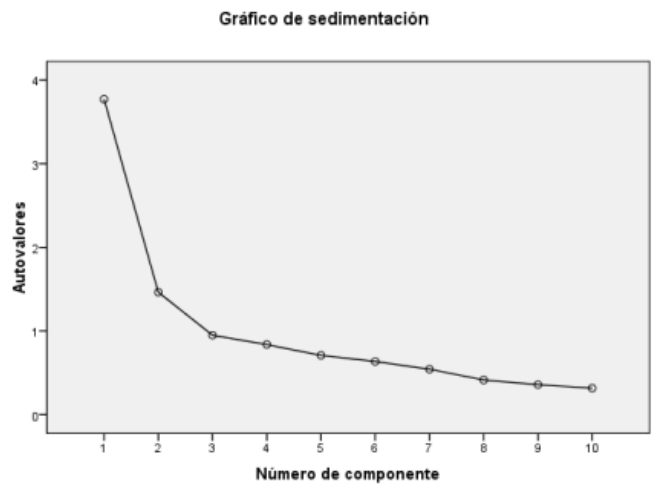

Fig. 13-6 
Anexo J. Correlaciones Bivariadas 
Anexo J: Correlaciones Bivariadas

Correlaciones entre los factores que componen cada variable y cada par de variables objeto de análisis y correlaciones parciales

Sección J1: EUROPA.

J1_1. Correlaciones bivariadas entre los factores del éxito laboral y los factores del rol.

Tabla J1-1 Correlaciones bivariadas Exlab Rol

\begin{tabular}{|c|c|c|c|c|}
\hline \multicolumn{2}{|c|}{ Rho de Spearman } & Responsa_E_1 & Relacion_E_1 & Perjuicio_E_1 \\
\hline \multirow[t]{2}{*}{ Exlabob_E_1 } & $\begin{array}{c}\text { Coeficiente } \\
\text { de } \\
\text { correlación }\end{array}$ &,- 056 & 147 & ,296 \\
\hline & $\begin{array}{c}\text { Sig. } \\
\text { (bilateral) }\end{array}$ & ,000 & ,000 & ,000 \\
\hline \multirow[t]{2}{*}{ Exlabsu_E_1 } & $\begin{array}{c}\text { Coeficiente } \\
\text { de } \\
\text { correlación }\end{array}$ & 237 & ,246 &,- 002 \\
\hline & $\begin{array}{c}\text { Sig. } \\
\text { (bilateral) }\end{array}$ & ,000 & ,000 & ,682 \\
\hline
\end{tabular}

J1_2 Correlaciones bivariadas entre los factores del éxito Laboral y los factores de las competencias personales

Tabla J1-2 Correlaciones bivariadas Exlab_Competencias Personales (CPE)

\begin{tabular}{|c|c|c|c|c|c|}
\hline \multicolumn{2}{|c|}{ Rho de Spearman } & CPE_F1_1 & CPE_F2_1 & CPE_F3_1 & CPE_F4_1 \\
\hline \multirow{2}{*}{ Exlabob_E_1 } & $\begin{array}{c}\text { Coeficiente } \\
\text { de } \\
\text { correlación }\end{array}$ &, 040 &, 004 &, 050 &, 027 \\
\cline { 2 - 6 } & $\begin{array}{c}\text { Sig. } \\
\text { (bilateral) }\end{array}$ &, 000 &, 462 &, 000 &, 000 \\
\hline & $\begin{array}{c}\text { Coeficiente } \\
\text { de } \\
\text { Exlabsu_E_1 }\end{array}$ &, 126 &, 106 &, 045 &, 088 \\
\cline { 2 - 6 } & $\begin{array}{c}\text { Sig. } \\
\text { (bilateral) }\end{array}$ &, 000 &, 000 &, 000 &, 000 \\
\hline
\end{tabular}


J1_3 Correlaciones bivariadas entre los factores del éxito laboral y los factores de las competencias requeridas en el trabajo

Tabla J1-3 Correlaciones bivariadas Exlab_Competencias requeridas en el trabajo (CRE)

\begin{tabular}{|l|c|c|c|c|}
\hline \multicolumn{2}{|c|}{ Rho de Spearman } & CRE_F1_1 & CRE_F2_1 & CRE_F3_1 \\
\hline \multirow{2}{*}{ Exlabob_E_1 } & $\begin{array}{c}\text { Coeficiente } \\
\text { de } \\
\text { correlación }\end{array}$ &, 000 &,- 009 &, 001 \\
\cline { 2 - 5 } & $\begin{array}{c}\text { Sig. } \\
\text { (bilateral) }\end{array}$ &, 991 &, 145 &, 902 \\
\hline Exlabsu_E_1 & $\begin{array}{c}\text { Coeficiente } \\
\text { de } \\
\text { correlación }\end{array}$ &, 153 &, 215 &, 148 \\
\cline { 2 - 5 } & $\begin{array}{c}\text { Sig. } \\
\text { (bilateral) }\end{array}$ &, 000 &, 000 &, 000 \\
\hline
\end{tabular}

J1-4 Correlaciones bivariadas entre los factores del éxito laboral y los factores de los valores laborales personales

Tabla J1-4 Correlaciones bivariadas Exlab _ Valores laborales personales (VPE)

\begin{tabular}{|c|c|c|c|c|}
\hline \multicolumn{2}{|c|}{ Rho de Spearman } & VPE_F1_1 & VPE_F2_1 & VPE_F3_1 \\
\hline \multirow{2}{*}{ Exlabob_E_1 } & $\begin{array}{c}\text { Coeficiente } \\
\text { de } \\
\text { correlación }\end{array}$ &,- 100 &, 021 &,- 262 \\
\cline { 2 - 5 } & $\begin{array}{c}\text { Sig. } \\
\text { (bilateral) }\end{array}$ &, 000 &, 001 &, 000 \\
\hline \multirow{2}{*}{ Exlabsu_E_1 } & $\begin{array}{c}\text { Coeficiente } \\
\text { de } \\
\text { correlación }\end{array}$ &,- 041 &, 178 &, 022 \\
\cline { 2 - 5 } & $\begin{array}{c}\text { Sig. } \\
\text { (bilateral) }\end{array}$ &, 000 &, 000 &, 000 \\
\hline
\end{tabular}


J1-5 Correlaciones bivariadas entre los factores del éxito laboral y los factores de los valores laborales en el trabajo

Tabla J1-5 Correlaciones bivariadas Exlab_ Valores laborales en el trabajo (VLTE)

\begin{tabular}{|c|c|c|c|c|}
\hline \multicolumn{2}{|c|}{ trabajo (VLTE) } \\
\hline \multirow{2}{*}{ Rho de Spearman } & VLTE_F1_1 & VLTE_F2_1 & VLTE_F3_1 \\
\hline \multirow{2}{*}{ Exlabob_E_1 } & $\begin{array}{c}\text { Coeficiente } \\
\text { de } \\
\text { correlación }\end{array}$ &, 078 &, 185 &,- 115 \\
\cline { 2 - 5 } & $\begin{array}{c}\text { Sig. } \\
\text { (bilateral) }\end{array}$ &, 000 &, 000 &, 000 \\
& $\begin{array}{c}\text { Coeficiente } \\
\text { de } \\
\text { correlación }\end{array}$ &, 466 &, 227 &, 073 \\
\cline { 2 - 5 } & $\begin{array}{c}\text { Sig. } \\
\text { (bilateral) }\end{array}$ &, 000 &, 000 &, 000 \\
\hline
\end{tabular}

J1-6 Correlaciones bivariadas entre los factores del rol y las competencias Personales (CPE)

Tabla J1-6 Correlaciones bivariadas Rol_CPE

\begin{tabular}{|c|c|c|c|c|c|}
\hline \multicolumn{2}{|c|}{ Rho de Spearman } & CPE_F1_1 & CPE_F2_1 & CPE_F3_1 & CPE_F4_1 \\
\hline \multirow{2}{*}{ Responsa_E_1 } & $\begin{array}{c}\text { Coeficiente } \\
\text { de } \\
\text { correlación }\end{array}$ &, 256 &, 020 &,- 006 &, 098 \\
\cline { 2 - 6 } & $\begin{array}{c}\text { Sig. } \\
\text { (bilateral) }\end{array}$ &, 000 &, 001 &, 313 &, 000 \\
\hline Relacion_E_1 & $\begin{array}{c}\text { Coeficiente } \\
\text { de } \\
\text { correlación }\end{array}$ &, 273 &, 125 &, 192 &, 259 \\
\cline { 2 - 6 } & $\begin{array}{c}\text { Sig. } \\
\text { (bilateral) }\end{array}$ &, 000 &, 000 &, 000 &, 000 \\
\hline Perjuicio_E_1 & $\begin{array}{c}\text { Coeficiente } \\
\text { de } \\
\text { correlación }\end{array}$ &, 089 &, 036 &,- 080 &,- 003 \\
\cline { 2 - 6 } & $\begin{array}{c}\text { Sig. } \\
\text { (bilateral) }\end{array}$ &, 000 &, 000 &, 000 &, 581 \\
\hline
\end{tabular}


J1-7 Correlaciones bivariadas entre los factores del rol y las competencias requeridas en el trabajo (CRE)

Tabla J1-7 Correlaciones bivariadas Rol_CRE

\begin{tabular}{|c|c|c|c|c|}
\hline \multicolumn{2}{|c|}{ Rho de Spearman } & CRE_F1_1 & CRE_F2_1 & CRE_F3_1 \\
\hline Responsa_E_1 & $\begin{array}{c}\text { Coeficiente } \\
\text { de } \\
\text { correlación }\end{array}$ &, 315 &, 109 &, 059 \\
\cline { 2 - 5 } & $\begin{array}{c}\text { Sig. } \\
\text { (bilateral) }\end{array}$ &, 000 &, 000 &, 000 \\
\hline Relacion_E_1 & $\begin{array}{c}\text { Coeficiente } \\
\text { de } \\
\text { correlación }\end{array}$ &, 181 &, 226 &, 144 \\
\cline { 2 - 5 } & $\begin{array}{c}\text { Sig. } \\
\text { (bilateral) }\end{array}$ &, 000 &, 000 &, 000 \\
\hline Perjuicio_E_1 & $\begin{array}{c}\text { Coeficiente } \\
\text { de } \\
\text { correlación }\end{array}$ &, 062 &,- 100 &, 089 \\
\cline { 2 - 5 } & $\begin{array}{c}\text { Sig. } \\
\text { (bilateral) }\end{array}$ &, 000 &, 000 &, 000 \\
\hline
\end{tabular}

J1-8 Correlaciones bivariadas entre los factores del rol y los valores laborales personales (VPE)

Tabla J1-8 Correlaciones bivariadas Rol_VPE

\begin{tabular}{|l|c|c|c|c|}
\hline \multicolumn{2}{|c|}{ Rho de Spearman } & VPE_F1_1 & VPE_F2_1 & VPE_F3_1 \\
\hline Responsa_E_1 & $\begin{array}{c}\text { Coeficiente } \\
\text { de } \\
\text { correlación }\end{array}$ &, 018 &, 114 &,- 005 \\
\cline { 2 - 5 } & $\begin{array}{c}\text { Sig. } \\
\text { (bilateral) }\end{array}$ &, 005 &, 000 &, 409 \\
\hline Relacion_E_1 & $\begin{array}{c}\text { Coeficiente } \\
\text { de } \\
\text { correlación }\end{array}$ &, 026 &, 277 &,- 057 \\
\cline { 2 - 5 } & $\begin{array}{c}\text { Sig. } \\
\text { (bilateral) }\end{array}$ &, 000 &, 000 &, 000 \\
\hline \multirow{2}{*}{ Perjuicio_E_1 } & $\begin{array}{c}\text { Coeficiente } \\
\text { de } \\
\text { correlación }\end{array}$ &, 092 &, 023 &,- 066 \\
\cline { 2 - 5 } & $\begin{array}{c}\text { Sig. } \\
\text { (bilateral) }\end{array}$ &, 000 &, 000 &, 000 \\
\hline
\end{tabular}


J1-9 Correlaciones bivariadas entre los factores de rol y los valores laborales en el trabajo (VLTE)

Tabla J1-9 Correlaciones bivariadas Rol_VLTE

\begin{tabular}{|l|c|c|c|c|}
\hline \multicolumn{2}{|c|}{ Rho de Spearman } & VLTE_F1_1 & VLTE_F2_1 & VLTE_F3_1 \\
\hline Responsa_E_1 & $\begin{array}{c}\text { Coeficiente } \\
\text { de } \\
\text { correlación }\end{array}$ &, 287 &, 115 &, 041 \\
\cline { 2 - 5 } & $\begin{array}{c}\text { Sig. } \\
\text { (bilateral) }\end{array}$ &, 000 &, 000 &, 000 \\
\hline Relacion_E_1 & $\begin{array}{c}\text { Coeficiente } \\
\text { de } \\
\text { correlación }\end{array}$ &, 270 &, 079 &,- 026 \\
\cline { 2 - 5 } & $\begin{array}{c}\text { Sig. } \\
\text { (bilateral) }\end{array}$ &, 000 &, 000 &, 000 \\
\hline Perjuicio_E_1 & $\begin{array}{c}\text { Coeficiente } \\
\text { de } \\
\text { correlación }\end{array}$ &, 006 &, 122 &,- 144 \\
\cline { 2 - 5 } & $\begin{array}{c}\text { Sig. } \\
\text { (bilateral) }\end{array}$ &, 320 &, 000 &, 000 \\
\hline
\end{tabular}

J1-10 Correlaciones bivariadas entre los factores de las competencias personales (CPE) y las competencias requeridas en el trabajo (CRE)

Tabla J1-10 Correlaciones bivariadas CPE CRE

\begin{tabular}{|c|c|c|c|c|}
\hline \multicolumn{2}{|c|}{ Rho de Spearman } & CRE_F1_1 & CRE_F2_1 & CRE_F3_1 \\
\hline CPE_F1_1 & $\begin{array}{c}\text { Coeficiente } \\
\text { de } \\
\text { correlación }\end{array}$ &, 507 &, 013 &, 032 \\
\cline { 2 - 5 } & $\begin{array}{c}\text { Sig. } \\
\text { (bilateral) }\end{array}$ &, 000 &, 028 &, 000 \\
\hline CPE_F2_1 & $\begin{array}{c}\text { Coeficiente } \\
\text { de } \\
\text { correlación }\end{array}$ &, 112 &,- 039 &, 397 \\
\cline { 2 - 5 } & $\begin{array}{c}\text { Sig. } \\
\text { (bilateral) }\end{array}$ &, 000 &, 000 &, 000 \\
\hline CPE_F3_1 & $\begin{array}{c}\text { Coeficiente } \\
\text { de } \\
\text { correlación }\end{array}$ &, 002 &, 461 &,- 027 \\
\cline { 2 - 5 } & $\begin{array}{c}\text { Sig. } \\
\text { (bilateral) }\end{array}$ &, 745 &, 000 &, 000 \\
\hline \multirow{2}{*}{ CPE_F4_1 } & $\begin{array}{c}\text { Coeficiente } \\
\text { de } \\
\text { correlación }\end{array}$ &,- 071 &, 190 &, 186 \\
\cline { 2 - 5 } & $\begin{array}{c}\text { Sig. } \\
\text { (bilateral) }\end{array}$ &, 000 &, 000 &, 000 \\
\hline
\end{tabular}


J1-11 Correlaciones bivariadas entre los factores de las competencias personales (CPE) y los valores laborales personales (VPE)

Tabla J1-11 Correlaciones bivariadas CPE_VPE

\begin{tabular}{|c|c|c|c|c|}
\hline \multicolumn{2}{|c|}{ Rho de Spearman } & VPE_F1_1 & VPE_F2_1 & VPE_F3_1 \\
\hline \multirow[t]{2}{*}{ CPE_F1_1 } & $\begin{array}{c}\text { Coeficiente } \\
\text { de } \\
\text { correlación }\end{array}$ & 126 & ,229 & ,040 \\
\hline & $\begin{array}{c}\text { Sig. } \\
\text { (bilateral) }\end{array}$ & ,000 & ,000 & ,000 \\
\hline \multirow[t]{2}{*}{ CPE_F2_1 } & $\begin{array}{c}\text { Coeficiente } \\
\text { de } \\
\text { correlación }\end{array}$ & 144 & 141 & 071 \\
\hline & $\begin{array}{c}\text { Sig. } \\
\text { (bilateral) }\end{array}$ & ,000 & ,000 & ,000 \\
\hline \multirow[t]{2}{*}{ CPE_F3_1 } & $\begin{array}{c}\text { Coeficiente } \\
\text { de } \\
\text { correlación }\end{array}$ & ,033 & 215 &,- 071 \\
\hline & $\begin{array}{c}\text { Sig. } \\
\text { (bilateral) }\end{array}$ & ,000 & ,000 & ,000 \\
\hline \multirow[t]{2}{*}{ CPE_F4_1 } & $\begin{array}{c}\text { Coeficiente } \\
\text { de } \\
\text { correlación }\end{array}$ & ,057 & 191 &,- 104 \\
\hline & $\begin{array}{c}\text { Sig. } \\
\text { (bilateral) }\end{array}$ & ,000 & ,000 & ,000 \\
\hline
\end{tabular}


J1-12 Correlaciones bivariadas entre los factores de las competencias personales (CPE) y los valores laborales en el trabajo (VLTE)

Tabla J1-12 Correlaciones bivariadas VPE_VLTE

\begin{tabular}{|c|c|c|c|c|}
\hline \multicolumn{2}{|c|}{ Rho de Spearman } & VLTE_F1_1 & VLTE_F2_1 & VLTE_F3_1 \\
\hline \multirow[t]{2}{*}{ CPE_F1_1 } & $\begin{array}{c}\text { Coeficiente } \\
\text { de } \\
\text { correlación }\end{array}$ & 198 & ,095 & ,031 \\
\hline & $\begin{array}{c}\text { Sig. } \\
\text { (bilateral) }\end{array}$ & ,000 & ,000 & ,000 \\
\hline \multirow[t]{2}{*}{ CPE_F2_1 } & $\begin{array}{c}\text { Coeficiente } \\
\text { de } \\
\text { correlación }\end{array}$ & ,056 & ,087 & ,011 \\
\hline & $\begin{array}{c}\text { Sig. } \\
\text { (bilateral) }\end{array}$ & ,000 & ,000 & 104 \\
\hline \multirow[t]{2}{*}{ CPE_F3_1 } & $\begin{array}{c}\text { Coeficiente } \\
\text { de } \\
\text { correlación }\end{array}$ & 138 & ,010 &,- 064 \\
\hline & $\begin{array}{c}\text { Sig. } \\
\text { (bilateral) }\end{array}$ & ,000 & 120 & ,000 \\
\hline \multirow[t]{2}{*}{ CPE_F4_1 } & $\begin{array}{c}\text { Coeficiente } \\
\text { de } \\
\text { correlación }\end{array}$ & ,091 & ,026 &,- 009 \\
\hline & $\begin{array}{c}\text { Sig. } \\
\text { (bilateral) }\end{array}$ & ,000 & ,000 & 166 \\
\hline
\end{tabular}

J1-13 Correlaciones bivariadas entre los factores de las competencias requeridas en el trabajo (CRE) y los valores laborales personales (VPE)

Tabla J1-13 Correlaciones bivariadas CRE VPE

\begin{tabular}{|c|c|c|c|c|}
\hline \multicolumn{2}{|c}{ Rho de Spearman } & VPE_F1_1 & VPE_F2_1 & VPE_F3_1 \\
\hline \multirow{2}{*}{ CRE_F1_1 } & $\begin{array}{c}\text { Coeficiente } \\
\text { de } \\
\text { correlación }\end{array}$ &, 097 &, 168 &, 105 \\
\cline { 2 - 5 } & $\begin{array}{c}\text { Sig. } \\
\text { (bilateral) }\end{array}$ &, 000 &, 000 &, 000 \\
\hline \multirow{2}{*}{ CRE_F2_1 } & $\begin{array}{c}\text { Coeficiente } \\
\text { de } \\
\text { correlación }\end{array}$ &, 086 &, 186 &,- 071 \\
\cline { 2 - 5 } & $\begin{array}{c}\text { Sig. } \\
\text { (bilateral) }\end{array}$ &, 000 &, 000 &, 000 \\
\hline \multirow{2}{*}{ CRE_F3_1 } & $\begin{array}{c}\text { Coeficiente } \\
\text { de } \\
\text { correlación }\end{array}$ &, 100 &, 120 &, 026 \\
\cline { 2 - 5 } & $\begin{array}{c}\text { Sig. } \\
\text { (bilateral) }\end{array}$ &, 000 &, 000 &, 000 \\
\hline
\end{tabular}


J1-14 Correlaciones bivariadas entre los factores de las competencias requeridas en el trabajo (CRE) y los valores laborales en el trabajo (VLTE)

Tabla J1-14 Correlaciones bivariadas CRE_VLTE

\begin{tabular}{|c|c|c|c|c|}
\hline \multicolumn{2}{|c|}{ Rho de Spearman } & VLTE_F1_1 & VLTE_F2_1 & VLTE_F3_1 \\
\hline CRE_F1_1 & $\begin{array}{c}\text { Coeficiente } \\
\text { de } \\
\text { correlación }\end{array}$ &, 250 &, 151 &, 014 \\
\cline { 2 - 5 } & $\begin{array}{c}\text { Sig. } \\
\text { (bilateral) }\end{array}$ &, 000 &, 000 &, 042 \\
\hline \multirow{2}{*}{ CRE_F2_1 } & $\begin{array}{c}\text { Coeficiente } \\
\text { de } \\
\text { correlación }\end{array}$ &, 341 &, 144 &,- 107 \\
\cline { 2 - 5 } & $\begin{array}{c}\text { Sig. } \\
\text { (bilateral) }\end{array}$ &, 000 &, 000 &, 000 \\
\hline \multirow{2}{*}{ CRE_F3_1 } & $\begin{array}{c}\text { Coeficiente } \\
\text { de } \\
\text { correlación }\end{array}$ &, 173 &, 118 &,- 166 \\
\cline { 2 - 5 } & $\begin{array}{c}\text { Sig. } \\
\text { (bilateral) }\end{array}$ &, 000 &, 000 &, 000 \\
\hline
\end{tabular}

J1-15 Correlaciones bivariadas entre los factores de los valores laborales personales (VPE) y los valores laborales en el trabajo (VLTE)

Tabla J1-15 Correlaciones bivariadas VPE_VLTE

\begin{tabular}{|c|c|c|c|c|}
\hline \multicolumn{2}{|c|}{ Rho de Spearman } & VLTE_F1_1 & VLTE_F2_1 & VLTE_F3_1 \\
\hline \multirow[t]{2}{*}{ VPE_F1_1 } & $\begin{array}{c}\text { Coeficiente } \\
\text { de } \\
\text { correlación }\end{array}$ &,- 082 & ,322 &,- 093 \\
\hline & $\begin{array}{c}\text { Sig. } \\
\text { (bilateral) }\end{array}$ & ,000 & ,000 & ,000 \\
\hline \multirow{2}{*}{ VPE_F2_1 } & $\begin{array}{c}\text { Coeficiente } \\
\text { de } \\
\text { correlación }\end{array}$ & 397 &,- 010 & ,021 \\
\hline & $\begin{array}{c}\text { Sig. } \\
\text { (bilateral) }\end{array}$ & ,000 & 107 & ,001 \\
\hline \multirow[t]{2}{*}{ VPE_F3_1 } & $\begin{array}{c}\text { Coeficiente } \\
\text { de } \\
\text { correlación }\end{array}$ & ,064 &,- 032 & ,339 \\
\hline & $\begin{array}{c}\text { Sig. } \\
\text { (bilateral) }\end{array}$ & ,000 & ,000 & ,000 \\
\hline
\end{tabular}


Sección J2: LATINOAMERICA.

J2-1. Correlaciones bivariadas entre los factores del éxito laboral y los factores del rol.

Tabla J2-1 Correlaciones bivariadas Exlab_Rol

\begin{tabular}{|c|c|c|c|c|}
\hline \multicolumn{2}{|c|}{ Rho de Spearman } & Relacion_LA_2 & Responsa_LA_2 & Autonomia_LA_2 \\
\hline \multirow[t]{2}{*}{ Exlabob_LA_2 } & $\begin{array}{c}\text { Coeficiente } \\
\text { de } \\
\text { correlación }\end{array}$ & 121 &,- 071 & ,062 \\
\hline & $\begin{array}{c}\text { Sig. } \\
\text { (bilateral) }\end{array}$ & ,000 & ,000 & ,000 \\
\hline \multirow[t]{2}{*}{ Exlabsu_LA_2 } & $\begin{array}{c}\text { Coeficiente } \\
\text { de } \\
\text { correlación }\end{array}$ & 285 & ,226 & 108 \\
\hline & $\begin{array}{c}\text { Sig. } \\
\text { (bilateral) }\end{array}$ & ,000 & ,000 & ,000 \\
\hline
\end{tabular}

J2-2 Correlaciones bivariadas entre los factores del éxito Laboral y los factores de las competencias personales

Tabla J2-2 Correlaciones bivariadas Exlab_Competencias personales (CPLA)

\begin{tabular}{|c|c|c|c|c|}
\hline \multicolumn{2}{|c|}{ Rho de Spearman } & CPLA_F1-2 & CPLA_F2_2 & CPLA_F3_2 \\
\hline Exlabob_LA_2 & $\begin{array}{c}\text { Coeficiente } \\
\text { de } \\
\text { correlación }\end{array}$ &, 039 &, 165 &, 105 \\
\cline { 2 - 5 } & $\begin{array}{c}\text { Sig. } \\
\text { (bilateral) }\end{array}$ &, 002 &, 000 &, 000 \\
\hline \multirow{2}{*}{ Exlabsu_LA_2 } & $\begin{array}{c}\text { Coeficiente } \\
\text { de } \\
\text { correlación }\end{array}$ &, 167 &, 189 &, 095 \\
\cline { 2 - 5 } & $\begin{array}{c}\text { Sig. } \\
\text { (bilateral) }\end{array}$ &, 000 &, 000 &, 000 \\
\hline
\end{tabular}


J2-3 Correlaciones bivariadas entre los factores del éxito laboral y los factores de las competencias requeridas en el trabajo

Tabla J2-3 Correlaciones bivariadas Exlab_Competencias requeridas en el trabajo (CRLA)

\begin{tabular}{|c|c|c|c|}
\hline \multicolumn{2}{|c|}{ Rho de Spearman } & CRLA_F1_2 & CRLA_F2_2 \\
\hline \multirow[t]{2}{*}{ Exlabob_LA_2 } & $\begin{array}{c}\text { Coeficiente } \\
\text { de } \\
\text { correlación }\end{array}$ & 090 & 124 \\
\hline & $\begin{array}{c}\text { Sig. } \\
\text { (bilateral) }\end{array}$ & ,000 & 000 \\
\hline \multirow[t]{2}{*}{ Exlabsu_LA_2 } & $\begin{array}{c}\text { Coeficiente } \\
\text { de } \\
\text { correlación }\end{array}$ & 185 & 237 \\
\hline & $\begin{array}{c}\text { Sig. } \\
\text { (bilateral) }\end{array}$ & ,000 & ,000 \\
\hline
\end{tabular}

J2-4 Correlaciones bivariadas entre los factores del éxito laboral y los factores de los valores laborales personales

Tabla J2-4 Correlaciones bivariadas Exlab_Valores laborales personales (VPLA)

\begin{tabular}{|c|c|c|c|}
\hline \multicolumn{2}{|c|}{ Rho de Spearman } & VPLA_F1_2 & VPLA_F2_2 \\
\hline Exlabob_LA_2 & $\begin{array}{c}\text { Coeficiente } \\
\text { de } \\
\text { correlación }\end{array}$ &, 113 &,- 121 \\
\cline { 2 - 4 } & $\begin{array}{c}\text { Sig. } \\
\text { (bilateral) }\end{array}$ &, 000 &, 000 \\
\hline \multirow{2}{*}{ Exlabsu_LA_2 } & $\begin{array}{c}\text { Coeficiente } \\
\text { de } \\
\text { correlación }\end{array}$ &, 097 &, 118 \\
\cline { 2 - 4 } & $\begin{array}{c}\text { Sig. } \\
\text { (bilateral) }\end{array}$ &, 000 &, 000 \\
\hline
\end{tabular}


J2-5 Correlaciones bivariadas entre los factores del éxito laboral y los factores de los valores laborales en el trabajo

Tabla J2-5 Correlaciones bivariadas Exlab _ Valores laborales en el trabajo (VLTLA)

\begin{tabular}{|c|c|c|c|}
\hline \multicolumn{2}{|c|}{ Rho de Spearman } & VLTLA_F1_2 & VLTLA_F2_2 \\
\hline Exlabob_LA_2 & $\begin{array}{c}\text { Coeficiente } \\
\text { de } \\
\text { correlación }\end{array}$ &, 114 &,- 065 \\
\cline { 2 - 4 } & $\begin{array}{c}\text { Sig. } \\
\text { (bilateral) }\end{array}$ &, 000 &, 000 \\
\hline \multirow{2}{*}{ Exlabsu_LA_2 } & $\begin{array}{c}\text { Coeficiente } \\
\text { de } \\
\text { correlación }\end{array}$ & , 406 &, 109 \\
\cline { 2 - 4 } & $\begin{array}{c}\text { Sig. } \\
\text { (bilateral) }\end{array}$ &, 000 &, 000 \\
\hline
\end{tabular}

J2-6 Correlaciones bivariadas entre los factores del rol y las competencias Personales (CPLA)

Tabla J2-6 Correlaciones bivariadas Rol_CPLA

\begin{tabular}{|c|c|c|c|c|}
\hline \multicolumn{2}{|c|}{ Rho de Spearman } & CPLA_F1-2 & CPLA_F2_2 & CPLA_F3_2 \\
\hline \multirow[t]{2}{*}{ Relacion_LA_2 } & $\begin{array}{c}\text { Coeficiente } \\
\text { de } \\
\text { correlación }\end{array}$ & , 251 & 251 & 147 \\
\hline & $\begin{array}{c}\text { Sig. } \\
\text { (bilateral) }\end{array}$ & ,000 & ,000 & ,000 \\
\hline \multirow{2}{*}{ Responsa_LA_2 } & $\begin{array}{c}\text { Coeficiente } \\
\text { de } \\
\text { correlación }\end{array}$ & 137 & ,067 &,- 013 \\
\hline & $\begin{array}{c}\text { Sig. } \\
\text { (bilateral) }\end{array}$ & ,000 & ,000 & 266 \\
\hline \multirow{2}{*}{ Autonomia_LA_2 } & $\begin{array}{c}\text { Coeficiente } \\
\text { de } \\
\text { correlación }\end{array}$ & 168 & , 080 & ,052 \\
\hline & $\begin{array}{c}\text { Sig. } \\
\text { (bilateral) }\end{array}$ & ,000 & ,000 & ,000 \\
\hline
\end{tabular}


J2-7 Correlaciones bivariadas entre los factores del rol y las competencias requeridas en el trabajo (CRLA)

Tabla J2-7 Correlaciones bivariadas Rol_CRLA

\begin{tabular}{|c|c|c|c|}
\hline \multicolumn{2}{|c|}{ Rho de Spearman } & CRLA_F1_2 & CRLA_F2_2 \\
\hline \multirow[t]{2}{*}{ Relacion_LA_2 } & $\begin{array}{c}\text { Coeficiente } \\
\text { de } \\
\text { correlación }\end{array}$ & 262 & 242 \\
\hline & $\begin{array}{c}\text { Sig. } \\
\text { (bilateral) }\end{array}$ & ,000 & ,000 \\
\hline \multirow{2}{*}{ Responsa_LA_2 } & $\begin{array}{c}\text { Coeficiente } \\
\text { de } \\
\text { correlación }\end{array}$ & 175 & ,095 \\
\hline & $\begin{array}{c}\text { Sig. } \\
\text { (bilateral) }\end{array}$ & ,000 & ,000 \\
\hline \multirow[t]{2}{*}{ Autonomia_LA_2 } & $\begin{array}{c}\text { Coeficiente } \\
\text { de } \\
\text { correlación }\end{array}$ & 204 & ,041 \\
\hline & $\begin{array}{c}\text { Sig. } \\
\text { (bilateral) }\end{array}$ & ,000 & ,001 \\
\hline
\end{tabular}

J2-8 Correlaciones bivariadas entre los factores del rol y los valores laborales personales (VPLA)

Tabla J2-8 Correlaciones bivariadas Rol_VPLA

\begin{tabular}{|c|c|c|c|}
\hline \multicolumn{2}{|c|}{ Rho de Spearman } & \multirow{2}{*}{$\begin{array}{c}\text { VPLA_F1_2 } \\
142\end{array}$} & \multirow{2}{*}{$\begin{array}{c}\text { VPLA_F2_2 } \\
137\end{array}$} \\
\hline Relacion_LA_2 & $\begin{array}{l}\text { Coeficiente } \\
\text { de } \\
\text { correlación }\end{array}$ & & \\
\hline & $\begin{array}{c}\text { Sig. } \\
\text { (bilateral) }\end{array}$ & ,000 & ,000 \\
\hline \multirow[t]{2}{*}{ Responsa_LA_2 } & $\begin{array}{l}\text { Coeficiente } \\
\text { de } \\
\text { correlación }\end{array}$ & ,037 & 104 \\
\hline & $\begin{array}{c}\text { Sig. } \\
\text { (bilateral) }\end{array}$ & ,003 & ,000 \\
\hline \multirow[t]{2}{*}{ Autonomia_LA_2 } & $\begin{array}{l}\text { Coeficiente } \\
\text { de } \\
\text { correlación }\end{array}$ & 128 & ,011 \\
\hline & $\begin{array}{c}\text { Sig. } \\
\text { (bilateral) }\end{array}$ & ,000 & ,374 \\
\hline
\end{tabular}


J2-9 Correlaciones bivariadas entre los factores de rol y los valores laborales en el trabajo (VLTLA)

Tabla J2-9 Correlaciones bivariadas Rol_VLTLA

\begin{tabular}{|c|c|c|c|}
\hline \multicolumn{2}{|c|}{ Rho de Spearman } & VLTLA_F1_2 & VLTLA_F2_2 \\
\hline \multirow[t]{2}{*}{ Relacion_LA_2 } & $\begin{array}{c}\text { Coeficiente } \\
\text { de } \\
\text { correlación }\end{array}$ & ,279 & , 062 \\
\hline & $\begin{array}{c}\text { Sig. } \\
\text { (bilateral) }\end{array}$ & ,000 & ,000 \\
\hline \multirow[t]{2}{*}{ Responsa_LA_2 } & $\begin{array}{l}\text { Coeficiente } \\
\text { de } \\
\text { correlación }\end{array}$ & 294 & ,074 \\
\hline & $\begin{array}{c}\text { Sig. } \\
\text { (bilateral) }\end{array}$ & ,000 & ,000 \\
\hline \multirow[t]{2}{*}{ Autonomia_LA_2 } & $\begin{array}{c}\text { Coeficiente } \\
\text { de } \\
\text { correlación }\end{array}$ & ,068 & , 079 \\
\hline & $\begin{array}{c}\text { Sig. } \\
\text { (bilateral) }\end{array}$ & ,000 & ,000 \\
\hline
\end{tabular}

J2-10 Correlaciones bivariadas entre los factores de las competencias personales (CPLA) y las competencias requeridas en el trabajo (CRLA)

Tabla J2-10 Correlaciones bivariadas CPLA_CRLA

\begin{tabular}{|c|c|c|c|}
\hline \multicolumn{2}{|c|}{ Rho de Spearman } & CRLA_F1_2 & CRLA_F2_2 \\
\hline \multirow{2}{*}{ CPLA_F1-2 } & $\begin{array}{c}\text { Coeficiente de } \\
\text { correlación }\end{array}$ & 625 & ,080 \\
\hline & Sig. (bilateral) & ,000 & ,000 \\
\hline \multirow{2}{*}{ CPLA_F2_2 } & $\begin{array}{c}\text { Coeficiente de } \\
\text { correlación }\end{array}$ & 193 & ,273 \\
\hline & Sig. (bilateral) & ,000 & ,000 \\
\hline \multirow{2}{*}{ CPLA_F3_2 } & $\begin{array}{l}\text { Coeficiente de } \\
\text { correlación }\end{array}$ & ,073 & , 452 \\
\hline & Sig. (bilateral) & ,000 & ,000 \\
\hline
\end{tabular}


J2-11 Correlaciones bivariadas entre los factores de las competencias personales (CPLA) y los valores laborales personales (VPLA)

Tabla J2-11 Correlaciones bivariadas CPLA_CRLA

\begin{tabular}{|c|c|c|c|}
\hline \multicolumn{2}{|c|}{ Rho de Spearman } & CRLA_F1_2 & CRLA_F2_2 \\
\hline \multirow{2}{*}{ CPLA_F1-2 } & $\begin{array}{l}\text { Coeficiente de } \\
\text { correlación }\end{array}$ & ,625 & , 080 \\
\hline & Sig. (bilateral) & ,000 & ,000 \\
\hline \multirow{2}{*}{ CPLA_F2_2 } & $\begin{array}{c}\text { Coeficiente de } \\
\text { correlación }\end{array}$ & 193 & ,273 \\
\hline & Sig. (bilateral) & ,000 & ,000 \\
\hline \multirow{2}{*}{ CPLA_F3_2 } & $\begin{array}{l}\text { Coeficiente de } \\
\text { correlación }\end{array}$ & ,073 & , 452 \\
\hline & Sig. (bilateral) & ,000 & ,000 \\
\hline
\end{tabular}

J2-12 Correlaciones bivariadas entre los factores de las competencias personales (CPLA) y los valores laborales en el trabajo (VLTLA)

Tabla J2-12 Correlaciones bivariadas CPLA_VLTLA

\begin{tabular}{|c|c|c|c|}
\hline \multicolumn{2}{|c|}{ Rho de Spearman } & VLTLA_F1_2 & VLTLA_F2_2 \\
\hline \multirow[t]{2}{*}{ CPLA_F1-2 } & $\begin{array}{c}\text { Coeficiente } \\
\text { de } \\
\text { correlación }\end{array}$ & 239 & 110 \\
\hline & $\begin{array}{c}\text { Sig. } \\
\text { (bilateral) }\end{array}$ & ,000 & ,000 \\
\hline \multirow[t]{2}{*}{ CPLA_F2_2 } & $\begin{array}{c}\text { Coeficiente } \\
\text { de } \\
\text { correlación }\end{array}$ & 163 & , 087 \\
\hline & $\begin{array}{c}\text { Sig. } \\
\text { (bilateral) }\end{array}$ & ,000 & ,000 \\
\hline \multirow[t]{2}{*}{ CPLA_F3_2 } & $\begin{array}{c}\text { Coeficiente } \\
\text { de } \\
\text { correlación }\end{array}$ & 149 & 109 \\
\hline & $\begin{array}{c}\text { Sig. } \\
\text { (bilateral) }\end{array}$ & ,000 & ,000 \\
\hline
\end{tabular}


J2-13 Correlaciones bivariadas entre los factores de las competencias requeridas en el trabajo (CRLA) y los valores laborales personales (VPLA)

Tabla J2-13 Correlaciones bivariadas CRLA_VPLA

\begin{tabular}{|c|c|c|c|}
\hline \multicolumn{2}{|c|}{ Rho de Spearman } & VPLA_F1_2 & VPLA_F2_2 \\
\hline \multirow{2}{*}{ CRLA_F1-2 } & $\begin{array}{c}\text { Coeficiente de } \\
\text { correlación }\end{array}$ &, 286 &, 157 \\
\cline { 2 - 4 } & Sig. (bilateral) &, 000 &, 000 \\
\hline \multirow{2}{*}{ CRLA_F2_2 } & $\begin{array}{c}\text { Coeficiente de } \\
\text { correlación }\end{array}$ &, 119 &, 102 \\
\cline { 2 - 4 } & Sig. (bilateral) &, 000 &, 000 \\
\hline
\end{tabular}

J2-14 Correlaciones bivariadas entre los factores de las competencias requeridas en el trabajo (CRLA) y los valores laborales en el trabajo (VLTLA)

Tabla J2-14 Correlaciones bivariadas CRLA_VLTLA

\begin{tabular}{|c|c|c|c|}
\hline \multicolumn{2}{|c|}{ Rho de Spearman } & VLTLA_F1_2 & VLTLA_F2_2 \\
\hline \multirow{2}{*}{ CRLA_F1-2 } & $\begin{array}{c}\text { Coeficiente de } \\
\text { correlación }\end{array}$ &, 301 &, 025 \\
\cline { 2 - 4 } & Sig. (bilateral) &, 000 &, 057 \\
\hline \multirow{2}{*}{ CRLA_F2_2 } & $\begin{array}{c}\text { Coeficiente de } \\
\text { correlación }\end{array}$ &, 290 &, 088 \\
\cline { 2 - 4 } & Sig. (bilateral) &, 000 &, 000 \\
\hline
\end{tabular}


J2-15 Correlaciones bivariadas entre los factores de los valores laborales personales (VPLA) y los valores laborales en el trabajo (VLTLA)

Tabla J2-15 Correlaciones bivariadas VPLA_VLTLA

\begin{tabular}{|c|c|c|c|}
\hline \multicolumn{2}{|c|}{ Rho de Spearman } & VLTLA_F1_2 & VLTLA_F2_2 \\
\hline \multirow{2}{*}{ VPLA_F1_2 } & $\begin{array}{c}\text { Coeficiente de } \\
\text { correlación }\end{array}$ &, 255 &, 059 \\
\cline { 2 - 4 } & Sig. (bilateral) &, 000 &, 000 \\
\hline \multirow{2}{*}{ VPLA_F2_2 } & $\begin{array}{c}\text { Coeficiente de } \\
\text { correlación }\end{array}$ &, 191 &, 270 \\
\cline { 2 - 4 } & Sig. (bilateral) &, 000 &, 000 \\
\hline
\end{tabular}


Sección J3: ESPAÑA

J3-1. Correlaciones bivariadas entre los factores del éxito laboral y los factores del rol.

Tabla J3-1 Correlaciones bivariadas Exlab_Rol

\begin{tabular}{|c|c|c|c|c|}
\hline \multicolumn{2}{|c|}{ Rho de Spearman } & Responsa_Spn_3 & Relacion_Spn_3 & Perjuicio_Spn_3 \\
\hline \multirow{2}{*}{ Exlabob_Spn_3 } & $\begin{array}{c}\text { Coeficiente } \\
\text { de } \\
\text { correlación }\end{array}$ & 104 & 175 & ,034 \\
\hline & $\begin{array}{c}\text { Sig. } \\
\text { (bilateral) }\end{array}$ & ,000 & ,000 & ,030 \\
\hline \multirow[t]{2}{*}{ Exlabsu_Spn_3 } & $\begin{array}{c}\text { Coeficiente } \\
\text { de } \\
\text { correlación }\end{array}$ & 317 & ,306 & ,039 \\
\hline & $\begin{array}{c}\text { Sig. } \\
\text { (bilateral) }\end{array}$ & ,000 & ,000 & ,009 \\
\hline
\end{tabular}

J3-2 Correlaciones bivariadas entre los factores del éxito Laboral y los factores de las competencias personales

Tabla J3-2 Correlaciones bivariadas Exlab_Competencias Personales (CPSPN)

\begin{tabular}{|c|c|c|c|c|c|}
\hline \multicolumn{2}{|c|}{ Rho de Spearman } & CPSpn_F1_3 & CPSpn_F2_3 & CPSpn_F3_3 & CPSpn_F4_3 \\
\hline Exlabob_Spn_3 & $\begin{array}{c}\text { Coeficiente } \\
\text { de } \\
\text { correlación }\end{array}$ &, 075 &,- 062 &, 083 &, 114 \\
\cline { 2 - 5 } & $\begin{array}{c}\text { Sig. } \\
\text { (bilateral) }\end{array}$ &, 000 &, 000 &, 000 &, 000 \\
\hline \multirow{2}{*}{ Exlabsu_Spn_3 } & $\begin{array}{c}\text { Coeficiente } \\
\text { de } \\
\text { correlación }\end{array}$ &, 141 &, 096 &, 088 &, 076 \\
\cline { 2 - 6 } & $\begin{array}{c}\text { Sig. } \\
\text { (bilateral) }\end{array}$ &, 000 &, 000 &, 000 &, 000 \\
\hline
\end{tabular}


J3-3 Correlaciones bivariadas entre los factores del éxito laboral y los factores de las competencias requeridas en el trabajo

Tabla J3-3 Correlaciones bivariadas. Exlab_Competencias requeridas en el trabajo (CRSPN)

\begin{tabular}{|c|c|c|c|c|}
\hline \multicolumn{2}{|c|}{ Rho de Spearman } & CRSpn_F1_3 & CRSpn_F2_3 & CRSpn_F3_3 \\
\hline Exlabob_Spn_3 & $\begin{array}{c}\text { Coeficiente } \\
\text { de } \\
\text { correlación }\end{array}$ &, 120 &, 117 &, 158 \\
\cline { 2 - 5 } & $\begin{array}{c}\text { Sig. } \\
\text { (bilateral) }\end{array}$ &, 000 &, 000 &, 000 \\
\hline \multirow{2}{*}{ Exlabsu_Spn_3 } & $\begin{array}{c}\text { Coeficiente } \\
\text { de } \\
\text { correlación }\end{array}$ &, 201 &, 221 &, 238 \\
\cline { 2 - 5 } & $\begin{array}{c}\text { Sig. } \\
\text { (bilateral) }\end{array}$ &, 000 &, 000 &, 000 \\
\hline
\end{tabular}

J3-4 Correlaciones bivariadas entre los factores del éxito laboral y los factores de los valores laborales personales

Tabla J3-4 Correlaciones bivariadas. Exlab _ Valores laborales personales (VPSPN)

\begin{tabular}{|c|c|c|c|}
\hline \multicolumn{2}{|c|}{ Rho de Spearman } & VPSpn_F1_3 & VPSpn_F2_3 \\
\hline Exlabob_Spn_3 & $\begin{array}{c}\text { Coeficiente } \\
\text { de } \\
\text { correlación }\end{array}$ & ,010 &,- 018 \\
\cline { 2 - 4 } & $\begin{array}{c}\text { Sig. } \\
\text { (bilateral) }\end{array}$ &, 543 &, 255 \\
\hline \multirow{2}{*}{ Exlabsu_Spn_3 } & $\begin{array}{c}\text { Coeficiente } \\
\text { de } \\
\text { correlación }\end{array}$ & $\begin{array}{c}\text { Sig. } \\
\text { (bilateral) }\end{array}$ &, 004 \\
\cline { 2 - 4 } & 000 &, 819 \\
\hline
\end{tabular}


J3-5 Correlaciones bivariadas entre los factores del éxito laboral y los factores de los valores laborales en el trabajo

Tabla J3-5 Correlaciones bivariadas. Exlab _ Valores laborales en el trabajo (VLTSPN)

\begin{tabular}{|c|c|c|c|c|}
\hline \multicolumn{2}{|c|}{ Rho de Spearman } & VLTSpn_F1_3 & VLTSpn_F2_3 & VLTSpn_F3_3 \\
\hline \multirow[t]{2}{*}{ Exlabob_Spn_3 } & $\begin{array}{c}\text { Coeficiente } \\
\text { de } \\
\text { correlación }\end{array}$ & 163 &,- 032 & 265 \\
\hline & $\begin{array}{c}\text { Sig. } \\
\text { (bilateral) }\end{array}$ & ,000 & ,048 & ,000 \\
\hline \multirow{2}{*}{ Exlabsu_Spn_3 } & $\begin{array}{c}\text { Coeficiente } \\
\text { de } \\
\text { correlación }\end{array}$ & ,514 & 162 & 124 \\
\hline & $\begin{array}{c}\text { Sig. } \\
\text { (bilateral) }\end{array}$ & ,000 & ,000 & ,000 \\
\hline
\end{tabular}

J3-6 Correlaciones bivariadas entre los factores del rol y las competencias Personales (CPSPN)

Tabla J3-6 Correlaciones bivariadas Rol_CPSPN

\begin{tabular}{|c|c|c|c|c|c|}
\hline \multicolumn{2}{|c|}{ Rho de Spearman } & CPSpn_F1_3 & CPSpn_F2_3 & CPSpn_F3_3 & CPSpn_F4_3 \\
\hline \multirow{2}{*}{ Responsa_Spn_3 } & $\begin{array}{c}\text { Coeficiente } \\
\text { de } \\
\text { correlación }\end{array}$ & ,263 & ,002 & ,096 & ,032 \\
\hline & $\begin{array}{c}\text { Sig. } \\
\text { (bilateral) }\end{array}$ & ,000 & 907 & ,000 & ,045 \\
\hline \multirow{2}{*}{ Relacion_Spn_3 } & $\begin{array}{c}\text { Coeficiente } \\
\text { de } \\
\text { correlación }\end{array}$ & ,239 & 108 & 188 & 158 \\
\hline & $\begin{array}{c}\text { Sig. } \\
\text { (bilateral) }\end{array}$ & ,000 & ,000 & ,000 & ,000 \\
\hline \multirow[t]{2}{*}{ Perjuicio_Spn_3 } & $\begin{array}{c}\text { Coeficiente } \\
\text { de } \\
\text { correlación }\end{array}$ & 141 & ,006 & ,043 &,- 063 \\
\hline & $\begin{array}{c}\text { Sig. } \\
\text { (bilateral) }\end{array}$ & ,000 & 687 & ,007 & ,000 \\
\hline
\end{tabular}


J3-7 Correlaciones bivariadas entre los factores del rol y las competencias requeridas en el trabajo (CRSPN)

Tabla J3-7 Correlaciones bivariadas Rol_CRSPN

\begin{tabular}{|c|c|c|c|c|}
\hline \multicolumn{2}{|c|}{ Rho de Spearman } & CRSpn_F1_3 & CRSpn_F2_3 & CRSpn_F3_3 \\
\hline \multirow{2}{*}{ Responsa_Spn_3 } & $\begin{array}{c}\text { Coeficiente } \\
\text { de } \\
\text { correlación }\end{array}$ & 292 & 075 & 182 \\
\hline & $\begin{array}{c}\text { Sig. } \\
\text { (bilateral) }\end{array}$ & ,000 & ,000 & ,000 \\
\hline \multirow[t]{2}{*}{ Relacion_Spn_3 } & $\begin{array}{c}\text { Coeficiente } \\
\text { de } \\
\text { correlación }\end{array}$ & 249 & 242 & 198 \\
\hline & $\begin{array}{c}\text { Sig. } \\
\text { (bilateral) }\end{array}$ & ,000 & ,000 & ,000 \\
\hline \multirow[t]{2}{*}{ Perjuicio_Spn_3 } & $\begin{array}{c}\text { Coeficiente } \\
\text { de } \\
\text { correlación }\end{array}$ & 115 & 179 &,- 064 \\
\hline & $\begin{array}{c}\text { Sig. } \\
\text { (bilateral) }\end{array}$ & ,000 & ,000 & ,000 \\
\hline
\end{tabular}

J3-8 Correlaciones bivariadas entre los factores del rol y los valores laborales personales (VPSPN)

Tabla J3-8 Correlaciones bivariadas Rol_VPSPN

\begin{tabular}{|c|c|c|c|}
\hline \multicolumn{2}{|c|}{ Rho de Spearman } & VPSpn_F1_3 & VPSpn_F2_3 \\
\hline \multirow[t]{2}{*}{ Responsa_Spn_3 } & $\begin{array}{c}\text { Coeficiente } \\
\text { de } \\
\text { correlación }\end{array}$ & 117 &,- 056 \\
\hline & $\begin{array}{c}\text { Sig. } \\
\text { (bilateral) }\end{array}$ & ,000 & ,000 \\
\hline \multirow{2}{*}{ Relacion_Spn_3 } & $\begin{array}{c}\text { Coeficiente } \\
\text { de } \\
\text { correlación }\end{array}$ & 223 &,- 004 \\
\hline & $\begin{array}{c}\text { Sig. } \\
\text { (bilateral) }\end{array}$ & ,000 & 779 \\
\hline \multirow[t]{2}{*}{ Perjuicio_Spn_3 } & $\begin{array}{c}\text { Coeficiente } \\
\text { de } \\
\text { correlación }\end{array}$ & ,072 &,- 011 \\
\hline & $\begin{array}{c}\text { Sig. } \\
\text { (bilateral) }\end{array}$ & ,000 & ,495 \\
\hline
\end{tabular}


J3-9 Correlaciones bivariadas entre los factores de rol y los valores laborales en el trabajo (VLTSPN)

Tabla J3-9 Correlaciones bivariadas Rol_VLTSPN

\begin{tabular}{|c|c|c|c|c|}
\hline \multicolumn{2}{|c|}{ Rho de Spearman } & VLTSpn_F1_3 & VLTSpn_F2_3 & VLTSpn_F3_3 \\
\hline \multirow[t]{2}{*}{ Responsa_Spn_3 } & $\begin{array}{l}\text { Coeficiente } \\
\text { de } \\
\text { correlación }\end{array}$ & ,342 & ,070 & ,091 \\
\hline & $\begin{array}{c}\text { Sig. } \\
\text { (bilateral) }\end{array}$ & ,000 & ,000 & ,000 \\
\hline \multirow[t]{2}{*}{ Relacion_Spn_3 } & $\begin{array}{l}\text { Coeficiente } \\
\text { de } \\
\text { correlación }\end{array}$ & ,323 &,- 016 & ,021 \\
\hline & $\begin{array}{c}\text { Sig. } \\
\text { (bilateral) }\end{array}$ & ,000 & ,312 & 171 \\
\hline \multirow[t]{2}{*}{ Perjuicio_Spn_3 } & $\begin{array}{l}\text { Coeficiente } \\
\text { de } \\
\text { correlación }\end{array}$ & 105 &,- 085 & , 082 \\
\hline & $\begin{array}{c}\text { Sig. } \\
\text { (bilateral) }\end{array}$ & ,000 & ,000 & ,000 \\
\hline
\end{tabular}

J3-10 Correlaciones bivariadas entre los factores de las competencias personales (CPSPN) y las competencias requeridas en el trabajo (CRSPN)

Tabla J3-10 Correlaciones bivariadas CPSPN_CRSPN

\begin{tabular}{|c|c|c|c|c|}
\hline \multicolumn{2}{|c|}{ Rho de Spearman } & CRSpn_F1_3 & CRSpn_F2_3 & CRSpn_F3_3 \\
\hline \multirow[t]{2}{*}{ CPSpn_F1_3 } & $\begin{array}{c}\text { Coeficiente } \\
\text { de } \\
\text { correlación }\end{array}$ & ,437 & ,000 & ,054 \\
\hline & $\begin{array}{c}\text { Sig. } \\
\text { (bilateral) }\end{array}$ & ,000 & 977 & ,001 \\
\hline \multirow{2}{*}{ CPSpn_F2_3 } & $\begin{array}{c}\text { Coeficiente } \\
\text { de } \\
\text { correlación }\end{array}$ & ,223 & 217 &,- 062 \\
\hline & $\begin{array}{c}\text { Sig. } \\
\text { (bilateral) }\end{array}$ & ,000 & ,000 & ,000 \\
\hline \multirow[t]{2}{*}{ CPSpn_F3_3 } & $\begin{array}{c}\text { Coeficiente } \\
\text { de } \\
\text { correlación }\end{array}$ &,- 031 & ,321 & ,064 \\
\hline & $\begin{array}{c}\text { Sig. } \\
\text { (bilateral) }\end{array}$ & ,049 & ,000 & ,000 \\
\hline \multirow{2}{*}{ CPSpn_F4_3 } & $\begin{array}{c}\text { Coeficiente } \\
\text { de } \\
\text { correlación }\end{array}$ &,- 007 & ,048 & ,460 \\
\hline & $\begin{array}{c}\text { Sig. } \\
\text { (bilateral) }\end{array}$ & 673 & ,003 & ,000 \\
\hline
\end{tabular}


J3-11 Correlaciones bivariadas entre los factores de las competencias personales (CPSPN) y los valores laborales personales (VPSPN)

Tabla J3-11 Correlaciones bivariadas CPSPN_VPSPN

\begin{tabular}{|c|c|c|c|}
\hline \multicolumn{2}{|c|}{ Rho de Spearman } & \multirow{2}{*}{$\begin{array}{c}\text { VPSpn_F1_3 } \\
\text {,263 }\end{array}$} & \multirow{2}{*}{$\begin{array}{c}\text { VPSpn_F2_3 } \\
-, 002\end{array}$} \\
\hline CPSpn_F1_3 & $\begin{array}{c}\text { Coeficiente } \\
\text { de } \\
\text { correlación }\end{array}$ & & \\
\hline & $\begin{array}{c}\text { Sig. } \\
\text { (bilateral) }\end{array}$ & ,000 & ,884 \\
\hline \multirow{2}{*}{ CPSpn_F2_3 } & $\begin{array}{c}\text { Coeficiente } \\
\text { de } \\
\text { correlación }\end{array}$ & 194 & 139 \\
\hline & $\begin{array}{c}\text { Sig. } \\
\text { (bilateral) }\end{array}$ & ,000 & ,000 \\
\hline \multirow[t]{2}{*}{ CPSpn_F3_3 } & $\begin{array}{c}\text { Coeficiente } \\
\text { de } \\
\text { correlación }\end{array}$ & 138 & ,030 \\
\hline & $\begin{array}{c}\text { Sig. } \\
\text { (bilateral) }\end{array}$ & ,000 & ,039 \\
\hline \multirow[t]{2}{*}{ CPSpn_F4_3 } & $\begin{array}{c}\text { Coeficiente } \\
\text { de } \\
\text { correlación }\end{array}$ & ,129 &,- 067 \\
\hline & $\begin{array}{c}\text { Sig. } \\
\text { (bilateral) }\end{array}$ & ,000 & ,000 \\
\hline
\end{tabular}


J3-12 Correlaciones bivariadas entre los factores de las competencias personales (CPSPN) y los valores laborales en el trabajo (VLTSPN)

Tabla J3-12 Correlaciones bivariadas VPSPN_VLTSPN

\begin{tabular}{|c|c|c|c|c|}
\hline \multicolumn{2}{|c|}{ Rho de Spearman } & VLTSpn_F1_3 & VLTSpn_F2_3 & VLTSpn_F3_3 \\
\hline \multirow{2}{*}{ CPSpn_F1_3 } & $\begin{array}{c}\text { Coeficiente } \\
\text { de } \\
\text { correlación }\end{array}$ & 223 & 031 & 044 \\
\hline & $\begin{array}{c}\text { Sig. } \\
\text { (bilateral) }\end{array}$ & 000 & ,048 & ,006 \\
\hline \multirow{2}{*}{ CPSpn_F2_3 } & $\begin{array}{c}\text { Coeficiente } \\
\text { de } \\
\text { correlación }\end{array}$ & 088 & 018 & 059 \\
\hline & $\begin{array}{c}\text { Sig. } \\
\text { (bilateral) }\end{array}$ & 000 & 246 & ,000 \\
\hline \multirow{2}{*}{ CPSpn_F3_3 } & $\begin{array}{c}\text { Coeficiente } \\
\text { de } \\
\text { correlación }\end{array}$ & 074 &,- 023 & 052 \\
\hline & $\begin{array}{c}\text { Sig. } \\
\text { (bilateral) }\end{array}$ & ,000 & 143 & 001 \\
\hline \multirow{2}{*}{ CPSpn_F4_3 } & $\begin{array}{c}\text { Coeficiente } \\
\text { de } \\
\text { correlación }\end{array}$ & 121 &,- 031 &,- 015 \\
\hline & $\begin{array}{c}\text { Sig. } \\
\text { (bilateral) }\end{array}$ & ,000 & 052 & 341 \\
\hline
\end{tabular}


J3-13 Correlaciones bivariadas entre los factores de las competencias requeridas en el trabajo (CRSPN) y los valores laborales personales (VPSPN)

Tabla J3-13 Correlaciones bivariadas CRSPN_VPSPN

\begin{tabular}{|c|c|c|c|}
\hline \multicolumn{2}{|c|}{ Rho de Spearman } & VPSpn_F1_3 & VPSpn_F2_3 \\
\hline CRSpn_F1_3 & $\begin{array}{c}\text { Coeficiente } \\
\text { de } \\
\text { correlación }\end{array}$ &, 208 &, 053 \\
\cline { 2 - 4 } & $\begin{array}{c}\text { Sig. } \\
\text { (bilateral) }\end{array}$ &, 000 &, 001 \\
\hline \multirow{2}{*}{ CRSpn_F2_3 } & $\begin{array}{c}\text { Coeficiente } \\
\text { de } \\
\text { correlación }\end{array}$ &, 157 &, 04 \\
\cline { 2 - 4 } & $\begin{array}{c}\text { Sig. } \\
\text { (bilateral) }\end{array}$ &, 000 &, 010 \\
\hline \multirow{2}{*}{ CRSpn_F3_3 } & $\begin{array}{c}\text { Coeficiente } \\
\text { de } \\
\text { correlación }\end{array}$ &, 139 &,- 059 \\
\cline { 2 - 4 } & $\begin{array}{c}\text { Sig. } \\
\text { (bilateral) }\end{array}$ &, 000 &, 000 \\
\hline
\end{tabular}

J3-14 Correlaciones bivariadas entre los factores de las competencias requeridas en el trabajo (CRSPN) y los valores laborales en el trabajo (VLTSPN)

Tabla J3-14 Correlaciones bivariadas CRSPN_VLTSPN

\begin{tabular}{|c|c|c|c|c|}
\hline \multicolumn{2}{|c|}{ Rho de Spearman } & VLTSpn_F1_3 & VLTSpn_F2_3 & VLTSpn_F3_3 \\
\hline \multirow[t]{2}{*}{ CRSpn_F1_3 } & $\begin{array}{c}\text { Coeficiente } \\
\text { de } \\
\text { correlación }\end{array}$ & ,290 & ,003 & ,070 \\
\hline & $\begin{array}{c}\text { Sig. } \\
\text { (bilateral) }\end{array}$ & ,000 & ,843 & ,000 \\
\hline \multirow[t]{2}{*}{ CRSpn_F2_3 } & $\begin{array}{c}\text { Coeficiente } \\
\text { de } \\
\text { correlación }\end{array}$ & 313 &,- 141 & ,091 \\
\hline & $\begin{array}{c}\text { Sig. } \\
\text { (bilateral) }\end{array}$ & ,000 & ,000 & ,000 \\
\hline \multirow[t]{2}{*}{ CRSpn_F3_3 } & $\begin{array}{c}\text { Coeficiente } \\
\text { de } \\
\text { correlación }\end{array}$ & ,321 &,- 006 & ,035 \\
\hline & $\begin{array}{c}\text { Sig. } \\
\text { (bilateral) }\end{array}$ & ,000 & ,712 & ,028 \\
\hline
\end{tabular}


J3-15 Correlaciones bivariadas entre los factores de los valores laborales personales (VPSPN) y los valores laborales en el trabajo (VLTSPN)

Tabla J3-15 Correlaciones bivariadas VPSPN_VLTSPN

\begin{tabular}{|c|c|c|c|c|}
\hline \multicolumn{2}{|c|}{ Rho de Spearman } & VLTSpn_F1_3 & VLTSpn_F2_3 & VLTSpn_F3_3 \\
\hline \multirow[t]{2}{*}{ VPSpn_F1_3 } & $\begin{array}{c}\text { Coeficiente } \\
\text { de } \\
\text { correlación }\end{array}$ & ,349 & ,022 &,- 028 \\
\hline & $\begin{array}{c}\text { Sig. } \\
\text { (bilateral) }\end{array}$ & ,000 & 160 & ,068 \\
\hline \multirow[t]{2}{*}{ VPSpn_F2_3 } & $\begin{array}{c}\text { Coeficiente } \\
\text { de } \\
\text { correlación }\end{array}$ &,- 033 & 182 & 106 \\
\hline & $\begin{array}{c}\text { Sig. } \\
\text { (bilateral) }\end{array}$ & 031 & ,000 & ,000 \\
\hline
\end{tabular}




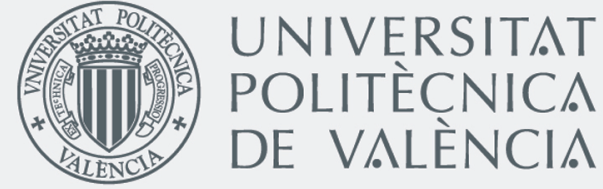

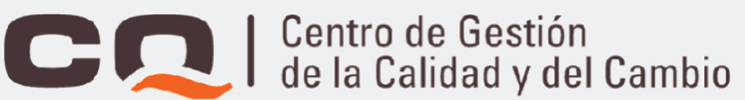

